\title{
Reinterpreting chronology and society at the mortuary complex of Jebel Moya (Sudan)
}

Michael Jonathan Brass

Doctor of Philosophy

Institute of Archaeology

University College London 


\section{Declaration}

I, Michael Jonathan Brass, confirm that the work presented in this thesis is my own. Where information has been derived from other sources, I confirm that this has been indicated in the thesis. 


\begin{abstract}
The largest known pastoral cemetery in sub-Saharan Africa is found in the Jebel Moya massif, south-central Sudan. It was excavated from 1911 to 1914 by Henry Wellcome and first published in 1949. With more than 3100 human burials, the site provides extraordinary scope for exploring the interaction of indigenous and external cultural traditions on the southern boundary of the Meroitic state. This dissertation revises our understanding of Jebel Moya and its context. The few known archaeological localities of the southern Gezira and pre-Meroitic and Meroitic-era cemeteries are compared to elucidate the nature of pastoral social organisation at Jebel Moya.
\end{abstract}

After reviewing previous applications of social complexity theory to mortuary data within and outside of Africa, new questions are posed for the applicability of such theory to pastoral cemeteries. Reliable radiometric dating of Jebel Moya for the first time by luminescence dates is tied into an attribute-based approach to discern three distinctive pottery assemblages. Three distinct phases of occupation are discerned, dating from (1) the early fifth millennium BC, (2) the mid-second to early first millennium BC, and (3) a mortuary phase from the first century BC into the sixth century AD. Analytically, new statistical and spatial analyses such as cross-pair correlation function and multidimensional scaling provide information on zones of interaction across the mortuary assemblages. Finally, an analysis of Meroitic and non-Meroitic mortuary locales from the central Sudan and Upper and Lower Nubia are examined to show how changing social, economic and power relations were conceptualised, and to highlight Jebel Moya's potential to serve as a chronological and cultural reference point for future studies in south-central and southern Sudan. 


\section{Table of Contents}

$\begin{array}{ll}\text { Acknowledgements } & 17\end{array}$

Chapter 1: Introduction $\quad 18$

$\begin{array}{ll}\text { 1.1 Aims and methods } & 18\end{array}$

1.2 The prehistoric geological context of Jebel Moya 20

$\begin{array}{ll}\text { 1.3 Wellcome's excavations and subsequent research } & 21\end{array}$

1.4 Records concerning the Wellcome excavations at Jebel 27

Moya

1.5 Structure of the research 31

Chapter 2: The evolution of complexity theory and 33 mortuary studies

2.1 Forms and processes of political and social organisation 34

2.2 Expressions of social complexity in the Saharan and 37

Sahelian Belts

2.2.1 History of the cultural complexity debate in North 37

Africa

2.2.2 Conceptualising the construction of social complexity in the Sudan during the Neolithic and post-Neolithic

2.3 Modelling social organisation in mortuary assemblages $\quad 45$

$\begin{array}{ll}\text { 2.3.1 Early mortuary practice studies } & 45\end{array}$

2.3.2 Moving beyond the Saxe-Binford modelling 48

2.4 Approaches to social structure in the Jebel Moya 59

mortuary complex

Chapter 3: Ceramic assemblages and a revised chronology 66 for Jebel Moya

$\begin{array}{ll}\text { 3.1 Previous studies of the Jebel Moya pottery } & 67\end{array}$

3.1.1 Frank Addison $\quad 67$

3.1.2 J. Desmond Clark, Haaland, Caneva, Gerharz and 71 Manzo

3.1.3 Discussion

3.2. Analytical methods of pottery studies 78

$\begin{array}{ll}\text { 3.2.1 History of approaches to pottery studies } & 78\end{array}$

3.2.2 Typological-based approaches in the Sudan 82

$\begin{array}{ll}\text { 3.2.3 Attribute-based approaches } & 84\end{array}$

3.2.4 Weighing up analytical options $\quad 85$

3.3 Analysing the British Museum's pottery collection 86

$\begin{array}{ll}\text { 3.3.1 Describing the newly classified assemblages } & 87\end{array}$

3.3.2 Description of the sherds per tray $\quad 89$

$\begin{array}{ll}\text { 3.3.3 Single and co-occurrence of sherd attributes } & 97\end{array}$

3.3.3.1 Single attribute occurrences 98

3.3.3.2 Attribute co-occurrences 105

3.3.4 Description of the three assemblages as determined 114

by attribute analysis of the strata

3.3.4.1 Assemblage 1 (Figure 3.11a-d) 
3.3.4.2 Assemblage 2 (Figure 3.12a-d) 115

3.3.4.3 Assemblage 3 (Figure 3.13a-d) 117

3.3.4.4 Pottery from burials 119

$\begin{array}{ll}\text { 3.4 The absolute dating of Jebel Moya } & 121\end{array}$

3.5 Implications of the new pottery and radiometric analyses 126

3.5.1 Claimed non-local artefacts in the burial assemblages 127

$\begin{array}{ll}\text { 3.5.2 Claimed non-local artefacts in non-burial contexts } & 128\end{array}$

$\begin{array}{ll}\text { 3.5.3 Cardinal directionality and burial posture of burials- } & 130\end{array}$ without-goods versus burials-with-goods

3.6 Resituating Jebel Moya in a Classic-Late Meroitic 132 context in the southern Gezira

Chapter 4: Implications of occupational traces and spatial 136 use of the site over time

4.1 Re-examination of claimed habitation remains at Jebel 136 Moya

4.1.1 Floors, pavements and post-holes 136

$\begin{array}{ll}\text { 4.1.2 Fireplaces and ovens } & 145\end{array}$

$\begin{array}{ll}\text { 4.1.3 Cultivation } & 146\end{array}$

4.1.4 Discussion of occupational traces 147

$\begin{array}{ll}\text { 4.2 Intra-site mortuary data } & 149\end{array}$

4.2.1 Distribution of the burials 149

4.2.2 Origins of the cemetery layout 156

4.2.2.1 Comparative nature of the burial assemblages 156

4.3 Discussion: Site spatial use over time 159

Chapter 5: The bioanthropology of Jebel Moya 161

5.1 The original 1955 analysis: Mukherjee, Rao and Trevor 162

5.2 Rachel Hutton MacDonald: Jebel Moya as a pastoral 171

population

5.3 Irish and Konigsberg: Population affinity using dental 174 traits

5.4 The Duckworth Laboratory collection revisited 178

5.5 Discussion: The bioanthropological make-up of Jebel 180

Moya

Chapter 6: Social patterning in the Jebel Moya mortuary complex

6.1 Introducing Inverse Distance Value 181

6.2 Differential patterns in biological age groups: Inverse 186

Distance Value and burial orientations

$\begin{array}{ll}\text { 6.2.1 Infants, juveniles, young adults and adults } & 187\end{array}$

$\begin{array}{lr}\text { 6.2.1.1 Infants } & 190\end{array}$

6.2.1.2 Juveniles 192

$\begin{array}{ll}\text { 6.2.1.3 Young adults } & 193\end{array}$

$\begin{array}{ll}\text { 6.2.1.4 Adults } & 194\end{array}$

6.3 Spatial methods for examining the Jebel Moya burial 206 assemblage inventory

6.3.1 Correspondence Analysis 206

$\begin{array}{ll}\text { 6.3.2 Pair Correlation Function } & 210\end{array}$ 
6.3.3 Multi-dimensional scaling

$\begin{array}{ll}\text { 6.4 Burial treatment } & 227\end{array}$

$\begin{array}{ll}\text { 6.5 Discussion } & 232\end{array}$

Chapter 7: Situating Jebel Moya's cemetery within a wider 235

Sudanese context

7.1 The socio-political nature of the Meroitic state 238

7.2 Mortuary patterns in Meroitic and Post-Meroitic Nubia 242

$\begin{array}{ll}\text { 7.2.1 Lower Nubia } & 243\end{array}$

7.2.1.1 Ballana and Qustul 244

$\begin{array}{ll}\text { 7.2.2 Upper Nubia } & 248\end{array}$

7.2.3 Shendi Reach: The heart of the Meroitic state 253

$\begin{array}{ll}\text { 7.2.4 Gezira Plain } & 256\end{array}$

$\begin{array}{ll}\text { 7.2.4.1 Abu Geili } 258 & 256\end{array}$

$\begin{array}{ll}\text { 7.2.4.2 Sennar } & 259\end{array}$

7.2.4.3 Other cemeteries and settlements near Jebel 260 Moya

7.2.5 Western Butana 263

$\begin{array}{ll}\text { 7.3 Discussion } & 264\end{array}$

Chapter 8: Conclusion $\quad 267$

8.1 Research questions on burial and society at Jebel Moya 268

$\begin{array}{ll}\text { 8.2 Positioning Jebel Moya as a pastoralist occupational site } & 271\end{array}$

in the southern frontier zone of the Meroitic state

$\begin{array}{ll}\text { 8.3 Final thoughts } & 273\end{array}$

$\begin{array}{ll}\text { Bibliography } & 276\end{array}$

Appendix I Burial distribution map of Jebel Moya On CD

Appendix II New Register of Graves for Jebel Moya On CD

Appendix III British Museum sherd trays On CD

Appendix IV Jebel Moya burials with illustrated pottery 302 sherds

Appendix V Foreign objects from Jebel Moya at the On CD

Griffiths Institute 


\section{List of Tables}

\section{Chapter 1}

1.1 The breakdown of the different geographical excavated sectors into their constituent $20 \times 20 \mathrm{~m}$ excavation squares, as reconstructed by Frank Addison, and the attendant percentage of excavated burials, including a duplicate recording, with accompanying percentages.

1.2 Current location of artefacts from Wellcome's 1911 14 expedition. The types and numbers of digitised excavation records from the Duckworth Laboratory.

1.3 The types and numbers of digitised excavation records from the Duckworth Laboratory.

1.4 A breakdown of the recorded and excavated burials as determined from the new Register of Graves.

\section{Chapter 3}

3.1 J.D. Clark's (1973b: 59-60) $C^{14}$ dates for Jebel Moya; implied but not explicitly stated as being from two different samples. Adapted from Clark and Stemler (1975: Table 1) with new calibration using OxCal 4.3 (IntCal13, Sigma 2 (95.4\%) confidence interval).

3.2 C14 dates for Rabak. Adapted from el Mahi and

Haaland (1984: Table 1) with new calibration using OxCal 4.3 (IntCal13, Sigma 2 (95.4\%) confidence interval).

3.3 Breakdown of the British Museum Jebel Moya trays by stratum.

3.4 The different rim forms present across the strata and their respective percentage within each stratum.

3.5 Surface treatments across the strata and their respective percentage out of all sherds (including unburnished and unslipped) within each stratum.

3.6a Rim sherds: Single attribute occurrences of comb as a decor tool and the corresponding motor action across the strata and their respective percentage within each stratum.

3.6b Rim sherds: Single attribute occurrences of spatula, hollow reed and fillet as decor tools, the corresponding motor action across the strata and their respective percentage within each stratum.

3.6c Rim sherds: Single attribute occurrences of stylus as a decor tool and the corresponding motor action across the strata and their respective percentage within each stratum.

3.7a Body sherds: Single attribute occurrences of comb as a decor tool and the corresponding motor action across the strata and their respective percentage of occurrence on body sherds within each stratum. 
3.7b Body sherds: Single attribute occurrences of spatula as a decor tool and the corresponding motor action across the strata and their respective percentage of occurrence on body sherds within each stratum.

3.7c Body sherds: Single attribute occurrences of wrapped cord, hollow reed, nails and fillets as decor tools and the corresponding motor action across the strata and their respective percentage of occurrence on body sherds within each stratum.

3.7d Body sherds: Single attribute occurrences of stylus as a decor tool and the corresponding motor action across the strata and their respective percentage of occurrence on body sherds within each stratum.

3.8a Co-occurrence of rim types and comb tool motor actions. \% occurrence is calculated against the number of overall rim sherds per strata.

3.8b Co-occurrence of rim types and spatula tool motor actions. \% occurrence is calculated against the number of overall rim sherds per strata.

3.8c Co-occurrence of rim types and stylus tool motor actions. \% occurrence is against the number of overall rim sherds per strata.

3.8d Co-occurrence of rim types and cord tool motor actions. $\%$ occurrence is against the number of overall rim sherds per strata.

3.9 Jebel Moya: The breakdown of the spatial distribution of pottery in recorded association with human burials by sector.

3.10 Jebel Moya: Summary of the OSL dating results.

3.11 Jebel Moya: Summary of the sampled sherds curated at the British Museum.

3.12 Surface finds of plaques and scarabs, and their chronological attribution of manufacture by Addison. The point references refer to the squares on the Jebel Moya site plan. From Addison (1949: 117).

3.13 Breakdown of the burial postures between burials-withgoods and burials-without-goods.

\section{Chapter 4}

4.1 The known features recorded as evidence for human habitation activity in the South-West sector, their reevaluated designation and depth above or below the surface of Stratum C. The ground surface here at the time of excavation was $210 \mathrm{~cm}$ above the surface of Stratum C.

4.2 Numerical distribution of burials in each stratum.

4.3 Breakdown of burials across the different sectors and through the strata. 
4.4 The breakdown of human and separate animal burials, and the percentage of grave goods associated with the human burials, per sector and per square meter.

4.5 The sum of the occurrences of artefact categories in each area of the cemetery with corresponding percentage out of the total number of burials-withgoods.

\section{Chapter 5}

5.1 Re-sexing of the adult skeletal remains at the

Duckworth Laboratory by Mukherjee et al. (1955).

From Mukherjee et al. (1955: Table 2.1).

5.2 The numbers of individuals re-sexed by Mukherjee $e t$ al.

(1955) in the laboratory compared to the original field sexings. The male and male?, female and female? categories have been subsumed under male and female. The total of 330 individuals differs from 369 reported in Table 4.3 due to the removal by Mukherjee et al. of 39 specimens whose numbering appeared doubtful. Based on Mukherjee et al. (1955: Table 2.4).

5.3 The dental samples and their numbers. Adapted from Rachel Hutton MacDonald (1999: Table 3.1) using the new chronology for Jebel Moya.

5.4 The comparative series of skeletal remains used by Mukherjee et al. (1955) (20) and Irish \& Konigsberg (2007) (19). The old designation of Nubian BGroup is no longer valid. From Irish \& Konigsberg (2007: Table 1).

5.5 Aged and re-sexed individuals per season derived from the Duckworth Laboratory's database. Only adults were sexed. $\%$ in brackets: age as a $\%$ of the overall total, with adult sex \& unknown as a $\%$ of adult.

5.6 Breakdown by age and sex of all recorded individuals across the last three field seasons in the new Register of Graves.

5.7 Accuracy of the original field physical anthropological measurements of adult specimens compared against the adult individuals re-sexed by Mercedes Okumura, using the latter as the comparative baseline.

\section{Chapter 6}

6.1 The number of occurrences of each imported raw material category in the rich North-East sector burials and their percentage of the total North-East occurrences.

6.2 The range of raw materials from which burial artefacts were manufactured from and their potential points of origin. From Clark (1973a), Humphries and Rehren (2014), Nicholson and Shaw (1999), Shinnie and Anderson (2004), Whiteman (1971) and Williams and 
Adamson (1982).

6.3 Breakdown of the total number of human burials and human burials with accompanying goods in the different sectors of the site. The Inverse Distance Value is the total for each sector with the accompanying mean and median values per human burial in brackets.

6.4 The number of total burials in which imported raw materials occurred across the site and their presence/absence outside of the North-East and East sectors.

6.5 The number of individuals with accompanying burial items, derived from the Duckworth Lab's recent resexing attempt, divided by age categories. The range, and the mean and median, are given for their Inverse Distance Value.

6.6 Using the field anatomists' categorisations and their corresponding Inverse Distance Values were calculated.

6.7 Comparative list of the bodily orientation, grave form and burial posture of the different field-derived age categories.

6.8 Frequency of the raw material composition of burial artefacts per Duckworth Laboratory adult-sexed individuals in each sector of the cemetery. The two columns "ceramics" and "pottery" refer to ceramic wares and clay lipstuds/nosestuds/earstuds respectively.

6.9 Breakdown of the IDV per Duckworth Laboratory aged and sexed burials per sector. The category numbers includes the totals for the female and male adult individuals (see Table 5.1).

6.10 North-East sector burials with an Inverse Distance Value of 10+ sorted in descending order of their values. The listed lab sexing was done by the Duckworth Laboratory on their extant human remains.

\section{Chapter 7}

7.1 Summary of the different regions in the Sudan, reflecting their currently known burial and socioeconomic activities. 


\section{List of Illustrations}

\section{Chapter 1}

1.1 The location of Jebel Moya in south-central Sudan. Adapted from Edwards (1989: Figure 1) and Winchell (2013: Figure 1.2).

1.2 View of the Jebel Moya excavations from the northwest. Reproduced from the Griffiths Institute's photographic archive with permission.

\section{Chapter 3}

3.1 Form of vessels as reconstructed by Addison and the Maryleborne staff. From Addison (1949: Plate LXXXIX).

3.2 Addison's Impressed Ware divided into four sections, A-B in the top row and C-D in the bottom row. From Addison (1949, Plate XCIV).

3.3 Bone pottery decoration tools found in unspecified context at Jebel Moya. (1) A potential toothed rocker, (2) too damaged to identify, ( $3 \& 7$ ) toothed rockers, (4) stylus, (5, $8 \&$ \&) combs, and (6) a spatula stylus. They can be used to make dragged and incised impressions as well as rocker-stamping and parallel channels. They, or any other decor tools, have not been re-located in any of the UK curated collections. From Addison (1949: Plate LVII B).

3.4 Rolled/everted rim from the Jebel Moya-like pottery found at Rabak, termed 'Rabak Ware' by Haaland. From Haaland (1987: 57).

3.5 Manzo's categories: $a-b$ external thickened rims mostly from large jars, $c$ - $d$ zone impressed with straight or slightly everted rims, and $e-f$ rims with comb-impressed bands or incised rim bands. From Manzo (2011: Figure 2).

3.6 Gerharz's Phase II Incised and Rocked pottery with horizontal bands filled with comb-pricked designs. From Gerharz (1994: Figure 47 (1-5))

3.7 Gerharz's Phase II Incised and Rocked pottery related to C-Group and Kerma pottery. From Gerharz (1994: Figure 47 (6-9))

3.8 Gerharz's Phase III pottery (1) claimed to represented at Napatan and Meroitic sites to the north (2-4: Kadada, Sennar, Amir). From Gerharz (1994: Figure 50).

3.9 "Egyptian-style" beaker from Gerharz's Phase III. From Gerharz (1994: Figure 56(3)).

3.10 Sherd from Tray JM6 (British Museum, $6 \mathrm{~cm}$ width at rim) of a type previously mistaken as resembling Kerma or C-Group Wares. Reproduced with the kind permission of the Trustees of the British Museum. 
3.11 Jebel Moya: Assemblage 1: (a) body sherd 2 - 3mm

thick with comb-stamped decoration; (b) rim and body sherd $3 \mathrm{~mm}$ thick with comb-stamped and pivoted comb décor; (c) body sherd $5-6 \mathrm{~mm}$ thick with dragged comb lines and stamped comb décor; (d) a selection of Assemblage 1 body and rim sherds. The temper of all the sherds is sand paste with bone and mica. $(a-c)$ are from tray JM 3 and reproduced with the kind permission of the Trustees of the British Museum; (d) is from Addison (1949:, Plate XCIV).

3.12 Jebel Moya: Assemblage 2: (a) thick, rolled everted rim and body sherd $5-10 \mathrm{~mm}$ thick with dragged comb chevrons on the rim and a comb-stamped line under the lip; (b) thick, rolled everted rim and body sherd 3 $24 \mathrm{~mm}$ thick with dragged comb chevrons on the lip and a wad of cord impression just under the lip; (c) thick, simple rim and body sherd 8-26 mm thick with incised angular lines on the lip and rows of vertical incised fillets just under it. The temper of all the sherds is coarse grit. (a-c) are from tray JM 4 and are reproduced with the kind permission of the Trustees of the British Museum; (d) is from Addison (1949: Plate CIV).

3.13 Jebel Moya: Assemblage 3: (a) body sherd 2.5 - 4.5mm thick with comb-stamped angular lines forming quadrangles; (b) simple rim and body sherd 3-6 mm thick with two comb-stamped channels under the lip and comb-stamped triangles on the body; (c) body sherd 1 $4.5 \mathrm{~mm}$ thick with stylus-stamped wavy-lines, stylusstamped chevron lines and comb-stamped triangular and vertical wavy-lines. The temper of all the sherds is sand with mica (with some organics). (a-c) are from tray JM 2 and are reproduced with the kind permission of the Trustees of the British Museum; $(d)$ is a selection of large rim sherds from Addison (1949: Plate CI).

3.14 Jebel Moya: the spatial distribution of pottery (red) in recorded association with human burials (grey). From Brass and Schwenniger (2013: Figure 6).

3.15 Jebel Moya: The plotted luminescence date intervals from the Assemblage 2 and 3 samples which fall into two distinct clusters. The Assemblage 1 range is hypothetical based on Caneva (1991). From Brass and Schwenniger (2013: Figure 7).

3.16 Jebel Moya: The relative density of burials-with-gravegoods to burials-without-grave-goods is greater in the southwest and north $(>0.5)$ than in the east and northeast. The overall ration of burials-with-gravegoods to all burials is $1108 / 3135=0.35$, which is the global average risk or probability of burials with goods. From Brass and Schwenniger (2013: Figure 8). 
3.17 Cardinal co-ordinates and their frequency for burials-

without-goods across the site.

3.18 Cardinal co-ordinates and their frequency for burialswith-goods across the site.

3.19 Abu Geili: Pottery: 1 - 3 and 5 stylus-stamped wavy lines. 4 and 6 - 9 comb-stamped decoration sometimes within incised lines. All are burnished black and brown sherds originally infilled with red pigment. From Crawford and Addison (1951: Plate XXXVIIIB).

3.20 Abu Geili: Locally produced wheel-made pottery. From Crawford and Addison (1951: Plate XLIII).

3.21 Abu Geili: Painted Meroitic pottery. From Crawford and Addison (1951: Plate XLA).

\section{Chapter 4}

4.1 The distribution of claimed fireplaces and floors in the different squares and through the stratigraphy. From Addison (1949: Figure 80).

4.2 (1) Mud plaster remnants of wattle \& daub structure, (2) claimed floor, $(3 \& 4)$ hardened clay impregnated with calcium carbonate, formerly claimed by the excavators and Addison to be a living floor. From Addison (1949: Plate XXXV).

4.3 Hardened earth, claimed by Addison to be a tukl (grass hut) floor. From Addison (1949: Plate XXXVI 2).

4.4 A pot or pots crushed under pressure but claimed by Addison to be a flooring of red-ware sherds. From Addison (1949: Plate XXXVI 3).

4.5 Addison's plan showing the location of claimed floors over the site. From Addison (1949: Figure 81).

4.6 Six small stone structures which were located in the south-east portion of the East sector of the cemetery and recorded in Oric Bates' diary from the second field season, $1911-12$.

4.7 Examples of mud plastered, barrel-shaped pits serving as ovens. From Addison (1949: Plate XXXVII).

4.8 Two ovens from square M.5, N.6 which cut through the 'third flooring' marked in Figure 4.1b. From Addison (1949: Plate XXXVIII 2).

4.9 Mapping of the surface of Stratum $C$ in relation to the modern ground surface at the time of excavation across the excavated sectors of the valley. From Addison (1949: Figure 5).

4.10 Reconstruction of the number of burials (vertical axis) dug from levels above and below the surface of Stratum C (horizontal axis) for the South-West sector.

4.11 Reconstruction of the number of burials (vertical axis) dug from levels above and below the surface of Stratum C (horizontal axis) for the East sector. 
4.12 Reconstruction of the number of burials (vertical axis)

dug from levels above and below the surface of Stratum

C (horizontal axis) for the North-West sector.

4.13 Reconstruction of the number of burials (vertical axis)

dug from levels above and below the surface of Stratum

$\mathrm{C}$ (horizontal axis) for the North-East sector.

\section{Chapter 5}

5.1 Mahalanobis $\mathrm{D}^{2}$ technique applied to Jebel Moya and comparative African samples to determine population affinity. From Mukherjee et al. (1955: 85).

5.214 trait Mahalabois D2 distance on dental records using

Multi-Dimensional Scaling. The triangles are sub-

Saharans, with the black squares representing Saharan populations. From Irish and Konigsberg (2007: Figure $3)$.

\section{Chapter 6}

6.1 Jebel Moya: the relative density of burials with grave goods (red) to burials without grave goods (yellow) is greater in the south-west and north-west $(>0.5)$ than in the east and north-east.

6.2 Burial distribution of individuals categorised as Infants by the original field anthropologists.

6.3 Burial distribution of individuals categorised as Juveniles by the original field anthropologists.

6.4 Burial distribution of individuals categorised as Young Adults by the original field anthropologists.

6.5 Occurrence of raw materials amongst the burials of the South-West, North-West, East and North-East per (a) adult female and (b) adult male burials. Each sex category includes those tentatively assigned to it.

6.6 Occurrence of artefact categories amongst the burials of the South-West per (a) adult female and (b) adult male burials. Each sex category includes those tentatively assigned to it.

6.7 Occurrence of raw materials amongst the burials of the

North-West per (a) adult female and (b) adult male burials. Each sex category includes those tentatively assigned to it.

6.8 Occurrence of artefact categories amongst the burials of the North-West per (a) adult female and (b) adult male burials. Each sex category includes those tentatively assigned to it.

6.9 Occurrence of raw materials amongst the burials of the

North-East per (a) adult female and (b) adult male burials. Each sex category includes those tentatively assigned to it.

6.10 Occurrence of artefact categories amongst the burials of 
the North-East per (a) adult female and (b) adult male burials. Each sex category includes those tentatively assigned to it.

6.11 Occurrence of raw materials amongst the burials of the East per (a) adult female and (b) adult male burials. Each sex category includes those tentatively assigned to it.

6.12 Occurrence of artefact categories amongst the burials of the East per (a) adult female and (b) adult male burials. Each sex category includes those tentatively assigned to it.

6.13 Correspondence analysis of the artefact categories against all burials across the cemetery with accompanying burial assemblages.

6.14 Correspondence analysis of the raw material categories against all burials across the cemetery with accompanying burial assemblages.

6.15 Correspondence analysis against burials containing the 20 most commonly occurring types of artefact categories.

6.16 Correspondence analysis against burials containing the 20 most commonly occurring types of raw material categories.

6.17 Pair Correlation Function plot of richer burials versus each across all sectors of the cemetery. $\mathrm{X}$-axis: metres out from any given rich burial. Y-axis: an estimate of the density of neighbouring rich graves for difference distances along the $\mathrm{x}$-axis. Red line: average PCF value for 99 random sets. Black line: the burial data. Grey shaded area: wider envelope of possible values from the random sets.

6.18 Pair Correlation Function plot of richer burials versus lesser-rich burials across all sectors of the cemetery. Xaxis: metres out from any given rich burial. Y-axis: an estimate of the density of neighbouring rich graves for difference distances along the $\mathrm{x}$-axis. Red line: average PCF value for 99 random sets. Black line: the burial data. Grey shaded area: wider envelope of possible values from the random sets.

6.19 Pair Correlation Function of richer burials versus lesserrich burials in four sectors of the cemetery: (a) SouthWest, (b) East, (c) North-West and (d) North-East. Xaxis: metres out from any given rich burial. Y-axis: an estimate of the density of neighbouring rich graves for difference distances along the $\mathrm{x}$-axis. Red line: average PCF value for 99 random sets. Black line: the burial data. Grey shaded area: wider envelope of possible values from the random sets.

6.20 The 27 IDV 10+ burials in relation to the distribution map of all the burials plotted against Addison's original 
grave distribution map.

6.21 The plotted location of the 27 IDV $10+$ burials in the

North-East sector.

6.22 Comparative histograms of the (a) cardinal

directionality of the 27 IDV 10+ burials, and (b)

cardinality directionality of all burials in the North-East sector.

6.23 Comparative compass map of the (a) cardinal

directionality of the 27 IDV 10+ burials, and (b)

cardinality directionality of all burials in the North-East sector.

6.24 Reconstruction of the number of IDV 10+ burials dug from levels above and below the surface of C Stratum for the North-East sector.

6.25 NMDS plot of all burials across the cemetery using the occurrence of artefacts and the raw material each was made from.

6.26 NMDS plot of all burials across the cemetery for the presence/absence of the artefact categories.

6.27 NMDS plot of all burials in the North-East sector for the presence/absence of the artefact categories.

6.28 DMMDS plot of all burials across the cemetery with three or more artefacts-with-material-type categories.

6.29 DMMS plot of all burials across the cemetery with three or more presence/absence occurrences of artefact categories.

6.30 Comparative chart of the occurrence of artefact categories between the laboratory-sexed male and female individuals.

6.31 Compass map of the recorded bodily (not head) orientation of all individuals across the cemetery.

(Duckworth Laboratory) across the cemetery: (a) adult, (b) adult male, (c) adult female, and (d) young adult.

6.33 Breakdown of tooth extraction amongst individuals resexed by the Duckworth Laboratory.

\section{Chapter 7}

7.1 Colour-coded map of select Mesolithic, Neolithic, Meroitic and Post-Meroitic sites in the Sudan: blue (Meroitic), brown (Mesolithic), green (Meroitic, PostMeroitic/X-Group), orange (Neolithic), purple (Mesolithic, Neolithic, Meroitic), red (Neolithic, Meroitic, Post-Meroitic/X-Group) and light grey (Neolithic, Meroitic).

7.2 The chronology of Jebel Moya and its main contemporary (Post-)Meroitic sites elsewhere in the Sudan used in analysing comparative mortuary behaviours. 


\section{Acknowledgments}

I am greatly indebted to my primary supervisor, Professor Kevin MacDonald, who first suggested Jebel Moya as a potential candidate for my doctoral research. Our discussions and meetings have always been lively and highly stimulating, and his guidance invaluable. I would also like to thank my secondary supervisors, Professors Andrew Bevan and Dorian Q. Fuller. Professor Bevan provided incalculable assistance and guidance with the spatial analyses, while Professor Fuller gave very graciously of his time to answer any questions I had about wider Sudanese archaeology.

The support of other colleagues in the Institute of Archaeology and the intellectual freedom offered by the Institute has been significant. The director, Professor Sue Hamilton, encouraged me to publish the luminescence dates on the Jebel Moya pottery. Professor David Wengrow and Dr Richard Bussmann were always available for queries, and provided the opportunity to speak to the British Association of Near East Archaeology 2015 conference hosted by the Institute.

Dr Neil Spencer and Dr Derek Welsby kindly provided access to the Jebel Moya collection at the British Museum, and Dr Welsby extended gracious invitations to present my research to The Sudan Archaeological Research Society in 2008 and 2015. Dr Marta Lahr kindly granted access to the records archived at the Duckworth Laboratory, University of Cambridge, while the Griffiths Institute (Oxford) provided access to their collection. I am indebted to Professor Azhari Sadig, Dr Donatella Usai and my colleagues from many conferences and organisations, notably the annual African Archaeology Research Day in the UK, Later Prehistory of Northeastern Africa (LPNEA 2011 and 2015, Poznan, Poland) and the Society of Africanist Archaeologists. There are too many people to thank individually but you know who you are.

A very special thank you goes to my wife, Dr Isabelle Vella Gregory, for her unstinting support and for her invaluable discussions and input at vital stages of my research. Any mistakes which remain are my responsibility. Finally, my research would not have been possible without the generous financial support of the Wellcome Trust, for which I am very grateful. 


\section{Chapter 1: Introduction}

\subsection{Aims and methods}

The Jebel Moya massif is situated in the relatively under-explored southern Gezira Plain in the Sudan, approximately $250 \mathrm{~km}$ south south-east of Khartoum and $c a$. $30 \mathrm{~km}$ west of Sennar (Figure 1.1). The massif has a perimeter of $c a$. $11 \mathrm{~km}$. Its north-eastern valley was excavated by (later Sir) Henry Wellcome, the founder of the Wellcome Trust, over four field seasons from 1911 - 1914 (Addison 1949: 1). Around a fifth of the estimated 10.4 hectares of the valley floor was excavated over four seasons, yielding a recorded 3135 human burials from 2791 graves. It is by far the largest and most intensively excavated cemetery anywhere in sub-Saharan Africa.

The archaeological and bioanthropological reports were published in 1949 and 1955 respectively (Addison 1949; Mukherjee et al. 1955). The vast majority of extant assemblages and the expedition records are curated at different institutions in the United Kingdom. The excavation cards and extant skeletal assemblages at the Duckworth Laboratory (University of Cambridge) together with a field diary from the second season's field director, geological reports from the third and fourth seasons, a topographical survey map, Addison's correspondences, plans of some of the burials excavated during the fourth and final season, cards describing artefacts and the photographic archive at the Griffiths Institute (Oxford) and the pottery samples at the British and Petrie Museums comprise the key materials curated in the United Kingdom. They have not been comprehensively re-evaluated, subsequent to the original reports, to determine the nature of social evolution at Jebel Moya.

Developments in archaeological inference and techniques provide a unique opportunity to re-orientate the published and extant material evidence within an updated interpretive framework on mortuary social organisation at Jebel Moya. The present work places the site's different phases of occupation in secure temporal contexts to allow for informed social analysis of change over time. In particular, it focuses on questions of social organization and evaluates the nature of socio-political order in the southern Gezira 
Plain. This enables a focus on the site's cultural evolution and provides a basis for addressing the key research questions:

- How is the nature of the human occupation of Jebel Moya reflected in the habitation and mortuary remains across the different temporal periods?

- $\quad$ Are the mortuary remains at Jebel Moya from one discrete period, and can the processes behind the cemetery's evolution and layout be disentangled?

- How do phenomena including biological age groups and sex, composition and distribution of burial assemblages, and burial postures shed light on the forms and signification of status in death?

- How does the manifestation of social differentiation indicated by the mortuary remains at Jebel Moya compare spatially and temporally to mortuary assemblages elsewhere in the Sudan?

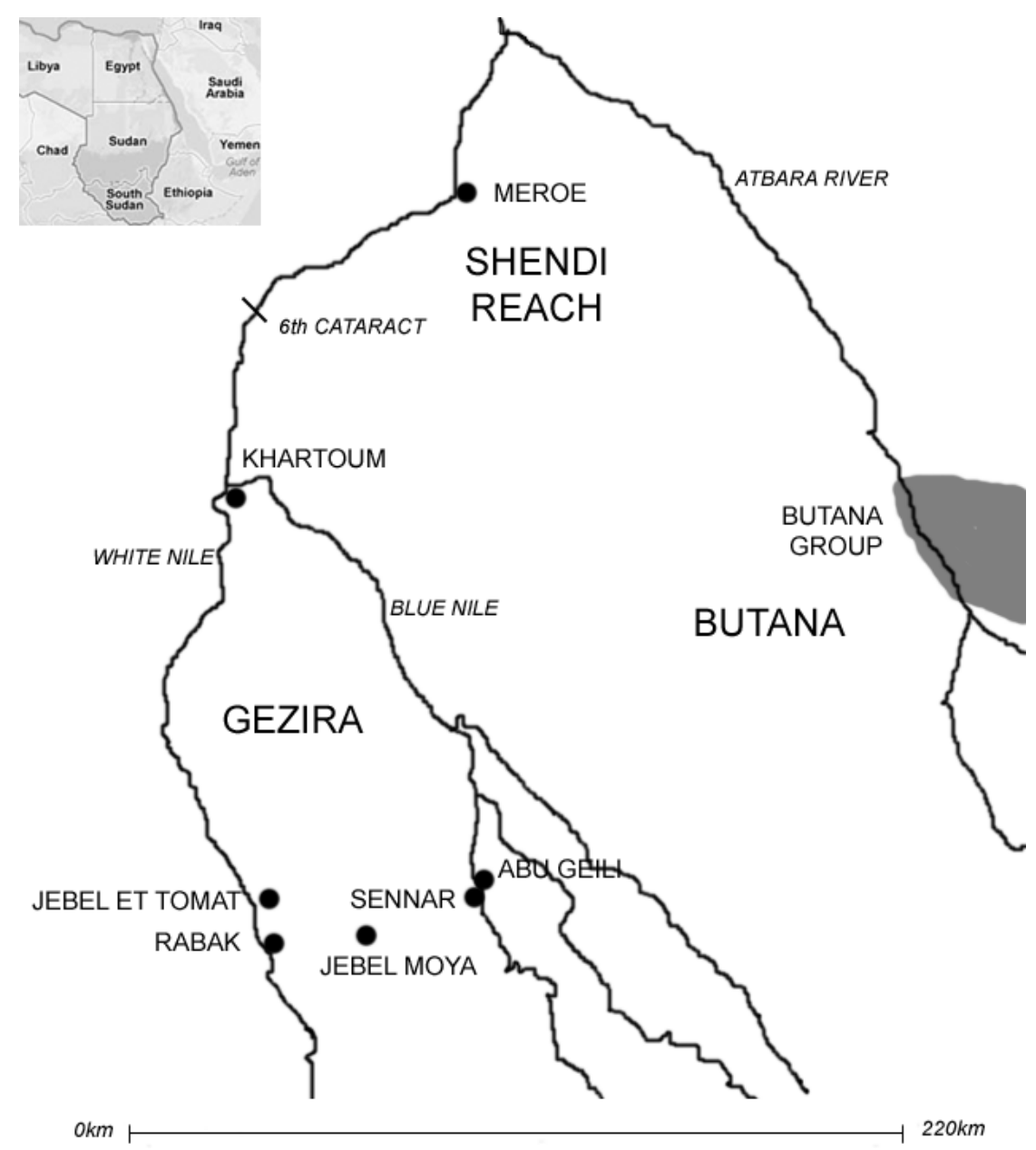

Figure 1.1 The location of Jebel Moya in south-central Sudan. Adapted from Edwards (1989: Figure 1) and Winchell (2013: Figure 1.2). 


\subsection{The prehistoric geographic context of Jebel Moya}

Understanding and reconstructing the geological, site formation and destructive processes in the southern Gezira Plain is important for understanding the backdrop against which the archaeological, chronometric and physical anthropological data from Jebel Moya will be analysed.

The fertile Gezira, Arabic for Island, is a megafan built by the Blue Nile and crisscrossed by Late Pleistocene and Early Holocene channels (Williams 2009: 7). Examples are the depressions and sandy ridges of palaeo-channels fanning out to the north and north-west from the area around Sennar (Mubarak et al. 1982: 179; Williams et al. 1982: 113). Jebel Moya itself is a granitic outcrop of the Basement Complex breaking through the above Sandstone Formation and its overlay (Williams and Adamson 1982). The Basement Complex contains an underground aquafer, resulting in fresh water rising to ground level surface around the bases of outcrops like Jebel Moya. This is particularly important in a plain without permanent surface water for maintaining animal herds. The underground aquafer is replenished by the waters from both the Blue and White Niles. The Blue Nile is highly seasonal, accounting for $68 \%$ of the peak flow and $72 \%$ of the annual sediment in the Gezira Plain (Williams 2009). The White Nile has an almost constant flow throughout the year with $83 \%$ of the Nile flow during the lowest month. The Blue and White niles join north of Khartoum (Williams 2009: 3).

From the early to middle Holocene, the $500 \mathrm{~mm}$ isohyet was north of Jebel Moya near Khartoum, which increased the northern range of the biting Tabanidae fly. The bite of the Tabanidae fly has detrimental effects on the survival rates of cattle (Wickens 1982: 43) and this may help explain why the remains of early cattle have not been found in early-middle Holocene occupational debris in the northern Gezira (Salvatori et al. 2011). Moreover, the distribution of snails has been taken as suggestive of intransient rather than permanent swamp conditions away from the flood plain of the Blue and White Niles during the middle to late Holocene (Williams and Adamson 1973). This includes the late Mesolithic period of the late sixth - early fifth millennium BC marked by the first appearance of pottery at Jebel Moya (see section 3.2.2). 
However, the transition from swampy conditions to a mostly acacia-tall grass savannah and subsequent semi-desert steppe, was complete by the third millennium BC (Wickens 1982: 44-6). There was a brief interlude of wetter weather around the end of the second millennium $\mathrm{BC}$ before the drying trend resumed. By the early centuries $\mathrm{AD}$, few swamp conditions remained; one such instance was at Jebel et Tomat, situated to the north-east of Jebel Moya near the banks of the White Nile, where it co-existed with dry land (Clark 1973b). Today, the nearest riparian swamps are over $12 \mathrm{~km}$ distant. Further evidence for different ecological conditions is provided by the Roman authors Pliny the Elder (HN 6, 181-5) and Seneca (Nat. Qu. 3-5, 6, 8). The former writes about summer rains at Alexandria (Egypt) brought by southerly winds from the south. The latter reports on two centurions sent by the Roman Emperor Nero to find the source of the Nile in the first century AD. The centurions reported their progress was halted by vast swamps, the Sudd, within which were two rock outcrops now identified as Jebel Ahmed Agha, which is to the souh of Jebel Moya. If correct, the Sudd extended $200 \mathrm{~km}$ north of its current position, although it was in slow south-bound retreat (Mawson and Williams 1984: 51).

In modern times, though, this zone can be sub-divided into swamp vegetation, riverine woodland, grassland and jebel (mountain) vegetation. The mean annual rainfall recorded from 1921 - 1950 across the Gezira is approximately $400 \mathrm{~mm}$ for the isohyet line nearest to Jebel Moya (Williams and Adamson 1982: 136-7). To put it into perspective, Khartoum received an annualised $164 \mathrm{~mm}$ over the same period. Overall, these different strands of data place the Jebel Moya surrounds near the transitional belts both in modern times and during the Classic and Later Meroitic Periods (late first millennium $\mathrm{BC}-c a$. AD. 350).

\subsection{Wellcome's excavations and subsequent research}

The first intensive archaeological expeditions in the Sudan began at the turn of the $20^{\text {th }}$ century after the final defeat and death of the Khalifa Abdullahi by British forces in November 1899. The cores of these early expeditions were formed of Egyptologists, which had the effect of focusing early Sudanese archaeology on cemeteries and sites such as Meroe and Kerma, amongst others, which had large standing structures 
(Edwards 2004; Reisner 1923). In addition, until the late 1970s and early 1980s, excavation efforts were almost exclusively concentrated along the river Nile north of the $6^{\text {th }}$ Cataract (Dann 2009; Edwards 2007; Fuller 2003).

It was in this intellectual setting that Wellcome launched his archaeological expedition at Jebel Moya in response to a request from Lord Kitchener (former Governor-General of the Sudan, 2 September 1898 - 19 January 1899) to assist in unspecified "upliftment" of the indigenous inhabitants of the Sudan (Addison 1949: 1). Wellcome decided to combine paid employment with his archaeological interests. By the close of the fourth and final field season in April 1914, more than 4000 workmen from the nearby villages were engaged in various excavation and other activities such as construction and cooking (Figure 1.2) (Addison 1949: 7).

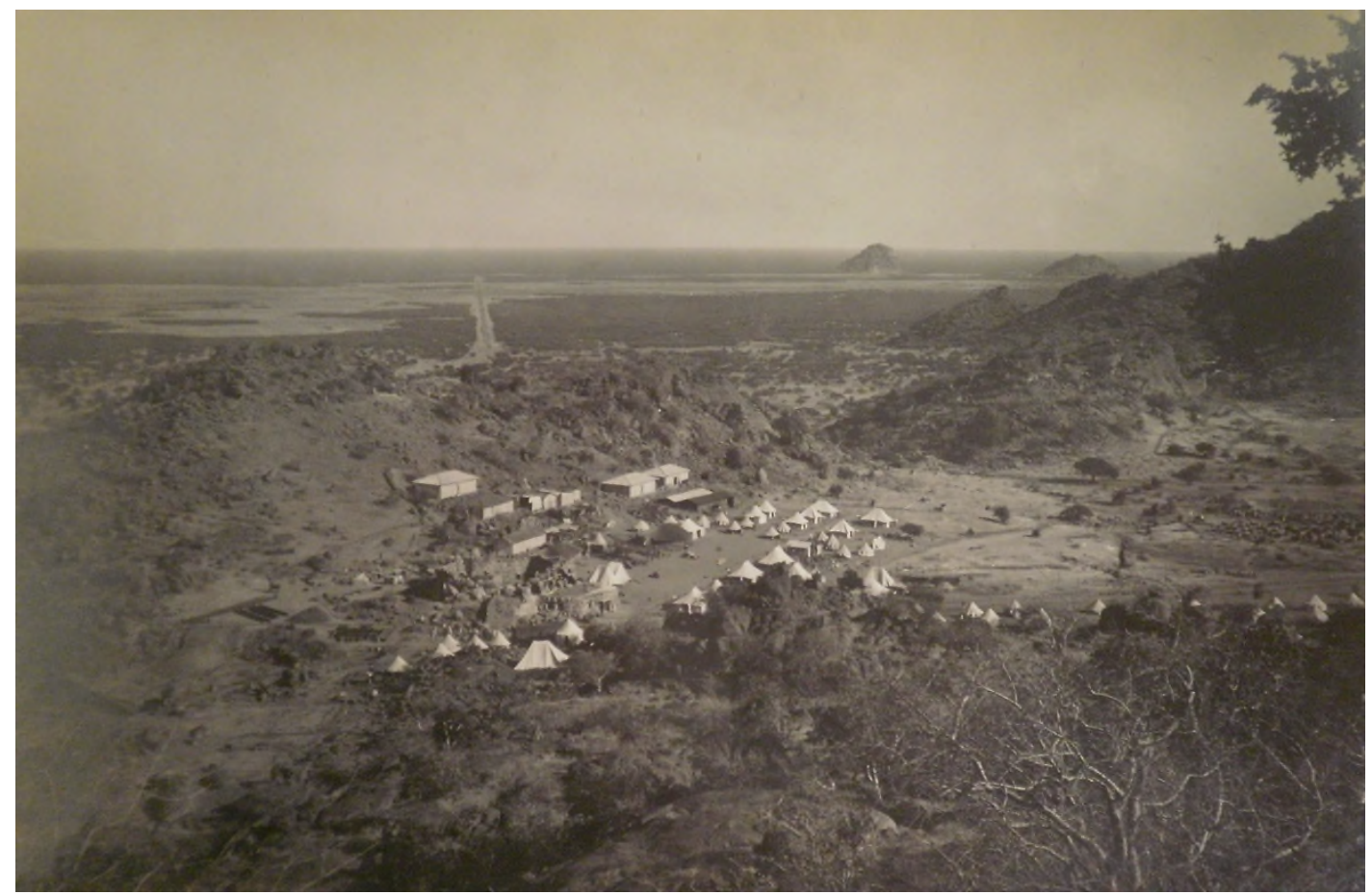

Figure 1.2 View of the Jebel Moya excavations from the north-west. Reproduced from the Griffiths Institute's photographic archive with permission.

Wellcome personally supervised the work during the first season $\left(29^{\text {th }}\right.$ January - April 1911), when five test areas were excavated (Addison 1949: 3). An unrecorded number of graves and skeletons were uncovered, but it was enough for Wellcome to apply for and be granted a concession license (Addison 1949: 3-4). Subsequently, acting on the advice of the Egyptologist George Reisner who he consulted with but who did not form 
part of the expedition except for a few weeks before the close of the fourth field season, Wellcome appointed Oric Bates as field director for the second field season (December 1911 - April 1912) (Addison 1949: 4). Other appointments included Douglas Derry as the first chief medical officer and field bioanthropologist. These actions placed the staffing and direction of the excavations on a more scientific footing. Bates re-examined the spoil heaps from the first season and excavated a total of 709 graves in the East and South Jebel sectors (see Table 1.1 and Appendix I). It was also during this second season that construction began on the famous "House of Boulders", designed to absorb labourers not required for excavation work and the erection of workshops and iron shed stores (Addison 1949: 5).

\begin{tabular}{|c|c|c|}
\hline Cemetery area & Squares & Burial goods \\
\hline South & $\begin{array}{l}\text { R.11, S.12.; R.12, S.13; S.11, T.12; S.12, T.13; } \\
\text { S.13, T.14; Q.12, R.13 }\end{array}$ & $\begin{array}{c}19 / 49 \\
(38.78 \%)\end{array}$ \\
\hline South-West & $\begin{array}{l}\text { M.3, N.4; M.4, N.5; M.4, N5; M.5, N.6'; M.6, } \\
\text { N.6; M.6, N.7; M.7, N.8; M.8, N.9; N.1, O.2; } \\
\text { N.2, O.3; N.3, O.4; N.4, O.5; N.5, O.6; N.6, } \\
\text { O.7; N.7, O.8; N.8, O.9; N.9, O.10; O.1, P.2; } \\
\text { O.2, P.3; O.4, P.5; O.5, P.6; O.6, P.7; O.7, P.8; } \\
\text { O.8, P.9; P.1, Q.2; P.2, Q.3 }\end{array}$ & $\begin{array}{c}429 / 824 \\
(52.06 \%)\end{array}$ \\
\hline West & J.2, K.3; K.2, L.3; K.3, L.4; K.5, L.6; K.7, L.8 & $\begin{array}{c}4 / 17 \\
(23.5 \%)\end{array}$ \\
\hline East & $\begin{array}{l}\text { L.9, M.10; L.10, M.11; L.11, M.12; L.12, M.13; } \\
\text { K.8, L.9; K.9, L.10; K.10, L.11; K11, L.12; } \\
\text { K.11, L.12; K.12, L.13; M.10, N.11; M.100, } \\
\text { N.1; M.11, N.12; M.12, N.13 }\end{array}$ & $\begin{array}{c}216 / 859 \\
(25.15 \%)\end{array}$ \\
\hline North-West & $\begin{array}{l}\text { G.5, H.6; G.6, H.7; G.7, H.8; G.8, H.9; H.6, I.7; } \\
\text { H.7, I.8; H.8, I.9; I.6, J.7; I.7, J.8; J.6, K.7 }\end{array}$ & $\begin{array}{c}85 / 174 \\
(49.7 \%)\end{array}$ \\
\hline North-East & $\begin{array}{l}\text { H.9, I.10; H.10, I.11; I.8, J.9; I.9, J.10; I.10, J.11; } \\
\text { I.11, J.12; J.8, K.9; J.9, K.10; J.9, K.11; J.10, } \\
\text { K.11; J.11, K.12; J.12, K.13 }\end{array}$ & $\begin{array}{l}339 / 1196 \\
(28.34 \%)\end{array}$ \\
\hline “G1” & $\begin{array}{l}\text { Burials with no assigned square or assigned } \\
\text { squares off the map (Appendix I) }\end{array}$ & $\begin{array}{c}21 / 73 \\
(28.77 \%) \\
\end{array}$ \\
\hline TOTAL & & $\begin{array}{c}1114 / 3192 \\
(34.9 \%)\end{array}$ \\
\hline
\end{tabular}

Table 1.1 The breakdown of the different geographical excavated sectors into their constituent 20 x 20m excavation squares, as determined by Frank Addison, and the attendant percentage of excavated burials, including a duplicate recording, with accompanying assemblages.

James Dixon and G. A. Wainwright took over the field directorship for the third season (November 1912 - April 1913), assisted by M. B. Ray and L. Dudley Buxton who 
replaced Derry (Addison 1949: 5). Wainwright was only present for a few weeks at the onset of the season, while Dixon continued until shortly prior to the end of the fourth season (November 1913 - April 1914). The use of sifting machines was instituted and arguably one of the oldest experiments in aerial photography occurred via the use of 'kite trolleys' carrying the kite along a string (Addison 1949: 6). A total of 310 graves were excavated in the South-West, West, South and North-East, but not East, sectors during the third season (Addison 1949: 5).

The fourth and final season (November 1913 - April 1914) spanned all recorded sectors of the valley, and yielded 1772 excavated graves. During this season, Reisner conducted limited excavations with a team of his trained Egyptian workmen (Addison 1949: 8-9). Reisner made now lost recommendations to Wellcome for improvements in excavation and recording methodologies for subsequent seasons. However, the onset of the First World War disrupted any plans for future seasons. Work did not resume after the war ended and Wellcome passed away in 1936 (Addison 1949: 9).

The Trustees of the Wellcome Trust subsequently agreed with the recommendation of Reisner to appoint Frank Addison in 1936. His remit was to analysis and publish the archaeological materials from the four field seasons. Addison was an archaeologist at the Institute of Archaeology, University College London, who had been Inspector of Schools \& Conservator of Antiquities in the Sudan from 1927-31. Wellcome had shipped the vast majority of the artefacts, all of the physical anthropological remains and the expedition's records to England - to both a depot in Maryleborne and a warehouse in Dartford (London). The Maryleborne staff classified the artefacts, repaired broken pottery sherds and reconstructed whole vessels where possible. The Dartford staff washed and sorted pottery sherds while leaving the remainder of the boxes unopened. The Dartford warehouse was flooded in 1928. The undamaged boxes were shipped along with the Maryleborne materials to Stanmore in Middlesex. It was here that Addison and his assistant (L.P. Kirwan) began their examination of Wellcome's materials and records in 1937. It was here too that pottery sherds considered to be undiagnostic or undecorated were treated as waste and discarded by Addison. The depot was sold shortly afterwards. The remaining artefacts and records were moved within London to Willesden for storage until after the Second World War, when Addison also completed his analysis. 
Addison (1949: 249-260) initially placed Jebel Moya in an uninterrupted sequence dating from $1000-400 \mathrm{BC}$, paralleling the then recognized chronology of the Napatan period of Upper Nubia, based on the purported presence of Napatan amulets, beads, faience and metal objects within select graves and on his reconstruction of the rate of soil deposition. He later modified his dating to the last centuries BC - AD 400, contemporary with the Meroitic state to the north, with its heartland in the Shendi Reach between the $5^{\text {th }}$ and $6^{\text {th }}$ Nile Cataracts, on the basis of (a) a purportedly Meroitic pot found in the uppermost stratum, and (b) a grave containing a purported Meroitic period pot overlying a burial with a Napatan period scarab (Addison 1956: 10-12).

Subsequent to the publication of Addison's investigation in 1949, the materials were spread out between different institutions. Oric Bates' field journal, geological reports from the third and fourth seasons, a topographical survey map, photographs and photographic negatives, plans of some of the burials excavated during the fourth and final field season, and cards describing artefacts were transferred by Addison to the Griffiths Institute (Oxford) in 1948. Representative pottery samples were donated to the British Museum and the Petrie Museum in London, artefacts to the Museum of Archaeology and Anthropology (University of Cambridge) and small (but unquantifiable due to the lack of consistent museum cataloguing) samples to other institutions (Table 1.2). Finally, the field cards were re-united with the osteological remains which had been transferred to the Duckworth Laboratory (headed by J. Trevor, University of Cambridge) after the Second World War ended. Independent of Addison, the Trustees of the Wellcome Trust appointed Trevor to examine the osteological remains. Trevor recruited two former pupils of his statistician colleague Prasanta Mahalanobis, R. Mukherjee (a trained bioanthropologist) and C. Rao (a statistician with experience of collaborating on bioanthropological projects). Their joint publication was released in 1955. 


\begin{tabular}{|c|c|}
\hline Location & Types of artefacts \\
\hline British Museum, London (U.K.) & Pottery \\
\hline $\begin{array}{l}\text { Duckworth Laboratory, Cambridge } \\
\text { (U.K.) }\end{array}$ & $\begin{array}{l}\text { Physical anthropological remains and } \\
\text { excavation records }\end{array}$ \\
\hline $\begin{array}{l}\text { National Museum of Sudan, Khartoum } \\
\text { (Sudan) }\end{array}$ & $\begin{array}{l}\text { Lipstuds, pendants, beads, polishing } \\
\text { pebbles, pottery, figurines, drills, points, } \\
\text { earstuds, stone implements, celts, rings, } \\
\text { copper coils, bracelets, ear pins, shells, } \\
\text { red pigment }\end{array}$ \\
\hline Louvre Museum, Paris (France) & Lipstuds, beads, hammerstones \\
\hline $\begin{array}{l}\text { Museum of Archaeology and } \\
\text { Anthropology, Cambridge (U.K.) }\end{array}$ & $\begin{array}{l}\text { Some pottery, stone implements, shells, } \\
\text { lipstuds, bone implements, bone points, } \\
\text { copper coils, beads, drills, palettes, } \\
\text { figurines }\end{array}$ \\
\hline $\begin{array}{l}\text { Nairobi National Museum, Nairobi } \\
\text { (Kenya) }\end{array}$ & $\begin{array}{l}\text { Lipstuds, pendants, stone implements, } \\
\text { beads, polishing pebbles, bracelets, rings, } \\
\text { pendants, shells, figurines }\end{array}$ \\
\hline $\begin{array}{l}\text { Peabody Museum of Archaeology and } \\
\text { Ethnology, New Haven (U.S.) }\end{array}$ & $\begin{array}{l}\text { Lipstuds, earstuds, stone implements, } \\
\text { beads, figurines, ochre, pendants, } \\
\text { bracelets, shells, copper coils, pottery, } \\
\text { drills, polishing pebbles, stone picks, } \\
\text { rings }\end{array}$ \\
\hline Petrie Museum, London (U.K.) & Pottery \\
\hline Pitt Rivers Museum, Oxford (U.K.) & $\begin{array}{l}\text { Lipstuds, beads, copper coils, celts, rings, } \\
\text { drills, awls, bone and stone implements, } \\
\text { pottery, ivory, figurines }\end{array}$ \\
\hline $\begin{array}{l}\text { Royal Ontario Museum, Toronto } \\
\text { (Canada) }\end{array}$ & $\begin{array}{l}\text { Lipstuds, beads, stone implements, } \\
\text { polishing pebbles, pottery, celts, copper } \\
\text { coils, shells, rings, iron implements, } \\
\text { pendants }\end{array}$ \\
\hline
\end{tabular}

Table 1.2 Current location of artefacts from Wellcome's 1911 - 14 expedition.

Subsequent scholars, Randi Haaland (1984, 1987) and, to a lesser extent, J. Desmond Clark (1973b; Clark and Stemler 1975) drew almost exclusively upon Addison's descriptions and illustrations of the pottery (1949) in claiming that there were similarities between select Jebel Moya pottery and Butana Group wares, dating to the fourth millennium $\mathrm{BC}$, from the neighbouring Butana region to the east (see section 3.2.2). Subsequently, Isabelle Caneva (1991) recognised a previously unidentified a late sixth - early fifth millennium BC Mesolithic component to the Jebel Moya pottery collection at the British Museum, but she did not undertake a re-examination of the remainder of the collection. In the mid-1990s, Andrea Manzo (1995) briefly looked at the non-Mesolithic pottery sherds from the British Museum collection, but his published description of them is problematic (see section 3.2.2). Finally, Rudolf Gerharz (1994) 
revisited the issue of chronology in the early 1990s. Gerharz's analysis relied entirely upon Addison's dataset, Caneva's study and the conclusions reached by Haaland and Clark over chronological similarities with Butana wares. He neither re-examined any of the extant expedition records or curated assemblages, nor undertook radiometric dating to define a temporal sequence for the assemblages, habitation remains and graves (see section 3.2.2). The conclusion reached by Gerharz was that Jebel Moya epitomized an early, potentially hierarchical, pastoral complex with mortuary remains spanning nearly 3000 years until ca. $100 \mathrm{BC}$.

The sporadic research on Jebel Moya since its excavation is therefore tantalizing, but superficial and sporadic. It was evident that a great deal remained to be done. The wealth of the extant archive provides a unique opportunity to extend the presently poor representation of social archaeological knowledge of the areas south of Khartoum by returning to critically re-examine the surviving excavation records and materials from Jebel Moya.

\subsection{Records concerning the Wellcome excavations at Jebel Moya}

Addison's task of making sense of and interpreting the disparate data from Jebel Moya was made harder by its field directors no longer being alive, with the exception of Wainwright (Addison 1949: VI). Addison visited Jebel Moya in 1938, but he otherwise relied on the descriptions provided by Wellcome's camp leader, Major Uribe, for understanding the camp life and activities during the second to fourth field seasons he was present. Moreover, no detailed contextual records existed pertaining to the first season, for which the only records available to Addison (1949) were John Holmes' manuscript diary, providing little information on archaeological context, and Wellcome's brief paper presented to the British Association in 1912. The diaries of Bates and Dixon, who perished during the first World War, were technical and provided little contextual and stratigraphic setting to the excavations (Addison 1949: VI). However, Addison (1949: 20) was aided by the existence of (1) anatomical, grave and object cards, (2) an object register which was abandoned by the excavators as it effectively became a duplication of the object cards, and (3) a grave list. The grave list was a book which noted the graves' depth below the modern ground surface and the 
section and stratum in which the grave occurred. Unfortunately, the original object register and grave list have not survived to the present day.

In reconstructing the geological strata of Jebel Moya, Addison was aided by a report written by the geologist P. Middleton during the fourth and final season (Addison 1949: 22-3). Four strata were discerned, demarcated Stratum A - D in descending order. The record of levels used by the excavators could not be located. Instead, Addison (1949: 18) used the reconstructed original surface of Stratum $C$ as his datum point, a reference which I have retained for the sake of continuity. Addison's secretary, M.J. Halford, attempted to bring the information together by overseeing the compilation of a Register of Graves (Addison 1949: VI).

The present study is based on the expedition's surviving records and material culture. It also draws primarily upon the published works by Addison (1949), Mukherjee et al. (1955), Caneva (1991), and Irish and Konigsberg (2007), as well as the unpublished study of dental characteristics by Rachel Hutton MacDonald (1999). From the Griffiths Institute, all the records were consulted in order to determine whether any pertinent information had been missed in Addison's (1949) publication. At the Duckworth Laboratory, I was able to examine and digitise the anatomical, grave and tombs cards (Table 1.3). These cards together record details of each excavated from the second to fourth seasons. Mercedes Okumura, who was a research curator at the Duckworth Laboratory, kindly made her Access database available, which provides a catalogue of the human osteological remains. Okumura's database records the locality, original catalogue numbers (relating the remains to the grave cards), the presence or absence of cranial, mandibular and dental remains, the composition and state of preservation of the remains, and her re-sexing determinations (see section 5.4).

\begin{tabular}{|l|c|}
\hline \multicolumn{1}{|c|}{ Type of excavation record } & Number \\
\hline Anatomical cards $\left(4^{\text {th }}\right.$ season $)$ & 302 \\
\hline Grave cards $\left(2^{\text {nd }}\right.$ and $3^{\text {rd }}$ seasons $)$ & 51 \\
\hline Tomb cards $\left(2^{\text {nd }}-4^{\text {th }}\right.$ seasons $)$ & 5360 \\
\hline Total & $\mathbf{5 7 1 3}$ \\
\hline
\end{tabular}

Table 1.3 The types and numbers of digitised excavation records from the Duckworth Laboratory. 
I used the information recorded on the cards and from the osteological database to construct a new and expanded Register of Graves (Appendix II). I cross-correlated the information with Addison's (1949) Register of Graves. Where there was a conflict between information written on the excavation cards and in Addison's register, I used the former. The data in the new Register of Graves consists of:

- $\quad$ The excavation season (in years).

- $\quad$ The burial number.

- $\quad$ The square number.

- If the burial was originally omitted from Addison's grave distribution map and needed to be added.

- Distance below the ground surface at the time of excavation.

- Distance above/below surface of Stratum C (which serves as Addison's datum point).

- $\quad$ The grave type.

- Burial orientation.

- $\quad$ Length of body.

- Orientation co-ordinates.

- Burial positioning.

- $\quad$ Level of disturbance.

- $\quad$ Field sexing.

- Laboratory sexing.

- $\quad$ Presence of skeletal elements in the field and the Duckworth Laboratory.

- $\quad$ Presence of artefacts (marked in burial association and in the grave infill).

- $\quad$ Present day location of the artefacts.

- Number of the linked scanned excavation card.

- $\quad$ Further remarks on the burial positioning.

My new Register of Graves comprises a total of 2882 recorded graves, of which 2791 were excavated; the remaining 91 were unexcavated but allocated grave numbers by the field directors. In total there are 3191 recorded burials in the 2791 excavated graves, of which 3135 are human burials distributed across the whole of the excavated sectors of 
the valley (Table 1.4). Of the recorded human burials, 1114 (35.53\%) have accompanying burial assemblages. The spreadsheet containing the data for the new Register of Graves was linked in the GIS database to the distribution map of the graves compiled by Addison (Appendix I).

\begin{tabular}{|l|c|}
\hline \multicolumn{1}{|c|}{ Burials } & Number \\
\hline Human burials & 3135 \\
\hline $\begin{array}{l}\text { Not a grave or pit } \\
\text { (shells in hole, arrangements of } \\
\text { stones, collection of pottery wares, } \\
\text { collections of assorted objects) }\end{array}$ & 6 \\
\hline Animal burials (dog, cow) & $\begin{array}{c}18 \text { cow } \\
\text { cow \& dog } \\
10 \text { dog }\end{array}$ \\
\hline Pits & 10 \\
\hline Burials with details unrecorded & 11 \\
\hline
\end{tabular}

Table 1.4 A breakdown of the recorded and excavated burials as determined from the new Register of Graves.

In addition, I contacted Kathy Schick and Nick Toth at the University of Indiana, who curate J. Desmond Clark's materials and unpublished notes from his different expeditions. These were deposited with the University of Indiana upon his death. The following records of Clark's were located concerning Jebel Moya:

- A very brief short finds register of pottery, bone and stone.

- A very short list of pottery found during his test excavation. It consists of the number of sherds, wares, vessel type, rim type, base type, decoration type, possible decoration (exterior and interior), colour (exterior and interior), holes, internal scouring, diameter, paste and comments. However, no key to the coding system is readily apparent.

- A draft copy of the subsequently published paper Early domesticated sorghum from Central Sudan (Clark and Stemler 1975).

- A notebook mostly composed of photocopies of published articles relating to the site of Shabona to the north of Jebel Moya. There is a typed section in the front titled Preliminary report of an archaeological and geomorphological survey in the Central Sudan, January to March, 1973; the latter was published (Clark 1973).

- Two pages of what appears to be cross-sections of the stratigraphy from the test 
pits dug by his team at Jebel Moya

Taken together, these data permit various analyses examining bodily orientation and the spatial clustering of burials, the spatial and temporal distribution of grave goods and pottery, the attribution of grave goods to age sets, and the mortuary death profiles and its spatial placements.

\subsection{Structure of this research}

My research therefore re-evaluates the nature and timing of the occupation of Jebel Moya. First, the literature on social complexity and mortuary theory is reviewed, and new questions are posed for their applicability to pastoral cemeteries in Chapter 2. In Chapter 3, reliable radiometric dating of Jebel Moya, for the first time via luminescence dates, is tied into an attribute-based approach to discern three distinctive pottery assemblages, each corresponding to a phase in the site's use or occupation.

Underpinning the subsequent Chapters $4-6$ is a re-examination of the original excavation records and the creation of a new Register of Graves, cross-correlated with Addison's original Register and the integrated with both results of the re-sexing of the extant skeletons curated at the Duckworth Laboratory and previous bioanthropological analyses (Hutton MacDonald 1999; Irish and Konigsberg 2007; Mukherjee et al. 1955). The resulting information and the original grave distribution map are linked together in a GIS database, permitting the plotting of multiple variables such as the quantity and spatial variability of grave goods, the number of adults and their sex, the number of infants, artefacts of demonstrable social significance in the mortuary realm, spatial neighbourhoods, and potential clusters of artefacts and burials.

Analytically, new statistical and spatial analyses such as cross-pair correlation function and multi-dimensional scaling provide information on zones of interaction across the mortuary assemblages. This is particularly valuable as social identities are fluid and defined and modified in relation to internal and external relationships, both material and personal (Richard and MacDonald 2015: 23-4). Finally, in Chapter 7, Meroitic and nonMeroitic mortuary locales from the central Sudan and Upper and Lower Nubia are 
examined to show how changing social, economic and power relations were conceptualised, and to highlight Jebel Moya's potential to serve as a chronological and cultural reference point for future studies in south-central and southern Sudan. 


\section{Chapter 2: The evolution of complexity theory and mortuary studies}

There is no direct, inherent correlation between complexity as a conceptual tool and the material expression of formalized inequality, which goes against the tendency of previous neo-evolutionary studies to look for patterns in differences and similarities between societies and to regard variation in grave goods as reflecting the monopolization of power and resources in life (McGuire 1983; McGuire and Paynter 1991; Paynter 1989). The latter was used to extrapolate the presence of incipient, transient and semi-permanent hierarchies. The argument was that the diversity resulted from (1) increased socio-cultural and thus mortuary heterogeneity as elites consolidated their control over more diverse groups of people and material resources, and (2) simultaneous differential levels of access to those resources depending on the scale of social hierarchies and the number of groups involved (McGuire 1983: 101, 104, 109). As such, my examination of how social practices and structures were reconstructed and reinterpreted by the living at Jebel Moya for the mortuary domain required the framing of questions at different scales of analysis.

For the present study, the difficulty lay in determining how the diverse material and spatial dimensions of life were reflected in and transformed through burial rites, and how they could be reconstructed from the resulting material and skeletal remains. After all, different members of society are disposed of according to the social norms which recognise that death is a transformative process and is an integral part of the conceptual reproduction of the social order (Bloch and Parry 1982). Mortuary rituals help bring understanding to the arbitrary nature of death and to re-establish and re-enforce social order amongst the living (van Beek 2012). As acknowledged by Fried (1967: 112), though burial practices may reflect aspects of socially stratified societies, the resultant material traces may not "confirm to later generations the existence of differential status".

Status relates to the nature of social power between kinship groups which is situational, fluid, overlapping and intersecting (Chapman 2003a; Mann 1986; Pauketat 2007). Their changing inter-relationships creates material differences. Such expressions of shifting alliances or increases/decreases in power can result in material differences between spatial clusters of burials (Wobst 1977). Overall, burial differences may be seen as a 
form of social advertising by relatives and/or social elites amongst the living. Deciphering to what extent spatial or material pointers remain in the mortuary domain to indicate elements of relatedness and social structure continues to be a central topic in Saharan and North-East African studies (Di Lernia and Manzi 2002; Dunham 1999; Salvatori and Usai 2008a; Smith 2002).

This chapter outlines the history of cultural complexity studies in Africa and the Sudan, compares archaeological models for mortuary cemeteries and details the approach used in this study. I argue that the most suitable theoretical approach to understanding how social structure is represented in the mortuary domain at Jebel Moya is through treating it as a depiction of ideologically-derived representations of socio-economic status relations which have horizontal and vertical dimensions.

\subsection{Forms and processes of political and social organisation}

The framing of archaeological research was dominated until the 1980s by a tendency to downplay the full range of social diversity while focusing on high-level society as the epitome of social formation through the development of over-arching models. These approaches have their conceptual origins in the old Enlightenment ladder of social progress. In the twentieth century, this evolutionary ladder was reworked by Elman Service $(1958,1962,1971,1975)$ and others to include a neo-evolutionary progression of band-tribe-(bigman collectivity)-chiefdom-state (see, for example, Johnson and Earle 2000). Later, Boyd and Richerson (2005) developed their dual inheritance theory which instead integrated ritual and social inequality into a model outlining how ritually sanctioned justification may be monopolized by high-ranking individuals to increase their lineage's social status.

Such studies tended to remain rooted within a social evolutionary paradigm that conflated individual agency, identity, diverse power structures and interactions, and mechanisms of economic and social control (Kohring and Wynne-Jones 2007). The characteristics of many ethnographic societies are too variable for social and political evolution to be condensed and categorised into a three or four or five-fold sequence. This is acknowledged in Yoffee (2005) and others' (for example, Chapman 2003a and 
Pauketat 2007) attempts, to move beyond punctuated changes in socio-political and economic entities by focusing on developing appropriate models of social complexity at a regional scale.

Indeed, the manifestations and nature of egalitarian political and socio-economic societies are well documented in the literature (Barnard 1992; Fried 1967; Smith 2000). What is important to note is that the development of a ranked society from an egalitarian base in a pristine situation occurs through a combination of indigenous stimuli and variables (Fried 1967). Such societies regulate behaviour through shared group membership differentiated into a formalised kinship network based on descent principles, labour divisions based on age and sex, redistributing integrated economic resources on a village as opposed to individual level (thus enhancing the status of the redistributor) and having the loci of co-operation centred around the group (Fried 1967; McElreath et al. 2003).

Moreover, fieldwork conducted amongst the Moors and Tuaregs of the Sahara and Sahel (Bonte et al. 1977), the Dii of Cameroon (Muller 1996) and the Nanumba polity in northern Ghana (Skalnik et al. 1996), amongst others, has reinforced the notion of recognition of multiple forms of political and social organisation. The incorporation of symbols into the ideological trappings of political power raises questions on the integration of these processes with the continual re-negotiations of social power in social hierarchies.

McElreath et al. (2003) describe three variables distinguishing the distribution of traits which are useful in demarcating internal and external cultural expressions and the emergence of social hierarchies:

- $\quad$ Differences within bounded territories will be less than at the periphery.

- The division of norm differences should have a clear correlation to marker traits.

- Markers with the greatest differential potential should be amongst the first highly visible signs. 
Further delineations are required for segmentary lineage systems. In them, ritual and political influence have contrasting spheres of control: ritual activities in the peripheral areas are in constant flux, while the seat of political authority is centred on the core domains of the territory held in place by checks and balances of ritual sanction and institutionalised interdependence (Southall 1988b). Kept together by ritual needs, which require a separate system dependent upon age and physical organisation, the effect of kinship units within clan and segmentary lineages is to accept subordination without coercive pressure being exerted (Bonte et al. 1977; Southall 1988b). Among some modern Afro-Asiatic speaking pastoralists, the kinship unit is also the production unit, barring access to pasture land outside units, and whose reproduction replicates the community's inter-kinship relations (Bonte et al. 1977). The tribute collected favoured conditions in which tendencies for stratification arose and flourished. The accumulation of cattle is also an accumulation of wealth, with reinvestment and its consequent work affecting the social and economic fabric of the relevant cultural unit.

The Nanumba political structure of northern Ghana is an example of a society whose power does not rest on the formalised structure of a state, but whose different groups and institutions function interdependently through a shared symbolic/cognitive manifestation of ritual, tradition and authority as the source of legitimation (Skalnik et al. 1996). Another example of different but intertwined political entities is the political and ideological groupings of the Dii and Gbaya in Cameroon as examples of different political entities, as highlighted by Muller (1996). The Dii chief undergoes a series of induction rites upon his succession which are seen to legitimise his rule and provide him with the strength, knowledge and humility to govern. Through this process, the right of rulership is based on contracts between the institution of the chief, who is also the chief priest, and those who are ruled. The Gbaya are a population living to the south of the Dii. While they too are organised into clans, the difference between them and the Dii is that the Gbaya have no formalised hereditary leadership; their ideology of egalitarianism promotes splinter tendencies (Muller 1996).

Further illustration of political fluidity within and between societies, this time with a stronger pastoral economic component, is found in the politically stratified Eastern Tuareg of the Saharan Ahagger and the Aïr Tuareg of Niger. Their system of production 
relies upon a division of labour between social classes, which arose from exploiting the trans-Saharan caravan trade in pre-colonial times (Saenz 1991).

While the contrasting manifestations of social complexity are influenced by different internal and external stimuli, demographic factors must also be accounted for. Access to status and the resource base is based on age, gender and kinship criteria which are well socially defined, as are the land boundaries in which the lineages move (Southall 1988a). Ritual leadership roles, which overlap to a degree, are present but they are primarily divorced from political structures (Skalnik et al. 1996). As such, studies of mortuary practices must attempt to address the processes which are conducive to the evolution and reconstruction of socio-economic and ideological structures.

\subsection{Expressions of social complexity in the Saharan and Sahelian Belts}

In Sudanese mortuary studies, processual methodologies have predominated, preceded by and in conjunction with culture-historical frameworks heavily influenced by practices from early ancient Egyptian studies. This section looks at how approaches to social complexity have been historically applied in North Africa. It is noted that archaeologists working in the Sudan need to pay closer attention to theoretical developments elsewhere in the Sahelian Belt and in wider Africa.

\subsubsection{History of the cultural complexity debate in North Africa}

Over the last four decades in particular, debates on cultural complexity in Africa have centred around the origins and spread of pastoralism, and/or economic diversity, the manifestations of diverse subsistence specialists and - especially for North-East Africa - monumentality (Di Lernia 2001, 2006; Di Lernia and Manzi 2002; Edwards 1996; Fuller 2003; Garcea and Hildebrand 2009; MacDonald 1998; McIntosh 1998; McIntosh 1999a; Smith 1992; Török 1997; Wendorf et al. 2001).

Previously, Susan Keech McIntosh and Roderick McIntosh (1988) argued that there is no convincing evidence for cultural hierarchy in West Africa and the Sahara before the advent of iron production in the first millennium BC. Subsequently, Roderick McIntosh 
(1993, 1998) has contended that corporate diversification (non-hierarchical, kinshipbased, specialist communities living in symbiotic relationships) developed into horizontally, rather than vertically, stratified societies, or heterarchical social forms, prior to their disruption by contact with Arabic 'imperial traditions' in the late first millennium AD. His version of heterarchical communities living in the Niger Delta is founded on the premise that environmental unpredictability resulted in the "integration of the non-hierarchical regional social networks comprised of kinship cross-cutting, pan-residential corporations that characterise many pre-state societies" (McIntosh 1993: 111). More recently, Kevin MacDonald (2011b) has argued instead in favour of a plurality of hierarchical and heterarchical structures dependent upon contextualised political traditions in West Africa stretching back to at least the first millennium BC.

At around the same time, Wendorf and Schild (1998) hypothesised that North-East Africa was the location for the claimed earliest expression of institutionalised pastoral social inequality. The postulated degree of control over labour and the expression of ritual activity by Nabta Playa's Late Neolithic ( $c a .5000$ BC) inhabitants for the construction of the cattle tumuli and stone structures has been heralded as the earliest material manifestation of hereditary socio-economic inequality in the Egyptian Western Desert, which subsequently influenced the ideology and social structures of the Predynastic Nile Valley inhabitants (Wendorf and Schild 1998; Wendorf et al. 2001).

By contrast with the Nabta Playa socio-political model, Kevin MacDonald (1998) has put forward early Saharan pastoral complexity as the harbinger of (particularly) sedentary West African states. His economic model of mobile elites, arising in the Eastern Sahara pre-4000 BC, but not necessarily first manifest at Nabta Playa, and spreading across the Sahara by 1800 BC, stressed long-distance mediums of exchange with cattle serving as repositories of wealth. He also argued for the use of tumuli fields as social and territorial boundary markers, and for the applicability of polished stone items as primitive currency between and amongst the different pastoral societies across the Sahara. He concludes that the incipient social complexity, with transitory leadership, eventually took hold and developed into complex hierarchical societies such as seen at Dhar Tichitt from 2000 BC onwards (Holl 1993, 1998) and Kerma starting around 2500 BC (Bradley 1992). 
The Italian-Libyan Archaeological Mission, led by Savino di Lernia in the Acacus mountains and the Messak Settafet escarpment (south-central Libya), has also elucidated the concept of territorial marking in a Saharan context. Here, tumuli containing human burials first appear $c a .4000 \mathrm{BC}$, positioned first along strategic wadi routes and later in cemeteries (Di Lernia 1999; Paris et al. 1997). Slightly to the south at Adrar Bous (Niger), human-interred tumuli occur from $c a .4300 \mathrm{BC}$ onwards (Milburn 1996, Paris 1995). This ideological adjustment to how humans were buried now related and fixed social groups permanently to focal points in the landscape. Social differentiation by age and sex can be discerned at the site of In Habeter (Messak Settafet) (Di Lernia and Manzi 2002). Taken together with the tumuli of Wadi Tanezzuft (Acacus Mountains), these are hypothesised to be the first visible signs of vertical differentiation in the Central Sahara and mark a separation between political and religious leadership through hierarchical differentiation: the social identity and memory of the individual was enshrined through the labour investment in and strategic place-making of human burials in the landscape.

Further to the east, at Sai Island in northern Sudan, attention has been drawn to the role that shifting networks of social relations and spheres of influence played in opening up new trading networks. These were accompanied by attendant changes in economic makeup, demography and cultural differentiation of some of the cultural entities involved in the Pre-Kerma periods from $5000-2600$ BC, as socio-ideologically materialised in ceramic assemblages (Garcea and Hildebrand 2009). Such socioeconomic changes occurred in tandem with shrinking geographic scales and increasingly localised social differentiation, with opportunities for specialised extraction and production. The shift from diffuse interactions to smaller, more defined locales and activities across social boundaries were proposed to have created the necessary groundwork through which increasingly sophisticated cultural complexity could develop and then flourish with the advent of Kerma (Garcea and Hildebrand 2009).

However, it was 1999 when the cultural complexity debate in Africa received its major conceptual boost. Combining archaeology, oral traditions and historical linguistics, the key edited volume Beyond Chiefdoms: Pathways to Complexity (McIntosh 1999a) aimed to challenge the prevailing neo-evolutionary paradigm which had marginalised 
Africa for the previous two decades in the debates on the forms, trajectories and manifestations of social complexity. Arguing also against Fortes and Evans-Pritchard's (1940) lumping of African societies into state and stateless categories characterised by kinship of lineage systems, the contributors presented case studies where political power was diffused heterarchically and invested in diverse structures such as age-groups, lineages, spirit cults and title societies.

At their heart, these models recognise that social complexity in the Saharan and Sahelian belts was and is composed of variable sources of power counterpoised between diverse population segments (McIntosh 1999a). These diverse political systems reflected different trajectories of power and different socio-economic resources, from centralised states to segmentary societies and to new complex polities arising on the internal and external frontiers of other polities. These social relationships, their interconnectivity and mediation through communities, pastoral wealth, landscape and material culture created and create the different, overlapping modes of complexity embedded at all levels of society underpinning individual and corporate identities.

With multiple loci of power, African ideologies and conceptions of power often balance several competing interests transecting society, resulting in contemporary polities with different scales and levels of integration across the vast continent. Where present, individual offices of leadership often involve shared distribution systems such that ritual suzerainty and political sovereignty did and do not necessarily correspond (Southall 1999). Through the understanding that complex societies can exist without the presence of monumentality, the contributors to Beyond Chiefdoms: Pathways to Complexity also re-orientated their focus on regional ecological, cultural, and historical fluidity and attendant processes of cultural development and their material manifestations.

These and other non-African attempts to move on from the perceived stagnation of the "complex society" debate have drawn upon theoretical tools such as, for example, Giddens' (1984) and Bourdieu's (1977) theories of structuration and habitus (whereby individual social engagement is an embodied experience and cannot be divorced from institutions and society). Also utilised are concepts of agency (demonstrating that social landscapes, individual experiences and technology are inter-connected within socially constructed environments) (Dobres and Robb 2000) and, to a lesser extent, indirectly 
biased transmission (where a cultural trait developed or utilised by a successful or high profile person is adopted by the wider society if it proves advantageous) (Richerson and Boyd 2005) to explain how social complexity has been manipulated and expressed through material culture.

How complexity emerges within (usually extra-African) societies has been the subject of numerous studies with different formulaic definitions of complexity and evolutionary trajectories (Arnold 1996; Earle 1989, 1991; Johnson and Earle 2000; Southall 1999; Southall and Gutkind 1970; Vail 1991; Yoffee 2005; Yoffee and Sherratt 1993). One such study used these theoretical constructions to model how transient, achieved status could have evolved into permanent elites by using agency as the catalyst and structuration as the cultural limitations framing the process (Spencer 1993). Such agencies can include exchange, inter-regional cultural exchanges, and the continual fluid evolution of linking discrete landscapes, including mortuary areas, into conceptual systems (Brass 2007; Smith 2002). However, the analytical focus of these studies has tended to be pitched at the level of socio-political formulation and integration. Some recent studies have attempted to move beyond such vocabulary, recognising that creates conceptual obstacles through its historical baggage within socio-evolutionary theories as deployed by archaeologists (MacDonald in press; McIntosh 1999a; Pauketat 2007).

Such studies attempt to reformulate complexity as a conceptual tool through approaching the material culture with the aim of elucidating the multiple layers and scales of meaning, and their interactions. They go beyond the recognition that archaeological cultures do not in themselves equate to ethnic groupings and artificially constructed entities. This has the effect of removing artificial boundaries on what constitutes a complex society and its material manifestations (Hegmon 1998, Kohring and Wynne-Jones 2007). They explore how everyday practices and beliefs operate(d) within multi-layered activities as part of complex social dynamics and how they are crystallised in material form. The resulting artefacts are fragments of a symbolic reservoir of identity (kinship, lineage affiliation in intra- and inter-group relationships) transmitted through social networks, moulded by the transformational effects of the attendant socio-economic benefits and costs, although just how it is re-moulded in the mortuary domain for pastoral societies has not been extensively investigated by anthropologists (Baroin et al. 1995; van Beek 2012). 


\subsubsection{Conceptualising the construction of social complexity in the Sudan during the}

\section{Neolithic and post-Neolithic}

Recognising the need to use complexity as a conceptual tool, although still operating within a predominantly processual framework, Sandro Salvatori and Donatella Usai (2008a) have argued that shifts in the ideology of status need to be examined more closely in the Sudan. They contend that it was the advent of co-residential patterns in central Sudan by different lineages and/or corporate groups which laid the groundwork of social stability and co-operation behind the rising trend of population growth in the fifth and fourth millennia BC, and which culminated in the rise of Kerma (Salvatori and Usai 2008a: 132).

The recognition of such dynamics, which do not focus primarily upon structural entities like monuments, has not yet adequately permeated archaeological practice of all time periods in the Sudan. There has been a failure to build more theoretically sophisticated models of mortuary behaviour and practice since Arthur Saxe's (1971) seminal paper on a combined living and mortuary site in the Wadi Halfa, in which he modelled mortuary practices as broadly reflecting the social practices of the living.

Instead, focus has partly been on explaining the presence or absence of different selective archaeological features. For instance, Late C-Group III (ca. 1800 - 1500 BC, northern Sudan) heterogeneity is framed as being exhibited by diverse forms of pottery decoration, some of which are not present in the preceding C-Group I and II, and which is a consequence of the complex trade and cultural network links to the north (Egypt), south (Kerma) and into the Eastern Desert (Pan Grave tradition) (Edwards 2007: 98; Hafsaas 2006). In addition, the explanations for an absence of elaborate graves outside of the ruling Kerma elite vary from Egyptianisation of the elites to suppression of their status (Edwards 2007: 98). Such hypotheses, part culture historical and part processualbased, do not adequately model the nature of internal social change and how such change is expressed through mortuary practices.

Other processual methodologies have been employed in studies on semi-settled EarlyLate Neolithic (fifth - end of the fourth millennium BC) agro-pastoral sites such as those of Kadero (Krzyźaniak 1991) and El Geili (Caneva 1988), and more recent studies at 
other sites in the Dongola Reach (Upper Nubia) and Central Sudan (Reinold 2008; Sadig 2010; Welsby 2001). For example, Krzyźaniak assessed the quality and quantity of the grave goods to determine the emergence of social inequality at Kadero I. He divided the graves into four classes based upon his determination of what constituted a rich burial, very much following a strict processual approach. Class 1 consists only of skeletal remains, Class II comprises burials with one pottery vessel, Class III comprises burials with one to three pottery vessels and small personal adornments, while Class IV is comprised of burials with fine pottery vessels, beakers, weapons and ornaments. Krzyźaniak argued that Class III and IV graves represented elites and reinforced his argument by the spatial separation of graves attributed to Class IV from Classes I and II. He concluded that the mortuary pattern for the burial grounds was the consequence of an increasing concentration of goods and political power in the hands of incipient elites, although its emergence was undetected in the corresponding settlement remains.

Another example is Reinold's (2008) attempt to elucidate the meaning behind burial practices at el Ghaba and el Kadada. He focused on the spatial relationships between the graves. Clusters of graves were conceived as belonging to smaller social groups, while the accompanying items were correlated with activities undertaken when alive and by extension with their social status. A similar approach was adopted by Caneva (1988) in her analysis of the El Geili cemetery, purportedly contemporary with el Kadada. She concluded that the peoples buried in both cemeteries drew from a shared reservoir of mortuary beliefs.

Such processual approaches to social personas and to the spatial distribution of graves are dependent upon the social values ascribed by the excavators to the grave goods, while the deposition of the grave goods was taken as being reflective of the social life and status of the people when alive. For example, Krzyźaniak (1991) postulates that maceheads at Kadero are symbols of an elite, while wealthy graves at Kadruka in the Kerma basin (northern Dongola) have been ascribed to local chieftains (O'Connor 1993). These interpretations do not critically engage with the literature on the variable manifestations of social complexity and their application in localised contexts (for example, McIntosh 1999a; Pauketat 2007 and Wynne-Jones and Kohring 2007). 
By contrast, one of the key studies of Sudanese mortuary practices, that of the R12 cemetery in the Dongola Reach (Salvatori and Usai 2008a), draws upon both processual and post-processual bodies of mortuary theory. They note that it is likely that the full range of social behaviours, status and wealth distribution was not represented in the burial treatment for different age groups. They proposed that ideological drivers were behind how different people of different ages were ceremonially acknowledged and represented. In a further cautionary note for mortuary studies in the region, they concluded that "social status seems to be well mirrored by grave goods more in terms of quantity than quality" for those burials where wealth appears to be represented (Salvatori and Usai 2008a: 135).

For later periods, the centralised economic and ritual models derived from studies of Pharaonic Egypt have traditionally been applied to the early Sudanese states, with the advent of the Kerma state and its successor Kushite Napatan and Meroitic states from ca. 2500 BC - AD 350 (Adams 1977; Török 1997). These models place heavy emphasis on architecture, textual analysis, and osteological studies and epigraphy remains to form a historical outline of events. One consequence of this influence is that there has been no widespread, comparative, systematic and theoretically informative study of the Napatan state's (ca. $800-300 \mathrm{BC}$ ) mortuary practices. What is known is that there are changes in practice spatially and temporally, with a vibrant mixture of indigenous and Egyptianised forms, though the details of these changes in socio-ideological practices have yet to be fully elucidated. A major example of the inappropriate influence of this early Egyptological approach to Nubian studies is that the early reports on the cemeteries excavated from this time period, for example at Sanam, El Kurru, Nuri (Napatan) (Griffith 1923; Reisner 1923) and Meroe (Napatan, Meroitic) (Dunham 1957, 1963), have insufficient data about age, sex and the distribution of grave goods across the cemeteries. The focus was on the pyramids and proposed elite burials, overlooking likely significant developments and changes in social practices over these periods - for example, Sanam alone has an estimated 1500 graves of various kinds. The formation of more sophisticated chronological frameworks for subsequent detailed re-analyses of their internal development is essential, and initial attempts at the former in particular are currently underway (Yellin 2012). 
Consequently, Sudanese mortuary archaeology has largely has not kept pace with archaeological theoretical developments elsewhere in Africa, particularly in relation to the study of ritual practices and social relations. Renewed focus on different scales of interaction and their dynamics, ranging from the individual to institutional or organisational levels, would open up new avenues for research and for the development of new models on how they may be recognised in the material record.

\subsection{Modelling social organisation in mortuary assemblages}

Anthropological and archaeological enquiries have recognised the composite make-up of mortuary rites and their manipulation of social relations through material culture, social actions, socio-ideological and economic ideals, the human body, and gender expressions (Gilchrist 1999; Homiak 1995; Pauketat 2007; Rakita et al. 2005; Turner 1996; Vida 1998). In this section, early influential studies are detailed and evaluated, as are the myriad of more recent approaches.

\subsubsection{Early mortuary practice studies}

From the early days of anthropology and archaeology, mortuary rites and their material manifestations have been considered under different guises. These range from Petrie's Predynastic excavations in Upper Egypt (Petrie and Quibell 1896) to Kroeber's (1927: 314) dismissal of mortuary patterning as "fashionable" in his ethnographic crosscultural study:

"In their relative isolation or detachment from the remainder of culture, their rather high degree of entry into consciousness, and their tendency to strong, emotional toning, social practices of disposing of the dead are of a kind with fashions of dress, luxury, and etiquette... It may be added that in so far as mortuary practices may be accepted as partaking of the nature of fashions, they will tend to discredit certain interpretations based upon them."

Kroeber's stance, echoed in 1969 by Ucko (1969), was highly influential. A generation of anthropologists and archaeologists in the Anglo-Saxon academic sphere proceeded 
extremely cautiously with few innovative studies of mortuary ritual advanced over the interim decades engaging with inferences and approaches being developed in mortuary studies elsewhere (Gluckman 1937; Härke 2000; Wilson 1939).

However, the 1960s were the beginning of a renewed critical focus on mortuary studies. Robert Hertz's “Contribution a une étude sur la representation collective de la mort", originally published in 1907, was translated into English and published in 1960. He examined issues of secondary burial and performance of mortuary rites. Its publication coincided with another translation, that of van Gennep's 1908 subsequently highly influential work "Les Rites de Passage". A florescence of anthropological work followed, such as Goody's (1962) ethnographic study of the LoDagaa (West Africa) and Bloch's (1971) Merina mortuary practices.

It was in this intellectual environment that Saxe (1970) wrote his influential unpublished doctoral dissertation looking at how socio-cultural systems were inter-related with mortuary practices. He formulated eight hypotheses which he tested against three ethnographic studies in an attempt to develop a model that could be applied more widely to elucidate the manner of social complexity and the structural nature of the living from the mortuary practices. His hypotheses were formulated to determine the extent to which the living social persona and/or socio-political structures were mirrored in death rituals. The effect of his work was to orient the focus of archaeologists, particularly in the Anglo-American tradition, excavating cemeteries to re-examine the remains from a social perspective.

Saxe's (1971) Hypothesis 8 was particularly interesting as it proposed linkages between territoriality, degree of sedentism, social structure and cemeteries. It has $19^{\text {th }}$ century antecedents, from Fustel de Coulanges' emphasis on private family tombs (Morris 1991: 150) to Maine's (1883) slant on religious beliefs affecting inheritance patterns. Saxe (1970: 121) also acknowledged his reliance on the ethnographic work done by Mervyn Meggit amongst the Mae Enga of New Guinea when formulating his neo-evolutionary model:

"In Hypothesis 8 we have merely carried Meggitt's formulation one step further. Since effective agnation is a response to ecological factors, and ancestor-centered 
dogma is a reinforcement of agnation, we have hypothesized a direct link between ecosystem factors and treatment of the dead (who are the ancestors) as mediated by cultural practices such as inheritance rules."

The effectiveness and applicability of Saxe's use of Meggitt's data has been called into question by subsequent studies showing that the formation of Melanesian cemeteries produced a disconnect with lineage skull cults which resulted in a weakening of land ties and of agnation (Strathern 1981). Furthermore, the underlying basis for Saxe's hypotheses derived from ethnographic observations of variable quality of rituals rather than comprehensive studies of the entire mortuary ritual and aftermath; as such, it does not adequately account for variable degrees of preservation in the archaeological record which affect the recognition and reconstruction of his hypothesised social personae.

Saxe's analytical techniques heavily influenced the landmark edited volume by James Brown (1971) which concluded that inferences could be drawn from mortuary data to infer status/rank. This has subsequently been elaborated to justify assigning elite rank to individuals buried with rare and/or notionally valued items (Peebles and Kus 1977; Tainter 1978). Binford's (1971) cross-ethnographic paper in the same volume, drawing from 40 cultures represented in the Human Relations Area Files (HRAF), sought to refute Kroeber's assertion of mortuary rituals being "fashionable" and to replace it with a model correlating funeral practices with modes of subsistence characterised by different levels of socio-economic and structural complexity. He argued that the social persona of the dead had to be evaluated and that these were expressed through age, sex, social standing, group and sub-group affiliations, nature of death and the locale of disposal.

Binford (1971: 14-5) also proposed that "the heterogeneity in mortuary practice...of a single sociocultural unit would vary directly with the complexity of the status hierarchy, as well as the complexity of the overall organisation of the society which regard to membership units and other forms of sodalities." He divorced burial practices from everyday life and stated that its variations should be linked to the living's organisational structure. He concluded "that these findings permit the generalization that the form and structure which characterise the mortuary practices of any society are conditioned by the form and complexity of the organizational characteristics of the society itself" 
(Binford 1971: 23). In other words, the range of social personae will determine and be reflected in how individuals are memorialised or symbolised in death. He further hypothesised (Binford et al. 1970) that the formal spatial structure would be directly correlated with various social units and their activities. Saxe (1970) expanded upon these determinants by using componential, evolutionary, information, role and systems theories in his development of a set of principles which linked mortuary behavioural patterns with the degree of complexity in the living's social structures.

The influence of the Saxe-Binford approaches was to situate mortuary practices within social contexts, recognising different degrees of treatments and possible distinctions between types of artefacts in mortuary disposal.

\subsubsection{Moving beyond the Saxe-Binford modelling}

Saxe's paper was the basis for later modelling of social organisational type, rank and status to determine the nature of social inequality using, amongst others, cluster and principal component analyses (Shennan 1975). Using the conceptualization of identity as "social persona" or social identity in different relationships (Goodenough 1965; Saxe 1970), this new focus proposed parameters by which the social standing of the deceased can be measured through energy expenditure (Brown 1995; Tainter 1978). It stressed correlations between energy expenditure, body treatment and status, and was ultimately derived from ideas formulated by John Lubbock (1900) in his work on British tumuli. It gained currency, especially in North American archaeology, as part of an evolution of processualism in which positivist mortuary studies played a large role. An example of one such attempt was to look beyond the technical achievements in the construction of the Old Kingdom Egyptian pyramids to understand burials in terms of their social role as "powerfacts," with mortuary rituals being "one of the most socially, economically and politically sensitive indicators of the rise of the state" (Hoffman 1979: 336). Hoffman's work drew upon social anthropological work on the transformation of kinship during death rituals and the treatment of corpses (Huntington and Metcalf 1979).

Goldstein (1976) also modified these founding principles to include a consideration of spatial dimension for the relationship between mortuary differentiation and the living 
society's social organisation. In particular, she revised Saxe's Hypothesis 8, dividing it into three categories (Goldstein 1981: 61):

1. "To the degree that corporate group rights to use and/or control crucial but restricted resources are attained and/or legitimised by lineal descent from the dead (i.e. lineal ties to ancestors), such groups will, by the popular religion and its ritualization, regularly reaffirm the lineal corporate group and its rights. One means of ritualization is the maintenance of a permanent, specialized, bounded area for the exclusive disposal of the dead."

2. "If a permanent, specialized, bounded area for the exclusive disposal of the group's dead exists, then it is likely that this represents a corporate group that has rights over the use and/or control of crucial but restricted resources. This corporate control is most likely to be attained and/or legitimized by means of lineal descent from the dead, either in terms of an actual lineage or in the form of a strong, established tradition of the critical resource passing from parent to offspring."

3. "The more structured and formal the disposal area, the fewer alternative explanations of social organization apply, and conversely."

Goldstein (1981: 61) further sought to address inherent implications in Saxe's model, namely that

“...cultures will ritualize a particular aspect of their social organization in the same form, i.e. by maintaining formal specialized disposal areas when corporate group rights to restricted resources are legitimized by lineal descent... The evidence supporting the hypothesis suggests that if there is a formal bounded disposal area, used exclusively for the dead, then the culture is probably one which has a corporate group structure in the form of a lineal descent system. The more organized and formal a disposal area is, the more conclusive this interpretation... Using this hypothesis in conjunction with what is already known, the culture's organization can be discussed with a greater degree of certainty, and the critical resources can perhaps be determined in the case of a formal disposal system."

To this McGuire (1983) added elements of power and religion. Of these parameters, wealth predominated and was defined as the abundance (or lack thereof) of grave goods, 
a parameter which lent itself to more easily accessible statistical analysis for social ranking and inference. He also built upon Tainter's (1978) work, which had expanded Saxe's quantitative measure of social complexity by measuring, amongst others, the energy expenditure in grave construction in order to determine rank gradings. These could include differential treatment of the body and grave, ranging from location to grave cut or tumulus size (Binford 1971), and also the ratio of the size of the facility (e.g. dolmen, mound, tumulus) to the actual size of the interment. Tainter (1978) argued that these parameters correlated with status. Thus, inequality was measured through energy expenditure with distinctions made for achieved vs ascribed (usually hereditary) status. The key indicator for the latter is wealthy burials cross-cutting age and sex boundaries. This idea of two separate dimensions was also iterated by Peebles and Kus (1977), who argued for an underlying practice based on age and sex being superimposed over by wealthy elites, particularly males.

Kamp's (1998) later HRAF Research Series in Quantitative Cross-Cultural Data survey lends support to the notion that a rough correlation can be drawn from the level of expenditure to the presence of hierarchical status. However, she contended that the definition of expenditure (how the body is displayed, the diversity of accompanying items and the nature of the items - i.e. their rarity) have been too easily ascribed to status and/or wealth when alive. It is a notion which has also been previously critiqued by others (Hodder 1982; Ucko 1969). Kamp found that status (authority and wealth) was more frequently denoted than other variables. This was not necessarily hereditary and could be situational and/or transitory. She concluded that it was a consequence of social norms about competitive display rather than a direct correlation of hierarchy. She went beyond prior hypotheses which limited competition to societies where social standing was fluid. Furthermore, this variable may be solely designated by the inclusion of perishable types of items which might leave no traces for archaeologists to detect. She also notes that people who were regarded as having more wealth or in positions of authority (however contextually defined) were usually, but not always, buried in ways which differed to a degree from other members of society even in those communities recorded as not having institutionalised hierarchies and who were more inclined towards egalitarianism (Kamp 1998: 90). 
Criticisms of the Saxe-Binford approach and its intellectual descendents have centred around how variability is disguised by the application of processual quantitative approaches (Chapman and Randsborg 1981; Hodder 1982; Parker Pearson 1999), which have been used to measure the emergence of inequality and hierarchical social complexity (Bard 1994; Savage 2001; Tainter 1978; Wilkinson 1996). Braun (1981), for example, critiqued the subjective assumptions behind the unsubstantiated qualitative rankings of different mortuary treatments in terms of energy expenditure in procuring and utilising raw materials and/or select artefacts, while McHugh (1999) argued that such quantifications failed to account for burial spatial variability.

This change in focus raises interesting questions on the value placed upon highly visible burials versus not-so-highly visible structures which otherwise reflect the same degree of expenditure in their construction:

- $\quad$ Are any parts of a cemetery more sacred than other portions (i.e. how was the cemetery area divided up and what values were placed upon each sub-section)?

- How does orientation reflect status if at all?

- If and/or how do multiple burial instances reflect group or corporate identity?

- What determines the value placed on burial items and who are the participants in the mortuary rites charged with making the offerings accompanying the deceased? This may affect the type and quantity of the burial goods.

Sometimes death is metaphorically denied by the living while being embraced at other times, necessitating meaningful inter-disciplinary approaches to understand the context and nature of mortuary practices (Aries 1981; Bloch and Parry 1982; Humphreys and King 1981). Due to different dimensions of burial customs, the construction of the death image also involves items attached to or placed around the body and the material remnants of items used during mourning or celebratory funeral rites (Parker Pearson 1998). John O'Shea's (1979, 1981) modelling of mortuary practices in Bronze Age Hungary and 19th century American Plain Indians, for example, indicated that analysis of social status in mortuary assemblages was most productive for societies between the conceptual stages of egalitarian and state, placing an emphasis then on the social context of the burials. 
Goldstein (1981: 57) noted similar points when criticising Binford's approach, recognising that the nature of mortuary behaviour was multi-dimensional, which had largely gone unrecognised in Anglo-American archaeological circles. Goldstein argued that detailed spatial analysis was needed to decipher the organisational and behavioural conceptual underpinnings of the layout of cemeteries. Such an approach aims to disentangle the interweaving relationships between the different components of mortuary rituals (Morris 1991). It led researchers to look beyond the number and type of grave goods, and acknowledge that a poor grave may contain a well-respected individual, who had no requirement to be "indexed" further by the living, in a form of subversion where the socio-ideological superstructure is malleable with different themes at different levels for contrasting social agents who place primacy upon competing ritual socio-ideological constructions (Parker Pearson 1998: 39).

Consequently, this differential indexing of status in the mortuary realm means that there needs to be an understanding of 'ancestral cults' and 'cults of the dead' when reexamining mortuary rites from the archaeological record (Gluckman 1937). In other words, between ritual performances opening communication channels between this world and the afterlife, and performances designed to separate the recently deceased from the living (van Genep's rites of passage). It is not always the case that the appearance of formal disposal areas can be directly associated with changes in these two interconnecting spheres (Goldstein 1976: 27). Goody (1962) linked the intensity and nature of mortuary rituals with the amount of material resources needed to be redistributed, suggesting that greater elaboration would occur in delayed-return societies who have a reservoir of shared social storage (Ingold 1983). However, the material correlates in the archaeological record may not reflect the full diversity of this complexity.

The criticisms recognised that wealth and/or status differentiation can be reflected in various ways, including at various points during the pre-interment ritual. Simple secondary burials may have originated from an elaborate primary locality or facility. Furthermore, social inequalities may be masked in the mortuary realm since death is a transformative process and may not necessarily reflect differentiations in life. On the other hand, a society may decide to express differentiation at a family level, with differences between individuals reflected by their proximity to a founding ancestor. So 
while the Saxe-Goldstein territorial model attempts to address the inadequacy over linking mortuary disposal areas and control over critical resources to social significance and structure, the dead are manipulated through contextually-situated control over ritual symbolism.

Later, early post-processualism, as represented by Hodder (1982), Parker Pearson (1982, 1999), and Shanks and Tilley (1987) countered the Saxe-Binford model by attempting to unravel how ritual follows different rules to how social organisation is structured in the land of the living. Understanding how power and relationships are used as social advertisements through idealisation is crucial to unravelling how ideology and notions of inequality (rights, customs and inter-societal play) are manifested in and manipulated through the material expression of mortuary rites: the past legitimates the present through the inter-connected relationship of the living and the dead. Therefore, as stated by Parker Pearson (1982: 112), "The symbolism of ritual communication does not necessarily refer to the actual relations of power but to an idealised expression of these relations." However, Durkheim (1915) had long-ago acknowledged the impact that the range of social variability has on the complexity and form of rituals, while McHugh (1999: 16-7) emphasised that all social dimensions are open to possible manipulation and should be studied in their own right to determine the extent to which social organisation is presented and how.

As Parker Pearson (1982: 99-100) also noted, "The reconstruction of social organisation through the identification of roles (whether in burial, craft specialisation, settlement hierarchies, etc) can be challenged by the theoretical stance that social systems are not constituted of roles but by recurrent social practices." It is a conclusion echoed by Hodder (1982: 196-9) in his study of the Mesakin Nuba in which he concluded that death represents a certain type of societal ideal which only partly exists in everyday life, whereby everyday social relations were inverted and altered due to ideologies of fertility and purity, i.e. death is manipulated by the living for reasons of power relations. Finally, a later study by Cannon (1989) also recognised that aspects of mortuary rites and displays should not be related to the nature of social complexity and hierarchical structures amongst the living due to the cyclical nature of emphasis on different aspects of funeral sets for display by elites and non-elites. 
These early post-processual critiques predominantly presented ethnographic and historical archaeological case studies. Subsequent studies attempted to address this deficiency (Curet and Oliver 1998; McGuire 1992; Silverman and Small 2002) by branching out to examine issues of gender (Crown and Fish 1996), embodied landscape (Insoll 2004), the inter-relationship between the living and the ancestors (Helms 1998), and the integration of bioarchaeology and mortuary ceremonalism (Stodder 2005). All, however, recognise that periods of social unrest and requirements to delineate boundaries are also important factors in the potential for status to be reflected in mortuary complexes. These studies examined societies from the perspective of individuals, gender and inter-relationships between different socio-economic strata placed within wider intra- and inter-societal economic and political contexts.

An additional warning about inferring direct correlations about status between mortuary remains and the living was expressed by Bloch (1971), who built upon Turner's (1969) rites of passage model whereby an individual moves between different socially ascribed roles and rules of engagement. He argues that any hypothesis about social groupings and individual roles arrived at through examinations of mortuary remains should be understood not as insight into the living social hierarchy but rather within the context of mortuary practices and rites. Such an approach recognises that evaluations of disposal and mortuary treatment go beyond intra-cemetery variability to look at how material culture and society are integrated. This particularly applies to burial goods, where displays of wealth should not be automatically assumed to have correlations with status and wealth in the realm of the living. Mortuary analyses from Cambridge (Parker Pearson 1982) and Philadelphia (Kephart 1950) are two examples where lower classes could and did spend more on display.

It is therefore through the manner of burial - for example, both the actions and the social make-up of the mourners - that the deceased is represented and identified (Parker Pearson 1999; Stevenson 2009). It is a point which had earlier been iterated by Brown (1981) but which was not fully taken up within the processual investigations utilising the Saxe-Binford approach. Brown also recognised that "such rituals had to be studied within the broader contexts of ideological constraints, political manipulation and economic transactions (e.g. the allocation of time, wealth and effort in the rituals in relation to what could be mobilized from social groups" (Chapman 2003b: 310). 
Overall though, both processualists and post-processualists have attempted to address the same underlying problems, namely how to (a) rearticulate features of social organisation from what has survived of the mortuary ritual practices in material form, and (b) discern temporal phases and social dimensions from the composition, nature, comparative frequencies and co-occurrences, energy expenditure and distribution of the graves and their interments. By attempting to better understand the nature of rites and their behavioural correlates which do not leave material traces, a more holistic understanding of apparent differences in burial treatment can be developed (Van Gennep 1960), whereby the funeral rites sustain, negotiate and revitalise the social order and identities (Bloch and Perry 1982). In addition, some societies in which status is achieved view it as socially acceptable to deposit high value goods in the graves with older individuals (Binford 1972: 226), while young adults (even those who have already achieved some form of standing) may not be buried with similar goods due to it being regarded as socially unacceptable to mourn the loss of a life not yet fully lived and infants may not be buried with any or very few artefacts (MacDonald 2001: 708; Tarlow 1999).

Moreover, what constitutes burial assemblages may have been subject to inheritance rules (Chapman and Randsborg 1981: 13) or prohibition against removal from everyday circulation, which may explain some of the poor quantity of grave goods in prehistoric semi-sedentary pastoralist societies in the eastern Sahara (Kobusiewicz et al. 2010). Other issues concern the effect sampling bias and the time depth of sites have on determining the rate and scale of social change from burial assemblages due to evolving customs, living social orders and the temporal spread of burials whereby burials which seemingly reflect different statuses may be comparable (O'Shea 1981: 45; Parker Pearson 1999: 85). Grave goods may also be comprised, in part or in whole, of requisite religious items that are not necessarily directly reflective of the social standing of the individual (Robb 2007; Tarlow 1999).

In an attempt to circumvent these issues, Stephen Savage (1997) developed a diachronic model based on intergroup competition. He hypothesised that short-lived chiefly and sub-chiefly lineages were in competition with each other, with different lineages predominating at different times. He suggested that these actions are reflected in the 
spatial clusters and material burial goods found at the fourth millennium BC cemetery N7000 at Naga-ed-Der in Upper Egypt (Savage 1997: 228). Drawing upon ethnography of the Central African Mango, who are said to divided their burial spaces along similar lines (Maes 1924), Savage equated Ortner's successive "acting units" or "social types" with Predynastic social structures based on kinship. Their fluctuating power was attributed to the expression and/or suppression of organised activities designed to enhance social status. Longue durée change in mortuary patterning is therefore a sideeffect of continual action of political change.

However, Paynter (1989) also cautioned that such mortuary material expressions are not inherently indicative of inheritable elite roles and therefore formal vertical stratification. Power can be heterarchical, i.e. "counterpoised rather than ranked" (Crumley 1995: 3), with fluid heterarchical relationships permissible at given scales within broader hierarchical social systems. The heterarchical inter-relationships can be seen as a mechanism through which different social units aggregate (McIntosh 1993). Thus, the mortuary populations of Jenne-jeno in the first millennium AD have been presented as a homogenised group (burials in large clay jars without grave goods) representative of a heterarchical society attempting to de-emphasise difference in the interests of stability (McIntosh 1995).

Recognising that the treatment and placement of the body can also reflect notions of heterarchical differentiation or alignment, Carr (1995: 156) suggested that gender and personal identity are secondary to social standing and dependent on age in kinship-based societies. It is an assertion which can be challenged ethnographically where the concepts are heavily intertwined (Hutchinson 1996) but which can shed light on rules marking the conceptual transformation of living society expressed in material form during death's cultural formation processes. Indeed, Carr's own cross-cultural survey from the HRAF repository shows a mosaic of age, heterarchical, hierarchical, sex and temporal drift determining factors (Carr 1995).

The make-up of the grave assemblages is thus not necessarily reflective of a person's status and wealth while alive, or a mirror of the social complexity layers of a society, but rather a mechanism through which the living create links to the dead, reflecting on overcoming the social disruption caused by death through the continual creation of 
burial spaces within the social and physical landscape of the living. Metcalf and Huntington (1991) noted that dominant themes underpinning mortuary ritual include the imposition of a predominant political ideology and potential social resistance, which cautions against any overly rigid application of Durkheim's model of collective actions driven by contextualised socially specific factors. Although there are instances where the perceived natural order is subverted by death, both individual and collective burials have been linked to the re-creation of the living through the act of burying the dead: it not only addresses economic concerns such as the re-allocation of property, and material and family rights, but also symbolically reinforces the ties which bind society together (Bloch 1971; Hertz 1960: 72).

Meanwhile, Marxist archaeologists have attempted to exploit the resulting seeming contradictions between the ideology of living societies and the variation reflected in their mortuary cemeteries through modelling the suppression or subversion of social differences in the burial goods and/or burial architecture and expression of labour value (McGuire 1992). Marxist studies of burials in the American South-West, for example McGuire's (1992) study of the Hohokam community of La Ciudad, suggested that mortuary ritual also functions to mediate social tensions between egalitarian tendencies and the existing inequality social structures.

This approach of mediation of social tension has also been applied by some archaeologists utilising kin selection and grief theory (MacDonald 2001). The latter use age profiles and numbers to evaluate the relative ratio of sub-adults to adults for the purpose of determining the numerical loss of reproductive members of society in terms of both labour value and kin fitness. Sub-adults may also be accompanied by more grave goods than juveniles and adults. This could be due to lack of descendants for inheritance, parental grief, or the creation of a power vacuum that was exploited by wider kin to show competitors their unity and strength. The Lodagaa agro-pastoralists from West Africa wrap their dead in robes similar to those worn by their chiefs, thus warping the processual concept that the treatment of the dead mimics the power and social relationship structures of the living (Goody 1962: 71). They also lavish more attention and ceremony upon deceased youth as their passing is held as being against the natural order of life. Consequently, a young person's funeral, except that of an infant, is a more bitter experience than the obsequies of either a parent or grandparent (Goody 1962: 92, 
MacDonald 2001). It is also an uncritical assumption - though rarely expressed amongst archaeologists that wealth is only deposited with children if the parents are wealthy and that therefore the wealth is hereditary, signifying the presence of social elites.

Such works provide additional warnings against the processual notion that the presence of burial goods provides an automatic correlation with status of the deceased when alive, and that the social organisation of the living can be read in a direct correlation from the mortuary record. As Preucel and Hodder (1996: 311) note: "It is not enough simply to describe burial practices and relate them socially to power." The idea that grief plays a role in the type and wealth of goods buried with an individual has been termed an adaptive, evolutionary behavioural response on account of the intensity and form the grief takes, which influences how societies respond culturally through rites of passage to the transformative effect of death. To date, models utilising this concept have incorporated aspects of evolutionary theory, processual reconstruction methodologies of social ranking (particularly those formulated by Binford (1972) and Saxe (1970)) and Marxism (mediation of social tension).

Meanwhile, outside of the Anglo-American stream of archaeological thought in Spain, Lull (2000) argued that organisation and control of mortuary behaviour should be approached through focus on social labour and social relations of production, i.e. through comparison with everyday activities, evidence for exploitation and integration with settlement patterns. Such arguments can, however, shift social representation and malleability of mortuary behaviour at an individual or sub-group level to the periphery.

Consequently, drawing upon Althusser's (1977) definition of ideology, societal beliefs function as a window through which their relationship with the world is perceived as reality ("lived relation"). At the core of the inter-dependent relations which make-up social practices are issues of dominance, influence and power. How these principles are structured delineates and shapes the behaviour of individuals, groups and communities. Although certain behaviours are legitimated by the actions of one or more dominant sectors of the society, potentially creating a mirage of independence, there are countertrends and push-backs by lesser dominant peoples or subversives which also form part of the inter-woven social fabric (Reid and Lane 2004). 
These fundamental beliefs and social actions are expressed and partly materialised during the ritual communications and actions comprising the mortuary rites. These behavioural signals take both verbal and non-verbal forms. They transform the environment through their repetition and stylised actions which are effectively rulebounded performances merging the past with the present (Robb 2007). These rituals, in which individuals are assigned particular roles dependent upon their particular status, serve to both demystify and mystify the meanings behind why an action is taken and/or why an event occurred; the meanings themselves are context-dependent. As such, the rate of change is quicker for social actions other than mortuary rituals (Bloch 1989).

Even so, the symbolism behind the mortuary rituals changes over time and an explanatory framework is needed on how to recognise and interpret. Categories of symbolism within a material context include the goods deposited with the body or bodies (in cases of multiple burials in a grave), treatment of the corpse, where the grave was situated and how it was marked, and the placement in the landscape of the cemetery. Social advertisement is achieved not only at individual or group level within the cemetery but also at community level: a cemetery or cemeteries can be situated along trade routes (Acacus Mountains, Libya) (Di Lernia and Manzi 2002), at a particular sacred locale (e.g. Giza in Egypt (Roth 1993)) or associated with a naturally prominent feature in the landscape (Jebel Moya).

\subsection{Approaches to social structure in the Jebel Moya mortuary complex}

Mortuary rituals are therefore ideologically manipulated social practices not just between the living and the dead but between groups of the living at both micro- and macro-levels. What these strategies comprise and how they are executed relates to social advertising both during and post-burial. They are part of the dynamic processes creating, reinforcing and modifying both social organisation and social structure, where organisation refers to the day-to-day activities of the living and structure to the set of idealised relations. In essence, because of its nature, the practices are a focal point for competition. 
Processual archaeology attempted to unravel structural principles behind the mortuary data to link the structure to social organisation ( $c f$ Binford 1972; Brown 1995; Goldstein 1981; Peebles and Kus 1977; Saxe 1970; Tainter 1978). Communities and societies were placed upon an evolutionary continuum marked by their reconstructed degree of complexity. These concepts were expressed earlier by V. Gordon Childe (1956: 1) when he stated that artefacts are "concrete expressions and embodiments of human thoughts and ideas". Anthropological and archaeological case studies were integrated using three basic principles:

1. Living status and identity is correlated and reflected in mortuary rites and disposal.

2. The differences in the composition, volume and dispersal of burial goods, types of graves and markers are a material reflection of the social embodiment of status and identity in life.

3. These factors can be used for direct inter-individual and inter-group correlations to determine the nature of hierarchical structure of the living society or societies.

As subsequently recognised, non-verbal objects and subsequent archaeological artefacts are a medium embodying wide-ranging social and ideological concepts which are actively manipulated for purposes of resistance, social negotiation, display, control, wealth, masking and transformation (Parker Pearson 1999). Although the placement of cemeteries is deliberate and socio-ideologically significant, the decisions and mortuary rites which leave behind material remains in the disposal areas vary and limit the effectiveness of specific cross-cultural generalisations such as those of Saxe-BinfordGoldstein and also Carr, although competiveness can remain as a social factor (Kamp 1998).

Recognition of the perception and reality of variability was largely unaddressed by the Saxe-Binford paradigm. Demarcated burial areas are also arenas and agents for the appropriation and delineation of cultural phenomena through the selection and actioning of mortuary materials, rites and sighting or non-sighting of culturally important attributes which are historic- and context-specific. Forms of economic transfers of materials and property upon death has been shown to be more important than subsistence modes (Brown 1995, contra Binford 1971 and Saxe 1971), again 
underlining that causation of mortuary practices has a strong economic component which is facilitated by the social actions and constructs of the living.

As very eloquently stated by Chapman (2003b: 311),

"Archaeological analyses of death now occur at a variety of scales, from the individual body through to the cemetery and the regional landscape. Problems under study range from the body and its representation of identity, to differences of age, gender, social position, health, ethnicity, the long-term roles of the ancestors, symbolism and cosmology in the delineation of social landscapes and social reproduction, and even discussion of emotional responses to death. Interestingly the majority of studies still focus on the cemetery as the unit of analysis, as in Social Dimensions, and use quantitative methods to define patterning in the cultural and biological data."

I would add corporate descent groups, polities and political hierarchies to Chapman's list. He also issued a call to arms for finer-scaled chronologies and tighter integration between cemetery and settlement analyses to aid in understanding issues of social representation.

Traditionally, several variables have been used to determine the nature of the burial treatment: cause of death, gender, age, religious affiliation and social status. The latter is usually ascribed to people in positions of authority (hereditary or attained) or wealth, or both, but it can also be a consequence of competitive display according to social rules. The rules of mortuary behaviour can only be accessed indirectly by archaeologists through inference and through reference to known ethnographically and historically recorded instances, with the caveat that which rules are broken or heavily manipulated and which are considered immovable are inadequately discussed in many cases. Finally, there are also instances of individuals expressing their own identity within a group or via a kinship-based over-arching set of rules (MacDonald 1990).

As noted by Kamp (1998: 90-2) and detailed by Levinson and Wagner (1986), some form of increased expenditure may accompany the interment of persons regarded as being wealthier or senior in status in relation to others in their community or other 
kinship groups in line with increased competitive rules for social display. As noted, the level of funerary expenditure does not necessarily correlate with status (Parker Pearson 1982), but it does draw focus away from the interment to the level of mortuary rites as an entity (Trinkaus 1984). What this expenditure is comprised of, the degrees of difference and how they are expressed is highly variable and can be manifested in a variety of forms.

Consequently, in line with the consensus that material expression of social structure is not necessarily a direct reflection of hierarchy amongst the living and that ideological mortuary performances are manipulated for purposes of social standing, I approach the burials at Jebel Moya as being one of the available "avenues for competing for social recognition through display" by inhabitants with the ability to manipulate and project their idealised social ideology in the mortuary realm (Kamp 1998: 93). Indeed, the massif is in the middle of a flat plain and had the potential to serve as a striking backdrop for socio-political manipulation of the mortuary rituals (Chapman 1995), leaving an indelible mark within the landscape cosmology of the communities which used it, similar to what has been proposed for the Acacus Mountains (Libya) (Di Lernia and Manzi 2002).

I also look for variability in mortuary treatments. Minor differences are an inherently unreliable indication of hereditary social elites as they made signify other social dimensions due to funerary rituals being a dynamic part of the social system open to manipulation. Status is also not the only variable for how the dead are treated; other variables include social identities (gender, kin membership, marital status, ceremonial membership, ritual practitioner and social membership or exclusion) and personal identity (accomplishments, age, number of extended kin, number of children, bravery).

Although my approach views the Jebel Moya complex as having a structure to the distribution of its mortuary remains, it is not a structure in the way that the Saxe-Binford model envisages. Rules underpinning the organisation of the burial space are not necessarily reflective of the social relationships between the living and therefore the nature of social complexity of the society. Rather, the burials are approached from the premise that where the dead were interred and what the contents of their graves were was determined by the living for the purposes of social manipulation and display during 
the mortuary rite and within living memory. Rather than eschewing either the SaxeBinford or the Hodder et al. inspired approaches, I tend towards McHugh's (1999) melding of the two paradigms to focus on the horizontal and vertical dimensions of burials to arrive at an archaeologically derived account of the social components represented in the mortuary complex.

Unfortunately, the paucity of records detailing the nature and extent of habitation remains across all the excavated sectors of the valley (see section 4.1) precludes a comparative analysis of the living's social relations with the social dimensions represented in the mortuary domain. Therefore, a range of analytical scales are employed to study the composition and changes in the material practices of the mortuary rituals at Jebel Moya. By accounting for the deposition practices of individual bodies, age categories, sex and wealth distributional practices, and integrating them within the wider social landscapes, the examination of mortuary representations of social personae moves beyond mere designations or tags of rank and wealth.

In order to tease apart this particularistic analysis of social formation at Jebel Moya, I employ three categorisation variables, borrowing from Binford (1971), to determine if there were differences in mortuary treatment between different sectors of the cemetery:

- Treatment: differences in the form and nature of the disposition of the body in the graves.

- Grave preparation: form of the grave (surface or sub-surface, architecture, orientation and location (inside/outside living spheres).

- $\quad$ Grave goods: form, quantity and social value, and patterns of co-occurrences.

The location, form and (perhaps) intensity of funerary rituals during the period of mortuary activities at Jebel Moya is understood as resulting from the interaction of meaningful symbolic systems, participatory agency, and specific social, economic and political contexts. In order to tease apart the internal patterning and to discern any discrete elements of ideologically-represented social organisation, the following null hypotheses will be tested: 
- $\quad$ The cemetery expanded from one or more core centres. If so, homogeneity should be reflected in different combinations of grave goods as outward expansion occurred over time and would form distinct spatial shifting clusters. This assumption can be tested by analysing the co-occurrences of artefact categories in the different sectors of the cemetery.

- $\quad$ Segregation practices along age and sex lines sub-divided the burial space. If so, this would constitute a form of social differentiation and can be tested by analysing the spatial patterning of the skeletal remains sexed by the Duckworth Laboratory.

- The demographic balance does not favour any one sex group. This might suggest that communities did not practice the polygamous movement of females between groups as proposed by Saxe (1971: 43) for Wadi Halfa 6-B-36. Such a theory might be tested by evaluating the spatial occurrences of skeletal remains curated by the Duckworth Laboratory.

- Depositional mortuary homogeneity amongst different corporate or kinship groups from various communities is reflected in distinct group affiliations. If so, it might be expected that body orientations (cardinal and depositional) would have been used to express social affiliations or memberships (gender, clan, group), and that similar ratios of sex and age were represented. This expectation can be tested by evaluating the data in the new Register of Graves.

- Differences in wealth distributional patterns reflect hereditary rather than incipient (ascribed) social status, as proposed by Gerharz (1994) for the East and North-East sectors of the cemetery (see Table 1.1). Qualitative and quantitative analyses of the distribution of burial items involving spatial and statistical (hierarchical clustering, correspondence analysis, non-metric multi-dimensional scaling, cross pair correlation function) methods will be used to determine data patterning and distribution. Differential levels of the quantity and type of artefacts in the graves and along sex and age lines would be expected.

- Heterogeneity of symbolised status is based on the quantity and variety of goods present in burials. If so, it would be expected that there would be differentiation in the types of artefacts present in female and male burials. Status would be relative to artefacts made from materials procured through long distance trade, when such items and/or materials are imbued with demonstrable wealth status. 
The wealth status would be due to energy expenditure and competition display in death. While general wealth may be spread across the cemetery, this may disguise competitive status symbolised through spatial arrangements of select graves. Wealth is evaluated according to values derived from the data collected in the new Register of Graves.

Therefore, contra Lull (2000), mortuary rituals are not only products of social labour but involve inversions of and differences with the social relations of the living (van Beek 2012). While accepting Parker Pearson's argument that social difference may not be reflected in the mortuary domain, the internal patterning in cemeteries is comprised of discrete elements which can be used to gauge the degree and nature of depositional practices. How the spatial patterning of human burials, their anatomical remains and accompanying, grave goods, and the presence of habitation remains, may reflect the biological composition and social order of the inhabitants and how they interacted with their neighbours in the region will shed light on a site (Jebel Moya) long overdue for comprehensive re-examination (see Chapters $4-6$ ). 


\section{Chapter 3: Ceramic assemblages and a revised chronology for Jebel Moya}

A fundamental component of any chronological re-evaluation of Jebel Moya is its ceramics. As there are very few securely datable, imported artefacts amongst the burial goods, Jebel Moya's chronology relies largely on the local pottery sequence. In the first instance, given the absence of dateable organic remains in the extant assemblages, the direct luminescence dating of sherds provides the only currently viable approach to obtaining absolute dates for the site. However, to do so required that a reasoned grouping of pottery from the site be undertaken in order to sample specimens for dating. Likewise, the establishment of a GIS database has been essential for the contextual analysis of my new Register of Graves to evaluate any evidence for chronological markers across the whole mortuary landscape in the Jebel Moya valley. Such analyses provide the backdrop against which to arrive at a new, firmer chronological framework to assist with the re-interpretation of the mortuary remains.

Two approaches to pottery analysis have been used in Africa and elsewhere in the world since the 1950s: attribute- and typological-based analyses (Caneva 1987; Dunnell 1986; Ford 1954a, 1954b; Gosselain 1992; Haour et al. 2010; Keech McIntosh 1995; Mohammed-Ali and Khabir 2003; Spaulding 1953, 1954, 1977; Whittaker et al. 1998; Winchell 2013). Their respective applicability and pitfalls are outlined below in order to evaluate their usefulness as a technique to distinguish coherent archaeological ceramic assemblages with chronological and spatial significance. Attribute-based analysis, looking at what aspects of the pottery are changing and which are remaining stable spatially and temporally, is argued to be a more statistically nuanced and justifiable approach to defining assemblages and is subsequently applied to the British Museum's collection of Jebel Moya pottery.

Next, two of the three assemblages distinguished by this new analysis are directly dated by luminescence and are the first convincing radiometric dates for Jebel Moya. These results not only confirm the chronological integrity of the newly described assemblages but also assist in re-situating the mortuary phase of the site from Gerharz's (1994) reconstructed timespan of from the Neolithic (3000 - 1000 BC), Napatan (ca. $800-300$ 
BC) and Early-Classic Meroitic (300 - 100 BC) to the Classic-Late (100 BC - AD 350) and (possibly) Post-Meroitic periods. The newly constructed chronology better aligns with the known occupations of other sites (Jebel et Tomat, Abu Geili and Sennar) in the southern Gezira Plain.

\subsection{Previous studies of the Jebel Moya pottery}

There have been two phases of attempts at analysing the Jebel Moya pottery. The first was by Addison in the late 1930s into the 1940s, published as a chapter in his 1949 site report. The second was from J. Desmond Clark in the early 1970s until Andrea Manzo in the mid-1990s. Their typological approaches and assemblages reconstructions are reconsidered here to determine what their respective contributions are to understanding the chronology of the occupation of Jebel Moya.

\subsubsection{Frank Addison}

The vast majority of the excavated sherds from Wellcome's expedition were transported to the UK where the first and some of the second season's sherds were sorted at a depot in the High Street of Marylebone district, London (Addison 1949: 9). However, Addison and Kirwin adopted an unfortunately policy of "ruthless but not indiscriminate discarding" upon starting their process of analysis in 1937 (Addison 1949: 199). Only a handful of complete pots were found, and the sherds that were retained were mainly those judged sufficient to reconstruct the form of pots and other vessels (Figure 3.1) (Addison 1949, Plates LXXXIX-XCII). This work also built upon some of the reconstructive work (gluing together) undertaken earlier by the Maryleborne staff.

The majority of the pottery was not directly associated with the burials. Most of the few complete or partially complete pots which could be reconstructed by Addison were found in burial contexts (Addison 1949: 199). The possibility remains that some of the reconstructed pots found in contexts recorded as being external to the burials might have come from disturbed, unrecognised graves. In addition, Addison (1949: 199-200) claimed that pottery included with the burials was usually the "plainest and coarsest 
ware," mostly devoid of ornament. By contrast, he also claimed that the pottery from notionally non-burial contexts had a higher proportion of different types of motifs and decorations. He dismissed the prospect of this variability having been produced in situ by communities living at the site, instead claiming that it derived from multiple sources in surrounding regions Addison (1949: 201).

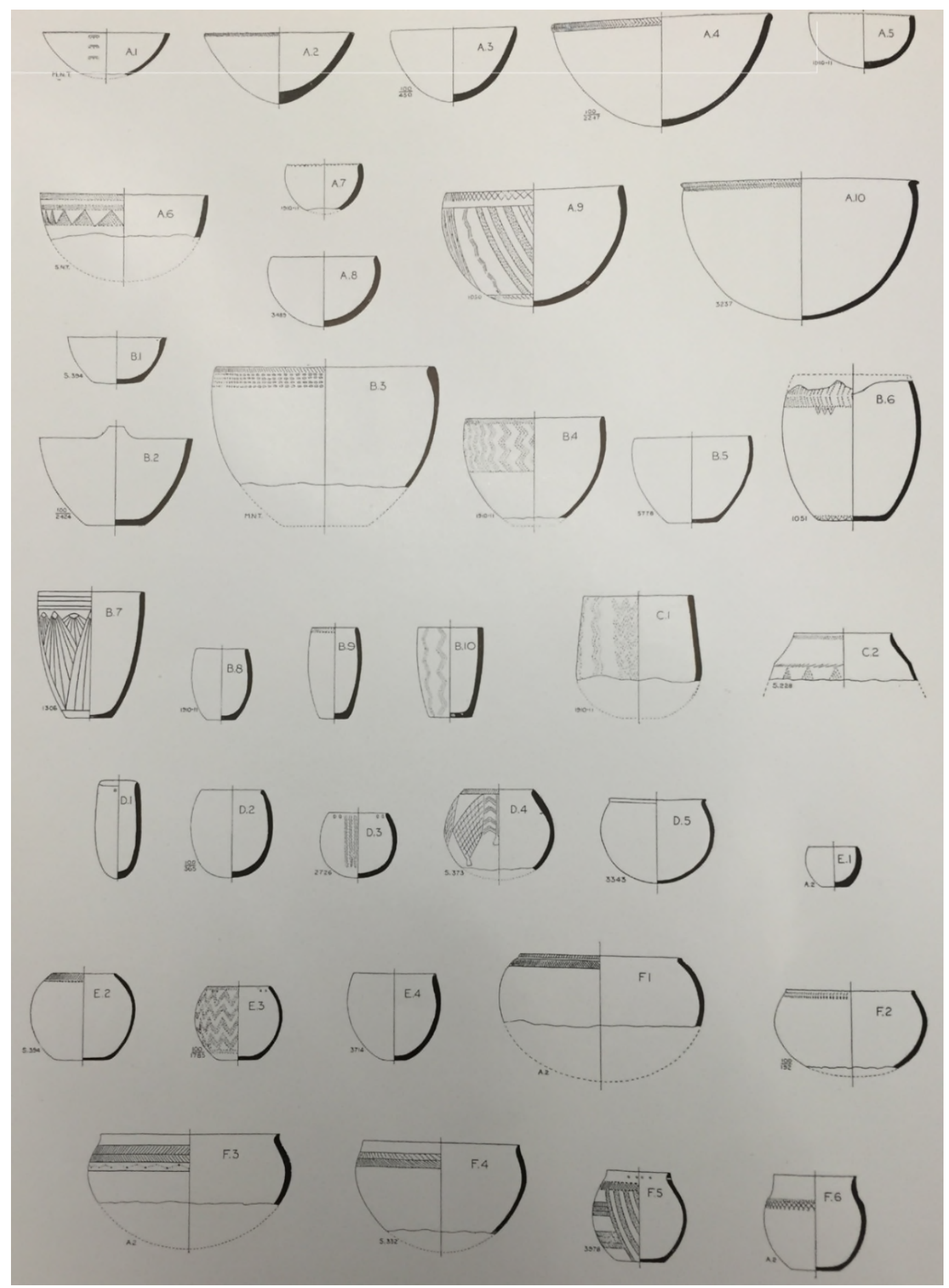

Figure 3.1 Form of vessels as reconstructed by Addison and the Maryleborne staff. From Addison (1949: Plate LXXXIX). 
Addison (1949: 202-3) regarded the earliest pottery as having 'impressed' decoration. He described the category of 'impressed ware' as covering dotted wavy line, chevron (Figure 3.2, A: 1, 2, 3, 4, 11 and 13 from D surface; 6 from Stratum C; and 5 and 7 from Stratum A) and notched rollers (Figure 3.2, B 2, D 7 and 8, and the overlap on the rim of 2, as well as the base of sherd A 14). The context of the other sherds in Figure 3.2 is unknown. The 'impressed ware' excavated in the first session was unrecorded, as was a small proportion from the second session. The chevron sub-category can be compared technically to sherds from the tray JM2 from the British Museum (described in section 3.3.2) where the chevrons were made by dragged comb and stabbed impressions with the chevrons made by the potters' combs, spatulas or styluses (Figure 3.3). Overall, Addison (1949: 203) studied the stratigraphic distribution of 481 impressed sherds from the last two seasons of fieldwork to test his view that they were common through the occupational sequences. He found their distribution increased through the strata: 40 from A, 166 from B, and 275 from C (including the surface of Stratum D). He claimed the earliest deposits were found on the surface of Stratum D in square O.7, P.8. A second collection was found in a shallow pit in square K.10, L.11 which was dug into the bedrock beneath Stratum D.
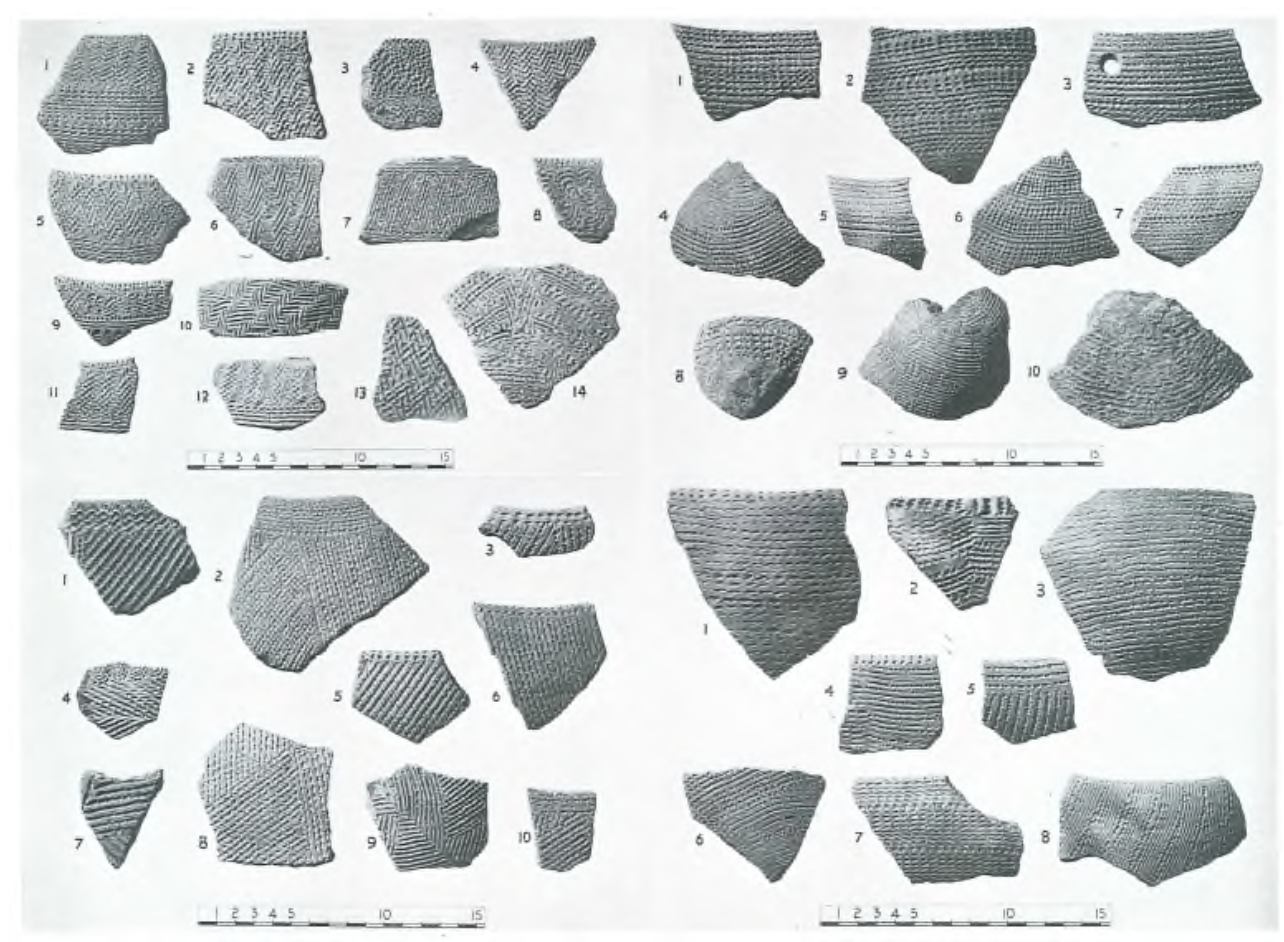

Figure 3.2 Addison's Impressed Ware divided into four sections, A-B in the top row and C-D in the bottom row. From Addison (1949: Plate XCIV). 

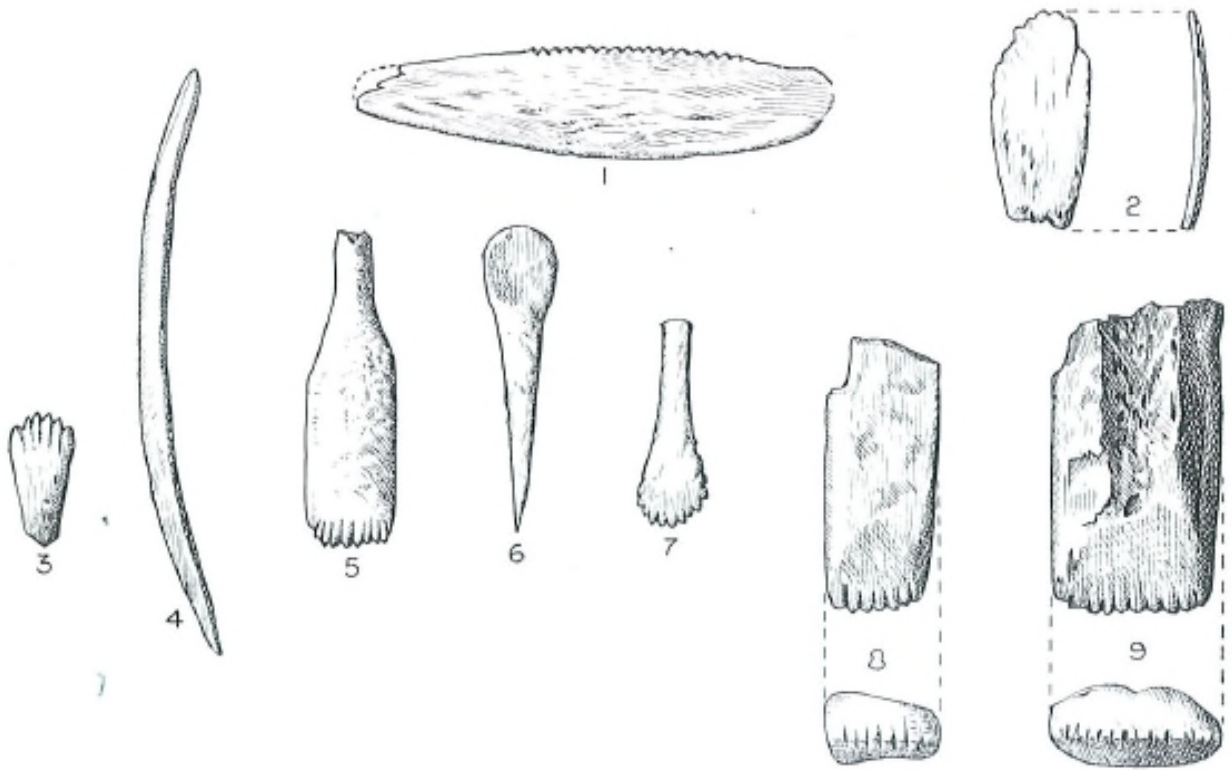

Figure 3.3 Bone pottery decoration tools found in unspecified context at Jebel Moya. (1) A potential toothed rocker, (2) too damaged to identify, (3\& 7 ) toothed rockers, (4) stylus, (5, $8 \&$ \&) combs, and (6) a spatula stylus. They can be used to make dragged and incised impressions as well as rocker-stamping and parallel channels. They, or any other decor tools, have not been re-located in any of the UK curated collections. From Addison (1949, Plate LVII B).

The horizontal distribution of 'impressed wares' was primarily concentrated in the East Sector of Jebel Moya. The 'impressed ware' generally was found within the rectangle of excavation square designations M.5, P.9 where 452 of the 481 sherds were recorded (Addison 1949: 204). Seven of the remaining fragments came from to the west of the triangle, 22 from the north-east in the rectangle I.9, L.13 (Addison 1949: 204). The limited numbers of 'impressed ware' from the first and second sessions would have come from the south-western and north-eastern areas respectively.

Overall, Addison's published classificatory forms lacked an adequate description of types, lumping together different forms of motifs and concentrated on a visual evaluation of the colour and random descriptions of the decorative patterns. Although his report was superficial, it has value in his recognition of the inter-mixing of different categories of pottery through the strata. 


\subsubsection{J. Desmond Clark, Haaland, Caneva, Gerharz and Manzo}

In 1973, J. Desmond Clark's team briefly visited the southern Gezira on the advice of the geologist Martin Williams, on their way back from excavating at Adrar Bous in the Central Sahara (Clark 1973b; Clark et al. 2008). Unpublished field notes from Clark's collection curated at the Stone Age Institute, University of Indiana, record the following:

"It seems clear that both of these sites share a number of cultural traits in common with the Butana Industry from the Khashm el Girba area further to the east and adjacent to the Ethiopian border, and for which there is a date of 2460 B.C. (Joel L. Shiner, 1971, The Prehistory and Geology of northern Sudan, Vol. 2:381). These common traits include certain pottery decoration motifs (in particular internal scoring), vessel forms, stone lip-plugs and macehead forms, choppers, grindstones, ground and polished stone as well as awls and lunates. Flaked stone tools are quantitatively more important at the Butana sites, as might be expected in view of their earlier dating. It can hardly be doubted, however, that all these settlements belong to a single, long-lived, cultural tradition that had its beginnings in the Neolithic in the third millennium and in its later stages shows a number of traits in common with Meroitic culture in the centuries immediately prior to and following the beginning of the present era. It would be appropriate to name this the "Jebel Moya tradition" and, as investigation proceeds, we can expect it to be manifested in several regionally and chronologically distinct industries or cultures. This is a characteristically Sudanese tradition developing contemporaneously with and independently of the Egyptianised civilisation of Nubia."

Clark's team obtained two radiocarbon dates on charcoal from the site dating from the first half of the third millennium BC (Table 3.1) (Clark and Stemler 1975). However, the charcoal was not in any stated association with human occupational activity. Clark (1973b; Clark and Stemler 1975: 589) also claimed that the thick everted chevrondecorated pottery from Jebel Moya was similar to sherds from the early occupation of nearby Jebel et Tomat, which they dated to the mid-third millennium BC. This latter interpretive leap was, however, based a single radiocarbon sample from freshwater shell 
obtained from a pit dug at the edge of a surface-observed midden and in uncertain association with cultural materials.

\begin{tabular}{|c|c|c|c|c|}
\hline Provenience & Material & Lab number & Uncalibrated bp & $\begin{array}{c}\text { Calibrated } \\
\text { BC }\end{array}$ \\
\hline $\begin{array}{c}\text { Test pit: Western } \\
\text { perimeter }\end{array}$ & Charcoal & UCLA1874D & $4200+/-80$ & $3009-2500$ \\
\hline $\begin{array}{c}\text { Test pit: Western } \\
\text { perimeter }\end{array}$ & Charcoal & UCLA1874E & $4200+/-80$ & $3009-2500$ \\
\hline
\end{tabular}

Table 3.1 J.D. Clark's $\mathrm{C}^{14}$ dates for Jebel Moya; implied but not explicitly stated as being from two different samples. Adapted from Clark and Stemler (1975: Table 1) with new calibration using OxCal 4.3 (IntCal13, Sigma 2 (95.4\%) confidence interval).

Subsequently, Randi Haaland and Ali Tigani el Mahi (Haaland 1984) conducted an archaeological survey from January - February 1983 between Jebel et Tomat and Rabak. The latter is situated $c a$. 70km west of Jebel Moya. Out of the five recorded sites, Rabak was excavated. The cultural deposits extend over an area of $c a .200 \times 80 \mathrm{~m}$ of the midden situated $c a .3 \mathrm{~km}$ to the east of the current course of the White Nile. Mousterian artefacts were found scattered in the ground surface. Test excavations occurred in the centre and the outer limits of the midden, encompassing $c a .18 \mathrm{~m}^{2}$. Depth averaged 50 $80 \mathrm{~cm}$, with the uppermost being $150 \mathrm{~cm}$ in an area used as a kitchen refuse disposal (el Mahi and Haaland 1984: 28). An unspecified number of domesticated cattle bones were found in layer 6 (el Mahi and Haaland 1984: 30), indicating the presence of a pastoralist or a mixed economy. However, crucially "the cultural deposit showed no stratification and arbitrary levels of 10cm were employed" (el Mahi and Haaland 1984: 28).

The lowermost deposits yielded comb rocker-stamped sherds from the Khartoum Tradition while Jebel Moya-like pottery was found in levels 2 and 3 (el Mahi and Haaland 1984: 30). The latter pottery was chevron and cross-hatched decorated, thickened/everted rims and was termed 'Rabak Ware' (Figure 3.4) (Haaland 1984: 1987). A series of three radiocarbon dates were taken from levels 2, 6 and 15 (Table 3.2). It is unstated, however, whether the 'Rabak Ware' came from the same area of the site as the radiocarbon-dated shell for Level 2, which is particularly important due to the stated lack of discernible stratigraphy for the cross-site correlation of cultural layers. Furthermore, no correction was made to account for any potential freshwater reservoir effect (FRE) which would have yielded too early a date due to 'hard water' with 
dissolved old carbonates. The FRE can range from 0 up to nearly 6000 years under freshwater system conditions (Philippsen 2013: 1). Although Williams et al. (2010) do not detect a FRE for living gastropods, they used modern AMS dating techniques and not the standard $\mathrm{C}^{14}$ radiocarbon techniques in use three decades previous, and a fuller range of samples including modern aquatic plants need to be tested using standard $\mathrm{C}^{14}$ to determine the nature of the FRE for the While Nile due to known fluctuations in uptake and concentration of $\mathrm{C}^{14}$-deficient carbonates (Philippsen 2013: 16). For the time being, the dates from Rabak need to be treated with extreme caution.

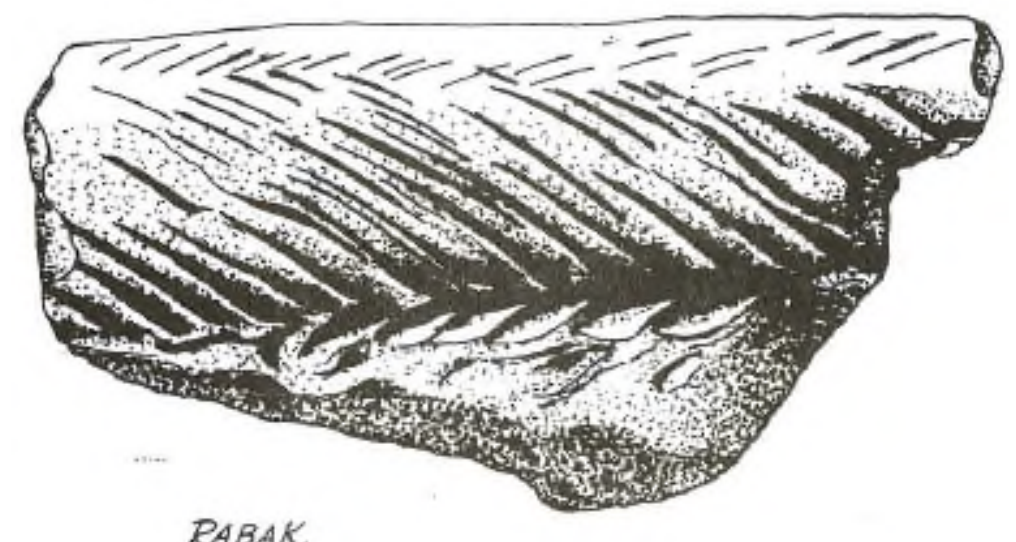

RABAK.

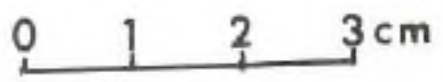

Figure 3.4 Rolled/everted rim from the Jebel Moya-like pottery found at Rabak, termed 'Rabak Ware' by Haaland. From Haaland (1987: 57).

\begin{tabular}{|c|c|c|c|c|}
\hline Provenience & Material & Lab number & Uncalibrated bp & Calibrated BC \\
\hline $\begin{array}{c}107 \mathrm{x} / 100 \mathrm{y} \\
\text { Level 2 }\end{array}$ & Shell & $\mathrm{T}-5132$ & $4490+/-100$ & $3378-2909$ \\
\hline $\begin{array}{c}107 \mathrm{x} / 100 \mathrm{y} \\
\text { Level 6 }\end{array}$ & Shell & $\mathrm{T}-5133$ & $6050+/-100$ & $5219-4722$ \\
\hline $\begin{array}{c}107 \mathrm{x} / 100 \mathrm{y} \\
\text { Level 15 }\end{array}$ & Shell & $\mathrm{T}-5134$ & $6020+/-130$ & $5308-4686$ \\
\hline
\end{tabular}

Table 3.2 $\mathrm{C}^{14}$ dates for Rabak. Adapted from el Mahi and Haaland (1984: Table 1) with new calibration using OxCal 4.3 (IntCal13, Sigma 2 (95.4\%) confidence interval).

The first scholar to begin a re-examination of the Jebel Moya pottery was Isabelle Caneva in the early 1990s. She identified and re-examined a small sample of 'Mesolithic' sherds in the collection curated at the British Museum, dating them typologically to the late sixth or early fifth millennium BC (Caneva 1991). This small 
sample included Dotted Wavy Line (DWL) decorated sherds from the site which were assigned to the Khartoum Tradition further north, suggesting some form of population movement when high Nilotic flooding ceased in and the swamps receded from the previously uninhabitable southern Gezira Plain (Caneva 1991; Williams and Adamson 1982).

The presence of DWL wares was reconfirmed by Andrea Manzo's (1995) brief examination of the Jebel Moya pottery assemblages curated at the British Museum in the mid-1990s. His work had two aims: to determine the main classes of ceramics using a typological perspective, and to determine whether there are any similarities with the Gash Group and Jebel Mokram Group ceramics. Three additional classes were defined (Figure 3.5) (Manzo 1995: 13-4): (1) external thickened rims, (2) zoned impressed designs, and (3) rims with comb-impressed bands or incised rim bands.
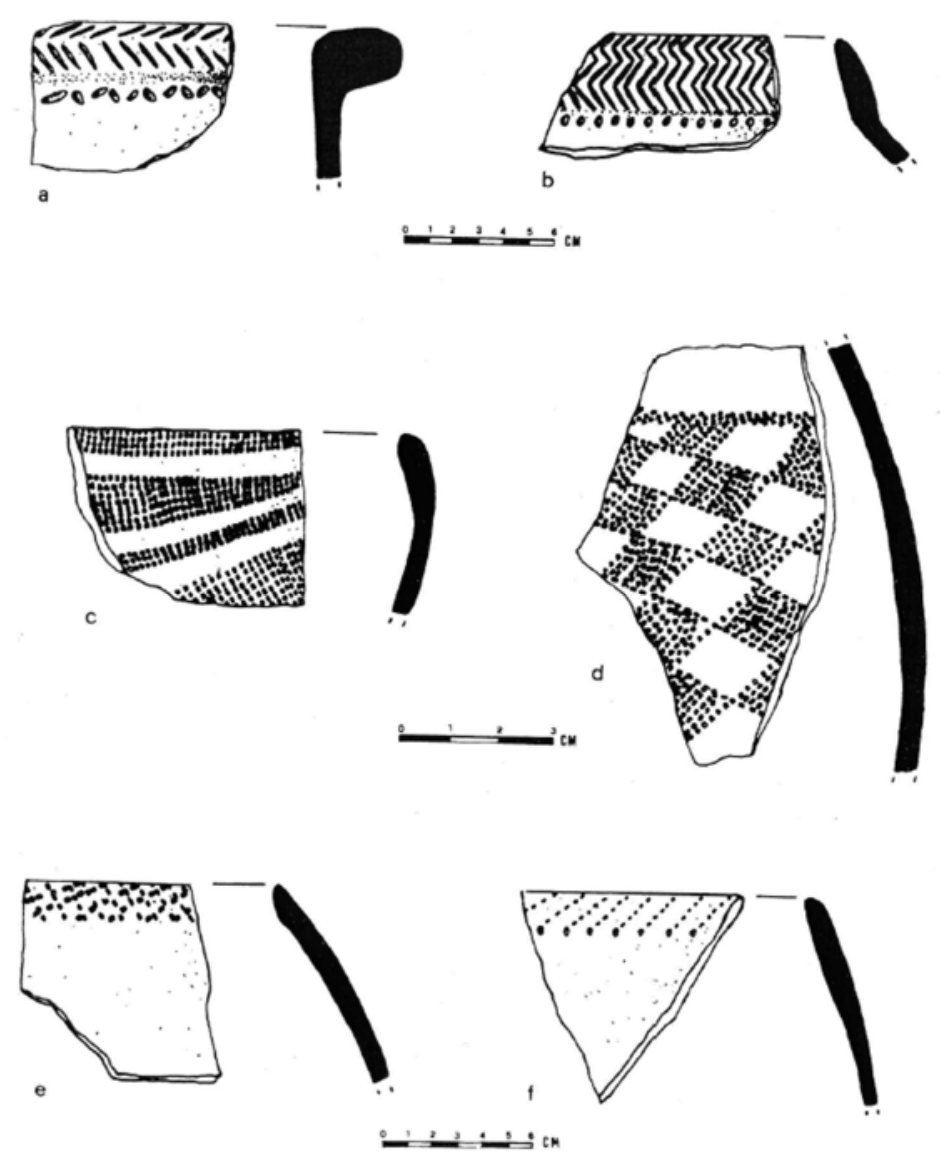

Figure 3.5 Manzo's categories: $a-b$ external thickened rims mostly from large jars, $c-d$ zone impressed with straight or slightly everted rims, and $e-f$ rims with comb-impressed bands or incised rim bands. From Manzo (2011: Figure 2). 
Gerharz's (1994) doctoral research - which took place before the publication of Manzo's brief study - drew largely upon Addison, Clark and Caneva's work. He proposed that there were three phases of occupation: Phase I, late sixth or early fifth millennium BC, ephemeral, sporadic visitations; Phase II from ca. 3000 - 1000 BC, with the burials in the western half of the valley and many (unspecified) of the burials with no or little grave goods from the eastern half; and Phase III from $c a .800$ - 100 BC which encompassed the remainder of the graves in the eastern half of the valley. $\mathrm{He}$ arrived at nine pottery categories (Gerharz 1994: 334-5):

1. Impressed and Dotted Wavy Line pottery, dated to the late sixth or early fifth millennium BC, associated with the late Khartoum Tradition. He assigned it to his Phase I.

2. Rabak Ware with everted rims and decorated lips. He assigned it to his Phase II.

3. Incised and Rocked pottery which he regarded as being prominent in both Phases II and III. The terms are used to designate a number of different pottery sherds. He described some early sherds as showing horizontal bands filled with combpricked designs (Figure 3.6), while others are claimed to have similarities with CGroup (ca. 2500 - 1500 BC) and C-Group contemporary Kerma pottery (Figure 3.7). He states that the later variations show more sophistication in their external designs (Figure 3.8), and is similar to pottery from Napatan and Meroitic sites.

4. Scratched ware, Phase III. Designs were itched onto the surface of the vessel using a blunt instrument after the surface was relatively or completely dry.

5. Notched ware, Phase III. A few sherds with regular dots impressed using a notched "rocker" tool.

6. Red-painted ware, Phase III. The rims are often notched and the sherds are painted with parallel lines. A few similar sherds were found at Abu Geili.

7. Channelled ware, Phase III. These are sherds with deeply incised parallel lines.

8. Moulded ware, Phase III. Small occurrences of pottery resembling crescent horns in shape.

9. Specific vessel types from Phase III: (a) feeding cups, late, (b) footed dishes, late, (c) beaker "Egyptian style (Figure 3.9), probably an import, and (d) bowls with pedestal rings. 

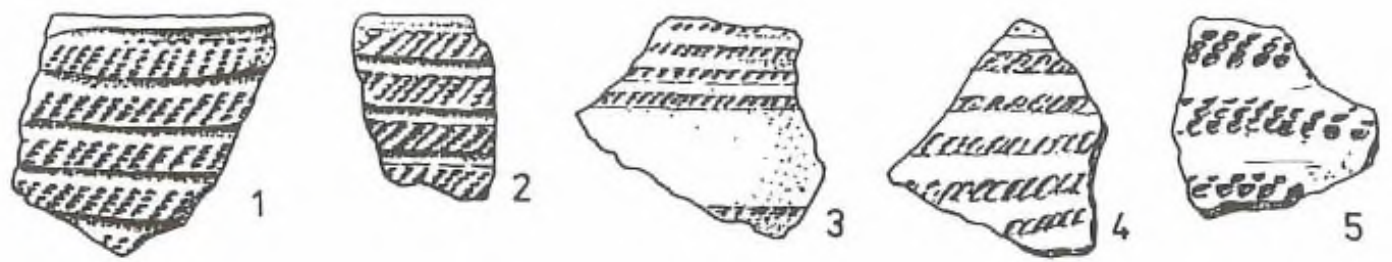

Figure 3.6 Gerharz's Phase II Incised and Rocked pottery with horizontal bands filled with comb-pricked designs. From Gerharz (1994: Figure 47 (1-5))
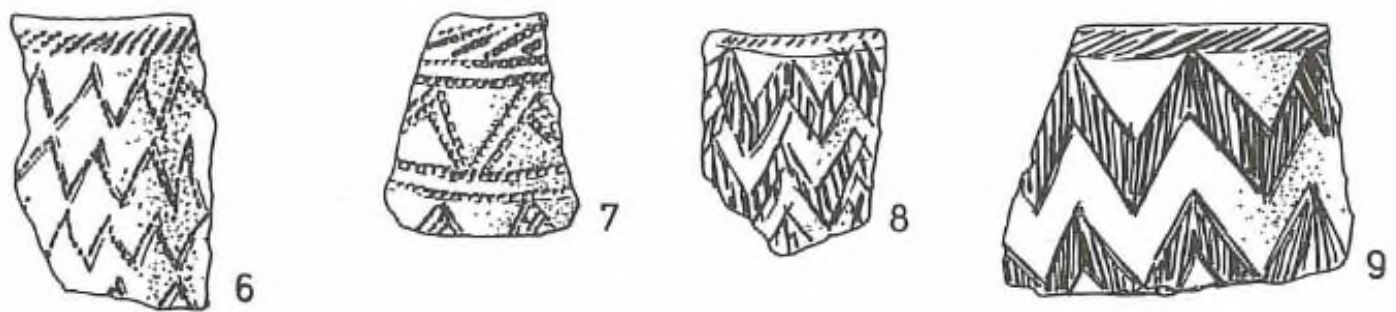

Figure 3.7 Gerharz's Phase II Incised and Rocked pottery related to C-Group and Kerma pottery. From Gerharz (1994: Figure 47 (6-9))
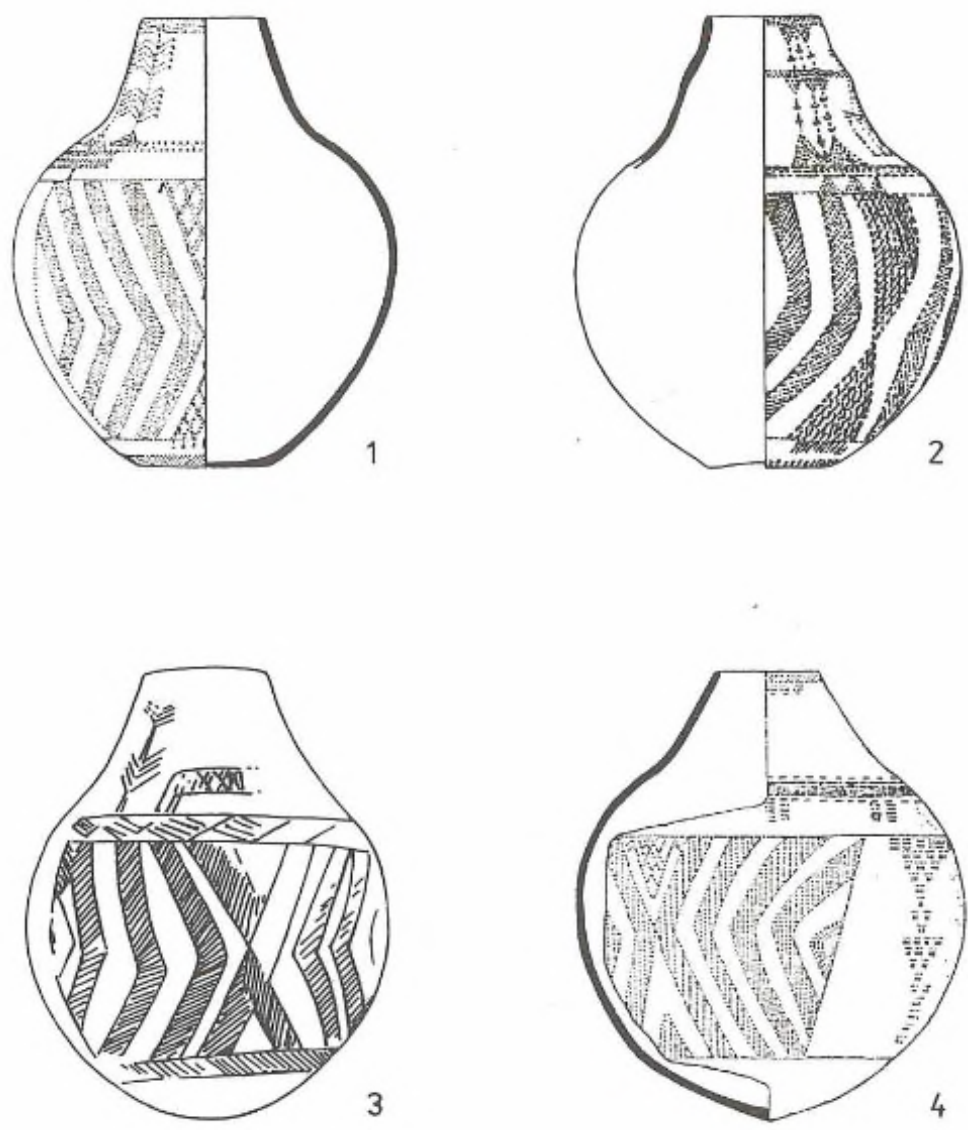

Figure 3.8 Gerharz's Phase III pottery (1) claimed to represented at Napatan and Meroitic sites to the north (2-4: Kadada, Sennar, Amir). From Gerharz (1994: Figure $50)$. 


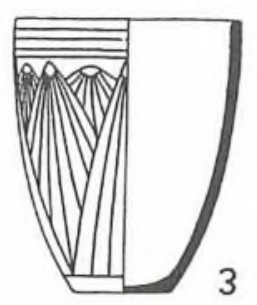

Figure 3.9 "Egyptian-style" beaker from Gerharz's Phase III. From Gerharz (1994: Figure 56(3)).

In deriving these categories, Gerharz (1994) only drew upon Addison's analysis and added information derived by Clark and Haaland's expeditions. Gerharz did not attempt to re-examine what remained of the original pottery. Re-use of inadequate typological categories lumps together different forms of motifs by concentrating on a visual evaluation of the colour and unsystematic descriptions of the decorative patterns.

\subsubsection{Discussion}

Fundamentally, the analyses undertaken by Addison, Clark, Caneva and Manzo did not engage with interpretive methodologies beyond attempted typological groupings. Moreover, excluding Addison as hardly any sites were then known and explored outside of the Nile Valley, only basic attempts were made at cross-correlation with the material culture and dates from other sites in the Gezira and neighbouring regions. The primary reason for this state of affairs was that Sudanese archaeologists have traditionally operated within both a narrow typological classificatory methodological approach to pottery analysis and a broader discourse of Nubian archaeology long labouring under the continuing influence of the culture history paradigm (Dann 2009: 80-1):

"Lack of interpretation [is partly] due to the specific conditions surrounding the development of archaeological interest in the ancient Sudan. Since its inception, the history of archaeological activity in Nubia and Sudan has broadly been that of international cooperation in order to survey, record, and rescue material and monuments in the Nile valley. Unsurprisingly, such conditions have necessarily led to an emphasis on practical excavation work, recording, and publishing of archaeological material, often in the form of site reports... Nubiology has yet to fully shake off the characteristics of the culture-historical approach. These 
interrelated trends in the history of the development of the discipline of Nubiology have fostered an academic interest that has been focused upon empirical data collection and collation. Nubian archaeology has remained largely disengaged from the theoretical and methodological debates that have gained currency within the wider discipline."

Finally, particularly in the case of Clark and Haaland, too much reliance has been placed upon poorly associated and intrinsically unreliable dates, derived in the case of Haaland from freshwater shell, with its carbonate reservoir effect.

\subsection{Analytical methods of pottery studies}

There is a long-standing body of literature which critiques typological approaches to pottery analysis (Dunnell 1971, 1986; Haour et al. 2010; Keech McIntosh 1995; Wright 1967). Yet advances in pottery theory and analysis offer an opportunity to set in place an approach, methodology, classification and interpretation which (a) avoids the pitfalls inherent in typological approaches, and (b) sheds light on attributes of the pottery assemblages in their respective mortuary and non-mortuary contexts by documenting their variability spatially and temporally (MacDonald 2011a; Mayor et al. 2005).

\subsubsection{History of approaches to pottery studies}

Typological classifications of pottery in the late $19^{\text {th }}$ and early $20^{\text {th }}$ centuries focused upon whole vessels and their properties (firing, ornamentation, surface treatment and temper). The aim was to produce pottery groups for the purpose of understanding intrasite variability to develop spatial and temporal chronologies at local and regional levels (Ford 1938; Holmes 1886; Kroeber 1916; Valliant 1931). What emerged was a variety of ad hoc pottery types due to the lack of agreed standards. Consequently, there were efforts to introduce scientific rigour into the typological classificatory process through systematising description and naming (Dunnell 1986: 164-5; Ford 1938). Yet, these initial forays were ultimately descriptive. They usually did not define or detail the range of attributes to be used in the designation of archaeological units termed "types" which were utilised for chronological purposes (Dunnell 1986: 165). 
Subsequently, the classificatory core of the mature culture-historical, typological operation of pottery analysis was primarily developed by James Ford (1938, 1954a, 1954b), Alex Krieger (1944) and Irving Rouse (1939: 1960). Rouse (1939) recommended separating out analytical classification (determining classes of attributes, resulting from standardised sets of behaviours, effectively behavioural modes) from taxonomic classification (the type). He recognised there was a wide range of variation in attributes with functional, stylistic and technological dimensions, but he thought of types as being the most valuable chronological tools and therefore placed his analytical focus upon them.

Like Rouse, Krieger's types were one-dimensional, his sorting inductive and his testing for spatial-temporal significance deductive (Dunnell 1986: 170; Krieger 1944). He broadly followed Rouse's definition of a type which "should represent a unit of cultural practice equivalent to the culture trait of ethnography... [to ultimately identify and classify] patterns of behaviour or technology which can be acquired by one human being from another, and thus serve as tools for the retracing of cultural developments and interactions" (Krieger 1944: 28). Addressing the question of whether types, now equated with styles, were the creation of archaeologists or were empirical entities, Krieger illuminated the essentialist underpinnings of his form-chronology typology by regarding types as real empirical entities and by treating variability within types as background noise.

Ford's contribution was largely practical. It arose from his efforts at chronological seriation in the American South-East, whereby types were analytic tools for assembling chronologies. However, Ford failed to overcome the problem that spatial variability was required to be restricted in order for localised changes to types to pass what Dunnell (1986: 173) has termed the "test of historical significance". Furthermore, "even in the late 1950s it was still not possible to explain the regular distributional properties of historical types... Ford never clearly distinguishes between the type as a class and objects that are assigned to it." (Dunnell 1986: 172-3)

Influenced particularly by Rouse, the Type Variety (typological) classificatory system was developed in the late 1950 to specifically address comparability between inter- and intra-regional types, of types being predominantly stylistic and not directly equitable to 
either decorative or technical style, and spatial-temporal scale of change (Wheat et al. 1958; Winchell 2013). It introduced hierarchically nested units. Attribute variations with local spatial-temporal significance were termed varieties, while those with regional significance were grouped into types. Thus comparability was emphasised and Krieger's concept of historical significance testing was retained. Also, the initial object of reference was the pot sherd: sherds had to represent a whole vessel, the fundamental unit of manufacture, before it could be termed a type and/or a variety.

The defining characteristic used by Type Variety analysts to sort the remains into types and varieties is the decorative style used. Paste characteristics, form and function are important, but there was recognition that there could be different kinds of paste within a single type and/or variety. Decorative style has been used as the main attribute to track movements of 'peoples' or 'influence' across space and time when types are grouped together through shared technological attributes (fabrics) as 'wares' (Winchell 2013: 197-210).

However, despite these improvements in spatial-temporal resolution, through combining classic typological with selective attribute analyses (Sabloff and Smith 1969), Type Variety has continued to conflate definition and interpretation: they are post hoc rationalizations where their units have been assigned hierarchical and sociological meanings to justify their levels (Dunnell 1971, 1986: 175; Hill and Evans 1972; Smith 1979). There are also issues over changing definitions of what attribute criteria are valuable, how to recognise them and whether to split or lump within Type Variety (Whittaker et al. 1998: 150). Moreover, recordings of attributes were rare, outside of the few characteristics defined as characterising the variety (Smith 1979). Finally, Type Variety's visual stylistic attributes (decorative style) relate to how a vessel was finished rather than how it was formed, which is different to the concept of technological style

"[where] pottery chaînes opératoires should not be viewed simply as functionally oriented and monolithic systems. In fact, most technical options related to different stages of the manufacturing process are functionally equivalent; that is, they allow potters to achieve similar goals. That means, first, little interdependence exists between different stages of the process; a choice made at 
one level does not automatically condition the choices made at other levels. Second, both the manufacturing processes and uses of clay artifacts permit substantial flexibility in the selection and processing of raw materials. Consequently, changes may be made at almost any stage of the chaînes opératoire without jeopardizing the whole system. Thus, technical behaviors offer room for manipulation, or choices, and may be approached as full stylistic phenomena." (Gosselain 2000: 190)

Consequently, Arthur Spaulding (1953, 1954, 1977) proposed that co-occurrences of attributes form a more statistically verifiable means of quantifiably analyzing variation across time and space. He addressed inherent weaknesses in typological systems in doing so, namely that selective combinations of decorative styles had to be tested until spatial-temporal distributional characteristics were derived and that sociological inferences were attached to these types as if they were real empirical entities (i.e. "pots become peoples') (Ford 1954a; Gifford 1960). Spaulding (1954) proposed three explicitly quantitative levels of analyses: determining and counting the attribute combinations, analyzing the proportionality of each attribute in relation to the combinations, and clustering distinctive attribute combinations.

During his resulting debate with Ford (1954a), Spalding's approach was criticized for potentially being unrepresentative accidents of sampling which would skew analyses and therefore lack validity. In turn, Spaulding (1954, 1977) re-emphasized the importance of inductive work through rigorous quantitative analysis to identify attribute classes organized along different dimensions of the sherds into statistical "types" which arose from the data instead of imposing arbitrary conceptual classes upon it.

Dunnell (1978, 1986: 180-1) has termed these occurrences as "positive nonrandom attribute associations" in so far as Spaulding's combinations are the starting point in analyses and are not the end point (the ad hoc index fossils of typological analysis). They arise from active behavioural choices which lend themselves to a continuous gradient of cultural change (Spaulding 1954: 391-2, contra Ford 1954). Moreover, small-scale variability, which may otherwise cross-cut types in typological or Type Variety systems, is not merely dismissed as background 'noise'. 
Despite it being incompatible with typological analyses due to the units of analyses being very different, Spaulding's alternative model shared some of the same problems: it was designed to be 'theory-free', and there is no argument on which specific qualities are best used to describe and quantify for particular investigative purposes. The effect, however, was to shift focus within pottery studies to issues of methodology and consistent classification (Adams and Adams 1991).

\subsubsection{Typological-based approaches in the Sudan}

Arkell's (1949, 1952, 1953) pioneering work at Khartoum, Shaheinab and el-Qoz laid the foundations for typological analysis of pottery in the Sudan. He has been criticised for not defining his classificatory system, for combining motifs, techniques, fabric, temper and firing as co-occurring and not mutually exclusive variables, for example in his definition of wavy-line pottery (Arkell 1949: 81; Mohammed-Ali and Khabir 2003: 29), and for subjectively on relying upon visual impressions of the decorative element of the motif (Caneva 1987: 233). Subsequent scholars have proposed alternative taxonomic classificatory schemes (Adams and Adams 1991; Camps-Fabrer 1966; Caneva 1987, 1988; Gatto 2006; Hays 1971; Marks et al. 1985; Mohammed-Ali and Khabir 2003; Nordstrom 1972; Winchell 2013).

Hays (1971) was the first to use the explicit Type Variety system in North-East Africa. He examined the decorative techniques and motifs from several pre-Neolithic period sites in the Sahara and the Sudan. The Sudanese sites included Khartoum (Early), Site 340 (Second Cataract), Site 282 (Dongola Reach) and Site 78 (Khashm el Girba, Atbai). He suggested a commonality in "design style" held in commonality from Hogar (Central Sahara) to the southern Atbai (Sudan), and termed it "Khartoum Horizon Style" to explain the apparent widespread dissemination (Hays 1971: 88, 134). It was comprised of fourteen motifs: Straight line, wavy line, dotted straight line, dotted wavy line, woven matt, linear matt, dotted para-sawtooth, dotted sawtooth, dotted wolftooth, fish net, chevrons and fern branch. The vessels and sherds were unburnished, had decor covering most of the surface, and were coil-manufactured bowls or jars with a round base.

By contrast, Camps-Fabrer (1966) just a few years earlier had instead emphasised decorative pottery technologies such as rouletting rather than a sole focus on finished 
motif and surface treatments, although she did not propose methods for analysing the décor. Subsequently, Nordstrom (1972) produced the first technological indices encompassing all then-known variables of fabric, techniques and decor which, however, failed to provide a chronological means of ordering due to the homogenous nature of his material in northern Nubia (Mohammed-Ali and Khabir 2003: 51).

These attempts at pottery typologies provided the chronological backbone of Sudanese Holocene archaeological studies, which helps explain their continued influence despite the increased application and resolution of radiometric dating in the past three decades (Adams and Adams 1991; Caneva 1988; Gatto 2006; Honegger 2014; Mohammed-Ali and Khabir 2003; Salvatori 2012; Salvatori and Usai 2007, 2008b). Such was the reliance on these typologies that concerns such as a $10 \%$ divergence of opinion between analysts working on the same assemblage may impact upon chronological ordering were dismissed (Adams and Adams 1991).

These issues resulted in Isabella Caneva (1987) proposing a new explicitly taxonomic, hierarchical but still typological classificatory system. It gave precedence to "decorative techniques" as the primary method of analysis. Caneva downplayed the usefulness of tools in assessing spatial-temporal and cultural significance. In descending order of importance and with increasing levels of specificity in a tree-like typology, her typology emphasised technique -> implement $->$ element $->$ motif $->$ structure (Caneva 1987; Caneva and Marks 1990: 14). As such, it partly moves away from the previous typological systems employed in the Sudan towards an attribute:vessel system but it remains structured within a typological framework.

Caneva's aim was to stipulate a system whereby the preferential order of variables is predetermined through standardisation. It would enable different scholars to repeat investigations without significant variations and would assist in establishing local and regional chronological sequences through the reconstruction of the internal evolution of decorative patterns. It has since become the dominant classificatory system in use in Saharan and Sudanese pottery studies (Caneva and Marks 1990; Gatto 2011a, 2011b; Jesse 2002, 2010; Salvatori 2012). Type Variety has only employed twice since, at Shaqadud (Marks et al. 1985) and with the Butana Group (Winchell 2013). The latter study overlaid Type Variety on top of Caneva's typology with external surface treatment 
designated as primary and decor as secondary. Caneva's system is effectively operational taxonomic units in decreasing order of perceived utility where the classificatory category is the object of reference. Her hierarchical organisation is not therefore a function of the association structure of the assemblage as per Spaulding's attribute analysis formulation. Caneva (1987: 233-4) places primary emphasis upon the technique of how decor was created (e.g. rocker-stamping) instead of the implements used by claiming that tools are "personal objects" for which there are "no standardised materials, shape or size permitting them to be associated specifically with decoration motifs", rendering them somehow subjective as an analytical tool.

Familiarity with Caneva's system has become ingrained within Sudanese archaeology and this has bred belief in it as natural and obvious, i.e. despite Caneva's lack of engagement with analytical developments elsewhere in Africa to situate Sudanese pottery studies within wider methodological and theoretical trends, her typology has come to be regarded as primary data. Objections to this system have been raised, namely its over-reliance on the appearance of motifs rather than the tools which made them, thereby undermining classification by elements of technical style which is normally a more reliable indice of social boundaries (Haour et al. 2010).

\subsubsection{Attribute-based approaches}

It is beginning to become apparent that datasets resulting from the employment of typological approaches limit our ability to understand variability through emphasising only a limited number of attributes (McIntosh 1995: 130). It obscures the greater presence of formal variability within and between assemblages, which are better arrived at through the employment of different analytical variables. In other words,

"Attribute analysis is more effective in maintaining the continuity of trends through time and space since the trends are not disrupted by a forced relationship with other attributes (types) which may reflect differing degrees of temporal and spatial significance. As the attribute is ideally the smallest definable feature, it should be the most accurate unit of analysis and, therefore, the most sensitive indicator of time and space relationships." (Wright 1967: 100) 
Attribute-based approaches work particularly well with hand-made ceramic vessels. This approach aims at recording the widest possible range of an object's characteristics, for example, parameters of dimensions, material, colour, tool usage, motor actions and motif placement, etc. An attribute-based approach can be applied to various types of material culture. On a broader level, its advantage is that one can analyse morphology and design. When applied to pottery, it permits the researcher to break a vessel down into its constituent components which can then be compared intra- and inter-site statistically (Haour et al. 2010; McIntosh 1994). Aims have included quantitatively assessing attributes to provide a better view of evolutionary changes, including those marked disjunctures, thereby providing a better understanding as to which attributes are culturally and temporally sensitive markers (Garcea and Hildebrand 2009). The tools used during the manufacturing process must be defined and not merely the patterns that they make: technological aspects have spatial and temporal significance (Gosselain 2000; Mayor et al. 2005). These attributes allow for subsequent sorting to identify trends and generate statistically derived typologies, termed attribute clusters.

It can also ease inter-regional comparisons. Sometimes large-scale variation means that this needs to be narrowed down to the frequencies of select attributes from which attribute clusters can be generated. Multi-dimensional datasets permit the study of more than one variable by moving beyond limited characterisations of type membership through separation of data collection, classification and analysis. Each sherd's attributes are recorded, which permit different classifications to be used to examine for patterned variability. Cumulatively, the data gathered are useful when analysing the social implications of technology, especially since they enable the researcher to see various phases of practice. The application of such a textured approach enables engagement with complex behaviours to shed light on socio-economic, ideological, political and personal motives reflected by the methods chosen by potters, and permits archaeologists to move beyond mundane and inadequate descriptions such as 'red burnished' or 'dotted wavy line' pottery.

\subsubsection{Weighing up analytical options}

In essence, typological classificatory systems ultimately lack sufficient fluidity and subtlety to (a) fully explore situations where overlapping pottery tradition transmissions 
have occurred, (b) avoid imposing a mask of relative homogeneity upon diverse pottery traditions, and (c) establish chains of transmission in attributes between pottery traditions from neighbouring regions. There is also a danger that typologies, in seeking to have a broad inter-regional utility, may become so stretched or fuzzy as to be unreliable (e.g. any 'wavy line' motif no matter how made or placed becomes a signal of a 'wavy line' type). I do not seek to create a taxonomic hierarchy which would fossilise the diagnostic nested, reoccurring co-variables. Instead, I employ an attribute system which permits the selection of the appropriate attributes pertinent to the questions being asked.

The variety and types of tools which are used to produce these motifs may reflect stylistic and technological diversity and/or social choice. Ethno-archaeological studies, particularly from the last two decades, have provided invaluable data on the temporal and spatial variation of technical pottery attributes, and their evolution (David et al. 1988; Gallay 2007; Gosselain 2000; Livingstone Smith 2000; Mayor et al. 2005). The identification of tools and the motor actions are thereby the starting point and not an outcome or side effort in the analysis, their use helps minimise bias in determining the highest level grouping of attributes.

\subsection{Analysing the British Museum's pottery collection}

A thorough re-examination of the Jebel Moya pottery repertoire currently stored at the British Museum was essential to both re-evaluate and supplement the published descriptive information and illustrations (Addison 1949; Caneva 1991; Gerharz 1994; Manzo 1995). Recognition of aspects of decor as socially embedded technological choices permits a move away from typological categories and towards an understanding of nature and usage of the tools used to produce the range of pottery in the British Museum collection and their grouping into temporally significant attribute clusters. Furthermore, this analysis lays the foundations for an integrated approach to ceramic studies for material from future excavations in the southern Gezira plain.

Jebel Moya pottery samples are present in good numbers at three UK-based institutions: The British Museum (London), the Museum of Archaeology and Anthropology (MAA, 
University of Cambridge) and the Petrie Museum (University College London, London). These were given out as 'representative collections' by Frank Addison in the late 1940s with the agreement of the Trustees of the Wellcome Trust after his examination was completed. Visits in July and from October - December 2011 to the British Museum and in June 2011 to MAA, together with examination of the comprehensive online catalogue of the Petrie Museum, established the nature of the respective assemblages as well as the surviving evidence of their provenance.

The Petrie Museum has a total of 623 sherds, while the MAA has 861 sherds and the British Museum 486 sherds. The sherds are mostly rims, although occasional body sherds (usually decorated) are also present. Apart from a unique small number of painted sherds, the nature and variability of the British Museum's collection matched that of the other institutions' collections.

However, unfortunately, there is no record of any excavation provenance for the Petrie Museum's collection: they are designated as simply 'Neolithic'. Likewise for the MAA's collection whose artefacts are said to have been used in student practicals and potentially mixed over the years with the consequence that it is unknown whether Addison's original labels are still applicable for the materials in each box. On the other hand, the provenance is much more secure at the British Museum: Derek Welsby (pers. comm. 2011 about the collection) only placed the sherds from their original Addisonpacked bags into separate trays in the 1990s. Welsby stressed that he was careful not to mix the sherds during the transfer and that he retained any of Addison's accompanying labels together with pottery inside the new trays. Since then the latter's collection has only been examined by Caneva and Manzo. Therefore, this study has focused on the British Museum assemblage: it has the unique advantage of having a good degree of context for each sherd.

\subsubsection{Describing the newly classified assemblages}

Three assemblages have been grouped from the remaining Jebel Moya pottery at the British Museum, totalling 486 (mostly) rim sherds attributed to different strata at the site. In order to make the re-examination and cataloguing of the sherds easier and to assist in any future attempt to cross-check the data, I marked the outside of each tray 
with an identifier in pencil, starting with the label JM1 for the first tray. There are a total of 19 trays and 1 bag (Appendix III). The information from each tray was entered into its own sheet in a spreadsheet with each individual sherd recorded using standardised parameters:

- $\quad$ Sherd number and stratum of origin

- The part or parts of the vessel under description

- The maximum thickness of the sherd

- $\quad$ The minimum thinness of the sherd

- $\quad$ The rim angle

- $\quad$ The type of rim

- $\quad$ The internal diameter of the vessel

- $\quad$ The composition of the sherd's temper

- $\quad$ The presence or absence of burnishing

- $\quad$ The presence or absence of a slip

- $\quad$ Tools used in generating motifs

- $\quad$ The form of motifs generated by tools

- $\quad$ The location of the motifs (décor)

The reasoning behind these categories is to keep the information collected as clear and concise as possible on the dimensions, condition and specific features of the pottery. The rim angle or orientation was measured to determine how restricted or open the vessel was. Plastic callipers were used to measure the thickness and thinness of the sherds. The vast majority of the sherds are of a similar hue having been fired in an oxygenated environment; there is the occasional occurrence of blackened sherds, obtained through intentional actions of firing in a deoxygenated environment such as higher in the kiln or partly/fully buried in the sand. I also compiled a photographic record of the sherds with the same numbers allocated against each sherd per tray. 


\subsubsection{Description of the sherds per tray}

Although an attribute-based analysis will follow later in this chapter, the broad contents of the trays - and a description of their excavation contexts - can be summarised as follows:

Tray JM1 was labelled 'flooring' and as deriving from the third excavation season by Addison; no stratum or excavation season was specified. It consists of 18 plain red body sherds that have coarse sanded grit and mica inclusions in the temper. The sherds are probably not flooring and likely come from a single, large collapsed storage pot instead. Their thickness ranges from $0.8-1.1 \mathrm{~cm}$ on the sherd body. All the sherds are slipped and burnished.

Tray JM2 is labelled as deriving from the first season of excavation. Although no stratum was specified, excavations did not go below Stratum B during the first season (Addison 1949: 16). Therefore, the sherds are from either Stratum A or B. There are 23 sherds ( 5 body, and 18 rim and body sherds). There are both simple and thin everted rims. The rims are simple and thin, with some everted and one thick everted. The rim angles vary between 50 to 90 degrees with the majority closer to the latter. The temper consists of sand paste with mica, some chaff and the occasional pebble. The decoration tools were dragged comb, stamped comb, stamped stylus, impressed stylus and one impressed cord-wrapped roulette. The thickness ranges from $0.4-1.05 \mathrm{~cm}$ on the sherd body. All the sherds are slipped and burnished.

Tray JM3 is labelled "Stratum C" with a note, from Welsby, labelling the pottery as 'Mesolithic'. There are 9 sherds ( 6 body, and 3 rim and body sherds). The 3 rims are simple and thin. The rim angles vary from 45 to 90 degrees. The decoration tools were stamped comb and pivoted comb. The temper is bone with strong mica content. The thickness ranges from $0.2-0.8 \mathrm{~cm}$ on the sherd body. Only one sherd is slipped and none are burnished.

Tray JM4 is labelled as sherds from the second season from the East sector. The stratum of origin is unknown as the season's excavations extended down into Stratum D. There 
are 21 sherds ( 3 body, 1 handle $\&$ rim, and 17 rim and upper body sherds). The rims are a mixture of thin and simple to thick, rolled and everted. The rim angles vary from 50 to 90 degrees. There are thick chevron-lipped sherds with bulb-shaped addition of clay at the lip. Comb-dragged and stylus-stamped chevrons on the lip as well as stabbed comb, incised angular lines, cross-hatched incisions and chevron spatula stamps. Beneath the chevron patterns is a series of stabbed impressions deriving from combs and styluses. One sherd has cord-wrapped stamp impressions under the rim. There are two sherds with vertical rows of incised fillets under the rim. The rim forms include closed jars and everted rimmed closed jars; handles are also present. There are wad of cord impressions under the rim of two sherds. The temper is coarse-sanded grit and sand paste with relatively little mica. The sherds which are richer in mica tend to be decorated using a single stylus rather than a comb, although a comb is sometimes used. The thickness varies from $0.1-2.6 \mathrm{~cm}$ on the sherd body. All the sherds are slipped and only one is not burnished.

Tray JM5 is labelled as originating from Stratum C over the course of the second and third seasons. There are 19 sherds ( 1 rim, 4 body, and 14 rim and body sherds). There are 6 thick everted rims, all with chevron patterns made using a spatula, and with coarse sanded grit and chaff as temper. The chevrons are on the thickened collar with alternative design lines beneath, e.g. sherd 1 has fingernail impressions and sherd 5 has stamped impressions. On one sherd is an impression of cord or cord-wrapped roulette with a rectilinear pattern; it has a similar paste to the chevron-patterned type. The rims are of vessels ranging from open to closed, with the angles ranging from 30 to 90 degrees. In addition, there are 5 jar collars with chevron motifs on thin simple rims. There is also a curious vessel with a coupling of stabbed comb and decorated fillets in a chained motif beneath it. The temper is coarse sanded grit (with and without chaff) and sand paste. The thickness ranges from $0.175-3.1 \mathrm{~cm}$ on the sherd body. All the sherds are slipped while 10 are burnished.

Tray JM6 is also labelled as originating from Stratum C during the second and third seasons. There are 21 sherds ( 3 body, and 18 rim and body sherds). The temper comprises of sand paste and coarse sanded grit, both sometimes with chaff. The decorative tools are stamped stylus (including stabbed v-shaped stylus), dragged comb, 
impressed comb and incised lines with a stylus or knife. There is a diagnostic sherd which bears a superficial resemblance to Kerma or C-Group ware which is probably part of the reason why previous investigators have postulated an occupation at Jebel Moya coincidental temporally with these northern groups (Figure 3.10) (Gerharz 1994). This sherd is most likely of local origin (David Edwards 2011, pers. comm.); it is dark grey (almost visually black), slipped and burnished; the decor was made using a spatula and the paste is fine. There is another dark grey fine-ware with spatula stamp. There are four thick-bulbed, chevron-patterned sherds. There are also two open chevron-lipped simple rimmed vessels. There is an outlier sherd with a rim angle of 15 degrees. The remainder are from more open vessels with rim angles between 65 - 90 degrees. Their thickness ranges from $0.1-2.9 \mathrm{~cm}$ on the sherd body. Seventeen sherds are burnished and 18 are slipped.

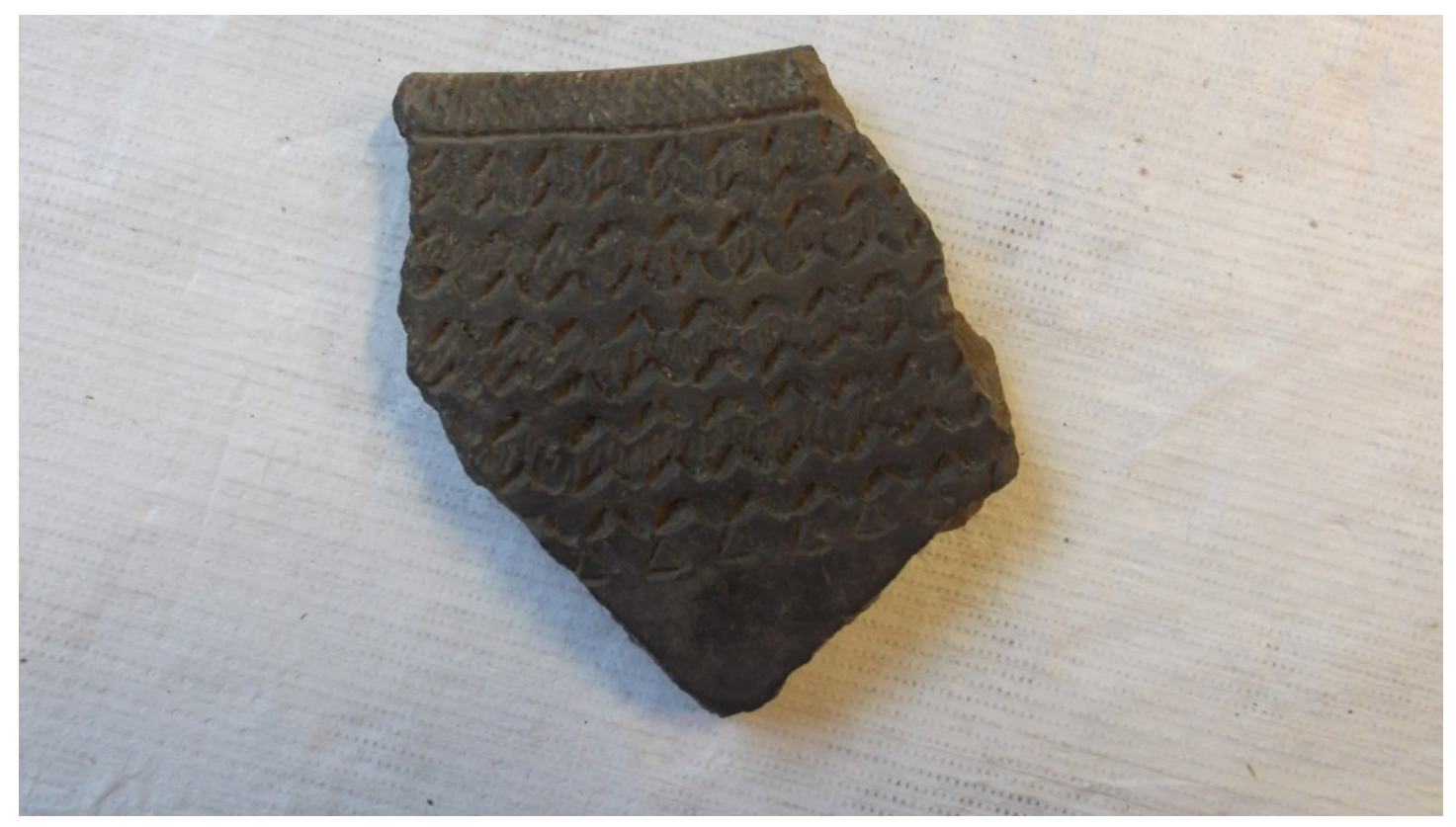

Figure 3.10 Sherd from Tray JM6 (British Museum, $6 \mathrm{~cm}$ width at rim) of a type previously mistaken as resembling Kerma or C-Group Wares. Reproduced with the kind permission of the Trustees of the British Museum.

Tray JM7 is marked as being from the first season of excavation and so are from either Stratum A or B. There are 37 sherds ( 7 body, 3 handle, 1 handle \& body, 1 base, 25 rim and body). The temper comprises of sand paste with mica. The decorative tools are dragged comb, stamped comb, stamped stylus, stamped spatula, impressed cord and probably a knife or a stylus used for the incised lines. Most of the rim decoration is made using stylus or comb stamps in angular lines. There is one rim example of dragged comb 
chevron, one comb-stamped cross-hatching, one incised cross-hatching and one incised angular lines. There is a variety of motifs under the rim: lines, triangles, incised lines, spatula stamped V-shaped lines, incised channels, incised triangles, stylus stamped chevron, dragged comb lines forming triangles and comb-stamped triangles. The majority of the measured rimmed pieces are from open vessels: 12 out of 23 have rim angles of 80 degrees or greater. The motifs are zoned: lip, under lip and on the body, and with demarcated spacings on the body. The thickness ranges from $0.1-1.4 \mathrm{~cm}$ on the sherd body. All the sherds are slipped with only 5 unburnished.

Tray JM 8 is from the second season in the East sector. The accompanying label states that the sherds are possibly from Stratum B and also that there are "four sherds possibly stylistically connected to Gash" [southern Atbai, second millennium BC]. There are 25 sherds ( 6 body, 1 spout, 1 handle, 1 base \& body, 16 rim and upper body) with a thickness varying from $0.18-2.9 \mathrm{~cm}$ on the body. The rim angles vary widely from $25-$ 90 degrees. The decorative tools are dragged comb, stamped stylus, stamped comb, hollow reed and possibly a comb for the grooved channels. Of the sherds, 4 are from Assemblage 3 and the remainder from Assemblage 2. The four Assemblage 3 sherds are different from the rest of the sherds and there is a note in the box asking whether they are possibly connected to the Gash Industry, dated to the second millennium BC. Two are rims \& body, and two are bodies. They are burnished, slipped and undecorated with nothing to link them to Gash ceramics. There is one burnished sherd with comb stamped cross-hatching on the lip. There are other single sherds: dragged comb (on collar) with hollow-reed puncture base (on rim), chevron with high mica paste and zoned decoration as if it is a link or transitional between assemblages 2 and 3 , and 1 chevron with irregular applied fillets. Finally, there are thickened and everted rim types. There are 21 burnished and 20 slipped sherds.

Tray JM9 is labelled as sherds from Stratum A. There are 42 sherds ( 8 body, 3 base \& body, 31 rim and body) with a thickness varying from $0.1-2.9 \mathrm{~cm}$ on the body. The rims and simple and thin, and their angles vary widely from 20 - 90 degrees. The temper comprises of sand paste, sometimes with mica or chaff, gritted sand paste with mica and coarse sanded grit. There is only 1 chevron-lipped sherd. The remainder are very diverse Assemblage 3 sherd fragments. The latter include sherds resembling those from box JM6: dark grey and thinner with tight zigzag lines. These latter sherds are thinner than 
the other sherds, for example number 21's thickness varies between $0.3-0.5 \mathrm{~cm}$ while number 24 is $0.25-0.5 \mathrm{~cm}$. In addition, there is red burnished-only pottery which is relatively thin. There are geometric forms in an assemblage of fine, thinned, redburnished ware with some dark grey burnishing. The assemblage is more internally diverse than Assemblage 2 of the chevron-ware and some red-ware. All the sherds are slipped while 38 are burnished

Tray JM10 is labelled as sherds from Stratum A. There are 37 sherds (29 rim and body, 3 base and body, 2 handles, 1 neck and 2 body). The rims are simple and thin, and their angles vary from 0 to 90 degrees with the majority of the rimmed sherds possessing an angle of 85 degrees or greater. The temper consists of sand paste with mica and/or chaff and coarse sanded grit with mica. The decoration tools consist of stamped spatula, stamped stylus, stamped comb, impressed cord and incisions probably made with a form of a knife or stylus. The sherds are thin, ranging from 0.1 to a rare $2.5 \mathrm{~cm}$ on the body. All the sherds are burnished and slipped.

Tray JM11 consists of two groups which are labelled Stratum A for the first 6 sherds and 'Mesolithic' (the latter by Derek Welsby) for the remaining 4 sherds. There are no rims. There are 6 footed plate (Stratum A) and 4 body sherds ('Mesolithic'). Their thickness ranges from $0.3-0.7 \mathrm{~cm}$ for the Stratum A sherds. The temper consists of sand paste, sometimes with chaff, grit and mica. The footed plates display a variety of motifs from incised lines to comb stamped lines and chevrons. By contrast, the small and thin 'Mesolithic' sherds have comb stamped lines. All the sherds are slipped. All 6 of the Stratum A sherds are burnished whereas none of the 'Mesolithic' sherds are.

Tray JM12 is labelled 'Moya New Trench' and 'Sagadi New Trench', and as such the sherds are from the first season of excavation and either from A or Stratum B or both. There are 27 sherds ( 6 body, and 21 rim and body) with thickness varying from 0.15 $0.85 \mathrm{~cm}$ on the body. The rims are either simple or simple and thick. Their angles vary from 30 to 90 degrees with the majority between 80 - 90 degrees. The temper consists of sand paste and mica with many also containing chaff. The decoration tools consist of stamped comb, stamped stylus, impressed cord and incisions probably made by a knife or stylus. All the sherds are burnished and slipped. 
Tray JM13 is labelled 'Moya New Trench' and 'Sagadi New Trench', and as such the sherds are from the first season of excavation and either from Stratum A or B or both. There are 25 sherds ( 4 body, 1 rim, and 20 rim and body) with thickness varying from $0.1-0.85 \mathrm{~cm}$ on the body. The rims are either simple or simple and thick. Their angles vary from 0 to 90 degrees with the majority between 70 - 90 degrees. The temper consists of sand paste and mica with many also containing chaff. The decoration tools consist of stamped comb, stamped stylus, impressed cord and incisions probably made by a knife or stylus. The decor include cross-hatching, angular lines made from comb stamping, comb stamped quadrangular, stylus stamped rows and incised lines. All the sherds are burnished and slipped.

Tray JM14 is labelled as being sherds from Stratum B. There are 34 sherds (1 base and body, 3 body, 2 handle, and 28 rim and body) with thickness varying from $0.1-2.2 \mathrm{~cm}$ on the body. The rims are predominantly simple with some thin or thick everted. The temper consists of coarse sanded grit with chaff and sand paste with either mica and/or chaff. The decoration tools consist of stamped spatula, stamped comb, impressed cord, dragged comb, comb (grooved channels) and a knife and/or spatula for incised lines. The decor include angular incised lines, cross-hatching, grooved channels, dragged comb and spatula stamped chevrons, fillets, cord impressed lines, raised knobs, combstamped and infilled v-shaped lines, nail impressions, and banded comb-stamped angular lines separated by non-decorated bands with channelled grooves. All the sherds are slipped with only one unburnished.

Tray JM15 is labelled as 'Moya New Trench' and 'Sagadi New Trench', and as such the sherds are from the first season of excavation. It is also labelled as deriving from Stratum B. There are 17 sherds (9 handles, 5 handle and body, 1 base and body, and 2 rim and handle and body) with thickness varying from $0.4-1.4 \mathrm{~cm}$ on the sherd body. The rim angle is 90 degrees. The temper is coarse sanded grit and sand paste (sometimes with chaff and mica). The decoration tools consist of stamped comb, stamped stylus, stylus and incised lines made by a stylus. The motifs on two sherds, with one being zoned, appear to be part of a repertoire that visually looks to be transitional between Assemblage 2 and 3 sherds from tray JM8. The decor includes incised cross-hatched quadrangles. The majority of the wares are handles with varying degrees of decoration. All the sherds are burnished and slipped. 
Tray JM16 is labelled as Stratum A. There are 47 sherds ( 3 body, and 44 rim and body) with thickness varying from $0.15-1.4 \mathrm{~cm}$ on the sherd body. The rim angles vary between 75 - 90 degrees. The temper is sand paste, sometimes with chaff and mica. The decoration tools consist of stabbed stylus, stamped comb, incised stylus, dragged comb, impressed stylus, wrapped cord and incisions made by a knife or stylus. The sherds are from open, thin vessels. The motifs on the rim are comb stabbed, comb dragged, stylus stamped and stylus impressed. There are also incised triangles. Below the rim and on the sherd body are comb stamped triangles, comb stamped channels, cord impressed lines, comb stamped and spatula derived wavy lines, chevrons and various in-filled triangles. All the sherds are slipped, while only 2 are unburnished.

Tray JM17 is labelled as 'Moya New Trench' and 'Sagadi New Trench', and as such the sherds are from the first season of excavation (1911) and from either A or Stratum B or both. There are 19 sherds (1 handle, 8 rim and body, 2 base and body, and 8 body) with thickness varying between $0.3-0.85 \mathrm{~cm}$ on the body. The rim angle is 90 degrees. The temper consists of sand paste, with mica predominating and with chaff sometimes present. The decoration tools consist of impressed cord, stamped comb and incised lines probably made with a knife or stylus. There are raised fillets on the body of one sherd, as well as infilled triangles, incised angular bands, comb stamped v-shaped lines and grooved channels on other sherds. All the sherds are slipped while only 1 is unburnished.

Tray JM18 is labelled as 'Moya New Trench' and 'Sagadi New Trench', and as such the sherds are from the first season of excavation and from either A or Stratum B or both. There are 24 sherds ( 8 body, 1 base and body, and 15 rim and body) with thickness varying between $0.1-1.5 \mathrm{~cm}$ on the sherd body. The rim angles are between $40-90$ degrees. The temper consists of sand paste with mica, sometimes with chaff. The decoration tools comprise stamped comb, stamped stylus, impressed stylus, impressed cord and dragged comb. Of the 12 rim angles, one is from a closed vessel and six are from open vessels. None of the rims are everted. Four of the sherds have comb impressed lines on the rim and body. The rim decorations are comb and stylus stamped, and stylus impressed in lines and cross-hatching. The decorations are on the body are comb stamped triangles and lines, and dragged comb, with one example of incised triangles. There is one sherd which has raised chevron patterns in-filled with combstamp. All the sherds are slipped while only 2 are unburnished. 
Tray JM19 is labelled as 'Moya New Trench' and 'Sagadi New Trench', and as such the sherds are from the first season of excavation and from either Stratum A or B or both. There are 15 sherds ( 5 body, and 10 rim and body) with thickness varying between $0.1-0.85 \mathrm{~cm}$ on the sherd body. The rim angles are between $55-90$ degrees. The temper consists of sand paste, (sometimes with mica, sometimes with chaff. The decoration tools consist of stamped comb, stamped stylus, stamped spatula, incisions with either a knife or stylus and impressed cord. The majority of the decorations on the rims are either comb stamped or incised lines. There are comb-stamped and incised channels under the rim and one cord impressed line. Comb stamped lines, branded incised lines and triangles dominate the motifs on the body. All the sherds are burnished and slipped.

The sole bag had no label stating any contextual information. There were 16 sherds, consisting of 3 body and 13 rim and body sherds. The rim angles are all 90 degrees. Thickness ranges from $0.01-1.25 \mathrm{~cm}$. The temper is sand paste, mica and occasional chaff. There are 3 cord impressions which the other decoration tools are stamped comb, and stamped stylus and incisions. All the sherds are burnished and slipped.

The individual sherds in each tray were assigned to one of three assemblages (Table 3.3). Although Assemblage 3 sherds predominate, there are trays were there are greater proportions of Assemblage 2 sherds. There are clear distinctions between the three assemblages which, as detailed later in this chapter, reflect different temporal occupations at Jebel Moya. 


\begin{tabular}{|c|c|c|c|c|c|}
\hline Tray & Stratum A & Stratum B & Stratum C & $\begin{array}{c}\text { Mixed Stratum } \\
\text { A/B }\end{array}$ & None stated \\
\hline Bag & & & & & 16 \\
\hline 1 & & & & & 18 \\
\hline 2 & & & & 23 & \\
\hline 3 & & & 9 & & \\
\hline 4 & & & & & 21 \\
\hline 5 & & & 19 & & \\
\hline 6 & & & 21 & & \\
\hline 7 & & & & 37 & \\
\hline 8 & & 25 & & & \\
\hline 9 & 42 & & & & \\
\hline 10 & 37 & & & & \\
\hline 11 & 6 & & 4 & & \\
\hline 12 & & & & 27 & \\
\hline 13 & & & & 25 & \\
\hline 14 & & 34 & & & \\
\hline 15 & & 17 & & & \\
\hline 16 & 47 & & & & \\
\hline 17 & & & & 19 & \\
\hline 18 & & & & 24 & \\
\hline 19 & & & & 15 & \\
\hline Total & 132 & 76 & 53 & 170 & 55 \\
\hline
\end{tabular}

Table 3.3 Breakdown of the British Museum Jebel Moya trays by stratum.

\subsubsection{Single and co-occurrence of sherd attributes}

The presence and absence of design elements or attributes of the pottery sherds from trays clearly labelled with the originating stratum (A - C) are compared here in order to determine the nature of stratified variability present in the British Museum collection. This was accomplished by first quantifying the single occurrence of attributes in the different strata (Tables 3.4 - 3.7a-d) and subsequently by examining the co-occurrence of attributes across sherds on a per stratum basis (Table 3.8a-d).

Clear shifts in attribute distribution are detectable in the different strata (Tables 3.4 3.5). The proportion of everted and thick-everted rims increases from Stratum A to the lower Stratum C. Thin, simple rims predominate in Stratum A with the few occurrences of thick-everted rims possibly due to mixing during either the process of grave digging or by Wellcome's excavation, or both. The similar proportion of thin, simple rims in the Mixed A/B category to Stratum A, together with the $100 \%$ occurrence of slipping, 
suggests that perhaps many of those sherds derive from the latter. The incidences of burnishing and slipping decrease in Stratum C.

\begin{tabular}{|c|c|c|c|c|}
\hline Rim form & Stratum A & Stratum B & Mixed Stratum A/B & Stratum C \\
\hline RE & $3(2.88 \%)$ & $6(12.5 \%)$ & $9(7.89 \%)$ & $8(21.62 \%)$ \\
\hline RER & $4(3.85 \%)$ & $3(6.25 \%)$ & 0 & $9(24.32 \%)$ \\
\hline RSTN & $92(88.46 \%)$ & $33(68.75 \%)$ & $101(84.87 \%)$ & $17(45.95 \%)$ \\
\hline RSTK & $5(4.81 \%)$ & $6(12.5 \%)$ & $9(7.89 \%)$ & $3(8.11 \%)$ \\
\hline Total & $\mathbf{1 0 4}$ & $\mathbf{4 4}$ & $\mathbf{1 1 9}$ & $\mathbf{3 7}$ \\
\hline
\end{tabular}

Table 3.4 The different rim forms present across the strata and their respective percentage within each stratum.

\section{Rim codes}

RSTN

$(0.3-0.9 \mathrm{~cm})$

Simple thin

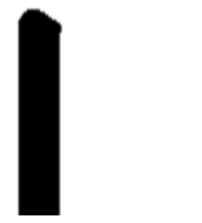

RSTK

$(1-2.6 \mathrm{~cm})$
Simple thick

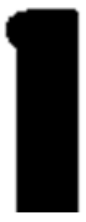

RER

$(2.4-2.6 \mathrm{~cm})$

Everted rolled

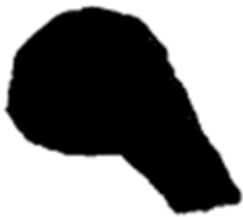

Everted

$R E$

$(0.6-3.1 \mathrm{~cm})$

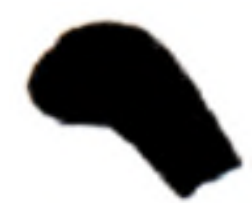

\begin{tabular}{|c|c|c|c|c|}
\hline Treatment & Stratum A & Stratum B & Mixed Stratum A/B & Stratum C \\
\hline Burnished & $124(93.94 \%)$ & $70(92.11 \%)$ & $162(95.29 \%)$ & $27(67.50 \%)$ \\
\hline Slipped & $132(100 \%)$ & $71(93.42 \%)$ & $170(100 \%)$ & $38(77.55 \%)$ \\
\hline
\end{tabular}

Table 3.5 Surface treatments across the strata and their respective percentage out of all sherds (including unburnished and unslipped) within each stratum.

\subsubsection{Single attribute occurrences}

Similar patterns of differentiation emerge from examining decoration tools and the decor motor actions (Tables 3.6a-c). Styluses were used on sherds from all three strata. The use of comb rises to $42.31 \%$ in Stratum A, while dragged comb chevrons are not present in the uppermost stratum, which contained dragged comb lines not present in the lower strata. Comb-stamped lines are also more prevalent in Stratum A (29.81\%) and in the Mixed A/B category (41.18\%) than both B and C (10.42\% and 13.51\%). 
Larger numbers of stylus- and spatula-stamped chevrons also occur in A and B strata. Decor made using spatulas occurs throughout the sequence. Cord, hollow reed and filleting are not present on rims from Stratum C. Finally, the 9 sherds from Tray 3 were labelled 'Mesolithic' and of these only 1 is burnished, none are slipped, the 3 rims are simple thin rims and the decor are always comb stamped lines.

The total count of body sherds is 90 (Stratum A), 76 (Stratum B), 169 (Mixed A/B) and 48 (Stratum C) respectively. From examining the single attribute occurrences of tool and motor actions on the body sherds (Tables 3.7a-d), it is apparent that there is a greater proportion of comb decor in Stratum A (57.78\%) and in the Mixed A/B category $(67.46 \%)$ than in either the B $(38.16 \%)$ or the C strata $(43.75 \%)$. Only 4 comb motor actions are used in Stratum C (SITIL, SL, SQ and SW), which are all used in Stratum B while Stratum B sees the addition of other categories (GC, SC, SCHT, SH, SI and SIT) which are mirrored in Stratum A. This, when taken together with the temporal break between the reconstructed assemblages (see below, section 3.5), suggests that a degree of mixing may have occurred between the stratum either due to the burial activities or the excavation methods, or both. The incidences of spatula decor remain relatively constant throughout the strata, although stamped spatula lines only occur in Stratum A and in the Mixed A/B category. A stylus was used to make banded and non-banded incised lines on sherds with the highest proportion being from Stratum A. Stratum C again has the lowest variety of different motor actions, while Stratum A has the highest. 


\begin{tabular}{|l|c|c|c|c|c|}
\hline Tool & $\begin{array}{c}\text { Motor } \\
\text { action }\end{array}$ & Stratum A & Stratum B & $\begin{array}{c}\text { Mixed Stratum } \\
\text { A/B }\end{array}$ & Stratum C \\
\hline Comb & & $44(42.31 \%)$ & $15(31.25 \%)$ & $66(55.46 \%)$ & $12(32.43 \%)$ \\
\hline & DC & & $6(12.5 \%)$ & $2(1.68 \%)$ & $6(16.22 \%)$ \\
\hline & DL & $9(8.65 \%)$ & & $4(3.36 \%)$ & \\
\hline & SC & $1(0.96 \%)$ & & $1(0.84 \%)$ & \\
\hline & SCHT & $1(0.96 \%)$ & $4(8.33 \%)$ & $9(7.56 \%)$ & $1(2.7 \%)$ \\
\hline & SIOT & $1(0.96 \%)$ & & & \\
\hline & SL & $31(29.81 \%)$ & $5(10.42 \%)$ & $49(41.18 \%)$ & $5(13.51 \%)$ \\
\hline & ST & & & $1(0.84 \%)$ & \\
\hline & SW & $1(0.96 \%)$ & & & \\
\hline
\end{tabular}

Table 3.6a Rim sherds: Single attribute occurrences of comb as a decor tool and the corresponding motor action across the strata and their respective percentage within each stratum.

\begin{tabular}{|c|c|c|c|c|c|}
\hline Tool & $\begin{array}{l}\text { Motor } \\
\text { action }\end{array}$ & Stratum A & Stratum B & $\begin{array}{c}\text { Mixed Stratum } \\
\text { A/B }\end{array}$ & Stratum C \\
\hline \multirow[t]{5}{*}{ Spatula } & & $3(2.88 \%)$ & $2(4.17 \%)$ & & $4(10.81 \%)$ \\
\hline & SC & $2(1.92 \%)$ & $1(2.08 \%)$ & & $3(8.11 \%)$ \\
\hline & SC-C & & & & $1(2.7 \%)$ \\
\hline & SL & $1(0.96 \%)$ & $1(2.08 \%)$ & & \\
\hline & SW & & & & \\
\hline \multirow[t]{2}{*}{ Cord } & & $1(0.96 \%)$ & & $4(3.36 \%)$ & \\
\hline & IL & $1(0.96 \%)$ & & $4(3.36 \%)$ & \\
\hline \multirow{2}{*}{$\begin{array}{l}\text { Hollow } \\
\text { reed }\end{array}$} & & & $1(2.08 \%)$ & & \\
\hline & $\mathrm{P}$ & & $1(2.08 \%)$ & & \\
\hline \multirow[t]{2}{*}{ Fillet } & & & $1(2.08 \%)$ & & \\
\hline & Fillet & & $1(2.08 \%)$ & & \\
\hline
\end{tabular}

Table 3.6b Rim sherds: Single attribute occurrences of spatula, hollow reed and fillet as decor tools, the corresponding motor action across the strata and their respective percentage within each stratum. 


\begin{tabular}{|c|c|c|c|c|c|}
\hline Tool & $\begin{array}{c}\text { Motor } \\
\text { action }\end{array}$ & Stratum A & Stratum B & Mixed Stratum A/B & Stratum C \\
\hline Stylus & & $39(37.5 \%)$ & $14(29.17 \%)$ & $34(28.57 \%)$ & $14(37.84 \%)$ \\
\hline & IC & $3(2.88 \%)$ & & $1(0.84 \%)$ & \\
\hline & ICHT & $2(1.92 \%)$ & & $2(1.68 \%)$ & \\
\hline & ILS & $21(20.19 \%)$ & $7(14.58 \%)$ & $18(15.13 \%)$ & $4(10.81 \%)$ \\
\hline & IT & $1(0.96 \%)$ & & & $1(2.7 \%)$ \\
\hline & SC & $2(1.92 \%)$ & $5(10.42 \%)$ & $3(2.52 \%)$ & $9(24.34 \%)$ \\
\hline & SH & & & $1(0.84 \%)$ & \\
\hline & SL & $9(8.65 \%)$ & $2(4.17 \%)$ & $9(7.56 \%)$ & \\
\hline & SW & $1(0.96 \%)$ & & & \\
\hline
\end{tabular}

Table 3.6c Rim sherds: Single attribute occurrences of stylus as a decor tool and the corresponding motor action across the strata and their respective percentage within each stratum.

\begin{tabular}{|c|c|c|c|c|c|}
\hline Tool & Motor action & Stratum A & Stratum B & Stratum A/B & Stratum C \\
\hline \multirow[t]{12}{*}{ Comb } & & $52(57.78 \%)$ & $29(38.16 \%)$ & $114(67.46 \%)$ & $21(43.75 \%)$ \\
\hline & BSH & $1(1.11 \%)$ & & & \\
\hline & $\mathrm{DC}$ & & & $2(1.18 \%)$ & \\
\hline & DL & $1(1.11 \%)$ & & & \\
\hline & $\overline{\text { DLT }}$ & & & $1(0.59 \%)$ & \\
\hline & GC & $4(4.44 \%)$ & $3(3.95 \%)$ & $5(2.96 \%)$ & \\
\hline & SC & $5(5.56 \%)$ & $1(1.32 \%)$ & $7(4.14 \%)$ & \\
\hline & $\overline{\text { SCHT }}$ & & $1(1.32 \%)$ & $1(0.59 \%)$ & \\
\hline & SH & $7(7.78 \%)$ & $1(1.32 \%)$ & $11(6.51 \%)$ & \\
\hline & SHT & & & & \\
\hline & SI & & $1(1.32 \%)$ & $3(1.78 \%)$ & \\
\hline & $\begin{array}{l}\text { SIBL } \\
\end{array}$ & & & $1(0.59 \%)$ & \\
\hline
\end{tabular}




\begin{tabular}{|l|c|c|c|c|c|}
\hline Tool & Motor action & Stratum A & Stratum B & Stratum A/B & Stratum C \\
\hline & SIOQ & $1(1.11 \%)$ & & & \\
\hline & SIOT & & & & \\
\hline & SIT & $7(7.78 \%)$ & $3(3.95 \%)$ & & $1(2.08 \%)$ \\
\hline & SITIL & $1(1.11 \%)$ & & & $17(35.42 \%)$ \\
\hline & SL & $20(22.22 \%)$ & $16(21.05 \%)$ & $36(21.30 \%)$ & $1(2.08 \%)$ \\
\hline & SQ & $2(2.22 \%)$ & $1(1.32 \%)$ & $5(2.96 \%)$ & \\
\hline & ST & & & $2(5.33 \%)$ & \\
\hline & SVSL & & & & \\
\hline & SW & $3(3.33 \%)$ & & & \\
\hline
\end{tabular}

Table 3.7a Body sherds: Single attribute occurrences of comb as a decor tool and the corresponding motor action across the strata and their respective percentage of occurrence on body sherds within each stratum.

\begin{tabular}{|c|c|c|c|c|c|}
\hline Tool & Motor action & Stratum A & Stratum B & Stratum A/B & Stratum C \\
\hline Spatula & & $3(3.33 \%)$ & $4(5.26 \%)$ & $12(7.1 \%)$ & $4(8.33 \%)$ \\
\hline & SC & & $3(3.95 \%)$ & $1(0.59 \%)$ & $2(4.17 \%)$ \\
\hline & SC-C & & $1(1.32 \%)$ & & \\
\hline & SH & & & $8(4.73 \%)$ & \\
\hline & SL & $2(2.22 \%)$ & & $3(1.78 \%)$ & \\
\hline & SW & $1(1.11 \%)$ & & & $2(4.17 \%)$ \\
\hline
\end{tabular}

Table 3.7b Body sherds: Single attribute occurrences of spatula as a decor tool and the corresponding motor action across the strata and their respective percentage of occurrence on body sherds within each stratum. 


\begin{tabular}{|c|c|c|c|c|c|}
\hline Tool & Motor action & Stratum A & Stratum B & Stratum A/B & Stratum C \\
\hline \multirow{5}{*}{$\begin{array}{l}\text { Wrapped } \\
\text { cord }\end{array}$} & & $29(32.22 \%)$ & $10(13.16 \%)$ & 40 & $5(10.42 \%)$ \\
\hline & ICT & $5(5.56 \%)$ & & & \\
\hline & $\mathrm{IL}$ & $24(26.67 \%)$ & $10(13.16 \%)$ & 34 & $3(6.25 \%)$ \\
\hline & IMT & & & $1(0.59 \%)$ & \\
\hline & RL & & & & $2(4.17 \%)$ \\
\hline \multirow{2}{*}{$\begin{array}{l}\text { Hollow } \\
\text { Reed }\end{array}$} & & $2(2.22 \%)$ & $1(1.32 \%)$ & & \\
\hline & $\mathrm{P}$ & $2(2.22 \%)$ & $1(1.32 \%)$ & & \\
\hline \multirow[t]{2}{*}{ Nail } & & $1(1.11 \%)$ & $1(1.32 \%)$ & $1(0.59 \%)$ & $1(2.08 \%)$ \\
\hline & $\mathrm{P}$ & $1(1.11 \%)$ & $1(1.32 \%)$ & $1(0.59 \%)$ & $1(2.08 \%)$ \\
\hline \multirow[t]{2}{*}{ Fillet } & & $1(1.11 \%)$ & $2(2.63 \%)$ & $2(1.18 \%)$ & $1(2.08 \%)$ \\
\hline & Fillet & $1(1.11 \%)$ & $2(2.63 \%)$ & $2(1.18 \%)$ & $1(2.08 \%)$ \\
\hline \multirow{2}{*}{$\begin{array}{l}\text { Cylinder } \\
\text { roulette }\end{array}$} & & & & $1(0.59 \%)$ & \\
\hline & RLLD & & & $1(0.59 \%)$ & \\
\hline
\end{tabular}

Table 3.7c Body sherds: Single attribute occurrences of wrapped cord, hollow reed, nails and fillets as decor tools and the corresponding motor action across the strata and their respective percentage of occurrence on body sherds within each stratum.

\begin{tabular}{|l|l|l|l|l|l|}
\hline Tool & Motor action & Stratum A & Stratum B & Stratum A/B & Stratum C \\
\hline Stylus & & $70(77.78 \%)$ & $47(61.84 \%)$ & $71(42.01 \%)$ & $32(66.67 \%)$ \\
\hline & BILS & $2(2.22 \%)$ & $4(5.26 \%)$ & $3(1.78 \%)$ & \\
\hline & GC & $11(12.22 \%)$ & $8(10.53 \%)$ & & $13(27.08 \%)$ \\
\hline & IC & $6(6.67 \%)$ & $4(5.26 \%)$ & $1(0.59 \%)$ & \\
\hline & ICHT & & $1(1.32 \%)$ & $3(1.78 \%)$ & \\
\hline & ICHTQ & & $3(3.95 \%)$ & & \\
\hline & ICL & & $2(2.63 \%)$ & $14(8.28 \%)$ & \\
\hline & IH & & & $2(1.18 \%)$ & \\
\hline
\end{tabular}




\begin{tabular}{|c|c|c|c|c|c|}
\hline Tool & Motor action & Stratum A & Stratum B & Stratum A/B & Stratum C \\
\hline & $\mathrm{IIH}$ & & & $1(0.59 \%)$ & \\
\hline & ILS & $26(28.89 \%)$ & $13(17.11 \%)$ & $17(10.06 \%)$ & $4(8.33 \%)$ \\
\hline & IIT-B & & $1(1.32 \%)$ & & \\
\hline & IS & $2(2.22 \%)$ & & & \\
\hline & IT & $3(3.33 \%)$ & & $2(1.18 \%)$ & $2(4.17 \%)$ \\
\hline & ITR & $7(7.78 \%)$ & & $7(4.14 \%)$ & $1(2.08 \%)$ \\
\hline & IQ & $1(1.11 \%)$ & $3(3.95 \%)$ & & \\
\hline & IWL & $2(2.22 \%)$ & & & \\
\hline & $\mathrm{SC}$ & $1(1.11 \%)$ & $5(6.58 \%)$ & $5(2.96 \%)$ & $2(4.17 \%)$ \\
\hline & SH & $1(1.11 \%)$ & & $3(1.78 \%)$ & $3(6.25 \%)$ \\
\hline & SHT & & & & $1(2.08 \%)$ \\
\hline & SL & $2(2.22 \%)$ & $2(2.63 \%)$ & $7(4.14 \%)$ & $1(2.08 \%)$ \\
\hline & ST & $1(1.11 \%)$ & & $2(1.18 \%)$ & \\
\hline & SW & $5(5.56 \%)$ & $1(1.32 \%)$ & $3(1.78 \%)$ & \\
\hline
\end{tabular}

Table 3.7d Body sherds: Single attribute occurrences of stylus as a decor tool and the corresponding motor action across the strata and their respective percentage of occurrence on body sherds within each stratum.

\section{Motor action codes}

$\begin{array}{llll}\text { BILS } & \text { Banded incised lines } & \text { BSH } & \text { Banded stamped herringbone } \\ D C & \text { Dragged chevrons } & D L & \text { Dragged lines } \\ D L T & \text { Dragged lined triangles } & G C & \text { Grooved channel } \\ I C & \text { Incised chevrons } & I C H T & \text { Incised cross hatching } \\ I C H T Q & \begin{array}{l}\text { Incised cross-hatched } \\ \text { quadrangles }\end{array} & I C L & \text { Incised channel } \\ I C T & \text { Impressed triangles } & I H & \text { Incised herringbone } \\ I I H & \text { Incised and infilled hut } & I I T-B & \begin{array}{l}\text { Incised, infilled triangles separated } \\ \text { by incised banded lines }\end{array} \\ I L & & & \text { Incised lines } \\ I M H & \text { Impressed lines } & I L S & \text { Impressed infill }\end{array}$


Motor action codes

$\begin{array}{llll}I M T & \text { Impressed triangles } & I Q & \text { Incised quadrangles } \\ I S & \text { Incised squares } & I T & \text { Incised and infilled triangle } \\ I T R & \text { Incised triangle } & I W L & \text { Incised wavy line } \\ P & \text { Puncture } & R L & \text { Rolled lines } \\ \text { RLLD } & \text { Rolled roulette } & S C & \text { Stamped chevrons } \\ \text { SC-C } & \text { Curved stamped chevrons } & S C H T & \text { Stamped cross hatching } \\ \text { SH } & \text { Stamped herringbone } & S H T & \text { Stamped hut } \\ \text { SI } & \text { Stamp infill } & S I B L & \text { Stamped infilled banded line(s) } \\ \text { SIOQ } & \text { Stamp infill of other } & S I T & \text { Stamped infilled triangles } \\ \text { qITIL } & \text { quadrangles } & & \\ & \text { Stamped infilled triangles } & S L & \text { Stamped lines } \\ S Q & \text { joined by incised infilled lines } & & \\ S W & \text { Stamped quadrangles } & S T & \text { Stamped triangles }\end{array}$

\subsubsection{Attribute co-occurrences}

Analysis of the co-occurrence of decorative tools and motor action against different rim types shows a similar pattern of internal differentiation (Table 3.8a-d). Comb-stamped lines are only present on simple thin rims from Stratum A where, at $29.81 \%$ of comb decor and rim-type co-occurrences, its presence shows an increase from $11.81 \%$ and $13.51 \%$ on all rim types from strata $\mathrm{B}$ and $\mathrm{C}$ respectively. It is likely, therefore, that the $41.17 \%$ on all rim types from the mixed A/B category was due to intermixing, particularly as $36.13 \%$ of which are occurrences on simple thin rims.

Dragged comb lines occur only on simple thin rims from Stratum A and A/B category. Dragged comb chevrons are on none of the rims from Stratum A, while on only two (both thin) from A/B category and on both thin and thick rims from Stratum C. Moreover, stylus-stamped chevrons occur on $24.33 \%$ of rims from Stratum C compared with $16.7 \%$ in the remaining strata. Stylus-stamped lines are also on simple thin rims, with only 1 out of the 20 occurrences present on a thick everted rim. The other 19 instances are on sherd rims which are burnished and slipped, and most likely should be grouped together. 


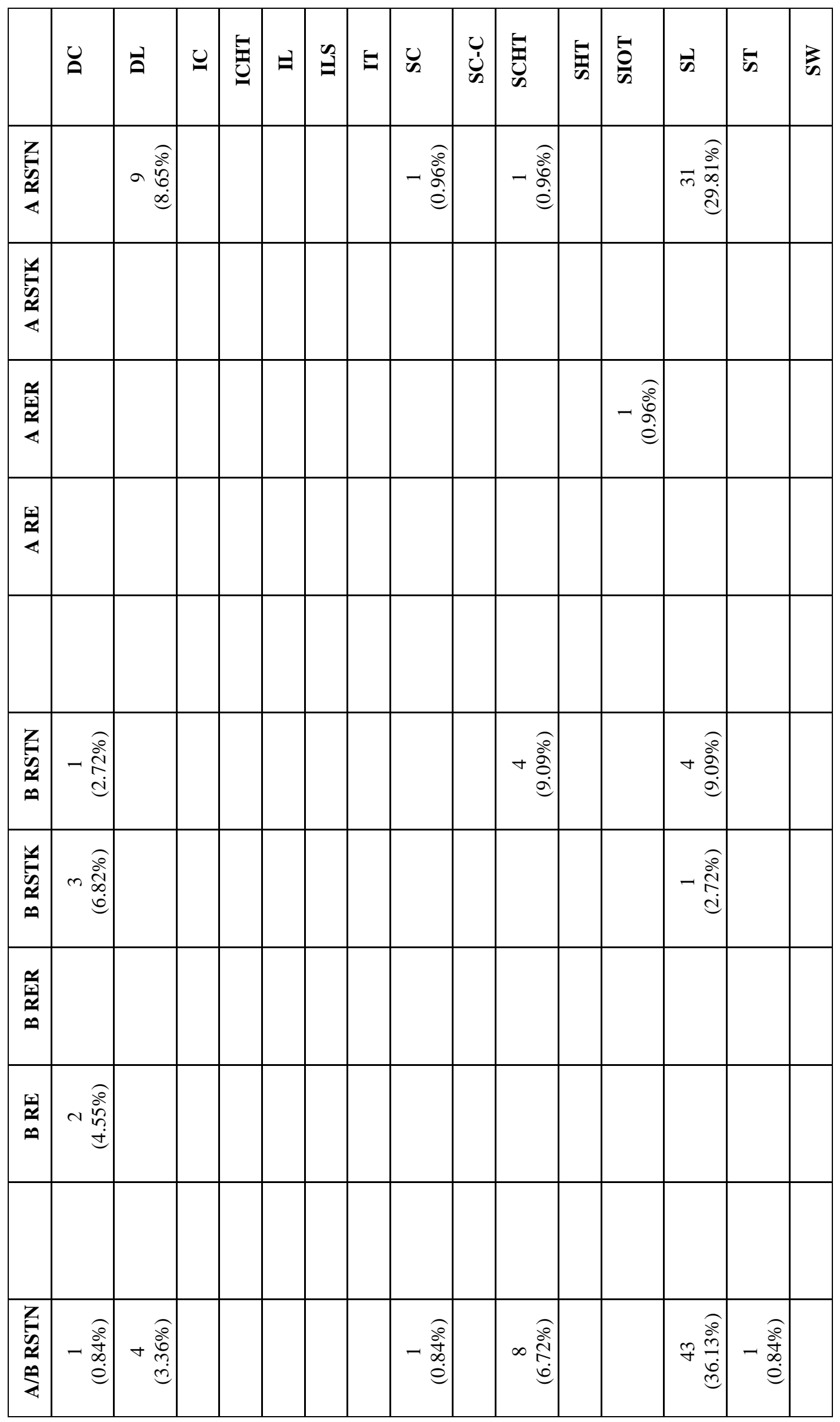




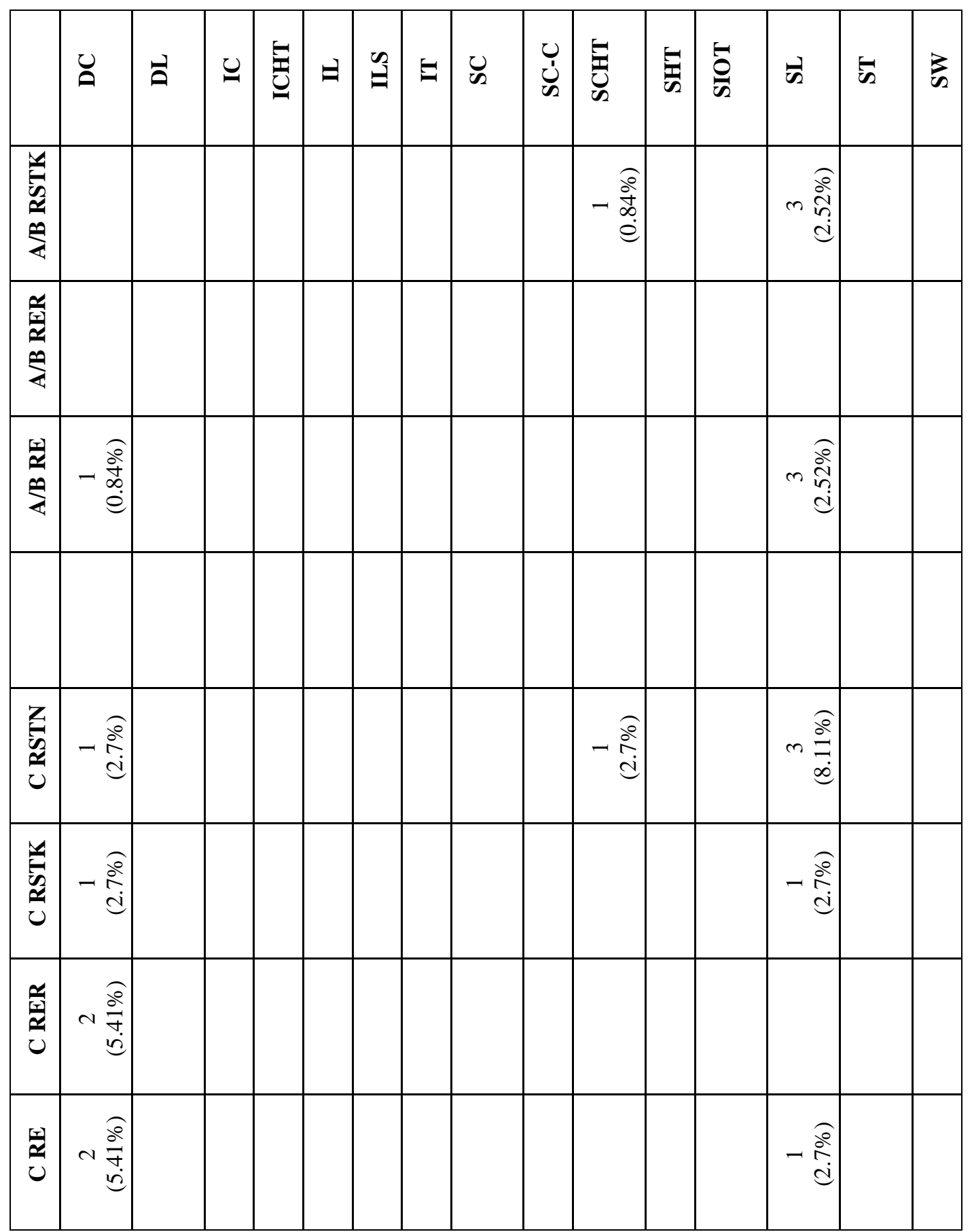

Table 3.8a Co-occurrence of rim types and comb tool motor actions. \% occurrence is calculated against the number of overall rim sherds per strata. 


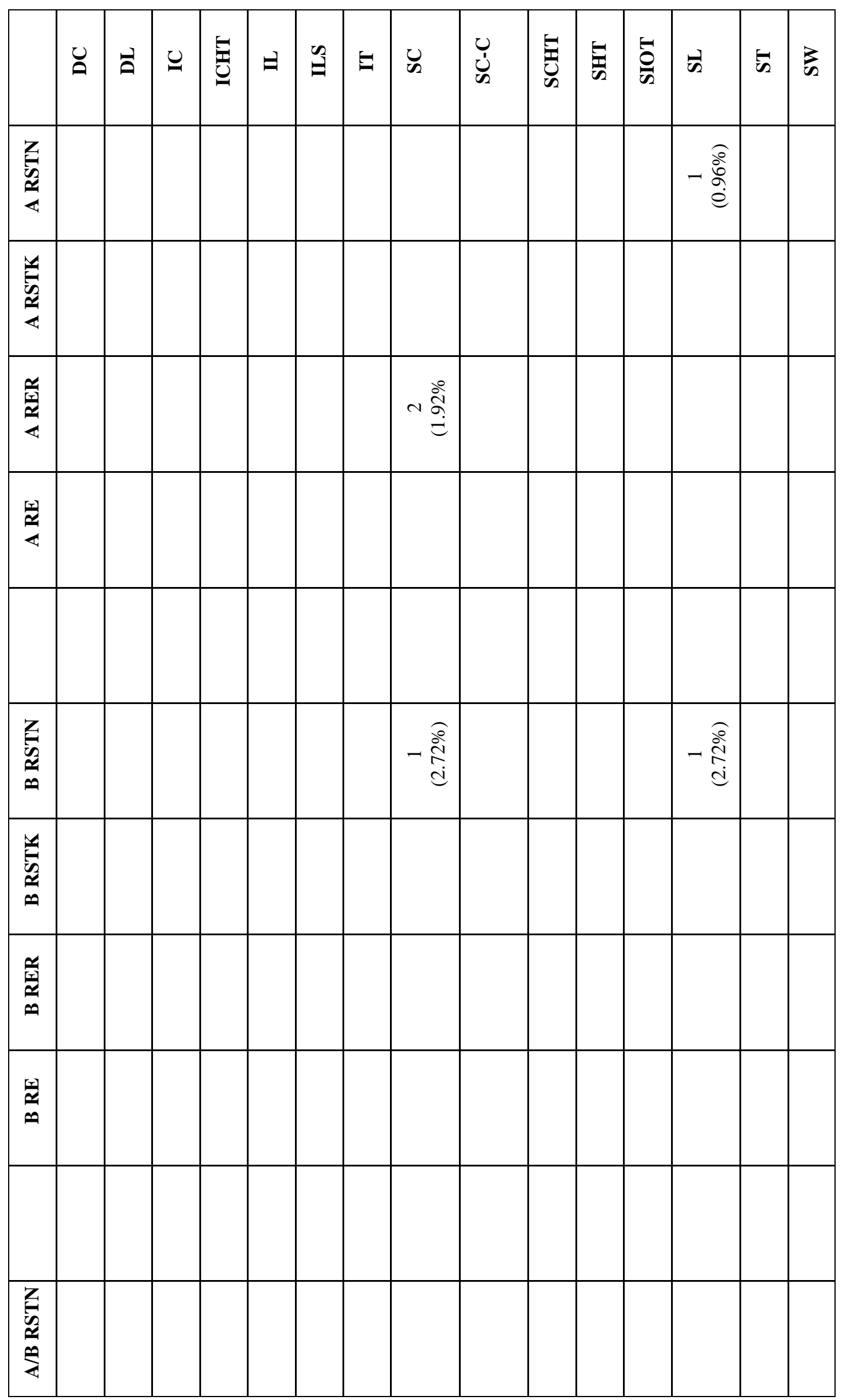




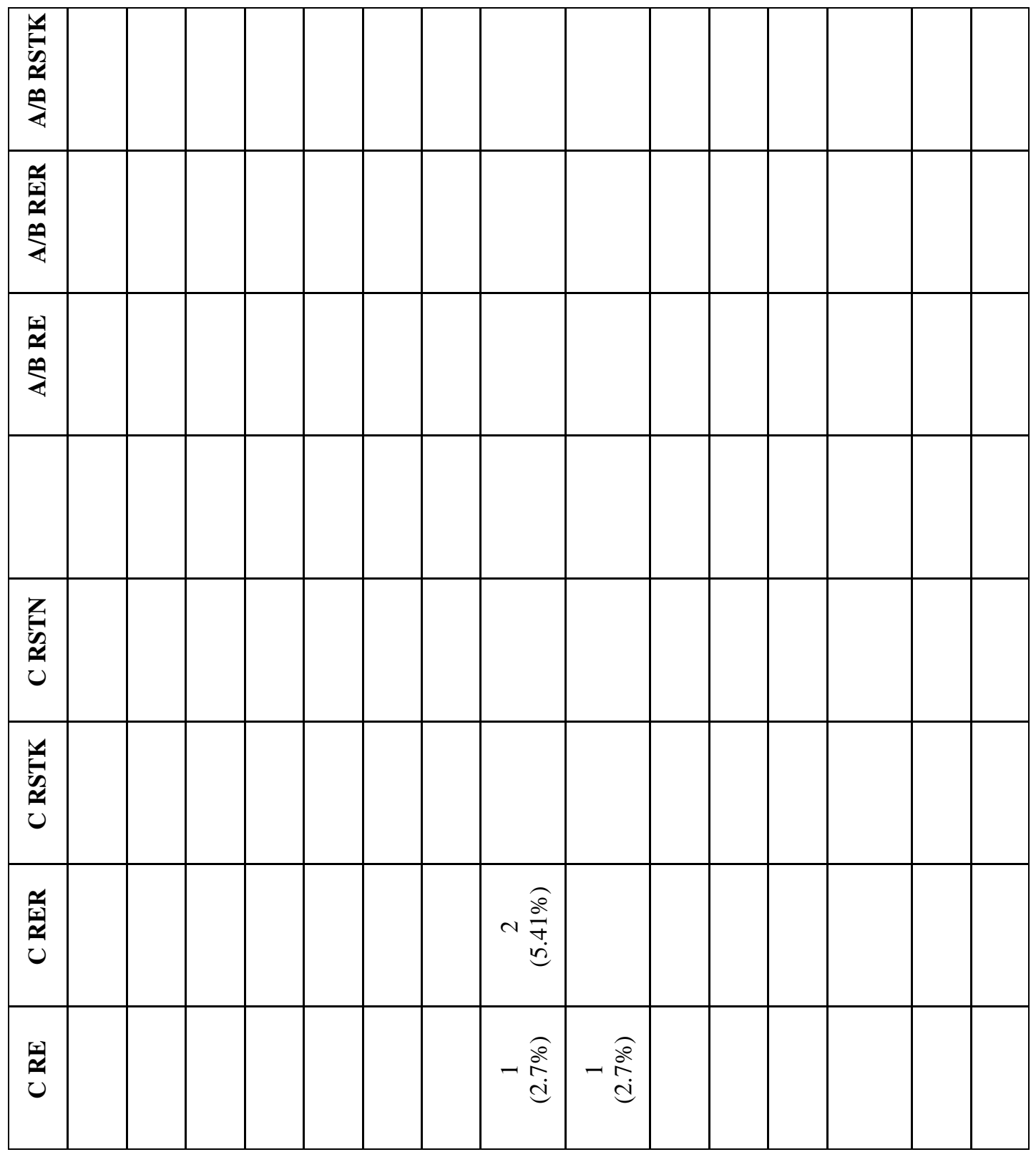

Table 3.8b Co-occurrence of rim types and spatula tool motor actions. \% occurrence is calculated against the number of overall rim sherds per strata. 


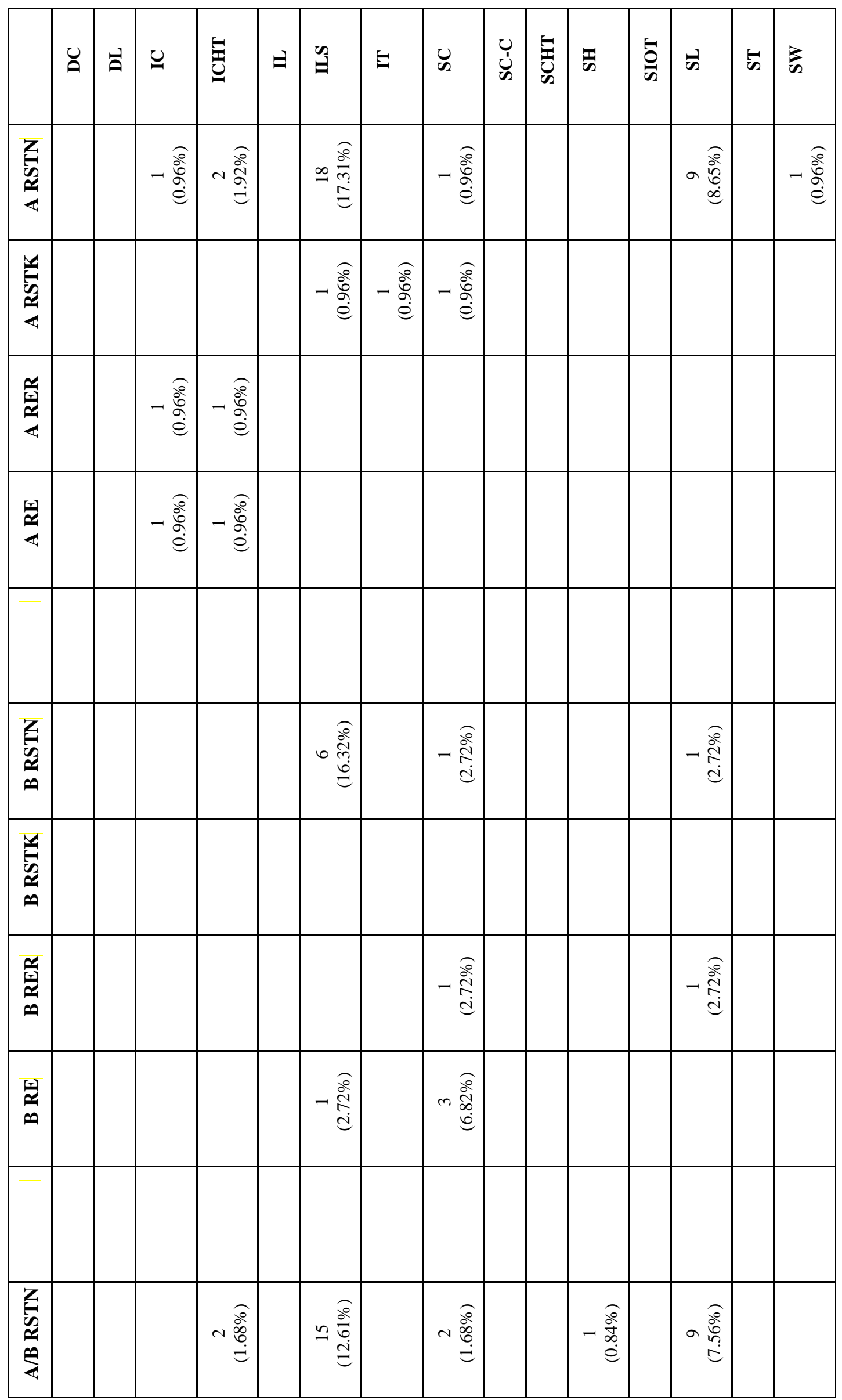




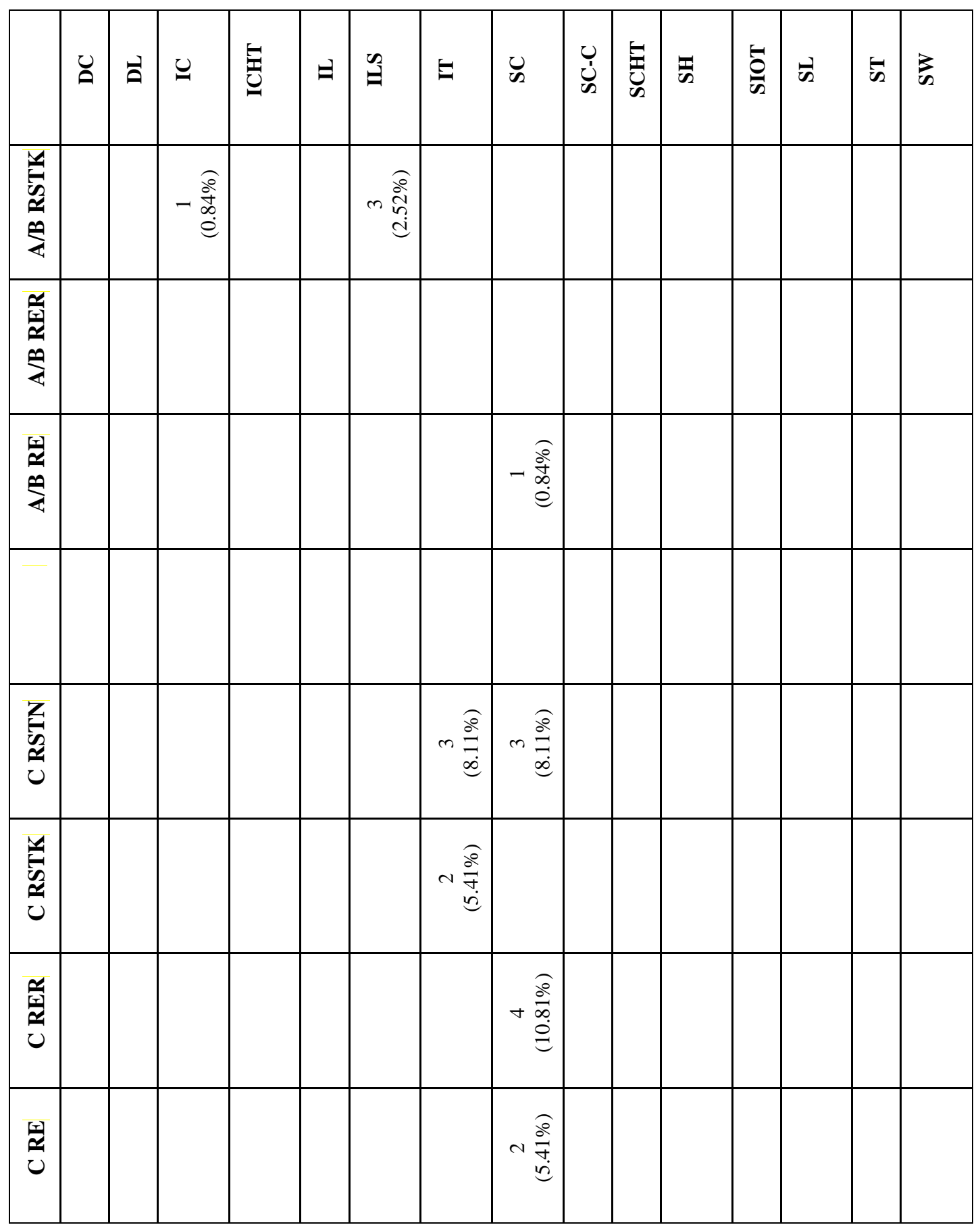

Table 3.8c Co-occurrence of rim types and stylus tool motor actions. \% occurrence is against the number of overall rim sherds per strata. 


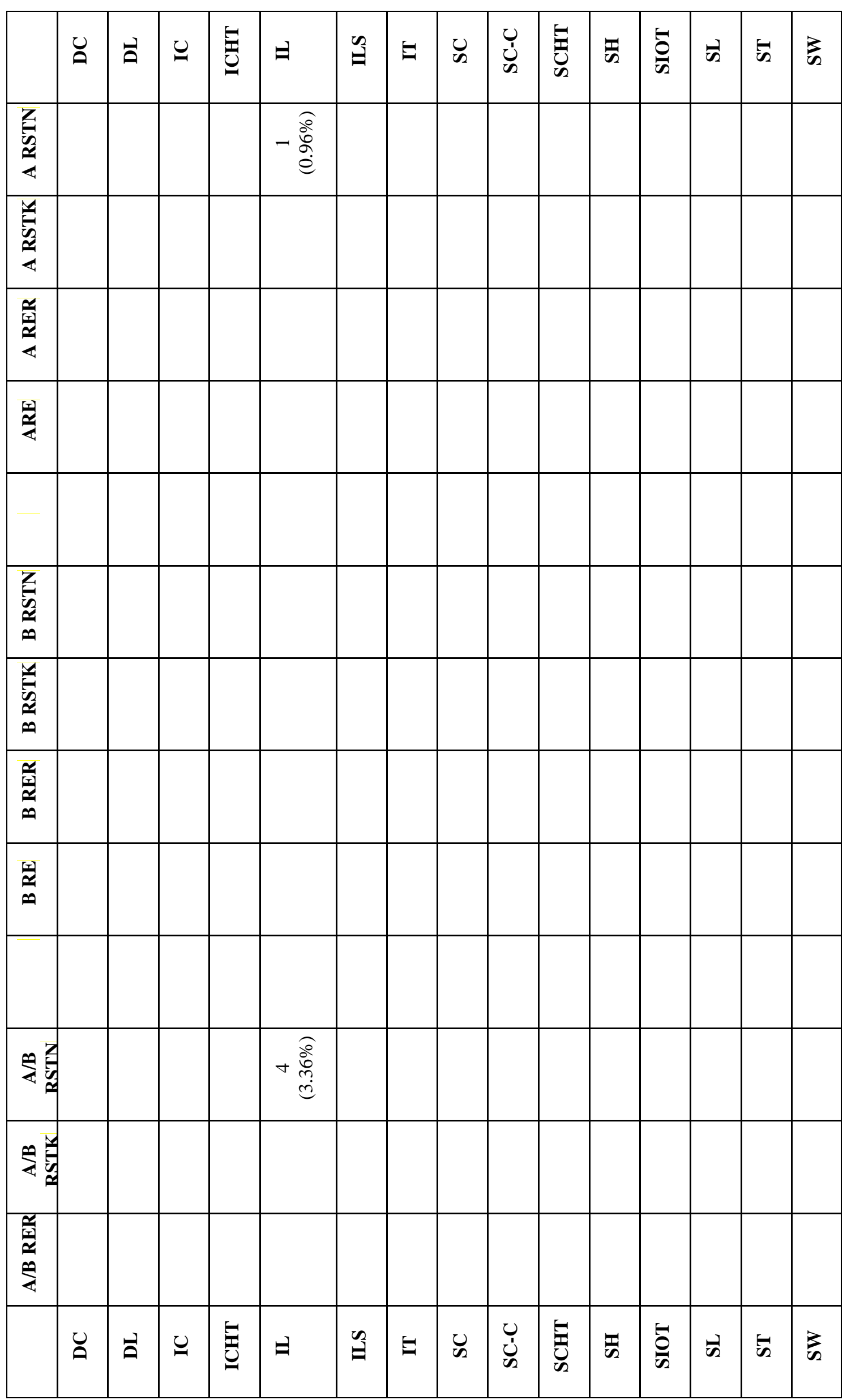




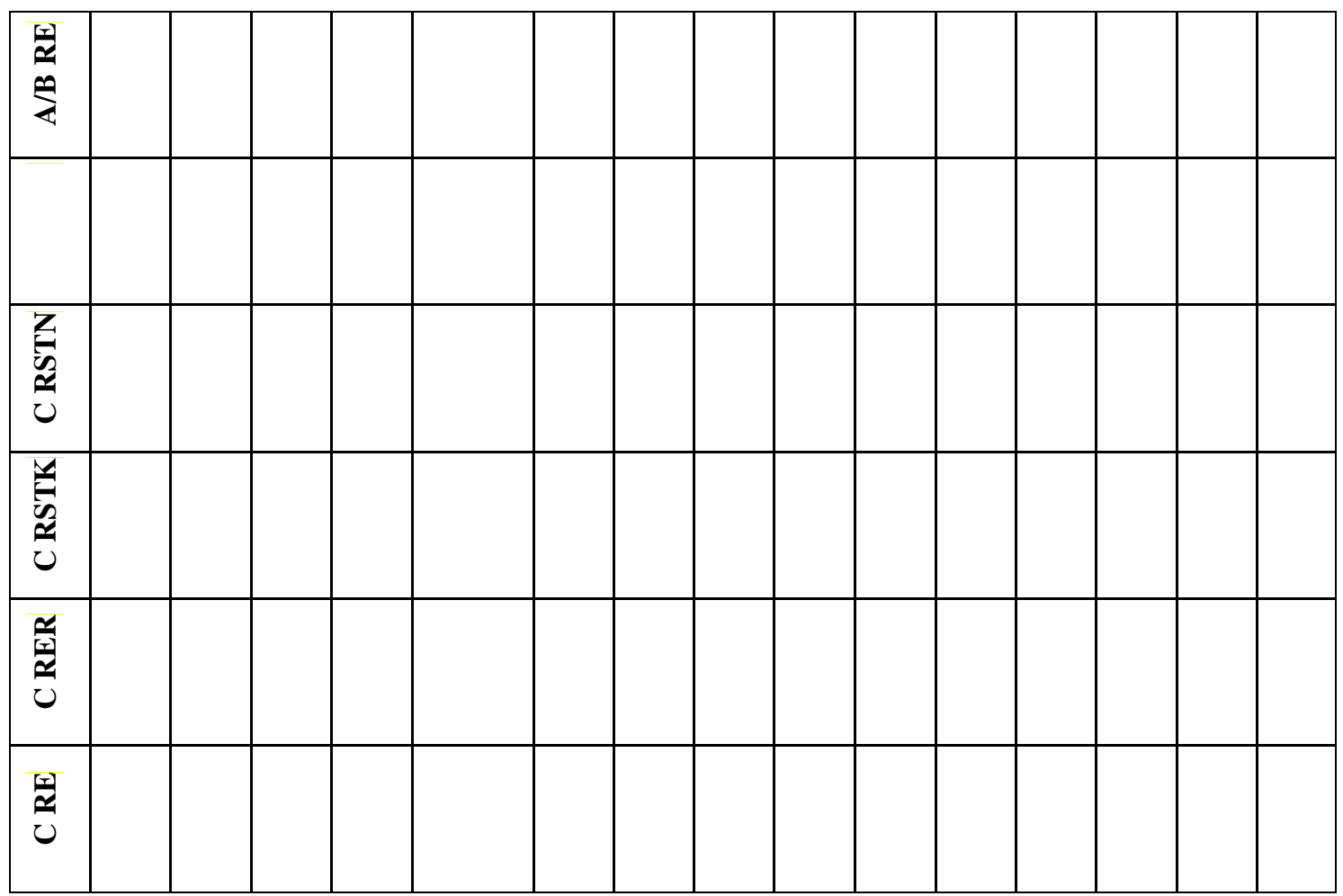

Table 3.8d Co-occurrence of rim types and cord tool motor actions. \% occurrence is against the number of overall rim sherds per strata.

Spatula decor appears as stamped chevron and stamped lines. The former are on both simple thin, simple thick and thick everted rims in strata A-C, while the latter occurs once each on simple thin rims in strata A and B. Impressed cord lines are present only on simple thin rims from Stratum A and the Mixed A/B category. Not included in the tables is the singular occurrence each of a fillet and a hollow reed puncture on simple thick (former) and thick everted (latter) rims from Stratum B.

These attributes are all indicative of changes occurring in the nature and type of ceramics at the site, and assisted in the division of the British Museum collection into three chronologically-relevant assemblages. The sherds in the Mixed A/B category belong to the same assemblage as the vast majority of the sherds from Stratum A. Strata B and C rata have mixed sherds, with $\mathrm{C}$ containing 'Mesolithic' and middle assemblage sherds. The youngest stratigraphic assemblage sherds are those from Stratum A which are also present in Stratum B, due to intermixing caused by the original burial activities and subsequently by the massive activity at the site during the excavation seasons. 
3.3.4 Description of the three assemblages as determined by attribute analysis of the strata

\subsubsection{Assemblage 1 (Figure 3.11)}

'Mesolithic' pottery is a rarity with only 13 remaining sherds in the British Museum collection. The decoration consists of rocker stamped and pivoted comb only, with no trace of a "wave" in the decorative pattern as previously noted and illustrated by Caneva (1991). The paste predominantly features sand, usually augmented with bone and mica, which agrees with Caneva's (1991: 265) description of the temper of her 'Dotted Wavy Line' sherds. There is no burnishing.

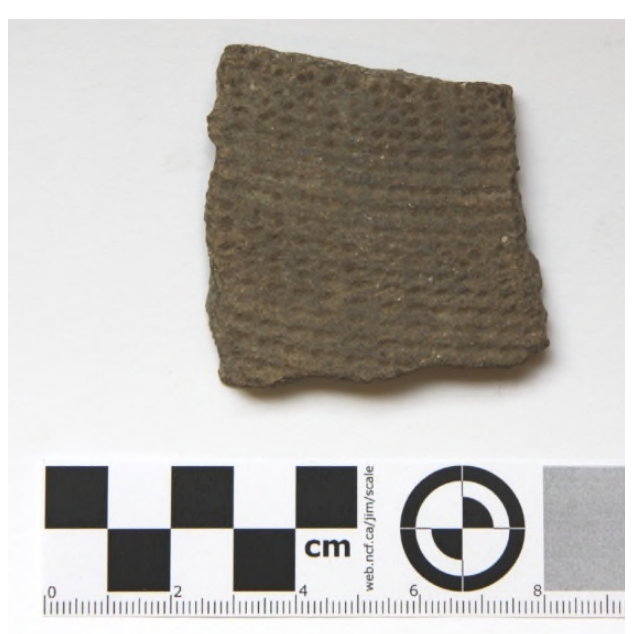

A

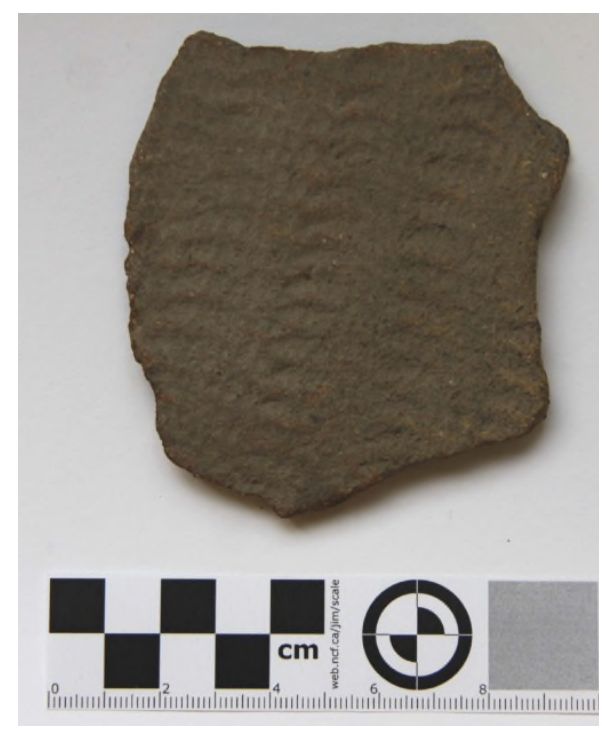

C

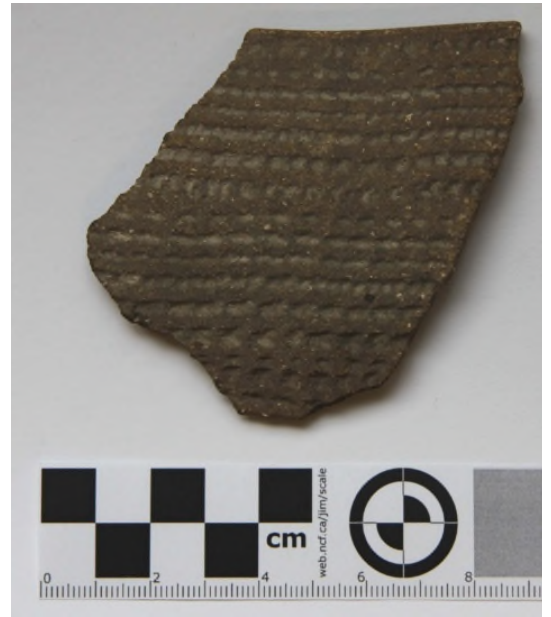

B 


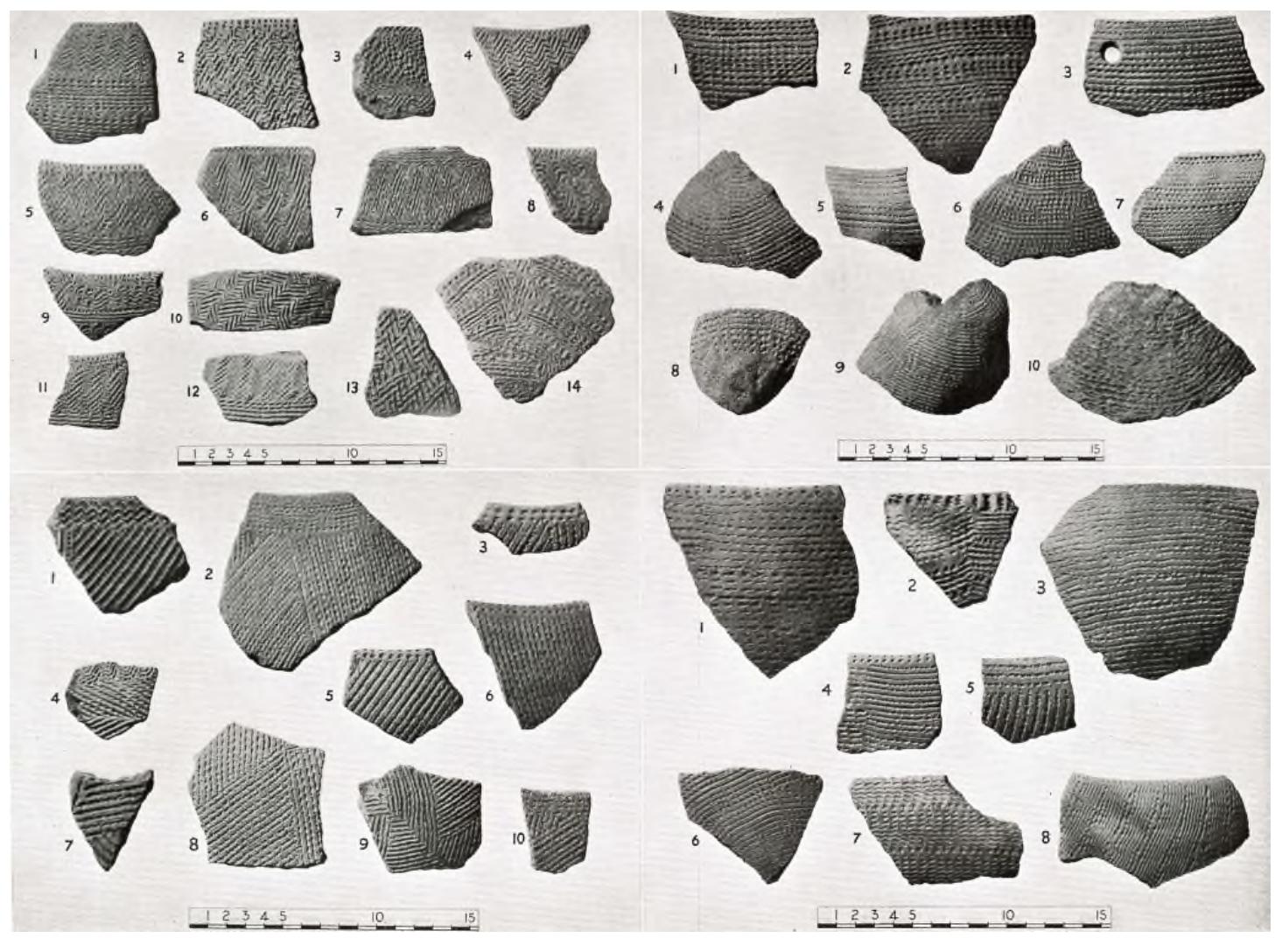

D

Figure 3.11 Jebel Moya: Assemblage 1: (a) body sherd 2 - 3mm thick with combstamped decoration; (b) rim and body sherd $3 \mathrm{~mm}$ thick with comb-stamped and pivoted comb décor; (c) body sherd 5 - $6 \mathrm{~mm}$ thick with dragged comb lines and stamped comb décor; (d) a selection of Assemblage 1 body and rim sherds. The temper of all the sherds is sand paste with bone and mica. ( $a-c)$ are from tray JM 3 and are reproduced with the kind permission of the Trustees of the British Museum; (d) is from Addison (1949: Plate $X C I V)$.

\subsubsection{Assemblage 2 (Figure 3.12)}

These 104 sherds comprise 73 sherds with diagnostic rims; of these $27.4 \%$ were thick (rolled) everted, $21.92 \%$ everted thin, 35.62\% simple thin and $15.07 \%$ simple thick. The remaining 31 consist of 2 indeterminable rims and 29 thick bodies and handles. The rim decor comprises dragged comb (21.92\%) as well as stamped (30.14\%) chevrons, incised and stamped lines (20.55\%), cross-hatching (2.74\%), hollow reed puncture holes $(1.37 \%)$, raised wavy lines $(1.37 \%)$ and an incised triangle infilled with comb lines $(1.37 \%)$; there are 13 rims without decor. There are 5 instances of fillets and 9 impressed cord elements either on the lip or on the body or base. The fine spatula-stamped 
impressions on the lip in diagonal or chevron patterns are very similar to those found by Randi Haaland in Level 2 at Rabak (see section 3.1.2).

In the decorative layout, the chevron motif is usually uppermost on vessels, after which there is a band of stamped comb, stylus or impressed cord decoration. There is no zoning of motifs. Motifs appear on the outer surface of the lips in all but 10 instances where they are present on the inside surface. The temper comprises coarse grit and sand, with mica $(12.5 \%)$ also sometimes present. Burnishing (83.65\%) and slipping (92.31\%) occur on most sherds. Where determinable, the rim angles show open vessels (78.7\%) predominated, with relatively rare closed forms.

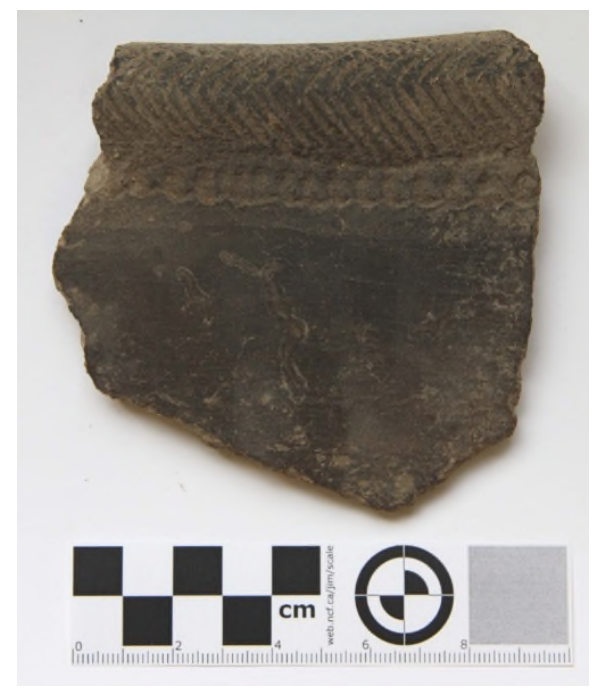

A

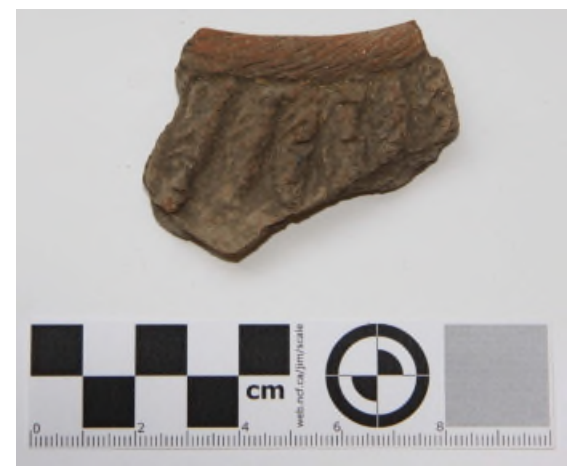

C

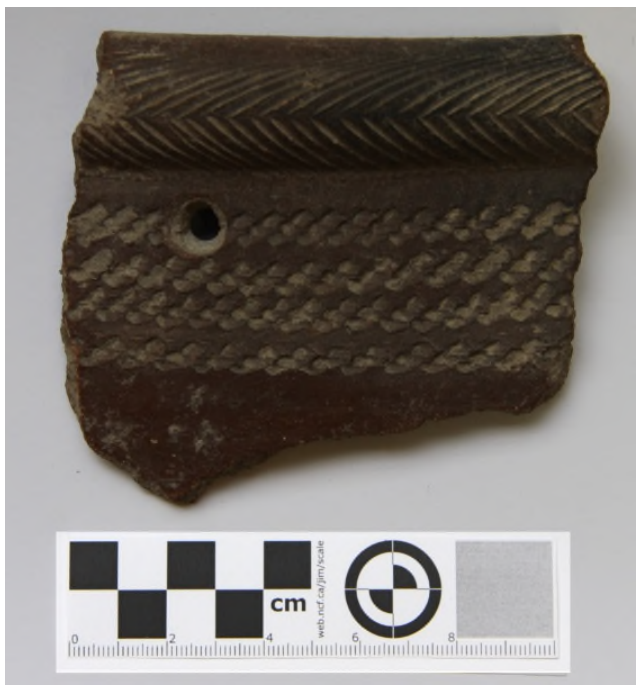

B 


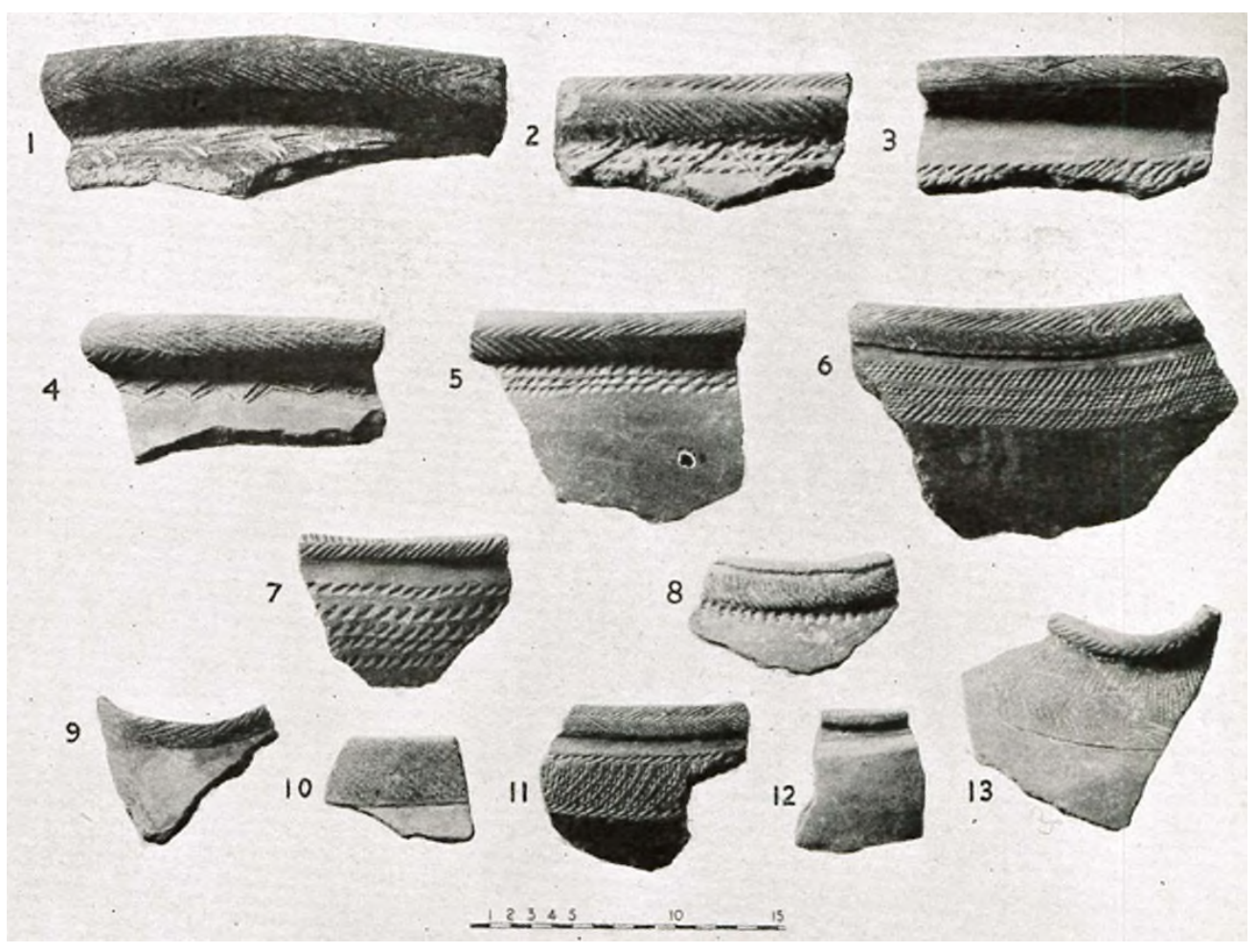

D

Figure 3.12 Jebel Moya: Assemblage 2: (a) thick, rolled everted rim and body sherd 5 $-10 \mathrm{~mm}$ thick with dragged comb chevrons on the rim and a comb-stamped line under the lip; (b) thick, rolled everted rim and body sherd 3 - 24mm thick with dragged comb chevrons on the lip and a wad of cord impression just under the lip; (c) thick, simple rim and body sherd $8-26 \mathrm{~mm}$ thick with incised angular lines on the lip and rows of vertical incised fillets just under it. The temper of all the sherds is coarse grit. $(a-c)$ are from tray JM4 and are reproduced with the kind permission of the Trustees of the British Museum; (d) is from Addison (1949: Plate CIV).

\subsubsection{Assemblage 3 (Figure 3.13)}

This group is comprised of 369 sherds, of which 258 have diagnostic rims. Sherds are highly burnished (100\%), relatively thin (when compared to Assemblage 2) and slipped $(100 \%)$. Rim forms are relatively elementary with only everted (5.81\%) and simple (94.19\%) rims, of which $96.90 \%$ are open vessels. Decorative motifs are present on 224 rims and consist of grooved and incised channels (0.89\%), comb-dragged chevrons $(1.79 \%)$, comb-dragged lines (5.8\%), cord-wrapped element $(2.23 \%)$, incised and stamped cross-hatching (8.48\%), fillets $(0.44 \%)$, incised chevrons (1.79\%), incised lines (20.54\%), raised bumps (0.44\%), stamped chevrons (4.02\%), stamped lines (52.23\%), stamped triangles $(0.44 \%)$ and indeterminate markings $(1.34 \%)$. 
Also frequently present, on the body of 62 out of 352 sherds (17.61\%), are pendant triangles (zoned forms) in-filled with fine stamping, either with comb or cord-wrapped elements. There are also 102 examples $(28.98 \%)$ of cord-wrapped elements (impressed, not rolled, sensu MacDonald and Manning 2010) on the body. Critically, motifs occur on the body of vessels as part of zoned (geometric) forms. Nine sherds (2.44\%) have motifs on their interior ranging from stylus-incised chevrons, comb-stamped crosshatching, impressed cord element and stylus-incised chevrons to comb-stamped or stylus-incised lines. Mica (90.24\%) predominates in the temper.

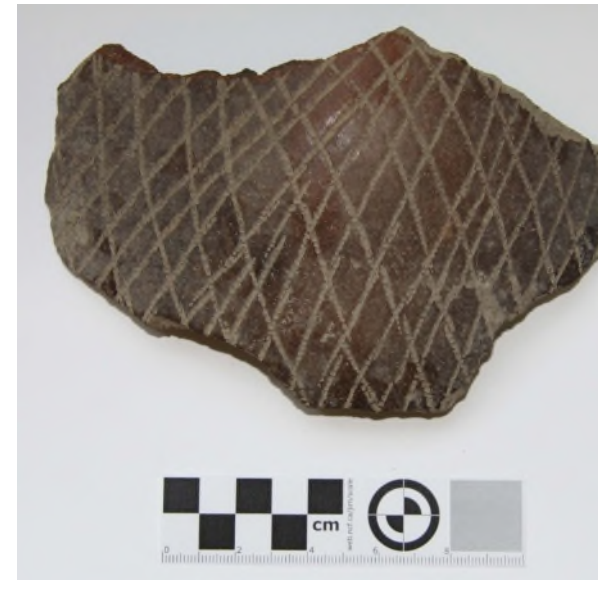

A

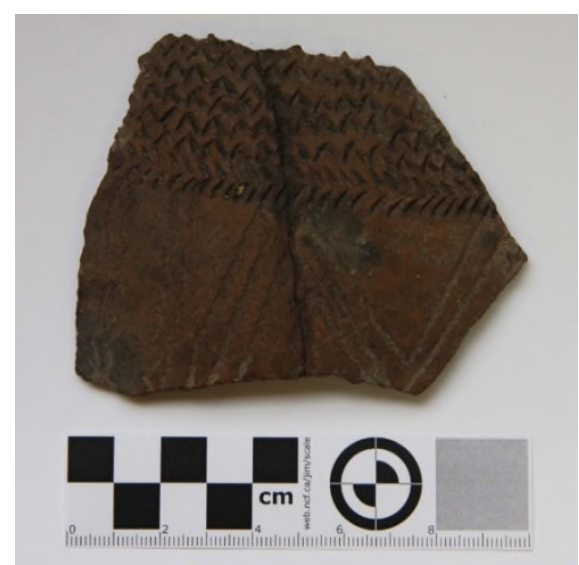

C

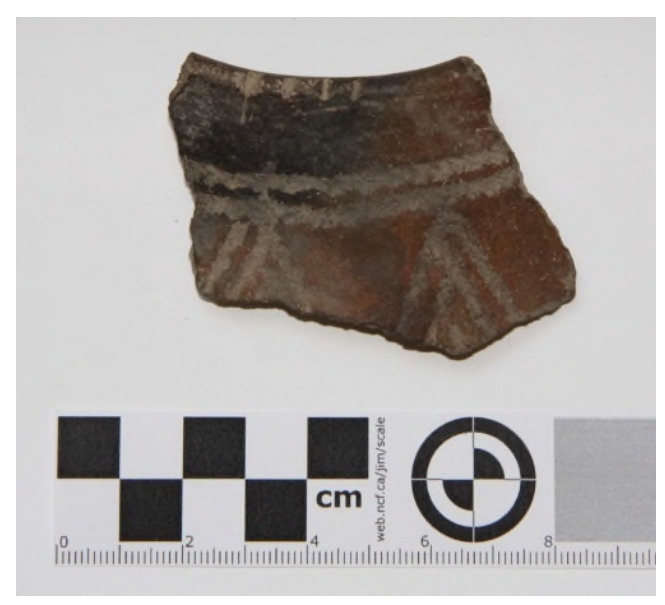

B 


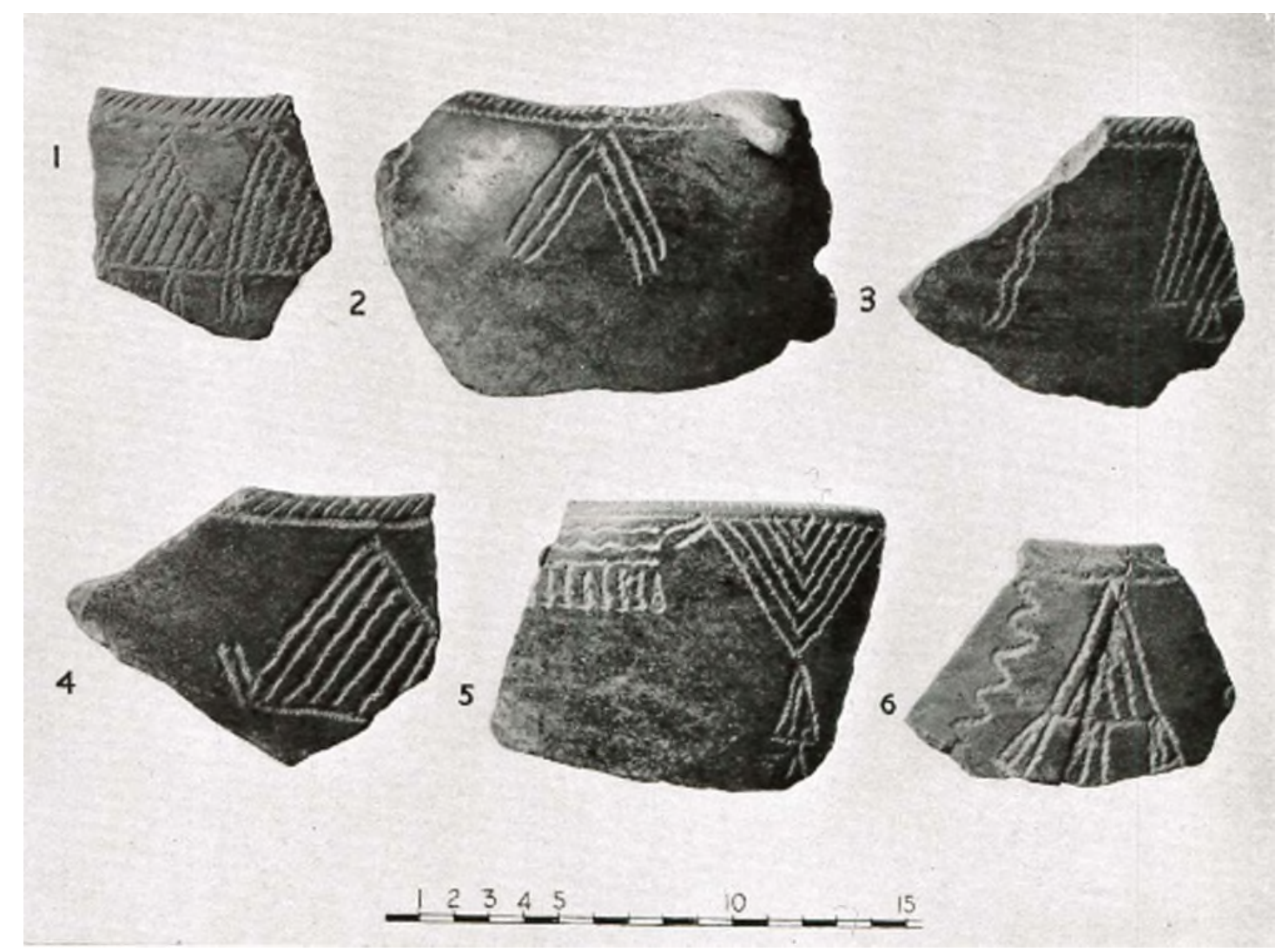

D

Figure 3.13 Jebel Moya: Assemblage 3: (a) body sherd 2.5 - 4.5mm thick with combstamped angular lines forming quadrangles; (b) simple rim and body sherd $3-6 \mathrm{~mm}$ thick with two comb-stamped channels under the lip and comb-stamped triangles on the body; (c) body sherd 1 - 4.5mm thick with stylus-stamped wavy-lines, stylus-stamped chevron lines and comb-stamped triangular and vertical wavy-lines. The temper of all the sherds is sand with mica (with some organics). (a-c) are from tray JM2 and are reproduced with the kind permission of the Trustees of the British Museum; (d) is a selection of large rim sherds from Addison (1949: Plate CI).

\subsubsection{Pottery from burials}

In my new Register of Graves, 77 instances of pottery are recorded in direct association with human burials distributed across the valley (Figure 3.14, Table 3.9). Of these 77 burials, twenty-four (also distributed across the site and through the strata) contain pottery sherds that were illustrated either on the excavation cards or in Addison's publication, or both (Appendix IV). Outside of the 24 illustrated sherds, it is not possible to know for certain how many are whole vessels or smashed/burst pots, and how many may merely be sherds from the grave fill interpreted as grave goods. Indeed, Addison and the original excavators had a tendency to record a whole vessel instead of the single 
sherd (for example see burial 2424). Consequently, the presence of original illustrations is used to determine the accuracy of the purported description.

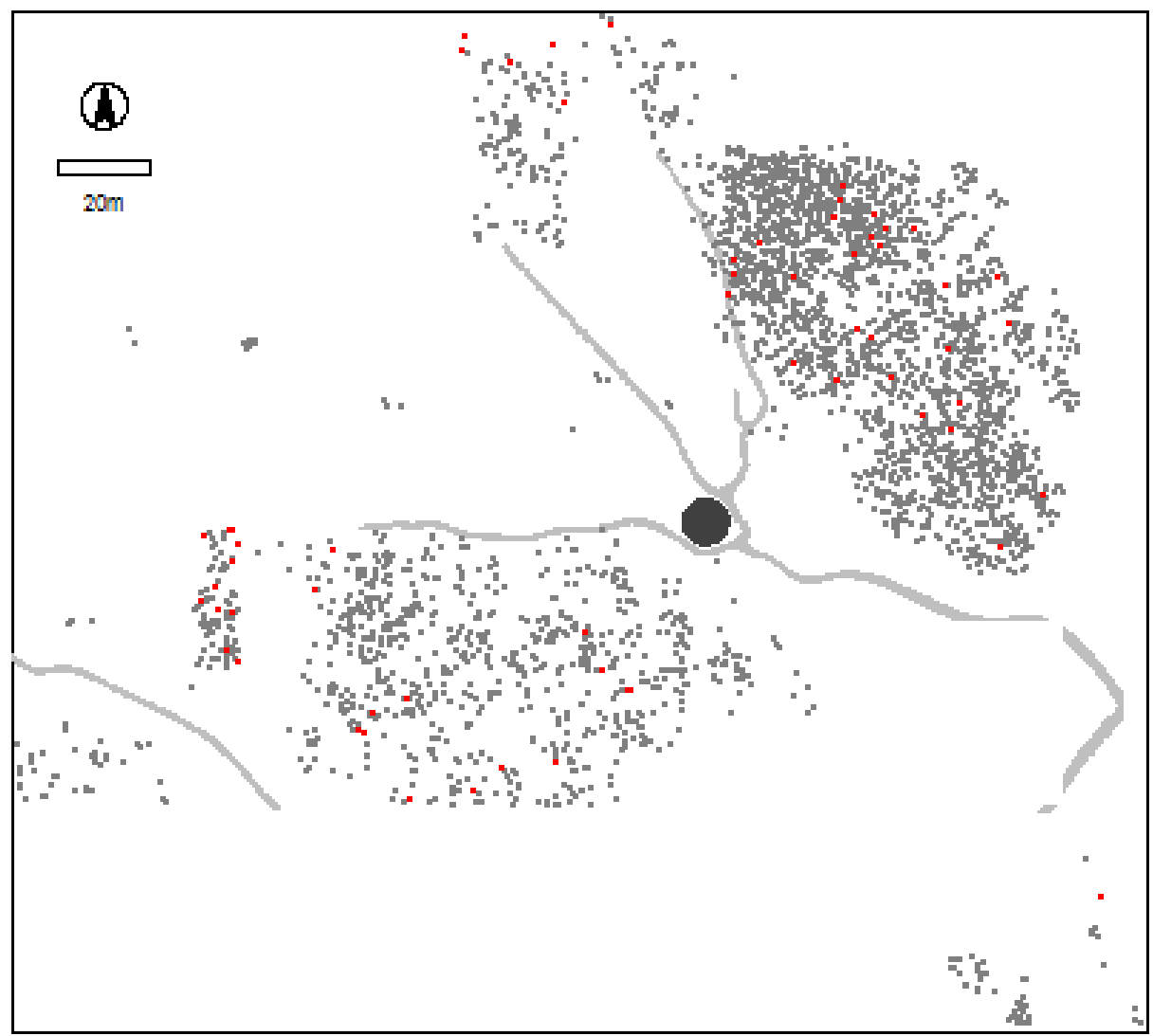

Figure 3.14 Jebel Moya: The spatial distribution of pottery (red) in recorded association with human burials (grey). From Brass and Schwenniger (2013: Figure 6).

\begin{tabular}{|l|l|}
\hline \multicolumn{1}{|c|}{ Area } & Burials \\
\hline South & 0 \\
\hline South-West & 31 \\
\hline West & 0 \\
\hline East & 11 \\
\hline North-West & 7 \\
\hline North-East & 23 \\
\hline Unknown & 5 \\
\hline Total & $\mathbf{7 7}$ \\
\hline
\end{tabular}

Table 3.9 Jebel Moya: The breakdown of the spatial distribution of pottery in recorded association with human burials by sector.

On this basis, of the 24 burials with illustrated pottery sherds and vessels found in stated association, sixteen are from whole or partially whole vessels, four are "pot bursts" with the sherds covering a portion of the body such as the upper body or face, and seven have one or more 'loose' pottery sherds. Of the latter, burial 1225 had two large pottery 
fragments over the head and burial 2386 had a sherd originally from a large red granite vessel over its knee; the other sherds may have been mis-recorded and belong instead to the fill. While burial 1290 had an Assemblage 2 sherd under its left hand, it is likely an accidental association. If we exclude all such dubious associations, all the remaining recorded sherds belong to Assemblage 3. Furthermore, none of the descriptions of nonillustrated burial assemblage pottery resemble any of the pottery assigned to Assemblage 2 - they are all attributable to Assemblage 3. The lack of pottery in definitive association with any grave which could be assigned to Assemblages 1 or 2 argues in favour of at least the vast majority of the burials being from a single phase.

\subsection{The absolute dating of Jebel Moya}

Initial AMS dating of 11 human bone samples was attempted at the Queens University (Belfast) dating laboratory concentrating on drilled samples from patellas curated by the Duckworth Laboratory (University of Cambridge). Unfortunately, the samples failed the initial \% Nitrogen test. The baseline percentage for continuing the testing is $0.79 \%$; the highest $\%$ Nitrogen in any of the samples was $0.13 \%$. Subsequently, funding was obtained from the Wellcome Trust and permission granted by the British Museum to attempt to OSL date some of the pottery sherds in the British Museum's collection. A total of six samples were submitted from six sherds: three from Assemblage 2 and three from Assemblage 3.

Each sample was a square of $2 \times 2 \mathrm{~cm}$, and more than $5 \mathrm{~mm}$ in thickness, ensuring that a portion of a larger diagnostic could be removed for destructive analysis, leaving behind a reference specimen. The samples were prepared for optical dating of extracted coarsegrained quartz (60-125 or 90-255 microns). OSL dating should indicate the time that the pottery was fired and has been shown to provide similar accuracy to AMS radiocarbon dating of organic remains in pottery (Manning et al. 2011).

Sample preparation and luminescence measurements were conducted at the Research Laboratory for Archaeology and the History of Art (Oxford University) using standard preparation procedures (Aitken 1985) that included wet sieving, treatment with hydrochloric and hydrofluoric acids and removal of heavy minerals using sodium 
polytungstate. All measurements were conducted on an automated Ris $\emptyset$ luminescence reader using small sized aliquots $(2-3 \mathrm{~mm})$ and a single-aliquot regenerative-dose measurement protocol (Murray and Wintle 2000) with the addition of a post-IR blue OSL procedure (Banerjee et al. 2001). Luminescence measurements were made at a raised temperature of $125^{\circ} \mathrm{C}$, with a preheat $1\left(\mathrm{PH}_{1}\right)$ value of $240^{\circ} \mathrm{C}$ for ten seconds, a preheat $2\left(\mathrm{PH}_{2}\right)$ of $200^{\circ} \mathrm{C}$ for ten seconds and up to six regeneration dose points. Palaeodose estimates were obtained using the weighted mean of between 6 and 12 aliquots derived from an exponential fitting procedure.

Internal and external dose rates were calculated on the basis of geochemical analysis by fusion ICP-MS. No sediment samples associated with the ceramics were available for dose rate determination because the sherds were collected from 1911 - 1914. However, three of the sherds (X5293, X5294 and X5295) contained small amounts of remnant soil stuck to the surface. This material was considered to be representative of the burial environment at Jebel Moya and was carefully removed and pooled to provide sufficient quantities of material for analysis. An inflated error of $10 \%$ was assigned to the external gamma-dose rate $(1.03 \mathrm{~Gy} / \mathrm{ka})$ in order to account for any additional uncertainty on the external dose rate contribution. Radioisotope concentrations were converted to dose rates using the conversion factors of Adamiec and Aitken (1998), the grain-size attenuation factors of Mejdahl (1979) and the absorption coefficient for water by Zimmerman (1971). The contribution of cosmic radiation to the total dose rate was calculated as a function of latitude, altitude, burial depth and average over-burden density based on data given by Prescott and Hutton (1994). It was assumed that overburden accumulated soon after deposition and was negligible relative to the burial period. OSL age estimates were calculated by dividing the mean palaeodose by the dose rate and presented as \pm one standard error (Table 3.10).

\begin{tabular}{|l|l|c|c|}
\hline Laboratory code & Palaeodose $(\mathbf{G y})$ & $\begin{array}{c}\text { Total dose rate } \\
(\mathbf{G y} / \mathbf{k a})\end{array}$ & $\begin{array}{c}\text { OSL age estimate } \\
\text { (years before 2012) }\end{array}$ \\
\hline X5291 & $9.71 \pm 1.49$ & $5.52 \pm 0.38$ & $1760 \pm 295$ \\
X5292 & $16.33 \pm 3.64$ & $5.03 \pm 0.33$ & $3245 \pm 755$ \\
X5293 & $7.19 \pm 1.20$ & $4.82 \pm 0.32$ & $1490 \pm 270$ \\
X5294 & $17.38 \pm 2.30$ & $5.06 \pm 0.33$ & $3435 \pm 260$ \\
X5295 & $17.96 \pm 2.14$ & $5.53 \pm 0.37$ & $3250 \pm 445$ \\
X5296 & $7.58 \pm 2.58$ & $4.90 \pm 0.33$ & $1545 \pm 535$ \\
\hline
\end{tabular}

Table 3.10 Jebel Moya: Summary of the OSL dating results. 
Although the OSL results have very large standard error deviations, there are no overlaps in the respective dates from the Assemblage 2 and Assemblage 3 sherds (Figure 3.15, Table 3.11). The results indicate that there were three broad temporal phases. The sherds assigned to Assemblage 1 were not directly dated as it was necessary to focus limited dating resources on the more numerous second and third assemblages. The association of Assemblage 1 to the sixth or early fifth millennium BC rests on Caneva's (1991) earlier stylistic analysis and on subsequent studies of the chronology and distribution of early Sudanese pottery (Jesse 2010; Salvatori et al. 2011).

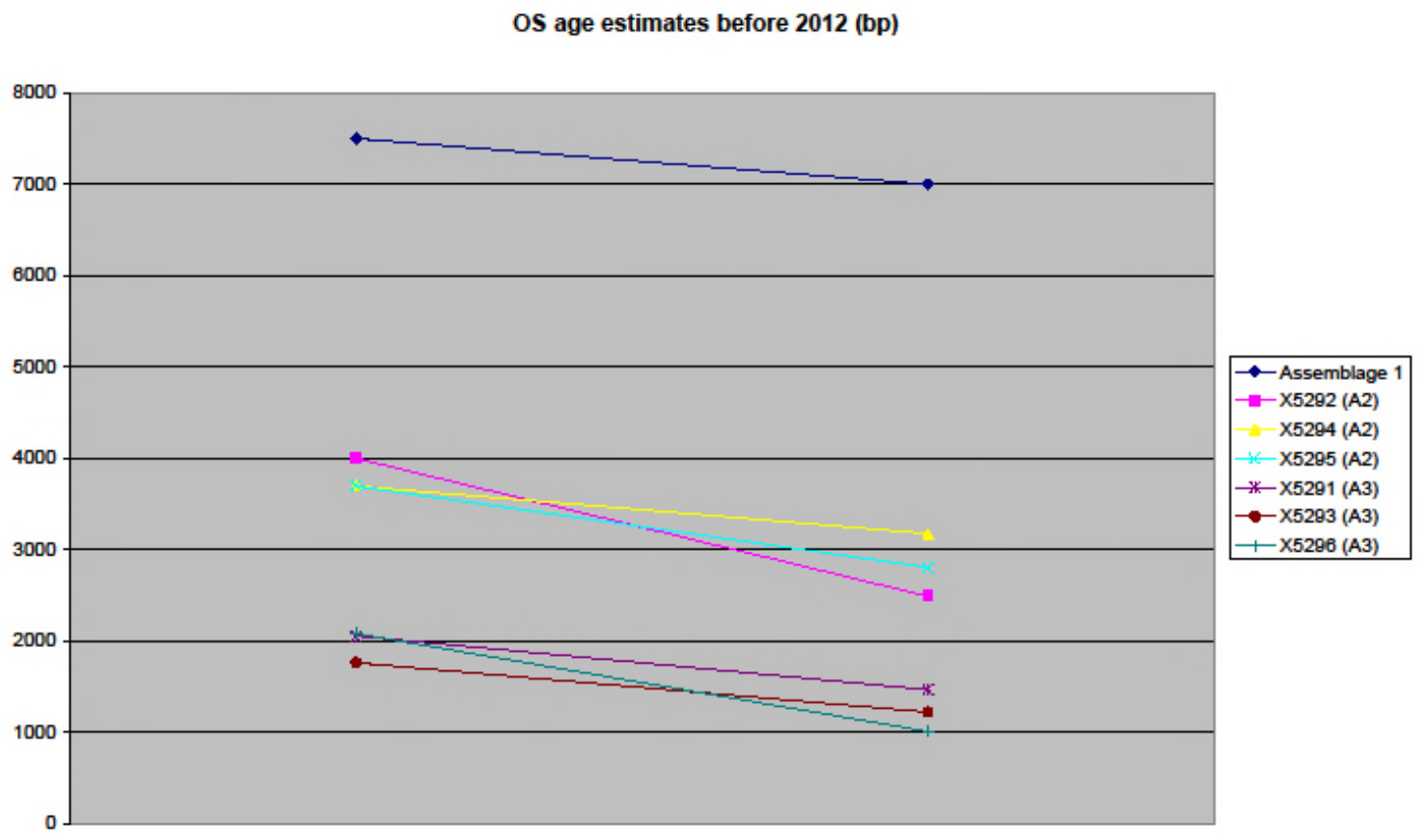

Figure 3.15 Jebel Moya: The plotted luminescence date intervals from the Assemblage 2 and 3 samples which fall into two distinct clusters. The Assemblage 1 range is hypothetical based on Caneva (1991). From Brass and Schwenniger (2013: Figure 7). 


\begin{tabular}{|c|c|c|c|c|}
\hline Laboratory code & $\begin{array}{l}\text { British Museum } \\
\text { code }\end{array}$ & Assemblage & $\begin{array}{l}\text { Decorative } \\
\text { description }\end{array}$ & $\begin{array}{c}\text { Calibrated OSL } \\
\text { dates }\end{array}$ \\
\hline X5291 & EA 81191 & 3 & $\begin{array}{l}\text { Thin simple rim. Comb- } \\
\text { stamped angular pattern } \\
\text { on rim. Comb-stamped } \\
\text { line on neck. Three } \\
\text { comb-stamped } \\
\text { triangular-shaped lines } \\
\text { on body }\end{array}$ & $40 \mathrm{BC}-\mathrm{AD} 550$ \\
\hline X5293 & EA 81192 & 3 & $\begin{array}{l}\text { Thin simple rim. Comb- } \\
\text { stamped angular pattern } \\
\text { on rim. Cord element } \\
\text { line on neck. Cord- } \\
\text { impressed and infilled } \\
\text { triangles on body }\end{array}$ & AD $255-790$ \\
\hline X5296 & B4 = EA 81191 & 3 & $\begin{array}{l}\text { Thin simple rim. Comb- } \\
\text { stamped angular pattern } \\
\text { on rim. Comb-stamped } \\
\text { line on neck }\end{array}$ & $70 \mathrm{BC}-\mathrm{AD} 1005$ \\
\hline X5292 & EA 81192 & 2 & $\begin{array}{l}\text { Thickened simple rim. } \\
\text { Spatula-stamped pattern } \\
\text { on rim with an incised } \\
\text { line on neck }\end{array}$ & $1985-475 \mathrm{BC}$ \\
\hline X5294 & EA 81193 & 2 & $\begin{array}{l}\text { Thickened everted rim. } \\
\text { Dragged comb chevron- } \\
\text { pattern on rim }\end{array}$ & $1680-1165 \mathrm{BC}$ \\
\hline X5295 & EA 81192 & 2 & $\begin{array}{l}\text { Thickened everted rim. } \\
\text { Dragged comb chevron- } \\
\text { pattern on rim with } \\
\text { cord element below }\end{array}$ & $1680-790 \mathrm{BC}$ \\
\hline
\end{tabular}

Table 3.11 Jebel Moya: Summary of the sampled sherds curated at the British Museum.

Assemblage 2 comprises occupations covering a relatively long period from the midsecond millennium to the mid-first millennium BC. The nature of the Assemblage 2 occupation at Jebel Moya cannot as yet be determined, but it can be stated with relative confidence that no burials are clearly attributable to this period by association with pottery. The period broadly coincides with the Middle and Classic Kerma Periods in Nubia until shortly after the emergence of the early Napatan élite who ruled in Egypt as the Twenty-Fifth Dynasty ca. 747 - 656 BC (Hafsaas 2006; Shaw 2000). No Kerma artefacts have been uncovered at Jebel Moya, while the few artefacts of possible Napatan origin have an uncertain depositional history (see sections 3.5.1 and 3.5.2). Any relationship between the Assemblage 2 pottery and with the Butana Group wares has been heavily disputed by Winchell (2013) on stylistic grounds. 
Furthermore, pottery resembling that from Assemblage 2 has not yet been found further north in the Gezira, apart from at Jebel et Tomat (of unknown date) to the northwest, although such sherds were found at Rabak to the west. Re-analysis and redating of the Rabak assemblages cannot be undertaken due to a lack of certainty over where the pottery is located and the subsequent destruction of the site (Randi Haaland, pers. comm. 2011). The mid-third millennium BC date available for the early occupation of Jebel et Tomat is based on a single radiocarbon date obtained on shell from a soil pit dug on the edge of the midden in uncertain association with cultural materials; Clark (1973b: 57) admits that this date needs to be regarded as tenuous. The new OSL dates from the Jebel Moya chevron-decorated 'thick-wares' (which overlap a period of 1680 - 790 BC) may therefore also have a bearing on the published chronologies of Jebel et Tomat and Rabak.

However, it is noteworthy that the second millennium BC sees increases in 'thick-wares' in areas to the east of the Gezira: the ratio of everted 'thick-wares', some with the distinctive stylus-stamped chevron patterns on the rims, increases in the Late Gash period ( $c a .1700$ - 1500 BC) in the south-eastern Sudan's Kassala and wider Gash Delta areas, for example, and is a major presence in its subsequent Jebel Mokram phase (Andrea Manzo and Valentina Perna, pers. comm. 2013; Manzo 2011).

The majority of the extant sherds come from Assemblage 3, which has now been OSLdated from the first century $\mathrm{BC}$ until the mid-first millennium AD. This time span covers the middle and late Meroitic periods, as well as the aftermath of the breakup of the Meroitic state, which had stretched south into the western Butana and with possible settlements along the Blue and White Niles. It is to this phase that the majority of the Jebel Moya cemetery may now be assigned, effectively to a society living along the southern frontier zone of the Meroitic state.

Of the 3135 human burials, 1108 (35.3\%) have associated grave goods, leaving 2026 burials $(64.7 \%)$ without goods or with artefacts listed as coming from the grave infill. Contrary to the view expressed by Gerharz (1994), GIS analysis reveals that the distribution of grave goods is not concentrated in the east and northeast of the valley (Figure 3.16). This includes items made from imported materials as accompanying burial goods. None are diagnostic of any temporal period earlier than the late first 
millennium BC and the only ceramics definitely associated with graves come from Assemblage 3. This revises the chronological reconstruction of Gerharz (1994: 331), who admitted that his notional end date for the site's sequence of the first century BC was guesswork: the absence of Meroitic pottery from Jebel Moya, and likewise the lack of Jebel Moya Assemblage 3 pottery in the Meroitic heartland of the Shendi Reach, are not by themselves reliable chronological indicators when the new OSL dates are considered.
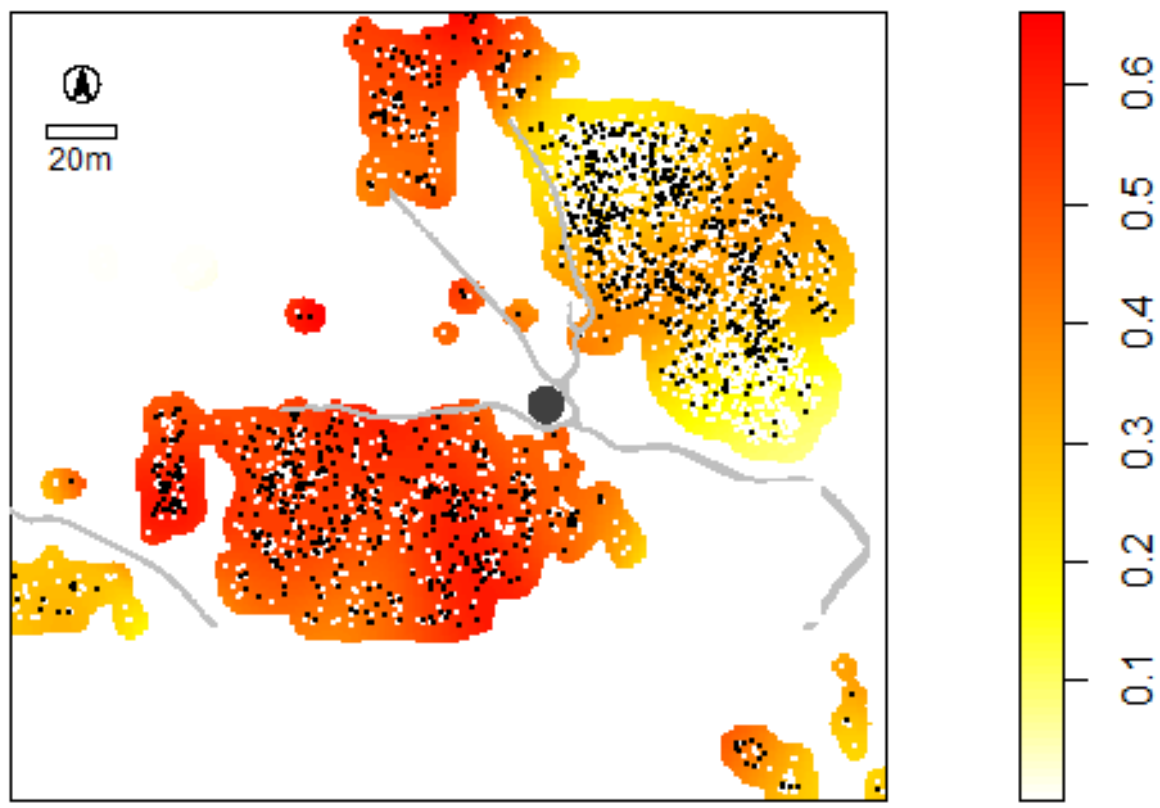

Figure 3.16 Jebel Moya: The relative density of burials-with-grave-goods to burialswithout-grave-goods is greater in the southwest and north $(>0.5)$ than in the east and northeast. The overall ration of burials-with-grave-goods to all burials is $1108 / 3135=$ 0.35 , which is the global average risk or probability of burials with goods. From Brass and Schwenniger (2013: Figure 8).

\subsection{Implications of the new pottery and radiometric analyses}

Addison's (1956) reassignment of the cemetery, and Clark's (1973b) attribution of its later occupational phase to Meroitic times, is seemingly largely vindicated by the new radiometric dates. However, it has been previously argued by Gerharz (1994) that the burials without accompanying grave assemblages could date from an earlier phase. Additionally, both Addison (in his earlier 1949 publication) and Gerharz (1994) used the presence of artefacts attributed to the Egyptian New Kingdom (ca. 1550 - 1070 BC) 
and the Napatan state, by Egyptologists consulted by Wellcome, to argue for a preMeroitic occupation with possible burial activities at Jebel Moya. These issues will be examined using (1) burial assemblages with claimed non-local artefacts, (2) non-locally manufactured artefacts not found in association with skeletal remains, and (3) comparisons of the cardinal directionality and burial postures of burials-with-goods versus burials-without-goods to determine any differences which may be of chronological significance.

\subsubsection{Claimed non-local artefacts in the burial assemblages}

The burial assemblages included a limited number of artefacts demonstrably manufactured from outside the southern Gezira (see section 6.1). Most notably, burials 263 and 524 (East and North-East sectors) each contain a bronze statuette of the Egyptian god Shu but its date of manufacture could be either Napatan or Meroitic. The scarab from burial 1577 (also in the North-East) was described by Addison (1949: 177) as a steatite scaraboid "engraved on both the back and the base. Back: Ram of Amen beneath a sacred tree. In front of the ram is an uraeus. Base: The name Men-Ka-Ra flanked by uraei." The name refers to Menkhepera (Piye), the first (Napatan) ruler of the $25^{\text {th }}$ Dynasty, $747-716$ BC. However, the scarab in burial 2225a (North-East), together with the $u d a t$ from burial 535 (North-East), are not described further. Bar burial 2225a from Stratum B, all the other burials are from Stratum C.

Addison (1949: 112) claimed that beads from 117 graves, predominantly from Stratum B and in the North-East Sector, were made from copper coils and therefore must have been imported in its final form. However, neither Addison's Register of Graves nor the original excavation card records for each burial provide information to (1) backup the composition of these beads, and (2) indicate which 117 graves he was referring to.

As such, all but the scarab from burial 1577 cannot be conclusively dated to pre-Meroitic times and even then it may have been manufactured later. However, this does not necessarily represent the date of deposition for which there is no corroborating burial evidence and so no definitive conclusion can be reached either way. 


\subsubsection{Claimed non-local artefacts in non-burial contexts}

In addition to the above artefacts in burial contexts, Addison also noted the presence of what he classified as non-local artefacts found outside of the burial assemblages, predominantly but not exclusively in the South-West sector (Table 3.12). The identification of the objects and the dates assigned were undertaken by Egyptologists whose notes are curated in the archive of the Griffiths Institute (University of Oxford) (Appendix V). Addison (1949: 118) records the following additional information as the extant notes also cover materials from the second field season:

"These notes give some idea of the probable periods to which the objects belonged, but in more than one case only a number and a date are assigned by the expert consulted, so that it is now impossible to ascertain what form the object took. No drawings or illustrations of the objects found during the 19101911 [first] season appear to exist. Professor Griffith, in two pages of notes dated the 8th of August 1912, records one plaque and one scarab, the former inscribed with the prenomen of Shabaka, Nefer-ka-re', of the XXVth dynasty... The scarab, listed as No. 75, Section A, Africa 27/28, had an inscription "which suggests the name of Psammeticus". The identification of the plaque is confirmed in notes by Professors Newberry and Petrie and Dr. Hall, while Professor Petrie identifies the scarab as indubitably of Psammeticus I... Griffith likewise records two inscribed or decorated plaques, one with the inscriptions "Amun kheper " and "Isis mother of the god, protecting ", one showing Isis and Horus in the marshes of Buto. Several of the faience rings or bracelets with the Nefer Renpet formula so common on Napatan sites are recorded."

The predominance of artefacts from the South-West sector may either be real or itself an artefact of survival of written documentation relating to their description and attribution. Unfortunately, particularly as scarabs are known from the Meroitic state, the above-mentioned artefacts could not be relocated for re-examination and re-dating, and their square location is indeterminable with any precision. None of the other artefacts listed in Table 3.12 could be located either. The deposition of the scarab with the inscribed name of the Pharaoh Sheshonq could reasonably fall within the temporal period for Assemblage 2. The three artefacts attributed to the Late Period (664 - 322 
$\mathrm{BC}$ ), including the one from the $26^{\text {th }}$ Dynasty (Saite Period, $664-525 \mathrm{BC}$ ), fall just outside the lower end of the luminescence dated range for Assemblage 2; they could either be from its terminus or be artefacts deposited during the later period of mortuary activity.

\begin{tabular}{|c|c|c|}
\hline Description & Location & Age \\
\hline $\begin{array}{l}\text { 1. Green or blue glaze scarab with a } \\
\text { Ma'at figure on its base flanked by } \\
\text { feather emblems. Two neb signs are } \\
\text { above and below }\end{array}$ & $\begin{array}{l}\text { West of point N.6 } \\
\text { (South-West) }\end{array}$ & $\begin{array}{l}\text { New Kingdom } \\
(1550-1069 \mathrm{BC})\end{array}$ \\
\hline $\begin{array}{l}\text { 2. Steatite scarab. Figures of a } \\
\text { crocodile and an oryx are carved on } \\
\text { the base }\end{array}$ & $\begin{array}{l}\text { O.1, P.2 } \\
\text { (South-West) }\end{array}$ & $\begin{array}{l}\text { New Kingdom } \\
(1550-1069 \mathrm{BC})\end{array}$ \\
\hline $\begin{array}{l}\text { 3. Fragment of a scarab. The base } \\
\text { was decorated with animal figures }\end{array}$ & $\begin{array}{l}\text { O.1, P.2. Stratum B } \\
\text { (South-West) }\end{array}$ & Uncertain \\
\hline $\begin{array}{l}\text { 4. Glazed composition plaque- } \\
\text { shaped bead with double boring. } \\
\text { The name of Amen is written on } \\
\text { one face, and on the other face } \\
\text { "Amen-nebu, lord of peace given } \\
\text { life (?)". }\end{array}$ & East Sector, Stratum B & $\begin{array}{l}\text { Late Period } \\
(664-332 \mathrm{BC})\end{array}$ \\
\hline $\begin{array}{l}\text { 5. Composition plaque-shaped bead } \\
\text { with longitudinal boring. Both faces } \\
\text { are decorated with a barbarous design }\end{array}$ & Unknown & Uncertain \\
\hline $\begin{array}{l}\text { 6. Badly damaged composition } \\
\text { scarab. Inscription on base } \\
\text { indecipherable }\end{array}$ & $\begin{array}{l}\text { Siftings of } 1^{\text {st }} \text { seasons } \\
\text { discard heaps } \\
\text { (Mixed A/B category) }\end{array}$ & Uncertain \\
\hline $\begin{array}{l}\text { 7. Steatite scarab with inscription } \\
\text { on base: "Lord of the Two Lands } \\
\text { and King of Upper and Lower Egypt. } \\
\text { Hedj-kheper-ra-setep-en-ra, } \\
\text { Sheshonq, beloved of Amen". } \\
\text { Beneath the two cartouches } \\
\text { containing the king's names } \\
\text { (Sheshonq I) is the sign nub "gold" }\end{array}$ & $\begin{array}{l}\text { M.4, N.5 } \\
\text { (South-West) }\end{array}$ & $\begin{array}{l}\text { Third Intermediate } \\
\text { Period } \\
(945-924 \text { BC) }\end{array}$ \\
\hline $\begin{array}{l}\text { 8. Composition scarab, no glaze } \\
\text { now visible. On the base is an } \\
\text { inscription, above the signs, which } \\
\text { reads "Living in truth" }\end{array}$ & $\begin{array}{l}\text { J.9, K.10 } \\
\text { (North-East) }\end{array}$ & $\begin{array}{l}\text { New Kingdom or } \\
\text { Saite Period } \\
(1550-1069 \text { or } \\
664-525 \mathrm{BC})\end{array}$ \\
\hline $\begin{array}{l}\text { 9. Glazed composition scarab } \\
\text { bearing on its base, between } \\
\text { recumbent lion and four hieroglyphs }\end{array}$ & $\begin{array}{l}\text { "Africa" trench, first } \\
\text { season }\end{array}$ & $\begin{array}{l}\text { Saite Period } \\
(664-525 \mathrm{BC})\end{array}$ \\
\hline $\begin{array}{l}\text { 10. Fragment of a sandstone plaque- } \\
\text { shaped bead. Parts of two signs } \\
\text { remain on one face and on the other } \\
\text { face a pattern consisting of rows of } \\
\text { incisions has been carved }\end{array}$ & $\begin{array}{l}\text { M.6, N.6, Stratum A } \\
\text { (South-West) }\end{array}$ & Uncertain \\
\hline $\begin{array}{l}\text { 11. Composition scarab with traces } \\
\text { of green glaze; inscription } \\
\text { uncertain }\end{array}$ & $\begin{array}{l}\text { O.1, P.2, Stratum A } \\
\text { (South-West) }\end{array}$ & $\begin{array}{l}\text { Saite Period } \\
(664-525 \mathrm{BC})\end{array}$ \\
\hline
\end{tabular}




\begin{tabular}{|l|l|l|}
\hline \multicolumn{1}{|c|}{ Description } & \multicolumn{1}{c|}{ Location } & \multicolumn{1}{c|}{ Age } \\
\hline $\begin{array}{l}\text { 12. Fragment of hard stone (flint?) } \\
\text { scarab. Uninscribed }\end{array}$ & $\begin{array}{l}\text { O.5, P.6, Stratum A } \\
\text { (South-West) }\end{array}$ & Uncertain \\
\hline $\begin{array}{l}\text { 13. Steatite scarab with traces of green } \\
\text { glaze; on the base is a figure of Amen }\end{array}$ & $\begin{array}{l}\text { P.1, Q.2, Stratum A } \\
\text { (South-West) }\end{array}$ & Uncertain \\
\hline 14. Small amethyst scarab & $\begin{array}{l}\text { N.4, O.5, Stratum A } \\
\text { (South-West) }\end{array}$ & $\begin{array}{l}\text { New Kingdom ? } \\
(1550-1069 \text { BC) }\end{array}$ \\
\hline $\begin{array}{l}\text { 15. Glazed composition scarab. On } \\
\text { the base are figures of two } \\
\text { crocodiles }\end{array}$ & $\begin{array}{l}\text { Siftings of 1 } 1^{\text {st }} \text { seasons } \\
\text { discard heaps } \\
\text { (Mixed A/B category) }\end{array}$ & Uncertain \\
\hline
\end{tabular}

Table 3.12 Surface finds of plaques and scarabs, and their chronological attribution of manufacture by Addison. The point references refer to the squares on the Jebel Moya site plan. From Addison (1949: 117)

Overall, no burials can be definitely assigned to the time period of Assemblage 2 based upon non-local artefacts in the accompanying assemblages. However, the artefacts found in both burial and non-burial contexts reinforce the earlier conclusion of two distinct periods of habitation at Jebel Moya after the late Mesolithic. Whether there was significant pre-Assemblage 3 mortuary activity though cannot be determined from burial assemblages alone.

\subsubsection{Cardinal directionality and burial posture of burials-without-goods versus burials-with-goods}

Of the 3191 excavated burials, 2083 have no associated assemblages. It should be expected that there would be differences in the cardinal orientations of the bodies and burial postures of the respective burials if all or a significant number of the burialswithout-goods were part of pre-Assemblage 3 period mortuary activity. Chronologically distinct groupings of burials with different dominant orientations of the body were determined for the site of R12 in Upper Nubia (Salvatori 2008). However, for the cardinal directions (Figures $3.17-3.18$ ), the patterns are distinctly similar. 


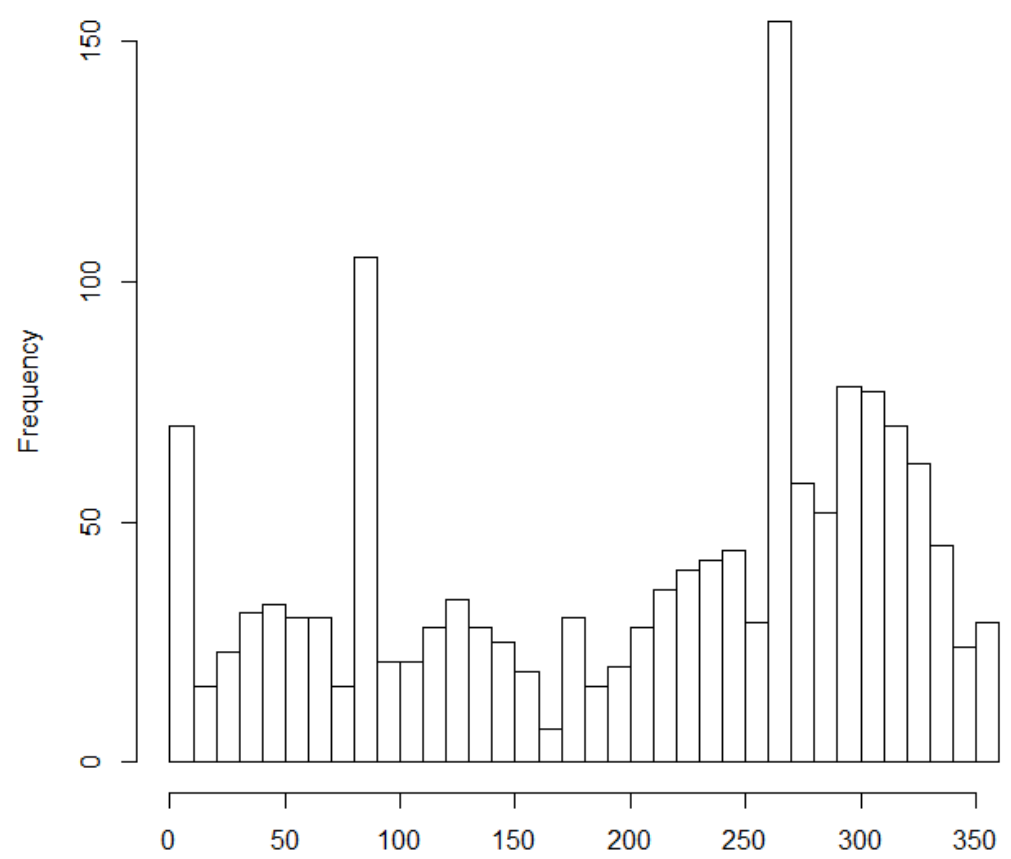

Figure 3.17 Cardinal co-ordinates and their frequency for burials-without-goods across the site.

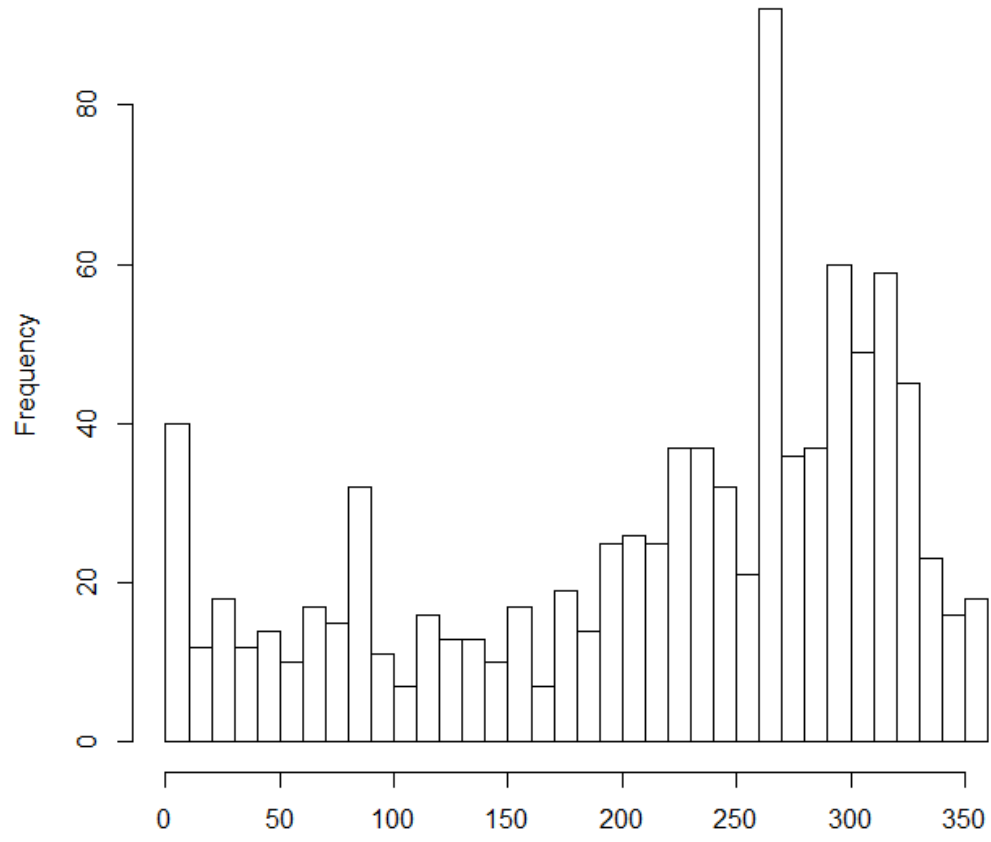

Figure 3.18 Cardinal co-ordinates and their frequency for burials-with-goods across the site.

Out of the 2083 burials with no accompanying artefacts, 1678 have their burials postures recorded, while the total for the 1108 burials-with-goods is 1004 (Table 3.13). Here, the 
respective distributions of different body positions are strikingly similar to the pattern exhibited by burials-with-goods.

\begin{tabular}{|l|c|c|}
\hline Burial posture & With assemblages & Without assemblages \\
\hline Supine & $644(64.14 \%)$ & $1066(63.53 \%)$ \\
\hline Prone & $71(7.07 \%)$ & $145(8.64 \%)$ \\
\hline Right side & $167(16.63 \%)$ & $249(14.84 \%)$ \\
\hline Left side & $122(12.15 \%)$ & $218(12.99 \%)$ \\
\hline Total & $\mathbf{1 0 0 4}$ & $\mathbf{1 6 7 8}$ \\
\hline
\end{tabular}

Table 3.13 Breakdown of the burial postures between burials-with-goods and burialswithout-goods

On the whole, while pre-Assemblage 3 burial activity cannot be ruled out, the balance of probability from the accumulative weight of the different strands of evidence is that the vast majority of burial activity at Jebel Moya occurred during the Classic to possibly Post-Meroitic periods. This conclusion aligns with other evidence for a spatial neighbourhood relationship between rich burials and less rich burials, including those without accompanying artefacts, in the North-East sector (see section 6.3.2). Furthermore, the phenomenon of occupations being subsequently used as cemeteries has parallels elsewhere in the Sahelian belt, for example at Dia (Mali) where a first millennium AD cemetery covers a first millennium BC settlement of similar size at Dia Shoma (Bedaux 2005; Bedaux et al. 2001).

\subsection{Resituating Jebel Moya in a Classic-Late Meroitic context in the southern Gezira}

Of the three phases of occupation at Jebel Moya, the first conclusive evidence for burial activity thus comes from no earlier than the first century BC. This marks the cemetery as contemporary with the later occupational phase of Jebel et Tomat, which five conventional radiocarbon dates place between the early first and the end of the fourth century AD (Clark and Stemler 1975). Assemblage 3 is also contemporary with the establishment of a Meroitic trading point at Sennar, postulated by Addison (1950) to have been a trading station, and of an agro-pastoral settlement at Abu Geili (see Chapter 
7), approximately $30 \mathrm{~km}$ to the east of Jebel Moya on the banks of the Blue Nile (Addison 1950; Crawford and Addison 1951). Assemblage 3 pottery was found at Abu Geili, though not at Sennar, together with locally manufactured wheel-made pottery (Figures 3.19 and 3.20) (Crawford and Addison 1951: 44). Meroitic painted pottery was present at both Abu Geili (Figure 3.21) and Sennar, but not at Jebel Moya.

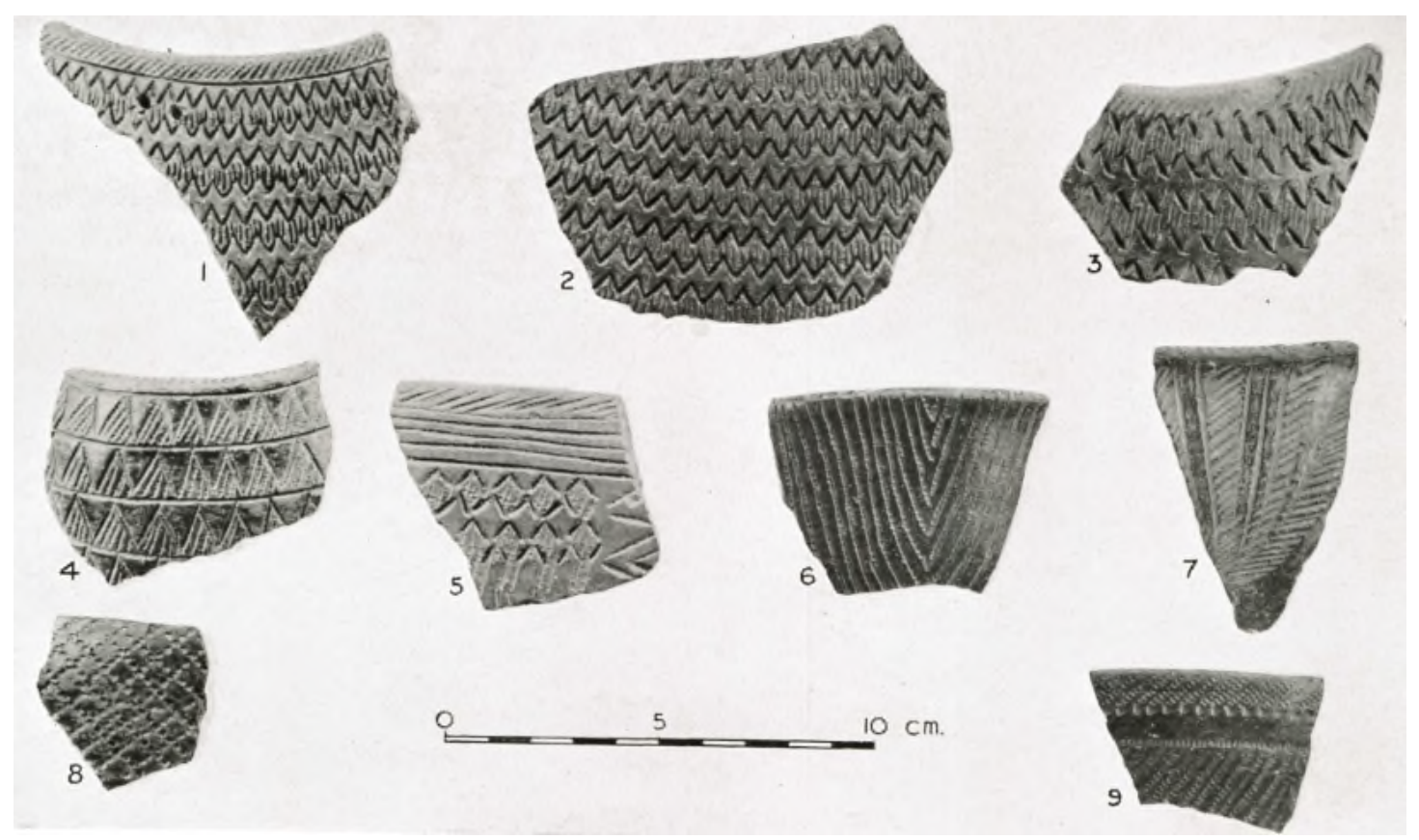

Figure 3.19 Abu Geili: Pottery: 1 - 3 and 5 stylus-stamped wavy lines. 4 and 6 - 9 combstamped decoration sometimes within incised lines. All are burnished black and brown sherds originally infilled with red pigment. From Crawford and Addison (1951: Plate $X X X V I I I B)$.
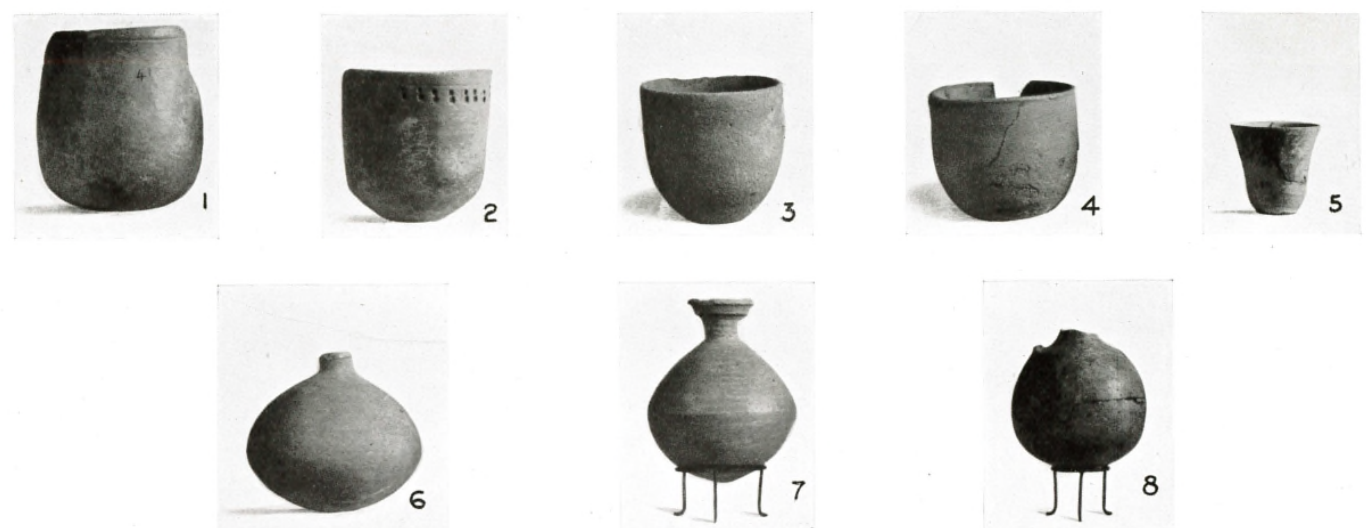

Figure 3.20 Abu Geili: Locally produced wheel-made pottery. From Crawford and Addison (1951: Plate XLIII). 


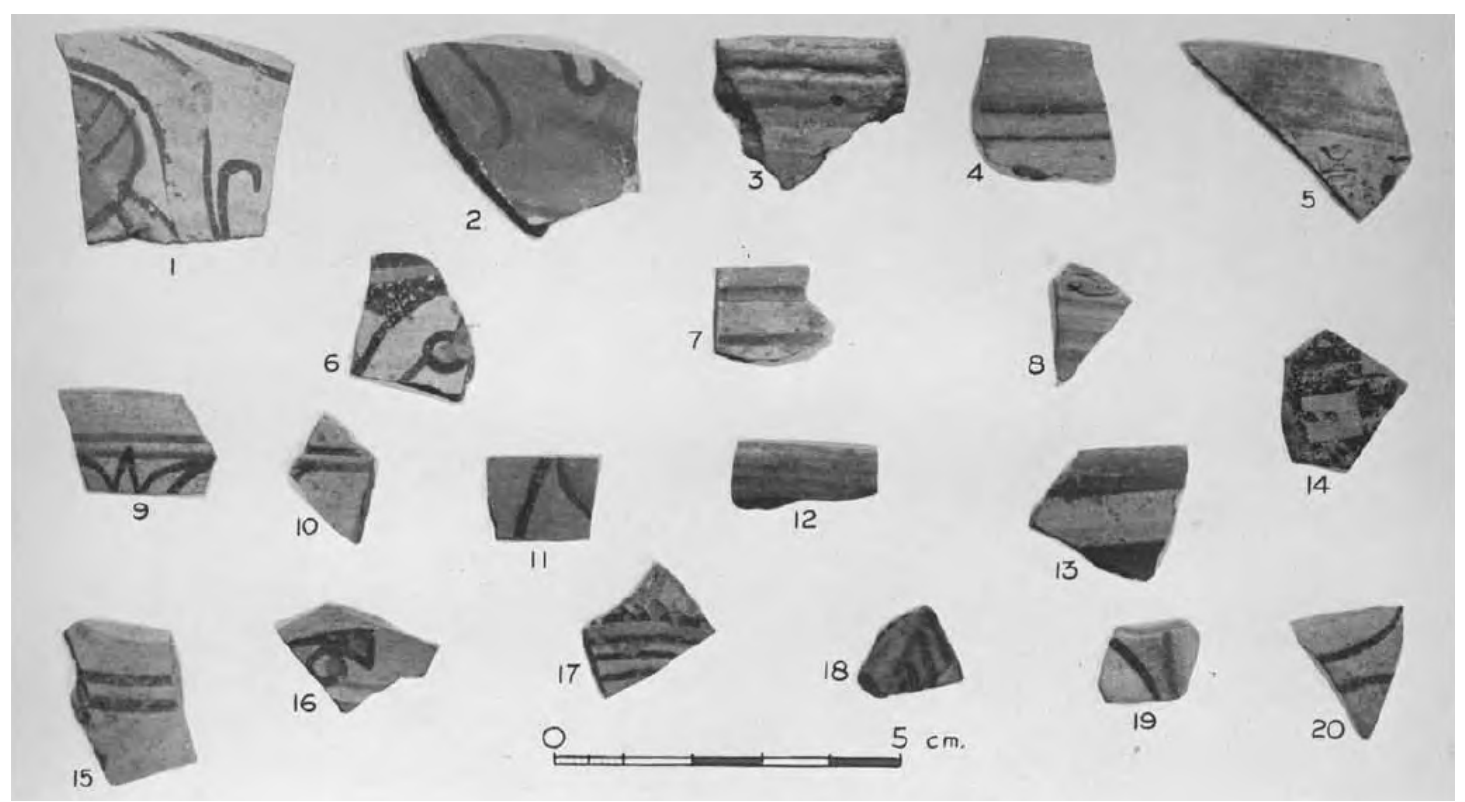

Figure 3.21 Abu Geili: Painted Meroitic pottery. From Crawford and Addison (1951: Plate XLA).

Sites to the south of Jebel Moya, including rescue excavations in that part of the Upper Blue Nile to be flooded by the Rossairis Dam and surface collections from the east bank of the White Nile have yet to be published (Hatim Elnour, pers. comm. 2012). Since these pottery collections have yet to be placed in a secure, radiometrically dated chronological framework potential comparisons with Jebel Moya must remain problematic. However, the new luminescence dates from Jebel Moya and the formation of a firm pottery assemblage framework will hopefully serve as a catalyst for further refining localised chronologies.

The new dates from this study thus provide a fresh opportunity to understand part of the archaeological scale and changing nature of interaction in the southern Gezira between notionally stateless populations and Meroitic trading points along the Blue Nile, and to contrast these social dynamics with what was occurring at the same time in the neighbouring Butana and areas farther south. Very little is known about the nature and extent of the Meroitic state's political, ideological and socio-economic reach southwards into the heart of the Gezira Plain (south-central Sudan) and beyond. The trade exchange networks and social organisation of the communities in this region along the southern frontier of the Meroitic kingdom have been little studied apart from some exploratory surveys (Edwards 1989, Fernández et al. 2003). Most of the few known sites in the Gezira were found by Wellcome's expedition in 1911 - 1914, supplemented by 
subsequent small-scale or brief surveys, particularly in the southern Gezira (Clark and Stemler 1975; Fernández et al. 2003).

Jebel Moya's geographic location places it in a frontier zone between the states of the Nile Valley (including Meroe) and the relatively little known savanna of modern South Sudan. In light of this, redefining its chronology also alters possible explanations of its raison d'être. The first direct dating of selected pottery sherds from different assemblages provides initial temporal ranges for the occupation of Jebel Moya and lays out a chronological backdrop permitting the examination through the application of statistical and spatial analyses of how social behavioural was represented in the mortuary realm. 


\section{Chapter 4: Implications of occupational traces and spatial use of the site over time}

Different cultural perspectives impact upon how social identities and layers of social organisation are represented in the mortuary domain, which requires examination using carefully constructed dimensions of analysis. For Jebel Moya, the first step in this chapter is to establish the extent to which settlement remains are present alongside the mortuary remains in order to understand the nature of the use of the site. Proceeding from this, it will be demonstrated that the cemetery layout was conceived as a coherent whole from the time of when the majority of mortuary activity began. This is determined on the basis of comparative analysis of the contents of grave assemblages in the different sectors of the cemetery. It lays the foundation for an analysis of the bioanthropological data (see Chapter 5) and how social structure was represented in the mortuary realm (see Chapter 6).

\subsection{Re-examination of claimed habitation remains at Jebel Moya}

There are very few certain habitation remains which can be attributed to dwellings at Jebel Moya. There are some claimed floors and circumstantial evidence which are recorded as consisting of burnt or hardened clay or mud and concentrations of broken shards which the excavators and Addison (1949) believed formed part of dwelling floors. There are also claims for evidence of ovens.

\subsubsection{Floors, pavements and post-holes}

Claims for the presence of pavements and floors come from the reports viewed by Addison (1949) from the third and fourth field seasons. One of the problems in being able to reliably reconstruct and evaluate the evidence for these remains is due to many being situated in the area where the 'African', 'Sagadi' and 'Moya'-named trenches were excavated in the first season. The effect of the first season's excavations was to remove the surface layers, making it difficult for the subsequent excavators to measure the depth below the extant ground surface of notional floors and pavements. This made 
the establishment of the relationship between the claimed floors and pavements across the excavated areas of the site difficult if not impossible.

Despite these problems, Addison attempted to use the available information to map the claimed occurrences in the different squares and through the stratigraphic sequences (Figure 4.1). The figure covers only a limited sector in the South-West because field notes for these features were found by Addison for only this limited area (Addison 1949: 101). There is a large red-brown, burnished, complete pot (Addison 1949: Plate CX1 and 2) embedded into the 'paving' in square M.5, N.6 (Figure 4.1, $3^{\text {rd }}$ flooring). Its dimensions are $65 \mathrm{~cm}$ in height and $61 \mathrm{~cm}$ in diameter. The pot belongs to Assemblage 3. The 'paving' is hard clay with a whitish colouring.

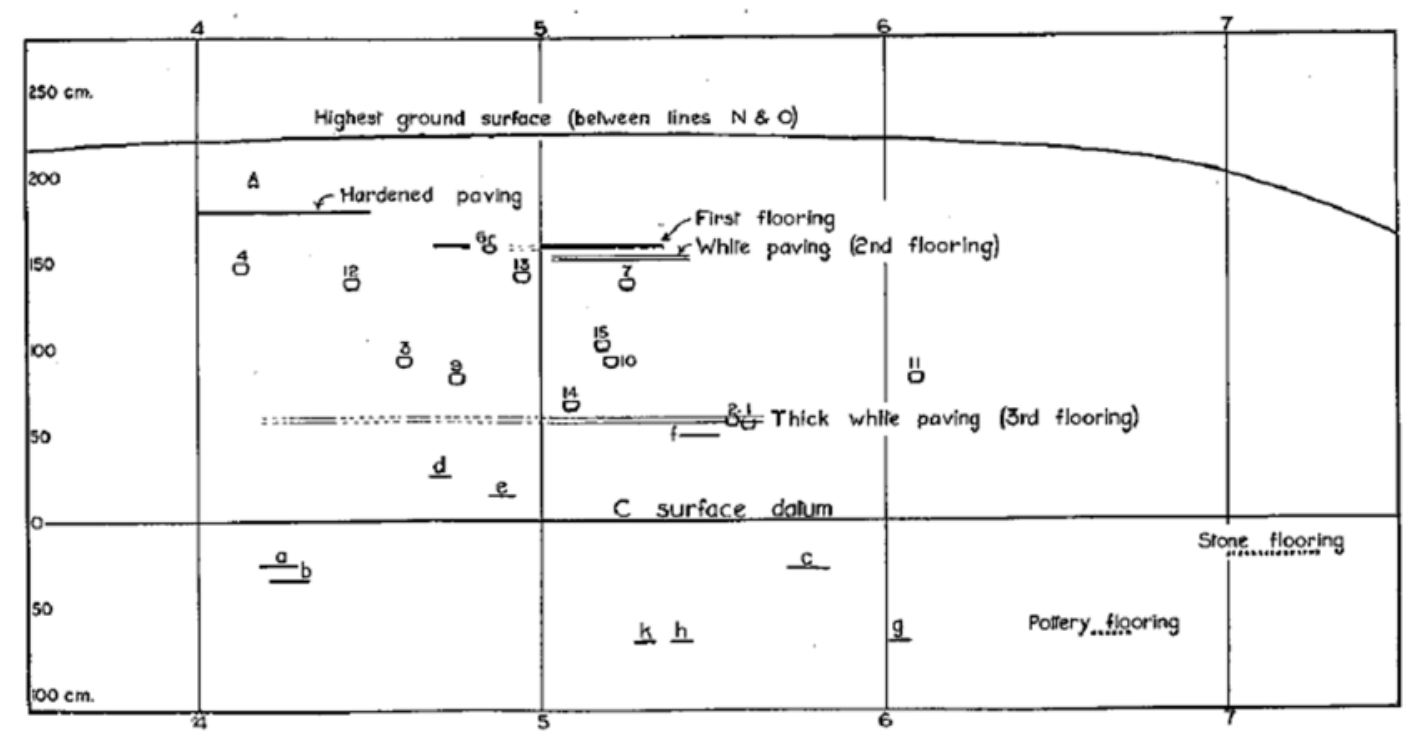

Figure 4.1 The distribution of claimed fireplaces and floors in the different squares and through the stratigraphy. From Addison (1949: Figures 79-80).

The highest 'floor' - labelled A ("a small patch of hard burnt clay flooring”) in Figure 4.1 - is $15 \mathrm{~cm}$ below the ground surface at the time of excavation, or $c a .195 \mathrm{~cm}$ above the surface of Stratum C (Addison 1949: 97). Below, at 20cm below the ground surface or $180 \mathrm{~cm}$ above the surface of Stratum C, was a "stretch of hardened paving" (Addison 1949: 97). Then there are two floors below labelled "first flooring" and "second flooring" or "white paving". The "first flooring" was patchy; "white paving" was situated ca 7cm below "first flooring", wasn't extensively burnt unlike the latter (Addison 1949: 97, 99). 
Further below is a thick $(10-15 \mathrm{~cm})$ layer of hard whitish matter, labelled the "third flooring" from square N.4, O.5 (Figures 4.1, 4.2 (2)) (Addison 1949: 99). This level was cut by many graves in the range of $1142-1175$. It was stated in the excavation records and as reconstructed by Addison that this 'flooring' was extensive in coverage, though its exact limits are unknown. It was $60 \mathrm{~cm}$ above the surface of Stratum C.

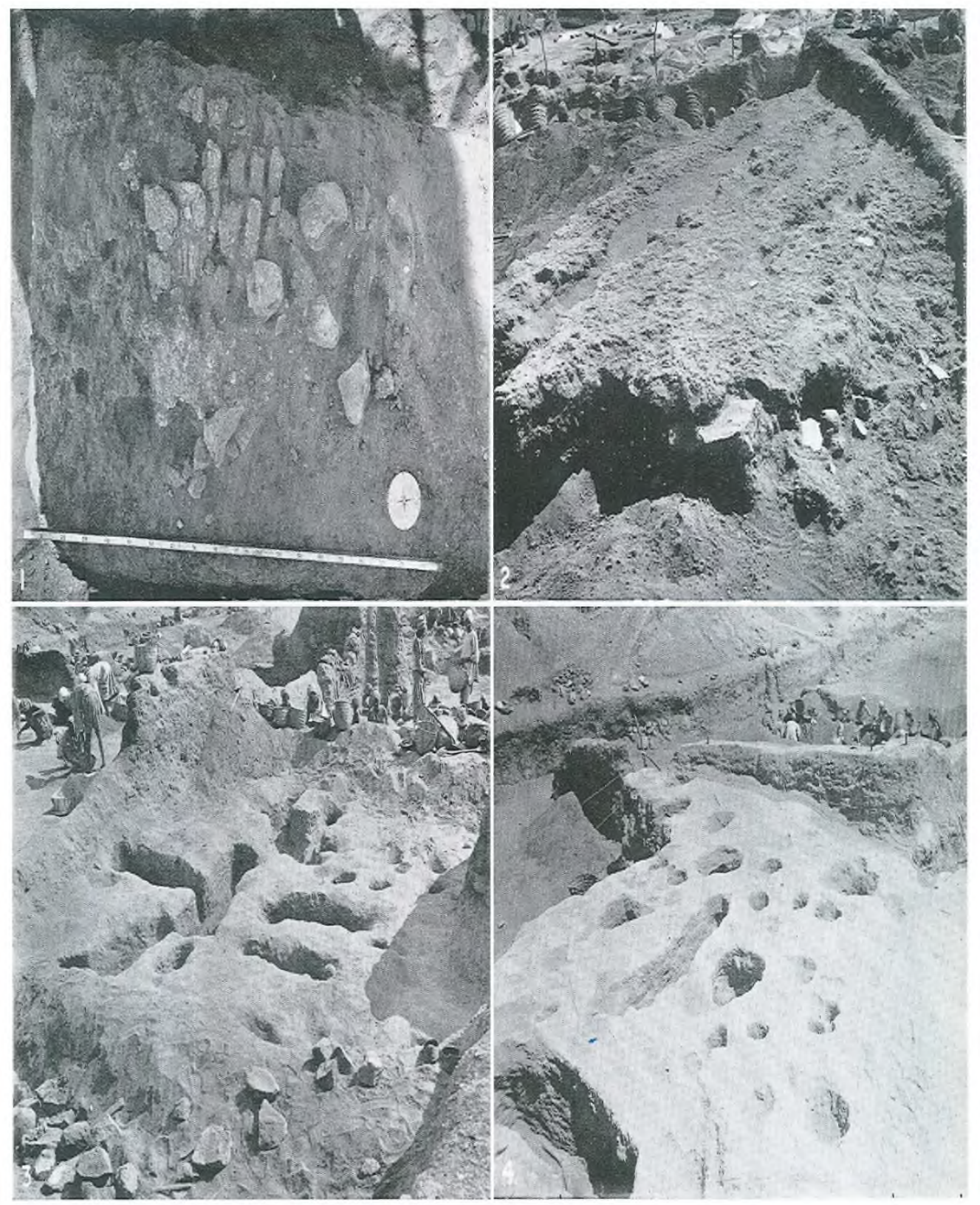

Figure 4.2 (1) Mud plaster remnants of wattle \& daub structure, (2) claimed floor, ( 3 \& 4) hardened clay impregnated with calcium carbonate, formerly claimed by the excavators and Addison to be a living floor. From Addison (1949: Plate XXXV). 
The first to third 'floorings' are clay impregnated with calcium carbonate, lending them a white colour (Martin Williams pers comm., 2013): it fizzed in a test by Wellcome's field geologist. Granite, the local bedrock, does not weather to form carbonate. Feldspars (present in the granite) are aluminium silicates with varying proportions of potassium, sodium or calcium. Feldspar weathers by hydrolysis to form kaolin, which is the main clay mineral - a soft, fine-grained white clay. Kaolin is found as bedded masses in soils and sedimentary rocks.

Therefore, the geologist Martin Williams (pers comm 2013) believes the hard, solid, thick, 'white pavings' were most likely produced by carbonate with an aeolian source the most likely in the environment. The calcium carbonate would have been blown in originally as calcareous wind-blown dust. This is quite common in semi-arid Australia, where similar crusts overlie ortho-quartzites that do not contain any carbonate. On the west bank of the White Nile to the west of Jebel Moya is a long and narrow belt of sand termed Qoz Abu Dulu which was formed by either aeolian action or was a levee of an ancient Nile stream; its sands underneath the surface are white (Vail 1982). Furthermore, more generally, the sands of the geological Gezira Formation in which Jebel Moya is situated, "is...in places...cemented by calcium carbonate" (Elboushi and Abdel Salam 1982: 71). The gravels in the Gezira Formation also contain scattered kankar nodules which are predominantly comprised of calcium carbonate. The calcium carbonate of these sediments, surrounding and nearby Jebel Moya, date to multiple periods during the Quaternary (Adamson et al. 1982). Around 2500 years ago, the last of the swamps and lakes were drying out in the southern Gezira (see section 1.2); it may be possible that the sands blown into the valley during this period of drying conditions contained the calcium carbonate which formed the "white floorings". Thus, the white floorings may not be human-made living floors at all.

The third 'flooring' was $c a .10-15 \mathrm{~cm}$ thick and $c a .60 \mathrm{~cm}$ above the surface of Stratum C (Addison 1949: 99). There are holes in this calcium carbonate feature, suggested to be tukl (grass hut) post-holes by Dixon (Addison 1949: 99), with some up to $20 \mathrm{~cm}$ in diameter. The hardened mud shown in Figure 4.2 (1) looks to be mud plaster from wattle and daub structures (Kevin MacDonald pers comm., 2013). Such structures are uncommon in present day Sudan (Addison 1949: 97). 
What is described as a 'mud pavement' was recovered $50 \mathrm{~cm}$ above the surface of Stratum C in square N.5, O.6; it is marked $f$ in Figure 4.1. Beneath it, $25 \mathrm{~cm}$ above the surface of Stratum C and the neighbouring square N.4,O.5, fragments of a claimed floor were found ( $d$ in Figure 4.1a $\&$ b). Together with $e$ (unspecified lower level above the surface of Stratum C), it is described as being comprised of smooth baked clay approximately $1 \mathrm{~cm}$ thick (Addison 1949: 99). The remainder of the dimensions are unknown and photographs of these particular features have yet to be found to verify their composition and original attribution.

Curiously, there is only one claimed hardened 'burnt clay' 'floor' or 'hearth' recorded below the surface of Stratum C. Labelled as $c$ in Figure 4.1a \& b, it is recorded in the relevant excavation journal: "In [square M.5,N.6 in the South-West sector], the C soil, was a patch of reddened burnt clay. It is roughly $5 \mathrm{~cm}$ thick and $100 \mathrm{x} 150 \mathrm{~cm}$ in size." (Addison 1949: 99) This appears more likely to have been a hearth area than a 'floor'.

However, there are also two 'pavings' which are recorded in the excavation journal as being from Stratum B but which Addison (1949: 99) assigns to Stratum C. The first is recorded as a "real burnt flooring" Addison (1949: 99). The second is stated to be at a depth of $10 \mathrm{~cm}$ below the first and to be "the lowest paving to be found in the B stratum at a depth of $195 \mathrm{~cm}$ below ground surface" (Addison 1949: 99). If the measurements of 185 and $195 \mathrm{~cm}$ are accurate, it would place the features at 25 and $35 \mathrm{~cm}$ below the surface of Stratum C. Addison (1949: 99) proposed that they are contemporary with the claimed hardened flooring mentioned above.

Furthermore, there are stones laid together in square O.7,P.8 which were recorded as 'stone flooring' in Stratum C. Dixon recorded its depth as $120 \mathrm{~cm}$ below the ground surface, which places it approximately $20 \mathrm{~cm}$ below the surface of Stratum C (Addison 1949: 99-100). It measures 5 x 15m, with a smaller outlier to its east. Dixon added, “The top is very rough and mixed up with the stones were fragments of clay figurines, pot handles, lipstuds, rough celts and natrolite nodules." (Addison 1949: 99-100) Illustrations or photographs of the pottery fragments were not published by Addison and have not been located, making it is impossible to associate these with any specific assemblage. 
Further down in the sequence is the earliest claimed evidence of habitation or visitation, apart from the Assemblage 1 sherds, on the surface of Stratum D in Figure 4.1. Beneath burial 1035 was a piece of burnt earth which is marked as $g$. In addition, marked as $k$ in Figure 4.1, Dixon noted, "Close to the head of burial 100/1149 there was a small patch of reddish burnt earth, sure sign of a fire in the days when D surface was a place of human habitation. Close by there was an undoubted tukl [grass hut] floor." (Addison 1949: 100) Sadly the photograph of the hardened earth (Figure 4.3) is not of fine enough resolution to determine whether it is human-made or whether there is a natural explanation. However, there are putative post-holes in it. Nearby ( $h$ in Figure 4.1), Dixon records, "On the surface of the Black Gebel D [surface of Stratum D], is a roughly round (1.5 x 1.5 metres) patch of hardened earth, in three places burnt... the general shape of the hardened patch with the burnt earth in the middle seems to point to it having been the floor of some round dwelling." (Addison 1949: 100). These appear to be the earliest and best available examples of occupation.

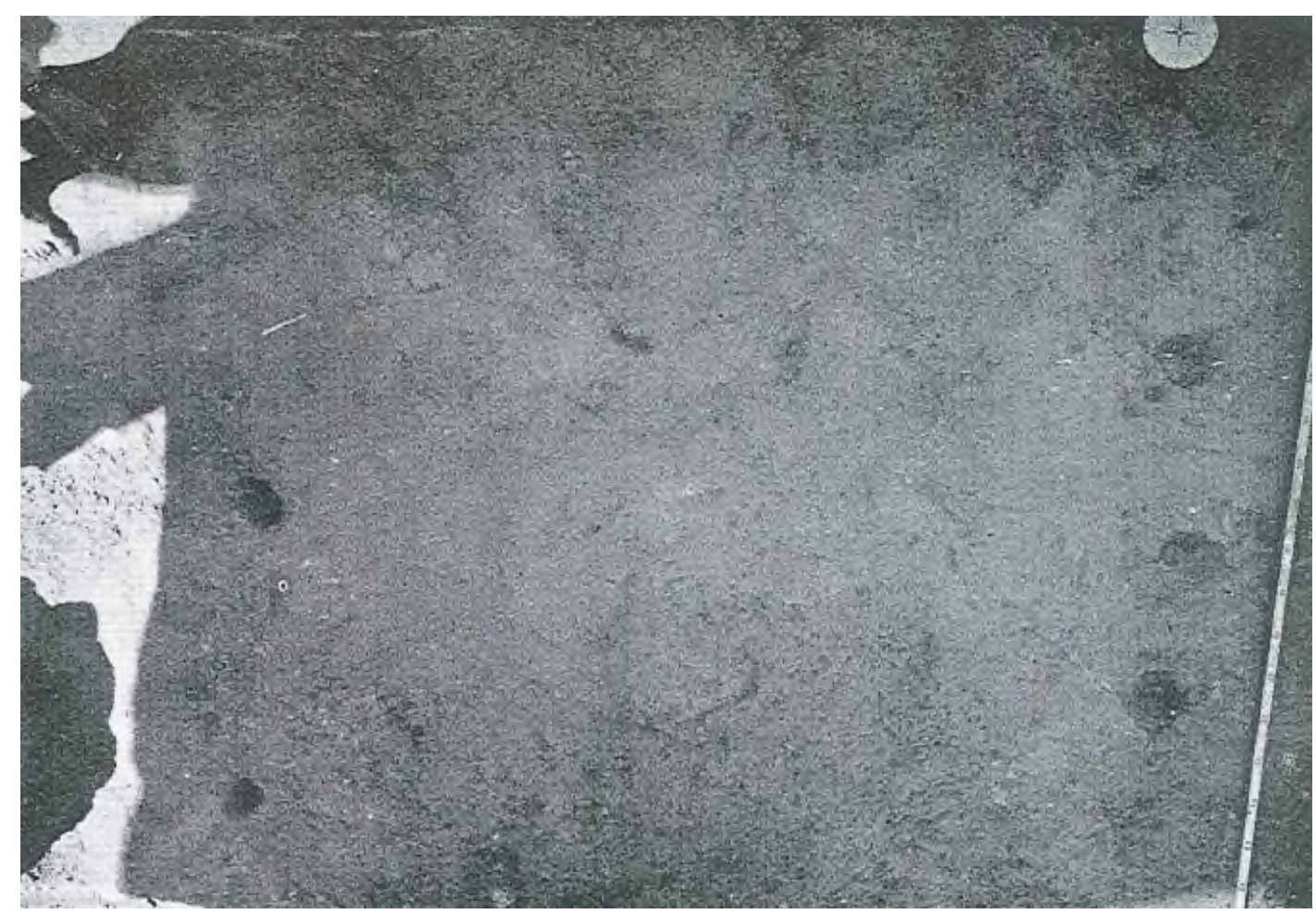

Figure 4.3 Hardened earth, claimed by Addison to be a tukl (grass hut) floor. From Addison (1949: Plate XXXVI 2).

There is also a purported flooring of red-ware sherds from one or more large pots on or near the surface of Stratum D (Figure 4.4). The thickness of the sherds range from 1 to 1.5cm and Addison (1949: 100) also reports that white grains are present in the temper. 
Although the sherd thickness and the possible presence of mica correlate with the measurements and temper composition of the red-ware sherds from tray JM1 at the British Museum (see Appendix III), it is unknown whether the tray's sherds (the only trade labelled as having sherds from a floor) are definitely from this feature. Also, its presence cannot be used in isolation as a chronological indicator of either deposition or the age of the stratum as red-ware is present over many different time periods in the Sudan.

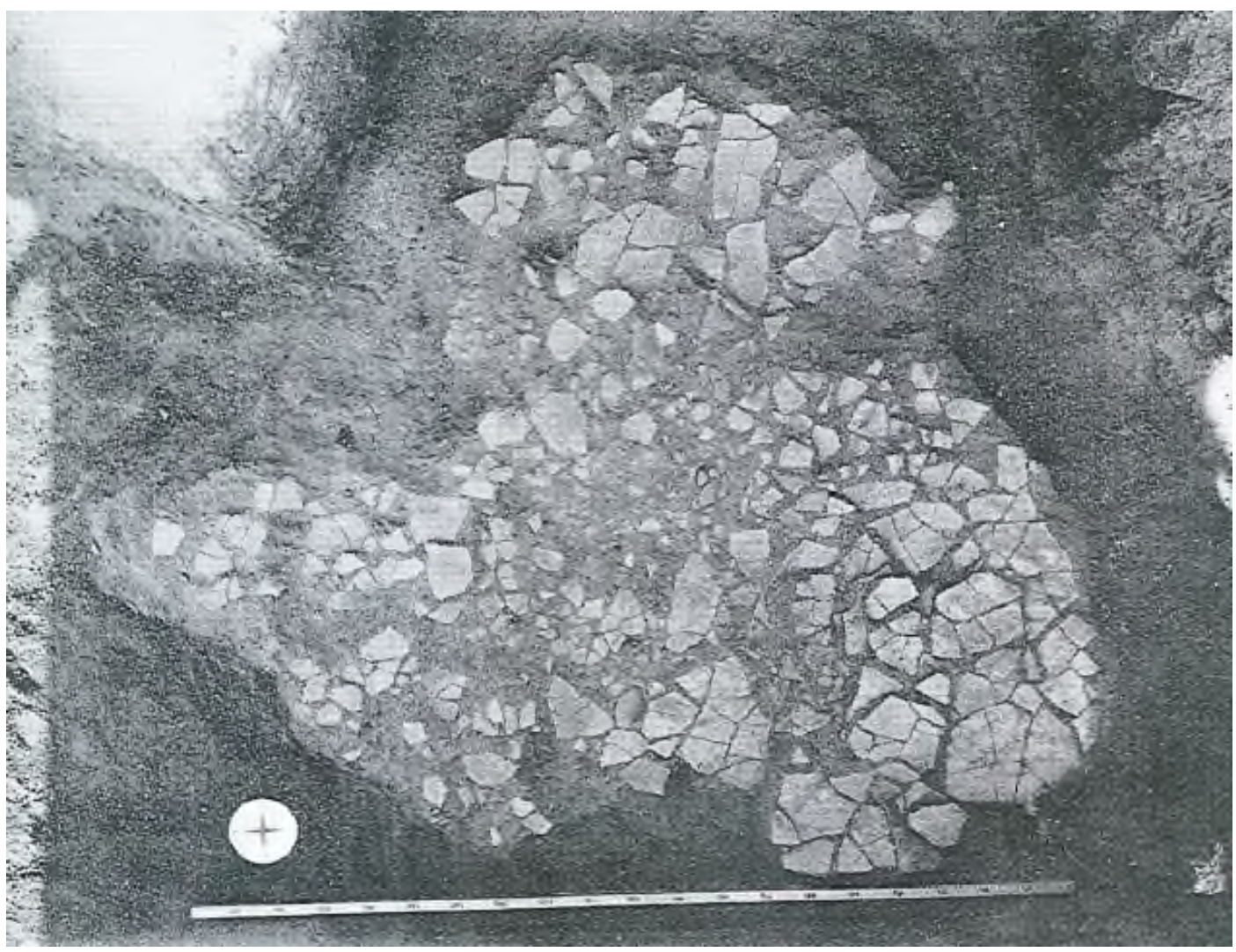

Figure 4.4 A pot or pots crushed under pressure but claimed by Addison to be a flooring of red-ware sherds. From Addison (1949: Plate XXXVI 3).

Addison (1949: 100) believed that the spread of the sherds is unlike that of an ordinary broken pot and that it was instead a deliberate pavement. He cited the example of the Lafofa and the Fari of the Nuba who mixed pottery with their flooring, while admitting that such examples are rarely found in archaeological contexts and only this example was recorded. It does not resemble the potsherd pavements known from sites in the Inland Niger Delta, north Benin or Nigeria (Kevin MacDonald per comm., 2013). These tend to be either carefully placed so there are few gaps between flat-lying sherds, or stacked at a diagonal to form rows of chevron (herringbone) patterns. Instead, a few of 
the breaks visible in Figure 4.4 look like bursts where pot fragments which would have had curvature were crushed under pressure. There was no burial underlying the sherds, although it does not rule out that a few large pots were deliberately broken and scattered in the vicinity of a grave.

Although only field notes on these remains from the south-west area of the site could be located by Addison, he saw field photographs showing what looked to him like flooring elsewhere on the site (Addison 1949: 101). Figure 4.5 is a plan derived by Addison from the photos showing the squares in which claimed flooring was found throughout the excavated portions of the valley. Interestingly, there are purported habitation flooring remains in the north-eastern portion of the site where there is the greatest concentration of burials. Yet there must be caution: some of the claimed flooring may be tightly trampled everyday debris or unrecognised geological features; the former is acknowledged as a real possibility by Addison (1949: 101).

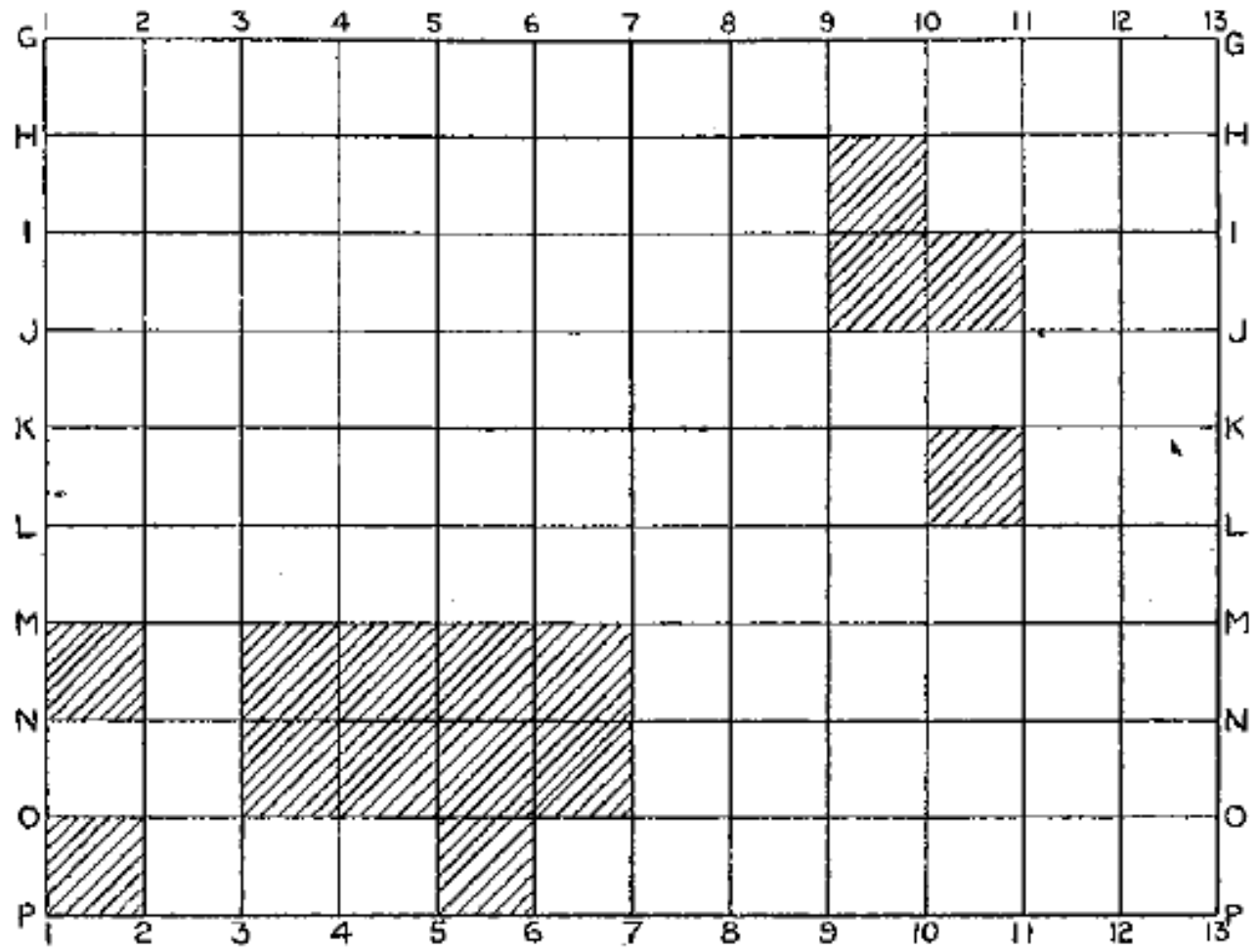

Figure 4.5 Addison's plan showing the location of claimed floors over the site. From Addison (1949: Figure 81).

Also in the vicinity of graves are a series of stone structures found on the modern ground surface during the second field season. Recorded in the diary of the field excavator Oric 
Bates, curated at the Griffiths Institute, but unmentioned by Addison, is a series of six small stone structures were measured on 20 January 1912 in the south-east portion of the East sector of the cemetery (Figure 4.6). A seventh was found $30 \mathrm{~cm}$ below the surface on $24^{\text {th }}$ January 1912 and it is described as being semi-circular and seven metres long. No further descriptions are provided. Comprised of small stones, Bates believed that these structures could not be directly associated with any particular burial and that perhaps they were sub-structures of shelters. However, the structures appear perhaps to be too small for shelters and another possibility may be that they could have served as stone platforms for sacrificing or feasting (cf Insoll et al. 2015, Sadr 1991, Welsby 2001).

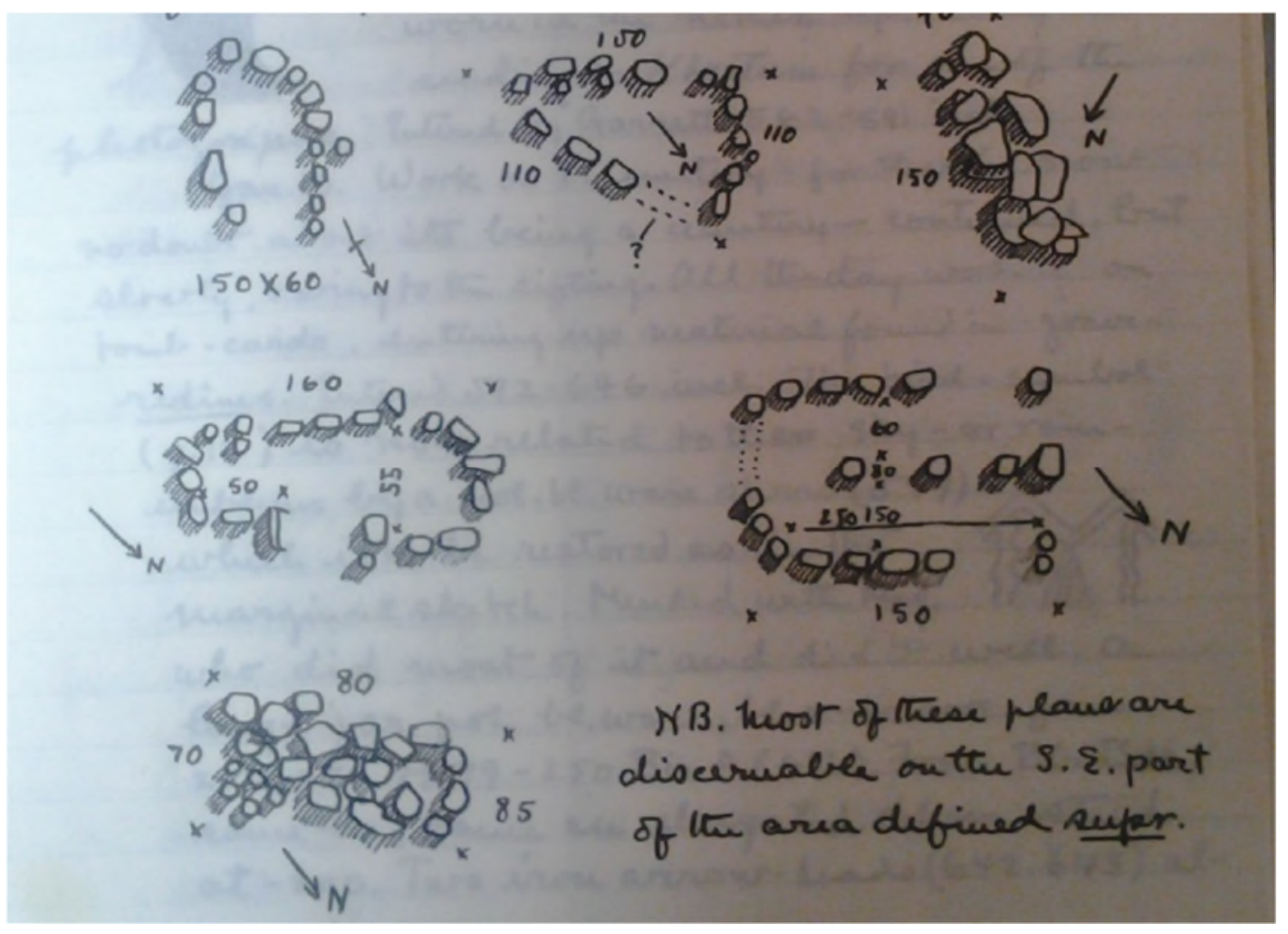

Figure 4.6 Six small stone structures which were located in the south-east portion of the East sector of the cemetery and recorded in Oric Bates' diary from the second field season, $1911-12$. 


\subsubsection{Fireplaces and ovens}

What the excavators recorded as "fireplaces", with the implicit implication that some may have been used to open-fire pottery, were re-interpreted by Addison (1949: 102) as "food ovens". All the recorded ovens are located between the first and third "floorings" in Stratum B (Addison 1949: 103). Fifteen of the nineteen ovens are marked in Figure 4.1b, while the remainder are known from squares N.4,O.5, N.4,O.5, M.3,N.4 and M.3,N.4 although their precise positions are unclear and so are not reflected on the plan. No ovens were recorded outside of the South-West sector of the valley. The average oven was a generally barrel-shaped and mud-plastered pit some $40-50 \mathrm{~cm}$ in depth and measuring $70-80 \mathrm{~cm}$ in diameter. Figure 4.7 (1\&2) illustrates a typical example of a single oven; it is from square N.4,O.5. The ovens in Figure 4.7 (3\&4) are from squares O.5,P.6 and M.4,N.5; they have a variation in shape with the top edge of the north side being raised at a higher level than the other sides.

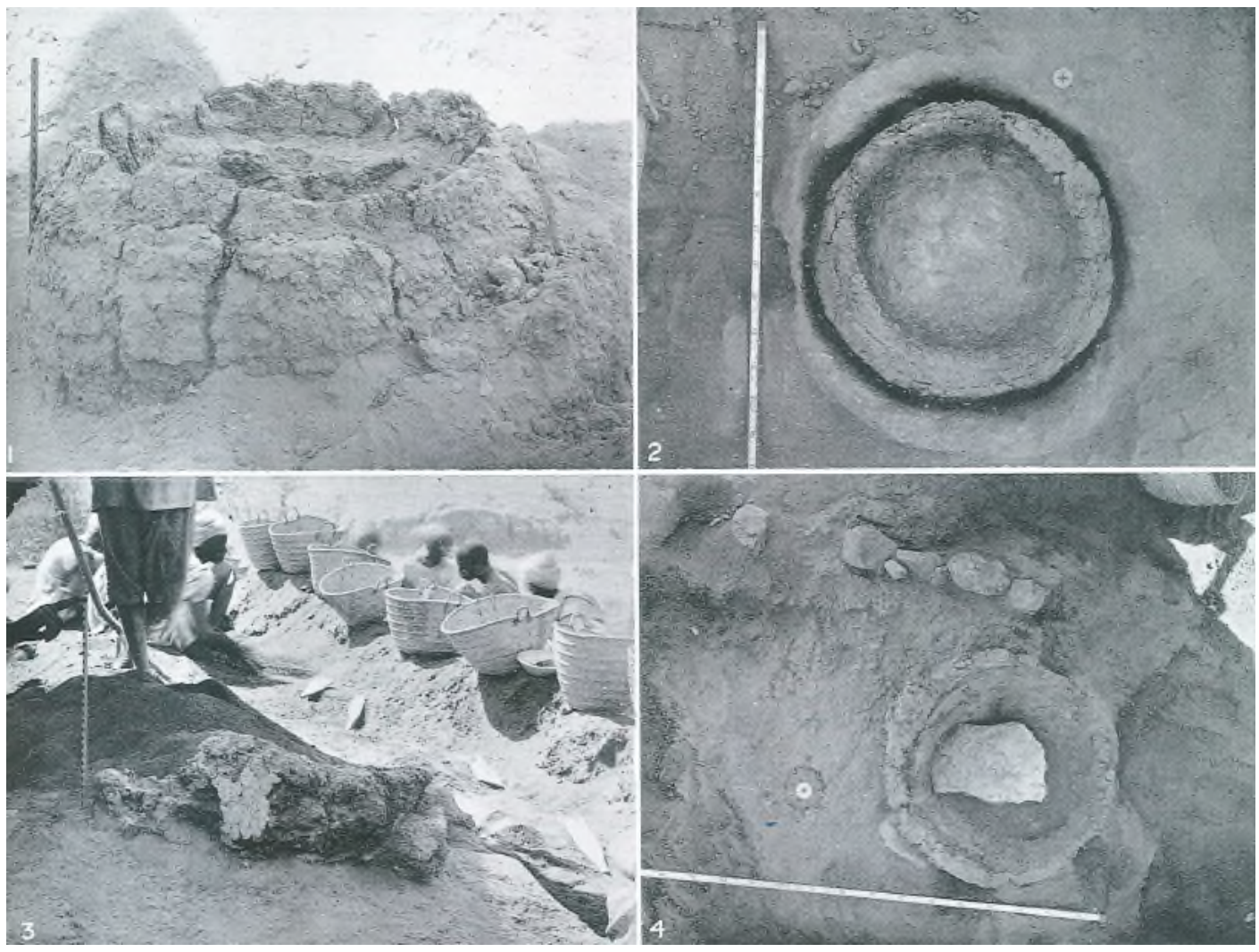

Figure 4.7 Examples of mud plastered, barrel-shaped pits serving as ovens. From Addison (1949: Plate XXXVII). 
The oven pits contained unspecified burnt animal bones, large stones, sherds and fragments of querns. The clay sides were unbaked in all but one of the nineteen recorded instances. Based upon examples like Figure $4.7(3 \& 4)$ where the stones were found in situ, Addison (1949: 102) suggests that the stones were heated in an external fire and placed inside the oven with the food over them to slowly cook. Two of the ovens were re-used, one built on an older pit (square M4,N.5) and the second being constructed partly inside its predecessor (square O.4,P.5), probably due to its walls being rendered unstable by the sand it was dug into according to notes from Dixon's journal (Addison 1949: 103). The former oven is the highest known above surface of Stratum $C$ and therefore is presumably the latest. By contrast, the two nearby ovens in Figure 4.8 from the north-east in square M.5, N.6 are the lowest in the stratigraphic sequence, cutting through the 'third flooring' marked in Figure 4.1.

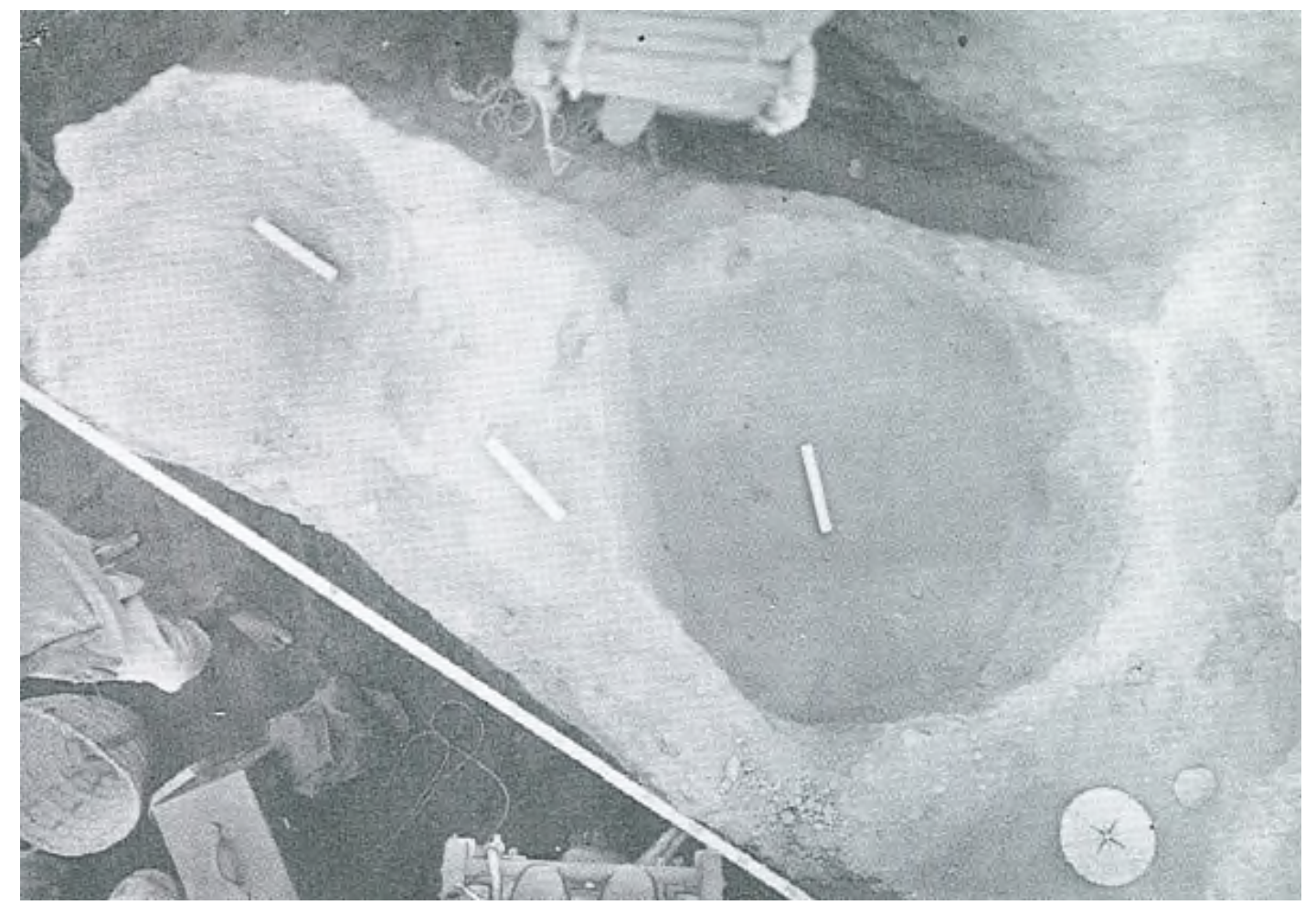

Figure 4.8 Two ovens from square M.5, N.6 which cut through the 'third flooring' marked in Figure 4.1b. From Addison (1949: Plate XXXVIII 2).

\subsubsection{Cultivation}

There are only up to 3 metres of deposit and the number of burials spread across the valley (see section 4.2.1) does not leave much room for active cultivation during the time of Assemblage 3 when the cemetery appears to have been in use. Contrary to the 
assertion by Gerharz (1994) that the users of the valley during the final phase may have cultivated within the valley, nothing in either Wellcome's field excavators' or Reisner's notes is suggestive of turbation caused by hoeing as the recognised depositional laminations were intact. Furthermore, Reisner also noted that the site's rocky soils were unsuitable for agricultural activities (Addison 1949: 34).

\subsubsection{Discussion of occupational traces}

More widely, attempts to discern the extent and nature of habitation activities within the valley are hampered due to the fore-mentioned lack of surviving field notes detailing the type and stratigraphic positioning of claimed floors and other features outside the South-West sector. In the South-West, the ground surface at the time of excavation was $210 \mathrm{~m}$ above the surface of Stratum $\mathrm{C}$ on average. There appears to be more evidence for habitation activity throughout most of the strata (Table 4.1). Of the claimed humanmade features, those below the surface of Stratum C consist of stone flooring, a probable hearth, three hardened mud floors with one exhibiting signs of post-holes and a second with a hearth, and two hearths. All bar the stone flooring and one hearth were on or in the immediate vicinity of the surface of Stratum D, which is consistent with habitation activity possibly contemporary with the pottery Assemblage 1 and/or (if including the stone flooring and hearth) Assemblage 2.

Above the surface of Stratum C, the claimed first to third 'floorings' were naturally occurring calcium carbonate features. However, three ovens were unearthed within the same levels ca. $157-60 \mathrm{~cm}$ above the surface of Stratum C. Also, the post-holes within the third "flooring" feature attest to habitation activity. There is also mud plastering from a wattle and daub structure and a claim stretch of hardened paving; however, there is no sketch or photograph of the latter feature to verify. The mud plaster is from Stratum B but its exact stratigraphic positioning cannot be reconstructed. The latest activity was a small patch of burnt clay flooring at $195 \mathrm{~cm}$ above the surface of Stratum C, which is in Stratum A and towards the end of the period of mortuary activity at the site. The stratigraphic positioning of these remains correlates with the sequence obtained for the pottery Assemblage 3, which is present in greater numbers in the upper strata than Assemblage 2 (see section 3.3.4). 


\begin{tabular}{|c|c|c|c|}
\hline Original & Re-evaluation & Level above & Level below \\
\hline $\begin{array}{l}\text { Small patch burnt } \\
\text { clay flooring }\end{array}$ & Probable hearth & $195 \mathrm{~cm}$ & \\
\hline $\begin{array}{l}\text { Stretch hardened } \\
\text { paving }\end{array}$ & $\begin{array}{l}\text { No information to re- } \\
\text { evaluate }\end{array}$ & $180 \mathrm{~cm}$ & \\
\hline $1^{\text {st }}$ flooring & $\begin{array}{l}\text { Calcium carbonate } \\
\text { formation }\end{array}$ & ca. $157 \mathrm{~cm}$ & \\
\hline $2^{\text {nd }}$ flooring & $\begin{array}{l}\text { Calcium carbonate } \\
\text { formation }\end{array}$ & ca. $150 \mathrm{~cm}$ & \\
\hline $3^{\text {rd }}$ flooring & $\begin{array}{l}\text { Calcium carbonate } \\
\text { formation }\end{array}$ & $60 \mathrm{~cm}$ & \\
\hline $\begin{array}{l}\text { Post-holes in } 3^{\text {rd }} \\
\text { flooring }\end{array}$ & $\begin{array}{l}\text { Post-holes in calcium } \\
\text { carbonate formation }\end{array}$ & $60 \mathrm{~cm}$ & \\
\hline 3 ovens & 3 ovens & $\begin{array}{l}\text { Between } 1^{\text {st }} \text { and } 3^{\text {rd }} \\
\text { 'floorings' }\end{array}$ & \\
\hline Hardened mud & $\begin{array}{l}\text { Mud plaster from } \\
\text { wattle \& daub } \\
\text { structure(s) }\end{array}$ & Unknown & \\
\hline Mud pavement & Unverifiable & $50 \mathrm{~cm}$ & \\
\hline Baked clay floor & Unverifiable & $25 \mathrm{~cm}$ & \\
\hline Stone flooring & Stone flooring & & $20 \mathrm{~cm}$ \\
\hline $\begin{array}{l}\text { Hardened burnt } \\
\text { clay }\end{array}$ & Probable hearth & & $25 \mathrm{~cm}$ \\
\hline Burnt floor paving & Unverifiable & & $25 \mathrm{~cm}$ \\
\hline Floor paving & Unverifiable & & $35 \mathrm{~cm}$ \\
\hline $\begin{array}{l}2 \text { places of burnt } \\
\text { earth }\end{array}$ & Probable hearths & & $\begin{array}{l}\text { Surface of } \\
\text { Stratum D }\end{array}$ \\
\hline Tukl floor & $\begin{array}{l}\text { Unverifiable, apart } \\
\text { from it being } \\
\text { hardened mud }\end{array}$ & & $\begin{array}{l}\text { Surface of } \\
\text { Stratum D }\end{array}$ \\
\hline $\begin{array}{l}\text { Post-holes in } t u k l \\
\text { floor }\end{array}$ & $\begin{array}{l}\text { Post-holes in hardened } \\
\text { mud }\end{array}$ & & $\begin{array}{l}\text { Surface of } \\
\text { Stratum D }\end{array}$ \\
\hline $\begin{array}{l}\text { Hardened floor of } \\
\text { round dwelling } \\
\text { with burnt earth in } \\
\text { middle }\end{array}$ & $\begin{array}{l}\text { Possible dwelling } \\
\text { floor with hearth }\end{array}$ & & $\begin{array}{l}\text { Surface of } \\
\text { Stratum D }\end{array}$ \\
\hline $\begin{array}{l}\text { Red-ware pot } \\
\text { sherd floor }\end{array}$ & $\begin{array}{l}\text { One or more vessels } \\
\text { crushed under pressure }\end{array}$ & & $\begin{array}{l}\text { Surface of } \\
\text { Stratum D }\end{array}$ \\
\hline
\end{tabular}

Table 4.1 The known features recorded as evidence for human habitation activity in the South-West sector, their re-evaluated designation and depth above or below the surface of Stratum C. The ground surface here at the time of excavation was $210 \mathrm{~cm}$ above the surface of Stratum C. 
Although indicative of habitation activity having occurred in the Jebel Moya valley at least from time the surface of Stratum D was formed, questions are raised regarding the degree and nature of settlement of the valley during the different time periods. There was little to no burial activity during the time represented by pottery assemblages 1 and 2, but there are pottery sherds on the surface of Stratum D and through Stratum C which may possibly belong to the time period of Assemblage 2. At least in the South-West sector, habitation remains are present to within $30 \mathrm{~cm}$ of the ground surface at the time of excavation; the burnt earth at $15 \mathrm{~cm}$ below may or may not have formed part of a dwelling as the extant evidence is too scanty to be able to narrow down beyond a plausible hearth.

From the available data, settlement occupation during Assemblage 1 was probably episodic. Settlement debris can be more readily attributed to Assemblage 2 times but the lack of data from the rest of the valley prevents a determination whether there was any permanent settlement or whether the valley was occupied during seasonal rounds at different times during the year. The presence of ovens in the upper strata, co-occurring with at least the majority of mortuary activity, suggests that the valley was perhaps permanently occupied, whether by structures which were rebuilt or by the village moving around the valley, during Assemblage 3. The nature of the burials in relation to the settlement evidence is discussed below in section 4.2.2.

\subsection{Intra-site mortuary data}

The sheer number of burials necessitated a re-modelling of their spatial distributions and their relationship to habitation remains. The data, including the composition of the mortuary assemblages, is used to determine the origins and potential evolution of the cemetery layout.

\subsubsection{Distribution of the burials}

There are 3191 recorded and excavated instances classified as burials (humans and animals) on the tomb cards, which includes pits. Of these, 72 are unassigned to a particular sector as their square was not marked on the field cards. Out of the remaining 
3119 burials, 70 are not attributed to a stratum (Table 4.2). The depth of a body from the ground surface was measured to the nearest $10 \mathrm{~cm}$ down to the pelvis between the second to the early fourth seasons. Note that this does not mean that the inhumations were 'cut' from the stratum mentioned - these are merely the strata in which the buried remains were recovered.

\begin{tabular}{|l|c|}
\hline \multicolumn{1}{|c|}{ Stratum } & Number \\
\hline Unattributed & 70 \\
\hline Stratum A & 8 \\
\hline Stratum B & 1775 \\
\hline Stratum C & 1031 \\
\hline Stratum D & 235 \\
\hline Total & $\mathbf{3 1 1 9}$ \\
\hline
\end{tabular}

Table 4.2 Numerical distribution of burials in each stratum.

The breakdown of the 3049 recorded-as-burials across the different sectors of the site down through the strata is broadly equivalent for the main South-West and North-East sectors (Table 4.3). By contrast, the East sector has more Stratum C than Stratum B burials. However, the level from which most of the burials were cut was either not determined or not recorded. George Reisner, who was at the site for a short period of time in the final session, was also unable to determine the surface from which his excavated graves were dug from: "The sides of the grave were clear but running upwards from these sides was an irregular breakage in laminated debris which made it impossible to fix the original depth of the grave." (Addison 1949: 30) However, although not noted on the tomb cards of burials from the East sector, Dixon apparently determined the surface level at the time of burial and thereby the depth dug for 203 graves, which he noted in his journal: 57 burials in Stratum B, 117 in Stratum C and 29 in Stratum D. By comparing these figures with the overall burial numbers in Table 4.2, the depth dug was determined by him for only $6.66 \%$ of the total burials assigned to a stratum: $3.21 \%$ for B Stratum, $11.35 \%$ for Stratum C and $12.34 \%$ for Stratum D. These reconstructed depths range from $10-140 \mathrm{~cm}$. 


\begin{tabular}{|l|c|c|}
\hline Sector & Stratum & Numbers \\
\hline South & A & 0 \\
\hline & B & 1 \\
\hline & C & 7 \\
\hline South-West & D & 0 \\
\hline & A & 4 \\
\hline & B & 320 \\
\hline & C & 50 \\
\hline West & D & 0 \\
\hline & A & 7 \\
\hline & B & 6 \\
\hline & C & 0 \\
\hline East & D & 3 \\
\hline & A & 296 \\
\hline & B & 416 \\
\hline & C & 138 \\
\hline North-West & D & 0 \\
\hline & A & 117 \\
\hline & B & 49 \\
\hline & C & 1 \\
\hline North-East & D & 912 \\
\hline & A & 233 \\
\hline & B & 46 \\
\hline & C & 1 \\
\hline & D & 4 \\
\hline
\end{tabular}

Table 4.3 Breakdown of burials across the different sectors and through the strata.

Addison (1949: 42-43) attempted to arrive at a balance of possibilities for an average depth of a burial. He derived an average of $50 \mathrm{~cm}$ for depth dug, arguing that a body would not have been buried a mere $10 \mathrm{~cm}$ below the surface and that perhaps Dixon got the measurement wrong at the other end of the scale, i.e. that $140 \mathrm{~cm}$ is perhaps too deep. However, $140 \mathrm{~cm}$ is 4.59 feet which, although on the deep side, is not altogether too deep for a prehistoric burial. At El Geili, Caneva (1988: 25) estimated that a combination of deflation and erosion removed $80 \mathrm{~cm}$ or more of surface depositional deposit. As the earliest graves there were $20-40 \mathrm{~cm}$ below the current ground surface, Caneva (1988: 24-25) estimated that all burials were dug from a surface of $c a .100 \mathrm{~cm}$ above. At Jebel Moya, water erosion had occurred, although it was not uniform across the site (Addison 1949: 25). Some burials, such as numbers 33 (square K.12, L.13), 38 and 39 (square M.11,N.12), occur only $5 \mathrm{~cm}$ below the modern ground surface. While the total depth of deposit lost to erosion across the valley was not determined by the field geologists, it is not unreasonable to adopt Caneva's determination as a reasonable working 
measurement to work out an approximate estimate of the strata from which the Jebel Moya burials were dug.

Addison constructed a reference datum in his attempt to place the burials in a chronological order. He accepted the original geological reports which strongly indicate that the strata were deposited almost uninterrupted and that denudation occurred after abandonment (Addison 1949: 29-30). There was no particular geological feature on the surface which could be used as the datum point due to the uneven nature of the erosion. However, the distinction between the more greyish soil of Stratum B and the blacker soil of Stratum C was well mapped across the site (Figure 4.9). The depth for the burials was originally recorded by the excavators as being from the modern ground surface at the time of excavation. Addison (1949: 27) adopted the surface of Stratum C as his datum reference point and marked the burials where possible as being above/below this surface.

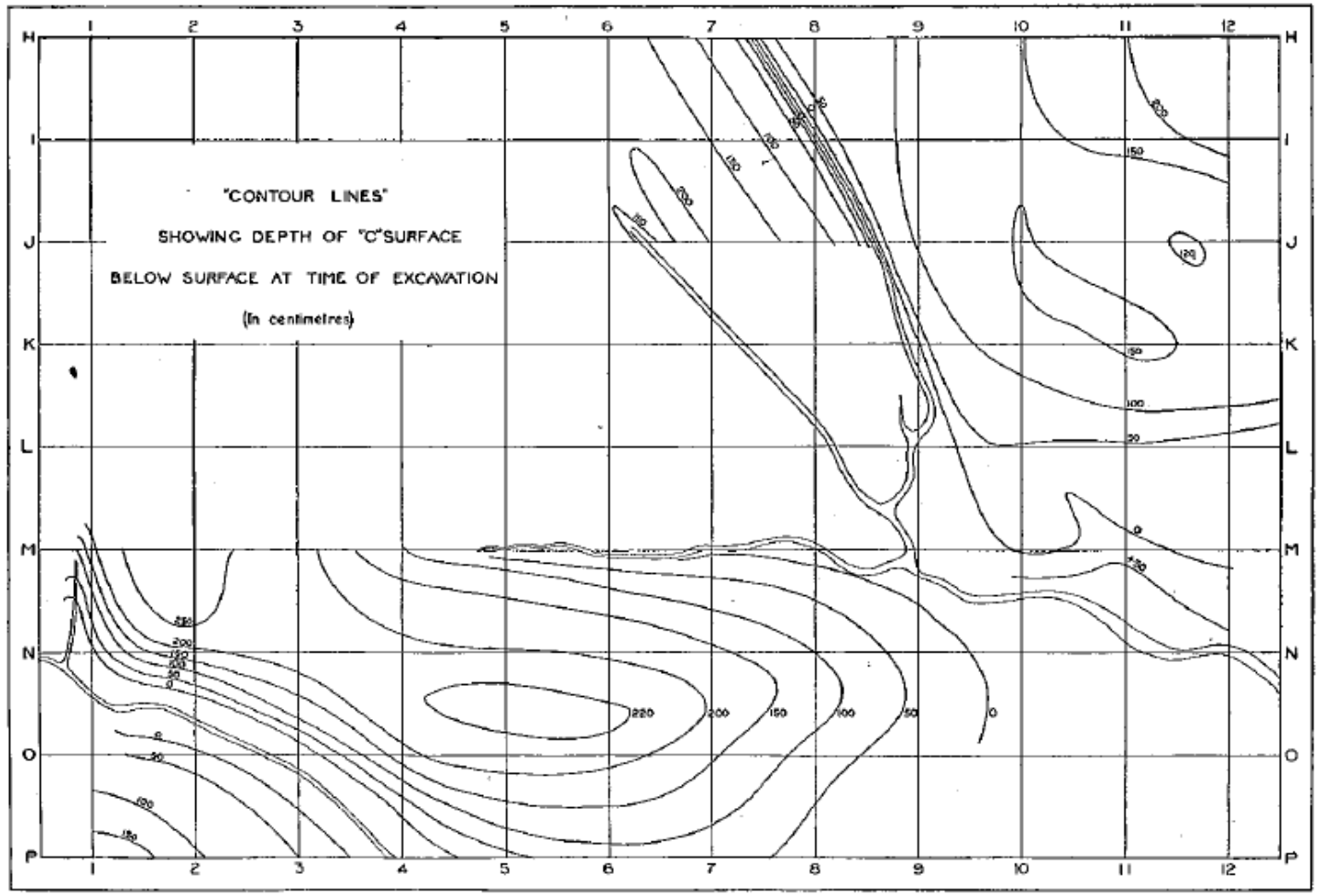

Figure 4.9 Mapping of the surface of Stratum $C$ in relation to the modern ground surface at the time of excavation across the excavated sectors of the valley. From Addison (1949: Figure 5).

On average, Stratum D was fixed at $70 \mathrm{~cm}$ and more below the surface of Stratum C, while Stratum A was $100 \mathrm{~cm}$ and over above the surface of Stratum C. The uppermost 
burial for which measurements can be obtained is number 828 at $115 \mathrm{~cm}$ above the surface of Stratum C in the South-West sector, with the deepest burial being number 1359 at $170 \mathrm{~cm}$ below the surface of Stratum C in the East sector. Overall, the depth from the modern surface at the time of excavation to the white calcium carbonate layer underlying Stratum D was up to just over $3 \mathrm{~m}$ in places, although this varied due to differential erosion. Taking into account the reconstructed surface levels from which burials occurred, the total depth of the deposit at the end of the use of the cemetery was likely around $4 \mathrm{~m}$.

There are four sectors of the valley where there is sufficient information from my new Register of Graves to reconstruct the surface from which the burials were dug. These are the South-West, East, North-West and North-East sectors.

In the South-West (Figure 4.10), there are 3 burials dug from below the surface of Stratum C. They were dug from $10 \mathrm{~cm}$ (2) and $20 \mathrm{~cm}$ (1) below the surface of Stratum C respectively. An additional 8 burials were dug from the level of the surface of Stratum C. The level from which the greatest numbers of burials were dug was at $100 \mathrm{~cm}$ above the surface of Stratum C. The majority of the burials were dug from levels ranging from $70-160 \mathrm{~cm}$ above the surface of Stratum C.

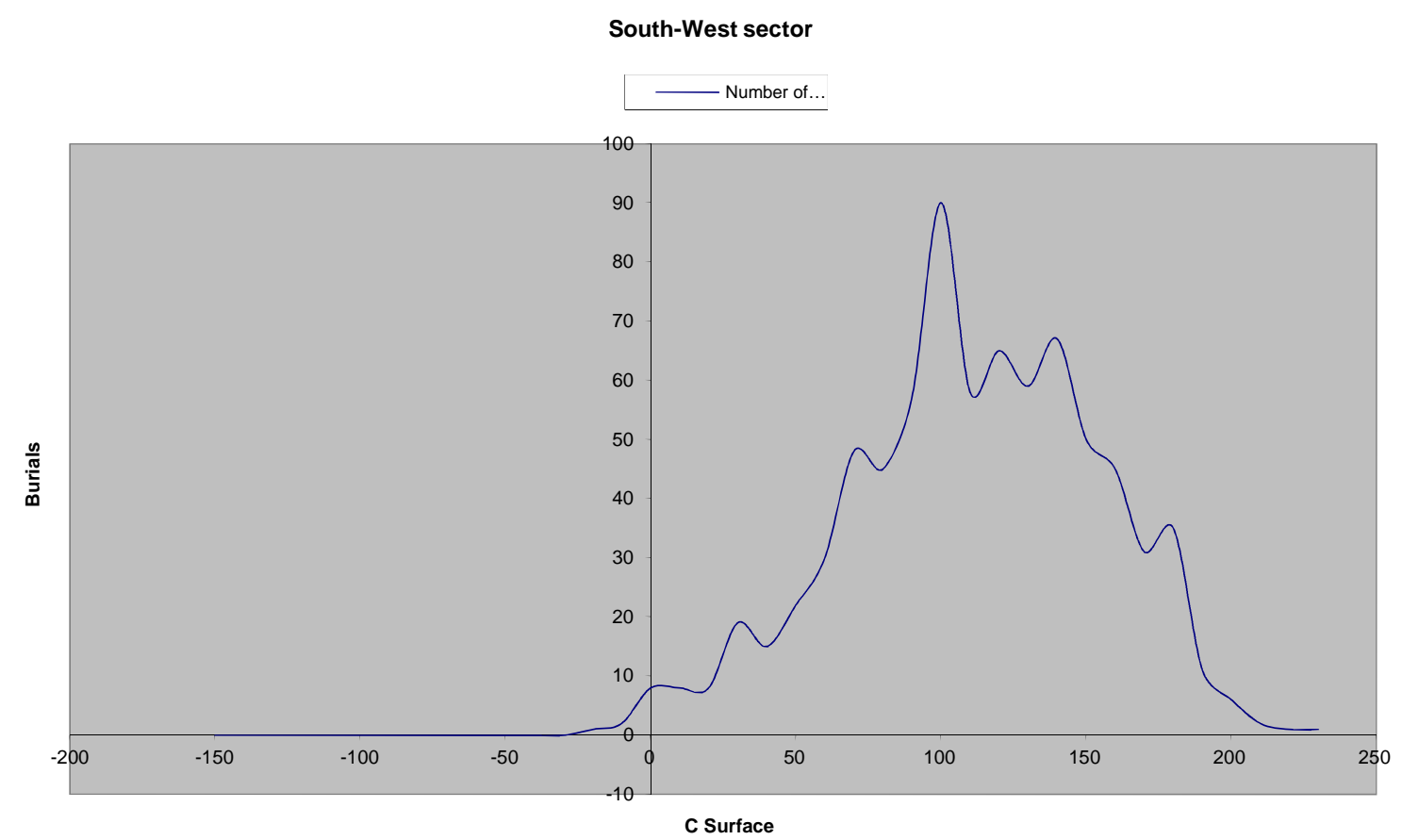

Figure 4.10 Reconstruction of the number of burials (vertical axis) dug from levels above and below the surface of Stratum C (horizontal axis) for the South-West sector. 
In the East (Figure 4.11), there are 35 burials dug from below the surface of Stratum C. They were dug from $10 \mathrm{~cm}(18), 20 \mathrm{~cm}(9), 30 \mathrm{~cm}(2), 40 \mathrm{~cm}(2), 50 \mathrm{~cm}(1), 60 \mathrm{~cm}(1)$, $70 \mathrm{~cm}(1)$ and $130 \mathrm{~cm}(1)$ below the surface of Stratum C respectively. An additional 14 burials were dug from the level of the surface of Stratum C. The level from which the greatest numbers of burials were dug was at $110 \mathrm{~cm}$ above the surface of Stratum C. The majority of the burials were dug from levels ranging from $30-160 \mathrm{~cm}$ above the surface of Stratum C.

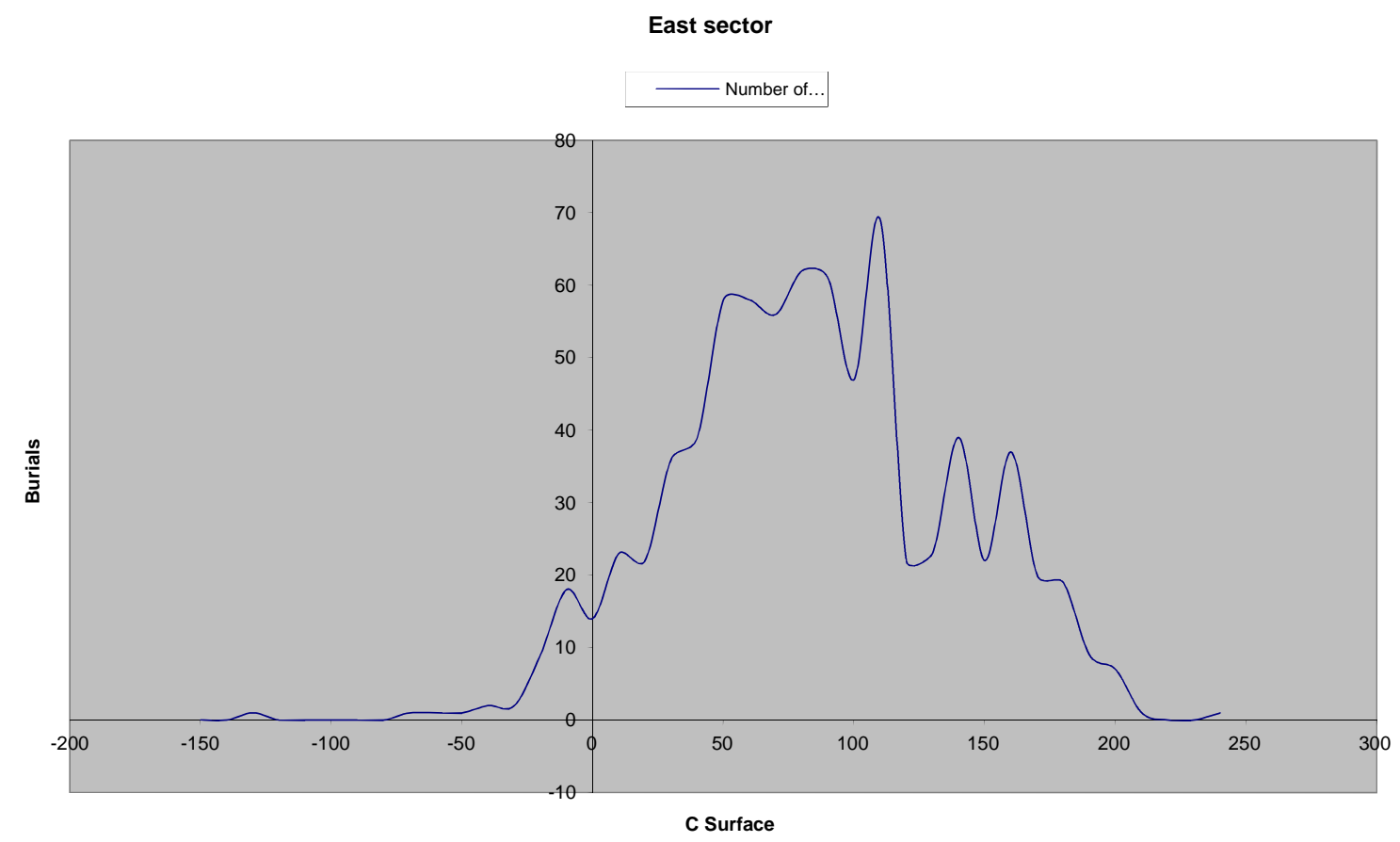

Figure 4.11 Reconstruction of the number of burials (vertical axis) dug from levels above and below the surface of Stratum $\mathrm{C}$ (horizontal axis) for the East sector.

In the North-West (Figure 4.12), all the burials were dug from above the surface of Stratum C, the lowest being $40 \mathrm{~cm}$ above. The level from which the greatest numbers of burials were dug was at $140 \mathrm{~cm}$ above the surface of Stratum C. The majority of the burials were dug from levels ranging from $100-170 \mathrm{~cm}$ above the surface of Stratum C.

In the North-East (Figure 4.13), there are 5 burials dug from below the surface of Stratum C. They were dug from $10 \mathrm{~cm}$ below the surface of Stratum C. An additional 6 burials were dug from the level of the surface of Stratum C. The level from which the greatest numbers of burials were dug was at $160 \mathrm{~cm}$ above the surface of Stratum $\mathrm{C}$. The majority of the burials were dug from levels ranging from $100-180 \mathrm{~cm}$ above the surface of Stratum C. 


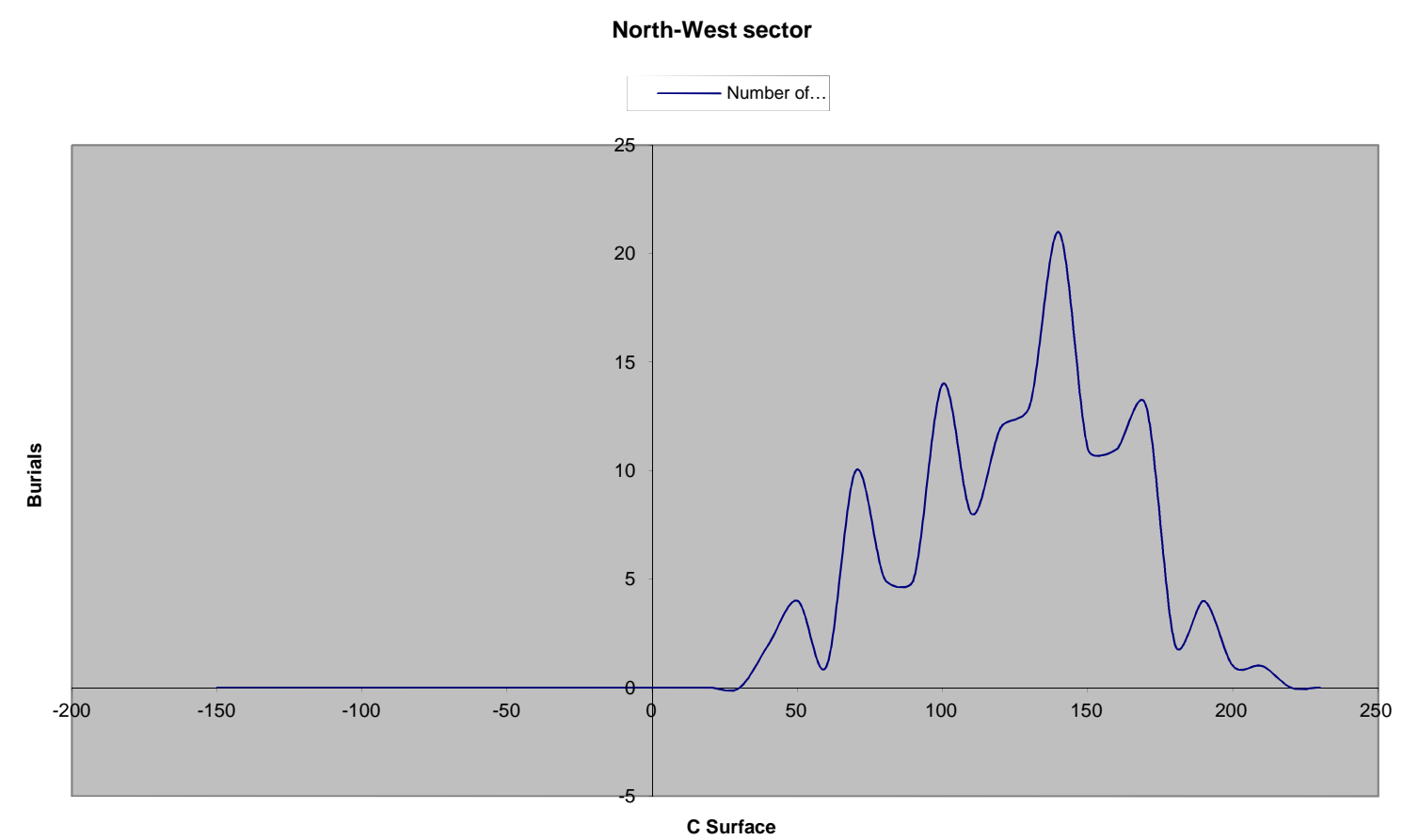

Figure 4.12 Reconstruction of the number of burials (vertical axis) dug from levels above and below the surface of Stratum C (horizontal axis) for the North-West sector.

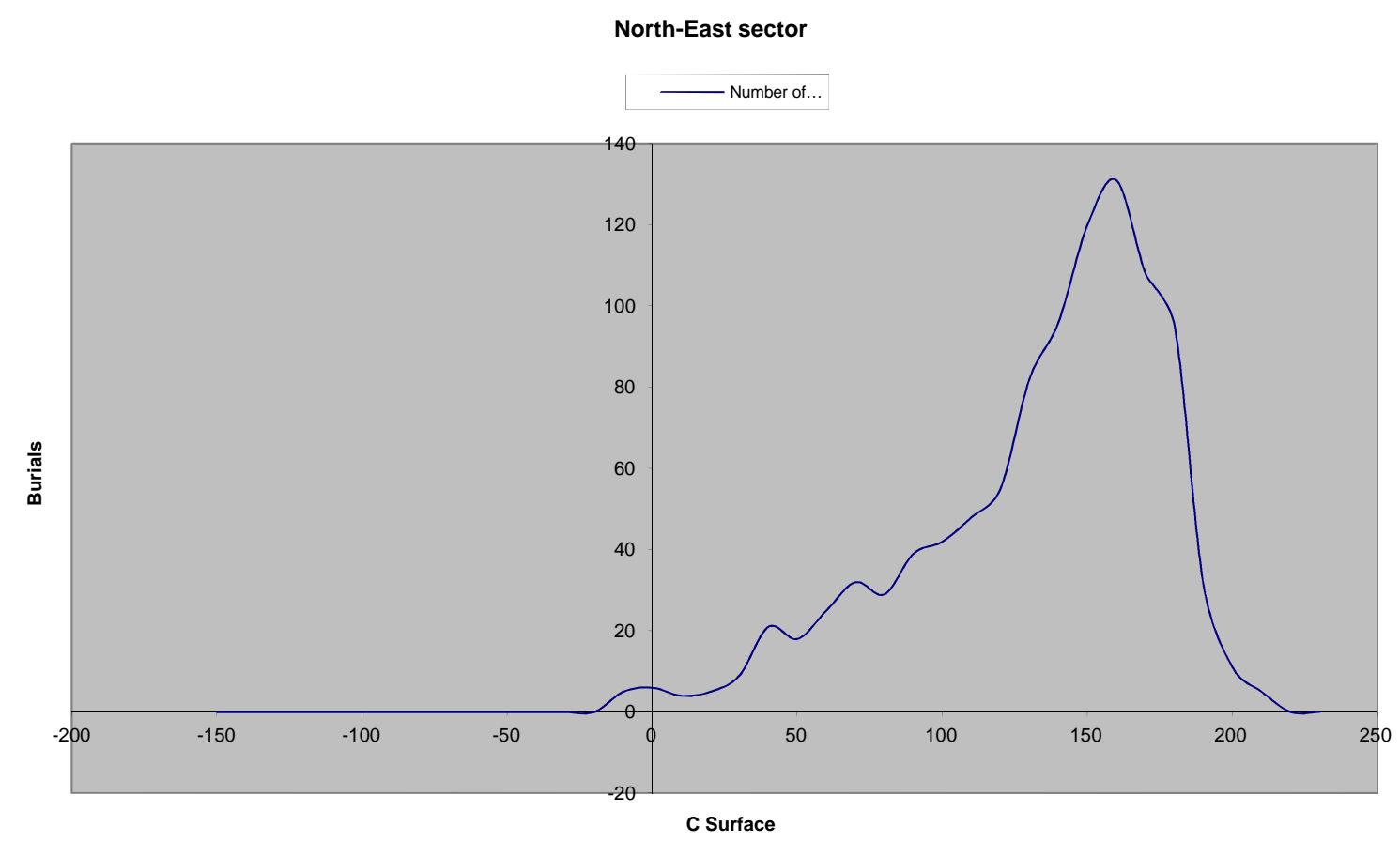

Figure 4.13 Reconstruction of the number of burials (vertical axis) dug from levels above and below the surface of Stratum C (horizontal axis) for the North-East sector.

Allowing for the probability that a few burials may have been dug from a higher or lower depth than the $1 \mathrm{~m}$ measurement used in calculating the average original burial surfaces, the greatest number of burials below the surface of Stratum C is in the East 
sector, though only the North-West sector has no burials dug from below the surface of Stratum C. The increase in the number of burials also starts at a lower level in the East sector at $30 \mathrm{~cm}$ above the surface of Stratum C. Together, the pattern is indicative of more burials being made initially in the east.

Subsequently, there is increased burial activity in the South-West sector, starting at $70 \mathrm{~cm}$ above the surface of Stratum C. Finally, the focus shifted to the North-East, which has the greatest number of overall burials, and the North-West sectors with their increases increase beginning at $100 \mathrm{~cm}$ above Surface of Stratum C, which is the same as the North-West sector. It therefore appears that while individuals were buried in different areas of the valley at approximately the same time, the main depositional focus shifted over the course of the period of Assemblage 3 time.

\subsubsection{Origins of the cemetery layout}

A few alternatives exist for how the spatial layout of the different burial sectors came into being and how they grew. The first is that there was organic growth over time with shifting burial grounds. The second is that the distribution of the burials was more or less established at the onset of the use of the valley as a cemetery. The former could be due to the dead being buried in temporarily unoccupied space, while the latter could be the result of burial beneath or next to huts occupying most of the valley. There is also the possibility that habitation was abandoned towards the end of the occupation sequence, leaving only mortuary activity occurring within the valley. To help distinguish between the different possibilities, the different sectors were examined for the composition and ratios of types of burial assemblage artefacts: the expectation is that the nature of the burial assemblages would show distinct differences if there were shifting burial grounds, and be similar if all the different sectors were, by and large, in use throughout this final phase.

\subsubsection{Comparative nature of the burial assemblages}

An average of $50 \%$ of the human burials in the South-West and North-West sector have accompanying artefacts, while the range is 25 - 30\% for the East and North-East sectors (Table 4.4). Comparatively, the number of human burials in the South and West sectors, 
at a combined total of 66 , is of lesser numeric importance. It is the first four sectors South-West, North-East, East and North-West - which are the main focus in determining how the burial layout arose in the Jebel Moya valley. The number of occurrences of all the artefact categories from these burials was determined for the different sectors (Table 4.4).

\begin{tabular}{|l|c|c|c|c|}
\hline & $\begin{array}{l}\text { Recorded } \\
\text { burials }\end{array}$ & $\begin{array}{c}\text { Animal } \\
\text { burials }\end{array}$ & $\begin{array}{c}\text { Human burials } \\
\text { with goods }\end{array}$ & $\begin{array}{c}\text { Human burials } \\
\text { (with goods) per } \\
\text { m }^{2}\end{array}$ \\
\hline South-West & 825 & 11 & $\begin{array}{c}427 / 814 \\
(52.46 \%)\end{array}$ & $\begin{array}{l}1.57 \\
(0.82)\end{array}$ \\
\hline North-East & 1196 & 7 & $\begin{array}{l}336 / 1189 \\
(28.25 \%)\end{array}$ & $\begin{array}{l}4.95 \\
(1.4)\end{array}$ \\
\hline East & 860 & 5 & $\begin{array}{l}217 / 855 \\
(25.38 \%)\end{array}$ & $\begin{array}{l}3.05 \\
(0.78)\end{array}$ \\
\hline North-West & 174 & 4 & $\begin{array}{l}85 / 170 \\
(50 \%)\end{array}$ & $\begin{array}{l}0.85 \\
(0.43)\end{array}$ \\
\hline South & 49 & 0 & $\begin{array}{c}17 / 49 \\
(34.7 \%)\end{array}$ & $\begin{array}{l}0.41 \\
(0.14)\end{array}$ \\
\hline West & 17 & 0 & $\begin{array}{c}4 / 17 \\
(23.53 \%)\end{array}$ & $\begin{array}{l}0.17 \\
(0.04)\end{array}$ \\
\hline
\end{tabular}

Table 4.4 The breakdown of human and separate animal burials, and the percentage of grave goods associated with the human burials, per sector and per square meter.

When the composition of the burial assemblages across the different sectors are broken down (Table 4.5), there are no obvious differences in the occurrences of the artefact categories. There are many categories and their respective occurrences are few across all sectors of the cemetery, with the prominent exceptions of beads and lipstuds. This suggests that any focus on signification in the mortuary realm was probably unrelated to the final form that the artefacts took. 


\begin{tabular}{|c|c|c|c|c|c|c|}
\hline $\begin{array}{l}\text { Artefact } \\
\text { type }\end{array}$ & South-West & North-East & East & North-West & South & West \\
\hline Amulets & $0(0 \%)$ & $0(0 \%)$ & $\begin{array}{l}3 \\
(0.69 \%)\end{array}$ & $0(0 \%)$ & $0(0 \%)$ & $0(0 \%)$ \\
\hline Anklets & $0(0 \%)$ & $1(0.30 \%)$ & $\begin{array}{l}1 \\
(0.23 \%)\end{array}$ & $0(0 \%)$ & $0(0 \%)$ & $0(0 \%)$ \\
\hline Armlets & $15(3.51 \%)$ & $1(0.30 \%)$ & $\begin{array}{l}2 \\
(0.46 \%)\end{array}$ & $0(0 \%)$ & $1(5.88 \%)$ & $0(0 \%)$ \\
\hline Beads & $\begin{array}{l}135 \\
(31.62 \%)\end{array}$ & $\begin{array}{l}119 \\
(35.42 \%)\end{array}$ & $\begin{array}{l}78 \\
(17.97 \%)\end{array}$ & $27(31.76 \%)$ & $1(5.88 \%)$ & $2(50 \%)$ \\
\hline Bone points & $5(1.17 \%)$ & $1(0.30 \%)$ & $\begin{array}{l}2 \\
(0.46 \%)\end{array}$ & $0(0 \%)$ & $0(0 \%)$ & $0(0 \%)$ \\
\hline Borers & $1(0.23 \%)$ & $0(0 \%)$ & $0(0 \%)$ & $0(0 \%)$ & $0(0 \%)$ & $0(0 \%)$ \\
\hline Bowls & $0(0 \%)$ & $0(0 \%)$ & $\begin{array}{l}2 \\
(0.46 \%)\end{array}$ & $0(0 \%)$ & $0(0 \%)$ & $0(0 \%)$ \\
\hline Bracelets & $30(7.03 \%)$ & $52(15.48 \%)$ & $\begin{array}{l}40 \\
(9.92 \%)\end{array}$ & $13(15.29 \%)$ & $1(5.88 \%)$ & $1(25 \%)$ \\
\hline Celts & $2(0.46 \%)$ & $10(2.98 \%)$ & $\begin{array}{l}5 \\
(1.15 \%)\end{array}$ & $1(1.18 \%)$ & $1(5.88 \%)$ & $0(0 \%)$ \\
\hline Ceramics & $31(7.26 \%)$ & $23(6.85 \%)$ & $\begin{array}{l}12 \\
(2.76 \%)\end{array}$ & $7(8.24 \%)$ & $1(5.88 \%)$ & $0(0 \%)$ \\
\hline Coils & $0(0 \%)$ & $14(4.17 \%)$ & $\begin{array}{l}6 \\
(1.38 \%)\end{array}$ & $0(0 \%)$ & $0(0 \%)$ & $0(0 \%)$ \\
\hline Earrings & $0(0 \%)$ & $0(0 \%)$ & $\begin{array}{l}1 \\
(0.23 \%)\end{array}$ & $0(0 \%)$ & $0(0 \%)$ & $0(0 \%)$ \\
\hline Earstuds & $5(1.17 \%)$ & $3(0.89 \%)$ & $\begin{array}{l}1 \\
(0.23 \%) \\
\end{array}$ & $6(7.06 \%)$ & $0(0 \%)$ & $0(0 \%)$ \\
\hline Flakes & $0(0 \%)$ & $1(0.30 \%)$ & $0(0 \%)$ & $0(0 \%)$ & $0(0 \%)$ & $0(0 \%)$ \\
\hline Grindstones & $0(0 \%)$ & $0(0 \%)$ & $\begin{array}{l}1 \\
(0.23 \%)\end{array}$ & $0(0 \%)$ & $0(0 \%)$ & $0(0 \%)$ \\
\hline $\begin{array}{l}\text { Hair } \\
\text { ornaments }\end{array}$ & $0(0 \%)$ & $0(0 \%)$ & $0(0 \%)$ & $1(1.18 \%)$ & $0(0 \%)$ & $0(0 \%)$ \\
\hline Hair clips & $2(0.46 \%)$ & $1(0.30 \%)$ & $0(0 \%)$ & $0(0 \%)$ & $0(0 \%)$ & $0(0 \%)$ \\
\hline Hair rings & $0(0 \%)$ & $0(0 \%)$ & $\begin{array}{l}1 \\
(0.23 \%)\end{array}$ & $0(0 \%)$ & $0(0 \%)$ & $0(0 \%)$ \\
\hline Knives & $3(0.70 \%)$ & $0(0 \%)$ & $0(0 \%)$ & $0(0 \%)$ & $0(0 \%)$ & $0(0 \%)$ \\
\hline Lipstuds & $\begin{array}{l}266 \\
(62.30 \%)\end{array}$ & $\begin{array}{l}128 \\
(38.10 \%)\end{array}$ & $\begin{array}{l}61 \\
(14.06 \%)\end{array}$ & $56(65.88 \%)$ & $\begin{array}{l}11 \\
(64.71 \%)\end{array}$ & $1(25 \%)$ \\
\hline Maceheads & $1(0.23 \%)$ & $0(0 \%)$ & $0(0 \%)$ & $0(0 \%)$ & $0(0 \%)$ & $0(0 \%)$ \\
\hline Needles & $1(0.23 \%)$ & $0(0 \%)$ & $\begin{array}{l}0 \\
(0 \%)\end{array}$ & $0(0 \%)$ & $0(0 \%)$ & $0(0 \%)$ \\
\hline Nosestuds & $3(0.70 \%)$ & $0(0 \%)$ & $\begin{array}{l}0 \\
(0 \%)\end{array}$ & $2(2.35 \%)$ & $0(0 \%)$ & $0(0 \%)$ \\
\hline Pebbles & $2(0.46 \%)$ & $2(0.60 \%)$ & $\begin{array}{l}1 \\
(0.23 \%)\end{array}$ & $0(0 \%)$ & $0(0 \%)$ & $0(0 \%)$ \\
\hline Pendants & $35(8.20 \%)$ & $22(6.55 \%)$ & $\begin{array}{l}17 \\
(3.92 \%)\end{array}$ & $5(5.88 \%)$ & $1(5.88 \%)$ & $0(0 \%)$ \\
\hline Pins & $9(2.11 \%)$ & $5(1.49 \%)$ & $\begin{array}{l}5 \\
(1.15 \%) \\
\end{array}$ & $3(3.53 \%)$ & $0(0 \%)$ & $0(0 \%)$ \\
\hline Quirms & $0(0 \%)$ & $0(0 \%)$ & $\begin{array}{l}1 \\
(0.23 \%)\end{array}$ & $0(0 \%)$ & $0(0 \%)$ & $0(0 \%)$ \\
\hline Rings & $1(0.23 \%)$ & $3(0.89 \%)$ & $\begin{array}{l}9 \\
(2.07 \%)\end{array}$ & $0(0 \%)$ & $0(0 \%)$ & $0(0 \%)$ \\
\hline
\end{tabular}




\begin{tabular}{|l|l|l|l|l|l|l|}
\hline $\begin{array}{c}\text { Artefact } \\
\text { type }\end{array}$ & South-West & North-East & \multicolumn{1}{|c|}{ East } & North-West & South & West \\
\hline Rubbers & $1(0.23 \%)$ & $2(0.60 \%)$ & $\begin{array}{l}1 \\
(0.23 \%)\end{array}$ & $0(0 \%)$ & $0(0 \%)$ & $0(0 \%)$ \\
\hline Scarabs & $0(0 \%)$ & $2(0.60 \%)$ & $0(0 \%)$ & $0(0 \%)$ & $0(0 \%)$ & $0(0 \%)$ \\
\hline Statuettes & $0(0 \%)$ & $0(0 \%)$ & $\begin{array}{l}2 \\
(0.46 \%)\end{array}$ & $0(0 \%)$ & $0(0 \%)$ & $0(0 \%)$ \\
\hline
\end{tabular}

Table 4.5 The sum of the occurrences of artefact categories in each area of the cemetery with corresponding percentage out of the total number of burials-with-goods.

\subsection{Discussion: Site spatial use over time}

No habitation debris can be definitely linked as co-occurring with the sherds from Assemblage 1, with any occupation likely to have been episodic. Although settlement debris can be more readily linked to Assemblage 2, the presence of reliable recorded data on non-mortuary structures outside of the South-West precludes a more precise determination on the nature and extent of the occupation.

Although earlier burials cannot be ruled out, the vast majority of the burial activity began at or very near the start of Assemblage 3. Barring the North-West sector, the other areas of the excavated valley were used from the outset of mortuary activity. This scenario is potentially corroborated by (a) there being mass burial activity from above the surface of Stratum C (Figure 4.9) in the South-West sector, and (b) evidence for habitation activities in the form of ovens, stone pavings, hearths and post-holes also from the South-West, whereas excavator reports of habitation traces from the other sectors are either scarce or cannot be verified.

Analysis of the spatial distribution of artefact categories from the burial assemblages in the different excavated areas of the cemetery is strongly suggestive of the mortuary layout having been established at or shortly after the onset of the Assemblage 3 occupation. No long-term distinct movement of burials can be detected from the distribution of the artefact types across the valley due to the low frequency of and uniformity of occurrences. However, analysis of the reconstructed surface from which burials were dug shows a shifting pattern of activity over the course of the use of the valley as a cemetery: the East sector at $30 \mathrm{~cm}$ above the surface of Stratum $\mathrm{C}$ and the 
South-West at $70 \mathrm{~cm}$ above, followed the North-East and North-West together at $100 \mathrm{~cm}$ above. The North-East sector also has the greatest density of burials.

Ethnographically, although burials amongst agro-pastoral populations near Lake Chad occurred at a designated area away from habitation (van Beek 2012), burials were still taking place beneath or just outside huts in south Sudan in the early $20^{\text {th }}$ century: amongst the Burun (southern Fung), Bongo (Tonj district, Bahr el Ghazal), Acholi, Anuak, Kuku, Langu, Lotuko and the Nuer (Addison 1949: 40). However, given the lack of information regarding the habitation remains in the other sectors of the site, it is impossible to determine whether people lived outside of the South-West sector right until up until mortuary activity ceased in the valley, as it appears they did in the SouthWest. 


\section{Chapter 5: The bioanthropology of Jebel Moya}

The Trustees of the Wellcome Trust approached the physical anthropologist Arthur Keith after the death of Henry Wellcome in 1936 to examine the skeletal remains from Jebel Moya as he was Wellcome's favoured choice (Addison 1949: V). Keith declined for reasons of poor health. The job was passed to G. M. Morant, who was assisted by Otto Samson. Morant and Samson though were unable to continue their examinations after the conclusion of the Second World War in 1945. The skeletal remains, from the second to fourth seasons (as no osteological data is available from the first season), and the excavation records were transferred at this point to the Duckworth Laboratory (University of Cambridge) under the curatorship of Professor J. C. Trevor. Trevor took up the challenge of overseeing the completion of the study. As his time was limited, he employed Messrs Mukherjee and Rao from India. Mukherjee was trained in physical anthropology and Rao was a statistician who had worked on human skeletal populations. The results were published in 1955 and, as detailed below, show internal homogeneity in the population.

This dataset is the basis for the only two subsequently completed biological studies on the Jebel Moya population. Rachel Hutton MacDonald (1999) examined the dental caries and wear on the extant teeth from the Duckworth Laboratory example in the late 1990s to determine their economic lifestyle. A couple of years later, Irish and Konigsberg (2007) also examined the dental sample but with the aim of testing population affiliation and degree of homogeneity.

The results of these three studies together show that the population of Jebel Moya were pastoralists forming a distinctive bio-cultural composition in a homogenous grouping which displayed affinities to sub-Saharan Africans. Finally, having established the internal biological grouping of the Jebel Moya population sample, the data from the unpublished re-sexing of the skeletal remains by Mercedes Okumura (a former curator at the Duckworth Laboratory) is compared to the original determinations in order to assess the latter's accuracy. 


\subsection{The original 1955 analysis: Mukherjee, Rao and Trevor}

Their aim of Mukherjee et al. (1955) was to undertake laboratory examination of identifiable and usable adult specimens, to analyse the measurements and observations of the field physical anthropologists, and to determine the relationship between the Jebel Moya inhabitants and other African peoples.

The records upon which they drew comprised of 2903 excavation cards with anthropometric and archaeological data. Of these, 326 contained all or most of the necessary physical anthropological data recorded for the cranial and post-cranial remains, while 1135 contained some data and 1442 none (Mukherjee et al. 1955: 3). Of these, 715 cards came from the second season where Derry was the anatomist, 212 cards from the third season with Ray and Dudley Buxton, and the remaining 1976 from the fourth season with Oldham, Hamly and Hussey. They omitted the first season of excavation due to the non-preservation of any human skeletal remains to re-examine.

However, the total number of available skeletal remains had been diminished due to destruction during warehouse flooding in the 1920s and in the Second World War. The examined human remains consisted of (Mukherjee et al. 1955: 3):

- 98 crania

- 139 mandibles

- 70 right femora

- 66 left femora

- 54 right tibiae

- 54 left tibiae

- 47 right humeri

- 42 left humeri

- 40 right radii

- 43 left radii

- 22 right ulnae

- 19 left ulnae

- 14 right clavicles 
- 17 left clavicles

- 1 right fibulae

- 1 left fibulae

There were 9 more or less fragmentary pelvises, of which 5 could be associated with other skeletal remains. The number of vertebrae and other extremities, together with non-adult remains, were discounted in their analyses. In addition, there were no preserved remains pertaining to the first field season of excavation. Mukherjee et al. (1955) decided to first depend upon on the measurements recorded by the field physical anthropologists and to use the surviving adult skeletal remains as quality control to test the former's degree of accuracy.

The anthropometric cards from the fourth season included the stratum designation, which was added by Samson to the respective cards from the second and third seasons (Mukherjee et al. 1955: 4). Other information captured by the anthropometric cards included locality, grave number, race, sex, age and total height, in addition to the measurement data on the cranial and post-cranial skeletal elements. The total height was the length of the skeleton as excavated, with the measurement varying according to posture; the measurement was not the stature of the individual.

The crania and post-cranial elements bear the number of the grave, with supernumeraries a, b, c, etc. Some of the bones have a queried number as the original had worn off; these bones were re-marked in England prior to their re-location to the Duckworth Laboratory (Mukherjee et al. 1955: 5). Mukherjee et al. (1955: 5) rejected the instances where bones were marked as NN (No Number) or where their measurements were too divergent from the details recorded on the cards.

They also consulted further select documentation (Mukherjee et al. 1955: 5): Derry's unpublished report written after the second season which dealt with the physical characteristics of the people, the anthropometric diaries from the third and fourth field seasons, Ray and Dudley Buxton's (1914) printed report on the pathologies and Samson's loose papers which contained field notes and some (of his) calculations. However, I have been unable to re-locate the anthropometric diaries and the referenced field notes, although a 1946 letter from Addison to Trevor was recovered which provides 
a summary background to the bioanthropological fieldwork and a breakdown of the numbers of skeletal remains by sex from the field physical anthropologists.

Mukherjee, Trevor and Rao's research was framed around four principle aims:

1. Was there any justification for the determination by the field physical anthropologists of greater numbers of women than men buried?

2. Different teams of physical anthropologists in each field season meant different standards and sets of measurements were invariably employed. How far could this data be standardised and be made interoperable with the British biometric system then in use?

3. To what degree was there heterogeneity or homogeneity?

4. What was the biological relationship of the people buried to the rest of Africa?

The re-sexing was done by Mukherjee and Trevor using the crania, mandible, pelvis and limb bones (Table 5.1). A total of 369 adult individuals were found to be in a condition permitting re-sexing (Mukherjee et al. 1955: 9): 199 males and possible males (54\%), and 170 females and possible females (46\%). Many individuals designated as female by the field physical anthropologists were re-assigned as male; despite this, the degree of bias is in question for the original sexing in one or more of the field seasons.

\begin{tabular}{|l|c|c|c|c|c|}
\hline \multicolumn{1}{|c|}{ Laboratory sex } & Male & Male? & Female & Female? & Total \\
\hline Cranium, mandible, pelvis & 1 & & & & 1 \\
\hline $\begin{array}{l}\text { Cranium, mandible, } \\
\text { limb bones }\end{array}$ & 13 & 4 & 6 & 1 & 24 \\
\hline $\begin{array}{l}\text { Mandible, } \\
\text { pelvis, limb } \\
\text { bones }\end{array}$ & 2 & & 2 & & 4 \\
\hline Cranium and mandible & 20 & & 14 & 2 & 36 \\
\hline $\begin{array}{l}\text { Cranium and } \\
\text { limb bones }\end{array}$ & 2 & & 3 & 1 & 6 \\
\hline $\begin{array}{l}\text { Mandible and } \\
\text { limb bones }\end{array}$ & 1 & 2 & 1 & 1 & 5 \\
\hline Cranium & 21 & 9 & 26 & 16 & 72 \\
\hline Limb bones & 76 & 16 & 42 & 23 & 157 \\
\hline Totals & $\mathbf{1 5 6}$ & $\mathbf{4 3}$ & $\mathbf{1 1 7}$ & $\mathbf{5 3}$ & $\mathbf{3 6 9}$ \\
\hline
\end{tabular}

Table 5.1 Re-sexing of the adult skeletal remains at the Duckworth Laboratory by Mukherjee et al. From Mukherjee et al. (1955: Table 2.1). 
Table 5.2 corrects for any imbalance in how Mukherjee et al. (1995: Table 2.4 and Table 2.5) calculated the degree of differences in the designation of sex between the field physical anthropologists and their laboratory re-sexing by subsuming the "sex" and "sex?" into one category. This eliminates the potential for distorted error counts. Contrary to Mukherjee et al. (1955: 11-13) who claimed that "the laboratory sexing tallies to a great extent with Derry's sexing in the second season, while it is very different from that of the anthropologists who worked in the fourth season", the revised figures suggest that Derry made mistakes assigning remains to both female and male categories.

\begin{tabular}{|l|l|c|}
\hline Field season & Field sexing & Differences with laboratory sexing \\
\hline Second & Male & $4 / 18(22.2 \%)$ \\
\hline & Female & $3 / 9(33.3 \%)$ \\
\hline & Undesignated & $10 / 10$ \\
\hline Third & Male & $1 / 14(7.14 \%)$ \\
\hline & Female & $6 / 15(40 \%)$ \\
\hline & Undesignated & $10 / 10$ \\
\hline Fourth & Male & $10 / 69(14.49 \%)$ \\
\hline & Female & $55 / 141(39 \%)$ \\
\hline & Undesignated & $44 / 44$ \\
\hline Total & & $\mathbf{1 4 3 / 3 3 0}$ \\
\hline
\end{tabular}

Table 5.2 The numbers of individuals re-sexed in the laboratory compared to their original field sexings. The male and male?, female and female? categories have been subsumed under male and female. The total of 330 individuals differs from 369 reported in Table 4.3 due to the removal by Mukherjee et al. of 39 specimens whose numbering appeared doubtful. Based on Mukherjee et al. (1955: Table 2.4).

Such a bias is evident from the field notes of Oldham (fourth season) (Mukherjee et al. 1955: 14):

"One hundred and sixty-nine bodies were taken up this week... They included 28 males, 47 females, and 92 of indeterminate sex. It will be recorded that the proportion of males is considerably higher than I have ever recorded before. I feel bound to record that this increase is coincident with the return of my assistant Mr Hussey to the anatomical dept. Owing to the severe pressure of work he and Mr Hambly worked together, and I was unable to keep a check on all of their observations. It is my opinion that many of the bodies marked as male should be taken with a query, for I have found no such increase in the bodies I studied myself." 
Mukherjee et al. (1955: 14) put errors in the field sexing down not just to the volume of graves being excavated but also to what they and Derry (on his field cards) indicate as "weak development of some of their sexual characteristics." Since not all the original skeletal material was available for re-evaluation and incorrect sexing cast doubt upon the measurements taken in the field, Mukherjee et al. grappled with the issue of how to ensure a uniform classification of the data. They adopted a form of mathematical sexing at the suggestion of Sir Ronald Fisher and implemented by Rao with the long bones and mandibles (Mukherjee et al. 1955: 103-6):

"In the case of sexing skeletal remains, one of the earliest methods suggested was to take the sum of the measurements on any individual bone and assign it to the male group, if this exceeded a certain value, and to the female group if it did not. In a paper by Dr E. S. Martin, Sir Ronald Fisher suggested the use of a linear function of the measurements which takes into account the variabilities and correlations of the various measurements compounded... The linear function so arrived at is known as the discriminant function. [The procedure] presupposes that characteristics such as the means, variances and correlations are known for the male and female groups. In some cases it is possible to estimate these quantities from measurements on bones whose sexes are accurately determined... In scrutinizing the field records it was found that some contained references to morphological features of the pelvic bones. Since sex differences are well marked in the pelvis it might reasonably be assumed that the field sexing is fairly accurate, at least for skeletons where the pelvis was preserved. This supplied the basic material for the determination of the mathematical formulae. Just before the analysis was undertaken, Trevor and Mukherjee resexed the remaining crania. The field records relating to these supplied additional material for estimating the characteristics of the two groups. The mean values of measurements as estimated from this material (Set A), and from the field records (Set B) which contained references to pelvic features, [were compared].”

The oblique length of femur, length of tibiae, length of humerus, length of radius and length of clavicle were measured for the long bones (Mukherjee et al. 1955: 104, Table A2.1). The condyloid height, body height, sigmoidal height, coronoid height, ramus breadth and condylo-symphysial length were measured for the mandible. The crania 
were not included due to the lack of measurements on its characteristics in the majority of the records (Mukherjee et al. 1955: 106).

Although there was a correlation between the laboratory sexing and the mathematical sexing in so far as both indicated to Mukherjee et al. that there were no significant differences in the sexing from the second field season's sexing, significant divergences emerged when compared to the third and fourth field seasons' sexing. The mathematical sexing was eventually discontinued due to errors in the measurements taken by the physical anthropologists in the third and fourth seasons (Mukherjee 1955: 18).

The femur lengths measured in the laboratory agree fairly well with the measurements taken in the field during the second and third seasons. The discrepancies increase again with the data captured during the fourth season. Deviation for the lengths of limb bones is greatest for the third season, with a wide range of variation for the third and fourth seasons:

"[As] regards the length of the limb bones, the data from the second and third seasons may be considered as reliable for the femur, but that the measurements taken on the femur in the fourth season and on other bones in the second, third and fourth seasons cannot be accepted with similar confidence." (Mukherjee et al. 1955: 29, Tables 22.16 and 22.17)

Mukherjee et al. thus took only select cranial and femoral measurements recorded in the field during the second season as reliable and employed them in their analysis, together with the measurements taken in the laboratory (Mukherjee et al. 1955: 30). Remeasurement of the skeletal remains in the laboratory revealed a discrepancy with the recorded measurements from the fourth field season (Mukherjee et al. 1955: 23). Many of the measurements recorded on the anatomical cards from the fourth season are beyond the range of normal human crania, while no such deviant values are recorded for the second and third seasons. The defective measurements are most likely due to the lack of proper equipment such as a mandible board with a set-square and scriber (Mukherjee et al. 1955: 25). 
Mukherjee et al. (1955: 45) determined that the shape of the crania does not differ significantly for males by stratum. For females, there is a greater proportion of longer headed crania in the upper strata. The shape of the face across the seasons were described as being long narrow or pointed, long oval, oval, square or broad, or triangular (Mukherjee et al. 1955: 35). Irrespective of stratum, male faces show a greater preponderance falling in the long oval, or square or broad categories; female faces are more inclined to be assigned to the oval category. The dominant categories overall are the oval and the square or broad types (Mukherjee et al. 1955: 37).

Facial prognathism remained proportionately the same between males and females irrespective of stratum (Mukherjee et al. 1955: 46), though no definitive conclusion can be reached due to the dubious nature of the original field data:

“[The] division of the Jebel Moya cranial series into 'prognathous' and 'nonprognathous' individuals...may have incorporated some sort of bias. Most of the field cards either recorded the individual as 'prognathous' or the space was left blank. Only in eight cases did the cards register orthognathism....[The] cards without any record for this character have been regarded as belonging to nonprognathous individuals on the assumption that the field anthropologists took pains to record all cases of prognathism or otherwise left the spaces blank. But it is possible that in many instances the specimens were too fragmentary even for the inclination of the face to the brain-case to be observed, and that all the cards with blank spaces need not have been intended for orthognathous individuals." (Mukherjee et al. 1955: 37)

Mukherjee et al. (1955: 47) concluded that "the hypothesis of non-Negroid immigrants mixing with the native Negroid stock at Jebel Moya can be based only on very slender evidence". The variation in the non-metrical characters presupposed to them that there was a degree of heterogeneity in the population which they set out to test further (Mukherjee et al. 1955: 47, 48-72), especially given the variability in the field measurements mentioned above. Their own laboratory measurements, together with the measurements from the second season, on the remaining skeletal elements show the sample to be homogenous in its internal consistency (Mukherjee et al. 1955: 56). 
In addition, the nature of the variability of their Jebel Moya sample was compared with that of two external samples believed to be homogenous: Predynastic Nagada and the Giza "E" series (Saite - Late Period Egyptian). The former was chosen for the rare availability of long-bone measurements from a neighbouring area, while the latter was the largest available on cranial and mandibular measurements (Mukherjee et al. 1955: 58). Overall, the Jebel Moya skeletal elements do not differ statistically significantly from the standard series which they were compared against and the population was regarded as homogenous (Mukherjee et al. 1955: 63-4). They also determined that the weighted mean stature for males was $175.57 \mathrm{~cm}$ and $163.17 \mathrm{~cm}$ for females (Mukherjee et al. 1955: 70, Table 74.20).

In order to consider potential affiliations between the Jebel Moya inhabitants and peoples both from neighbouring regions and elsewhere in Africa, Mukherjee et al. (1955: 73) based their primary analysis upon cranial characteristics. The best comparative sets were the cranial series. A second analysis was conducted on a series of mandibles, but these were done to confirm and/or expand upon the results from the former analysis. Large enough comparative sets of limb bones were unavailable. The analysis was based upon the Group Divergence model developed by P. C. Mahalanobis and associates. These two analyses were the first time where the Mahalanobis $\mathrm{D}^{2}$ technique was applied to craniological data from males only using seven measurements (e.g. maximum length, breadth, height, etc); the Mahalanobis $\mathrm{D}^{2}$ approach would not become common until the 1970s (Irish and Konigsberg 2007: 139).

The comparative series comprised the following 19 samples (Figure 5.1):

- Nearly 1800 crania from the Egyptian $26^{\text {th }}-30^{\text {th }}$ dynasties

- Predynastic Naqada (4000 - 3200 BC)

- Badarian from Badari (4400 - $4000 \mathrm{BC})$

- The Egyptian $9^{\text {th }}$ Dynasty cemetery of Sedment at Gebel Sedment, near Cairo

- Crania from the Egyptian sites of Elephantine and Philae; their date is unknown beyond being characterised as "dynastic"

- Qau, Upper Egypt $\left(4^{\text {th }}-11^{\text {th }}, 12^{\text {th }}, 17^{\text {th }}-18^{\text {th }}\right.$ dynasties $)$

- Egyptian $12^{\text {th }}$ and $13^{\text {th }}$ Dynastic era remains from Kerma, Nubia

- Nubian A (Pre- $4^{\text {th }}$ Dynasty), B ( $4^{\text {th }}-7^{\text {th }}$ dynasties $), C$ ( $7^{\text {th }}-16^{\text {th }}$ Dynasty), D 
- $\quad\left(18^{\text {th }}\right.$ Dynasty to the end of the Dynastic period), Meroitic $\left(1^{\text {st }}\right.$ and $2^{\text {nd }}$ centuries $\mathrm{AD}), \mathrm{X}\left(3^{\text {rd }}-6^{\text {th }}\right.$ centuries $\left.\mathrm{AD}\right)$ and Christian $\left(7^{\text {th }}-13^{\text {th }}\right.$ centuries $\left.\mathrm{AD}\right)$ groups

- Taita, Kenya

- Cameroon

- Formerly Tigre Province, Ethiopia

- Ashanti, Ghana

- Tetela, Congo, Gabon

- Ibo, south-eastern Nigeria

- Fernand Vaz crania, Gabon

Egyptian ' $E$ ' $\odot$

OSedment

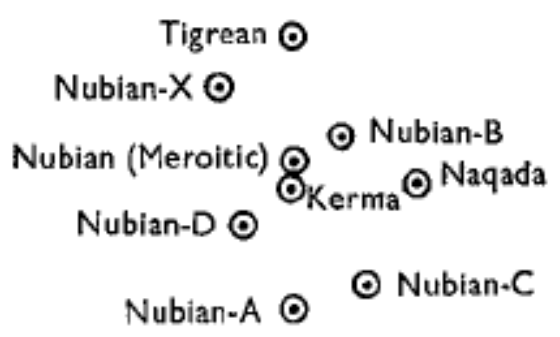

○ Jebel Moya

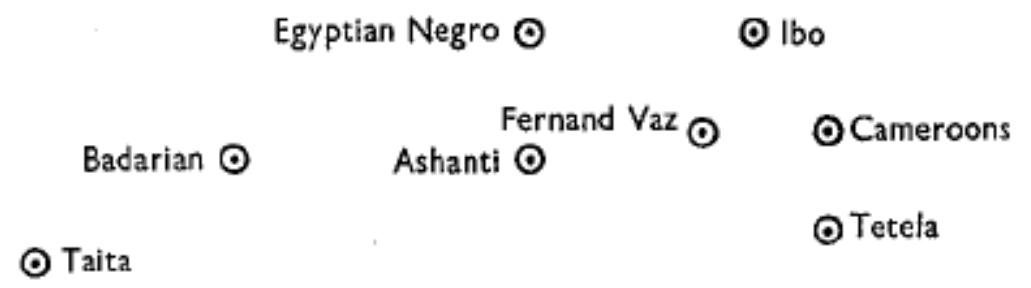

Figure 5.1 Mahalanobis $\mathrm{D}^{2}$ technique applied to Jebel Moya and comparative African samples to determine population affinity. From Mukherjee et al. (1955: 85).

The Jebel Moya series is nearer to the Ibo although still at an appreciable distance, followed closely by the Cameroons, than to the Egyptians and all but one of the Nubians. On the other hand, the Nubian and Kerma series are very similar: they are located in a cluster together with the Naqadan and the Tigrean. There is a clear separation of Jebel Moya from the Kerma and Egyptian series. Similar results were obtained (a) if the 
number and type of cranial characteristics used for study were changed, and (b) from examination of the mandibles (Mukherjee et al. 1955: 86-8).

\subsection{Rachel Hutton MacDonald: Jebel Moya as a pastoral population}

As Mukherjee et al. (1955) dealt with craniometric and long bone data from the then surviving 98 crania to focus on population affiliation, they did not compile data on population demography, economic affiliation, health and diet. Rachel Hutton MacDonald (1999) investigated whether or not dental anthropology could assist in the reconstruction of ancient diet in her unpublished $\mathrm{Ph} . \mathrm{D}$ dissertation, at a time when such studies were in their infancy (Hillson 2014). She compared dental samples from different ethnographic and archaeological populations of known economic type (agriculturalist, hunter-gatherer and pastoralist) (Table 5.3). Her analysis encompassed occlusal dental macrowear, buccal microwear, dental caries and wear facets while accounting for feature density due to age and wear. The dental caries study was comprised of three components: (1) Tooth class (Hillson 1996), (2) proportion of carious lesions for the total number of teeth examined for each population, and (3) the number of carious lesions expressed at an individual level. The carious lesions were scored using a modified version of Hillson's (1979) scoring method, while their location was recorded graphically (following Whittaker and MacDonald's 1989 system) which permitted the recording of the degree of carious destruction and the relationship between neighbouring caries.

Dental caries are caused by the action of acids on the enamel surface, leading to a loss of calcium and phosphate from the enamel (demineralisation). Demineralisation can be localised and progresses slowly. Active periods of demineralisation can be interspaced with remineralisation phases. The active phase occurs when the $\mathrm{pH}$ of the oral environment drops to 5.5 or below (Hillson 1986). An important contributor is dietary carbohydrates which encourage plaque development and tend to reduce $\mathrm{pH}$ levels (Hillson 1986; Navia 1994). 


\begin{tabular}{|c|c|c|c|c|}
\hline \multirow[t]{3}{*}{ Ethnographic } & Hunter-Gatherer & $\begin{array}{l}\text { Efe } \\
\text { Du Chaillu } \\
\text { collection }\end{array}$ & $\begin{array}{c}4 \\
50\end{array}$ & $\begin{array}{l}20^{\text {th }} \text { century } \\
19^{\text {th }} \text { century }\end{array}$ \\
\hline & Pastoral & Somali & 37 & $20^{\text {th }}$ century \\
\hline & Agricultural & $\begin{array}{l}\text { Haya } \\
\text { Teita } \\
\text { Igbo }\end{array}$ & $\begin{array}{l}50 \\
50 \\
50\end{array}$ & $\begin{array}{l}19^{\text {th }} \text { century } \\
19^{\text {th }} \text { century } \\
19^{\text {th }} / 20^{\text {th }} \text { century }\end{array}$ \\
\hline \multirow[t]{3}{*}{ Archaeological } & Hunter-gatherer & $\begin{array}{l}\text { Gwisho } \\
\text { Chencherere } \\
\text { Shun Laka }\end{array}$ & $\begin{array}{c}22 \\
1 \\
17\end{array}$ & $\begin{array}{l}2^{\text {nd }}-3^{\text {rd }} \text { mill BC } \\
1250-2410 \mathrm{bp} \\
8000-6000 \mathrm{bp}, \\
4000-2000 \mathrm{bp}\end{array}$ \\
\hline & Pastoral & $\begin{array}{l}\text { Jebel Moya } \\
\text { Adrar Bous }\end{array}$ & $\begin{array}{c}150 \\
4\end{array}$ & $\begin{array}{l}c a .100 \mathrm{BC}-\mathrm{AD} \\
600 \\
4^{\text {th }} \text { millennium } \\
\mathrm{BC}\end{array}$ \\
\hline & Agricultural & Tellem & 45 & \\
\hline
\end{tabular}

Table 5.3 The dental samples and their numbers. Adapted from Rachel Hutton MacDonald (1999: Table 3.1) using the new chronology for Jebel Moya.

In the samples analysed by Hutton MacDonald (1999), most of the caries were in between teeth rather than atop them which decreases the chances of bias through wear destruction. More specifically, the mandibular and maxilla teeth in the Jebel Moya sample (Duckworth Laboratory) did not exhibit the high levels of dental disease which are commonly known from peoples who cultivate. Out of the 2411 teeth, only $5(0.2 \%)$ had caries. This would normally indicate a non-cultivating, non-high carbohydrate consuming population: for example, the agriculturalist Igbo (West Africa) studied by Hutton MacDonald (1999: 161, Table 8.1.2) had a caries incidence of 19.7\%, while Meroitic Nubia has previous been estimated to have an incidence of $15.1 \%$ (Greene 1972). By contrast, Hutton MacDonald calculated an incidence of $0.9 \%$ for the pastoralists of Adrar Bous (Central Sahara), while incidences of $4.3 \%$ and $1.3 \%$ have been recorded for Riet River and Kakamas in South Africa (Morris 1992). The reading for the Jebel Moya populations could, however, just possibly also be due to favourable genetics, water chemistry and/or cultural factors governing oral hygiene such as chewing sticks.

The dental macrowear was examined in a number of ways. Comparison of the wear patterns between the first and second molars for individuals aged over 17 was looked at. The difference between these molars represents approximately 6 years of functional wear, to remove different effects of age and/or dietary variations. Data was collected on the wear stage (amount of visible dentine), wear angle and wear direction. Some 
differences were observed by Hutton MacDonald (1999). Hunter-gatherers exhibited different patterns of anterior tooth wear (incisors and canines) relative to posterior tooth wear (premolars and molars): They tended to use all of their dentition more frequently. The pastoralists and agriculturalists preferentially wore down their posterior dentitions. The hunter-gatherer teeth exhibited rounded horizontal wear forms, while the agriculturalists and pastoralists exhibited oblique wear angles and cupped wear forms. The pastoralists in Hutton MacDonald's (1999) study retained natural wear angles and forms longer relative to functional age indicated by first molar wear. The Jebel Moya samples followed the latter wear patterns.

High levels of enamel chipping were observed on the Jebel Moya dentition, which were cased in a fine layer of cemented sand. The molars and premolars were particularly damaged, being chipped and/or broken. Damage could be observed on several teeth per individual and was particularly common on the lingual dental cusps of both sexes. Hutton MacDonald (1999: 118) proposed that this

"may be suggestive of a dietary cause. The use of teeth as tools would tend to favour the damage of enamel on the buccal and labial surfaces of the teeth. Additionally, the occurrence of enamel chipping affected men and women equally, so it is unlikely that it was due to specific craft or cultural practices like the wearing of labrets [lipstuds]."

There was also dental mutilation through the deliberate removal of some teeth, though not always "as $12 \%$ of individuals who exhibited labret wear facets had not lost any of their anterior teeth" (Hutton MacDonald 1999: 147). The lipstuds were most commonly worn through the bottom lip, although there was one instance of labret facet wear on both the mandibular and maxillary incisors of an unspecified individual.

Lipstuds were not always buried with the individual who wore them: $29 \%$ of the known wearers (from dental facet evidence) had no lipstuds recorded in their burial assemblages. They must have been removed prior to burial. There is also the presence of lipstuds in the graves of two males and two adolescents whose dentition shows no evidence of wear. Poor recording in the field could have been a cause or they were not regarded as items of value in death or may have been possible keepsakes. 
The presence of abscesses in pastoralist populations has been attributed to dental attrition (mastication) or (at Jebel Moya) the use of lipstuds (Hutton MacDonald 1999: 168-9). In the samples examined by Hutton MacDonald (1999: 148, 174), modern or historic pastoralists had the least occurrence of ante mortem tooth loss with $32.6 \%$ of individuals, reflective of dental hygiene through use of dental sticks, compared to the highest percentage of $56.8 \%$ from hunter-gatherers. Finally, it is the posterior teeth which are more commonly lost in hunter-gatherer and agricultural societies than the anterior teeth in their pastoral counterparts. The ritual removal of anterior teeth at Jebel Moya accounts for many of these instances.

In support of designating the population of Jebel Moya as having a pastoral economic base $^{1}$, the archaeological dataset comprises no artefacts which may be indicative of cultivating activities, such as sickles or hoes, and only one grindstone was found in the burial assemblages. In addition to several small clay cattle figurines found in non-burial contexts, it is also worth noting that there are, in total, 55 occurrences of cattle remains among the burial assemblages, either as parts of the animal (e.g. foot) in association with a human burial or as a separate cattle inhumation. However, the population affiliation of Hutton MacDonald's pastoralists was not re-examined as she relied upon the work of Mukherjee et al. (1955).

\subsection{Irish and Konigsberg: Population affinity using dental traits}

Irish and Konigsberg (2007) revisited the Jebel Moya skeletal remains curated at the Duckworth Laboratory while undertaking other unrelated research. They modelled their study after Mukherjee et al. (1955). They compared the Jebel Moya series with the same or similar comparative samples in order to re-evaluate the results and to further facilitate the biological affinity of the Jebel Moya inhabitants to other African populations.

Many of the original sample series were either unavailable, too dispersed, no longer recognised as a valid entity or did not possess sufficient recorded information on their

\footnotetext{
${ }^{1}$ The degree of difference in mobility between the sexes is currently being investigated by Stacy Hackner of the Institute of Archaeology, University College London, as part of her doctoral dissertation.
} 
dentition. For example, the Nubian B Group is no longer recognised as a valid distinct cultural period and so Irish and Konigsberg (2007) opted against attempting to substitute an equivalent sample. Out of the 98 Jebel Moya crania, 58 were examined as they were the best preserved with complete lower and upper dentition. Overall, 1084 sets of dentition were examined across the 18 other comparative samples (Table 5.4). A total of 36 non-metric traits with a high genetic component, particularly useful for biodistance studies used in previous population affinities within Africa, were detected in the 20 comparative samples (Irish and Konigsberg 2007: 142). The most influential traits were then identified and a modified version of the original Mahalanbois $\mathrm{D}^{2}$ technique, developed by Konigsberg (1990), was employed for non-metric traits to establish phenotypic affinities. Apart from its usefulness in most closely emulating the practices of Mukherjee et al. (1955), its advantage over comparative methods is that it adjusts for phenotype correlations between traits. This avoids the placement of weight on groups of characteristics which may be present on the same sample.

On the presumption that the comparative samples are representative of the respective populations and phenotype correlation approximates genetic relatedness, the Jebel Moya inhabitants may have been an admixed population comprising genetic components from different areas, or they may have been a heterogeneous population of people from different regions (Konigsberg 1990: 152). Addison (1949) believed that the Jebel Moya inhabitants were heterogeneous, combining biologically diverse elements at the level of family or lineage units. The latter was a conclusion echoed by J.Desmond Clark (1984) and Gerharz (1994), while Caneva (1991) postulated an Eastern Saharan origin for the first inhabitants (Mesolithic Assemblage 1) and Graham Connah (1981) speculated that the figurines and bone tools from Daima (Nigeria, first millennium BC - second millennium AD) have similarities to their Jebel Moya counterparts. The latter is more likely to have been a consequence of similar materiality in Trans-Sahelian pastoralist repertoires (MacDonald 1998). 


\begin{tabular}{|c|c|c|c|c|c|c|}
\hline $\begin{array}{l}\text { Mukherjee et } \\
\text { al. (1955) } \\
\text { sample series }\end{array}$ & & & $\begin{array}{l}\text { Irish and Konigsberg } \\
\text { (2007) sample } \\
\text { series }\end{array}$ & & & \\
\hline Sample & Origin & Period & Sample & Origin & Affiliation & Period \\
\hline Jebel Moya & Sudan & Prehistoric & Jebel Moya & Sudan & Jebel Moya & $\begin{array}{l}100 B C-A D \\
600\end{array}$ \\
\hline Egyptian "E" & Egypt & $\begin{array}{l}\text { 26th - 30th } \\
\text { dynasties }\end{array}$ & Egyptian "E" & Giza & $\begin{array}{l}\text { 26th-30th } \\
\text { dynasties }\end{array}$ & $664-332 B C$ \\
\hline Naqada & Egypt & Predynastic & Naqada & Nagada & Predynastic & $4000-3200 B C$ \\
\hline Badarian & Egypt & Predynastic & Badarian & Badari & Predynastic & $4400-4000 \mathrm{BC}$ \\
\hline Sedment & Egypt & 9th Dynasty & Saqqara & Saqqara & 4th Dynasty & $2613-2494 B C$ \\
\hline "Negroes" & Egypt & Dynastic & El Hesa & El Hesa & Roman Period & AD $200-400$ \\
\hline Kerma & Nubia & $\begin{array}{l}\text { 12th - 13th } \\
\text { Egyptian } \\
\text { dynasties }\end{array}$ & Kerma & Kerma & $\begin{array}{l}\text { Classique } \\
\text { Nubian }\end{array}$ & $1750-1500 \mathrm{BC}$ \\
\hline A-Group & Nubia & Pre-4th Dynasty & A-Group & Faras - Gamai & A-Group Nubian & $3000 \mathrm{BC}$ \\
\hline B-Group & Nubia & $\begin{array}{l}\text { 4th - 6th Egyptian } \\
\text { dynasties }\end{array}$ & N/A & & & \\
\hline C-Group & Nubia & $\begin{array}{l}\text { 7th }-16 \text { th } \\
\text { Egyptian } \\
\text { dynasties }\end{array}$ & C-Group & Faras - Gamai & C-Group Nubian & $2000-1600 \mathrm{BC}$ \\
\hline D-Group & Nubia & $\begin{array}{l}\text { 18th Egyptian } \\
\text { Dynasty }\end{array}$ & D-Group & Faras - Gamai & Pharonic Nubian & $1650-1350 \mathrm{BC}$ \\
\hline Meroitic & Nubia & $\begin{array}{l}\text { 1st }-2 \text { nd } \\
\text { centuries } A D\end{array}$ & Meroitic & Semna; Faras/Gamai & Meroitic Nubian & $\begin{array}{l}100 B C-A D \\
350\end{array}$ \\
\hline X-Group & Nubia & $\begin{array}{l}\text { 3rd - 6th } \\
\text { centuries AD }\end{array}$ & X-Group & Semna; Faras/Gamai & X-Group Nubian & $A D 350-550$ \\
\hline Taita & Kenya & 20th century AD & Kenya & Kenya, Tanzania & $\begin{array}{l}\text { Kikuyu, Swahili, } \\
\text { Chaga, Pare }\end{array}$ & $\begin{array}{l}\text { 19th - 20th } \\
\text { century AD }\end{array}$ \\
\hline Cameroons & Cameroon & 19th century $A D$ & Nigeria-Cameroon & Nigeria, Cameroon & $\begin{array}{l}\text { Efik, Ibibio, Boki, } \\
\text { Anyang }\end{array}$ & $\begin{array}{l}\text { 19th century } \\
\text { AD }\end{array}$ \\
\hline Tigrean & Ethiopia & 19th century AD & Ethiopia & Ethiopia, Eritrea & $\begin{array}{l}\text { Tigre, Amhara, } \\
\text { Danakil, etc }\end{array}$ & $\begin{array}{l}\text { 19th - 20th } \\
\text { century AD }\end{array}$ \\
\hline Ashanti & Ghana & 19th century $A D$ & Ghana & Ghana & Ashanti, Fanti & $\begin{array}{l}\text { 19th century } \\
A D\end{array}$ \\
\hline Tetela & Congo, Gabon & 19th century AD & Congo & Congo, Gabon & $\begin{array}{l}\text { Teke, Kongo, } \\
\text { Binga, etc }\end{array}$ & $\begin{array}{l}\text { 19th - 20th } \\
\text { century AD }\end{array}$ \\
\hline Fernand Vaz & Gabon & 19th century $A D$ & Gabon & Gabon & $\begin{array}{l}\text { Fang, Nkomi, } \\
\text { Lumbo, etc }\end{array}$ & $\begin{array}{l}19 \text { th }-20 \\
\text { century AD }\end{array}$ \\
\hline Ibo & Nigeria & 20th century AD & Togo-Dahomey & Togo, Benin & Ewe, Fon & $\begin{array}{l}\text { 19th century } \\
A D\end{array}$ \\
\hline
\end{tabular}

Table 5.4 The comparative series of skeletal remains used by Mukherjee et al. (1955) (20) and Irish \& Konigsberg (2007) (20). The old designation of Nubian B-Group is no longer valid. From Irish \& Konigsberg (2007: Table 1). 
The individual revised Mahalanbois $\mathrm{D}^{2}$ values suggest that the closest dental affinity for the Jebel Moya inhabitants is to sub-Saharans: they are most similar to the Kenyan, Ethiopian and A-Group samples and least like the C-Group and Meroitic Nubians (Figure 5.2). Jebel Moya occupies an intermediate but distinct position. Mukherjee et al.'s original Mahalanbois $\mathrm{D}^{2}$ analysis (above) also placed Jebel Moya in an intermediary position between Sub-Saharan and North African samples, though closer to the West African samples. There is differential heritability between dental and cranial trait expressions, in effect a cline in selective forces favouring sub-Saharan features with decreasing latitude. However, Jebel Moya does not exhibit higher levels of inter-sample variability than most of the comparative samples which comprise homogeneous populations. Irish and Konigsberg (2007: 152) placed 31 of the 58 dental samples in Gerharz's Phases II, which have now been temporally re-allocated through the luminescence dating of pottery to the time of Assemblage 3 ( $c a$. first century BC - midfirst millennium $\mathrm{AD}$, see section 3.4).

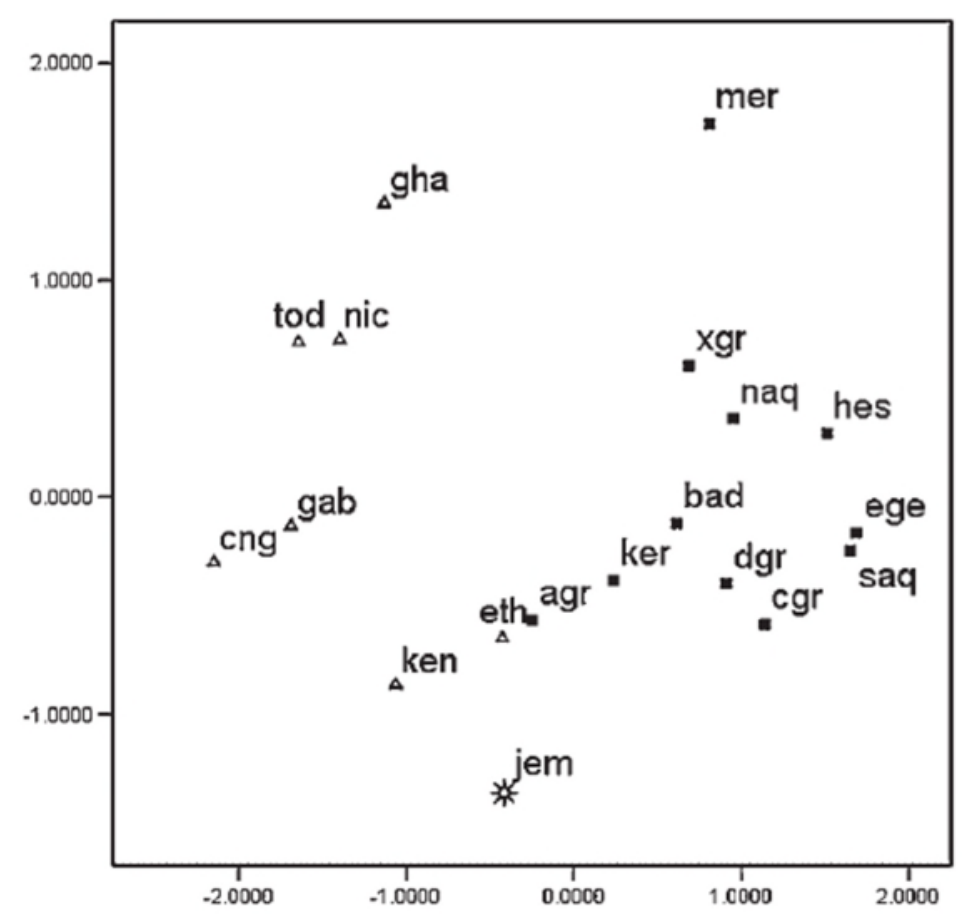

Figure 5.2 14 trait Mahalabois D2 distance on dental records using Multi-Dimensional Scaling. The triangles are sub-Saharans, with the black squares representing Saharan populations. From Irish and Konigsberg (2007: Figure 3).

There is therefore a biological continuity which is more easily explained not by the dental samples being up to 3000 years apart (what Irish and Konigsberg (2007: 152) 
term "an oxymoron, uniform heterogeneity through time") but rather from being from the same phase. For Jebel Moya, the end result was the retrieval of cranio-dental features from both sets of samples and recognition of a distinctive bio-cultural composition as a homogenous grouping within a greater North-East African sphere.

\subsection{The Duckworth Laboratory collection revisited}

The extant Jebel Moya human osteological (cranial and post-cranial) remains at the Duckworth Laboratory were re-sexed and catalogued by Mercedes Okumura over the course of the summer in 2008. The precise methods used for re-sexing are unknown. I was kindly provided with a copy of the Access database. The information covered by the osteological database is the site locality, new catalogue number, old Duckworth catalogue number, the burial number as distinguished from the inking on the bones (relating to the grave cards), the presence or absence of cranial, mandibular and dental remains, the composition and state of preservation of the remains, pathologies and the revised sex classification.

Some of the individuals are now represented by only one or two bones. Enough diagnostic skeletal material remained from 661 individuals to identify their ages at a minimum (Table 5.5). The remains are classified as infant if the individual is judged to be 5-years or younger, juvenile from $6-12$ years, young adult from $13-18$ years and adult from 19-years.

The results of the re-sexing strongly contradict the assertions by the original field anthropologists that female individuals predominated (Table 5.6). Possible males comprise $39.18 \%$ of the 661 individuals who were re-sexed, while females comprised $31.32 \%$. There therefore was no intentional or ideological or other reason eschewing the burial sex ratio in favour of females and this holds true for all excavated sectors of the valley.

In light of this, the accuracy of the assignment by the field physical anthropologists of sex to adult specimens needed to be revisited and compared against those adult individuals re-sexed by Okumura (Table 5.7). The results indicate that Derry's 
assignments from the second field season were largely accurate - although Derry made errors in his sex determinations, they largely cancelled each other out in numerical terms. By contrast though, too many individuals from the third and fourth seasons were incorrectly classified as female by Wellcome's field anatomists. Overall, the picture which emerges from the data from Okumura's re-sexing is that if there were any selective practices in who could be buried at Jebel Moya, it did not extend to favouring either biological sex.

\begin{tabular}{|c|c|c|c|c|}
\hline Field season & Age & Sex & Likely/Other & Total \\
\hline $1911-12$ & $\begin{array}{l}\text { Adult: } 55(90.16 \%) \\
\text { Infant: } 2(3.28 \%) \\
\text { Juvenile: } 2(3.28 \%) \\
\text { Young adult: } 2 \\
(3.28 \%)\end{array}$ & $\begin{array}{l}\text { Female: } 20 \\
(36.36 \%) \\
\text { Male: } 20(36.36 \%)\end{array}$ & $\begin{array}{l}\text { Female?: } 4(7.27 \%) \\
\text { Male?: } 3(5.45 \%) \\
\text { Unknown: } 8(12.72 \%)\end{array}$ & 61 \\
\hline $1912-13$ & $\begin{array}{l}\text { Adult: } 93(93.94 \%) \\
\text { Infant: } 1(1.01 \%) \\
\text { Juvenile: } 4(4.04 \%) \\
\text { Young adult: } 1 \\
(1.01 \%)\end{array}$ & $\begin{array}{l}\text { Female: } 16 \\
(17.20 \%) \\
\text { Male: } 35(37.63 \%)\end{array}$ & $\begin{array}{l}\text { Female?: } 2(2.15 \%) \\
\text { Male?: } 10(10.75 \%) \\
\text { Unknown: } 30 \\
(32.26 \%)\end{array}$ & 99 \\
\hline $1913-14$ & $\begin{array}{l}\text { Adult: } 456(19.02 \%) \\
\text { Infant: } 7(1.40 \%) \\
\text { Juvenile: } 16(3.19 \%) \\
\text { Young adult: } 22 \\
(4.39 \%)\end{array}$ & $\begin{array}{l}\text { Female: } 114(25 \%) \\
\text { Male: } 1(0.22 \%)\end{array}$ & $\begin{array}{l}\text { Female?: } 51(11.18 \%) \\
\text { Male?: } 190(41.67) \\
\text { Unknown: } 100 \\
(21.93 \%)\end{array}$ & 501 \\
\hline Totals & $\begin{array}{l}\text { Adult: } 604(91.38 \%) \\
\text { Infant: } 10(1.51 \%) \\
\text { Juvenile: } 22(3.33 \%) \\
\text { Young adult: } 25 \\
(3.78 \%)\end{array}$ & $\begin{array}{l}\text { Female: } 150 \\
(24.83 \%) \\
\text { Male: } 56(9.27 \%)\end{array}$ & $\begin{array}{l}\text { Female?: } 57(9.44 \%) \\
\text { Male?: } 203(33.61 \%) \\
\text { Unknown: } 138 \\
(22.85 \%)\end{array}$ & 661 \\
\hline
\end{tabular}

Table 5.5 Aged and re-sexed individuals per season derived from the Duckworth Laboratory's database. Only adults were sexed. $\%$ in brackets: age as a \% of the overall total, with adult sex \& unknown as a $\%$ of adult.

\begin{tabular}{|l|l|l|}
\hline \multicolumn{1}{|c|}{ Sex } & Numbers & \multicolumn{1}{c|}{ Percentage } \\
\hline Adult. Male & 463 & $18.32 \%$ \\
\hline Adult. Male? & 93 & $3.68 \%$ \\
\hline Adult. Female & 935 & $37 \%$ \\
\hline Adult. Female? & 96 & $3.80 \%$ \\
\hline Infant & 93 & $3.68 \%$ \\
\hline Juvenile & 199 & $7.87 \%$ \\
\hline Young adult & 114 & $4.51 \%$ \\
\hline Total & $\mathbf{2 5 2 7}$ & \\
\hline
\end{tabular}

Table 5.6 Breakdown by age and sex of all recorded individuals across the last three field seasons in the new Register of Graves. 


\begin{tabular}{|l|l|l|ll|}
\hline & \multicolumn{1}{|c|}{$\mathbf{1 9 1 1 - 1 2}$} & \multicolumn{1}{c|}{$\mathbf{1 9 1 2 - 1 3}$} & \multicolumn{2}{c|}{$\mathbf{1 9 1 3 - 1 4}$} \\
\hline Female - correct & 12 & 14 & 93 & \\
\hline Female - incorrect & 1 & 19 & 78 & \\
\hline Male - correct & 12 & 22 & 73 & \\
\hline Male - incorrect & 4 & 3 & 12 & \\
\hline Accuracy & Female 92.31\% & Female 42.42\% & Female $54.39 \%$ \\
& Male 75\% & Male $88 \%$ & Male $85.88 \%$ \\
\hline
\end{tabular}

Table 5.7 Accuracy of the original field physical anthropological measurements of adult specimens compared against the adult individuals re-sexed by Mercedes Okumura, using the latter as the comparative baseline.

\subsection{Discussion: The bioanthropological make-up of Jebel Moya}

Contrary to the assertions by the field anatomists in the third and fourth field seasons, both females and males are represented in fairly equal numbers. Overall, the buried individuals were from a homogenous but biologically distinct population in the southern Gezira which practised a pastoral way of life. Previously, Addison $(1949,1955)$ and Gerharz (1994) had suggested that the individuals were agro-pastoralists but Hutton MacDonald's (1999) conclusions mean that there were people pursuing different economic paths in the southern Gezira: agro-pastoralism at Jebel et Tomat (near the White Nile) and Abu Geili (Blue Nile)

Comparable skeletal samples are required from excavations in the broader Gezira Plain and up and down the Blue and White Niles, and in the neighbouring Western Butana, in order to investigate the degree to which non-pastoral peoples were affiliated to the Jebel Moya inhabitants. Both Mukherjee et al. (1955) and Irish and Konigsberg (2007) distance the Jebel Moya inhabitants from their Egyptian, Kerma and Nubian counterparts, which suggests that the Meroitic state did not engage in any detectable population resettlement or displacement practices when they expanded their southern frontier into the Gezira and established trading stations. What is certain is that the inhabitants of Jebel Moya did not come from populations with different biological affinities, which lends them to be treated as a single entity for the purposes of spatially and statistically analysing their accompanying burials assemblages to determine whether any significant patterns are present. 


\section{Chapter 6: Social patterning in the Jebel Moya mortuary complex}

Mortuary ritual has much to do with the creation of memory. Its performance creates social (collective) memories about the dead. In some instances, mourners and the living create memories that reflect who a person was in life, encompassing their wealth, social responsibilities and/or status. In other instances, the focus is on passing the deceased into the afterlife and creating new memories about the new spirit into which the person is transformed. The articulation of these memories and their intersections, are given expression through culturally specific mortuary rituals and patterning in the extant material record. The placement and identification of grave goods is a microcosm of this issue as items placed in association with bodies can have several purposes. They may reflect social roles and responsibilities, and personal possessions which are decommissioned with the dead to remove them from the living. However, they can also reflect family, lineage or communal interaction with the dead, including feeding the dead and small remembrances for the dead and invocations (Spencer 1982; van Beek 2012). Therefore, the identities of the dead and the living's interactions with them are shaped by the beliefs of the living towards the dead (Bollig 1997; Sterner 1995).

In this chapter, investigating how gender and horizontal and hierarchical social identities were represented in the mortuary realm involves analysing (a) the comparative burial wealth in different sectors of the cemetery, (b) the types of artefact categories accompanying male and female burials and their respective bodily orientations, and (c) cluster analyses, 'relative risk surfaces' and (cross) 'pair correlation functions' to look for potential spatial neighbourhoods.

\subsection{Introducing Inverse Distance Value}

Of the 3135 human burials, 1108 (35.3\%) have associated grave goods, leaving 2026 burials $(64.7 \%)$ without goods or with artefacts listed as coming only from the grave infill. Contrary to the view expressed by Gerharz (1994), my re-analysis reveals that the distribution of grave goods is not concentrated in the east and north-east of the valley. 
The density of burials-with-goods to burials-without-goods was calculated across the excavated areas using relative risk via the Spatstat package in the $\mathrm{R}$ statistical environment. Relative risk (RR) is a ratio-based case-control technique which has been demonstrated to work well with large-scale inventories (Bevan 2012). $\mathrm{R}$ is an integrated suite of software for data manipulation, calculation and graphical display which permits a wide variety of statistical and graphical analyses to be undertaken such as clustering, classic statistical tests, distance scaling, linear and non-linear modelling, and matrix calculations. Relative risk surfaces greatly simplify determining and eliminating potential biases in samples; widely used in the medical and geographical sciences, it is starting to find its way into archaeology to determine observed patterns through the adoption of a

“...form of ratio-based (or more formally, case control) mapping known as a "relative risk" surface... Such relative risk surfaces are increasingly in disciplines such as epidemiology where proper assessment of the factors effecting raw numbers of cases (e.g. of flu virus) can be confounded by variations in the underlying population (i.e. those potentially at risk) and/or variable recording. Put simply, relative risk surfaces involve calculating the ratio of the kernel density estimation of the observed cases of a particular type to that of the at-risk population...[For archaeology] the use of relative risk surfaces or similar techniques [can] identify interesting spatial patterns even when the data is patchy, and especially when breaking down patterns by subclasses of material." (Bevan 2012: 500, 504)

What is being measured through the application of RR is the ratio of cases to controls; the kernel density is used to map this smoothly across the study region. In Figure 6.1, for example, the relative risk's cases are the burials-with-goods and the controls are the burials-without-goods. In the South-West, the red zones on the plot, the ratio of burialswith-goods to burials-without-goods is much higher $(>0.5)$ than in the North-East sector. Therefore, while the North-East sector is richer in certain kinds of finds made from non-local raw materials (Table 6.1), fewer burials have grave goods here, i.e. the wealth distribution seems to be more skewed which may represent different rules of social engagement in mortuary practices whereby poorer burials are deliberately placed within the general vicinity of known richer burials. 


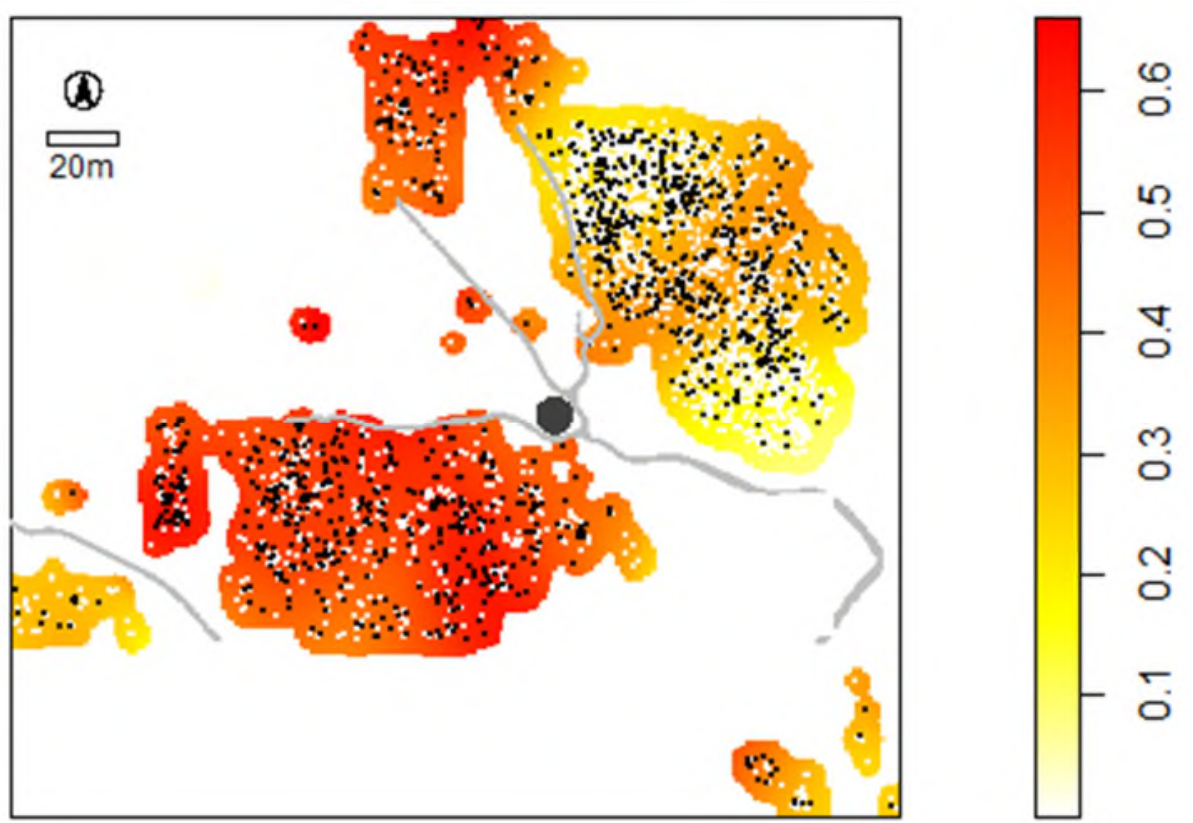

Figure 6.1 Jebel Moya: the relative density of burials with grave goods (red) to burials without grave goods (yellow) is greater in the south-west and north-west $(>0.5)$ than in the east and north-east.

\begin{tabular}{|l|c|c|c|}
\hline \multicolumn{1}{|c|}{ Raw material } & Number & Total & Percentage \\
\hline "Alabaster" & 1 & 4 & $25 \%$ \\
\hline Bronze & 1 & 2 & $50 \%$ \\
\hline Carnelian & 4 & 14 & $28.6 \%$ \\
\hline Copper & 5 & 34 & $14.71 \%$ \\
\hline Cowrie & 0 & 0 & $0 \%$ \\
\hline Crystal & 1 & 2 & $50 \%$ \\
\hline Faience & 7 & 38 & $18.42 \%$ \\
\hline Glass & 1 & 1 & $100 \%$ \\
\hline Gold & 2 & 4 & $50 \%$ \\
\hline Iron & 0 & 14 & $0 \%$ \\
\hline Jasper & 0 & 0 & $0 \%$ \\
\hline Lapis & 1 & 2 & $50 \%$ \\
\hline Limonite & 1 & 2 & $50 \%$ \\
\hline Marble & 1 & 14 & $7.14 \%$ \\
\hline Silver & 0 & 0 & $0 \%$ \\
\hline Table 6.1 The & 0 & 0 & \\
\hline
\end{tabular}

Table 6.1 The number of occurrences of each imported raw material category in the rich North-East sector burials and their percentage of the total North-East occurrences.

In addition, the North-East sector contains all six of the $1108(0.54 \%)$ burials-withgoods which have finished non-local products. Of these Egyptian or Meroitic items, amulets appear in recorded association with three burials, and both scarabs and statuettes occur in two burials each. Of these, one amulet and one statuette (of the Egyptian god Shu with an unknown date of manufacture) appear in the same burial 
(number 263), together with jasper, faience and carnelian beads, a bronze ear-ring, copper bowls and cylinders of rolled copper. The second occurrence of a statuette (burial 524) is also of Shu cast in bronze, accompanied by faience beads. The second occurrence of an amulet was a pale green udat (Eye of Horus Ra pendant) of unknown age from burial 535, accompanied by seven pale green disk beads with serrated edges. The remaining occurrence of amulets in a grave were two from burial 550 on each leg of the individual. Finally, the first of the two occurrences of scarabs from burials 1577 and 2225a was suspended around the neck of the individual while the second was made with a light green-glaze and accompanied by a necklace of mixed blue glass, carnelian and light green-blue faience beads. Unfortunately, neither the date of these finished foreign artefacts nor their exact points of origins can be determined.

As there are completed foreign objects in the burial assemblages and overall burial goods were manufactured from a wide variety of materials (Table 6.2), the approach taken here is that only potential sources of raw materials, rather than areas of manufacture, can be reasonably acted upon for analysis. This shifts the emphasis away from Grave Lot Value, which attempts to calculate the wealth of an individual based upon inherent assumptions regarding the perceived value of deposited artefacts (including the comparative total of artefacts per burial), an approach known as Grave Lot Values (LaMotta 2001).

Instead, I propose the utilisation of what I term Inverse Distance Value (IDV). IDV is defined here as the weight (value) assigned to a material which diminishes as the distance from the area/region of origin decreases. The effect of using IDV is to collapse these depositional pathways into a single measure and treated as an equivalent depositional unit. Underlying this is the inherent assumption that mortuary deposition, and hence the accompanying burial assemblage, is linked with and considered a function of the social identity of the individual. IDV thereby tackles the issue of variable linkages to social identity by breaking down the composition of the assemblages into its constituent raw materials. The wealth of each accompanying burial assemblage is the combined IDV value of all the artefact categories present. 


\begin{tabular}{|c|c|c|}
\hline Raw material & $\begin{array}{l}\text { Potential source } \\
\end{array}$ & Value \\
\hline Alabaster & $\begin{array}{l}\text { Egyptian Western Desert, and Mediterranean and Red } \\
\text { Sea coasts }\end{array}$ & 4 \\
\hline Beryl & Blue and White Niles & 2 \\
\hline Bone & Local & 1 \\
\hline Bronze & Alloy of copper and tin (below) & 4 \\
\hline Carnelian & $\begin{array}{l}\text { Small, water-worn pebbles found between the Nile } \\
\text { valley and the Red Sea, but larger pebbles occur in the } \\
\text { Eastern Desert and at quarries in the Western Desert }\end{array}$ & 4 \\
\hline Chalcedony & Eastern Desert & 4 \\
\hline Chert & Blue Nile & 2 \\
\hline $\begin{array}{l}\text { Clay for } \\
\text { ceramics }\end{array}$ & Local & 1 \\
\hline Copper & Nubian Desert, Eastern Desert and Sinai & 4 \\
\hline Cowrie & Red Sea & 4 \\
\hline Crystal & Eastern Desert & 4 \\
\hline Diorite & Nubian Desert, Red Sea Hills & 2 \\
\hline Faience & Nubian Desert & 4 \\
\hline Feldspar & $\begin{array}{l}\text { Sabaloka complex (near Khartoum), Nubian Desert, } \\
\text { Eastern Desert }\end{array}$ & 4 \\
\hline Flint & Blue and White Niles & 2 \\
\hline Glass & Glass known to be manufactured in the Meroitic state & 4 \\
\hline Gold & Eastern Desert, Nubian Desert & 4 \\
\hline Granite & Local & 1 \\
\hline Greenstone & $\begin{array}{l}\text { Inselbergs (Basement Complex outcrops) } c a .100 \mathrm{~km} \\
\text { north of Shabona in northern Gezira } \\
\text { Butana, Red Sea }\end{array}$ & 2 \\
\hline Iron & Shendi Reach, Western Butana, Eastern Desert & 4 \\
\hline Ivory & Local & 1 \\
\hline Jasper & Eastern Desert & 4 \\
\hline Lapis & Western Asia & 4 \\
\hline Limestone & Blue and White Niles & 2 \\
\hline Limonite & Western Butana & 4 \\
\hline Marble & $\begin{array}{l}\text { El Jebelien, near Kosti (southern Gezira) but no } \\
\text { evidence for ancient extraction activities } \\
\text { Wadi Atbarah (junction of the Nile and Atbara rivers) }\end{array}$ & 4 \\
\hline Natrolite & Blue Nile & 2 \\
\hline Ochre & Local & 1 \\
\hline $\begin{array}{l}\text { Ostrich } \\
\text { eggshell }\end{array}$ & Local & 1 \\
\hline Quartz & Blue and White Niles & 2 \\
\hline Shells & Blue and White Niles & 2 \\
\hline Silver & Northern Greece and southern Anatolia & 4 \\
\hline Stone & Local & 1 \\
\hline
\end{tabular}

Table 6.2 The range of raw materials from which burial artefacts were manufactured from and their potential points of origin. From Clark (1973a), Humphries and Rehren (2014), Nicholson and Shaw (1999), Shinnie and Anderson (2004), Whiteman (1971) and Williams and Adamson (1982). 
This approach has the advantage of examining the distribution of raw material sources against the manufacture of artefacts from in or around Jebel Moya, or from further afield, and how this reflects on population movement, procurement practices and possible reasons why particular items were deposited in the mortuary realm. Values of 1-4 were assigned based upon degree of accessibility to and distance from potential raw material sources, where 1 is local within a $20 \mathrm{~km}$ radius, 2 is the banks of the Blue and White Niles Niles and the Gezira, 3 is the Nuba Mountains, Kordofan and Darfur, and 4 is from further afield (Meroitic territory or through possible Meroitic trade networks into Egyptian territory).

\subsection{Differential patterns in biological age groups: Inverse Distance Value and} burial orientations

With the determination of the IDV for each sector of the cemetery, it needed to be established whether biological ages or variability between sexes are other non-status factors shaping their distribution (Table 6.3). This also had to take into account that ttems made from imported raw materials are almost entirely in the East and North-East sectors (Table 6.4), with the exception of marble lipstuds in three burial assemblages and one occurrence of faience beads in the South-West.

\begin{tabular}{|l|c|c|c|}
\hline \multicolumn{1}{|c|}{ Sector } & Total burials & Burials with goods & Inverse Distance Value \\
\hline South & 49 & 17 & $41(0.87 ; 0)$ \\
\hline South-West & 804 & 427 & $1758(2.16 ; 1)$ \\
\hline West & 17 & 4 & $6(0.35 ; 0)$ \\
\hline East & 852 & 217 & $1080(1.26 ; 0)$ \\
\hline North-West & 171 & 85 & $356(2.09 ; 0)$ \\
\hline North-East & 1185 & 336 & $2137(1.8 ; 0)$ \\
\hline Non-assigned & 57 & 22 & $86(1.48 ; 0)$ \\
\hline Total & $\mathbf{3 1 3 5}$ & $\mathbf{1 1 0 8}$ & \\
\hline
\end{tabular}

Table 6.3 Breakdown of the total number of human burials and human burials with accompanying goods in the different sectors of the site. The Inverse Distance Value is the total for each sector with the accompanying mean and median values per human burial in brackets. 


\begin{tabular}{|l|c|l|}
\hline \multicolumn{1}{|c|}{ Material } & Number & Present outside North-East or East sectors? \\
\hline "Alabaster" & 3 & No \\
\hline Bronze & 4 & No \\
\hline Carnelian & 14 & No \\
\hline Chalcedony & 4 & No \\
\hline Copper & 27 & No \\
\hline Cowrie & 2 & No \\
\hline Crystal & 1 & No \\
\hline Faience & 33 & Yes \\
\hline Feldspar & 1 & No \\
\hline Glass & 1 & No \\
\hline Gold & 3 & No \\
\hline Iron & 14 & No \\
\hline Jasper & 7 & No \\
\hline Lapis & 1 & No \\
\hline Limonite & 1 & No \\
\hline Marble & 34 & Yes \\
\hline Silver & 2 & No \\
\hline
\end{tabular}

Table 6.4 The number of total burials in which imported raw materials occurred across the site and their presence/absence outside of the North-East and East sectors.

\subsubsection{Infants, juveniles, young adults and adults}

Just what differential distribution, or the lack thereof, of artefact types between burials of different ages means has been much debated. According to the Binford-Saxe model (see section 2.3), children with inherited status would be expected to have determined, semi-fixed roles which should be reflected in the inheritance of items, particularly valued goods, subsequently deposited as part of the burial assemblage, and through forms of interment and spatial placement of the grave in the mortuary record. Children and young adults in more egalitarian societies were expected to have fewer burial goods and their burials were not thought to show any meaningful social patterns. This Binford-Saxe concept of "social persona" was later broken down by McGuire (1983: 101) into how embodiments of "sex, ethnicity, age, wealth, power and religion" were fused together in individuals. The implication was that greater social complexity would have been present amongst societies, or sectors of communities, where the number of distinct personae were greater.

By contrast, MacDonald's (2001) grief model proposes that child burials would have little to no accompanying burial items due to "children [not having yet] been 
incorporated into the society of the living [and so were unable to be] classified in that of the dead" (Van Gennep 1960: 152-3). MacDonald (2001) contrasts the fate of the children with that of sub- or young adults who he proposes should have a greater number of burial items as part of a more elaborate mortuary ritual due to (a) a sense of a loss of a life not yet fulfilled, (b) deposition of material possessions due to no biological offspring or other close living descendants, and/or (c) a power display by the extended family for the wider community through material representations.

At Jebel Moya, the presence of individual burials, rather than multiple interments in one grave, means that the possibility of distinctions between the social personae of infants, juveniles, young adults and adult can be investigated. Such an emphasis would be reflected in how the body was deposited and in re-occurring patterns of similar accompanying burial items. As noted by Hughes (1999: 19), examining how age is reflected in the burial domain of mortuary rites relates to how wealth relative to age is reflected in material goods, how the relationship with age is conceived in different societies and also how symbolic markers are recognised. The latter can comprise many variable forms including orientation of the body and/or grave, the form of the grave, the depositional location (separate locality or separation/clustering within one or more localities) and the accompanying burial artefacts. For more hierarchically-inclined societies, it would be expected that while adults have a greater proportion of wealth, there would be similar ranges of variation within adult and sub-adult categories due to involvement or trained-for involvement in similar roles.

In order to test these propositions, IDV was calculated for the different age categories of individuals examined by Okumura (Duckworth Laboratory) and as described by the original field anatomists (Tables 6.5 and 6.6), while the bodily orientations and burial type were also assessed (Table 6.7). 


\begin{tabular}{|c|c|c|c|}
\hline Age & Number & Burial assemblage & IDV range \\
\hline Infant & 10 & $\begin{array}{l}\text { 4 with goods ( } 40 \%) \\
\text { 1. Natrolite beads under head } \\
\text { 2. Bead collection by pelvis and } 1 \text { quartz lipstud } \\
\text { 3. Jar somewhat crudely made of red-ware; } \\
\text { discoloured; found broken but complete; shown } \\
\text { in (Addison 1949, Plate CX 7); Assemblage } 3 \\
\text { 4. OES beads at waist }\end{array}$ & $\begin{array}{l}0-3 \\
\text { Median: } 0 \\
\text { Mean: } 0.7\end{array}$ \\
\hline Juvenile & 22 & $\begin{array}{l}\text { 8 with goods (36.36\%) } \\
\text { 1. } 2 \text { lipstuds (pottery, broken quartz) at mouth. } \\
\text { OES and natrolite beads at neck } \\
\text { 2. Natrolite bead necklace at neck } \\
\text { 3. Natrolite lipstud at mouth. Natrolite bead at } \\
\text { neck. OES beads, shell pendant at waist. Large } \\
\text { pot in fragments over head } \\
\text { 4. Natrolite beads at neck } \\
\text { 5. } 2 \text { lipstuds (iory, broken pottery) at mouth } \\
\text { 6. OES bead necklace at neck and OES waist } \\
\text { band. } 2 \text { ivory bracelets on left wrist } \\
\text { 7. Ivory bracelet on right wrist } \\
\text { 8. Natrolite lipstud fallen from mouth. OES beads } \\
\text { at neck }\end{array}$ & $\begin{array}{l}0-8 \\
\text { Median: } 0 \\
\text { Mean: } 1\end{array}$ \\
\hline $\begin{array}{l}\text { Young } \\
\text { adult }\end{array}$ & 25 & $\begin{array}{l}\text { 8 with goods (32\%) } \\
\text { 1. Natrolite bead in unrecorded position } \\
\text { 2. Fragmentary ivory bracelet on right wrist. At } \\
\text { pelvis, collection of red, white and black beads } \\
\text { (carnelian, black quartz, crystal, milk quartz, } \\
\text { diorite, jasper, OES, natrolite). Grey pottery } \\
\text { lipstud, broken copper coil under body. About } \\
\text { 0.5m from burial: coarse, brown ware pottery jar; } \\
\text { rim incised before firing; below rim, on outside, } \\
\text { row of small clay bosses, applied before firing; } \\
\text { inside, unpolished brown ware pottery bowl } \\
\text { blackened on exterior } \\
\text { 3. } 6 \text { lipstuds (broken marble, marble, } 4 \text { pottery) at } \\
\text { mouth } \\
\text { 4. OES, natrolite beads at neck (necklace) and } \\
\text { waist } \\
\text { 5. } 2 \text { lipstuds (marble, pottery) at mouth } \\
\text { 6. Quartz lipstud at mouth } \\
\text { 7. } 3 \text { stones on right of body by shoulder, pelvis } \\
\text { and thighs } \\
\text { 8. Natrolite lipstud at mouth } \\
\end{array}$ & $\begin{array}{l}0-29 \\
\text { Median: } 0 \\
\text { Mean: } 2.44\end{array}$ \\
\hline Adult & 604 & 248 with goods $(41.06 \%)$ & $\begin{array}{l}0-23 \\
\text { Median: } 0 \\
\text { Mean: } 1.66\end{array}$ \\
\hline
\end{tabular}

Table 6.5 The number of individuals with accompanying burial items, derived from the Duckworth Lab's recent resexing attempt, divided by age categories. The range, and the mean and median, are given for their Inverse Distance Value. 


\begin{tabular}{|l|c|c|c|c|}
\hline Age category & $\begin{array}{c}\text { Number with } \\
\text { goods }\end{array}$ & IDV range & Median IDV & Mean IDV \\
\hline Infant & $35 / 93(37.63 \%)$ & $0-6$ & 0 & 0.90 \\
\hline Juvenile & $67 / 199(33.67 \%)$ & $0-22$ & 0 & 1.07 \\
\hline Young adult & $52 / 114(45.61 \%)$ & $0-29$ & 0 & 2.05 \\
\hline Adult & $\begin{array}{c}880 / 2421 \\
(36.35 \%)\end{array}$ & $0-811$ & 0 & 1.9 \\
\hline
\end{tabular}

Table 6.6 Using the field anatomists' categorisations, the number for each age category and their corresponding Inverse Distance Values were calculated.

\begin{tabular}{|c|c|c|c|}
\hline Age category & Orientation & Grave type & Posture \\
\hline Infant & $\begin{array}{l}\text { East: } 6(6.45 \%) \\
\text { North: } 12(12.90 \%) \\
\text { North-East: } 6(6.45 \%) \\
\text { North-West: } 18(19.35 \%) \\
\text { South: } 5(5.38 \%) \\
\text { South-East: } 9(9.68 \%) \\
\text { South-West: } 7(7.53 \%) \\
\text { West: } 14(15.05 \%)\end{array}$ & $\begin{array}{l}\text { Oval: } 15 \\
(16.13 \%) \\
\text { Rounded } \\
\text { rectangular: } 78 \\
(83.87 \%)\end{array}$ & $\begin{array}{l}\text { Supine: } 49 \\
(52.69 \%) \\
\text { Prone: } 2(2.15 \%) \\
\text { Left side: } 16 \\
(17.20 \%) \\
\text { Right side: } 14 \\
\text { (15.05\%) } \\
\text { Crouched: } 2 \\
(2.15 \%)\end{array}$ \\
\hline Juvenile & $\begin{array}{l}\text { East: } 10(5.03 \%) \\
\text { North: } 20(10.05 \%) \\
\text { North-East: } 20(10.05 \%) \\
\text { North-West: } 47(23.62 \%) \\
\text { South: } 3(1.51 \%) \\
\text { South-East: } 19(9.55 \%) \\
\text { South-West: } 28(14.07 \%) \\
\text { West: } 26(13.07 \%)\end{array}$ & $\begin{array}{l}\text { Oval: } 19 \\
(9.55 \%) \\
\text { Rounded } \\
\text { rectangular: } \\
180(90.45 \%)\end{array}$ & $\begin{array}{l}\text { Supine: } 90 \\
(45.23 \%) \\
\text { Prone: } 14(7.04 \%) \\
\text { Left side: } 24 \\
(12.06 \%) \\
\text { Right side: } 34 \\
(17.09 \%) \\
\text { Crouched: } 9 \\
(4.52 \%) \\
\end{array}$ \\
\hline Young adult & $\begin{array}{l}\text { East: } 11(9.65 \%) \\
\text { North: } 3(2.63 \%) \\
\text { North-East: } 16(14.04 \%) \\
\text { North-West: } 33(28.95 \%) \\
\text { South: } 4(3.51 \%) \\
\text { South-East: } 12(10.53 \%) \\
\text { South-West: } 13(11.40 \%) \\
\text { West: } 17(14.91 \%)\end{array}$ & $\begin{array}{l}\text { Oval: } 14 \\
(12.28 \%) \\
\text { Rounded } \\
\text { rectangular: } \\
100(87.72 \%)\end{array}$ & $\begin{array}{l}\text { Supine: } 69 \\
(60.53 \%) \\
\text { Prone: } 12(10.53 \%) \\
\text { Left side: } 11 \\
(9.65 \%) \\
\text { Right side: } 13 \\
(11.40 \%) \\
\text { Crouched: } 1 \\
(0.88 \%)\end{array}$ \\
\hline Adult & $\begin{array}{l}\text { East: } 178(7.35 \%) \\
\text { North: } 155(6.40 \%) \\
\text { North-East: } 232(9.58 \%) \\
\text { North-West: } 588 \\
(24.29 \%) \\
\text { South: } 82(3.39 \%) \\
\text { South-East: } 234(9.67 \%) \\
\text { South-West: } 365 \\
(15.08 \%) \\
\text { West: } 386(15.94 \%)\end{array}$ & $\begin{array}{l}\text { Oval: } 238 \\
(9.83 \%) \\
\text { Rounded } \\
\text { rectangular: } \\
2183(90.17 \%)\end{array}$ & $\begin{array}{l}\text { Supine: } 1330 \\
(54.94 \%) \\
\text { Prone: } 168(6.94 \%) \\
\text { Left side: } 256 \\
(10.57 \%) \\
\text { Right side: } 321 \\
(13.26 \%) \\
\text { Crouched: } 22 \\
(0.91 \%)\end{array}$ \\
\hline
\end{tabular}

Table 6.7 Comparative list of the bodily orientation, grave form and burial posture of the different field-derived age categories. 


\subsubsection{Infants}

Ages at which infants achieve social recognition varies. For the Mandari of the Sudan, for example, infants who survive beyond three days are named and are entitled to a degree of ritual (Buxton 1973: 146). There are 93 infants buried at Jebel Moya, of which 35 have accompanying artefacts. The greatest percentage of oval burials occurs for infants (16.13\%, Table 6.7), although this may be due to a smaller sample of burials as the percentage difference between it and that of the Young Adult category is not large. Also, the overall percentage of infant burials are not distinguishable from other burials using bodily orientation nor burial type (Table 6.7). Neither do the infant burials form a distinct cluster or predominate in any part of the cemetery, nor are they distinguished by where they occur in the cemetery: as shown in Figure 6.2, infants were buried in almost every sector.

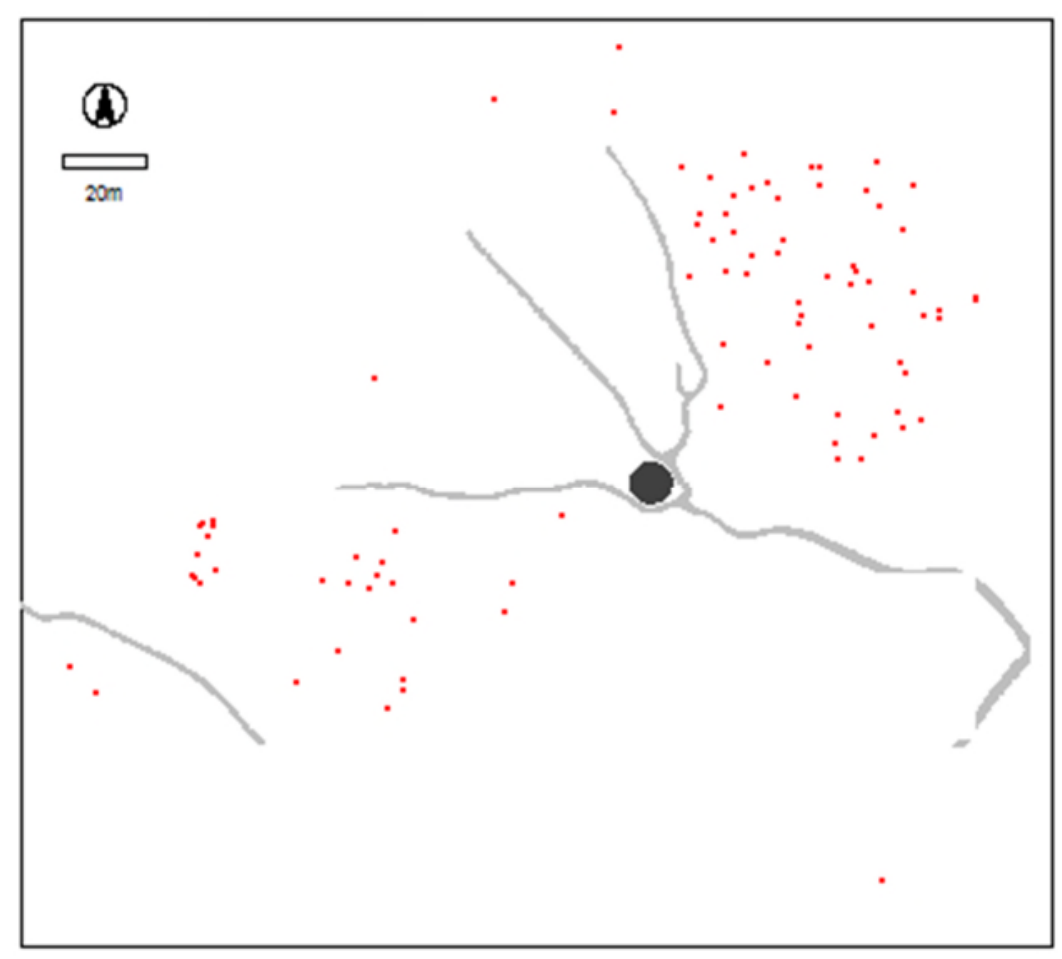

Figure 6.2 Burial distribution of individuals categorised as Infants by the original field anthropologists.

There are no artefact categories reserved exclusively or even semi-exclusively for infants, and the IDV mean is a lowly 0.7 which is close to the mean of 1 for juveniles (Table 6.5). However, the restricted range of artefact categories - beads, bracelets and 
more occasionally pendant and lipstuds - may indicate that a limited sub-set of artefacts were permitted in infant burials. These artefacts are manufactured from either local materials or materials obtained from likely sources along the Nile. No Meroitic or longdistance traded raw materials are present with them. By burying their infants with restricted artefact categories, this may be indicative of a limited attribution of social personae to them (Goody 1962: 92; MacDonald 2001: 707).

\subsubsection{Juveniles}

There are 199 juveniles buried at Jebel Moya, of which 67 have accompanying assemblages. Like the infants, there are no artefact categories reserved exclusively or semi-exclusively for juveniles. Unlike infants, however, a wider repertoire of artefacts were made from a variety of raw materials are present. These include an iron ring, an iron amulet, and faience beads in addition to pottery, quartz and natrolite beads, ceramic, a granite celt and associated cattle bones, amongst other items. However, two burials have an IDV of above 10 which artificially inflates the IDV range in Table 6.6; the mean IDV average of 1 is only just above that of the infant category if these are excluded.

The percentages of the types of grave shapes are very similar to that of the adult category. Also, the overall percentage of juveniles bodily aligned to different cardinal directions is within the range of the other categories (Table 6.7); in other words, juvenile burials were not distinguished from other burials using bodily orientation. Neither are they distinguished by their burial posture nor where they occur in the cemetery: as shown in Figure 6.3, juveniles were buried across the excavated sectors of the valley. They therefore were recognised as having progressed further through life and this is reflected in their mortuary social personae through their wider range of accompanying goods categories and presence in the same areas as adult burials. 


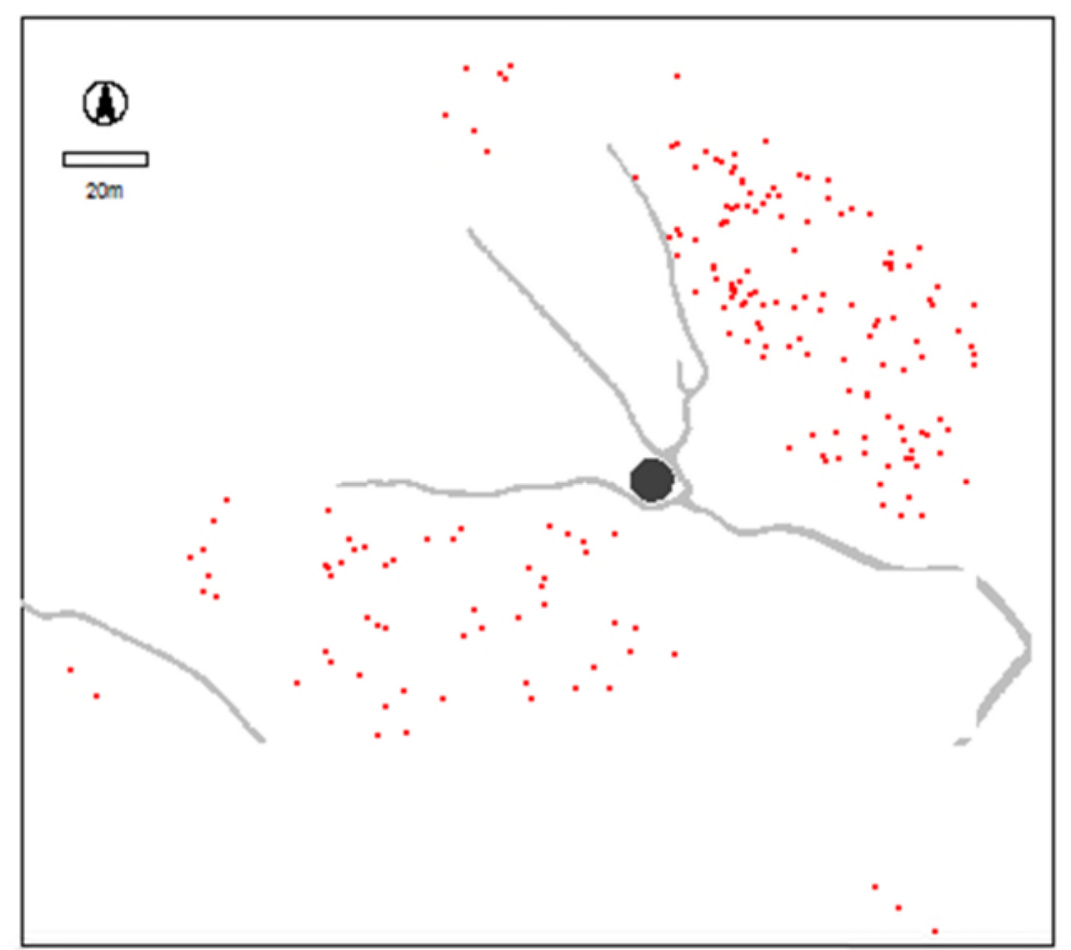

Figure 6.3 Burial distribution of individuals categorised as Juveniles by the original field anthropologists.

\subsubsection{Young adults}

Young adults are not present in any great number (114, of which 52 have accompanying burial assemblages). There are also no artefact categories reserved exclusively or semiexclusively for young adults. Like juveniles, a wide repertoire of artefacts made from a variety of raw materials was present, including quartz, pottery and natrolite lipstuds, shell, one occurrence of cattle bones, marble lipstuds, faience beads, a silver bead and a copper bracelet, amongst other items. Six burials have an IDV of above 10, with one above 20, which provides the upper range of Inverse Distance Values in Table 6.5. Importantly, the mean IDV average is significantly different to that of the infant and juvenile categories, and aligns with the mean IDV average of the Adult category.

The percentage difference for oval graves between the Infant and Young Adult categories is not large. Also, the percentage of young adults bodily aligned to different cardinal directions is within the range of the other categories (Table 6.7). Neither are they distinguished by their burial posture nor where they occur in the cemetery: as shown in Figure 6.4 and in Table 6.7, young adults were buried in almost every sector. 
Overall, the alignment of young adults - much closer to adults than to infants and juveniles - is indicative of the individuals being symbolised in the mortuary realm as everything which they would have become, even if unattained at the time of their deaths (van Beek 2012).

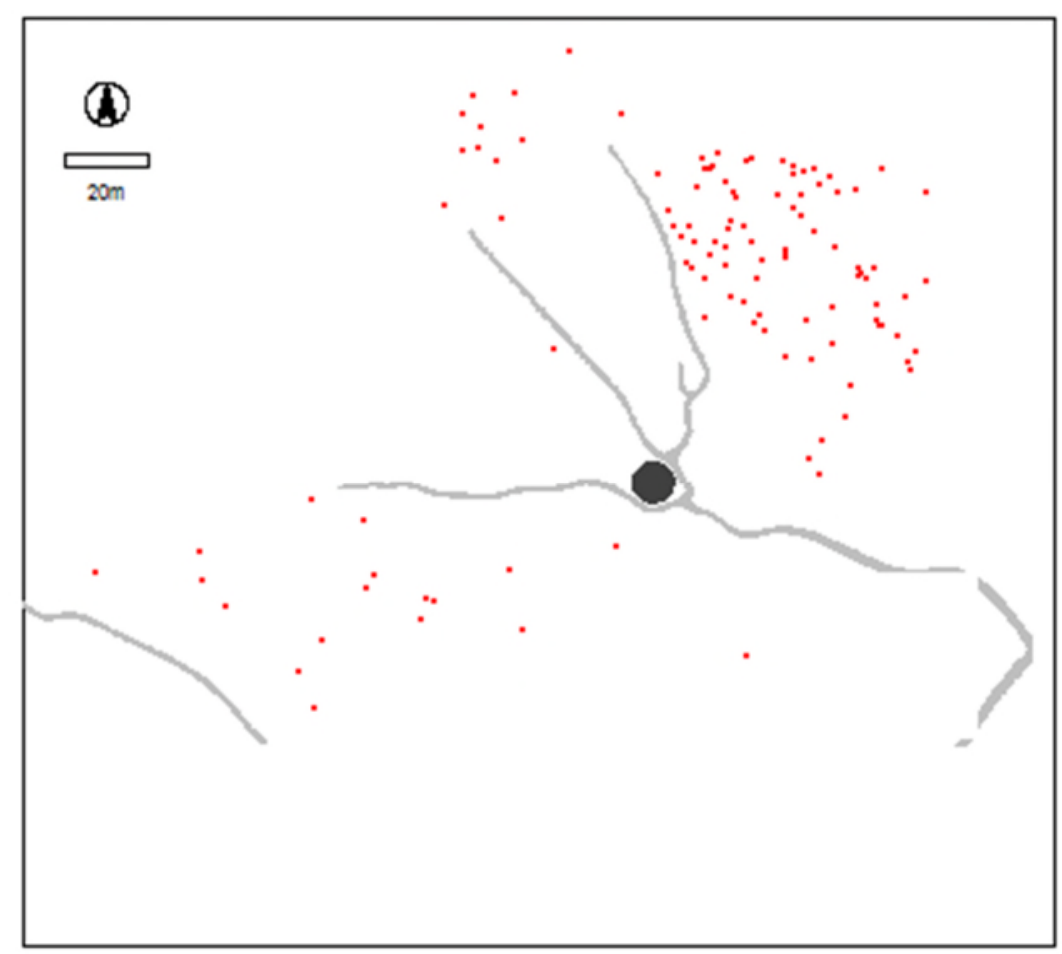

Figure 6.4 Burial distribution of individuals categorised as Young Adults by the original field anthropologists.

\subsubsection{Adults}

Adults comprise by far the greatest number of aged individuals, identified by the field anthropologists, totalling 2421 of which 880 have accompanying assemblages (Table 6.6). While there are no artefact categories reserved exclusively or semi-exclusively for adults, the quantity of items per grave with burial assemblages is by far the greatest of all the age categories. The widest repertoire of artefacts was present, including quartz, pottery and natrolite lipstuds, carnelian and jasper beads, shells, ceramics, cattle bones, marble lipstuds, faience and silver beads, iron rings and copper bracelets, amongst other items. The artefacts were made from local, Nile and Meroitic/long-distance traded raw materials. Seventy-three burials have an IDV of above 10, with fifteen above 20, which provides the upper range of Inverse Distance Value in Table 6.5. Importantly, the mean 
IDV average is significantly different to that of the infant and juvenile categories, while aligning with the mean IDV average of the Young Adult category.

A breakdown of the number of burials a particular raw material is present in, according to identifiable individuals re-sexed by the Duckworth Laboratory, indicates no strong depositional preference for particular materials to be associated more with either females or males (Table 6.8). The only tentative possibility takes the form of marble lipstuds which are associated with females in the South-West and no males; however, comparative data is unavailable for the remaining sectors to be able to adequately test to see if this pattern is replicated elsewhere.

\begin{tabular}{|c|c|c|c|c|c|c|c|c|c|c|}
\hline & South-West & & West & & North-West & & North-East & & East & \\
\hline & Female & Male & $\begin{array}{c}\text { Femal } \\
e\end{array}$ & Male & Female & Male & Female & Male & Female & Male \\
\hline "Alabaster" & 1 & 0 & 0 & 0 & 0 & 0 & 0 & 0 & 0 & 0 \\
\hline Beryl & 0 & 0 & 0 & 0 & 0 & 0 & 0 & 0 & 0 & 0 \\
\hline Bone & 8 & 6 & 0 & 0 & 1 & 0 & 5 & 1 & 4 & 3 \\
\hline Bronze & 0 & 0 & 0 & 0 & 0 & 0 & 0 & 0 & 0 & 0 \\
\hline Bark & 0 & 0 & 0 & 0 & 0 & 0 & 0 & 0 & 0 & 0 \\
\hline Carnelian & 0 & 0 & 0 & 0 & 0 & 0 & 0 & 1 & 0 & 0 \\
\hline Ceramic & 6 & 2 & 0 & 0 & 0 & 2 & 1 & 0 & 1 & 1 \\
\hline Chalcedony & 0 & 0 & 0 & 0 & 0 & 0 & 0 & 0 & 0 & 0 \\
\hline Chert & 0 & 0 & 0 & 0 & 0 & 0 & 0 & 0 & 0 & 1 \\
\hline Copper & 0 & 0 & 0 & 0 & 0 & 0 & 0 & 2 & 0 & 2 \\
\hline Cowrie & 0 & 0 & 0 & 0 & 0 & 0 & 0 & 0 & 0 & 0 \\
\hline Crystal & 0 & 0 & 0 & 0 & 0 & 0 & 1 & 0 & 0 & 0 \\
\hline Diorite & 0 & 0 & 0 & 0 & 0 & 0 & 0 & 0 & 0 & 1 \\
\hline Faience & 0 & 0 & 0 & 0 & 0 & 0 & 0 & 2 & 0 & 0 \\
\hline Feldspar & 0 & 0 & 0 & 0 & 0 & 0 & 0 & 0 & 0 & 0 \\
\hline Flint & 0 & 0 & 0 & 0 & 0 & 0 & 1 & 0 & 0 & 0 \\
\hline Glass & 0 & 0 & 0 & 0 & 0 & 0 & 0 & 0 & 0 & 0 \\
\hline Gold & 0 & 0 & 0 & 0 & 0 & 0 & 0 & 0 & 0 & 0 \\
\hline Greenstone & 1 & 0 & 0 & 0 & 0 & 0 & 0 & 0 & 0 & 0 \\
\hline Iron & 0 & 0 & 0 & 0 & 0 & 0 & 0 & 0 & 0 & 0 \\
\hline Ivory & 10 & 8 & 0 & 0 & 3 & 1 & 0 & 7 & 2 & 3 \\
\hline Jasper & 0 & 0 & 0 & 0 & 0 & 0 & 0 & 0 & 0 & 0 \\
\hline Lapis & 0 & 0 & 0 & 0 & 0 & 0 & 0 & 1 & 0 & 0 \\
\hline Limestone & 0 & 0 & 0 & 0 & 0 & 0 & 0 & 0 & 0 & 0 \\
\hline Limonite & 0 & 0 & 0 & 0 & 0 & 0 & 0 & 0 & 0 & 0 \\
\hline Marble & 7 & 0 & 0 & 0 & 0 & 0 & 0 & 1 & 0 & 0 \\
\hline Natrolite & 18 & 17 & 0 & 0 & 6 & 2 & 5 & 12 & 4 & 4 \\
\hline Ochre & 0 & 0 & 0 & 0 & 0 & 0 & 1 & 0 & 0 & 1 \\
\hline OES & 4 & 9 & 0 & 0 & 2 & 2 & 3 & 2 & 2 & 2 \\
\hline Pottery & 29 & 10 & 0 & 0 & 4 & 3 & 6 & 3 & 0 & 1 \\
\hline Quartz & 7 & 9 & 0 & 0 & 0 & 2 & 8 & 2 & 5 & 2 \\
\hline Shell & 6 & 3 & 0 & 0 & 2 & 0 & 1 & 1 & 1 & 2 \\
\hline
\end{tabular}




\begin{tabular}{|l|c|c|c|c|c|c|c|c|c|c|}
\hline & South-West & & West & & North-West & & North-East & & East & \\
\hline & Female & Male & $\begin{array}{c}\text { Femal } \\
\boldsymbol{e}\end{array}$ & Male & Female & Male & Female & Male & Female & Male \\
\hline Silver & 0 & 0 & 0 & 0 & 0 & 0 & 0 & 0 & 0 & 0 \\
\hline Stone & 5 & 9 & 0 & 0 & 0 & 1 & 5 & 6 & 0 & 3 \\
\hline
\end{tabular}

Table 6.8 Frequency of the raw material composition of burial artefacts per Duckworth Laboratory adult-sexed individuals in each sector of the cemetery. The two columns "ceramics" and "pottery" refer to ceramic wares and clay lipstuds/nosestuds/earstuds respectively.

The percentage difference of oval graves between the categories is not large. Also, the overall percentage of adults bodily aligned to different cardinal directions is within the range of the other categories, while there is nothing unique either about the burial postures (Table 6.7). Adult burials also occur throughout the cemetery. Although Addison and Gerharz cited the presence of different postures and bodily orientations as evidence for the presence of different ethnic groups, Sagar (1922: 150) notes that such variable postures are common amongst early $20^{\text {th }}$ century Nuba.

However, there appears to be a pattern in Inverse Distance Values between male and female burials, as aged and re-sexed by the Duckworth Laboratory (Table 6.9). The number of young adults is few when broken down by sector, making any attempt at testing the spatial distribution of IDV values and their relationship with the adult categories problematic. While the results seem to indicate some variation, this may well be an artefact of the low occurrences in each sector. However, the most interesting trend is the clear difference between the mean and median IDV values for adult females and adult males in the South-West: 3.35 and 2 versus 1.45 and 0 respectively. This pattern of greater female wealth in the South-West also appears to be present in the NorthWest, but is not obvious in other sectors. 


\begin{tabular}{|l|l|c|c|c|}
\hline & & Number of individuals & Mean & Median \\
\hline South-West & Adult. Female & 69 & 3.35 & 2 \\
\hline & Adult. Male & 100 & 1.45 & 0 \\
\hline & Adult & 222 & 2.4 & 1 \\
\hline & Young adult & 7 & 3.57 & 2 \\
\hline & Juvenile & 7 & 2.4 & 0 \\
\hline & & & & \\
\hline West & Adult. Female & 0 & 0 & 0 \\
\hline & Adult. Male & 1 & 0 & 0 \\
\hline & Adult & 0 & 0 & 0 \\
\hline & Young adult & 0 & 0 & 0 \\
\hline & Juvenile & 0 & 0 & 0 \\
\hline & & & & \\
\hline North-West & Adult. Female & 16 & 3.5 & 0.5 \\
\hline & Adult. Male & 24 & 1.17 & 0 \\
\hline & Adult & 47 & 1.94 & 0 \\
\hline & Young adult & 3 & 1 & 0 \\
\hline & Juvenile & 2 & 1.5 & 1.5 \\
\hline & & & & \\
\hline & Adult. Female & 33 & 1.52 & 0 \\
\hline & Adult. Male & 40 & 1.13 & 0 \\
\hline & Adult & 90 & 1.42 & 0 \\
\hline & Young adult & 3 & 9.67 & 0 \\
\hline & Juvenile & 5 & 0.4 & 0 \\
\hline & & & & \\
\hline & Adult. Female & 84 & 0.89 & 0 \\
\hline & Adult. Male & 90 & 1.03 & 0 \\
\hline & Adult & 233 & 0.98 & 0 \\
\hline & Young adult & 12 & 0.33 & 0 \\
\hline & Juvenile & 8 & 0.63 & 0 \\
\hline
\end{tabular}

Table 6.9 Breakdown of the IDV per Duckworth Laboratory aged and sexed burials per sector. The category numbers includes the totals for the female and male adult individuals (see Table 5.1).

In order to examine this pattern more closely, especially as previous analysis (Table 4.5) had not indicated any significant differences in artefact categories across the excavated sectors of the valley, the presence of artefact and material categories was determined for each adult re-sexed burial (Figures 6.5 - 6.12). No discernible differences are detected due to the large number of different categories occurring at low numbers. There are seven lipstuds amongst the females of the South-West sector, with none for the males. However, the number is too small to base conclusions about certain artefacts being buried exclusively or semi-exclusively with one sex or the other. Neither does the presence of only seven marble lipstuds drive the high IDV value for the SouthWest sector. On the contrary, the pattern of artefact category deposition between the biological sexes looks to have a degree of uniformity. 


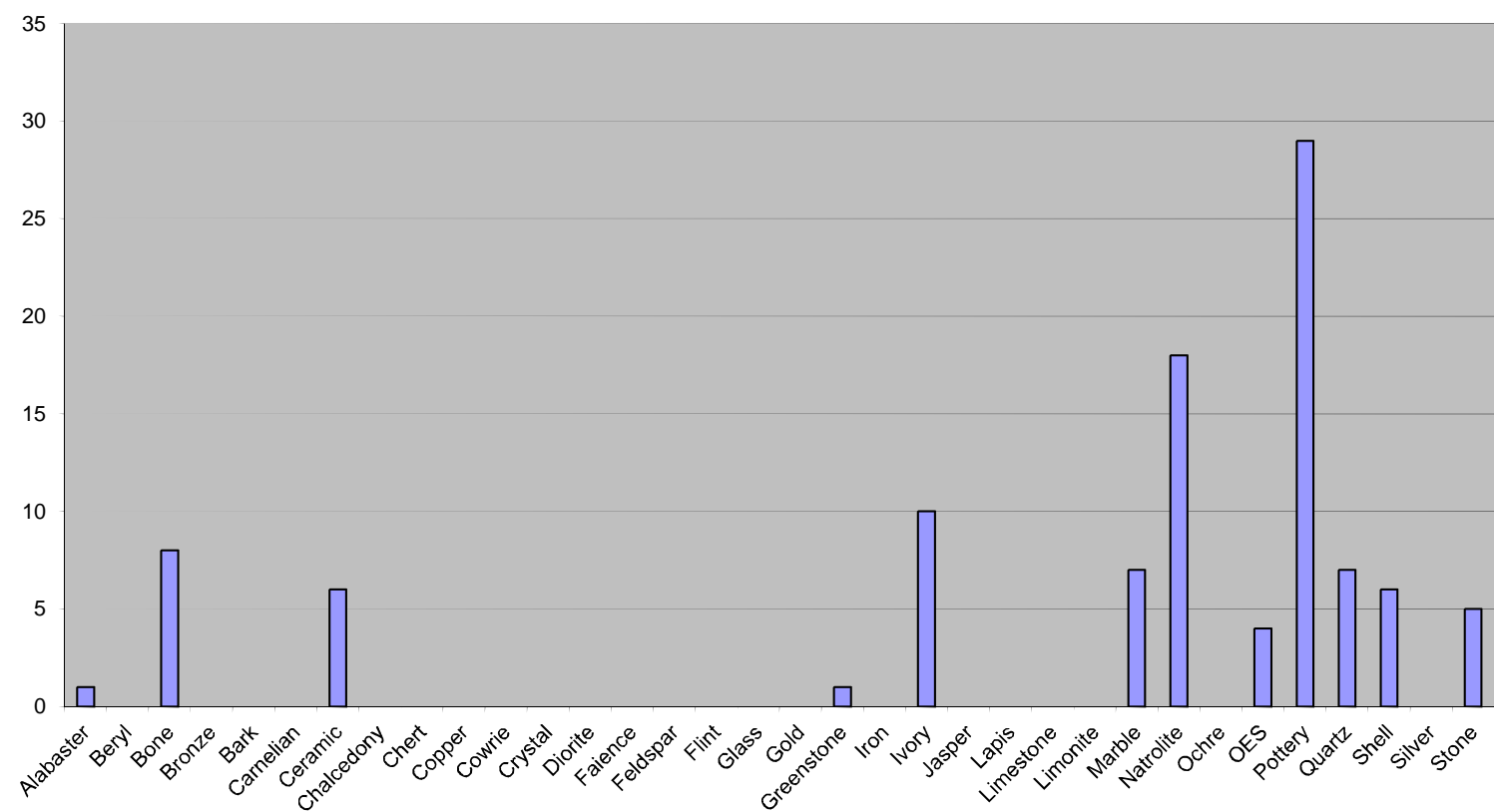

South-West: Adult males

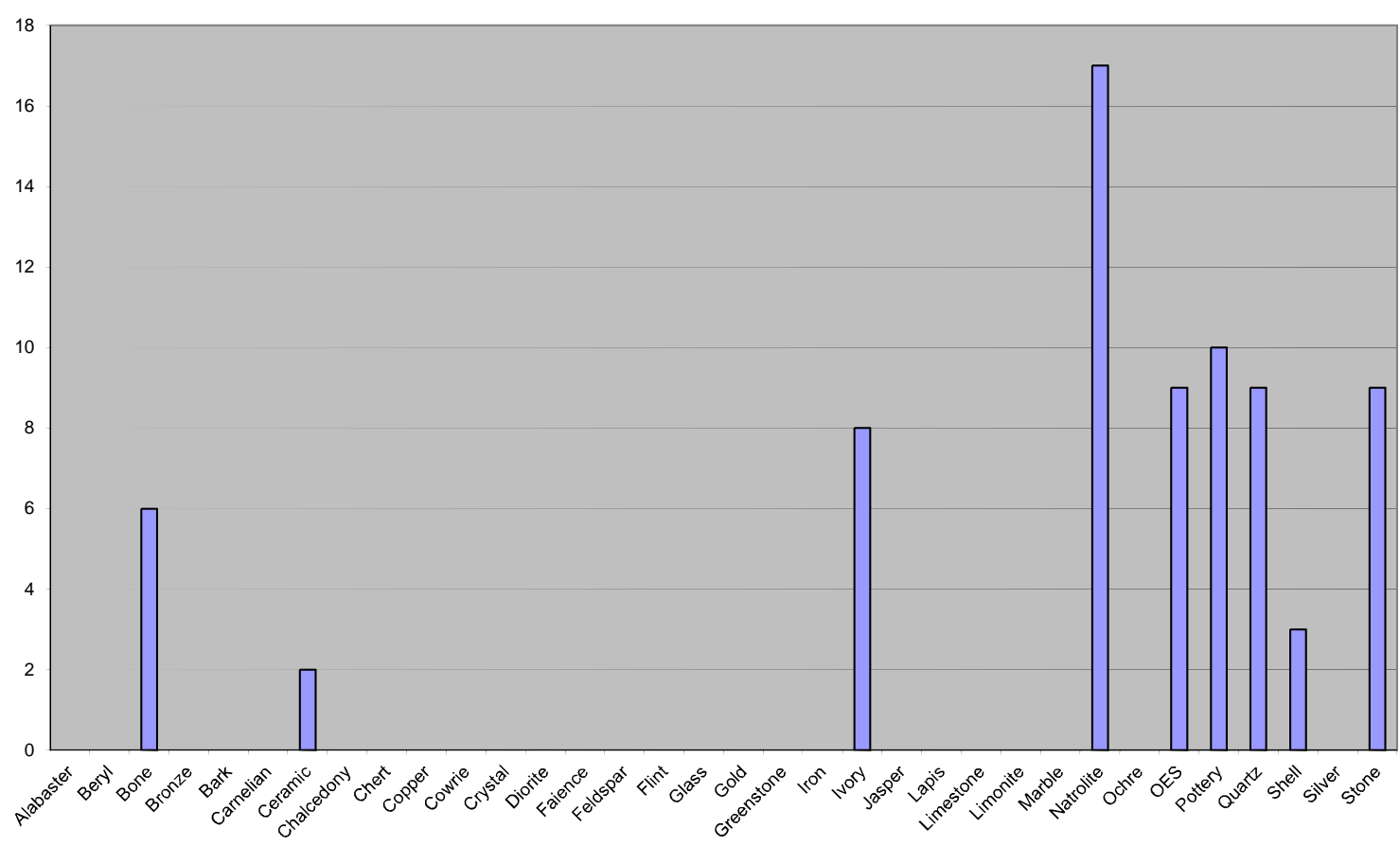

Figure 6.5 Occurrence of raw materials amongst the burials of the South-West, NorthWest, East and North-East per adult female and adult male burials. Each sex category includes those tentatively assigned to it. 


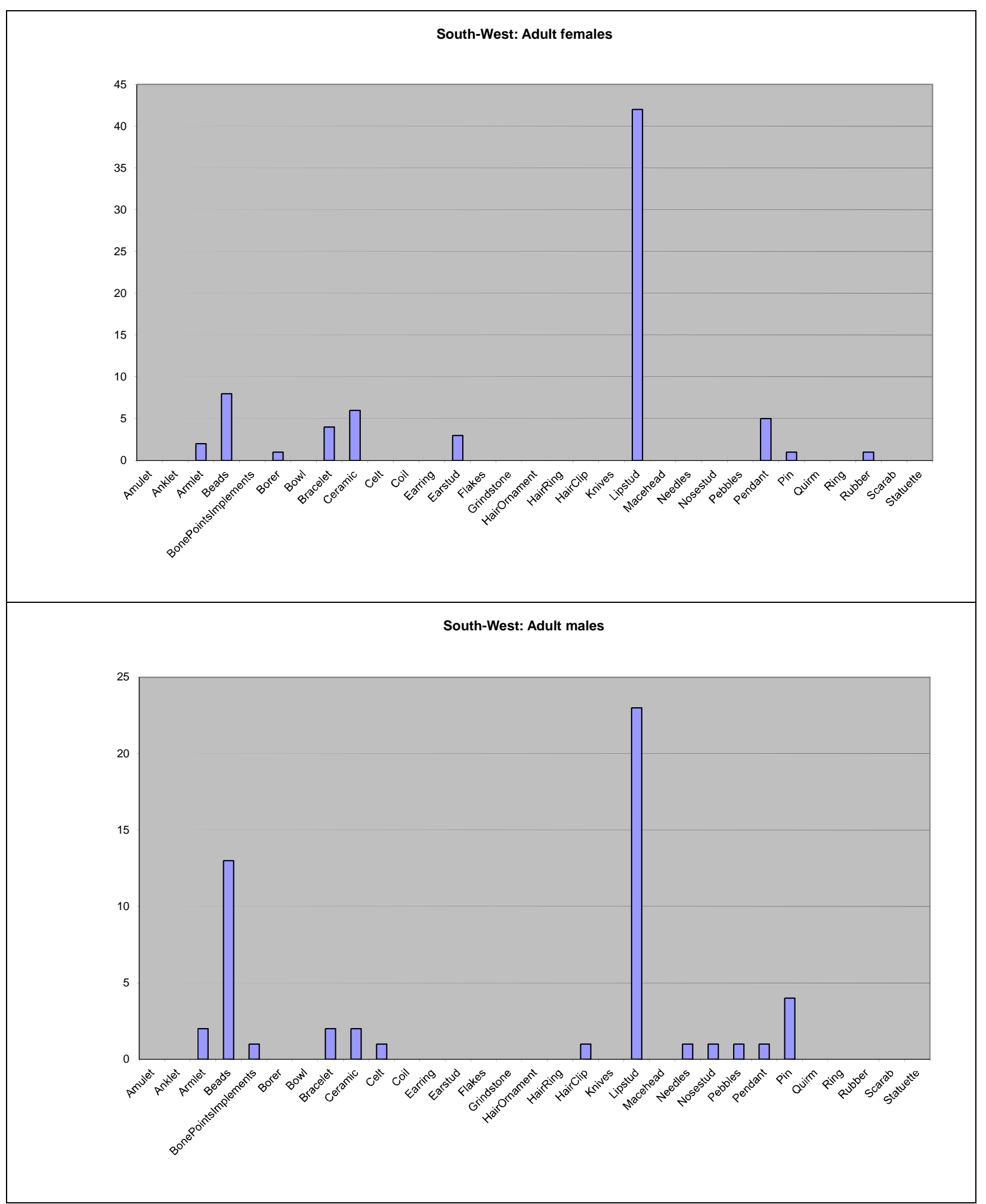

Figure 6.6 Occurrence of artefact categories amongst the burials of the South-West per adult female and adult male burials. Each sex category includes those tentatively assigned to it. 
North-West: Adult females

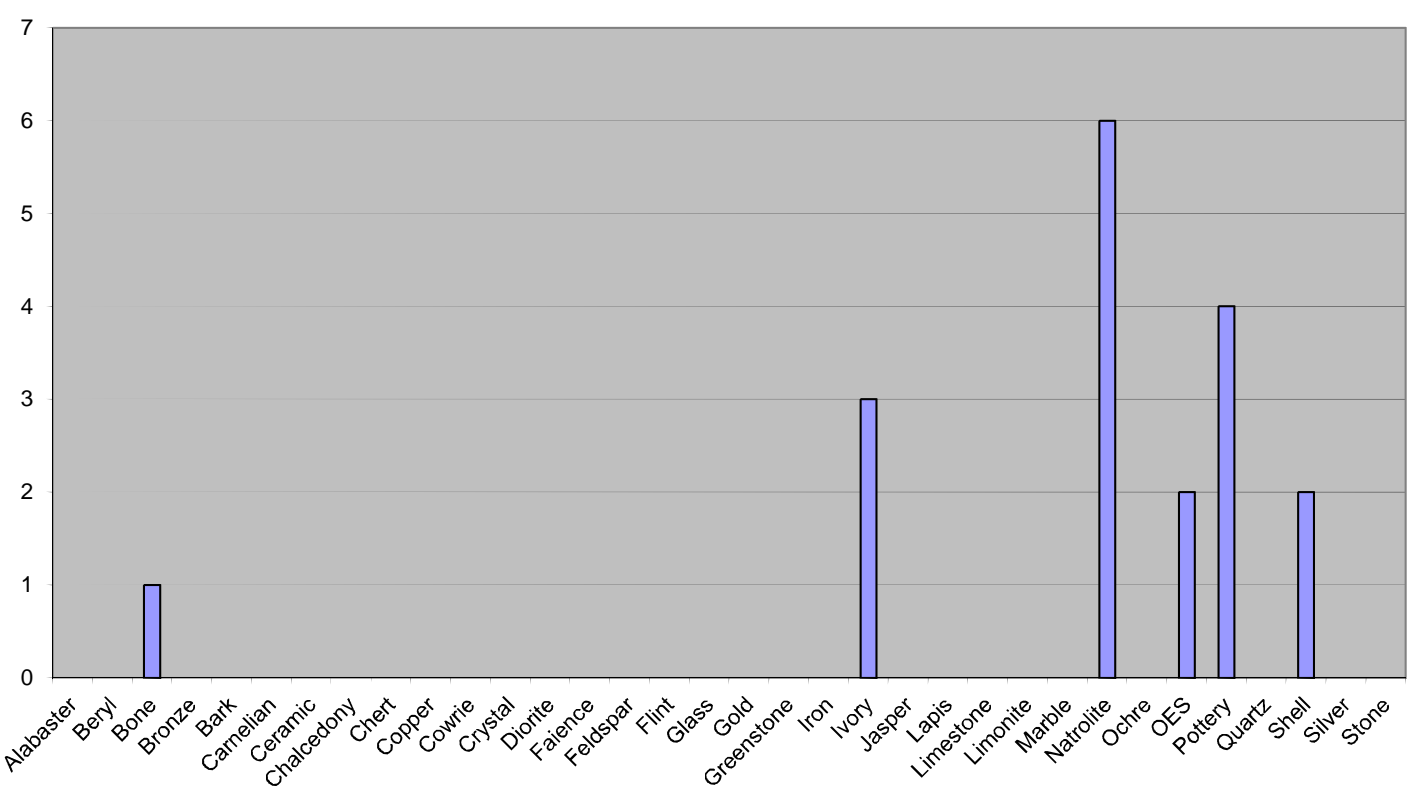

North-West: Adult males

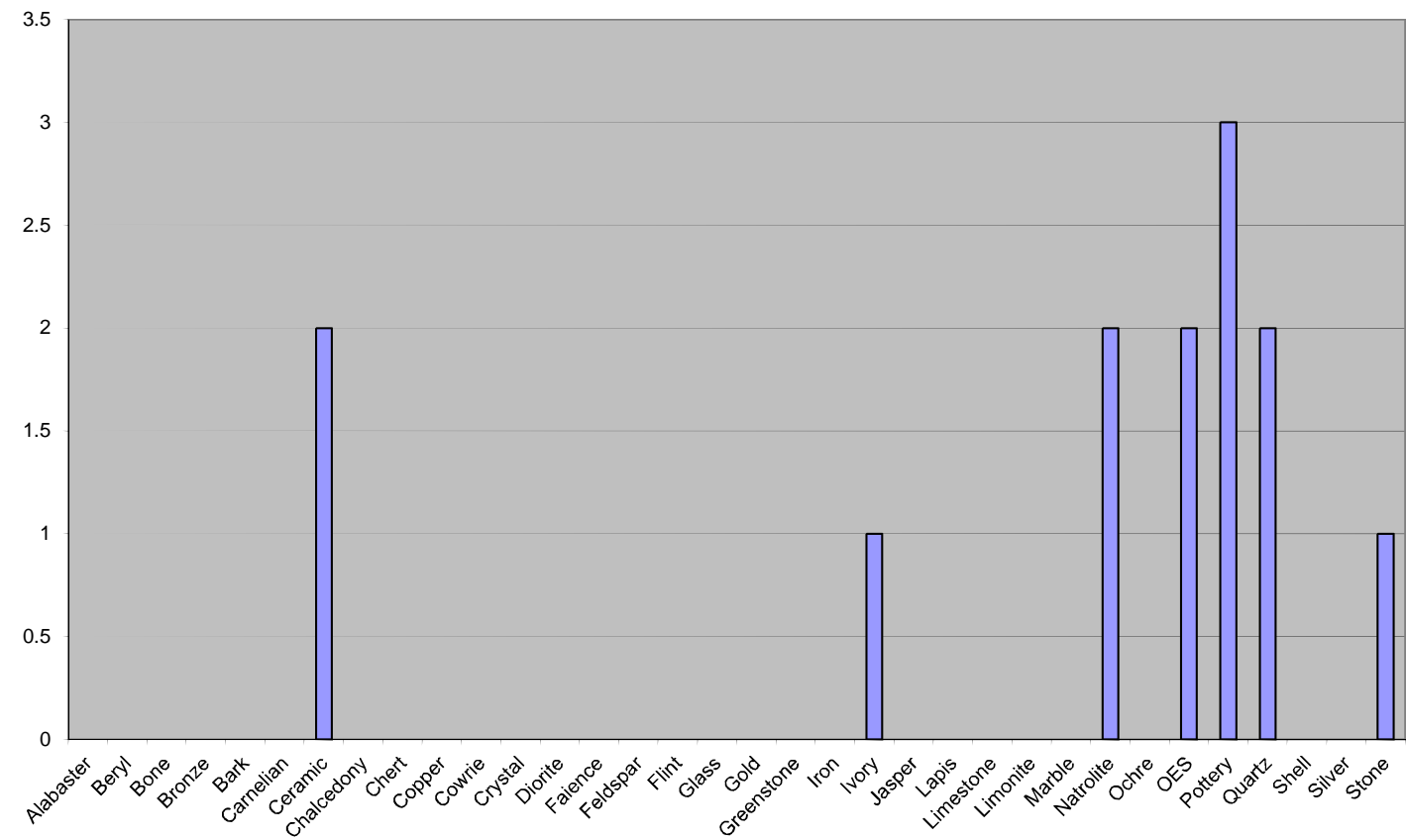

Figure 6.7 Occurrence of raw materials amongst the burials of the North-West per (a) adult female and adult male burials. Each sex category includes those tentatively assigned to it. 
North-West: Adult females

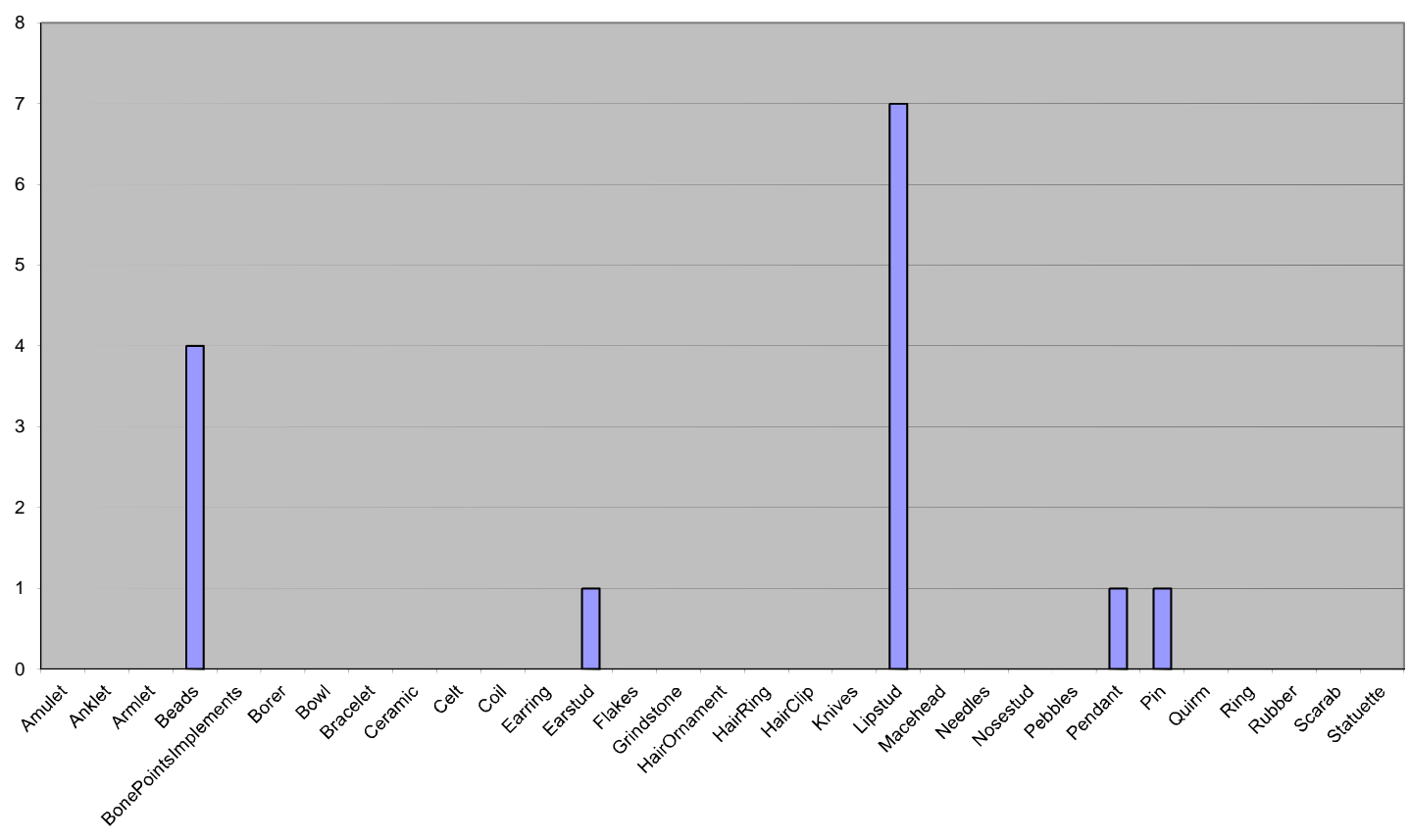

North-West: Adult males

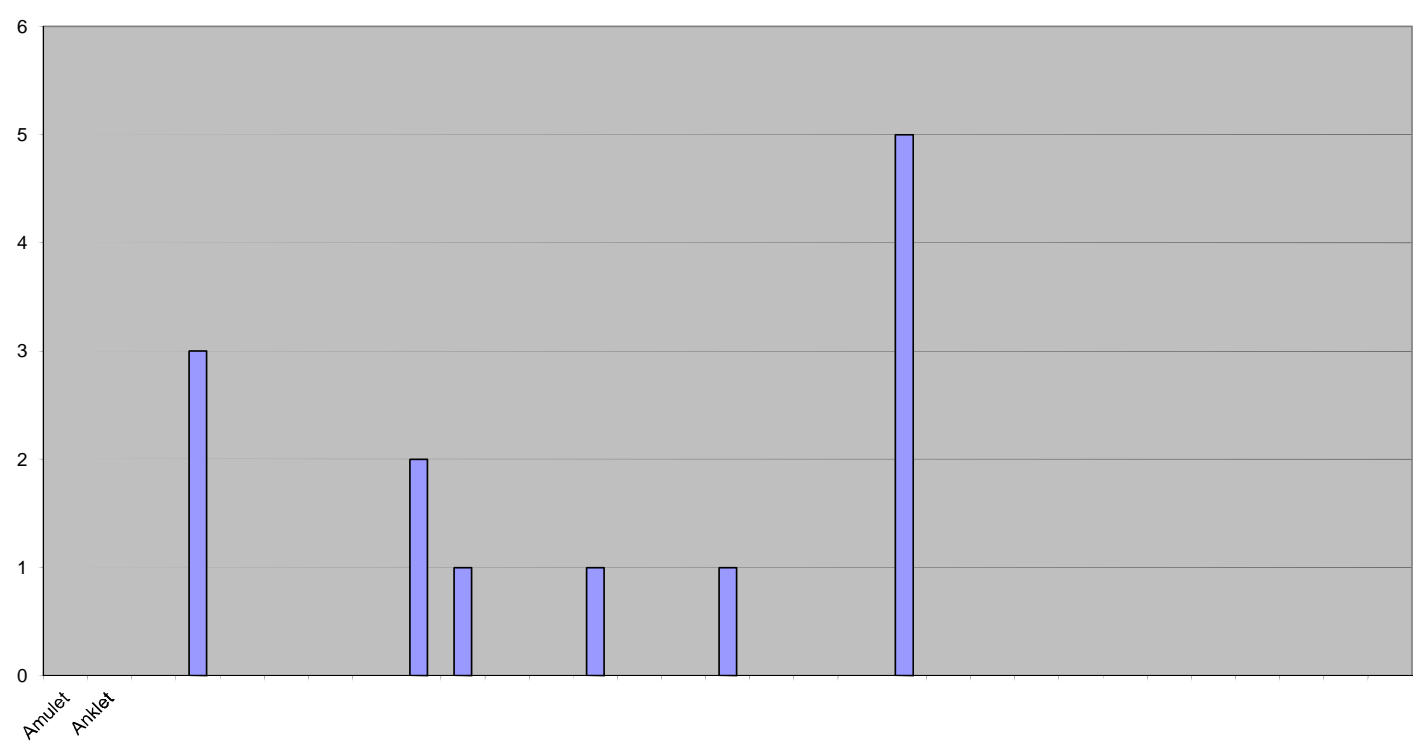

Figure 6.8 Occurrence of artefact categories amongst the burials of the North-West per adult female and adult male burials. Each sex category includes those tentatively assigned to it. 
North-East: Adult females

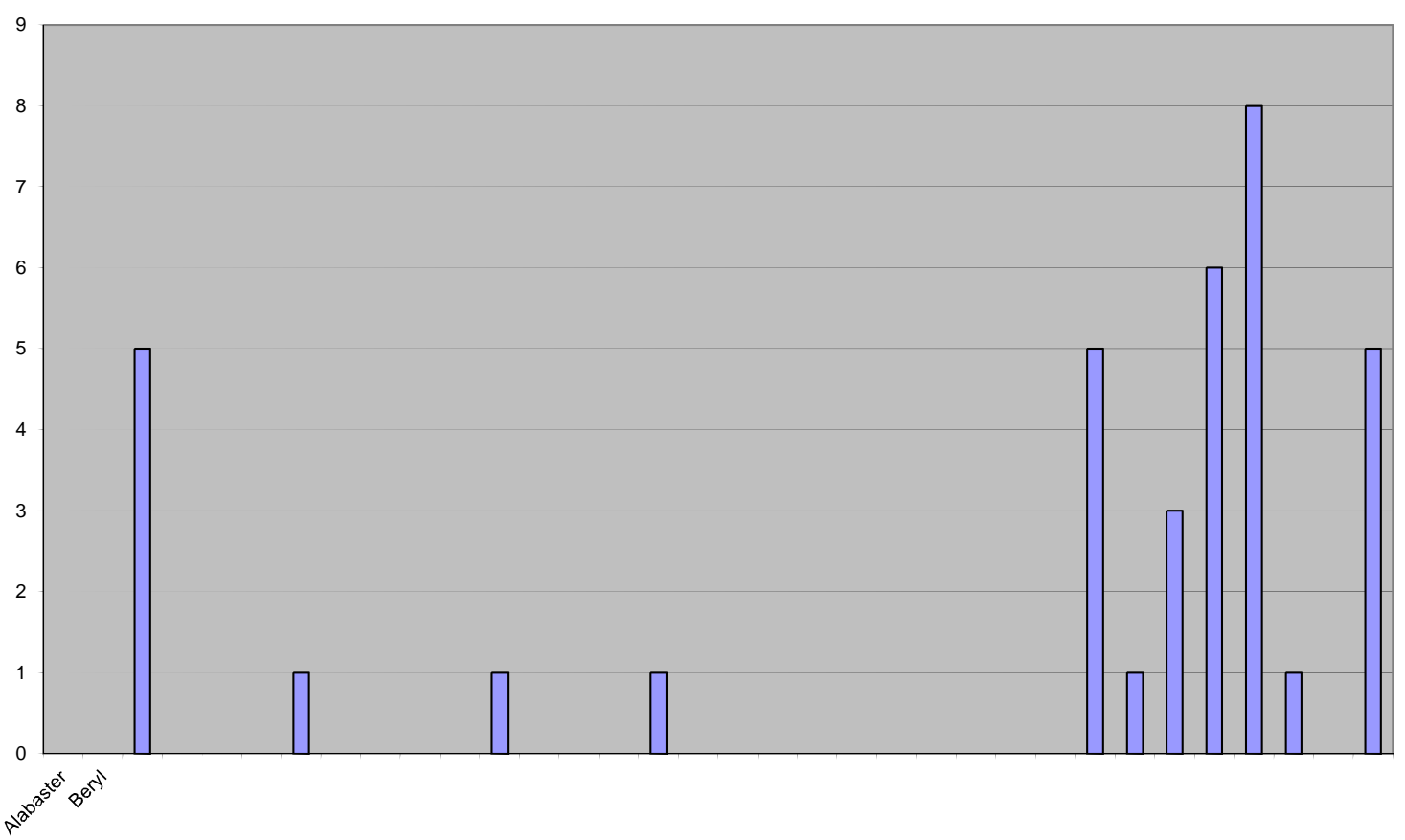

North-East: Adult males

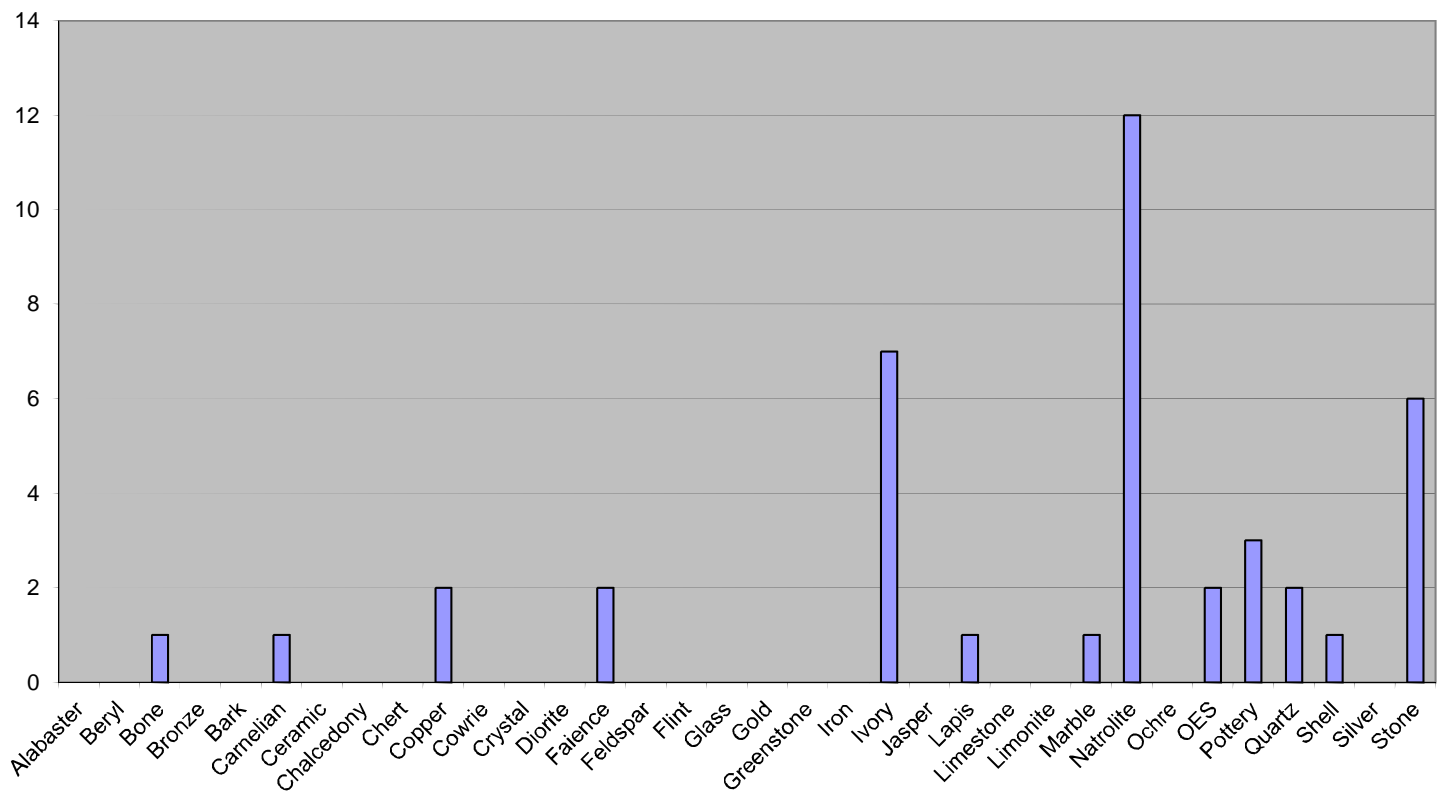

Figure 6.9 Occurrence of raw materials amongst the burials of the North-East per adult female and adult male burials. Each sex category includes those tentatively assigned to it. 
North-East: Adult females

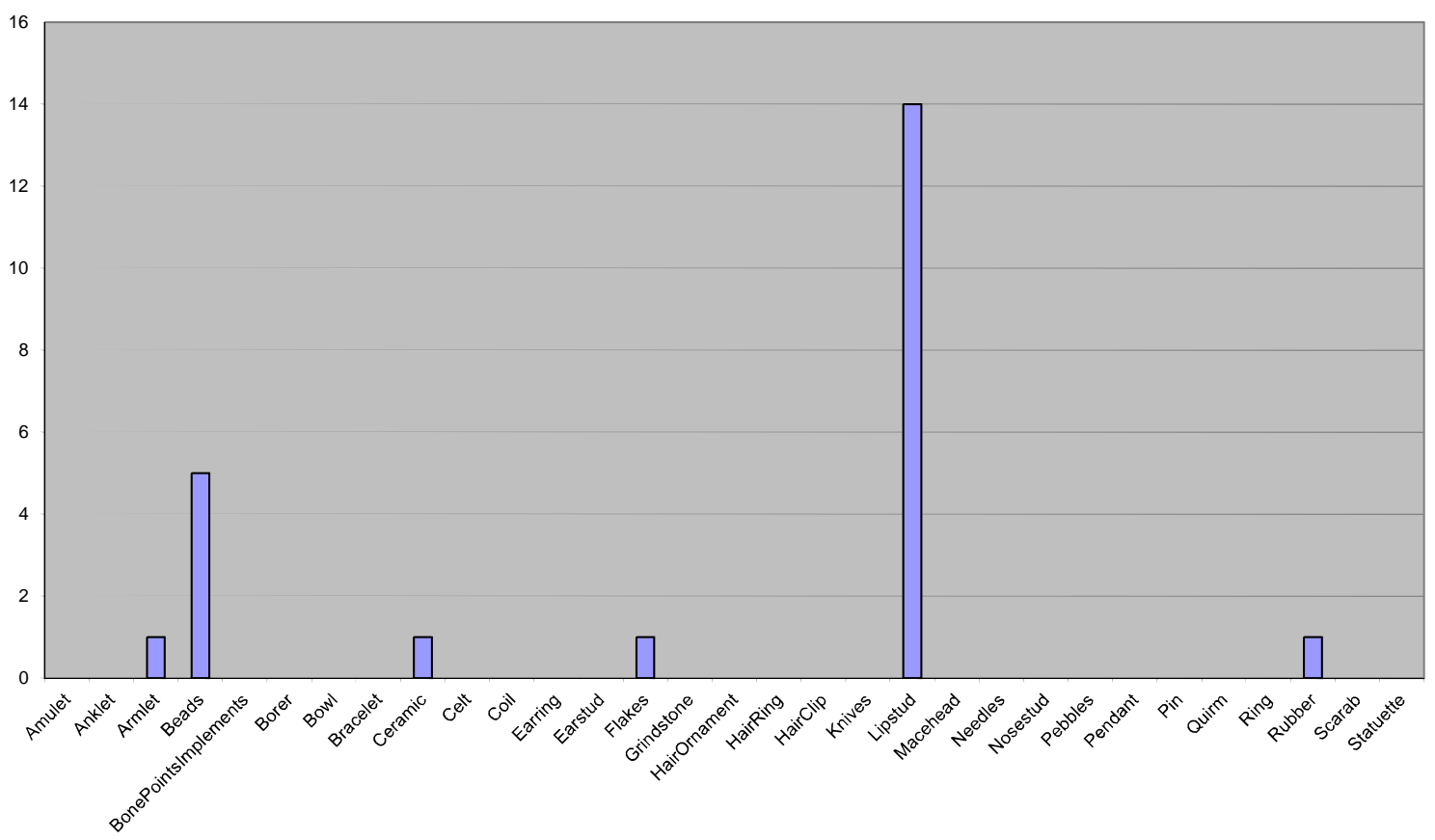

North-East: Adult males

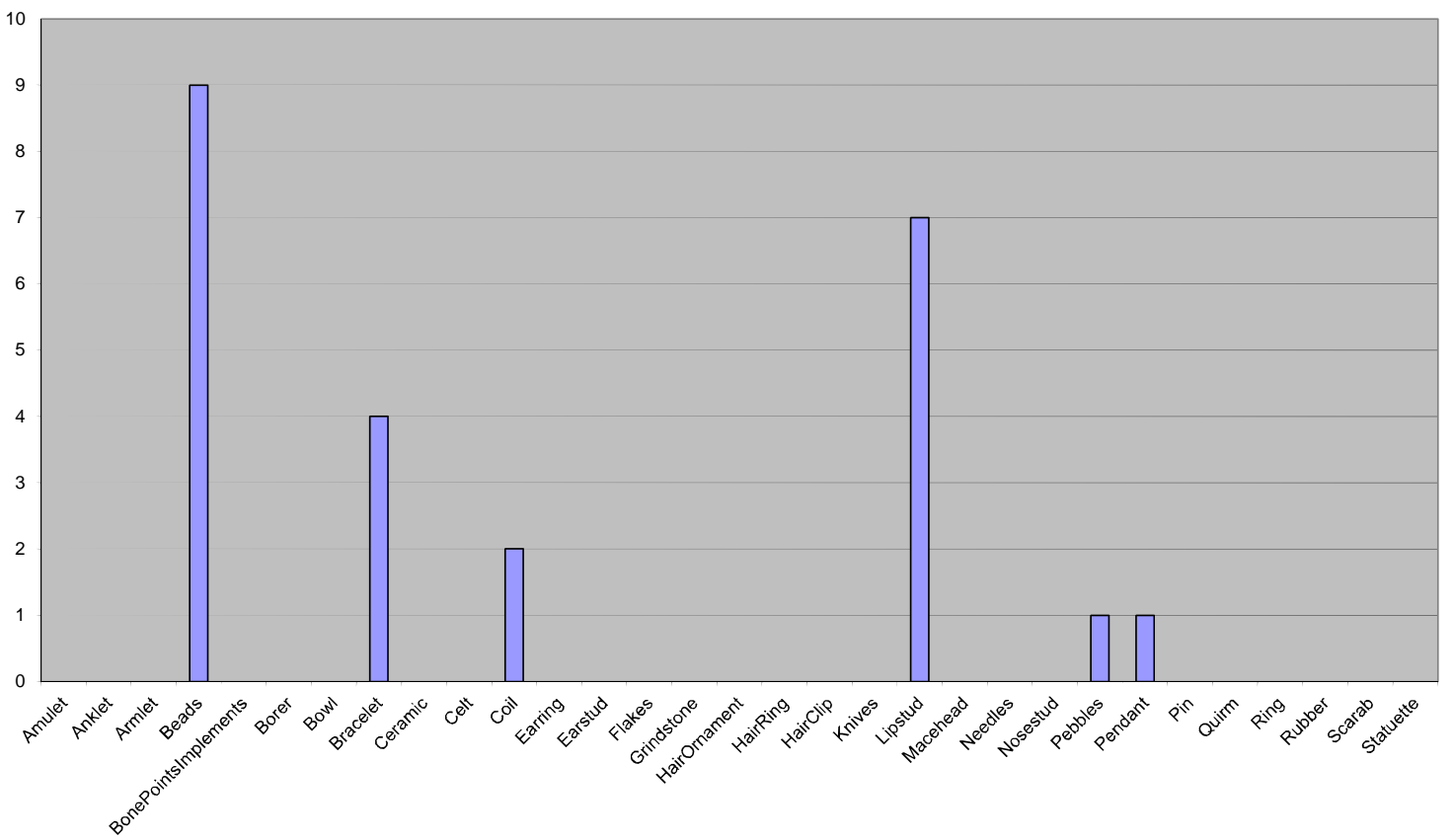

Figure 6.10 Occurrence of artefact categories amongst the burials of the North-East per adult female and adult male burials. Each sex category includes those tentatively assigned to it. 
East: Adult females

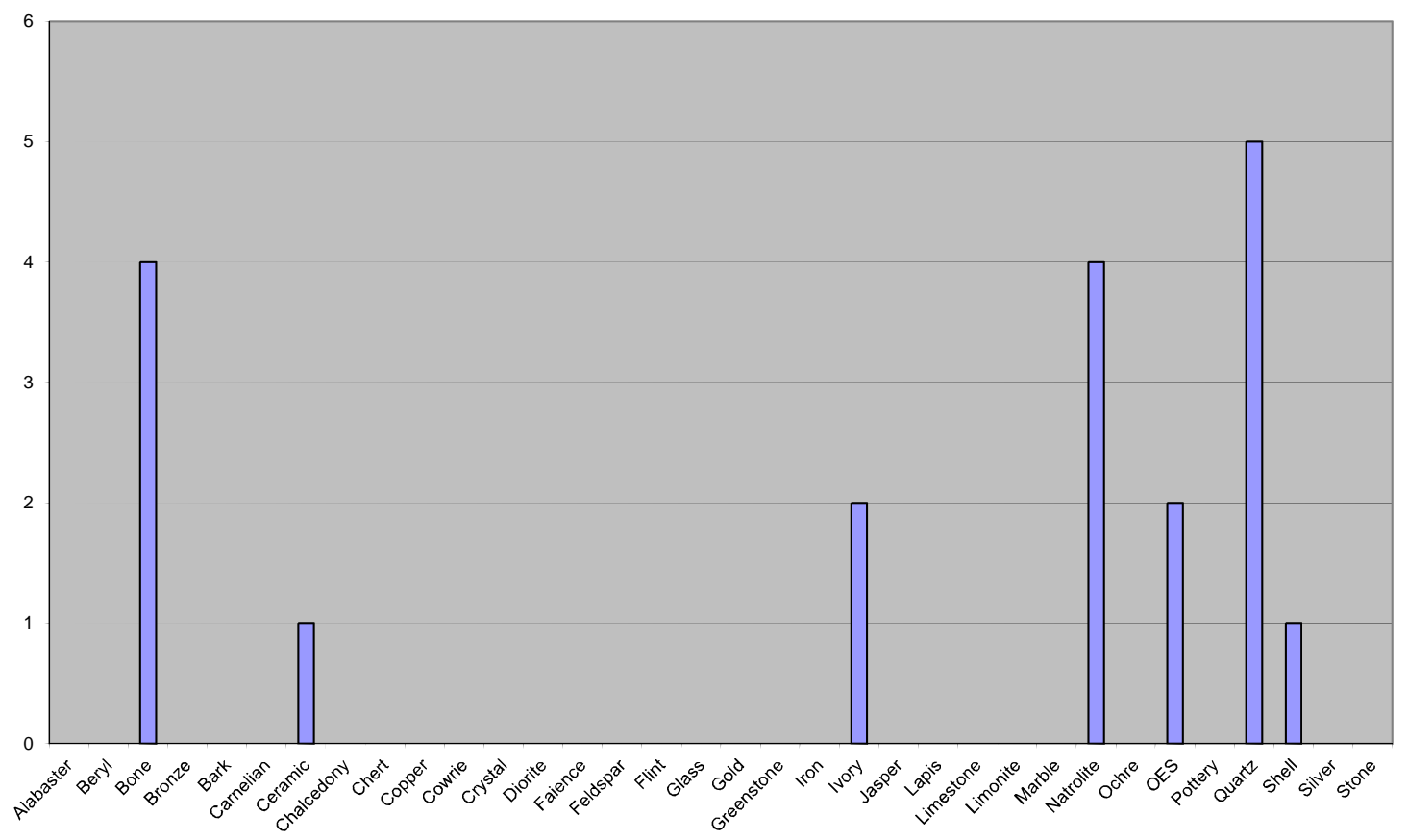

East: Adult males

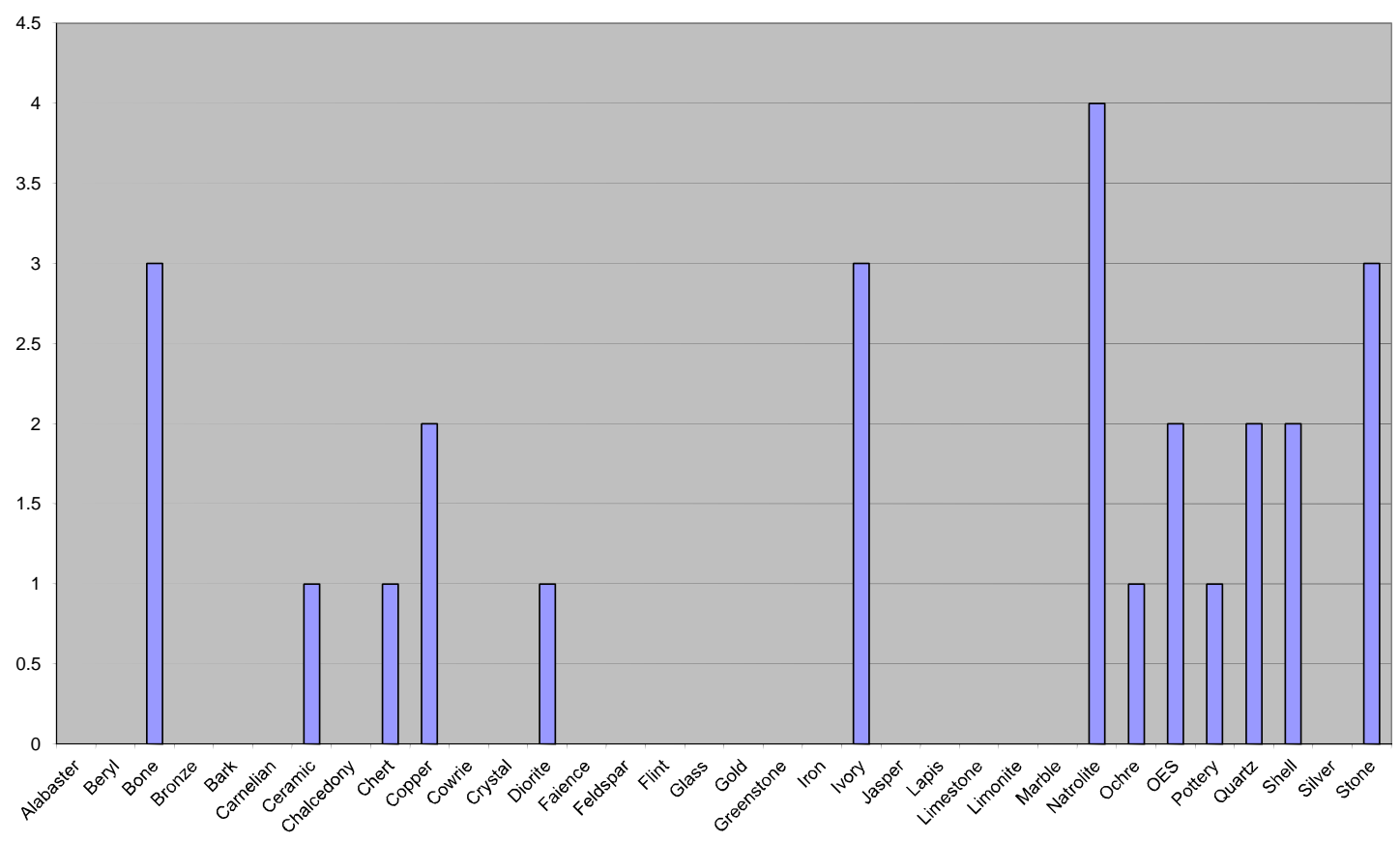

Figure 6.11 Occurrence of raw materials amongst the burials of the East per adult female and adult male burials. Each sex category includes those tentatively assigned to it. 


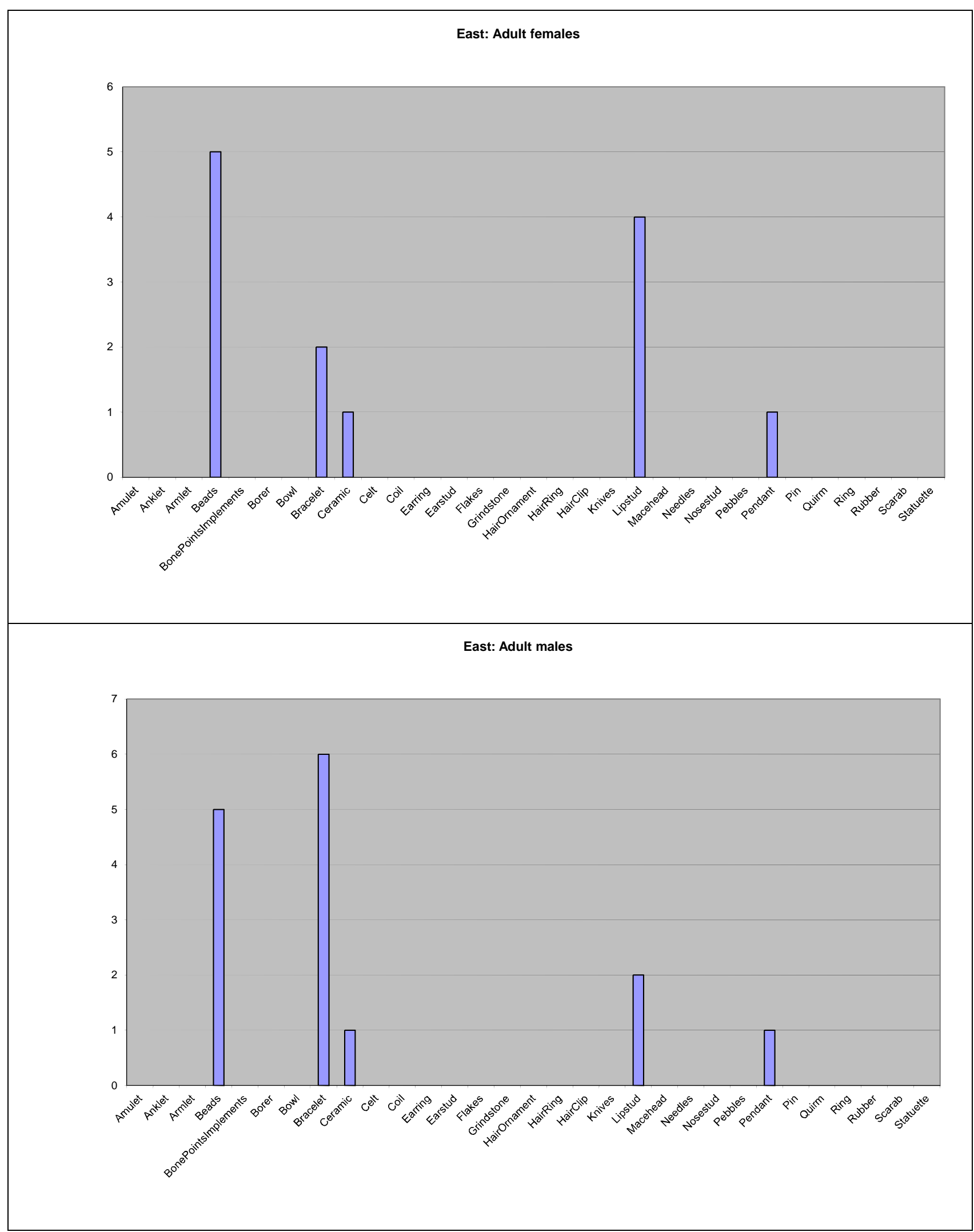

Figure 6.12 Occurrence of artefact categories amongst the burials of the East per adult female and adult male burials. Each sex category includes those tentatively assigned to it. 
While IDV cannot not be used on its own to pre-judge the nature of social complexity systems as it would be self-referential, it is best used to assist in looking at how social persona was deliberately represented at the point of deposition. It can be used as a springboard to see what cluster and spatial patterning may or may not be evident and to determine the extent to which any of those patterns have social meaning.

\subsection{Spatial methods for examining the Jebel Moya burial assemblage inventory}

The reliability of plotting finds distributions over landscapes has been questioned due to the recognition that modern recovery techniques can and do influence the areas surveyed, how the artefacts are recovered and indeed sometimes what artefacts are documented. For Jebel Moya, the potential for sample bias is lessened due to (1) the relatively large proportion of the valley excavated by Wellcome's teams, and (2) the employment of relative risk surface analysis (see section 6.1). Spatial analyses, namely correspondence analysis (CA) and multi-dimensional scaling (MDS), is undertaken against both the raw material and artefact type categories with the aim of determining whether there are any spatial clusters of burials based on similar presence/absence. Finally, pair correlation function is used to understand the spatial relationship between richer and poorer burials across the cemetery. The results allow movement beyond the concept of ambiguous social personae to look at how human actions reproduced and transformed social structure through rites are reflected in the mortuary domain. Such a stance thus moves beyond finding typologies of status differences based solely upon counting grave wealth. It also avoids the imposition of high-level theory without empirical grounding. By recognising the actions of human agency, the processes whereby status, power and resource access was embodied in the mortuary realm are shown to be vibrant social phenomena.

\subsubsection{Correspondence Analysis}

Correspondence analysis (CA) is an exploratory technique for examining relations between sets of variables (Shennan 1997). It is also a multivariate descriptive data analytic technique which simultaneously considers multiple categorical variables (Baxter and Cool 2010), i.e. data made up of "observations" - in this case the rows of 
graves in the new Register of Graves - of multiple "categories". The latter is either numerical counts of abundance data or set codes $-1 \mathrm{~s}$ and $0 \mathrm{~s}-$ for incidence data, the presence or absence of artefact and/or material categories in columns.

The multivariate nature ensures that any structural relationships can potentially be explored due to its flexible data requirements with a large data matrix and homogenously structured variables (in this case rows and columns of set data). It differs from principal component analysis (PCA) in that PCA is used with tables of continuous measurements, whereas CA utilises cross-tabulation tables. CA is usually presented in the form of a plot where each column and row is represented by a dot; if two rows have similar row profiles, their points will be located near each other. In other words, CA attempts to show how the variables are related in graphical form (Alberti 2013). Therefore, another advantage of CA is that it operates against tabulated data sets, unlike principal co-ordinate analysis which entails preliminary conversion of the data first into similarities or distances (Shennan 1997: 308).

For Jebel Moya, this entails examining whether there are any distinct relationships between burials based upon their accompanying burial assemblages in order to attempt to discern whether there was any meaningful differential structuring in how and where individuals were buried, as well as variability trends which may have spatial or temporal significance, or both. Four sets of multiple correspondence analysis were run in R (Nenadić and Greenacre 2007) against my Register of Graves as more than two categories variables (presence and absence of particular categories) were investigated: against all burials with accompanying burial assemblages for the artefact and raw material categories (Figures 6.13 - 14), and against burials containing the most commonly occurring types of artefact and raw material categories (Figures 6.15 - 16). 


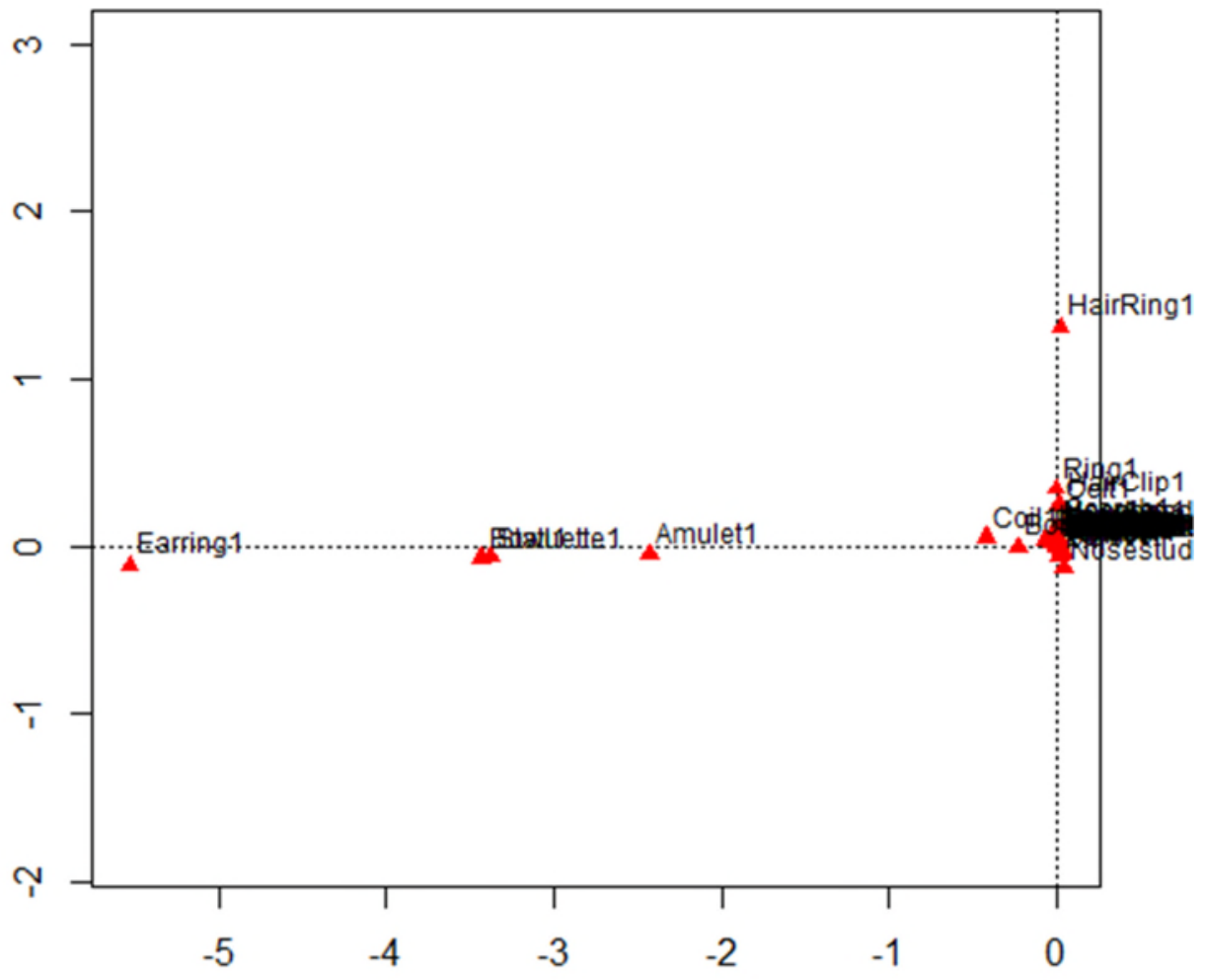

Figure 6.13 Correspondence analysis of the artefact categories against all burials across the cemetery with accompanying burial assemblages.

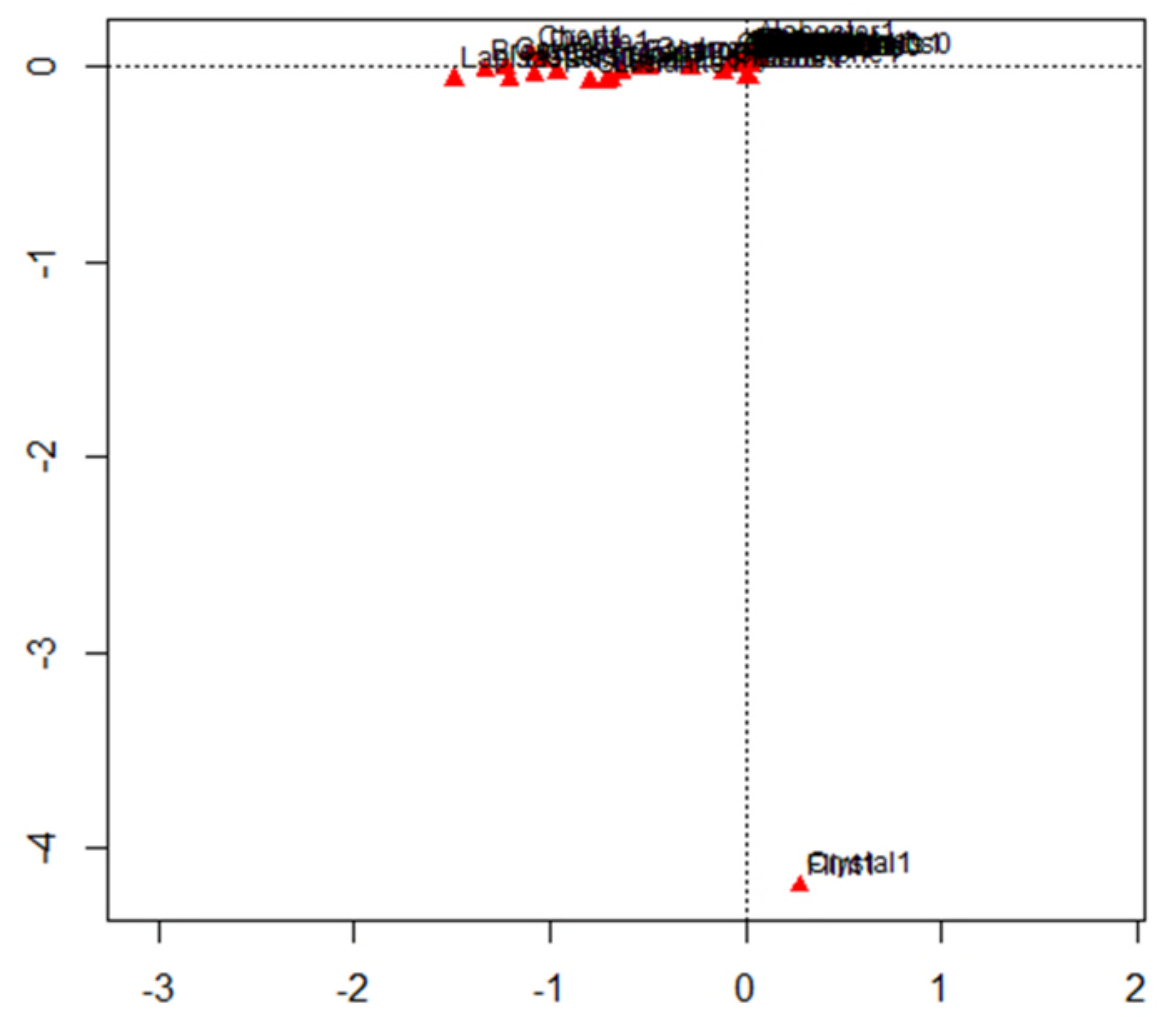

Figure 6.14 Correspondence analysis of the raw material categories against all burials across the cemetery with accompanying burial assemblages. 


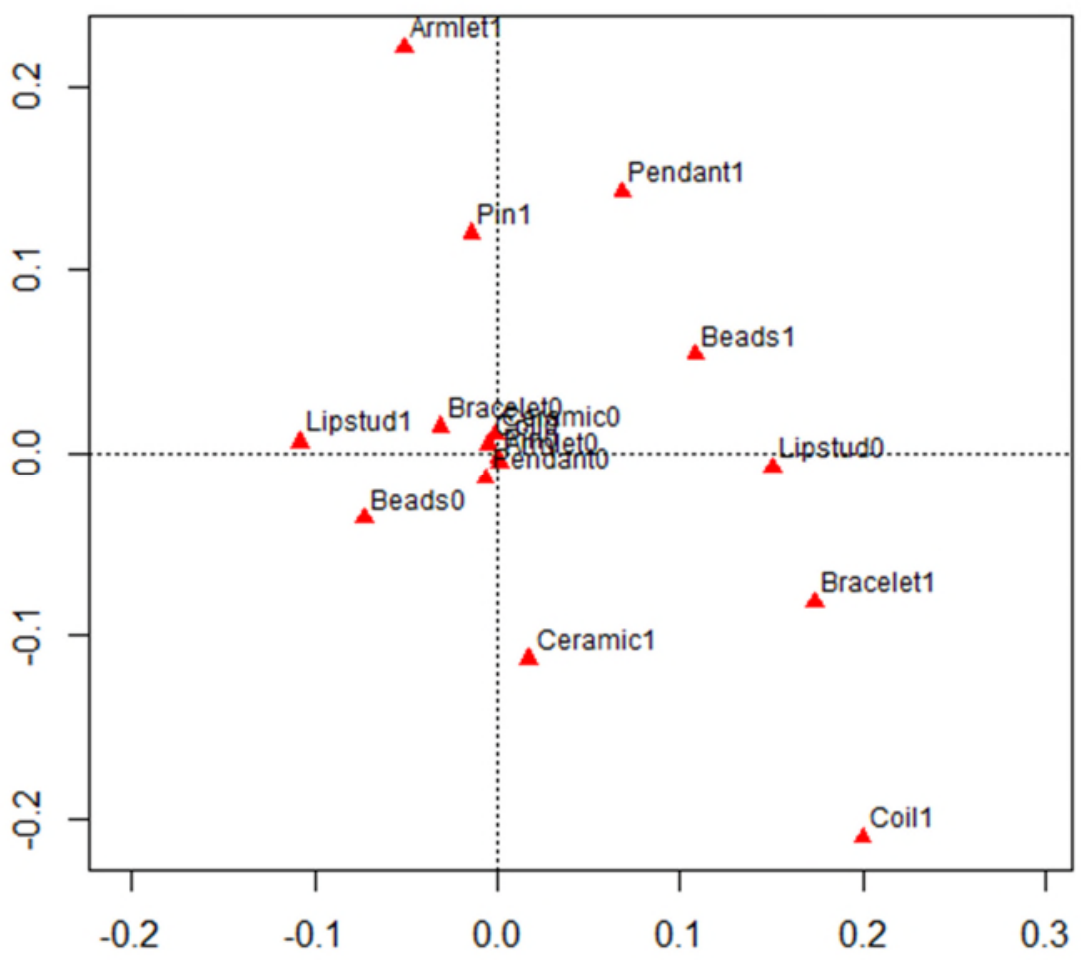

Figure 6.15 Correspondence analysis against burials containing the 20 most commonly occurring types of artefact categories.

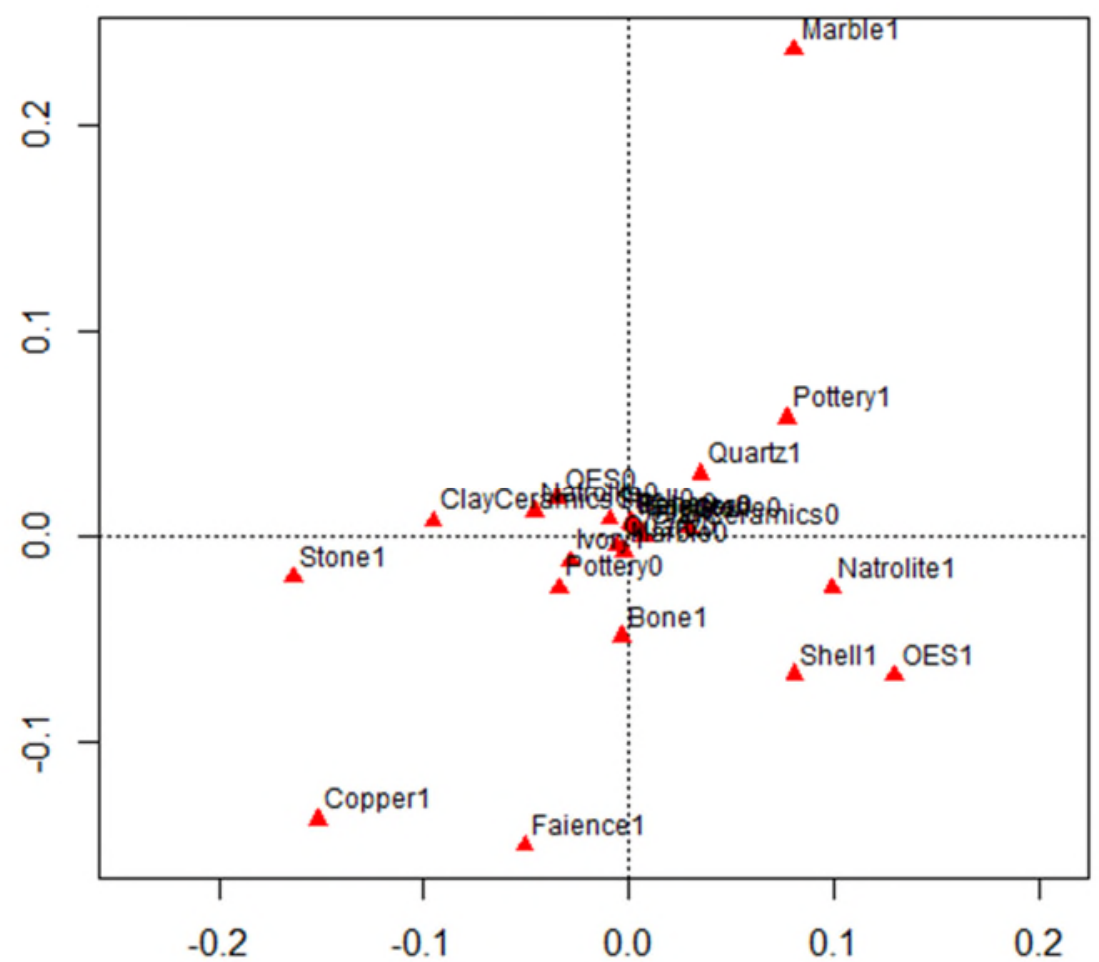

Figure 6.16 Correspondence analysis against burials containing the 20 most commonly occurring types of raw material categories. 
The resultant charts are normal 'symmetric' multiple correspondence plots. The position of each data-point relative to the others indicates the degree of association. Note the reason that there is a "1" at the end of each label is because there could also have been - but were not in this analysis - categories in the columns rather than 1/0 to indicate presence/absence. The distance between data points of the same time is indicative of the degree of similarity; the more points that are closer together, the more similar they are in terms of their assemblage composition (Alberti 2013: 481). The results from figures 6.13 - 14 indicate that the number of categories needed to be narrowed down. CA was subsequently conducted for raw material and artefact categories which occurred 20 or more times across all the burials. The value of 20 was chosen because it cut the category numbers down significantly, and the results are shown in figures 6.15 - 16. However, no valid clusters of burials were detected using either set.

\subsubsection{Pair Correlation Function}

Pair correlation function (PCF, also known as a radial distribution function) is a point pattern technique which looks at how spatially clustered, random or regularly-spaced a set of points are at different separation distances from one another. In this case, a 'cross pair correlation function' was used in which type A points are compared to type B points in the same overall spatial distribution (for example, to look at the spatial associations across the cemetery of one artefact type to another or one category of grave to another), and at what distance (e.g. short-rage clustering or only broader clustering). This method is less well known than but closely related to $\mathrm{K}$ and $\mathrm{L}$ functions, but its utility has been demonstrated as more valuable with highly variable and low frequency datasets (Illian et al. 2008). While $\mathrm{K}$ and L functions measure the density of points in ever expanding cumulative circles, PCF and cross-PCF measure how density of objects vary as a function of distance in non-cumulative ('doughnut') rings outwards from the specified reference points. The cross pair correlation function was chosen as the preferred method for examining the Jebel Moya data as the cumulative nature of (cross) $\mathrm{K}$ and $\mathrm{L}$ techniques can result in the swamping of larger patterns by small-scale clusters.

For the Jebel Moya dataset, PCF explores whether a clear spatial separation exists in the burials with goods, controlling for the underlying intensity of no-goods burials. It does so by determining the spatial configuration for richer burials and less-rich burials 
where each point represents a burial in two dimensional space. Richer burials are defined as having an Inverse Distance Value of $\geq 10$. Two tests were run in $\mathrm{R}$ against the burials of each sector of the cemetery: (1) The spacing of the richer burials versus each other, and (2) the spacing of richer burials against less-rich burials, with a randomisation of the labelling of 'rich' and 'non-rich' burials providing a Monte Carlo envelope of expected results.

For the first test (Figure 6.17), the spatial distribution of the richer burials shows no significant patterning, with no suggestion of standardised distances separating the burials. However, an interesting spatial neighbourhood phenomenon in terms of the distribution of richer versus poorer burials was observed in the second test when run against the cemetery as a single entity (Figure 6.18). When the overall study area was broken down into its constituent sectors for separate analysis, it became clear that this pattern is effectively driven by the North-East sector (Figure 6.19), where 336 of the 1185 human burials have accompanying burial assemblages, 27 of which have an IDV of 10 or greater (Figures 6.20 - 21, Table 6.10). The North-East sector is also where both the richest burials overall and the most skewed grave wealth distributions are observed and where there is some inhibition between richer and poorer burials at distances of up to $20 \mathrm{~m}$ where the line representing the data values dips below the randomisation envelope (Figure 6.19d). At larger distances, there is then significant clustering where the data values are greater than the randomisation envelope. Therefore, in this sector, there are fewer poorer burials than expected at short distances from richer burials, but a greater number of poorer burials than expected beyond: in other words, there appears an absence of poorer burials at shorter distances and then an unusually dense halo of such poorer burials at medium distances.

These results in the North-East sector in particular raise interesting questions about the meaning of spatial relationships. They suggest that to some degree it may not have been deemed appropriate to place poorer burials very close to the members of the communities buried with richer accompaniments in the North-East sector, i.e. there is clearly some kind of spatial neighbourhood. One possibility is that there may have been some form of above-ground marker for the rich graves indicating to the community where not to bury while the marker lasted and until the position of the grave(s) faded from memory. Such a spatial arrangement is unknown in the African pastoral 
ethnographic literature, but these burials cannot be uncritically assigned to hereditary elites or to a dominant clan lineage without critical analysis of the how different aspects of social organisation are represented (McHugh 1999), especially as there is a lack of spatially distinct clusters of both the physical burials and types of accompanying grave goods.

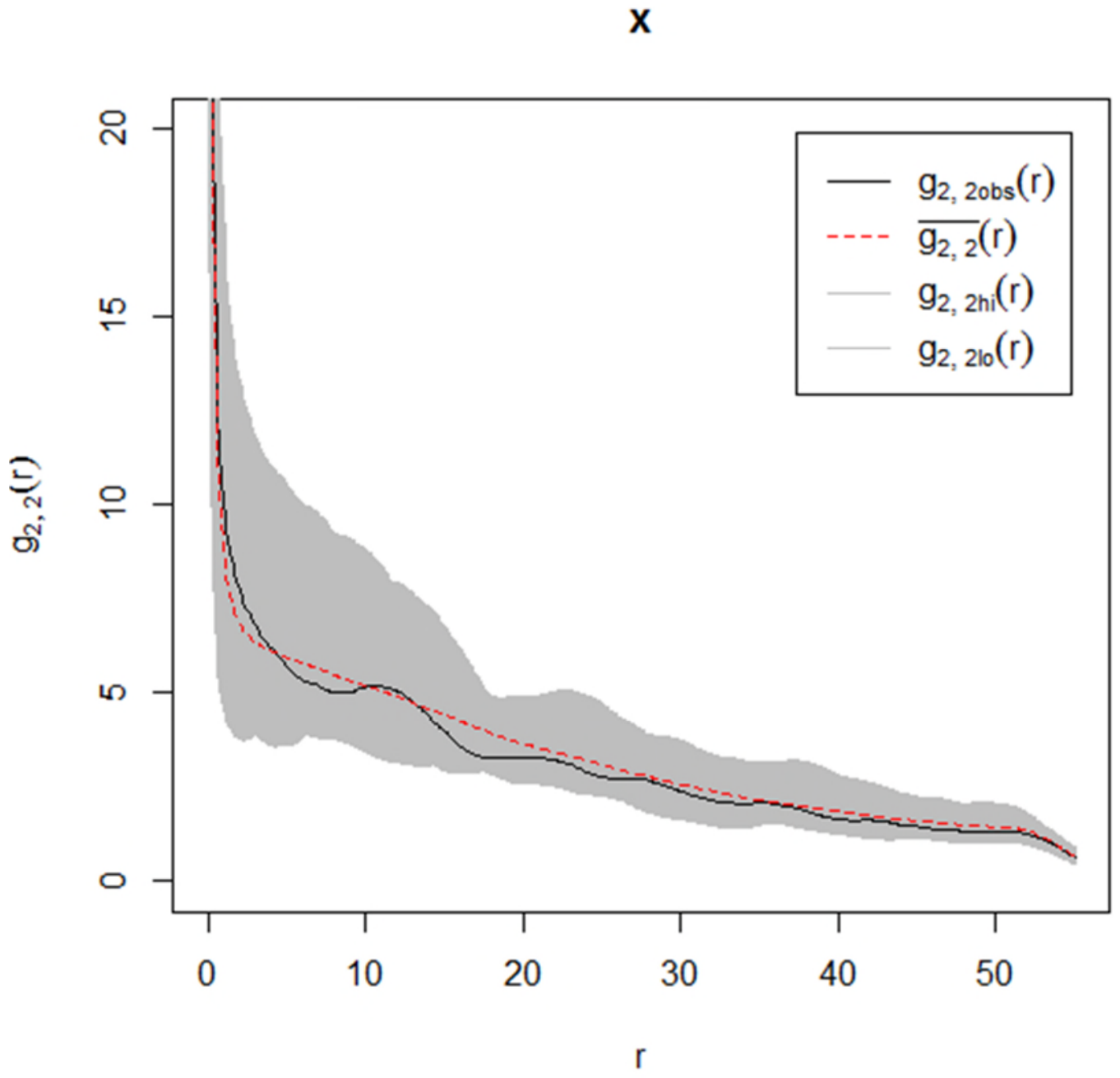

Figure 6.17 Pair Correlation Function plot of richer burials versus each across all sectors of the cemetery. X-axis: metres out from any given rich burial. Y-axis: an estimate of the density of neighbouring rich graves for difference distances along the $\mathrm{x}$-axis. Red line: average PCF value for 99 random sets. Black line: the burial data. Grey shaded area: wider envelope of possible values from the random sets. 


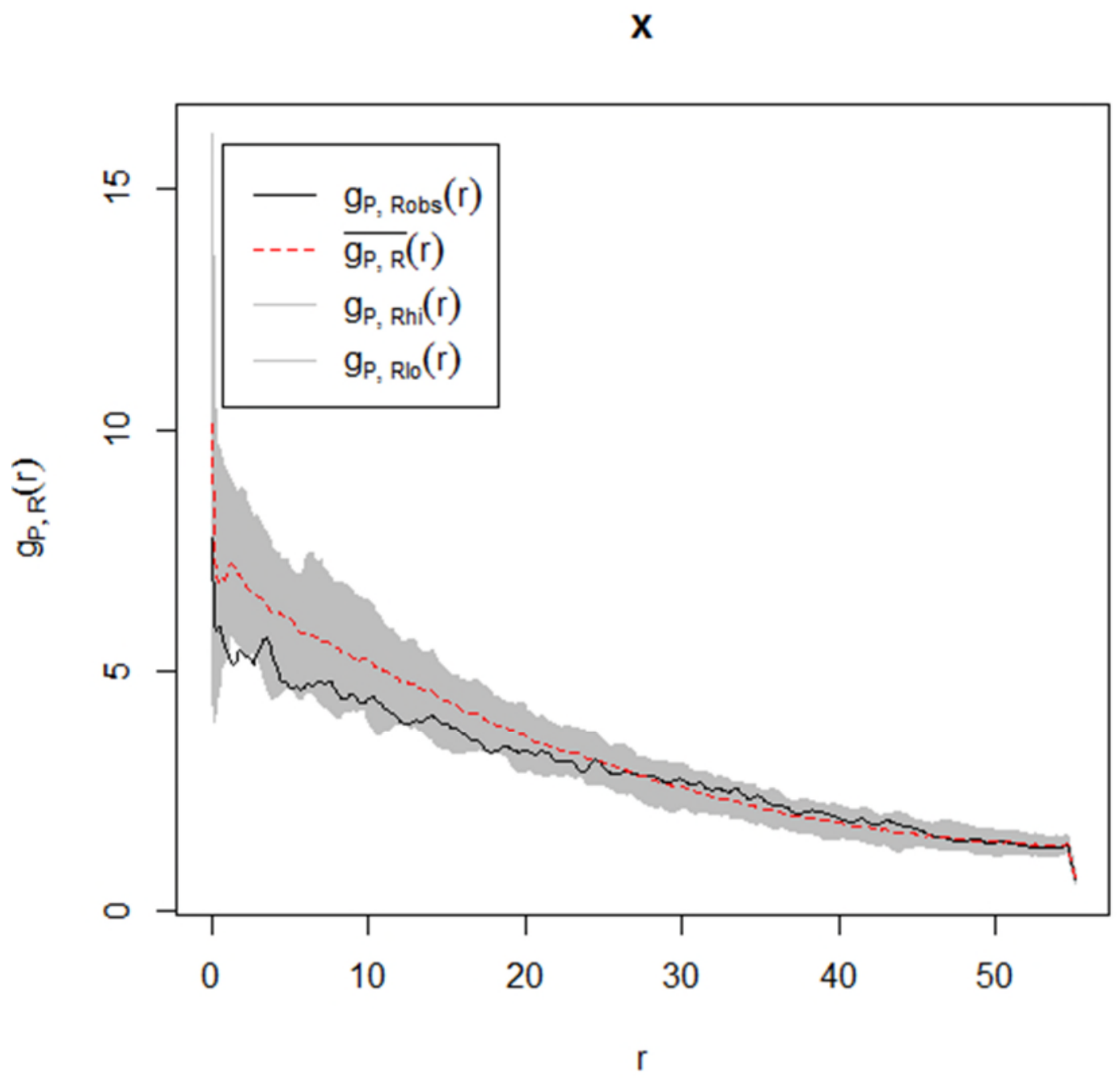

Figure 6.18 Pair Correlation Function plot of richer burials versus lesser-rich burials across all sectors of the cemetery. X-axis: metres out from any given rich burial. Yaxis: an estimate of the density of neighbouring rich graves for difference distances along the $\mathrm{x}$-axis. Red line: average PCF value for 99 random sets. Black line: the burial data. Grey shaded area: wider envelope of possible values from the random sets. 
$\mathbf{x}$

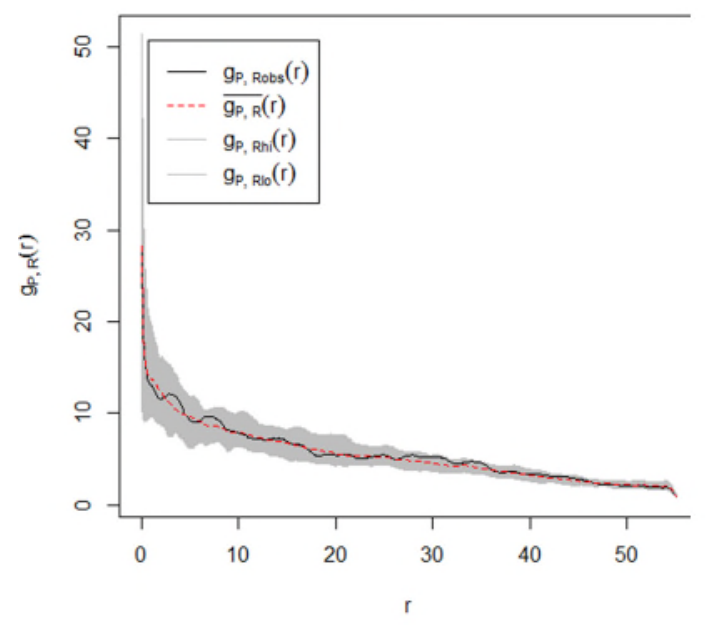

A

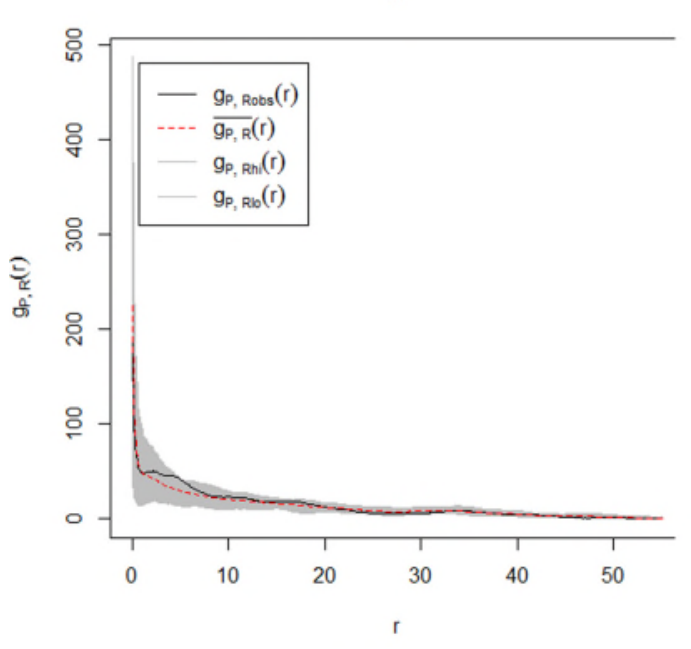

$\mathrm{C}$

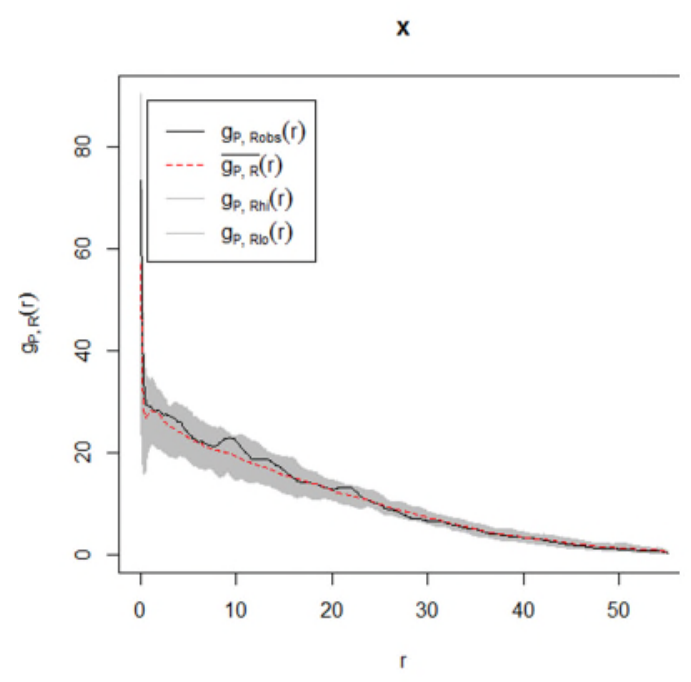

B

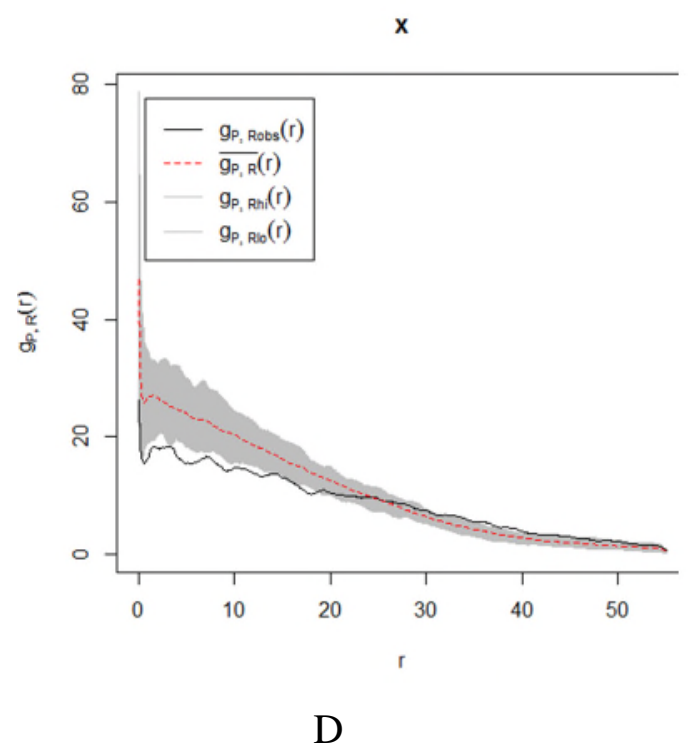

Figure 6.19 Pair Correlation Function of richer burials versus lesser-rich burials in four sectors of the cemetery: (a) South-West, (b) East, (c) North-West and (d) North-East. X-axis: metres out from any given rich burial. Y-axis: an estimate of the density of neighbouring rich graves for difference distances along the $\mathrm{x}$-axis. Red line: average PCF value for 99 random sets. Black line: the burial data. Grey shaded area: wider envelope of possible values from the random sets. 


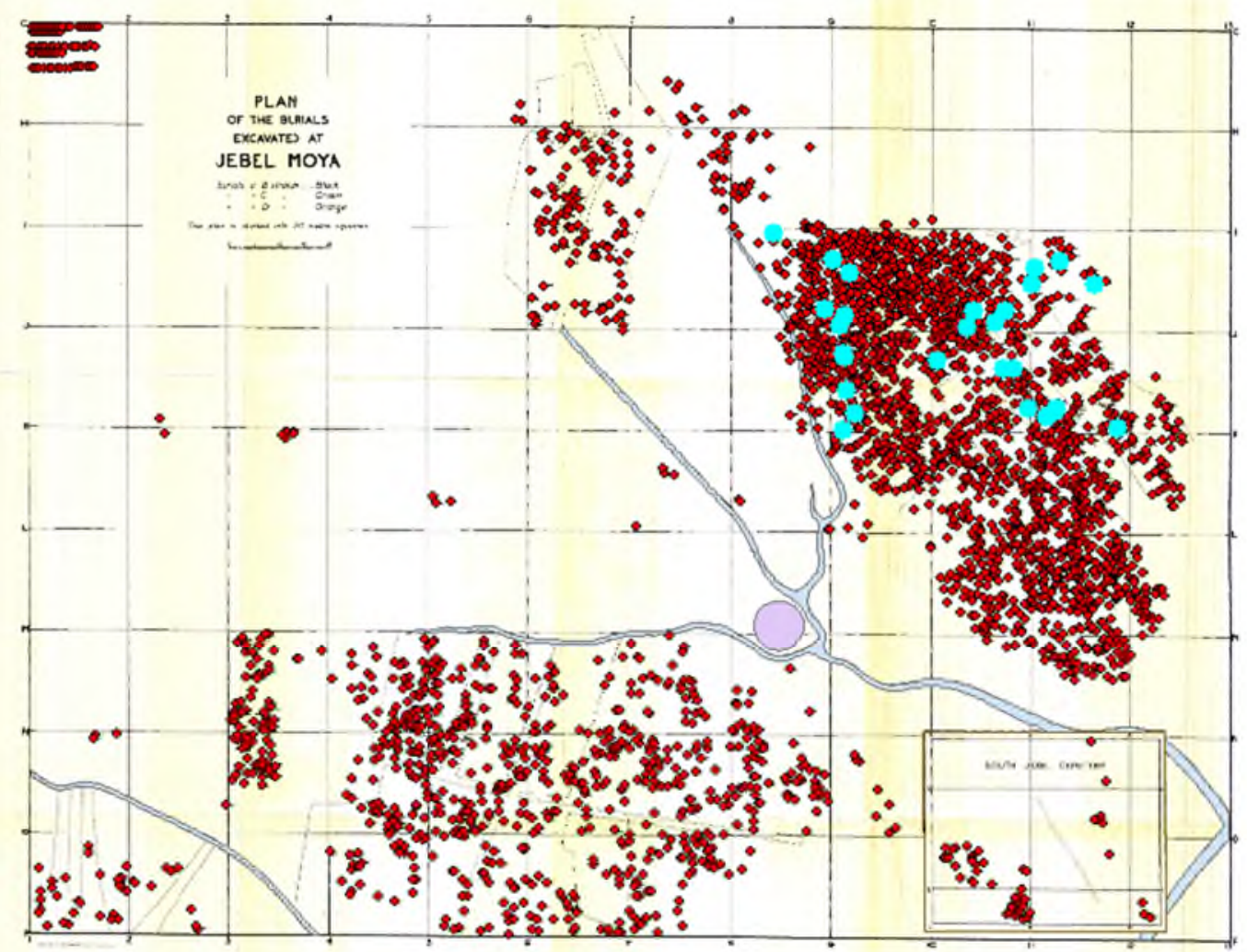

Figure 6.20 The 27 IDV 10+ burials in relation to the distribution map of all the burials plotted against Addison's original grave distribution map.

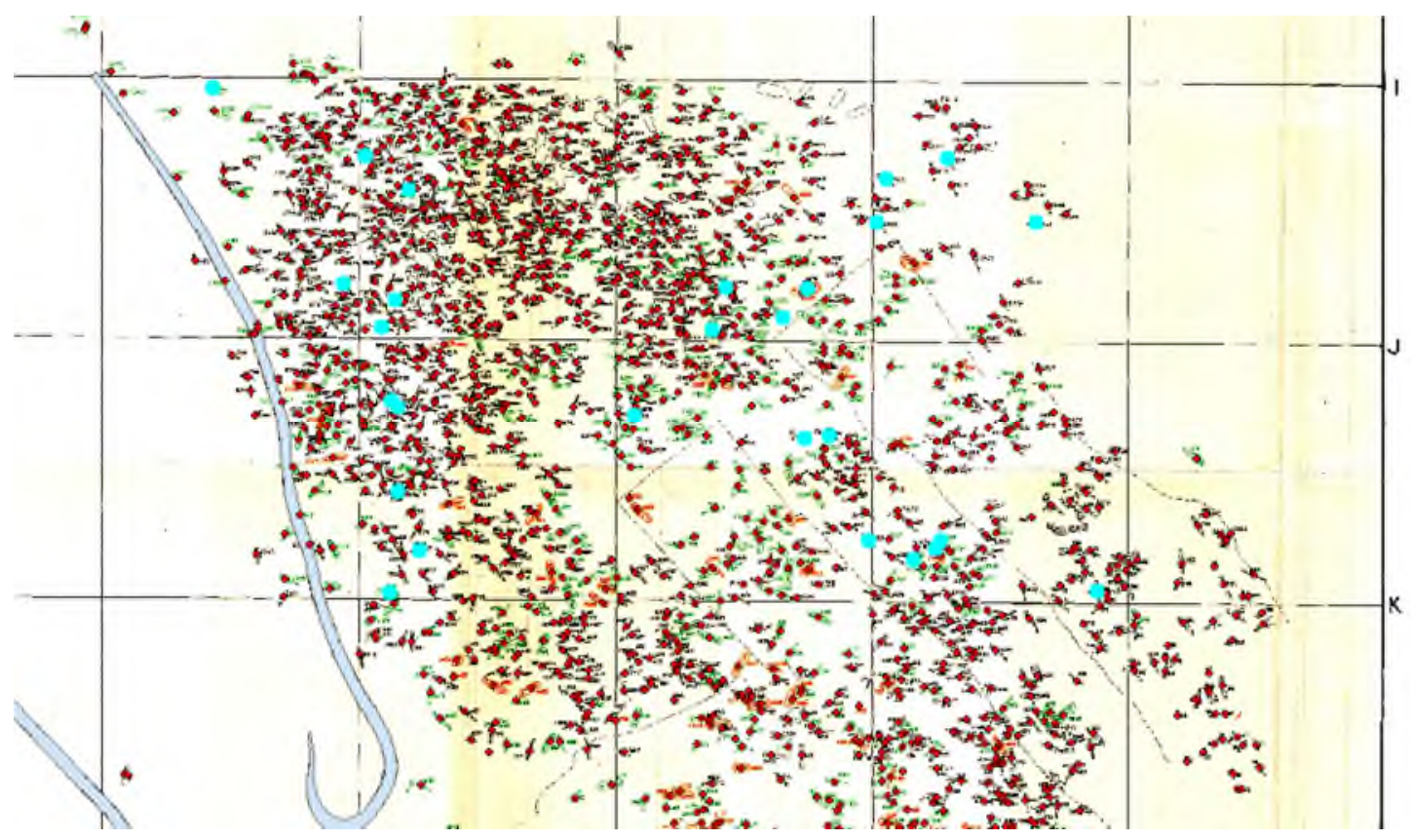

Figure 6.21 The plotted location of the 27 IDV 10+ burials in the North-East sector. 


\begin{tabular}{|c|c|c|c|c|c|}
\hline Burial & Square & $\begin{array}{c}\text { Distance above/below C } \\
\text { Surface }\end{array}$ & Orientation & Lab sex & IDV \\
\hline 2221 & $\begin{array}{l}\text { I.10, } \\
\text { J.11 }\end{array}$ & 0 & South-East & & 811 \\
\hline $2264 a$ & $\begin{array}{l}\text { I. } 10, \\
\text { J.11 }\end{array}$ & $110 \mathrm{~cm} \mathrm{-}$ & North-East & & 100 \\
\hline 1535 & $\begin{array}{l}\text { J.11, } \\
\text { K.12 }\end{array}$ & $95 \mathrm{~cm}+$ & South-West & $\begin{array}{l}\text { Adult. } \\
\text { Male }\end{array}$ & 23 \\
\hline $2432 b$ & $\begin{array}{l}\text { I.11, } \\
\text { J.12 }\end{array}$ & $35 \mathrm{~cm}+$ & North-West & & 22 \\
\hline 2069 & $\begin{array}{l}\text { J.11, } \\
\text { K.12 }\end{array}$ & $50 \mathrm{~cm}+$ & South-East & & 20 \\
\hline 1649 & $\begin{array}{l}\text { J.10, } \\
\text { K.11 }\end{array}$ & $100 \mathrm{~cm}+$ & & & 19 \\
\hline 1781 & I.9, J.10 & $35 \mathrm{~cm}+$ & East & & 19 \\
\hline $2225 a$ & $\begin{array}{l}\text { I.10, } \\
\text { J.11 }\end{array}$ & & & & 17 \\
\hline 2547 & $\begin{array}{l}\text { I.11, } \\
\text { J.12 }\end{array}$ & $60 \mathrm{~cm}+$ & East & & 15 \\
\hline 2155 & $\begin{array}{l}\text { I.10, } \\
\text { J.11 }\end{array}$ & & & & 14 \\
\hline 2622 & $\begin{array}{l}\text { I.11, } \\
\text { J.12 }\end{array}$ & & North-West & & 13 \\
\hline 1646 & $\begin{array}{l}\text { J.10, } \\
\text { K.11 }\end{array}$ & $85 \mathrm{~cm}+$ & North-West & & 13 \\
\hline $1939 a$ & $\begin{array}{l}\text { J.10, } \\
\text { K.11 }\end{array}$ & $15 \mathrm{~cm}+$ & & Adult & 13 \\
\hline 2732 & I. 8, J.9 & $40 \mathrm{~cm}+$ & North-West & Adult & 12 \\
\hline 2746 & I. 8, J.9 & $10 \mathrm{~cm} \mathrm{-}$ & West & & 12 \\
\hline 1839 & I.9, J.10 & $55 \mathrm{~cm}+$ & West & & 12 \\
\hline 1732 & J.9, K.10 & $45 \mathrm{~cm}+$ & East & Adult & 12 \\
\hline 1754 & J.9, K.10 & & South-West & & 12 \\
\hline 1713 & $\begin{array}{l}\text { J.11, } \\
\text { K.12 }\end{array}$ & $55 \mathrm{~cm}+$ & & & 12 \\
\hline 2332 & $\begin{array}{l}\text { I.11, } \\
\text { J.12 }\end{array}$ & $60 \mathrm{~cm}+$ & North-West & & 11 \\
\hline 1756 & J.9, K.10 & & South-East & $\begin{array}{l}\text { Adult. } \\
\text { Male }\end{array}$ & 11 \\
\hline 2148 & J.9, K.10 & & East & & 11 \\
\hline 100 & $\begin{array}{l}\text { J.11, } \\
\text { K.12 }\end{array}$ & $80 \mathrm{~cm}+$ & North & $\begin{array}{l}\text { Adult. } \\
\text { Female }\end{array}$ & 11 \\
\hline 2276 & I.9, J.10 & $15 \mathrm{~cm}-$ & West & & 10 \\
\hline 1755 & J.9, K.10 & & North & & 10 \\
\hline 2065 & $\begin{array}{l}\text { J.11, } \\
\text { K.12 } \\
\end{array}$ & $30 \mathrm{~cm}-$ & West & & 10 \\
\hline 1785 & I.9, J.10 & $75 \mathrm{~cm}+$ & South-West & & 10 \\
\hline
\end{tabular}

Table 6.10 North-East sector burials with an Inverse Distance Value of 10+ sorted in descending order of their values. The listed lab sexing was done by the Duckworth Laboratory on their extant human remains. 
Of these 27 'IDV rich' burials in the North-East sector (Table 6.10), only six were present in the Duckworth Laboratory's existing collection and re-aged and re-sexed: three adults, one adult female and two adult males. All 27 burials were excavated in the fourth (final) season and therefore the original field sex determinations cannot be relied upon (see Chapter 5.1).

A high proportion of the total number of occurrences of the imported raw materials categories within the North-East sector (Table 6.4) occur in these rich burials. Given that there are 336 burials with accompanying assemblages, a percentage figure of $18.42 \%$ for the occurrence of faience in the richer graves is quite significant. In other words, seven out of the 38 burials where faience occurs amongst the assemblages are amongst the 27 richest burials. For gold, there is a similar picture with two out of the four occurrences, while carnelian sees four out of 14 occurrences. These burial assemblages comprise not just an increased number of artefacts like lipstuds made from locally available materials but also hold a disproportionately high number of artefacts made from long-distance raw materials; the extraction of these valued goods from their social circulation and placement in the mortuary realm is an indicator of the different attitudes displayed towards those particular individuals in death (MacDonald 2011b). A notable example is burial 2221 with a comparatively lavish assemblage including 200300 faience beads and two items made from bronze: a clip and a ring.

However, there appears to be little differentiation in burial orientation between these 27 richer burials and the remaining 857 burials for the North-East sector which have cardinal co-ordinates recorded (Figures 6.22 - 23). In the wider literature, a common element of differentiation lies in the orientation of the body in select graves compared to other clusters of graves or sections of a cemetery in order to demarcate status, wealth or other social standings (McHugh 1999). This, however, is not the case at Jebel Moya where the richer burials fall within the range of cardinal variations, nullifying directionality as a distinguishing factor. 


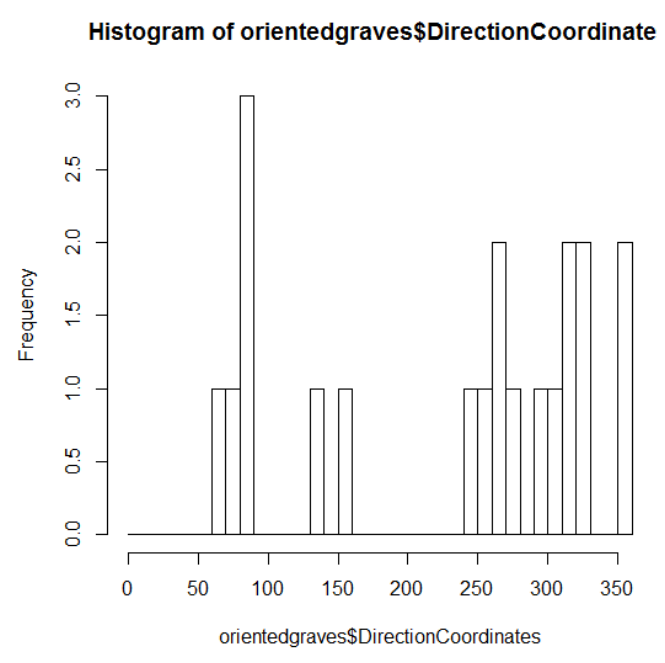

A

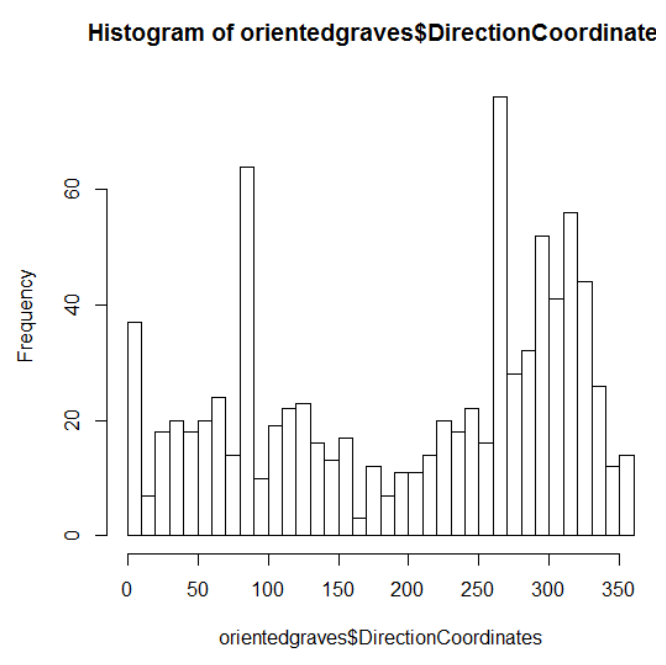

B

Figure 6.22 Comparative histograms of the (a) cardinal directionality of the 27 IDV $10+$ burials, and (b) cardinality directionality of all burials in the North-East sector.

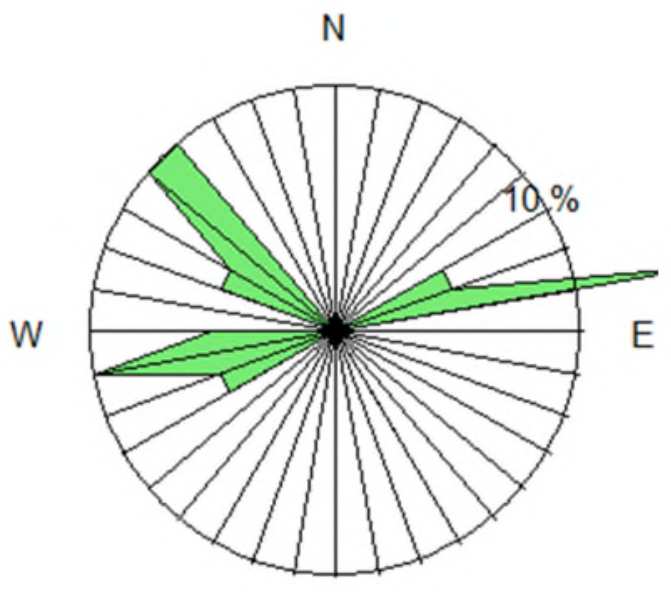

S

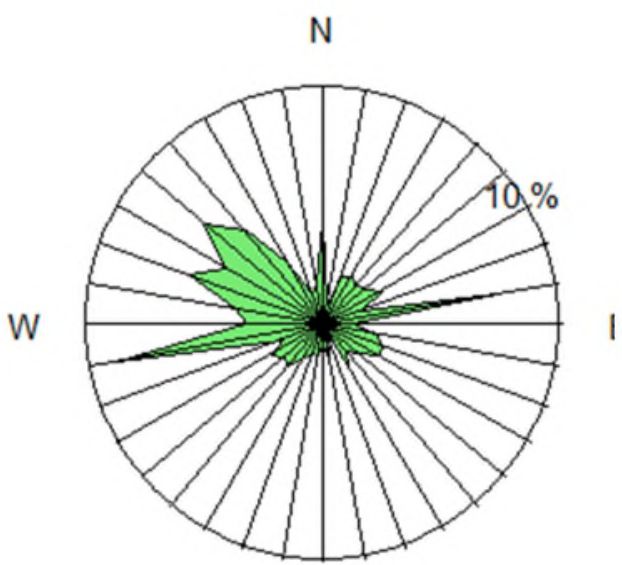

$\mathrm{S}$

A

B

Figure 6.23 Comparative compass map of the (a) cardinal directionality of the 27 IDV $10+$ burials, and (b) cardinality directionality of all burials in the North-East sector.

However, there is some interesting variation in the reconstructed surface levels from which the graves were most likely dug (Figure 6.24). While no depth measurements were provided for seven out of the 27 rich burials, and there is an outlier burial at $-10 \mathrm{~cm}$ below the surface of Stratum C, the remainder of the reconstructed burial surfaces start from $70 \mathrm{~cm}$ above the surface of Stratum C. The graph is consistent with the pattern shown in Figure 4.12, in so far as the concentration of rich burials coincides with the rise and decline of the peak period of burial activity in the sector. Figure 4.12 also 
indicates that there were few pre-existing burials in the North-East prior to the deposition of the richer burials within the time period demarcated by the OSL dates for Assemblage 3.This may indicate that this sector was deliberately chosen after the cemetery layout elsewhere had been established. So, it can be argued that what is being exhibited are intentional burial patterns with a portion of the cemetery delineated from a particular moment in time to a sector of the population who commanded enough respect and status to be actively spatially distinct from those individuals deposited in less rich graves.

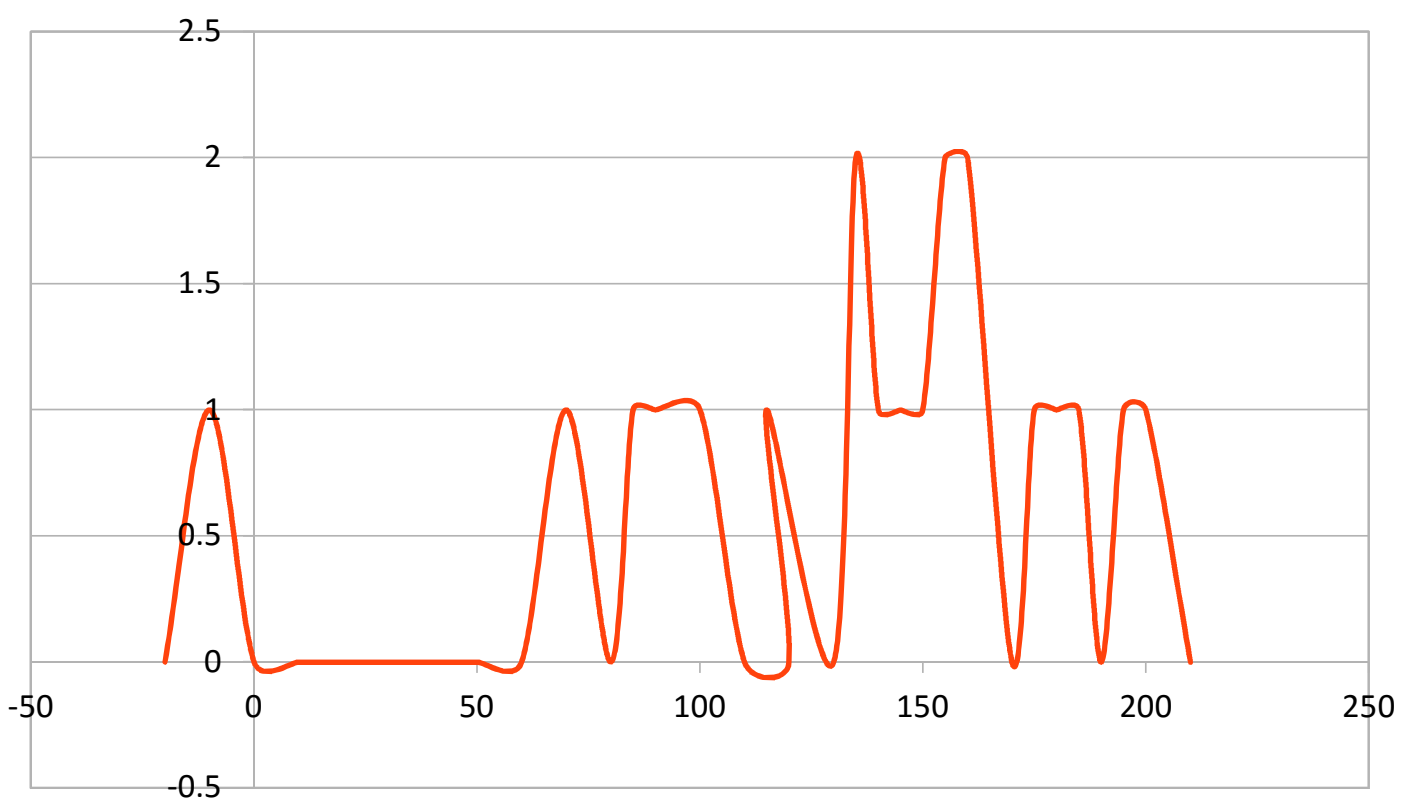

Figure 6.24 Reconstruction of the number of the IDV 10+ burials dug from levels above and below the surface of C Stratum for the North-East sector.

It is quite possible, therefore, that what is being seen is a spatial neighbourhood of an elite group of individuals who were buried in a known sector of the mortuary valley. In light of the new picture emerging from cross pair correlation function, it was decided to perform a multi-dimensional scaling to revisit the issue of clustering of burials based on the nature of their accompanying assemblages, as the latter technique is more widely in use in modern North American mortuary archaeology than correspondence analysis (Carr and Case 2005). 


\subsubsection{Multi-dimensional scaling}

Despite the clear age group patterns arising from the Inverse Distance Values and the spatial neighbourhood pattern determined by cross pair correlation Function, there is always a risk that an important burial containing just one or two items would have been overlooked. For example, a burial containing an item such as a horse hair whip (a potential symbol of leadership) would (a) be omitted by narrowing down the rich burials through high Inverse Distance Values, and (b) have its archaeological emphasis determined by the particular weight or score placed upon it by the investigator's judgement. For instance, in the North America Mississippian world, very important sets of remains end up as disarticulated bundles in the flanks of mounds (Sullivan and Mainfort 2010).

In order to minimise such instances, many US mortuary analysts employ multidimensional scaling (MDS) instead of correspondence analysis due to improved robustness to any potential variations in the sampling pattern and avoidance of potential distortions (Scott Thompson 2014; Sullivan and Mainfort 2010). Gaussian ordination (GO), principal components analysis (PCA) and principal co-ordinates analysis (PCoA) have been shown to be less effective, the former due to sensitivity to "noise" and the latter due to curvilinear distortions (Minchin 1987).

MDS examines the relationship between points in terms of similarity and dissimilarity,

"and a representation of the relationships between the cases in a multidimensional space, the number of dimensions being one less than the number of cases. From this starting point the method successively reduces the number of dimensions in which the points are represented, at the same time trying to keep to a minimum the distortion in the relations between the points which begins to arise as the number of dimensions is reduced." (Shennan 1997: 348)

In essence, MDS is used to look for patterns of co-occurrences ("bundled sets") and then to look for rare and/or unique items or sets of items at the margins of co-ordinate spaces. 
Going back to the horse hair whip example, this approach stands a chance of identifying such an item as somehow rare and/or unique, even if there is nothing else in the grave.

A principal method used in MDS is non-metric multi-dimensional scaling (NMDS). Shennan (1997: 348) explains NMDS thus:

"The specific feature of the method is that, in contrast to principal coordinate analysis, it is non-metric: it works not on the actual numerical values of the similarities/distances between the cases but on their rank-ordering. That is to say, it is the rank ordering of the distances/similarities between the points which the method tries to preserve as the dimensions are reduced. Thus, if the distance between point (item) $\mathrm{x}_{\mathrm{i}}$ and point (item) $\mathrm{x}_{\mathrm{j}}$ is the tenth smallest distance in the original distance matrix, it should remain the tenth smallest as the number of dimensions of the multidimensional representation is reduced. This property means that the similarity/distance measure used to create the matrix does not have to be fully quantitative, so long as we have a basis for saying "this is nearer to this than to that."

NMDS is therefore an ordination method that collapses multiple variables into just two or sometimes three axes for easier visualisation. For Jebel Moya, the co-ordinates of each burial were derived in ArcGIS from Addison's plotting each on his burial distribution map. Therefore, $\mathrm{x}$ and $\mathrm{y}$ co-ordinates were derived which enabled calculation of both distance (between burials) and similarity (of raw material and artefact categories) to be undertaken. NMDS was run in R (nMDS1 using metaMDS, daisy which is a function to calculate the dissimilarity matrix) against two sets of data from all the recorded burials across all sectors in the cemetery, producing 20 run stress points which were then plotted: (1) The artefact categories, but this time combined with the raw material categories to state what each occurrence of the artefact was comprised of (Figure 6.25), and (2) the presence or absence of the artefact categories (Figure 6.26). The latter was also run against the North-East sector's burials (Figure 6.27). 


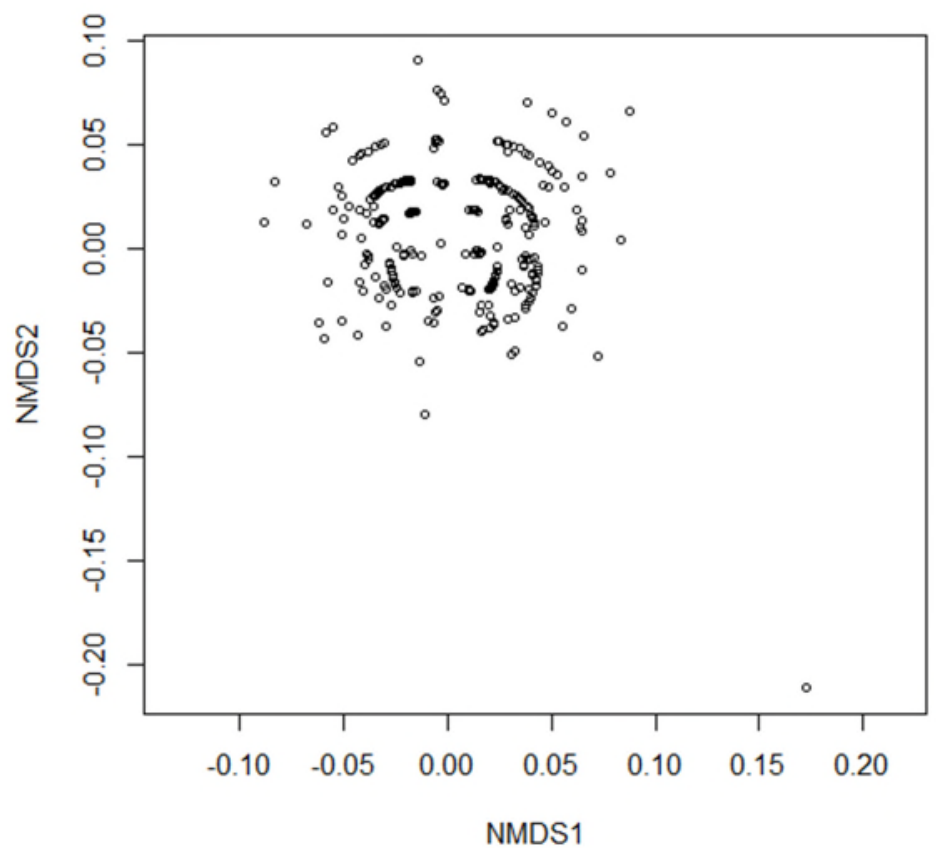

Figure 6.25 NMDS plot of all burials across the cemetery using the occurrence of artefacts and the raw material each was made from.

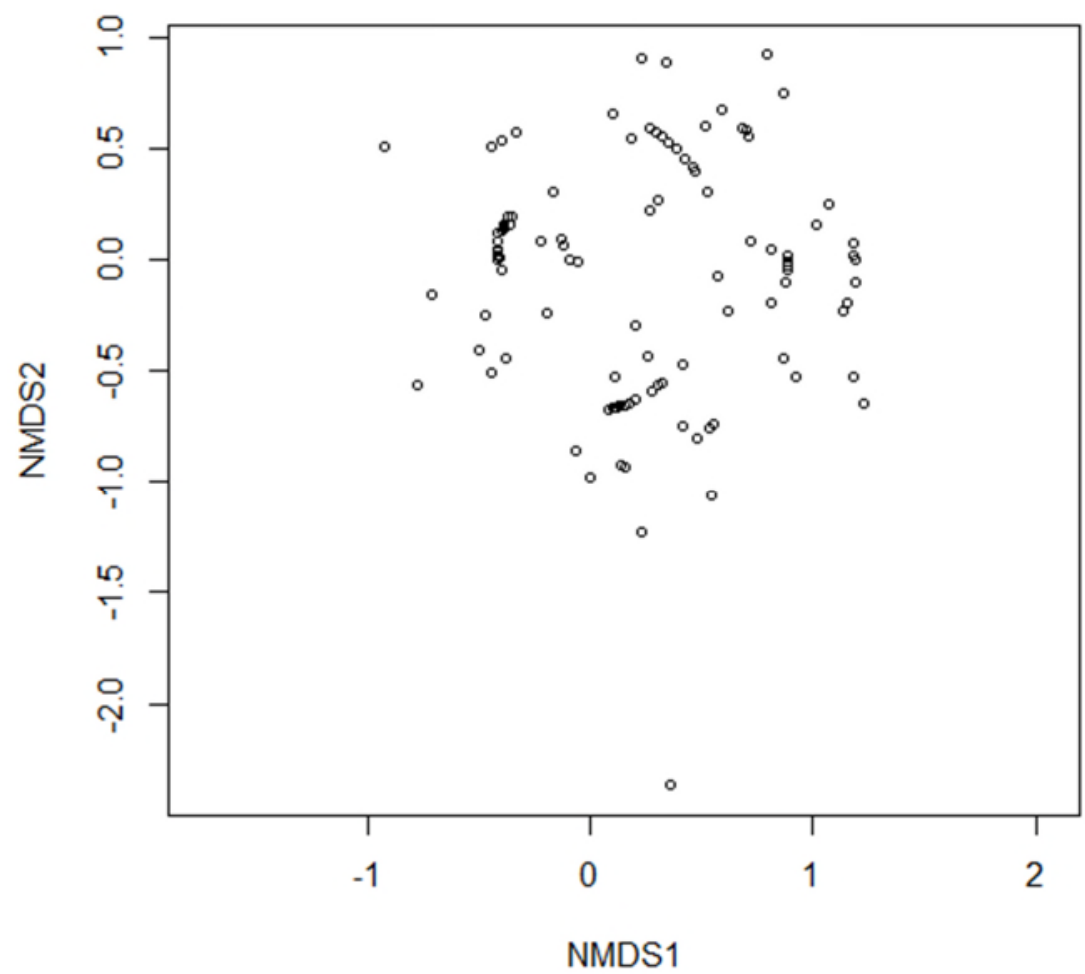

Figure 6.26 NMDS plot of all burials across the cemetery for the presence/absence of the artefact categories. 


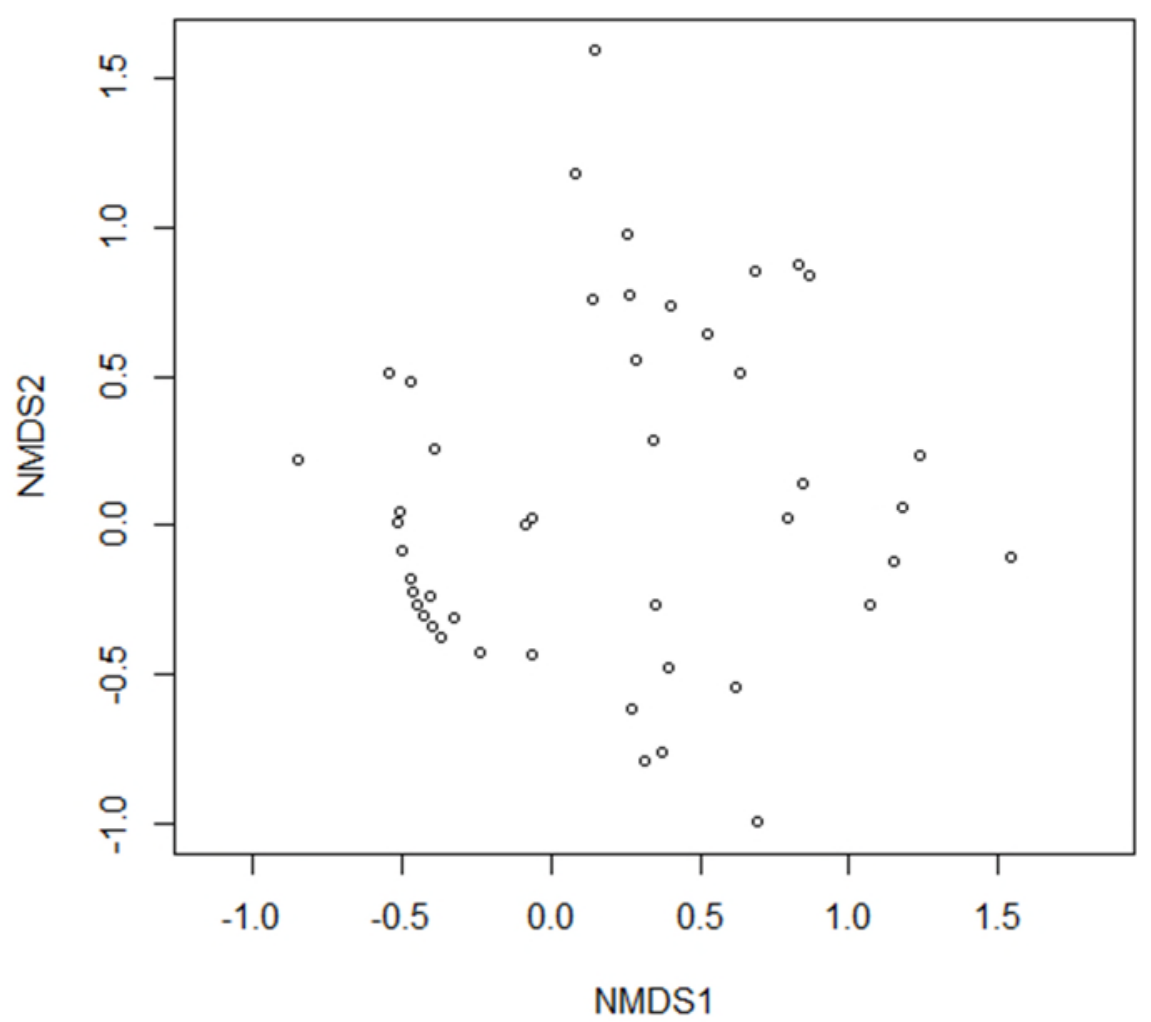

Figure 6.27 NMDS plot of all burials in the North-East sector for the presence/absence of the artefact categories.

Terminology for NMDS is typically derived from the ecological sciences where it is widely used: What the plots display are "sites" (burials) and "species" (burial good types), where the former is overlain by the varying emphasis of the burial good types in the result. The latter pull the burial data in different directions on the plots to a stronger or lesser degree. Neither axis is therefore a "species" but is rather the combining weighting of many "species" where the two axes are deliberately made to expose variation as much as possible (i.e. the weighted combinations of variables for each axis were chosen to do this).

There is an interesting radial arrangement in all the plots of cases, with each data point representing a burial. The radial nature of the plot could be due to the number of burials with identical, small assemblages. Although it looks at first sight like there are four clusters of cases in Figures 6.26 - 27, there is the risk that using the presence or absence of artefact categories may have compressed the readings as it operates at a higher practical level than the artefact-material-types categories. While the former produces what looks to be like distinct clusters, the latter does not, probably on account of the 
diversity of raw materials, i.e. that the sheer variability introduced by the inclusion of raw material types may have ended up glossing over other possible potential patterns/clusters.

Consequently, distance-based metric multi-dimensional scaling (DMMDS, also using daisy) was run against the dataset as DMMDS tends to produce strong visualisations of metric data, with a gradient-based optimisation procedure that tends towards a more robust neighbourhood alignment of feature sets (in this case, the burial assemblages). The DMMDS of all burials with the artefacts-with-material-types and presence/absenceof-artefacts categories was plotted across the cemetery, with a difference: all burials with two or less categories present were disregarded to assist in determining potentially valid outliers (Figures 6.28 - 29). At the same time, labels were applied to the resulting plotted burials to be able to identify and interpret them.

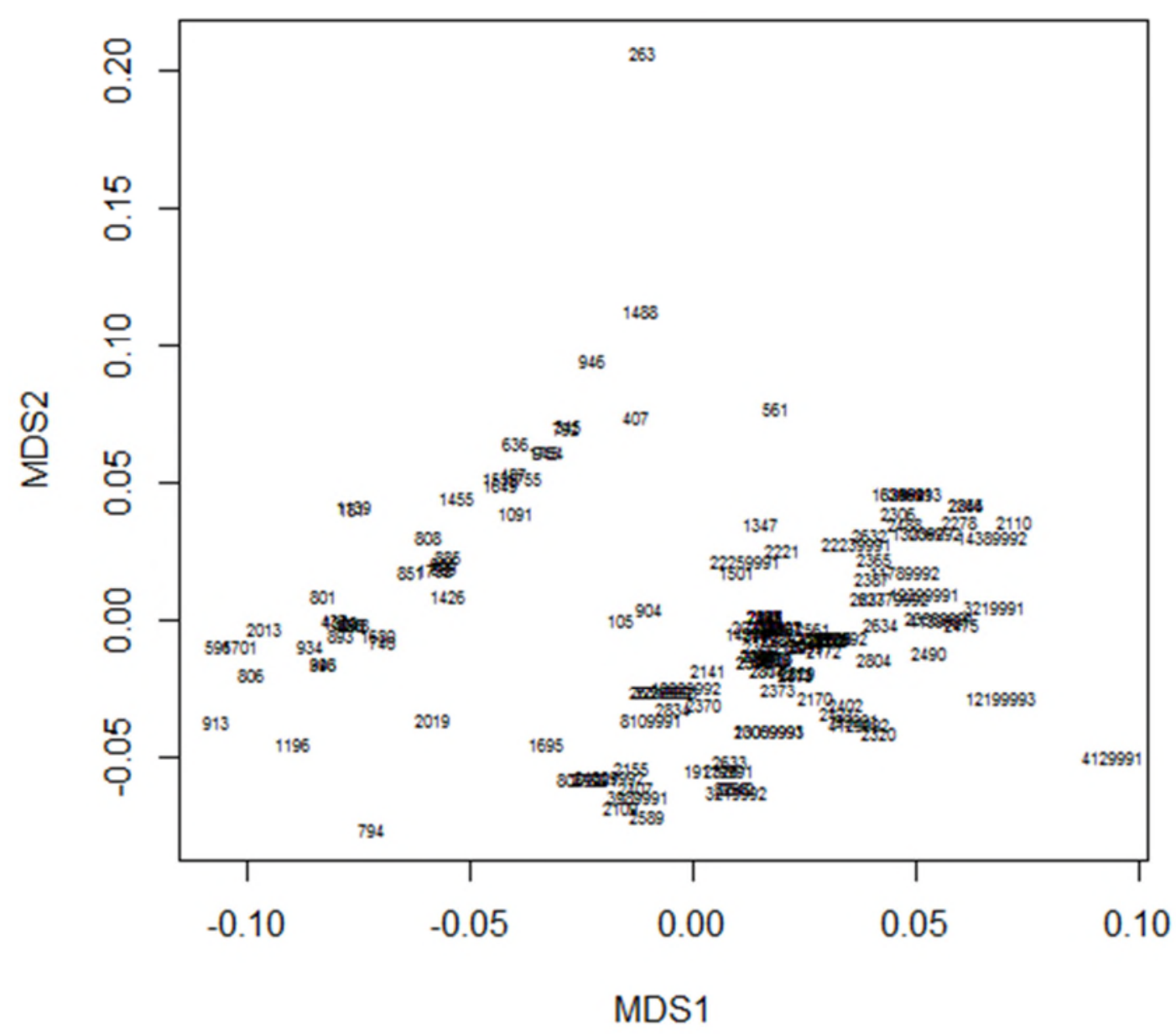

Figure 6.28 DMMDS plot of all burials across the cemetery with three or more artefacts-with-material-type categories. 
The number of burials with more than two artefacts-with-material-types categories present is 160 (Figure 6.28), twice that for the number of burials using the presence/absence of artefact categories (80) (Figure 6.29). The discrepancy in the numbers is due to some burials having two of the same object count made from different materials which the latter counts as one occurrence. The higher count for the former is due to it being an artefact of the variety of materials used in making a wide range of artefacts, with most present in low frequencies.

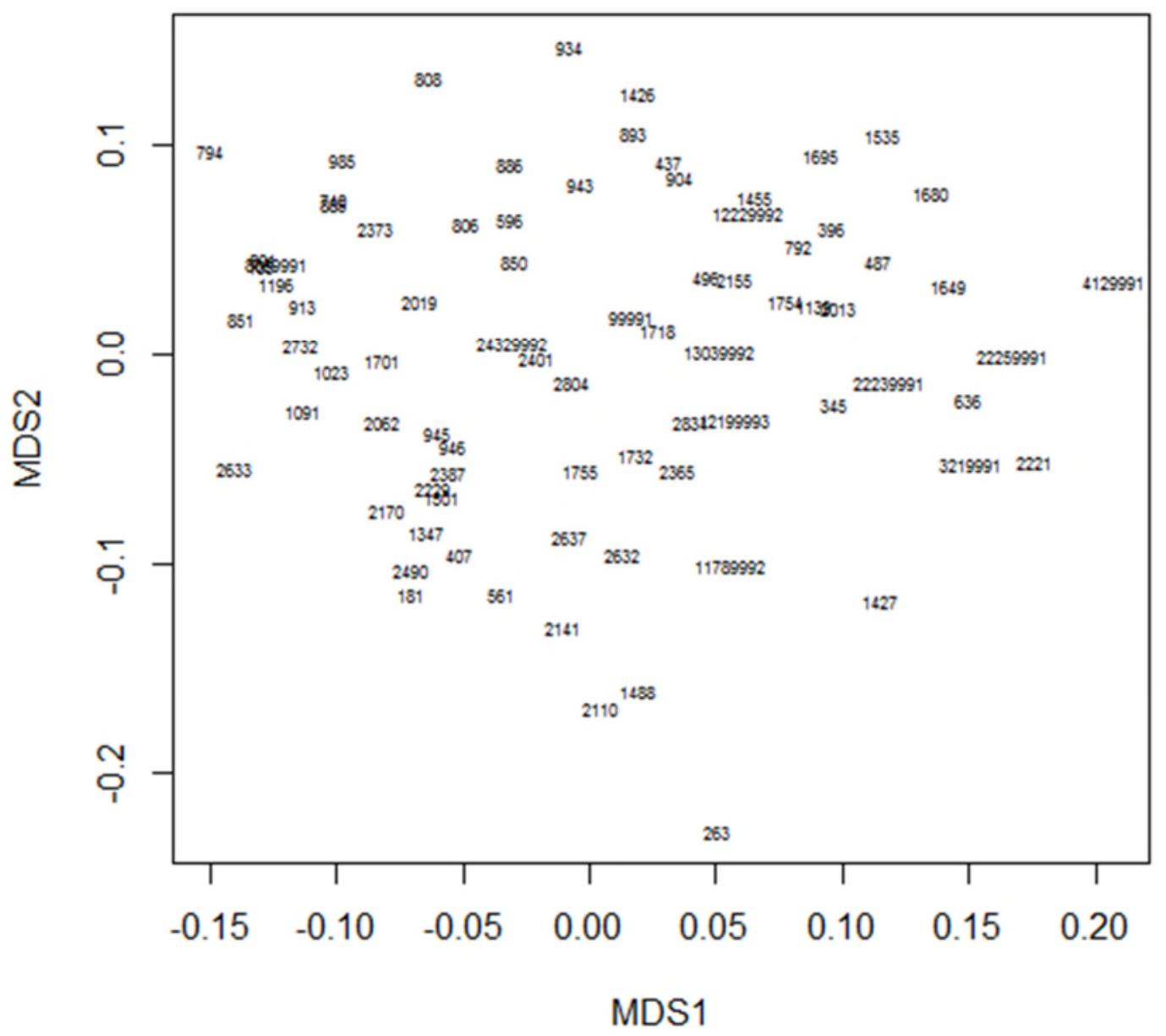

Figure 6.29 DMMS plot of all burials across the cemetery with three or more presence/absence occurrences of artefact categories.

With Figure 6.28 seemingly displaying a degree of clustering, it was divided up into three sectors: all of the bottom left, middle - top left, and all of the bottom - top right. Random burials were selected from each sector on the basis that they should display similarities in artefact categories if the perceived clustering was valid: 
Bottom left:

801: pottery lipstud, natrolite lipstud, natrolite beads, bone armlet, shell, bone pin

806: pottery lipstud, natrolite lipstud, OES beads, natrolite beads, natrolite pendant, shell pendants, bone armlets

934: natrolite lipstud, natrolite beads, OES beads, shell pendant

2013: OES beads, natrolite beads, bone pin, shell pendant

Middle - top left:

636: iron bracelet, quartz beads, carnelian beads, quartz beads, bronze signet ring, OES, cowrie beads, faience beads

1649: pottery lipstuds, OES beads, gold beads, faience beads, gold coil, copper coil

1091: natrolite lipstuds, natrolite earstud, stone pin, natrolite beads

1455: natrolite lipstuds, bone pin, OES beads

407: pottery lipstud, natrolite beads, ivory bracelets

851: natrolite beads, ivory pendant, bone armlet

All of bottom-top right:

2490: pottery lipstud, natrolite lipstud, natrolite earstud, stone bracelet

2804: natrolite beads, pottery lipstud, natrolite earstud

2370: natrolite beads, shell pendant

2141: natrolite beads, OES beads, stone bracelets, ivory bracelets, shell pendants

2373: ivory lipstud, pottery lipstuds, bone pins, natrolite beads, OES beads

The select categories of beads and lipstuds drove the manner of the distribution plot, while the materials these artefacts are made from provides additional variability but does not lead to clear-cut/distinct clusters. Consequently, no valid, clear-cut clusters or outliers are detectable in across the cemetery using NMMDS or DMMDS which correlates with the results of the correspondence analyses.

Thus, while the excavated sectors of the Jebel Moya valley appeared to exhibit a large degree of uniformity in terms of the appearance of artefact categories accompanying the burials, there remains a distinct patterning unique to the richer burials in the North-East sector. The North-East also has a high proportion of burials without accompanying assemblages. The 'social neighbourhood', in which no poorer burials were permitted 
within $20 \mathrm{~m}$ of the known/visible location of a richer burial, created a distinct area of prestige which probably encouraged other individuals to be buried in the same general vicinity for prestige association. The greater proportional presence in the North-East of select imported raw materials such as carnelian, a highly prized material elsewhere in this period (MacDonald 2011b), lends support to the notion that these individuals may have been a social elite.

In the other sectors of the cemetery, the lack of clustering and any definitive patterning suggests that perhaps the living were interested in performances that created similar spirits of the dead. In other words, there appears to be a collective mortuary ideology within which there are variations or manipulations reflective of types of status and attempted status association.

\subsection{Burial treatment}

The ways in which a body is disposed of can provide insights into how societies conceptualised and materialised mortuary rites, both separating and interlinking the living and the dead. At Jebel Moya, there were no differing methods of inhumation the graves were either round pits or oval, dug graves or dug graves of indeterminate shape. As mentioned above (see section 6.3), no permanent grave markers appear to have been used, at least none which survived to be recognised as such by the excavators.

There is also a remarkable degree of uniformity in the number of burial assemblages in which artefact categories are present between male and female individuals re-sexed by the Duckworth Laboratory (Figure 6.30). There appears to be a high level of androgyny, at least as the individuals are represented in the mortuary realm.

Orientation had originally been taken as a reliable guide to social affiliation, on the presumption that related peoples (whether by sex or by relation) would be buried according to a particular set of social rules (Binford 1971). However, it has been shown that orientation can depend upon a variety of factors: direction from which ancestors came, facing one's home, facing west (the setting sun), towards sacred markings in the landscape (e.g. a particular mountain or mountains), different orientations depending on 
how the body was flexed (not necessarily itself an indication of chronology) and differing interpretations of one or more mortuary rules underlying the cardinal direction the individual should be orientated towards (e.g. the Ashanti (Ucko 1969)), or a combination thereof (McHugh 1999: 43-4).
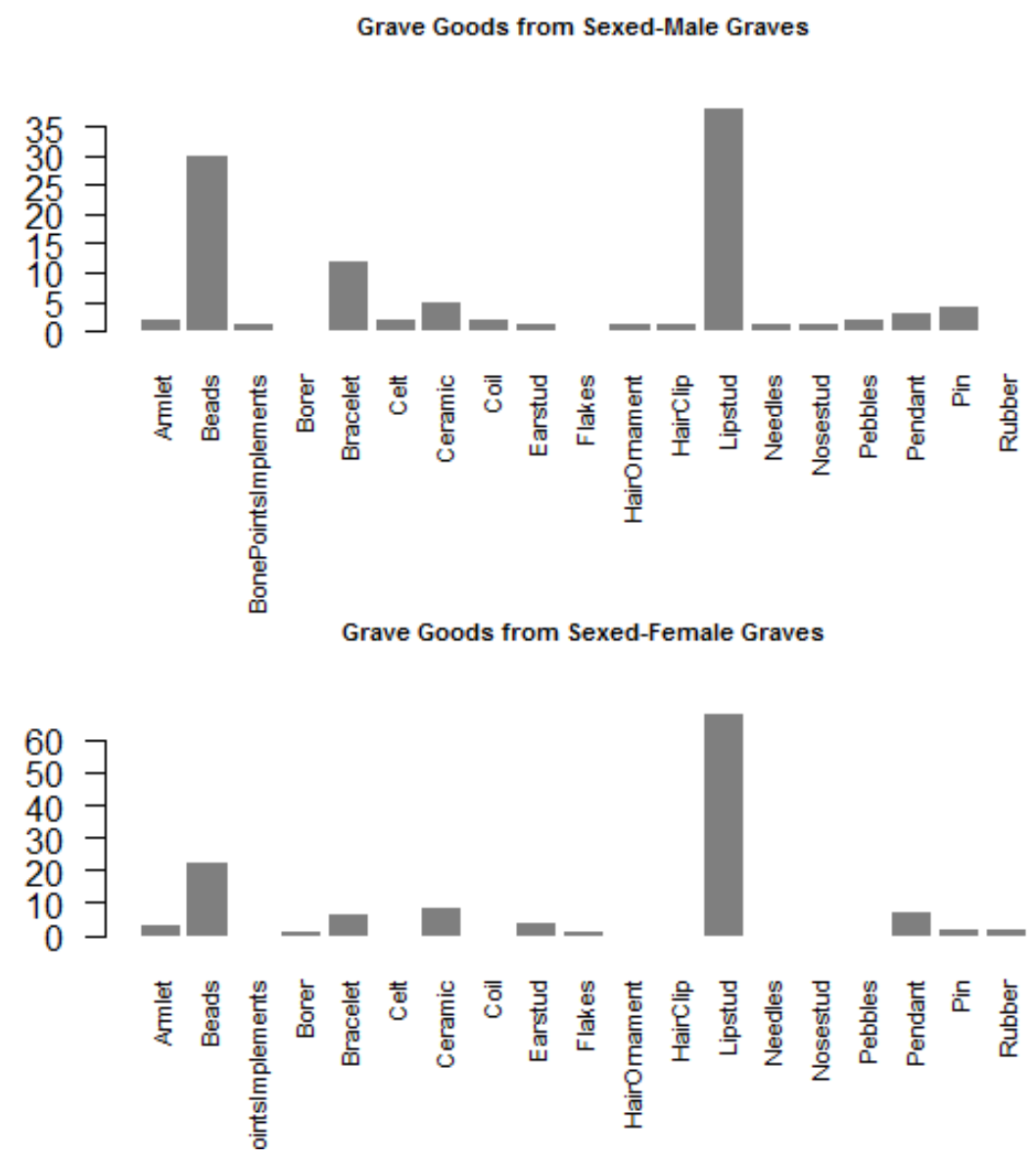

Figure 6.30 Comparative chart of the occurrence of artefact categories between the laboratory-sexed male and female individuals.

Therefore the contention by Gerharz (1994) that the variable orientation of burials at Jebel Moya should be put down to the site's use as an aggregation locale by various different pastoral communities in the southern Gezira cannot be taken at face value. Revised analysis reveals that the nature of directionality is not as mixed as claimed by Gerharz for all the burials across the cemetery: the majority of the burials are often buried in a south-westerly to north-westerly direction (Table 6.7) (Figure 6.31). When broken down by age and sex, as derived from the re-analysis done by the Duckworth Laboratory, adult males and females share a similar orientation pattern which drives the overall orientation pattern for the cemetery (Figure 6.32a-c). By contrast, the young adult category shows no discernible pattern (Figure 6.32d). It appears therefore that 
there was a general agreement on the direction in which an adult should be buried, although this does not extend to the positioning of the body as there is no standardised pattern to whether bodies were positioned prone, supine, on their left or right sides, and whether they were flexed or straight (Table 6.7). It also appears that this cardinal agreement was not in place for non-adults. It may be what is seen is directionality at Jebel Moya between age groups is a faint, archaeologically detectable marker between how adults and non-adults were treated during mortuary rites.

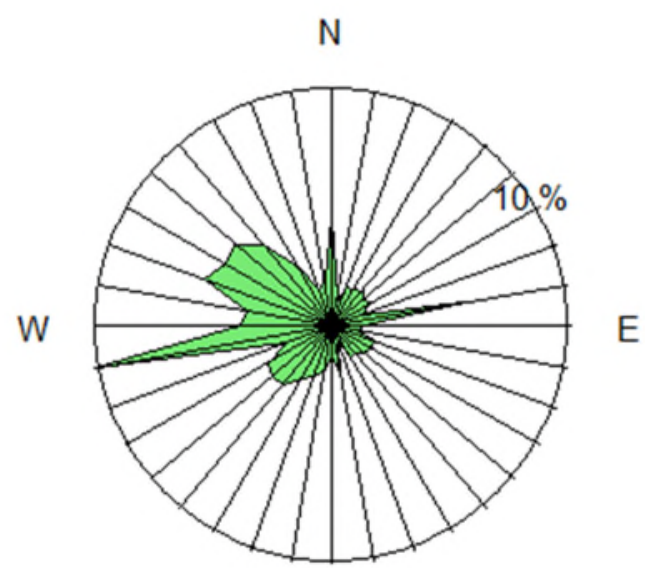

$\mathrm{S}$

Figure 6.31 Compass map of the recorded bodily (not head) orientation of all individuals across the cemetery.

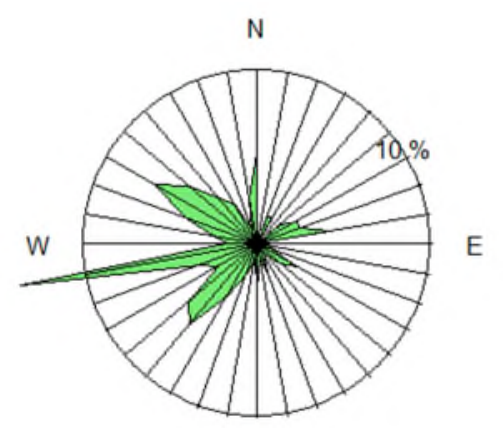

S

A

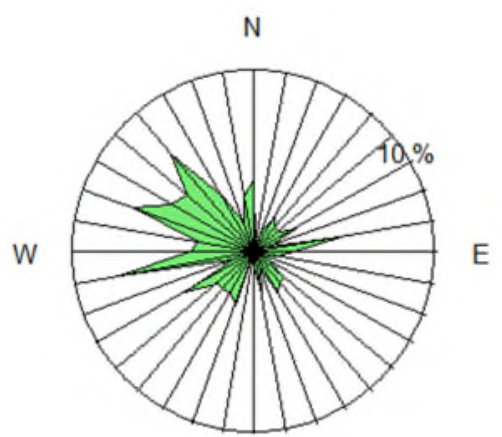

S

B 


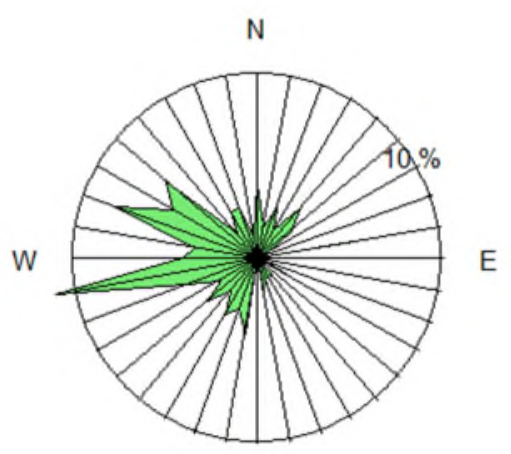

S

$\mathrm{C}$

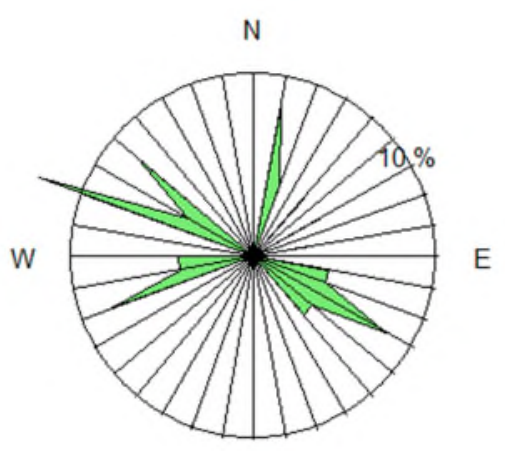

$\mathrm{S}$

$\mathrm{D}$

Figure 6.32 Compass map of the recorded orientations by age and sex (Duckworth Laboratory) across the cemetery: (a) adult, (b) adult male, (c) adult female, and (d) young adult.

Another archaeologically detectable marker is bodily modification. Out of all the human burials, there are 292 individuals where one or more teeth have been extracted. These teeth range from the lower (mandibular) central incisors to all lower incisors, lower left and right incisors, and the upper (maxilla) canines. There are 69 occurrences of upper incisors being extracted, sometimes in tandom with lower incisors. Canines were extracted in eight instances.

Of the individuals re-sexed by the Duckworth Laboratory, 87 are recorded by Addison as having had teeth extracted. These breakdown as 15 adults, 41 adult females, 29 adult males and two infants (Figure 6.33). There are no known juveniles or young adults but it is likely to be an artificial omission due to the presence of the two infants who had, in the first instances, all the upper and lower incisors extracted and, in the second instance, the lower central incisors removed. However, if the original field aging is used, only 15 of the 292 individuals are young adults, with two infants and two juveniles also present. Taken together, these figures suggest that both females and males wore lipstuds, and that the wearing lipstuds may have increased as an individual approached adulthood. 


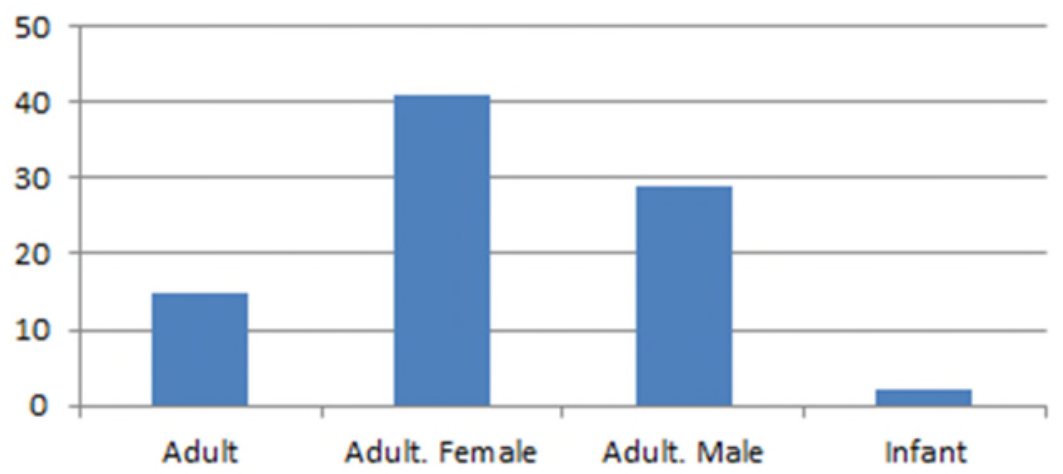

Figure 6.33 Breakdown of tooth extraction amongst individuals re-sexed by the Duckworth Laboratory.

The androgynous breakdown of lipstuds between the sexes contradicts Addison's (1949: 128-9) assertion that the wearing of lipstuds was predominantly the domain of women. Furthermore, the finding by Hutton MacDonald (see section 5.2) of labret-wear on teeth of individuals whose burials had no accompanying burial goods also contradicts Addison's (1949: 129) claim that

"It is obvious that none of the persons whose remains were found in the "barren" graves could have been wearing lipstuds at the time of burial; and, as there is no reason to suppose that such objects were deliberately removed from the bodies after death, it is safe to conclude that nearly half the population of Jebel Moya...never wore lipstuds at all."

Such assertions by Addison go against the Sudanese ethnographic literature which he cites and which support the conclusion that lipstuds are known to have been worn by both men and women, and cannot be used as direct indicators of division of gender or social order (Addison 1949: 128):

"The wearing of lip ornaments is a custom which still persists in some parts of the Southern Sudan. Thus "the women of Talodi [in SW. Kordofan] and the hills around perforate the lower lip in which they wear a plug or pendant". Among the men of the Acholi "the lip is pierced with a long curved piece of greenish glass", and some of the women and girls of the Anuak "pierce a hole in the lower lip and wear in it a piece of straw or even a nail". Among the Berri on Lafon Hill, who are racially akin to the Anuak and branched off from the latter 
comparatively recently, "the great majority of the men wear a glass spike about 3 inches long projecting through a hole in the lower lip. They are wound round the base with a bit of brass wire to prevent them slipping through the hole in the lip; they are easily removed from the inside." The Didinga men and women wear lip plugs of chalcedony and the women of the Kuku tribe adorn themselves with "a nail-like stud of copper that is worn by being passed through a hole in the lower lip, the base of the appendage supported by the lip while the rest of it, varying in length from two to four inches, hangs down free in space". West of the Nile, lipstuds are used by the Bari and old ones are sometimes used as rainstones, and the Bongo women used at one time to wear a large plug in the lower lip."

Multiple levels of social identity were made manifest in the mortuary realm at Jebel Moya. There are no distinctive differences in the orientation of bodies and their treatment. However, there is a spatial neighbourhood arrangement of richer versus lesser rich burials in the North-East sector. Additionally, the presence of more burials without accompanying goods in the North-East shows that there were attempts at social assimilation within the mortuary realm through broad spatial association with these rich burials.

\subsection{Discussion: The social implications of the mortuary patterns}

To begin to understand how individuals are represented in the mortuary realm at Jebel Moya first required an understanding of their burial assemblages and how the assemblages were used to represent wealth and possible status. Inverse Distance Value was used to determine the relative wealth of each burial assemblage.

Ultimately, the proposition that there would be a greater proportion of wealth amongst adults, and similar ranges of variation within adult and young adult categories if a hierarchically-inclined social structure was represented in the mortuary domain, cannot be ruled out. Examination of age dimensions through IDV, burial posture and burial orientation within biological age categories shows that defined social personae were attributed to all age-groups. There were also similarities in the types of artefacts 
deposited with young adults which are indicative of increasing involvement in similar roles to their adult counterparts. What is noteworthy is that, with adult burials being present throughout the cemetery, the valley became an environment imbued with actions by forebears and fitting into that context was an act of recreating the cycle.

The development of substantive inequality depends on what is socially regarded as constituting wealth, and the degree and nature of its transmission (Shennan 2002). The predictability and supply of material wealth, including animals, is characterised by the size of herds, the nature of inter-societal exchange and the number of exchange partners, and the skill sets within the society and those relied upon from their neighbours. Pastoralists draw upon livestock, technology and landscape patterns of usage for sources of power and wealth (MacDonald 1998). However, the greater degree of wealth transmission is not an artefact of utilisation of domesticated resources, but rather because animal husbandry is labour-intensive and requires a social institutionalisation of property rights within the society. Although there are a wide range of ethnographically and anthropologically-known pastoral societies, to claim as Salzman (1999) does that it is only by classifying many pastoralists as essentially egalitarian that the concept of 'power' is maintained in a continuum of equality $\rightarrow$ institutionalised inequality is misleading. Rather 'power' is a process, a culturally negotiated agreement which incorporates elements of hierarchy and heterachy, and can be manifested in a variety of material and social forms (Honeychurch 2013).

As such, Jebel Moya marks the use of a prominent massif as a facility to integrate different peoples within the broader community, as a medium for the negotiation of relationships amongst the living within a culturally manifested landscape and as a marker for group identity that persisted for a couple of hundred years. It is characterised by structured variation within a shared mortuary tradition in specific aspects of its treatment of the dead: in the distribution of imported raw materials, differential Inverse Distance Value mean and median values between sectors, a higher proportion of burialswithout-goods in the North-East sector, and in a spatial neighbourhood between the richer and poorer burials in the North-East. The continuation of the practices for a few centuries shows that the inhabitants were drawing upon what Nic David (David 1995) has elsewhere termed a symbolic reservoir, especially for their mortuary rites. 
The increased ratio of burials in the North-East sector by comparison with the rest of the cemetery may have been (1) an effort by competing or lesser lineages to associate themselves in death with the dominant lineage, or (2) an attempt by related lineages to emphasise their relationship in death with the dominant lineage through deposition in the same spatial vicinity. There are also no obvious indicators (age or biological sex) for preferential selection in deposition of certain individuals at Jebel Moya. Overall, a section of the society developed enough wealth and authority to be differentiated from everyone else in a mortuary realm open to all ages and sexes. 


\section{Chapter 7: Situating Jebel Moya's cemetery within a wider Sudanese context}

Until fairly recently, archaeologists have tended to give explanatory primacy to environmental stress as the de facto reason behind changes over time in pastoral and agro-pastoral lifestyles. This is particularly true, for example, with regard to existing discussion of changing social structures in the Western Desert and along the Nile (Hassan 2002; Kuper and Kröpelin 2006; Wendorf and Schild 1998, 2003; Wendorf et al. 2001). Yet there are cultural, economic and social differences between agropastoralist and pastoralist communities which have served as discouragement to pigeonholing them through definitions of specialisation at intra- or inter-community levels (Bollig et al. 2013: 23). Looking for evidence of agro-pastoralists or specialised pastoralists in the archaeological record requires the development of alternative sets of knowledge. Different kinds and degrees of specialisation might be expected to leave their own signature in material culture: how capital is structured, allocated and controlled is central. The establishment of polities or their expansion into areas where ecological conditions are limiting have been shown to have resulted in the establishment of certain types of infrastructure, for example, networks of bore wells, which have given rise to more specialised pastoralism. Two such examples would include the Himba in recent historic Namibia (Bollig et al. 2013) and the mix of agricultural, agro-pastoral and pastoral communities in the Butana after the southward expansion of the Meroitic state into the region from the late first millennium BC onwards (Ahmed 1984, Bradley 1986).

Given the above issues, it is reassuring that more recent Nilotic archaeological models have often managed to retained a recognition of the importance of ecological conditions while (a) examining when and how the emergence of specialist pastoral activity occurred (Linseele 2010; Sadr 1991), and (b) revealing the shifting emphasis in the ways in which social identities were constructed, reinforced and actively displayed through the material culture associated with ritual practice (Wengrow 2006; Wengrow et al. 2014). Wengrow and colleagues' model incorporates concepts of bounded territoriality, for example stating that: "enduring attachments between people and place appear to 
have been established primarily through elaborate funerary rites, collective feasting and repeated use of burial grounds, while habitation sites - on current evidence - remained for the most part fluid and ephemeral in nature" (Wengrow et al. 2014: 104). However, regional variability in mortuary practices and attendant socio-economic activities remained (see Figure 7.1 and Table 7.1 for regional variations during Mesolithic, Neolithic, Meroitic and Post-Meroitic times).

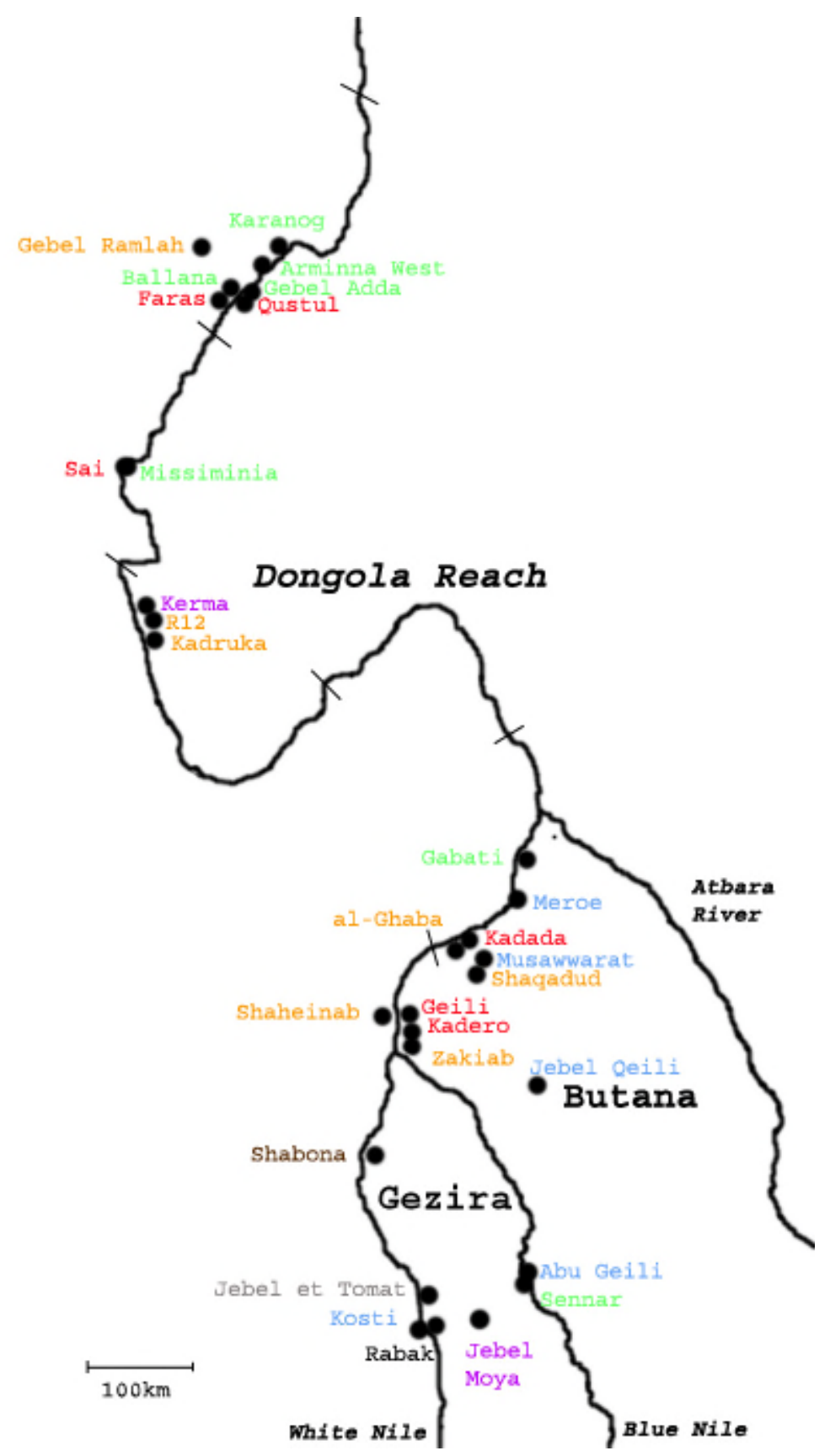

Figure 7.1 Colour-coded map of select Mesolithic, Neolithic, Meroitic and PostMeroitic sites in the Sudan: blue (Meroitic), brown (Mesolithic), green (Meroitic, PostMeroitic/X-Group), orange (Neolithic), purple (Mesolithic, Neolithic, Meroitic), red (Neolithic, Meroitic, Post-Meroitic/X-Group) and light grey (Neolithic, Meroitic). 


\begin{tabular}{|c|c|c|c|c|c|c|}
\hline & & Lower Nubia & Upper Nubia & Central Sudan & $\begin{array}{l}\text { South- } \\
\text { Eastern } \\
\text { Sudan }\end{array}$ & Gezira \\
\hline \multirow[t]{5}{*}{$\begin{array}{l}6000- \\
3100 \mathrm{BC}\end{array}$} & $\begin{array}{l}\text { Burial } \\
\text { orientation }\end{array}$ & Variable & Variable & Variable & $\begin{array}{l}\text { No known } \\
\text { cemeteries }\end{array}$ & $\begin{array}{l}\text { No known } \\
\text { cemeteries }\end{array}$ \\
\hline & $\begin{array}{l}\text { Burial } \\
\text { posture }\end{array}$ & Variable & Variable & Variable & $\begin{array}{l}\text { No known } \\
\text { cemeteries }\end{array}$ & $\begin{array}{l}\text { No known } \\
\text { cemeteries }\end{array}$ \\
\hline & $\begin{array}{l}\text { Grave } \\
\text { type }\end{array}$ & $\begin{array}{l}\text { Dug graves; A- } \\
\text { Group tumuli } \\
\text { (late 4th } \\
\text { millennium } \\
\text { BC) }\end{array}$ & Dug graves & Dug graves & & \\
\hline & $\begin{array}{l}\text { Socio- } \\
\text { economic }\end{array}$ & $\begin{array}{l}\text { Agro-pastoral; } \\
\text { Hunter- } \\
\text { gatherer }\end{array}$ & $\begin{array}{l}\text { Agro-pastoral; } \\
\text { Hunter- } \\
\text { gatherer }\end{array}$ & $\begin{array}{l}\text { Agro-pastoral; } \\
\text { Appearance of } \\
\text { pre-Kerma } \\
\text { nucleated } \\
\text { settlements at } \\
\text { end of 4th } \\
\text { millennium BC }\end{array}$ & $\begin{array}{l}\text { Agro- } \\
\text { pastoralist; } \\
\text { Hunter- } \\
\text { gatherer }\end{array}$ & $\begin{array}{l}\text { Hunter- } \\
\text { gatherer; } \\
\text { Agro- } \\
\text { pastoral or } \\
\text { pastoral \& } \\
\text { plant } \\
\text { exploitation }\end{array}$ \\
\hline & $\begin{array}{l}\text { Social } \\
\text { structure }\end{array}$ & $\begin{array}{l}\text { A-Group elites } \\
\text { in the late } 4 \text { th } \\
\text { millennium BC }\end{array}$ & $\begin{array}{l}\text { No definitive } \\
\text { evidence for } \\
\text { social } \\
\text { hierarchy }\end{array}$ & $\begin{array}{l}\text { Possible } \\
\text { presence of } \\
\text { elites, although } \\
\text { inherited status } \\
\text { is questionable }\end{array}$ & $\begin{array}{l}\text { Nucleated } \\
\text { settlements } \\
\text { near Kassala } \\
\text { suggestive of } \\
\text { social control } \\
\text { by elites }\end{array}$ & Unknown \\
\hline \multirow[t]{5}{*}{ Meroitic } & $\begin{array}{l}\text { Burial } \\
\text { orientation }\end{array}$ & $\begin{array}{l}\text { Variable, } \\
\text { though east- } \\
\text { west very } \\
\text { common } \\
\end{array}$ & $\begin{array}{l}\text { Variable, } \\
\text { though east- } \\
\text { west very } \\
\text { common } \\
\end{array}$ & $\begin{array}{l}\text { Variable, } \\
\text { though east- } \\
\text { west very } \\
\text { common } \\
\end{array}$ & & Variable \\
\hline & $\begin{array}{l}\text { Burial } \\
\text { posture }\end{array}$ & Variable & Variable & Variable & & Variable \\
\hline & $\begin{array}{l}\text { Grave } \\
\text { type }\end{array}$ & $\begin{array}{l}\text { Dug graves, } \\
\text { graves with } \\
\text { sub- and super- } \\
\text { structures, and } \\
\text { tumuli }\end{array}$ & $\begin{array}{l}\text { Dug graves, } \\
\text { graves with } \\
\text { sub- and super- } \\
\text { structures, and } \\
\text { tumuli }\end{array}$ & $\begin{array}{l}\text { Dug graves, } \\
\text { graves with } \\
\text { sub- and super- } \\
\text { structures, } \\
\text { tumuli and } \\
\text { small pyramids }\end{array}$ & Tumuli & Dug graves \\
\hline & $\begin{array}{l}\text { Socio- } \\
\text { economic }\end{array}$ & $\begin{array}{l}\text { Agricultural } \\
\text { and agro- } \\
\text { pastoral }\end{array}$ & $\begin{array}{l}\text { Agricultural } \\
\text { and agro- } \\
\text { pastoral }\end{array}$ & $\begin{array}{l}\text { Agricultural } \\
\text { and agro- } \\
\text { pastoral }\end{array}$ & $\begin{array}{l}\text { Pastoral; } \\
\text { Nucleated } \\
\text { settlements } \\
\text { at and near } \\
\text { Kassala }\end{array}$ & $\begin{array}{l}\text { Pastoral and } \\
\text { agro- } \\
\text { pastoral }\end{array}$ \\
\hline & $\begin{array}{l}\text { Social } \\
\text { structure }\end{array}$ & Hierarchical & Hierarchical & Hierarchical & Hierarchical & $\begin{array}{l}\text { Presence of } \\
\text { wealthy elite } \\
\text { at Jebel } \\
\text { Moya, } \\
\text { unknown if } \\
\text { hereditary }\end{array}$ \\
\hline $\begin{array}{l}\text { Post- } \\
\text { Meroitic } \\
\text { / X- } \\
\text { Group }\end{array}$ & $\begin{array}{l}\text { Burial } \\
\text { orientation }\end{array}$ & $\begin{array}{l}\text { East-West; } \\
\text { South-North }\end{array}$ & East-West & $\begin{array}{l}\text { South-North; } \\
\text { North-South; } \\
\text { East-West }\end{array}$ & & Variable \\
\hline
\end{tabular}




\begin{tabular}{|l|l|l|l|l|l|l|}
\hline & Lower Nubia & Upper Nubia & Central Sudan & $\begin{array}{l}\text { South- } \\
\text { Eastern } \\
\text { Sudan }\end{array}$ & Gezira \\
\hline $\begin{array}{l}\text { Burial } \\
\text { posture }\end{array}$ & $\begin{array}{l}\text { Predominantly } \\
\text { flexed }\end{array}$ & $\begin{array}{l}\text { Predominantly } \\
\text { flexed }\end{array}$ & $\begin{array}{l}\text { Predominantly } \\
\text { flexed }\end{array}$ & & Variable \\
\hline $\begin{array}{l}\text { Grave } \\
\text { type }\end{array}$ & $\begin{array}{l}\text { Dug graves, } \\
\text { graves with } \\
\text { sub- and super- } \\
\text { structures, and } \\
\text { tumuli }\end{array}$ & $\begin{array}{l}\text { Dug graves, } \\
\text { graves with } \\
\text { sub- and super- } \\
\text { structures, and } \\
\text { tumuli }\end{array}$ & $\begin{array}{l}\text { Dug graves, } \\
\text { graves with } \\
\text { sub- and super- } \\
\text { structures, and } \\
\text { tumuli }\end{array}$ & Tumuli & $\begin{array}{l}\text { Tumuli in } \\
\text { the north } \\
\text { and shallow } \\
\text { graves in the } \\
\text { south }\end{array}$ \\
\hline $\begin{array}{l}\text { Socio- } \\
\text { economic }\end{array}$ & $\begin{array}{l}\text { Agricultural } \\
\text { and agro- } \\
\text { pastoral }\end{array}$ & $\begin{array}{l}\text { Agricultural } \\
\text { and agro- } \\
\text { pastoral }\end{array}$ & $\begin{array}{l}\text { Agricultural } \\
\text { and agro- } \\
\text { pastoral }\end{array}$ & $\begin{array}{l}\text { Pastoral; } \\
\text { Nucleated } \\
\text { settlements } \\
\text { at and near } \\
\text { Kassala }\end{array}$ & $\begin{array}{l}\text { Pastoral and } \\
\text { agro- } \\
\text { pastoral }\end{array}$ \\
\hline $\begin{array}{l}\text { Social } \\
\text { structure }\end{array}$ & Hierarchical & Hierarchical & Hierarchical & Hierarchical & $\begin{array}{l}\text { Moya, } \\
\text { at Jebel } \\
\text { unknown if } \\
\text { hereditary }\end{array}$ \\
\hline
\end{tabular}

Table 7.1 Summary of the different regions in the Sudan, reflecting their currently known burial and socio-economic activities.

Comparable expressions of consistency in the pottery assemblages and expressions of social identity in the mortuary realm are visible particularly during Jebel Moya's third (mortuary) phase of occupation. This phase also falls within Veerle Linseele's (2010) reconstructed timeline of the emergence of specialised pastoralism alongside generalised economic activities (incorporating livestock) in North-East Africa from the first millennium BC onwards.

This chapter situates Jebel Moya's third phase within the contemporary social history of Meroitic Sudan. This provides providing a unique opportunity to examine for the first time how Jebel Moya compares with mortuary remains furthest afield in Upper and Lower Nubia, and subsequently closer in the Shendi Reach and its margins in the western Butana (Figure 7.2).

\subsection{The socio-political nature of the Meroitic state}

Early states in the Saharan and Sahelian belts were comprised of diverse political systems whose sources of power and systematic relationships were counter-poised between population segments and resulted in different trajectories of power and development (McIntosh 1999b). 


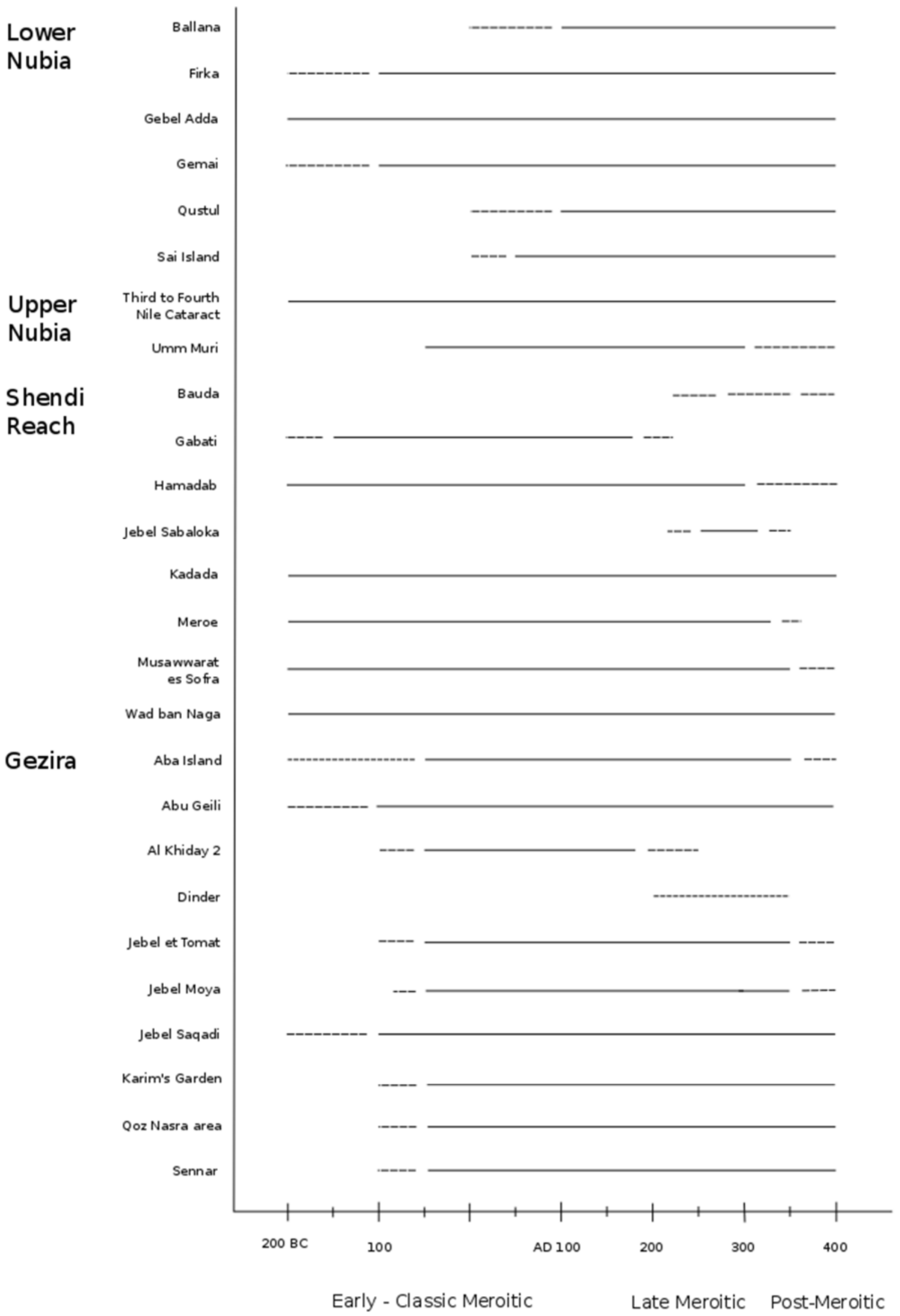

Figure 7.2 The chronology of Jebel Moya and its main contemporary (Post-)Meroitic sites elsewhere in the Sudan used in analysing comparative mortuary behaviours. 
Resting and drawing upon these different resources, such polities ranged from centralised states to segmentary societies and communities forming on internal and external frontiers. The centralised economic and ritual model derived from studies of Ancient Egypt has traditionally been applied to the Meroitic state which is traditionally regarded as evolving from its predecessor the Napatan state at the end of the fourth century BC with the relocation of the elite capital to Meroe (Adams 1977; Grzymski 2004; Török 1997) which had a long pre-Meroitic occupation sequence stretching back to the early first millennium BC (Shinnie and Anderson 2004), while little systematic attention has been paid to its southern frontier where the history of the Gezira and the Butana remain little understood (Bradley 1992; Kleppe 1986).

More recently, attempts have been made to place the Meroitic state in a Sahelian context in recent years. They draw upon Southall's ethnographic model of segmentary societies (Southall 1988a, 1988b, 1999) and upon studies of the sultanates of the Funj (based at Sennar along the Blue Nile from the $16^{\text {th }}$ to early $19^{\text {th }}$ centuries AD) and Keira (Darfur, $17^{\text {th }}$ century AD) (Edwards 1996, 1998b; Fuller 2003). In such segmentary systems, ritual and political influence have contrasting spheres of control: ritual activities in the peripheral areas are in constant flux, while the seat of political authority is centred on the core domains of the territory held in place by checks and balances of both ritualised sanction and institutionalised interdependence.

Although there are a myriad of different social systems in the Sahel Belt beyond segmentary societies (McIntosh 1999a), the effect of the application of anthropological data to the issue of the socio-economic structure of the Meroitic state was to move the discussion away from previous sole reliance upon interpretations of burial structures with an Egyptianised-interpretative slant. In the Edwards and Fuller hypothesis, which has been termed the Sudanic Model (Edwards 1998b), Meroitic political authority has been (re-)characterised as: (1) dependent on establishing and maintaining long distance exchange, and (2) appropriating and assimilating Egyptian and regional religious rites. The importation and redistribution of high value items and slaves from the south to the north and into Ancient Egypt established the ritual hegemony of the Meroitic royalty based at Meroe and integrated distinctive geographical and political areas to the north and south (Edwards 2007). 
In contrast to its Napatan predecessor, the Meroitic period saw an expansion southwards and away from the margins of the Nile (Fuller 2014). The Butana was at the northern edge of the savannah. Formal political ties were further cemented by titles and court privileges given to regional elites, and by inter-marriages with female royalty. In return, tribute flowed along exchange corridors to the centre, Shendi Reach, and the capital Meroe, from where a variety of goods including select fineware pottery vessels were redistributed outwards (Edwards 1996, 2010: 33).

The application of the Sahelian segmentary state concept to the Meroitic period has resulted in the recognition of the fluid, contextual nature of exploitation and power relations between and within the diverse regions and the social structures. Contra Adams (1977), Lower Nubia did not support a large continuous population and the economic basis was subsistence farming with little scope for long-term surplus (Fuller 2003). Instead, more plentiful arable land was available and cultivated in the Western Butana, which may have been the only area under the personal control of the Meroe royalty (Edwards 1996: 90). The royal palaces and the non-food producing centres of the Meroitic core in the Shendi Reach needed to be supported. The complexity, nature and scope of the exploitation have yet to be adequately fleshed out; however, the available data shows a veritable mix of agro-pastoral and pastoralist communities living in the Butana at this time (Ahmed 1984; Bradley 1992).

The end of the Meroitic state has been dated by Torok to the middle-late fourth century $\mathrm{AD}$ on the basis of a stela from Meroe's Apedemak M6 temple said to mention Yesebokheamani as ruler (Török 1997: 478-9). Torok also dates the end of "royal and elite burials of purely Meroitic type" in the South and West Meroe cemeteries to the second half of the fourth century AD (Török 1997: 481). By contrast, Fuller (1997: 120-1) asserts that control over Lower Nubia was lost between AD 280 and 300, the time of the last occurrence of a Meroitic ruler's name at Philae and when burial customs at Arminna West evolve very distinctive local styles. Fuller (2014) has subsequently argued that these changes were largely underwritten by new agricultural methods of production, resulting namely from the introduction of the Persian waterwheel (saqia) in the third century AD which permitted expanded production of winter (e.g. wheat) and summer rainfall (e.g. Sorghum bicolour) crops and cash crops (grapes, cotton in Lower Nubia). Using these, local elites were able to build up independent socio-economic and 
political power bases. In terms of the Sudanic Model whereby only the Butana (and possibly, but unknown, parts of the Gezira) were under the direct rule of the elite in Meroe, the foundations for the subsequent splintering of the Meroitic state was laid earlier than AD 280 in the third century AD (Fuller 2014).

The socio-economic and political differences between the broad areas falling under Meroitic state control also display different patterns in their mortuary remains. In the Sudan, where few large settlements have been located and excavated, the majority of information derives from localities with cemeteries. For this reason, I turn now to taking an examination of the mortuary patterns of the different regions to compare and contrast with Jebel Moya.

\subsection{Mortuary patterns in Meroitic and Post-Meroitic Nubia}

The rescue expeditions which have been conducted throughout the history of Sudanese archaeology have resulted in a focus on funerary archaeology. This is particularly true in northern Sudan and around the Fourth Cataract. An increasing number of cemeteries have been identified in the Shendi Reach in recent decades (Bashir 2010, 2013; Edwards 1998a; Judd 2012), where the history of settlement and the topography differs from the regions downstream. Renewed work is occurring in the Western Butana (Wolf and Nowotnick 2006) while Sandro Salvatori and Donatella Usai's (Salvatori et al. 2011; Usai and Salvatori 2006; Usai et al. 2014) work in the northern Gezira is beginning to shed light on its occupational history. However, as recently stated by Vincent Francigny (2012: 52), the incorporation and indeed recognition of regional variability in mortuary traditions from outside of the Nile Valley has been largely unaddressed in studies of funerary traditions dating to the Meroitic periods. By comparing the traditions from different areas in the Sudan and contrasting their material funerary manifestations with Jebel Moya and other sites in the Sudan, this chapter situates the southern Gezira within a broader regional context and thereby goes some way towards contributing to the knowledge of contemporaneous funerary traditions outside the confines of the Nile Valley. 


\subsubsection{Lower Nubia}

Other very large Meroitic and Post-Meroitic (X-Group) mortuary complexes come from the other side of the Sudan, in Lower Nubia. In Lower Nubia, local elites gained in strength and power from the mid-third century AD onwards. Kinship networks enabled the negotiation and flow of power relations, with honours being transferable according to funerary inscriptions (Millet 1981; Trigger 1970). This is suggested by the proliferation of titles in the small number of funerary inscriptions from Lower Nubian cemeteries such as Arminna West (north of the $2^{\text {nd }}$ Cataract) when compared to the corpus of inscriptions from earlier and politically more important cemeteries at Fara and Shablul (Fuller 1997). Here, as in Upper Nubia and the Shendi Reach (see sections 7.2.2 and 7.2.3), the nature of the graves and the placement of the bodies differ substantially from Jebel Moya. At Ballana and Qustul, in particular, the Post-Meroitic structures were built by communities descendent from intermixing between existing peoples and pastoralists migrating from the deserts who settled in the valley (Dann 2009).

Commoners during the Classic Meroitic in Lower Nubia were interred in graves with a distinctive different structure: either in rectangular pits overlain by a brick vault or in an axial chamber approached by a ramp and marked by a small mastaba or pyramid placed overhead if they were wealthy (Francigny 2010, Griffith 1925: 63-9; Rilly and Francigny 2010; Woolley and MacIver 1910: 32-45), or without any superstructure, such as at cemetery 8-B-5.A at Sai Island where the latter and former co-occurred in distinct clusters (Francigny 2010). By contrast, only at Gabati were mud-brick superstructures erected in the Shendi Reach (see section 7.2.3).

Generally during the Late Meroitic, poorer commoner graves were either unmarked on the surface or were flat-topped tumuli $10-15 \mathrm{~m}$ in diameter, small in height and with surrounded by small black stones (El-Tayeb 2010: 3). The sub-structures also changed: circular or rounded shafts, with either an east-west oval pit or single-step access on the northern side to the burial chamber or a side niche. There were few grave assemblages. Burial posture was normally crouched with the individual deposited on either side of its body with their hands raised to their face and their head facing east or west (El-Tayeb 2010: 3-4). 
However at Gebel Adda, downstream of Sai Island and just inside the southern border of Egypt, the third and fourth century AD Meroitic and X-Group graves had ramps and barrel vaults (Huber and Edwards 2010). The burial chamber was in the bedrock. The tumuli mounds are estimated to be as large as 2.3m in height (Huber and Edwards 2010: 86). Individuals were in crouched positions. Wooden bed-frames and accompaniments such as moulded reptile hide interpreted as armour, pottery, basketry, iron knives, beads, etc were found. There was also a rare dog burial (Huber and Edwards 2012: 84-7)

\subsubsection{Ballana and Qustul}

Also downstream from Sai Island and slightly upstream from Gebel Adda are the vast tumulus cemeteries of Ballana and Qustul, royal burials dating assigned to the X-Group (Williams 1991a). The Ballana and Qustul cemeteries were first officially excavated from 1931 onwards and described by Emery shortly afterwards, although Burckhardt makes first mention of them in the early nineteenth century (Williams 1991b: 1). Traditionally, it is claimed that the nomadic Blemmyes from east of the Nile and the nomadic Noubades from west of the Nile settled in the Nile Valley from the mid-third century AD onwards (Edwards 2004: 195). The Noubades were said to have settled in the area around the $2^{\text {nd }}$ Cataract and it is their dead buried at the Post-Meroitic cemeteries of Ballana and Qustul, with their capital at nearby Faras. However, Rachael Dann (2009) has more recently highlighted that these are external terms imposed upon peoples over a large area who pursued different ways of life. She also points out that changes in material boundaries do not necessarily correspond with ethnic markers and therefore the extent and nature of the claimed migrations remain unresolved; it is on this basis that the traditional designator names are not used in this chapter.

Apart from the disappearance of inscription stelae, mortuary practices became more variable in the immediate Post-Meroitic prior to a degree of standardisation. Tumuli replaced pyramidal structures, multiple burials were rare and bodily orientations became more diverse with the addition of north-south orientation to the prior Meroitic standard of extended east-west burials (Edwards 2004: 205). The north-south orientation follows the northerly flow of the Nile. Such orientations again highlight regional differences in burial patterns when compared with the multiple directionality evidenced at Jebel Moya and where tumuli were not present. 
Elites were buried at Ballana and Qustul where many rich non-kingly burials are also located: a minimum of seven of the former have been identified at Ballana (Edwards 2004: 206) and seven at Qustul (Török 1997; Williams 1991b: 2). Indeed, three of the largest tumuli at Qustul also have accompanying mudbrick funerary chapels (Williams 1991a). Smaller tumuli are also present. The kings' royal regalia formed part of the accompanying burial assemblages: military equipment, ceremonial spears, and "a wide range of imported artefacts...including metal vessels, items of furniture, elaborate horse harnesses, wooden boxes with ivory inlays, toilet articles, jewellery, as well as large quantities of pottery, including Mediterranean amphorae, probably used in funerary rituals" (Edwards 2004: 206). The amphorae in particular, together with Roman Egyptian pottery found elsewhere, show that trade continued with Egypt while the deposition of military equipment also occurred in central Sudan at al-Hobaji and may indicate the existence of social and trade networks to the south. The tumuli are multichambered. Animal burials are present buried in pits, while camels, dogs, donkeys and horses have been found combined with the remains of sacrificed humans in the entrances to tumuli (Edwards 2004: 207). Other objects included in the burial assemblages included daily items such as glass and metal vessels, cosmetics, jewellery, and beads, while stelae, $b a$ statutes and door jams are also present (Williams 1991a: 92). Overall, the grave assemblages did not comprise the total of items from daily routines to sustain the person in the afterlife as during his/her earthly existence.

Ballana and Qustul are not the only large cemeteries in the region of the $2^{\text {nd }}$ Cataract. Others include Gemai (Bates and Dunham 1927), Firka and Wawa (Kirwan 1939), with religious cult burials at Qasr Ibrim (Mills 1982). However, these two Meroitic cemeteries as well as fragmentary settlement at Ballana comprise one of the largest corpora in Lower Nubia in which both hand-made and wheel-made pottery vessels are also present together with imported vessels, particularly from Egypt (Williams 1991a: 61-72) and vessels with finishings bearing similarity with areas to the south (Williams 1991a: 72-3).

Cemetery Q at Qustul measures 160 x 40m. Its Meroitic component buttresses the subsequent X-Group cemetery to the south (Williams 1991a: 1). There is no evidence for a continuous evolution of one burial sector into the other. A total of 648 Cemetery Q tombs and pits were recorded, together with more than 100 chapels and other 
installations. Many graves, especially those near the centre, would have originally had pyramidal superstructures, while those particularly to the western edge were mastabas (Williams 1991a: 6). Substructures were normally shafts with chambers. Individuals were buried with their hands at or over their pelvis, or at their sides, or one hand at the side and the other over the pelvis in a god Osiris-like posture (Williams 1991a: 6). Coffins, black-incised pottery and incised offering tables were also present, unlike at Ballana where they are rare or non-existent (Williams 1991a: Table 1).

The Meroitic cemetery at Ballana was named Cemetery B (Williams 1991a: 2). It measured $110 \times 65 \mathrm{~m}$ and was in the desert. A total of 334 tombs and combined tumuli complexes were recorded. The settlement was to the east nearer the river. The earliest graves were contemporary with the main occupancy of the Meroitic Qustul cemetery and were dug into a low scarp (Williams 1991a: 2). After a break, later Meroitic tombs were constructed to the west and are thus of a different date to Cemetery Q. Only a handful of Post-Meroitic burials are present from the fifth century onwards. Generally, the mastaba superstructure predominated (Williams 1991a: 6). Many substructures contained brick vaults, although a few earlier Qustul-like chamber tombs were present which were later cut into or substituted. Many tombs were modified for re-use. The individuals were primarily buried with their hands at or over their pelvis.

Overall, four phases plus sub-phases were determined for Ballana and Qustul: IA-B, IIA-B, IIIA-B, IVA-B (Williams 1991a: 9-14). Phase I (Late Napatan) is present only at Qustul. Phase II began in the first century AD with the Ballana occupancy starting during in Phase IIB. There was no evidence for a transitional phase to the X-Group burials post-Phase IV and a break in occupancy is believed to have occurred after the end of Phase IV in the late third century AD (Williams 1991a: 20), although some of the settlement sites show continuous occupation but this could be due to limited suitable areas for habitation (Williams 1991b: 3).

The X-Group component of Qustul Cemetery Q dates from the early Post-Meroitic, in the late fourth century $\mathrm{AD}$, beginning in the south and expanding northwards until it abutted the older Meroitic remains (Williams 1991b: 2). Some of the tumuli were built as part of complexes and there are differences between those X-Group tumuli in the south compared to the north. Williams (1991b: 2) states that similar substructure 
changes can potentially be seen at Ballana but that it could not be empirically verified as the latter's X-Group necropolis was not excavated by the Oriental Institute of Chicago's Expedition of 1960-4. The X-Group Cemetery Q was excavated in 1962-3, while other X-Group remains were found in cemeteries R, V and W (Williams 1991b: 2).

For Qustul, 6 major types of substructures were defined. The tumuli which were not entered by a shaft through a pit had corridor approaches towards a series of chambers with variations in the type of corridors, how the corridors and chambers were positioned along an axis (Williams 1991b: 9-10). Wheel-made and hand-made pottery vessels are both present amongst the X-Group mortuary assemblages, together with imported Egyptian (including Coptic) wares (Williams 1991b: 37-72). These tumuli were not spread in large concentrations like their Meroitic predecessors. They appeared in scattered clusters at both Ballana and Qustul (Williams 1991b: 12).

It was during the middle of the X-Group period at Ballana that the Gamai mounds ceased to be constructed while those at Firka, Ibrim and Kosha East began. Nearby, a few kilometres to the north, the Gebel Adda cemeteries were flouring at the same time as the X-Group phase ended at Ballana with the Late X-Group. Overall, on the burial composition and numbers of the X-Group peoples, Williams (1991b: 19) notes:

"Although archaeological evidence seems to indicate that Lower Nubia was densely occupied between AD 350 and 370, it is probably based on too few and too elaborate tombs to adequately represent the general population. Even the evidence from fragmentary settlements that suggests a smaller and poorer population than existed in late Meroitic times indicates a larger number of individuals than the tumuli."

South of Qustul, the Scandanavian Joint Expedition to Nubia under the umbrella of the UNESCO - Sudan Antiquities Service Survey - conducted surveys and excavations from 1960 until the end of the decade in a $c a .60 \mathrm{~km}$ stretch of both banks of the Nile between Faras and Gemai (Adams 2005). The survey expanded upon prior work such as Griffith's 1910-12 excavations at the Faras cemetery which yielded 2000+ graves of Meroitic age (Griffith 1925). In this survey area, Meroitic and X-Group habitation sites 
were scarce and those which existed were denuded having been constructed on lowlying surfaces: more cemeteries are recorded than habitation sites. Although there were indications that some Meroitic graves had superstructures which were later removed through deflation, many did not (Adams 2005: 88). What remained were grave shafts leading to large, mudbrick rectangular chambers. There are a few side-niche graves. The chambers exhibited different construction techniques with them being made of bricks and either in pits of the same size or larger and vaulted, or made from earth with a vault and not in a pit (Adams 2005). Body position was extended with the head to the west, although many graves were plundered. Grave assemblages varied, with pottery and beads common. Coffins were sometimes also present (Adams 2005: 68). The X-Group graves - which William Adams (2005) calls "Ballana" - show a decrease in the use of end-chambers and vaults made of brick (Adams 2005: 152). Any superstructures were normally earthen tumuli, sometimes ringed with stones; only one copy of a Meroitic brick superstructure is known. Adams (2005: 153) attributes the lack of superstructure for many graves to deflation. Body orientation was to Nilotic north (north-east - southwest), although some followed the old Meroitic practice of east-west or even diverged to north-west - south-east. Both crouched and extended burials were present, but the prevailing hypothesis that crouching was the preferred depositional practice for the PostMeroitic could not be tested as most of the bodies were distarticulated during robbery.

\subsubsection{Upper Nubia}

The area around the $4^{\text {th }}$ Cataract has restricted arable land with the geological Basement Complex at the surface causing inhabitants to primarily use the Nile islands. Localities were reused here and at certain localities further downstream due to the lack of habitable land, resulting in ancient and modern destructive practices: for example, in the southern Letti Basin at Hambukol (halfway between the $3^{\text {rd }}$ and $4^{\text {th }}$ Cataracts, encompassing Old Dongola) are the remains of a Meroitic cemetery underneath the modern village of Jogob (Grzymski 1989: 80-9). The softer Nubian Series Formation is present on the surface downstream, resulting in a fertile alluvial valley where Kerma and other complexes have flourished.

The Meroitic burial traditions of the Fourth Nile Cataract are particularly well documented through the survey and excavation done, in particular, in papers presented 
at the 2006 conference on the $4^{\text {th }}$ Cataract (Wotzka 2012) and by the Hamdab Dam Archaeological Survey Project (Gdańsk Archaeological Mission) on the west bank of the Nile between the villages of Kareima and El-Lamer (El-Tayeb and Kolosowska 2007). Out of over 80 Meroitic and Post-Meroitic sites (300 BC - AD 550) identified by the latter project, 32 are cemeteries (El-Tayeb 2010: 3). Unlike earlier cemeteries situated on mounds or small hills, the Meroitic graves are primarily "situated in lowerlying areas of land, whether valleys between rocky hills, beds of dried-up wells or ridges on banks of watercourses" (El-Tayeb and Kolosowska 2007: 11).

The superstructures are of four types: (1) single-layered small stone ring, (2) elongated, low stone mound, (3) rounded low mound, and (4) low tumulus with a flat top and a stone kerb (El-Tayeb and Kolosowska 2007: 11). There are four types of sub-structures, some with sub-types not seen elsewhere in Nubia and therefore indicative of regional variation: (1) elongated pit or a horizontal shaft with a burial trench or side niche and (primarily) east-west alignment, (2) short but steep ramp leading to a cave-like burial room ("foot-shaped"), (3) rounded shaft leading to a deep, tub-like burial pit, and (4) an east-west descent ending a vertical shaft with a side burial room off the shaft (El-Tayeb and Kolosowska 2007: 11-2). These structures encompass the Early and Late Meroitic, with speculation that the Classic Meroitic may also be represented. Their chronological development was reinforced by radiocarbon dating (El-Tayeb and Kolosowska 2007: 23).

Type 1 burials are from the Early Meroitic. Some stone stelae were present by the shaft. Burial assemblages were extremely rare but whether this is due to robbing of all the graves or not is unclear, although Meroitic sherds were present on the surafce. Disarticulated human skeletal remains were found in a couple of the graves from $\mathrm{Ab}$ Gahoiya and Gerf El-Humma (El-Tayeb and Kolosowska 2007: 13). Some burials had a north-south alignment (El-Tayeb and Kolosowska 2007: 14). There was a lack of burial assemblages, though sherds scattered around the graves have been suggested to be indicative of offerings (El-Tayeb 2010: 4), though no residue tests have been conducted to test. Individuals were buried extended, not crouched, although on which side or supine was unimportant. This posture was widespread in Lower and Upper Meroitic Nubia (Näser 1999; Williams 1991a). 
Type 2 burials are also dated to the Early Meroitic. The structure is normally aligned east-west and some had been re-opened for subsequent inhumations. The individuals were buried in various extended positions. This type too is found elsewhere (Geus 1998; Näser 1999; Williams 1991a; Zurawski 1987).

Type 3 burials are assigned to the Late Meroitic and have a different typology to its predecessors. They generally comprise low, flat tumuli of up to $0.8 \mathrm{~m}$ in height and 10$15 \mathrm{~m}$ in diameter and are surrounded by a stone ring (El-Tayeb and Kolosowska 2007: 19). Interestingly, they exhibit diversity in their sub-structures with differences in the shape of their shafts and the types of chambers. One tumulus contains an individual buried in a crouched position (El-Tayeb and Kolosowska 2007: 21), in contrast to burials from the Shendi Reach where semi-flexed or crouched burial positions predominated (Edwards 1998a; El-Tayeb 2010). Some pottery vessels and assorted items such as beads and earrings remain as many tumuli were robbed.

Type 4 comes from one cemetery. They are flat-topped with a surrounding stone kerb. Their sub-structures are unrelated with those of Types 3 (El-Tayeb and Kolosowska 2007: 21):

"They represent a combination of two types which are well known in Central Sudan and the Dongola Reach. Each featured a short, E-W descendary, about 2.5 - $3 \mathrm{~m}$ long, ending with a deep, rectangular, vertical shaft that had a side burial chamber dug into the larger (west) side of the shaft. This same type of burial substructure was also discovered on the other side of the Nile in Gebel Kulgeili."

The known tumuli have been robbed, although a small number of artefacts such as assorted beads, iron arrowheads and pottery vessels (hand- and wheel-made) remain. This type of burial has been proposed as transitionary between the Late and PostMeroitic (El-Tayeb and Kolosowska 2007: 23). Long and short descendents are known at and El-Kadada and Gabati (Shendi Reach), while rectangular vertical shafts were frequent in the Dongola Reach's Post-Meroitic and are also known from Meroitic Lower Nubia, with none found south of the $5^{\text {th }}$ Cataract (El-Tayeb 2012: 54).

There are very few Classic Meroitic cemeteries between the $3^{\text {rd }}$ and $4^{\text {th }}$ Cataracts $"$ in 
comparison with their occurrence at major cultural centres which were continuously occupied throughout their history" (El-Tayeb 2012: 77), although recently a few Meroitic and Post-Meroitic graves have been found in the $3^{\text {rd }}$ Cataract (Osman and Edwards 2012). The individuals were buried supine in an east-west alignment. There are some multiple burials. The grave assemblages included $b a$ statues and offering tables, with the nature of their composition dependent on social status.

Multiple grave burials were also common during the Meroitic, continuing practices which originated during the Neolithic. Grave offerings, particularly pottery vessels, were also placed on the surface outside of the grave during the Meroitic, while the Gdańsk Archaeological Mission documented that Post-Meroitic offerings were deposited in a parallel pit under the same superstructure (El-Tayeb and Kolosowska 2007: 24). The Mission also noted that the Late Meroitic saw a transition to a greater number of crouched burials while the custom of positioning the individual mainly on either its left or right sides was maintained. However, a shift towards the individual's face positioned looking towards the shaft occurred and continued into the Post-Meroitic. Neither such mortuary rules on depositional practices are evident at Jebel Moya. It is also worth noting that four non-robber tunnels similar but larger in dimensions to those at Ballana, Firka, Gemmai and Qustul (Bates and Dunham 1927; Emery and Kirwan 1939; Kirwan 1939) to the north have been documented at ez-Zuma and HammurAbbassyia, leading to the main (ez-Zuma) and subsidiary (Hammur-Abbassyia) burial chambers respectively; the latter contained a second individual arranged in an extended, not crouched, position (El-Tayeb 2010: 8-9).

The burial posture during the Post-Meroitic was crouched with the hands positioned in front of the face or at shoulder level. The bodies were wrapped in linen cloth or woollen shrouds and placed either on an animal hide bier or else a bed. Those graves which contain accompanying assemblages have no distinctive differences to prior Meroitic deposits with bronze amulets, bracelets, bead necklaces, pendants, etc. Many of the grave shafts in the Dongola Reach were rectangular and vertical, and on an east-west axis with the burial chamber off to the side of the shaft, for which there were two trends (El-Tayeb 2012: 77):

"In some graves the body was placed on its right side in east-west alignment, 
head pointing east and facing north. Within this east-west tend, sometimes a body was placed on its left side with the head to the west; however, in both cases the face was turned to the north, or in other words toward the burial entrance."

Further evidence of inter-regional connectivity in the Fourth Cataract region is evident at Umm Muri. Downstream are the well-known sites of Jebel Barkal, Nuri, El Kurru, El Zuma, Sanam Abu Dom and Tanqasi, between which royal burials, palaces and large settlement architecture are to be found (Edwards 2004; El-Tayeb 2012). About 40km from Jebel Barkal is an identified but not adequately described is a Meroitic or PostMeroitic tumulus field at Usli (Bárta et al. 2013). Settlements were also uncovered in Umm Muri area, with some nearby graves. The pottery chronology for Umm Muri beings in the first century $\mathrm{AD}$ and continues into the Post-Meroitic, with many of the vessels attributable to the Late Meroitic (McCann 2007). Faience, kaolin and metal wares were introduced through regional trade networks. Later, a variety of storage vessels and undecorated red slipped vessels predominated in the assemblages. A large number of utilitarian vessels were also found with different forms and styles. Hand and wheel-made forms are present. Together, the ebb and flow of local and imported traditions from both upstream and downstream is evident through the pottery sequence (McCann 2007: 54-65).

Fine-wares with motifs of the goddess Hathor and satyrs, amongst others, have been compared to similar finds at Faras and Karanog, elite sites in Lower Nubia; while the Meroitic graves at Kerma also have motifs on the base of their beakers (McCann 2007: 55). Also present are red-slipped forms with painted friezes, together with undecorated red-slipped beer jars, bowls and saucers, which McCann (2007: 55) regards as preceding similar found later at Meroe and Musawwarat in the Western Butana. Pottery was present in domestic and funerary contexts.

Excavations over the past three decades have also revealed a considerable Meroitic presence in the northern Dongola, particularly around and upstream from Kerma and Selib, and south in the Letti Basin (Bonnet and Valbelle 2005; El-Tayeb 2012: 17; Fernandez 1984; Grzymaski 1987; Honegger 2009: 37). There is no evidence in the Letti Basin for important centres of and on the scale of Faras, Karanog, Gebel Adda and Qasr Ibrim in Lower Nubia. Until recently, the only known Post-Meroitic cemetery in 
the northern Dongola Reach was at Tabo, excavated in 1965 (Maystre 1973).

Hearths are known in cemeteries in the Dongola Reach in the known localities between the $3^{\text {rd }}$ and $4^{\text {th }}$ Cataracts during the Meroitic at Jebel Ghaddar, El-Zuma, El-Kassinger amongst others. Conversely, there is no evidence for human sacrifice. However, it is recorded in Post-Meroitic Lower Nubia at the X-Group cemeteries at Ballana and Qustul (Emery and Kirwan 1939). There was also limited animal sacrifice with only two known cases. The first is at the south cemetery at Jebel Ghaddar where an unidentified small animal (sheep or goat?) was buried beneath the mound on the ground surface by the western edge of the shaft. The second was a dog found at the bottom of a shaft at ElKassinger. Comparatively, the X-Group tumuli at Ballana and Qustul have animal burials as offerings outside the burial chamber.

\subsubsection{Shendi Reach: The heart of the Meroitic state}

Two large non-elite Meroitic cemeteries have been uncovered south of Meroe in the Shendi Reach which may relate to riverine settlement, though no associated settlement remains have been found and it is unclear whether such nucleated cemetery activity was the norm rather than the exception for the region: Kadada (Geus 1984; Lenoble 1994; Reinold 2008) and Gabati (Edwards 1998a). At the Gabati cemetery, whose Meroitic phase dates from the second century BC to the end of the second century AD and PostMeroitic from the start of the fourth century AD to the end of the eighth century AD, 63 of 74 identified Meroitic graves were excavated out of a total of 124 burials. The remaining 50 excavated burials were Post-Meroitic and Medieval.

The average density per square metre was two graves, which is a significant contrast to Jebel Moya where the density reached a maximum of 10 per square metre with 205 graves in square J.9, K.10 in the north-east. No offering tables or inscriptions were present. Mastaba-like superstructures were rare, not just at Gabati but for non-elite tombs generally in the Shendi Reach outside of Meroe (Edwards 2004: 175), by contrast with Lower and Upper Nubia: Of the 63, only four retain traces of a black sandstone chipped superstructure encased by mudbrick. Edwards speculated that the other graves may have been marked by a low sand mound. No such superstructures have been identified at Jebel Moya, where the pastoralists' graves were oval or rectangular without 
burial shafts. Two of the superstructures at Gabati have traces of a probable chapel on the east side. The four superstructure burials contained chambers accessed by ramps. By contrast with the variable orientation of the Jebel Moya graves, the bodies at Gabati were more uniformly orientated east-west (in superstructures, an orientation held in common with "classic" Meroitic burials (Adams 1977: 374)) or north-south (for the remainder at the end of sloping ramps in transverse chambers), potentially implying a more uniform local ideology. Furthermore, a larger proportion of human burials contained pottery: $62.9 \%$ (Gabati) to $2.41 \%$ (Jebel Moya), with hand- and wheel-made forms present.

Although non-elite, there may have been a restriction placed upon these types of large "rural" cemeteries for few have been found. Edwards (2004: 175) has speculated that there may have been a second-tier of restricted access to inclusion in such grounds. Similar burials have been found outside of the Shendi Reach to the south at Gereif East in the northern Gezira along the Blue Nile (Edwards 2004: 175). A shift to tumuli appears to have occurred in the Post-Meroitic, and tumuli cemeteries are known from Meroe, al-Hobaji (southern Shendi Reach, west bank)(Chittick 1975) and south of the $6^{\text {th }}$ Cataract near Jebel Qisi (Al-Hakim 1979). Coincident is the appearance of Eastern Desert ware similar to those found in layers dated from the third - fourth centuries AD at the Sudanese Eastern Desert site of Tabot (Barnard and Magid 2006). Tabot was at the juncture of cross-desert routes between Egypt, Nubia, the Shendi Reach and Aksum.

Few preserved tumuli are present in clustered cemeteries south of Khartoum but some tumuli and other graves with similar artefact repertoires are known as far south as Sennar (Addison 1950, Al-Hakim 1979, Babiker 1984, Dixon 1963, Edwards 1991, El-Tayeb 1999, Marshall and Adam 1953).

South of Gabati and 35km north of Omdurman is the cemetery of Bauda on the west bank of the Nile, just downstream of the juncture of the Blue and White Niles. It is near the Neolithic site of Shaheinab. It spans over a thousand years from $c a$. AD 220 until 1504 (Babiker 1984: 1). It covers a vast area: 1.5 x 0.6km with 118 burial mounds, of which 104 are excavated (Babiker 1984: 134). The mounds are comprised of earth and gravel, are small in height with variable diameters up to $15 \mathrm{~m}$ and are sometimes enclosed by a stone wall; this is something not known from the excavation records at 
Jebel Moya or visible in the photographs of when it was first seen in January 1911. However, vast grave and tumuli fields are known from El Goi in the region of the $5^{\text {th }}$ Cataract north of Berber which the surveyors attribute to the Kerma and Post-Meroitic periods respectably (Jesse et al. 2013).

The two Bauda mounds radiocarbon dated to the Late Meroitic were in the southern and northern sectors of the area, indicative of a variable spread of graves not confined to specific areas for different time periods. In total there were 147 graves, of which 110 are Meroitic, 36 Christian and one Post-Meroitic (Babiker 1984: 139). The bodies were contracted with their head to the south on their right side and facing east in a standardised orientation not evident at Jebel Moya. Although the bodily orientation to the south is different to Gabati and likely indicative of local regional variation, the overriding ideology of maintaining a standardised pattern is present. Unlike Meroe, burial coffins are not present.

At Meroe, many of the royal and non-royal graves suffered from the efforts of robbers which has hampered efforts to determine the original burial posture and sometimes also the number of retainers (Shinnie and Anderson 2004). Its major cemeteries were located to the east and are called the Meroe South, West and North cemeteries. Edwards (2010) has recently attempted to seriate the pottery assemblages from the West cemeteries to derive a reliable ceramic chronology which could be applied to both the other Meroe cemeteries and more widely in the Shendi Reach, the Meroitic heartland. The elite tombs were large, pyramid-shaped for royalty with a burial chamber. There were also poorer graves with narrow vertical shafts as well as chamber graves. All forms are very distinctive from those occurring at Jebel Moya.

Approximately $3 \mathrm{~km}$ south of Meroe is Hamadab on the east bank of the Nile. It consists of two mounds. The northern mound formed the town (Wolf and Nowotnick 2006). The southern mound was identified as the necropolis in 2005 due to robber activities. With some similarities to Kadada and to the Late Meroitic at Kadero (Krzyźaniak 2011), many graves lacked a superstructure. Contrary to Kadero though, they were richly furnished. It has been dated to the Meroitic and Post-Meroitic. While around $80 \mathrm{~km}$ upstream from Meroe is the town of Wad ban Naga where Meroitic and Post-Meroitic graves and features are located and where excavations have just been re-opened 
(Onderka 2014).

Also downstream from Meroe, and the juncture with the Atbai River, is the newly discovered cemetery of Berber where 34 tombs have been excavated in a rescue mission. It is dated from the mid-second to the mid-third centuries AD (Bashir 2010: 2013). No remnants of superstructures have been identified, but whether this is due to erosion or the lack of construction is indeterminable. The bodies in the burial chambers were normally flexed or semi-flexed, with the exception of BMC 8 who was extended and orientated south-north and may have been buried in a wooden coffin (Bashir 2010: 71). Orientations were either north-south, south-north or east-west.

Upstream from Gabati is Jebel Sabaloka, located in the Sabaloka Inlier which is part of the $6^{\text {th }}$ Nile Cataract around $80 \mathrm{~km}$ downstream from the confluence of the Blue and White Niles. Many of the known Meroitic period remains are located to the south-west of the mountain slopes. The remains consist of simple stone structures and camp sites attributed by the excavators to relatively mobile agro-pastoralists (Suková \& Cílek 2012). There and elsewhere are clusters of Meroitic and Post-Meroitic tumuli, some up to $9 \mathrm{~m}$ in diameter. Burials marked by cairns also occur on terraces in nearby wadis which also contained settlements. No tumuli are present at Jebel Moya, where the graves differ in design. The Inlier system of wadis, freshwater features, periodic swamps, constricted riverine landscape and hills made for a dynamic zone of interaction between peoples from the heart of the Meroitic state and agro-pastoralists exploiting both its ecological resources and security, and the outlier desert environment.

\subsubsection{Gezira Plain}

There is a lack of large enough sites in the Gezira to adequately address such issues as the Meroitic exchange systems extending into the Gezira due to the lack of comprehensive surveys. The survey by Eisa and Khabir of the nine surface sites along the White Nile in the northern Gezira yielded sherds from five localities (Masara, Tiriah, Diwaihia and Kalakla al-Tiriah) with chevron patterns that they attribute to what is now Jebel Moya's Assemblage 2; the description of their temper (sand-tempered and sometimes with chaff or straw inclusions) correlates with the temper in Assemblage 2 (Eisa and Khabir 2006: 38). However, many of the best known and excavated sites were 
discovered by Wellcome's expedition in the early half of the 20th century, subsequently supplemented in the early 1970s and mid-1980s by brief and somewhat haphazard surveys and test excavations, apart from Haaland's work at Rabak. From November 1986 - January 1987, Osman Osman collected some artefacts while collecting samples for his doctorate on Late Quaternary palaeochannels in the southern Gezira. The pottery comes from the palaeochannel system running north of the Managil Ridge, south of Jebel Moya (Caneva and Osman 1990: 27). The sherds were examined by Caneva who ascribed them to the Mesolithic (dotted wavy line), the equivalent of Jebel Moya's Assemblage 1, and also to the Meroitic and Post-Meroitic.

Recently, however, the Italian Archaeological Mission at Al Khiday also found four Meroitic-era graves at Site 16-D-4 or Al Khiday 2 (Salvatori et al. 2011). Interestingly, they are radiometrically dated to between the first century BC and the second century AD, contemporary with Jebel Moya. Unlike Jebel Moya, their construction bares signs of Meroitic influence with a bedrock-incised chamber off the trapezoidal or circularshaped pits. All were disturbed by robbers in antiquity and any accompanying burial assemblages await publication.

What is evident to date is that the Gezira is distinguished from the areas to the north of Shendi Reach by the comparative lack of status objects produced by the production centres in and around Meroe. This could be explained in terms of cultural or political distinctiveness. However, the status of rural inhabitants must also be considered and how their ability to obtain such objects was (unfavourably) impacted by their degree and type of access to exchange networks (Edwards 1996). Alternatively, the relative lack of status objects may have been because such items were not used in similar ways in mortuary rites which, coupled with the lack of adequate surveys and excavations of identified sites, would produce a distorted picture of the nature and subsequent use of the trade relationship between the peripheral local inhabitants and the Meroitic centre.

As such there, little is known about the outbound flow of prestige goods making their way down to the local populace whose remains have been found so far. There is a distinct lack of elite burials found to date. By contrast, the inward flow of tribute items to the Meroitic centre from where they were distributed onwards is better known: skins, ivory, gold, ostrich feathers and slaves (Edwards 1996: 90) 
Although the extent, nature and localities of the gold extraction is as yet undetermined, this doesn't have to necessitate direct exploitation; it does at least necessitate access to the resources via intermediaries. If there was a Meroitic trading point at Sennar, then the area to the west, including Jebel Moya, could have served as a nexus point for trade and the agro-pastoralist and pastoralist populations living in the southern Gezira could have acted as the intermediaries/conduits. Critically, the sites of Jebel Moya, Sennar and Abu Geili (the latter two on the banks of the Blue Nile) are the largest known sites dating to the Late Meroitic and Post-Meroitic periods.

\subsubsection{Abu Geili}

The site of Abu Geili is almost $2 \mathrm{~km}$ north of the ancient Sennar cemetery and $c a .30 \mathrm{~km}$ east of Jebel Moya. A village and a cemetery were excavated by O.G.S. Crawford, a member of Wellcome's expedition, in 1914. The cemetery was dated to the Funj Sultanate. Yet, while the village's pottery coincides in part with cemetery usage at Sennar, no Meroitic elite items are found in the village similar to those in the Sennar graves (Crawford and Addison 1951). They are probably from two different communities living in close proximity to each other. Crawford dates the village from $200 \mathrm{BC}-\mathrm{AD} 600$ based on the nature of the artefacts and types of pottery, spanning the Classic, Late and Post-Meroitic Periods, with its end probably coinciding with the introduction of Christianity in the region (Crawford and Addison 1951: 11). His dating has subsequently been roughly confirmed by AMS dating of a lump of charred sorghum grains and spikelets in the University College's Institute of Archaeology's collections to $1790+/-40$ bp (BETA 194245) (Fuller 2014: 169), calibrated to AD 127 - 344 (OxCal Intcal13, Sigma $2(95.4 \%)$ ).

The Abu Geili village also has occupational debris such as potsherds and beads (Addison 1950). Numerous pits were either dug by the inhabitants beneath their houses or their houses were built over earlier in-filled pits (Crawford and Addison 1951). Overall, there is some wheel-made pottery, but the majority are hand-made and were said by Addison (Crawford and Addison 1951: 42) to be distinct from the Jebel Moya assemblages although there were some Jebel Moya wares present (see section 3.6). These Jebel Moya wares correspond with those of Assemblage 3 and consist of black 
polished, incised, cord elements (stamped) and comb-stamped wares.

The most common sherds come from black-polished ware with impressed decoration in-filled with red pigment; similar 'black-ware' is present at Jebel Moya but the decoration is incised. There are also grooved channelled sherds which were not identified by either Crawford or Addison, who conducted some of the later pottery analysis for the site, as being related to Jebel Moya pottery; there are a few similar sherds amongst the Assemblage 3 pottery curated at the British Museum. Thus the original pottery analysis by Crawford and Addison contains more pieces than acknowledged either from Jebel Moya or from communities living in the vicinity who utilised the Jebel Moya cemetery. The possibility that Abu Geili was occupied down into the PostMeroitic period as well cannot be excluded.

\subsubsection{Sennar}

The cemetery at Sennar was discovered in 1921 on the east bank of the Blue Nile. The remains include carnelian, Lydian stone, faience, glass and quartzite beads, faience figurines (Bes and Amun ram with the sun disc), pottery and bronze vessels (Addison 1950). The wheel-made red-ware was probably imported from Meroe via the exchange networks as were the jars of common Meroitic form. The hand-made pots are regarded as being of local manufacture (Addison 1950). Some forms of the bronze vessels have been found at Meroe West Cemetery. Similar carinated bronze bowls occurred in elite burials at Meroe (Addison 1950), reinforcing the elite exchange network hypothesis of Edwards (1996). Addison further adds that there were a limited number of hand-made pottery forms similar to those found at Jebel Moya, indicating trade exchange and at least some contemporaneity.

A circular grave was subsequently found in 1925 on the west bank. All but one of the 40 pots were black-ware with no external decoration, unlike the Jebel Moya black-ware (Addison 1950). Addison claims there are affinities with the Abu Geili pottery where Jebel Moya Assemblage 3 types have also been found, suggesting that the sites were at least partly contemporary. As a caveat it should be noted that the grave does not contain any distinctly Meroitic pottery. Three more graves were found nearby by Arkell: one Funj, one Post-Meroitic and the other Meroitic suggesting the former presence of a small 
cemetery in the vicinity which was damaged or destroyed by riverine action (Addison 1950). The Post-Meroitic grave contains black-ware with incised decoration externally and internally which contrasts with the black-ware from Jebel Moya, which is incised externally.

The associated Sennar settlement remains undiscovered. The materials found in the cemetery differ from those found at the nearby habitation site of Abu Geili (Addison 1950). Addison proposed that the settlement held a similar status to that of Faras in Lower Nubia; however, the extent of the cemetery has yet to be determined and the precise number of imported items is unknown since many objects were lost over the course of time and others were lost on board a ship which sank en route to England. Addison further hypothesises that Sennar was abandoned during the late second century $\mathrm{AD}$, his reasoning being this is when the perimeter of the Meroitic state was beginning to break up and decrease in geographical size; this dating can be questioned on the basis of new archaeological knowledge which dates the break-up of the Meroitic state to the late third and early fourth centuries $\mathrm{AD}$ and, on the basis of the Jebel Moya sequence, corresponds with Assemblage 3 pottery.

\subsubsection{Other cemeteries and settlements near Jebel Moya}

A mere $4 \mathrm{~km}$ downstream from Sennar Dam, however, two cemeteries have been identified at at Karim's Garden consisting of 19 burials (Cemetery A) and one grave (Cemetery B) and accompanying burial assemblages and surface finds. The artefacts from Cemetery B contain pottery assigned to the Meroitic (Edwards 1991: 46). There are many wheel-manufactured pottery vessels in addition to hand-made forms, with the other known locality of smaller wheel-made forms being Sennar East. Cemetery A's pottery, however, is Post-Meroitic with similar shaped vessels like long-necked jars, gourd-shaped bowls and bevel-rimmed bowls known from Sennar to as far north as Kadada (Edwards 1991: 46).

Further downstream at Qoz Nasra, near Marangan village, surface finds encompass the Meroitic to modern periods. Umm Sunt is slightly upstream from Qoz Nasra, also on the west bank of the Nile. There, 19 of an approximate 45 burials have been investigated and a Meroitic to Post-Meroitic date assigned to the artefacts. 
Crawford and Addison (1951) claim that a sherd from a site at the foot of Jebel Saqadi, ca. $20 \mathrm{~km}$ north-west of Jebel Moya, resembles sherds from Jebel Moya's Assemblage 3. Saqadi (Site 200, with Jebel Moya being Site 100) was excavated by Duncan Mackenzie at the request of Wellcome in February 1913. A stone wall enclosure of 25 x 20m was uncovered inside which was a red mudbrick structure in the uppermost of three layers (Crawford and Addison 1951: 111). Trenches and pits were excavated alongside the inside and outside of the walls of the enclosure. As at Jebel Moya, calcium carbonate was detected; it resulted in the grey soil colour of the second stratum and the pottery from this stratum was encrusted with lime (Crawford and Addison 1951: 117). Only 21 sherds survived for re-examination by Crawford. Most were hand-made and either black with red-infilled decor or light brown in colour. The finer sherds were redware or black-polished while the coarse sherds were also black or red. Other colours were present in limited numbers. Many, but not all, are claimed by Crawford to have formal similarities to vessels from Abu Geili (Crawford and Addison 1951: 121). Other finds include pottery discs or ring fragments, stone rings, armlets and mace-heads which Crawford claims are similar to their counterparts at Jebel Moya; these remains have not been re-examined since to verify their validity. As at Jebel Moya (Assemblage 3), there is a portion of the pottery assemblage which is painted though their Saqadi counterparts are wheel-made and Jebel Moya's is distinct from Meroitic painted wares. The limited numbers of Jebel Moya painted ware ranges from thick and coarse to very thin; the designs are mostly painted lozenges with the occasional painted animals and human figures (Addison 1949: 213).

Still closer to Site 100 is Site 300, also known as Dar El Mek (Crawford and Addison 1951). It is located in the south-east of the Jebel Moya massif between two small peaks. Excavations began in March 1913 and ended in April of the same year. There are remains of terrace walls, huts and houses. However, the description of the remains and the artefacts does not match that from Site 100 or Abu Geili, and the likelihood is that it dates from a later period.

More recently, limited survey work has resulted in more evidence for Meroitic trade down the Blue Nile. An isolated grave to the north-east of Sennar was dated to the Meroitic by David Edwards (1991). The nature of the Meroitic burials at Site 16-D-4 
reinforce work done by Eisa (1999) which suggests that the northern Gezira, in particular the northern White Nile, was culturally or even politically influenced if not during the Napatan then during the Meroitic period. South of Jebel Moya and Sennar along the Blue Nile is Dinder where settlement and grave remnants were found in a mound in August 1997 (Ahmed and Ahmed 2004). The shape of the grave and the bodily orientation could not be determined, and no superstructure was evident. Four burials were excavated and numerous others recorded as visible during limited excavations. A late date is indicated by the presence of an iron bracelet on one individual. Pottery from Dinder and the village of El Sereifa just to its north are burnished black ware with limited incised decor mainly on the rim. Interestingly, there were a couple of blackened sherds amongst the Jebel Moya Assemblage 3 collection at the British Museum. Such pottery has traditionally been regarded as late or early Post-Meroitic (Ahmed and Ahmed 2004: 187), which would fall within the OSL range attained for Assemblage 3 (see Table 3.10).

Aba Island is situated near the right bank of the White Nile, with Rabak on the east bank. It is $c a$. 300km south of Khartoum (Adam 2013). As such, it is close to Jebel Moya. Survey work has found many broken pottery sherds with comb stamping, comb incisions, incised lines and zoned motifs which point to a late 1st millennium BC or early-mid first millennium AD attribution; no Jebel Moya sherds are present amongst the few published photographs (Adam 2013: 146).

Meroitic-era objects and burials have also been reported from Grisly village and sites between El Getaina and El Kawa (e.g. El Teresab, Hashaba, Ni'ma and Wad el Zaki) (Eisa 1999: 367), which remain to be comprehensively excavated and published. An incised scarab ("God Amun gives life like Re") was found at El Kawa, said to have been made during the Napatan period (Eisa 1999: 367) but its date of deposition remains unclear. Objects (iron bracelets, pottery, etc) speculated to be Meroitic in date but not in nature have been found south of Kosti and in western Sudan (west of the banks of the White Nile), but have as yet to be adequately dated. Furthermore, while the site of ROSE 5 along the Upper Blue Nile with settlement and burial activity, is potentially extremely informative as a link between the southern Gezira and South Sudan, no comprehensive analyses of the pottery and lithic assemblages and no radiometric dates have been undertake (Bashir et al. 2012). 


\subsubsection{Western Butana}

By contrast, the Butana is better known although even it remains relatively underexplored and excavated (Bradley 1992: Edwards 1989). Trade networks stretched through the Butana to the Red Sea coast and included the famous gold mines of Wadi al-Alaqi and Wadi Gabgaba which were captured by Ptolemy II (Egypt, 285 - 246 BC). Monuments in the Western Butana (an area measuring 25,000 sq. km) are generally accepted as indicative of direct rule by the Meroe elite (Ahmed 1984), with the southeastern boundary in the vicinity of Jebel Qeili $c a .148 \mathrm{~km}$ south-east of Khartoum marked by a rock inscription of King Shorakaror dating from the second half of the $1^{\text {st }}$ century AD (Edwards 1996: 12; Török 1997: 205). This inscription has been interpreted as commemorating the pacification of and establishment of rule over this area (Török 1997: 466-7). Some monsoonal rain agriculture was practised at this northern-most edge of the savannah belt (Ahmed 1984), notably sorghum (Fuller 2014), while potential pastoral trans-migratory patterns have been reconstructed (Bradley 1992).

Sadly, work in the Western Butana remains site-specific, particularly focused on the monumental architecture of Basa, Hamadab, Musawwarat es Sofra, and Naqa. Musawwarat es Sofra, together with small temples at other localities which are classed as religious "Lion temples", was a centre for the god Apedemak (Edwards 1999: 26). Apedemak was a war god and his cult was associated with the Meroitic royal elite. Large and smaller temples in his service are known in the Western Butana where he is especially closely associated with, lending further weight to the hypothesis that the region was under direct control from Meroe where control of the exploitation of resources was channelled through the royal palaces (Edwards 1996: 27).

Ahmed (1984) did not address issues of the social relations of production and the known Meroitic archaeological remains (settlements, monuments and hafirs ("dams") when proposing that an agricultural system was predominantly used in the Western Butana. By contrast, Bradley $(1986,1992)$ proposed that the distribution of these resources was indicative of a seasonal mobile pastoral exploitation with a symbiotic relationship between the pastoralists and settled communities along the edge of wadis. More fieldwork is required to evaluate these hypotheses. Furthermore, hafirs are also present in the Gezira but their distribution patterns have not been mapped and no published 
survey work undertaken to map occurrences of archaeological sites in their vicinities as a preliminary step towards excavations. What is clear though is that "emphasis should be placed on the Western Butana as a zone of political interaction. More generally, the history of the Meroitic expansion into the Western Butana should be conceived of as an essentially political phenomenon.” (Edwards 1996: 26)

What seems to be clear, from the existing evidence, is that the southern boundary of the Meroitic state was in the Western Butana to the east of the Blue Nile and in the region of Sennar on the Blue Nile for the Gezira, with the incorporation of the Gezira into the network of power relations (Adams 1977: 341-2; Edwards 1996: 22-7). A limited number of burials have been found in the northern Gezira which have either not been adequately described either through destruction or the lack of excavation (Fernández et al. 2003) or are in the process of being published (Salvatori 2012, Usai and Salvatori 2006). Very few contemporary pastoral mortuary complexes are known elsewhere in the Sudan to Jebel Moya. The agro-pastoral villages of Abu Geili and Jebel et Tomat are nearby in the Gezira, while sites to the north clearly display regional Meroitic burial traditions and while the neighbouring Western Butana was ruled directly from the capital Meroe. Post-Meroitic cemeteries such as Ballana and Qustul in Lower Nubia were from formerly nomadic cultures which settled in the Nile Valley and integrated with local populaces. Therefore, there were a myriad of social structures at play in the different regions of the Sudan, with variable integration with and control over local power and trade networks. These in turn fed into mortuary practices which held a degree of standardisation at a regional level.

\subsection{Discussion: The importance of Jebel Moya}

The archaeological context of known sites in the Gezira and correlations with the Butana reinforce findings from the new luminescence chronology at Jebel Moya and the Assemblage 3 dating of the main mortuary complex at the site. Never before have cemeteries in Meroitic and Post-Meroitic Nubia been actively compared to Jebel Moya in an attempt to elucidate the different social organisation reflected in mortuary assemblages between the core and the periphery of the Meroitic state. 
The presence of oval graves and crouched bodily positions in both Meroitic Lower and Upper Nubia (see above) means that Rudolf Gerharz's (1994) contention that such burials at Jebel Moya date from an earlier period, perhaps as early as Assemblage 1, is no longer tenable. Furthermore, hearths - with similar shapes to Addison's ovens at Jebel Moya - are found elsewhere in Meroitic mortuary contexts (El-Tayeb 2012: 84), which may mean that they served a dual habitation-mortuary ritual purpose. Indeed, ElTayeb (El-Tayeb 2012: 84) believes that hearths (or 'ovens') existed for burial purification or funerary banquets as part of the mortuary practices.

It is thus proposed that in waning days of the Meroitic state, nomadic peoples began settling more in the Nile Valley and integrating with the local inhabitants. The subsequent Post-Meroitic cemeteries, particularly those like Ballana and Qustul, were the result of the re-negotiation of identities and ethnicities and the subsequent expression of these identities through mortuary rites. Although there was a clear spatial separation of commoner from elite burials at Ballana and Qustul, and a distinction royal and other elite burials, these sites have a lesson for the study of Jebel Moya. Instead of explanations of variability at Jebel Moya that are grounded in chronological or biological/genetic distinctions, it is more effective to explain variation in mortuary practices as resulting from complex social behaviours, and inequality across a wider set of interwoven social networks continuously recreating personal and group identity both in life and in death.

Supporting the model of multiple socio-economic entities participating in trade and political alliances in the Gezira, and by extension throughout Meroitic Nubia (Edwards 1996) is the account by Seneca (Nat. Quest. VI 8, 3) of the Roman Emperor Nero's expedition to trace the Nile upstream. In this account, the Meroitic ruler issued supporting documentation to local elites as far south as the Sudd. Regardless of possible documentary biases, it is a clear written indication of social elites existing amongst the communities in the southern frontier zone of the Gezira and beyond (Welsby 1996). Unfortunately, no further particulars are known about the results of their journey or an account of what was witnessed. However, the archaeological evidence points towards the Gezira being a fluid zone of interaction of different economic and socio-political actors. 
The northern Gezira Plain most probably fell under an unknown form of Meroitic rule during the Classic and Late periods. The construction of the graves at Site 16-D-4 (Al Khiday 2, on the west bank of the White Nile) shows Meroitic influence with a bedrockincised chamber off the circular- or ellipsoidal-shaped pits accessed by a shaft (Usai et al. 2014: 187). Like Meroitic burials at El Geili to the north there is a west-east orientation of the burial chamber and the grave, while the individual is contracted and positioned facing north with the head to the west, and finally a stone pillow is sometimes present (Usai et al. 2014: 193). The contrast with Jebel Moya, with its shallow sandy burials that have no stone linings or permanent superstructures, has been taken to mean the funerary practices at Site 16-D-4 were influenced by their counterparts in the Shendi Reach and that the area was within Meroe's sphere of political control (Usai et al. 2014: 195), which was previously postulated by Eisa (1999).

The southern Gezira, therefore, formed a dynamic zone of interaction on the Meroitic state's southern frontier with settled and semi-settled agro-pastoralists, at least one Meroitic station at Sennar and a large pastoral occupation at Jebel Moya. Although there is little archaeological evidence, exchange may have included animals and animal products such as ivory. What is clear though is that the rise of an emergent elite at Jebel Moya, detectable in the mortuary realm with the spatial neighbourhood in its North-East sector, would have formed an integral part of the social configuration of communities at this time. 


\section{Chapter 8: Conclusion}

The words of Steve Mbutu (Mbutu 1991: 381) still ring true more than two decades later: "It is remarkable that after 60 years of archaeological research in the central Sudan, there still appear to be prominently marked cultural hiatuses." It is especially true when applied to the archaeology of the southern Gezira Plain in south-central Sudan. Very little archaeological work has been undertaken in the southern Gezira since the death of Henry Wellcome in 1936, with limited excavations at Jebel Moya and Jebel et Tomat by J. Desmond Clark, and at Rabak by Randi Haaland, plus Victor Fernandez et al.'s survey (2003) being notable exceptions.

The corpus of materials and excavation records from Jebel Moya comprise the most comprehensive assemblage currently available to understand the nature and timing of the occupation of the region. Despite much of the original skeletal and archaeological materials having been discarded or damaged, select excavation records (including grave, object and bioanthropological cards), representative pottery samples, artefacts and some human skeletal remains survive. The information on the cards and from the bioanthropological analysis of Mukherjee et al. (1955) and the Duckworth Laboratory have been incorporated into a new Register of Graves. My work presents a thorough statistical and spatial analysis of the remaining data (see chapters $4-6$ ), which builds upon the foundations laid by the creation of the first statistically-derived and justifiable pottery sequence and luminescence dating of the extant pottery assemblage at the British Museum to establish a reliable chronological sequence (see Chapter 3). It also places the site not just within the context of the other known sites from the southern Gezira but also compares it to sites elsewhere in North-East Africa to help elucidate the nature of social organisation as reflected in the mortuary realm (see Chapter 7).

This concluding chapter is organised around two inter-related concepts. The first part focuses on conclusions about the social nature of the burial complex at Jebel Moya, and the second on Jebel Moya as a pastoral society during the Classic and Late Meroitic periods on the southern frontier of the large Meroitic state. 


\subsection{Research questions on burial and society at Jebel Moya}

In order to examine the little known social order in the southern Gezira, it was necessary to derive a new chronology for Jebel Moya in order to determine the timing and the nature of its human occupation. With the opening of the southern Gezira plain after the lessening of the Nile floods and the retreat of swamp-like conditions in the midHolocene, which enabled its re-habitation by people which may have come from either the north, east or west, or a combination, it appears likely that Jebel Moya was sporadically visited by one or more mobile populations in the late sixth or early fifth millennium BC, as characterised by Assemblage 1. No structures can be definitely assigned to this occupational phase. The demands for mobility may have been because of the need to manage domestic herds or through the management of a diverse economy comprising of small-scale herding complimented by hunting and fishing activities similar to that evidenced at sites like Kadero (Chlodnicki et al. 2011) and El Geili (Caneva 1988) to the north of Khartoum.

After the 'Assemblage 1' population ceased frequenting Jebel Moya, there is no evidence for re-occupation until the mid-second millennium $\mathrm{BC}$, characterised by Assemblage 2 pottery. There are floorings and post-holes on the surface of Stratum D in the south-West sector which may possibly be contemporary with Assemblage 2 (see Table 4.1). It was not possible to determine their socio-economic structures and no individual burial could be definitely assigned to this period. They could have been hunter-gatherers or pastoralists, but there is currently no means to arrive at a plausible conclusion. They may not have been cultivators as the arid plains surrounding the Jebel Moya massif are thought to have been unsuitable for agriculture two millennia ago and earlier due to the lack of standing water and the difficulties in constructing wells by cutting through the overlying sandstone.

The vast majority of the burials are allocated to the succeeding period characterised by Assemblage 3 pottery (see Chapter 4). Such a scenario has parallels elsewhere such as at Dia (Mali) where a 50 hectare (first millennium AD) cemetery covered an early first millennium BC settlement of similar size (Bedaux 2005; Bedaux et al. 2001). At Jebel Moya, there is no discernible link between the time periods of Assemblages 2 and 3, which were separated by approximately 600 years (see Chapter 3 ). 
In Assemblage 3 times, it has been shown that the pastoralist occupants both lived and buried their dead in the Jebel Moya valley (see Chapters 4 and 5). The layout of the cemetery was broadly established at its advent towards the end of the first millennium $\mathrm{BC}$, and both habitation and mortuary activity very likely continued until the site's abandonment possibly as late as the mid-first millennium AD. The nature of their mortuary rituals was determined through looking for burial patterns in the presence and distribution of biological age groups and sexes, accompanying burial assemblages and the postures of the bodies. The internal structure of the cemetery can reflect (1) family, lineage or communal interaction with the deceased, and (2) social roles and responsibilities together with personal possessions decommissioned from the realm of the living. What arises out of the statistical and spatial analyses of the human remains and their accompanying burial assemblages is that there were differences in those assemblages present for different age sets, which is suggestive of social hierarchy, although this is not reflected in burial orientations which were similar. Indeed, the most persuasive evidence for social hierarchy is the spatial neighbourhood combining richer and poorer burials in the North-East sector (see section 6.3.3), which appear to have occurred during the time of peak burial activity (Figures 4.13 and 6.24). By contrast, there is no discernible spatial patterning for other sectors or for the deepest burials.

The spatial neighbourhood in the North-East sector is paralleled by the sector possessing the greatest number of burials, which may be due to an effort by (1) competing or lesser lineages to associate themselves in death with the dominant lineage, thus constructing a subservient undercurrent of affiliation within the broader ideological remit of group collectivity, or (2) related lineages emphasising their relationship in death with the dominant lineage through deposition in the same spatial vicinity. As such, the placement of the burials has a large ideologically-derived component. These acts linked kin and landscape in a mnemotype through a display of political power or strategy and commemoration of the dead legitimising the present (Bollig 1997, 2009; Durkheim 1915; van Beek 2012). Whether there was a corresponding population increase or if there was an internal socio-political structural reconfiguration cannot as yet be determined. What can be discerned is that it simultaneously advertised, confirmed and reinforced contemporary social order and it was done with the adult burials; infant and juvenile age sets had no distinguishing features or spatial distribution patterns, while 
young adults have some similarities with adults in terms of the composition of the burial assemblages but also have no determinable distribution pattern.

Although there is currently no evidence for cultivation activity in the immediate surrounding plain, the presence of the contemporary agro-pastoral villages of Abu Geili along the Blue Nile and Jebel et Tomat to the north-west of Jebel Moya is strong evidence for broadly contemporaneous but economically distinct groups who traded with each other while maintaining separate cultural identities (see Chapters 3 and 7). Such differences can be seen, for example, in the distinct pottery assemblages of Jebel Moya and Abu Geili, with evidence for social contact evidenced by sherds from the former present amongst the assemblages of the latter.

Jebel Moya, situated within a confined valley high above the surrounding plain, would have held social collective memories about the dead of such pastoralist trading communities (Bollig 1997: Sterner 1995). Daily life, politics and ritual are intertwined, and their social landscape is continuously recreated by the living. For example, ritual feasting accompanies commemoration of ancestral burials in many ethnographic examples and the spatial residue of this collective event is used as a socio-political medium visible to all communities in the neighbourhood (Bollig 2009). Mountains are particularly susceptible to this form of cultural appropriation (van Beek 2012: 9). As such, the Jebel Moya mortuary rituals may have been rituals of belonging, a continual reassertion of belonging to a common social landscape for a pastoralist community or communities.

It was amidst such a matrix of cultural interactions that the Meroitic state operated a point of trade at Sennar. In support of this contention is the well-known handbook Periplus Maris Erythraei, covering the early Indian Ocean trading networks, written in Greek by an unknown author or authors in the mid-first century AD which notes that ivory was brought to Aksum from an area or place called Kueneion (Kirwan 1972; Phillips 1997). Kueneion has been equated with, or in the immediate vicinity, of Sennar (Kirwan 1972; Phillips 1997). If the identification is correct, together with the presence of Meroitic and Jebel Moya artefacts at Abu Geili, the presence of a Meroitic trading point in the southern Gezira is a possible indicator that the source of the aforementioned ivory was the local populace. If the identification is inaccurate, it is still not beyond the 
realm of plausibility that the Meroitic state would have attempted to draw upon a ready source of animal resources. While not suggesting that the Jebel Moya populace was peripatetic during the Classic and Late Meroitic times, I hypothesise that mobile pastoral peoples in the southern Gezira took advantage of the southern expansion of the Meroitic state and established communities which engaged in trade with the State. They created their own traditions and identity, engraved into the social landscape through inscribing their mortuary rituals in the highest naturally occurring feature, the Jebel Moya massif, where they also resided.

\subsection{Positioning Jebel Moya as a pastoralist occupational site in the southern frontier zone of the Meroitic state}

Current data weighs heavily in favour of the inhabitants of Jebel Moya following a pastoral lifestyle during the first century BC to mid-first millennium AD (see Chapter 5). These include the lack of cultivation or cereal processing tools in either previously published or extant collections, and the alignment of dental wear and caries within the ranges of other pastoral samples examined by Hutton MacDonald (1999). The presence of pastoralists to the south of the Meroitic state feeds into a long-standing debate on the importance of pastoralism within the southern Meroitic state itself (Adams 1977; Ahmed 1984; Bradley 1986). Adams (1976: 123-4, 161) took issue with pastoralism being "a major factor contributing to the cultural differences...between Lower Nubia and the southern provinces", instead viewing herding activities as an adjunct to farming. However, subsequent research has established an entanglement of pastoral and agropastoral intermediaries integral to exchanges between Meroe, particularly in the Classic to Late periods, and societies further afield in the Butana (Ahmed 1984; Bradley 1986).

The cereal cultivation of the western Butana was the subsistence regime that underpinned the Meroitic state, centred on the alluvial soils and the wadis, possibly through seasonal patterns of exploitation (Ahmed 1984: 103). Interactions between what have been defined as nomadic populations (Al-Hakim 1972: 645; Edwards 1989: 149) and sedentary cultivators most probably occurred as nomadic populations migrated northwards during the onset of the rainy season to escape the tsetse fly belt. They would have utilised the available grazing at the edges of the wadis from the areas along the 
river margins of the Blue Nile (below the $6^{\text {th }}$ Cataract) and the Shendi Reach (above the $6^{\text {th }}$ Cataract), and in the northern Butana (Bradley 1986: 233-6).

Beyond generalised models for the neighbouring Butana (Ahmed 1984; Bradley 1992), the actual archaeological scale and changing nature of interaction between different forms of cultivators and pastoralists within a Meroitic state context and along the boundaries of the State have received little attention by archaeologists. For pastoralists, of course, access to water and pasture are critical, and their security is key to the establishment and maintenance of social relationships both within and beyond the local community by means of material exchanges (Hodgson 2000). Edwards (1996: 91) hypothesised that the cemetery of Jebel Moya may have been the result of communities being forced into the mountain range by raiding conducted by the Meroitic state, or its local elites, in this frontier zone. However, such a model would now require the raiding to continue over the course of up to four centuries and across the time of the breakup of the Meroitic state. Nor would it account for the number of burials from what must have been a fairly large population or populations over a sustained period of time. As such this hypothesis is not viable. The inhabitants of the southern Gezira were a critical part of a heterogenous zone of interaction between settled agro-pastoralists and likely Meroitic trading stations along the Niles and fairly biologically homogenous pastoralists enmeshed into trade networks across the southern Gezira frontier.

This manifestation of social differentiation at Jebel Moya, as indicated by the mortuary remains, and among the societies in the southern Gezira Plain answers the final research question (see Chapter 7) by showing how the former differs from the more structured patterning witnessed in the non-shallow and lined tombs of the (1) northern Gezira, and (2) Meroitic state in the Shendi Reach and Lower and Upper Nubia. However, regionally, the paucity of excavated sites and extensive, detailed survey works in the Gezira make the study of exchange systems between it and Meroitic-controlled lands difficult.

At Sennar, there was a limited number of hand-made pottery forms similar to those found at Jebel Moya, indicating a local exchange network, or some shared traditions between the two localities. There are also imported Meroitic artefacts, bronze vessels and wheel-made pottery (Addison 1950). Similar carinated bronze vessels have also 
been found amongst the elite burials at Meroe's West Cemetery (Addison 1950), reinforcing the idea of an elite exchange network hypothesis of Edwards (1996). The latter raises the strong possibility that there is an undiscovered accompanying settlement (now inundated by the Sennar Dam) which functioned as an outpost for Meroitic administrative and trading purposes. Such an outpost would have served a vital function in an area that had enormous potential to serve as a conduit for the supply of animal products (elephants, horn, ivory, leopards and ostrichs, and skins), human resources and gold from the southern frontier zone and the African interior for trading onwards down the Nile to the Shendi Reach for redistribution onwards (Edwards 1996: 90, Haaland 2014: 653).

\subsection{Final thoughts}

Jebel Moya's topographic prominence, standing above the plain, and its geographic location place it in the frontier zone of one of the earliest recorded states south of the Saharan belt. It is argued here that it was used as both a habitation and mortuary locality by pastoralists engaged in trade with neighbouring agro-pastoralists and Meroitic traders. The wealth of material permits initial hypotheses to be formulated as to how the communities organized ideologically and expressed social organization through their mortuary practices, and to do so from the perspective of pastoralists at the margins of a state.

Re-assessing the growth and structure of the mortuary remains at Jebel Moya has led to the suggestion in preceding chapters that the basic cemetery layout was conceived either at the outset or early on in its development, from the first century BC onwards (see Chapter 4). This conceptualization has permitted more detailed analyses to determine whether there are any patterns to the spread of wealth, burials and artefacts (see Chapters 4 and 6). While no valid clusters of human burials are detectable, the existence of a spatial neighbourhood of burials of 'influential individuals' detected in the North-East sector is suggestive of the presence of co-ordinating elites.

The demographic calculations presented in Chapter 4 pertaining to the expected number of adult and leader's burials suggest that only a few leaders were present at any point in 
time. However, it is unclear whether these represent hereditary elites or leading members of alternating powerful family lineages who rose to prominence at different times. The presence of females within the richer burials in the North-East sector which formed part of spatial neighbourhoods suggests access to important decision-making positions, as does an overall lack of a distinction of wealth between adult male and adult female burial assemblages.

Interestingly, wealth does not appear to have been limited to any age or gender group, perhaps suggestive that a degree of wealth was shared - at least in death - within prominent families or lineages. However, there are more burials without accompanying goods in the North-East sector, perhaps suggestive of a poorer sector of the population deriving legitimacy or social standing through association with more powerful others. This lends support to the idea that there is at least a two-tiered social status being displayed in the mortuary domain. For the richer burials in the North-East sector, the spatial neighbourhood is suggestive of prominent markers being present. Any markers or sandy burial mounds placed over the latter's shallow graves were not present at the time of excavation; none were recorded by the field directors and no visible traces are evident in the few remaining photographs of the valley as seen at the start of the first field season at the end of January 1911. However, as these markers wore out, the burials would have blended into the natural landscape, essentially transforming the individual into an eternal entity who was embedded in the sacred landscape through the actions and social decisions taken by the living.

This study has also added to a previous call by Krzysztof Grzymski (2004) to identify "ancient cultural constructs and meanings" in conceptual landscapes through detailed examination of how social practices were represented in the mortuary domain at Jebel Moya. Furthermore, the study has highlighted the potential gains to be achieved from a more comprehensive radiocarbon dating programme at Jebel Moya, marking it not just as a cultural reference point in the landscape but also as a well-dated locality against which artefacts collected from surface surveys elsewhere up and down the Blue and White Niles can be compared. This may well be possible as four-fifths of the valley floor remain unexcavated. In addition, the presence of pottery rouletting could be explored in more detail to fill in what is currently a blank area (southern Sudan) in the map of the pottery roulette distributions across Saharan and Sahelian North Africa 
(Haour et al. 2010; Livingstone Smith 2007), when a larger pottery sample is collected via future excavations at the site. When combined with the possibility of re-examining the excavation records and biological and artefact remains from nearby Rabak, and any extant artefacts from Jebel et Tomat, it is clear that a new excavation and survey programme in the southern Gezira would hold enormous possibility for (a) further enhancing our understanding of the type and nature of occupation of the region, (b) reasons for its abandonment, and (c) providing new information on the health and genetic (DNA) affiliations of its inhabitants. 


\section{Bibliography}

Adam, A. 2013. Archaeological survey of Aba Island: Preliminary report. Sudan \& Nubia 17: 142-148.

Adamiec, G. and Aitken, M. 1998. Dose-rate conversion factors: new data. Ancient TL 16: $37-50$.

Adams, W. 1977. Nubia, Corridor to Africa. London: Allen Lane.

Adams, W. 2005. The West Bank Survey from Faras to Gemai: 2 sites of Meroitic and Ballana age. Oxford: BAR.

Adams, W. and Adams, E. 1991. Archaeological typology and practical reality: A dialectical approach to artifact classification and sorting. Cambridge: Cambridge University Press.

Adamson, D., Gillespie, R. and Williams, M. 1982. Palaeogeography of the Gezira and of the lower Blue and White Nile valleys. In Williams, M. and Adamson, D. (eds.) A land between two Niles: Quaternary geology and biology of the Central Sudan, 165-220. Rotterdam: A.A. Balkema.

Addison, F. 1949. Wellcome Excavations in the Sudan: I, Jebel Moya, 1910-1914. Oxford: Oxford University Press.

Addison, F. 1950. Archaeological discoveries on the Blue Nile. Antiquity 24: 12-24.

Addison, F. 1956. Second thoughts on Jebel Moya. Kush 4: 4-18.

Ahmed, K. and Ahmed, S. 2004. Archaeological investigations at Dinder. Meroitica 21: 173-190.

Ahmed, K. 1984. Meroitic settlement in the central Sudan: An analysis of sites in the Nile Valley and the western Butana. Oxford: BAR.

Aitken, M. 1985. Thermoluminescence dating. New York: Academic Press.

Al-Hakim, A. 1972. Meroitic settlement of the Butana (Central Sudan). In Ucko, P., Tringham, R. and Dimbleby, G. (eds.) Man, settlement and urbanism: Proceedings of a meeting of the Research Seminar in Archaeology and Related Subjects held at the Institute of Archaeology, London University 639-646. London: Duckworth.

Al-Hakim, A. (ed.) 1979. University of Khartoum excavations at Sarurab and Bauda. Africa in Antiquity. Meroitica 5. Berlin: Akademie-Verlag. 
Alberti, G. 2013. Making sense of contingency tables in archaeology: The aid of correspondence analysis to intra-site activity areas research. Journal of Data Science 11: 479-499.

Althusser, L. 1977. For Marx. London: New Left Books.

Aries, P. 1981. The hour of our death. New York: Alfred A. Knopf.

Arkell, A. 1949. Early Khartoum. Oxford: Oxford University Press.

Arkell, A. J. 1952. Relations of the Nile Valley with the southern Sahara in Neolithic times. Paris: Arts and métiers graphiques.

Arkell, A. J. 1953. Shaheinab: An account of the excavation of a Neolithic occupation site carried out for the Sudan Antiquities Service in 1949-50. Oxford: Oxford University Press.

Arnold, J. (ed.) 1996. Emergent complexity: The evolution of intermediate societies. International Monographs in Prehistory Archaeological Series 9. Ann Arbor: University of Michigan.

Babiker, F. 1984. Research into mortuary practices in Sudanese prehistory and early history. Bauda Meroitic cemetery as a case study. Unpublished Ph.D. dissertation, University of Reading.

Banerjee, D., Murray, A., Bøtter-Jensen, L. and Lang, A. 2001. Equivalent dose estimation using a single aliquot of polymineral fine grains. Radiation Measurements 33: 73-94.

Bard, K. 1994. From farmers to pharaohs. Mortuary evidence for the rise of complex society. Sheffield: Sheffield Academic Press.

Barnard, A. 1992. Hunters and herders of Southern Africa: A comparative ethnography of the Khoisan peoples. Cambridge: Cambridge University Press.

Barnard, H. and Magid, A. 2006. Eastern Desert ware from Tabot (Sudan): More links to the north. Archéologie du Nil Moyen 10: 15-31.

Baroin, C., Barreteau, D. and von Fraffenreid, C. (eds.) 1995. Mort et rites funéraires dans le bassin du Lac Tchad. Paris: Orstom.

Bárta, M., Suková, L. and Brůna, V. 2013. The latest explorations at Usli, Northern Province. Sudan \& Nubia 17: 66-69.

Bashir, M. 2010. A recently discovered Meroitic cemetery at Berber, River Nile State, Sudan. Preliminary report. Sudan \& Nubia 14: 69-74.

Bashir, M. 2013. A third season of rescue excavations in the Meroitic cemetery at Berber, October 2012: Preliminary report. Sudan \& Nubia 17: 90-100. 
Bashir, M., Mohamed, M. and Abdalah, M. 2012. Rosieres Dam heightening archaeological salvage project. The excavations at Azaza site ROSE 5, Preliminary report. Sudan \& Nubia 16: 132-139.

Bates, O. and Dunham, D. 1927. The excavations at Gemmai. Cambridge: Harvard University Press.

Baxter, M. and Cool, H. 2010. Correspondence analysis in R for archaeologists: An educational account. Archeologia e Calcolatori 21: 211-228.

Bedaux, R. (ed.) 2005. Recherches archéologiques à Dia dans le Delta intérieur du Niger (Mali): bilan des saisons de fouilles 1998-2003. Leiden: CNWS Publications.

Bedaux, R., MacDonald, K., Person, A., Polet, J., Sanogo, K., Schmidt, A. and Sidibe, S. 2001. The Dia archaeological project: Rescuing cultural heritage in the Inland Niger Delta (Mali). Antiquity 75: 837-848.

Bevan, A. 2012. Spatial methods for analysing large-scale artefact inventories. Antiquity 86: 492-506.

Binford, L. 1971. Mortuary practices: Their study and potential. In Brown, J. (ed.) Approaches to the social dimensions of mortuary practices, 6-29. Memoirs of the Society for American Archaeology 25.

Binford, L. 1972. Mortuary practices and their potential. In Binford, L. (ed.) Approaches to the social dimensions of mortuary practices, 208-251. New York: Seminar Press.

Binford, L., Binford, S., Whallon, R. and Hardin, M. 1970. Archaeology at Hatchery West. Memoirs of the Society for American Anthropology 24.

Bloch, M. 1971. Placing the dead: Tombs, ancestral villages, and kinship organization in Madagascar. New York: Seminar Press.

Bloch, M. 1989. Ritual, history, and power: Selected papers in anthropology. London Atlantic Highlands, NJ: Athlone Press.

Bloch, M. and Parry, J. (eds.) 1982. Death and the regeneration of life. Cambridge: Cambridge University Press.

Bollig, M. 1997. Contested places: Graves and graveyards in Himba culture. Anthropos 92: $35-50$.

Bollig, M. 2009. Kinship, ritual, and landscape amongst the Himba of Northwest Namibia. In Bollig, M. and Bubenzer, O. (eds.) African landscapes: Interdisciplinary approaches, 327-352. New York: Springer. 
Bollig, M., Schnegg, M. and Wotzka, H.-P. (eds.) 2013. Pastoralism In Africa: Past, Present and Future. New York: Berghahn Books Ltd.

Bonnet, C. and Valbelle, D. 2005. Des Pharaons venus d'Afrique: la cachette de Kerma. Paris: Citadelles \& Mazenod.

Bonte, P., Friedman, J. and Rowlands, M. 1977. Non-stratified social formations among pastoral nomads. In Friedman, J. and Rowlands, M. (eds.) The evolution of social systems: Proceedings of a meeting of the Research Seminar in Archaeology and Related Subjects held at the Institute of Archaeology, London University, 173200. London: Duckworth.

Bourdieu, P. 1977. Outline of a Theory of Practice. Cambridge: University of Cambridge Press.

Bradley, R. 1986. A model for pastoralism in the Meroitic Butana. In Krause, M. (ed.) Nubische Studien, 25-32. Mainz: von Zabern.

Bradley, R. 1992. Nomads in the archaeological record: Case studies in the northern provinces of the Sudan. Meroitica 13. Berlin: Akademie-Verlag

Brass, M. 2007. Reconsidering the emergence of social complexity in early Saharan pastoral societies, 5000 - 2500 BC. Sahara 18: 1-16.

Brass, M. and Schwenniger, J.-L. 2013. Jebel Moya (Sudan): New dates from a mortuary complex at the southern Meroitic frontier. Azania 48: 455-472.

Braun, D. 1981. A critique of some recent North American mortuary studies. American Antiquity 46: 398-416.

Brown, J. 1971. Approaches to the social dimensions of mortuary practices. Washington: Memoir 25 of the Society for American Archaeology.

Brown, J. 1981. The search for rank in prehistoric burials. In Chapman, R., Kinnes, I. and Randsborg, K. (eds.) The archaeology of death, 25-37. Cambridge: Cambridge University Press.

Brown, J. 1995. On Mortuary Analysis - with Special Reference to the Saxe-Binford Program. In Beck, L. (ed.) Regional Approaches to Mortuary Analysis, 3-26. London: Plenum Press.

Buxton, J. 1973. Religion and healing in Mandari. Oxford: Clarendon Press.

Camps-Fabrer, H. 1966. Sur quelques techniques décoratives de la céramique impressionnée saharienne. In Congrès Préhistorique de France: Compte rendu de la XVIIIe session, 143-154. Paris: Société Préhistorique Francaise.

Caneva, I. 1987. Pottery decoration in prehistoric Sahara and Upper Nile: a new 
perspective. In Barich, B. (ed.) Archaeology and Environment in the Libyan Sahara: The Excavations in the Tadrart Acacus, 1978-1983, 231-254. Oxford: BAR.

Caneva, I. 1988. El Geili: The history of a Middle Nile environment 7000 B.C.-A.D. 1500. Oxford: BAR.

Caneva, I. 1991. Jebel Moya revisited: A settlement of the 5th millennium BC in the middle Nile basin. Antiquity 65: 262-268.

Caneva, I. and Marks, A. 1990. More on the Shaqadud pottery: Evidence for SaharoNilotic connections during the 6th-4th Millennium B.C. Archeologie du Nil Moyen 4: 11-35.

Caneva, I. and Osman, O. 1990. Late Neolithic pottery in the Gezira, Sudan. Nyame Akuma 34: 27-29.

Cannon, A. 1989. The historical dimension in mortuary expressions of status and sentiment. Current Anthropology 30: 437-458.

Carr, C. 1995. Mortuary practices: Their social, philosophical-religious, circumstantial, and physical determinants. Journal of Archaeological Method and Theory 2: 105200.

Carr, C. and Case, D. (eds.) 2005. Society, ritual and ritual interaction. New York: Springer.

Chapman, R. 1995. Ten years after - Megaliths, mortuary practices, and the territorial model. In Beck, L. (ed.) Regional approaches to mortuary analysis, 29-51. London: Plenum Press.

Chapman, R. 2003a. Archaeologies of Complexity. London: Routledge.

Chapman, R. 2003b. Death, society and archaeology: The social dimensions of mortuary practices. Mortality 8: 305-312.

Chapman, R. and Randsborg, K. 1981. Approaches to the archaeology of death. In Chapman, R., Kinnes, I. and Randsborg, K. (eds.) The archaeology of death, 124. Cambridge: Cambridge University Press.

Childe, V. G. 1956. Piecing together the past: the interpretation of archaeological data. London: Routledge \& Paul.

Chlodnicki, M., Kobusiewicz, M. and Kroeper, K. (eds.) 2011. Kadero: The Lech Krzyźaniak excavations in the Sudan. Poznan: Poznan Archaeological Museum.

Clark, J. D. 1973a. Preliminary report of an archaeological and geomorphological survey in the Central Sudan, January to March 1973. Berkeley: mimeographed. 
Clark, J. D. 1973b. Recent archaeological and geomorphological field studies in the Sudan: Some preliminary results. Nyame Akuma 3: 55-64.

Clark, J. D. 1984. Prehistoric cultural continuity and economic change in the Central Sudan in the Early Holocene. In Clark, J. D. and Brandt, S. (eds.) From hunters to farmers: The causes and consequences of food production in Africa, Berkeley: University of California Press.

Clark, J. D., Goffird-Gonzalez, D. and Associates. 2008. Adrar Bous: Archaeology of a Central Saharan granitic ring complex in Niger. Tervuren: Annals of the Musee Royal de l'Afrique Centrale.

Clark, J. D. and Stemler, A. 1975. Early domesticated sorghum from Central Sudan. Nature 254: 588-591.

Connah, G. 1981. Three thousand years in Africa: Man and his environment in the Lake Chad region of Nigeria. Cambridge: Cambridge University Press.

Crawford, O. and Addison, F. 1951. Abu Geili, Saqadi and Dar el Mek. The Wellcome excavations in the Sudan. Oxford: Oxford University Press.

Crown, P. and Fish, S. 1996. Gender and status in the Hohokam Pre-Classic to Classic transition. American Anthropologist 98: 803-817.

Crumley, C. 1995. Heterarchy and the analysis of complex societies. In Ehrenreich, R., Crumley, C. and Levy, J. (eds.) Heterarchy and the analysis of complex societies, 1-6. Arlington: American Anthropological Association.

Curet, L. and Oliver, J. 1998. Mortuary practices, social development, and ideology in Precolumbian Puerto Rico. Latin American Antiquity 9: 217-239.

Dann, R. 2009. The archaeology of Late Antique Sudan: Aesthetics and identity in the Royal X-Group tombs at Qustul and Ballana. New York: Cambria Press.

David, N. 1995. Mortuary practices, ideology and society in the central Mandara highlands, north Cameroon. In Baroin, C., Barreteau, D. and von Fraffenreid, C. (eds.) Mort et rites funéraires dans le bassin du Lac Tchad. Paris: Orstom.

David, N., Sterner, J. and Gavua, K. 1988. Why pots are decorated. Current Anthropology 29: 365-389.

Di Lernia, S. 1999. Discussing pastoralism. The case of the Acacus and surroundings (Libyan Sahara). Sahara 11: 7-20.

Di Lernia, S. 2001. Dismantling dung: Delayed use of food resources among Early Holocene foragers of the Libyan Sahara. Journal of Anthropological Archaeology 20: $408-441$. 
Di Lernia, S. 2006. Building monuments, creating identity: Cattle cult as a social response to rapid environmental changes in the Holocene Sahara. Quaternary International 151: 50-62.

Di Lernia, S. and Manzi, G. 2002. Sand, stones, and bones: The archaeology of death in the Wadi Tanezzuft Valley (5000-2000 BP). Firenze: All'insegna del giglio.

Dixon, D. 1963. A Meroitic cemetery at Sennar (Makwar). Kush 11: 227-234.

Dobres, M. and Robb, J. (eds.) 2000. Agency in archaeology. London: Routledge.

Dunham, D. 1957. Royal Tombs at Meroe and Barkal. Boston: Museum of Fine Arts.

Dunham, D. 1963. The South and West Cemeteries at Meroe. Boston: Museum of Fine Arts.

Dunham, G. 1999. Marking territory, making territory: Burial mounds in interior Virginia. In Robb, J. (ed.) Material symbols: Culture and economy in prehistory, 112-134. Carbondale: Center for Archaeological Investigations, Southern Illinois University at Carbondale.

Dunnell, R. 1971. Sabloff and Smith's "The importance of both analytic and taxonomic classficiation in the Type Variety system". American Antiquity 36: 115-118.

Dunnell, R. 1978. Style and function: A fundamental dichotomy. American Antiquity 43: 192-202.

Dunnell, R. 1986. Methodological issues in Americanist artifact classification. Advances in Archaeological Method and Theory 9: 149-207.

Durkheim, E. 1915. The elementary forms of the religious life: A study in religious sociology. London: George Allen \& Unwin Ltd.

Earle, T. 1989. The Evolution of Chiefdoms. Current Anthropology 30: 84-88.

Earle, T. 1991. Chiefdoms: Power, economy and ideology. Cambridge: Cambridge University Press.

Edwards, D. 1989. Archaeology and settlement in Upper Nubia in the 1st millennium A.D. Oxford: BAR.

Edwards, D. 1991. Three cemetery sites on the Blue Nile. Archéologie du Nil Moyen 5: 41-64.

Edwards, D. 1996. The archaeology of the Meroitic state: New perspectives on its social and political organisation. Oxford: BAR.

Edwards, D. 1998a. Gabati: A Meroitic, post-Meroitic and medieval cemetery in central Sudan London: Sudan Archaeological Research Society. 
Edwards, D. 1998b. Meroe and the Sudanic kingdoms. Journal of African History 39: 175-193.

Edwards, D. 1999. Musawwarat es Sufra III. A Meroitic pottery workshop at Musawwarat es Sufra. Meroitica 17:2. Weisbaden: Harrassowitz.

Edwards, D. 2004. The Nubian past: An archaeology of the Sudan. London: Routledge.

Edwards, D. 2007. The archaeology of Sudan and Nubia. Annual Review of Anthropology 36: 211-228.

Edwards, D. 2010. Meroitic ceramic chronology: Exploring the Meroe West cemeteries. Azania 34: 25-44.

Eisa, K. 1999. The extremities of the Kushite State during the Meroitic Period. Meroitica 15: 366-371.

Eisa, K. and Khabir, A. 2006. Pottery from survey sites along the White Nile Khartoum Province (Sudan): An interim report 1997-1998. Archéologie du Nil Moyen 10: $35-40$.

El-Tayeb, M. 1999. Rescue excavations at El Sabeil (Soba West). In Wenig, S. (ed.) Studien zum Antiken Sudan, 604-615. Meroitica 15. Wiesbaden: Harrassowitz.

El-Tayeb, M. 2010. The Kirwan Memorial Lecture: The Post-Meroitic from Kirwan to the present. Sudan \& Nubia 14: 2-14.

El-Tayeb, M. 2012. Funerary traditions in Nubian Early Makuria. African Reports vol. 9, Monograph Series 1. Gdańsk: Gdańsk Archeological Museum.

El-Tayeb, M. and Kolosowska, E. 2007. Meroitic burial traditions in the Fourth Cataract region. In Näser, C. and Lange, M. (eds.) Proceedings of the Second International Conference on the archaeology of the Fourth Nile Cataract, 11-25. Berlin, August 4th-6th, 2005. Harrassowitz Verlag: Wiesbaden.

El Mahi, A. and Haaland, R. 1984. Archaeological research in the area of Rabak and Atbara, Sudan. Nyame Akuma 24/25: 28-32.

Elboushi, I. and Abdel Salam, Y. 1982. Stratigraphy and ground-water geology of the Gezira Plain, central Sudan. In Williams, M. and Adamson, D. (eds.) A land between two Niles: Quaternary geology and biology of the Central Sudan, 65-80. Rotterdam: A.A. Balkema.

Emery, W. and Kirwan, L. 1939. The royal tombs of Ballana and Qustul. Cairo: Government Press.

Fernandez, V. 1984. Early Meroitic in Northern Sudan: The assessment of a Nubian archaeological culture. Aula Orientalis 2: 43-84. 
Fernández, V., Jimeno, A., Menėndez, M. and Lario, M. 2003. Archaeological survey in the Blue Nile area, Central Sudan. Complutum 14: 201-272.

Ford, J. 1938. A chronological method applicable to the Southeast. American Antiquity 3: 260-264.

Ford, J. 1954a. Comment on A.C. Spaulding, "Statistical techniques for the discovery of artifact types". American Antiquity 19: 390-391.

Ford, J. 1954b. The type concept revisited. American Anthropologist 56: 42-54.

Fortes, M. and Evans-Pritchard, E. (eds.) 1940. African Political Systems. Oxford: Clarendon Press.

Francigny, V. 2010. Second season at the Meroitic cemetery 8-B-5.A. Sudan \& Nubia 14: $56-59$.

Francigny, V. 2012. Preparing for the afterlife in the provinces of Meroe. Sudan \& Nubia 16: 52-59.

Fried, M. 1967. The evolution of political society: An essay in political anthropology. New York: Random House.

Fuller, D. 1997. The confluence of history and archaeology in Lower Nubia: Scales of continuity and change. Archaeological Review from Cambridge 14: 105-128.

Fuller, D. 2003. Pharaonic or Sudanic? Models for Meroitic society and change. In O'Connor, D. and Reid, A. (eds.) Ancient Egypt and Africa (Encounters with Ancient Egypt series, edited by Peter Ucko), 169-184. London: UCL Press.

Fuller, D. 2014. Agricultural innovation and state collapse in Meroitic Nubia: The impact of the savannah model. In Stevens, C., Nixon, S., Murray, M. and Fuller, D. (eds.) Archaeology of African plant use, 165-177. Walnut Creek: Left Coast Press.

Gallay, A. 2007. The decorated marriage jars of the inner delta of the Niger (Mali): Essay of archaeological demarcation of an ethnic territory. The Arkeotek Journal (www.thearkeotekjournal.org) 1.

Garcea, E. A. A. and Hildebrand, E. A. 2009. Shifting social networks along the Nile: Middle Holocene ceramic assemblages from Sai Island, Sudan. Journal of Anthropological Archaeology 28: 304-322.

Gatto, M. 2006. The Khartoum Variant pottery in context: Rethinking the Early and Middle Holocene cultural sequence. Archeologie du Nil Moyen 10: 57-72.

Gatto, M. 2011a. The Nubian pastoral culture as link between Egypt and Africa: A view from the archaeological record. In Exell, K. (ed.) Egypt in its African Context: 
Proceedings of the conference held at The Manchester Museum,University of Manchester, 2-4 October 2009 21-29. Oxford: BAR.

Gatto, M. 2011b. The relative chronology of Nubia. Archéo-Nil 21: 81-100.

Gerharz, R. 1994. Jebel Moya. Meroitica 14. Berlin: Akademie Verlag.

Geus, F. 1984. Excavations at el Kadada and the Neolithic of Central Sudan. In Krzyźaniak, L. and Kobusiewicz, M. (eds.) Origin and early development of foodproducing cultures in North-Eastern Africa, 361-372. Poznan: Poznan Archaeological Museum.

Geus, F. 1998. Sai 1996-1997. Archeologie du Nil Moyen 8: 85-126.

Giddens, A. 1984. The constitution of society: Outline of the theory of structuration. London: Polity.

Gifford, J. 1960. The type-variety method of ceramic classification as an indicator of cultural phenomena. American Antiquity 25: 341-347.

Gilchrist, R. 1999. Gender and archaeology: Contesting the past. London and New York: Routledge.

Gluckman, M. 1937. Mortuary customs and the belief in survival after death among the South-Eastern Bantu. Bantu 11: 117-136.

Goldstein, L. 1976. Spatial structure and social organization.Northwestern University, Unpublished Ph.D dissertation

Goldstein, L. 1981. One-dimensional archaeology and multi-dimensional people: Spatial organization and mortuary analysis. In Chapman, R., Kinnes, I. and Randsborg, K. (eds.) The archaeology of death, 53-70. Cambridge: Cambridge University Press.

Goodenough, W. 1965. Rethinking "status" and "role": Toward a general model of the cultural organization of social relationships. In Banton, M. (ed.) The relevance of models for social anthropology, 1-24. A.S.A. Monographs.

Goody, J. 1962. Death, property, and the ancestors: A study of the mortuary customs of the Lodagaa of West Africa. Stanford: Stanford University Press.

Gosselain, O. 2000. Materializing identities: An African perspective. Journal of Archaeological Method and Theory 7: 187-216.

Gosselain, O. P. 1992. Technology and style: Potters and pottery among Bafia of Cameroon. Man 27: 559-586.

Greene, D. 1972. Dental anthropology of early Egypt and Nubia. Journal of Human Evolution 1: 315-324. 
Griffith, F. 1923. Oxford excavations in Nubia. Liverpool Annals of Archaeology and Anthropology 10: 73-171.

Griffith, F. 1925. Oxford excavations in Nubia. Liverpool Annals of Archaeology and Anthropology 11: 57-172.

Grzymaski, K. 1987. Archaeological reconnaissance in Upper Nubia. Toronto: SSEA Publication XIV.

Grzymski, K. 2004. Meroe, the capital of Kush: Old problems and new discoveries. Sudan \& Nubia 9: 47-58.

Haaland, R. 1984. Continuity and discontinuity: How to account for a two thousand years gap in the cultural history of the Khartoum Nile Environment. Norwegian Archaeological Review 17: 39-51.

Haaland, R. 1987. Socio-economic differentiation in the Neolithic Sudan. Oxford: BAR.

Haaland, R. 2014. The Meroitic Empire: Trade and cultural influences in an Indian Ocean context. African Archaeological Review 31: 649-673.

Hafsaas, H. 2006. Cattle pastoralists in a multicultural setting: The C-Group people in Lower Nubia 2500 - 1500 BCE. Bergen \& Birzeit universities: The Lower Jordan River Basin Programme Publications 10.

Haour, A., Manning, K., Arazi, N., Gosselain, O., Guèye, N., Keita, D., Livingstone Smith, A., MacDonald, K., Mayor, A., McIntosh, S. and Vernet, R. (eds.) 2010. African pottery roulettes past and present: Techniques, identification and distribution. Oxford: Oxbow Books.

Härke, H. 2000. Social analyses of mortuary evidence in German protohistoric archaeology. Journal of Anthropological Archaeology 19: 369-384.

Hassan, F. 2002. Droughts, Food, and Culture: Ecological Change and Food Security in Africa's Later Prehistory. New York: Kluwer Academic/Plenum Publishers.

Hays, T. 1971. The Sudanese Neolithic: A critical analysis. Dallas: Southern Methodist University, Unpublished PhD dissertation.

Hegmon, M. 1998. Technology, style, and social practices: Archaeological approaches. In Stark, M. (ed.) The archaeology of social boundaries, 264-279. Washington: Smithsonian Instituion Press.

Helms, M. 1998. Access to origins: Affines, ancestors, and aristocrats. Austin: University of Texas Press.

Hertz, R. 1960. Death and the right hand. Rodney and Claudia Needham, trans. London: Cohen and West. 
Hill, J. and Evans, R. 1972. A model for classification and typology. In Clarke, D. (ed.) Models in archaeology, 231-273. London: Metheun.

Hillson, S. 1979. Diet and dental disease. World Archaeology 11: 147-162.

Hillson, S. 1986. Teeth. Cambridge: Cambridge University Press.

Hillson, S. 2014. Tooth development in human evolution and bioarchaeology. Cambridge: Cambridge University Press.

Hodder, I. 1982. Symbols in action: Ethnoarchaeological studies of material culture. Cambridge: Cambridge University Press.

Hodgson, D. L. (ed.) 2000. Rethinking pastoralism in Africa: Gender, culture \& the myth of the patriarchal pastoralist. Oxford: James Currey.

Hoffman, M. 1979. Egypt before the pharaohs: The prehistoric foundations of Egyptian civilization. New York: Barnes \& Noble Books.

Holl, A. 1998. Livestock husbandry, pastoralisms, and territoriality: The West African record. Journal of Anthropological Archaeology 17: 143-165.

Holl, A. 1993. Late Neolithic cultural landscape in South-Eastern Mauritania: An essay in spatiometrics. In Holl, A. and Levy, T. Spatial boundaries and social dynamics, 95-133. Ann Arbor: International Monographs in Prehistory.

Holmes, W. 1886. Pottery of the ancient Pueblos. In the Fourth Annual Report of the Bureau of Ethnology, 257-360. Washington D.C.: Smithsonian Institution.

Homiak, J. 1995. The Jamaican Body Social. American Anthropologist 97: 138-139.

Honegger, M. 2014. Recent advances in our understanding of prehistory in northern Sudan. In Welsby, D. and Anderson, J. (eds.) The Fourth Cataract and Beyond: Proceedings of the 12th International Conference for Nubian Studies, 19-30. London: Peeters.

Honegger, M., Bonnet, C., Dubosson, J., Jakob, B.,Fallet, C. and Ruffieux, P. 2009. Archaeological excavations at Kerma (Sudan). Documents de la mission archéologique suisse au Soudan. Neuchâtel: Universitéde Neuchâtel.

Honeychurch, W. 2013. The nomad as state builder: Historical theory and material evidence from Mongolia. Journal of World Prehistory 26: 283-321.

Huber, R. and Edwards, D. 2010. Gebel Adda Cemetery One, 1963: Post-medieval reuse of X-Group tumuli. Sudan \& Nubia 14: 83-90.

Huber, R. and Edwards, D. 2012. Gebel Adda cemeteries 3 and 4 (1963-1964). Sudan \& Nubia 16: 80-87. 
Humphreys, S. and King, H. (eds.) 1981. Mortality and immortality: The anthropology and archaeology of death. London: Academic Press.

Humphries, J. and Rehren, T. 2014. Iron production and the Kingdom of Kush: An introduction to UCL Qatar's research in Sudan. In Lohwasser, A. and Wolf, P. (eds.) Ein Forscherleben zwischen den Welten, 177-190. Berlin: Sonderheft MittSAG.

Huntington, R. and Metcalf, P. 1979. Celebrations of death: The anthropology of mortuary ritual. Cambridge: Cambridge University Press.

Hutchinson, S. 1996. Nuer Dilemmas: Coping with money, war and the state Berkeley: University of California Press.

Hutton MacDonald, R. 1999. In the teeth of the problem: Dental anthropology and the reconstruction of Africa dietary regimes. University College London, Unpublished Ph.D. dissertation

Illian, J., Penttinen, A., Stoyan, H. and Stoyan, D. 2008. Statistical analysis and modelling of spatial point patterns. New York: Wiley-Interscience.

Ingold, T. 1983. The significance of storage in foraging societies. Man 18: 553-571.

Insoll, T. 2004. Archaeology, ritual, religion. London: Routledge.

Insoll, T., Clack, T. and Rege, O. 2015. Mursi ox modification in the Lower Omo Valley and the interpretation of cattle rock art in Ethiopia. Antiquity 89: 91-105.

Irish, J. and Konigsberg, L. 2007. The ancient inhabitants of Jebel Moya redux: Measures of population affinity based on dental morphology. International Journal of Osteoarchaeology 17: 138-156.

Jesse, F. 2002. Wavy line ceramics: Evidence from Northeastern Africa. In Nelson, K. (ed.) Holocene settlement of the Egyptian Sahara (Volume 2): The Pottery of Nabta Playa, 79-96. New York: Kluwer Academic/Plenum Publishers.

Jesse, F. 2010. Early pottery in Northern Africa - An overview. Journal of African Archaeology 8: 219-238.

Jesse, F., Fielder, M. and Gabriel, B. 2013. A land of thousand tumuli - An archaeological survey in the region of El Gol, south of the 5th Nile Cataract, North Sudan. MittSAG 24: 59-74.

Johnson, A. and Earle, T. 2000. The evolution of human societies: From foraging group to agrarian state. Stanford: Stanford University Press. 
Judd, M. 2012. Gabati: A Meroitic, Post-Meroitic and Medieval cemetery in Central Sudan. Volume 2, the physical anthropology. Oxford: BAR.

Kamp, K. 1998. Social hierarchy and burial treatments: A comparative assessment. Cross-Cultural Research 32: 79-115.

Keech McIntosh, S. 1995. Pottery. In McIntosh, S. (ed.) Excavations at Jenne-jeno, Hambarketolo, and Kaniana (Inland Niger Delta, Mali), the 1981 season, 130213. Berkeley: University of California Press.

Kephart, W. 1950. Status after death. American Sociological Review 15: 635-643. Kirwan, L. 1972. An Ethiopian-Sudanese frontier zone in ancient history. Royal Geographical Society 138: 457-465.

Kirwan, L. 1939. Firka: The Oxford University excavations at Firka. Oxford: Oxford University Press.

Kleppe, E. 1986. The prehistory of southern Sudan: Approaches made before 1950. In Krause, M. (ed.) Nubische Studien, 109-113. Mainz: von Zabern.

Kobusiewicz, M., Kabacinski, J., Schild, R., Irish, J., Gatto, M. and Wendorf, F. (eds.) 2010. Gebel Ramlah: Final Neolithic cemeteries from the western desert of Egypt Poznan: Institute of Archaeology and Ethnology, Polish Academy of Sciences. Kohring, S. and Wynne-Jones, S. (eds.) 2007. Socialising complexity: Structure, interaction and power in archaeological discourse. Oxford: Oxbow Books.

Konigsberg, L. 1990. Analysis of prehistoric biological variation under a model of isolation by geographic and temporal distance. Human Biology 62: 49-70.

Krieger, A. 1944. The typological concept. American Antiquity 9: 271-288.

Kroeber, A. 1916. Zuni potsherds. American Museum of Natural History, Anthropological Papers 18: 7-21.

Kroeber, A. 1927. Disposal of the dead. American Anthropologist 29: 308-315.

Krzyźaniak, A. 2011. The Meroitic cemetery. In Chlodnicki, M., Kobusiewicz, M. and Kroeper, K. (eds.) Kadero: The Lech Krzyźaniak excavations in the Sudan, 199213. Poznan: Poznan Archaeological Museum.

Krzyźaniak, L. 1991. Early farming in the Middle Nile Basin: Recent discoveries at Kadero (Central Sudan). Antiquity 65: 515-532.

Kuper, R. and Kröpelin, S. 2006. Climate-controlled Holocene occupation of the Sahara: Motor of Africa's evolution. Science 313: 803-807.

LaMotta, V. M. 2001. Behavioral variability in mortuary deposition: A modern material culture study. Arizona Anthropologist 1: pp.53-80. 
Lenoble, P. 1994. Du Méroitique au Post-Méroitique dans la Region Méridionale du Royaume de Méroe. Recherches sur la période de transition. Sorbonne. Unpublished Ph.D dissertation

Levinson, D. and Wagner, R. 1986. HRAF research series in quantitative cross-cultural data: Vol. 1. General cultural and religious data. New Haven: Human Relations Area Files.

Linseele, V. 2010. Did specialized pastoralism develop differently in Africa than in the Near East? An example from the West African Sahel. Journal of World Prehistory 23: 43-77.

Livingstone Smith, A. 2000. Processing clay for pottery in northern Cameroon: Social and technical requirements. Archaeometry 42: 21-42.

Livingstone Smith, A. 2007. Histoire du decor à la roulette en Afrique subsaharienne. Journal of African Archaeology 5: 189-216.

Lubbock, J. 1900. Prehistoric times. London: Williams and Norgate.

Lull, V. 2000. Death and society: A Marxist approach. Antiquity 74: 576-580.

MacDonald, H. 2001. Grief and burial in the American southwest: The role of evolutionary theory in the interpretation of mortuary remains. American Antiquity 66: 704-714.

MacDonald, K. 1998. Before the Empire of Ghana: Pastoralism and the origins of cultural complexity in the Sahel. In Connah, G. (ed.) Transformations in Africa: Essays on Africa's later past, 71-103. London: Leicester University Press.

MacDonald, K. 2011a. Betwixt Tichitt and the IND: The pottery of the Faïta Facies, Tichitt Tradition. Azania 46: 49 - 69.

MacDonald, K. 2011b. A view from the south: Sub-Saharan evidence for contacts between North-Africa, Mauritania and the Niger, 1000 BC - AD 700. In Dowler, A. and Galvin, E. (eds.) Money, Trade and Trade Routes in Pre-Islamic North Africa, London: British Museum Press.

MacDonald, K. In press. A farewell to typologies: Towards an archaeology of African political tradition. In Davies, M. and MacDonald, K. (eds.) Connections, contributions and complexity: Africa's later Holocene archaeology in global perspective, Cambridge: McDonald Institute Monographs.

MacDonald, W. 1990. Investigating style: An explanatory analysis of some plain burials. In Conkey, M. and Hastorf, C. (eds.) The assessment of style in archaeology, 52-60. Cambridge: Cambridge University Press. 
Maes, J. 1924. Notes on the populations of the Kagai, Lukenie, and Lake Leopold II basins. In Annales du Musee do Congo Belge, Terveuren, Brussels: Nouvelle Serie, Miscellanees. Translated for Human Relations Files.

Maine, H. 1883. Dissertations on early law and custom. London: Murray.

Mann, M. 1986. The sources of social power: A history of power from the beginning to A.D. 1760. Volume 1. Cambridge: Cambridge University Press.

Manning, K., Pelling, R., Higham, T., Schwenniger, J.-L. and Fuller, D. 2011. 4500Year old domesticated pearl millet (Pennisetum glaucum) from the Tilemsi Valley, Mali: New insights into an alternative cereal domestication pathway. Journal of Archaeological Science 38: 312-322.

Manzo, A. 1995. Remarks on the Jebel Moya ceramics in the British Museum and their cultural significance. Sudan Archaeological Research Society newsletter 9: 1119.

Manzo, A. 2011. Italian Archaeological Expedition to the Eastern Sudan of the University of Naples "L'Orientale”: 2010 field season. Naples: Università degli studi di Napoli "L'Orientale".

Marks, A., Mohammed-Ali, A., Peters, J. and Robertson, R. 1985. The Prehistory of the Central Nile Valley as seen from the Eastern Hinterlands: Excavations at Shaqadud, Sudan. Journal of Field Archaeology 12: 262-272.

Marshall, K. and Adam, A. 1953. Excavation of a mound grave at Ushara. Kush 1: 4046.

Mawson, R. and Williams, M. 1984. A wetter climate in eastern Sudan 2,000 years ago? Nature 309: 49-51.

Mayor, A., Huysecom, E., Gallay, A., Rasse, M. and Ballouche, A. 2005. Population dynamics and Paleoclimate over the past 3000 years in the Dogon Country, Mali. Journal of Anthropological Archaeology 24: 25-61.

Maystre, C. 1973. Excavations at Tabo, Argo Island. 1965-8. Preliminary report. Kush 15: 193-199.

Mbutu, S. 1991. The Butana lithics industry: Its implications on regionalism during the Neolithic period in Northeastern Africa. Southern Methodist University, Unpublished Ph.D dissertation.

McCann, E. 2007. Umm Muri: Ceramics at the Fourth Cataract. In Näser, C. and Lange, M. (eds.) Proceedings of the Second International Conference on the archaeology of the Fourth Nile Cataract, 53-57. Berlin, August 4th-6th, 2005. Harrassowitz 
Verlag: Wiesbaden.

McElreath, R., Boyd, R. and Richerson, P. 2003. Shared norms and the evolution of ethnic markers. Current Anthropology 44: 122-129.

McGuire, R. 1983. Breaking down cultural complexity: Inequality and heterogeneity. In Schiffer, M. (ed.) Advances in archaeological method and theory, 91-142. New York: Academic Press.

McGuire, R. 1992. Death, society and ideology in a Hohkam community. Boulder: Westview Press.

McGuire, R. H. and Paynter, R. 1991. The Archaeology of inequality. Oxford: Blackwell Publishers.

McHugh, F. 1999. Theoretical and quantitative approaches to the study of mortuary practice. Oxford: BAR.

McIntosh, R. 1993. The Pulse Model: Genesis and Accommodation of Specialization in the Middle Niger. Journal of African History 34: 181-220.

McIntosh, R. 1998. The Peoples of the Middle Niger: The Island of Gold. Oxford: Blackwell Publishers.

McIntosh, S. 1995. Pottery. In McIntosh, S. (ed.) Excavations at Jenne-jeno, Hambarketolo, and Kaniana (Inland Niger Delta, Mali), the 1981 season, 130213. Berkeley: University of California Press.

McIntosh, S. and McIntosh, R. 1988. From stone to metal: New perspectives on the later prehistory of West Africa. Journal of World Prehistory 2: 89-133.

McIntosh, S. 1994. Excavations at Jenne-Jeno, Hambarketolo, and Kaniana (Inland Niger Delta, Mali), the 1981 season. Berkeley: University of California Press.

McIntosh, S. K. 1999a. Beyond chiefdoms: Pathways to complexity in Africa. Cambridge: Cambridge University Press.

McIntosh, S. K. 1999b. Pathways to complexity: An African perspective. In McIntosh, S. (ed.) Beyond chiefdoms: Pathways to complexity in Africa, 1-30. Cambridge: Cambridge University Press.

Mejdahl, V. 1979. Thermoluminescence dating: Beta-dose attenuation in quartz grains. Archaeometry 12: 61-72.

Metcalf, P. and Huntington, R. 1991. Celebrations of death: The anthropology of mortuary ritual. Cambridge: Cambridge University Press.

Milburn, M. 1996. Some recent burial dates for central and southern Sahara, including monuments. Sahara 8: 99-103. 
Millet, N. 1981. Social and political organization in Meroe. Zeitshcrift fur Aegyptische Sprache und Alterumskunde 108: 124-141.

Mills, A. 1982. The cemeteries of Qasr Ibrim. London: Egypt Exploration society.

Minchin, P. 1987. An evaluation of the relative robustness of techniques for ecological ordination. Vegetatio 69: 89-107.

Mohammed-Ali, A. and Khabir, A. 2003. The Wavy Line and the Dotted Wavy Line pottery in the prehistory of the Central Nile and the Sahara-Sahel Belt. African Archaeological Review 20: 25-58.

Morris, A. G. 1992. A master catalogue: Holocene human skeletons from South Africa. Johannesburg: Witwatersrand University Press.

Morris, I. 1991. The archaeology of ancestors: The Saxe/Goldstein hypothesis revisited. Cambridge Archaeological Journal 1: 147-169.

Mubarak, M., Bari, E., Wickens, G. and Williams, M. 1982. The vegetation of the central Sudan. In Williams, M. and Adamson, D. (eds.) A land between two Niles: Quaternary geology and biology of the Central Sudan, 143-164. Rotterdam: A.A. Balkema.

Mukherjee, R., Rao, C. and Trevor, J. 1955. The ancient inhabitants of Jebel Moya (Sudan). Cambridge: Cambridge University Press.

Muller, J.-D. 1996. Ideology and dynamics in Dii Chiefdoms. A study of territorial movement and population fluctuation (Adamawa Province, Cameroon). In Claessen, H. (ed.) Ideology and the Formation of Early States, 99-115. New York: E.J. Brill.

Murray, A. and Wintle, A. 2000. Luminescence dating of quartz using an improved single-aliquot regenerative-dose protocol. Radiation Measurements 32: 57-73.

Näser, C. 1999. Cemetery 214 at Abu Simbel North. Non-elite burial practices in Meroitic Lower Nubia. In Welsby, D. (ed.) Recent research in Kushite history and archaeology. Proceedings of the 8th International Conference for Meroitic Studies, 19-28. British Museum Occasional Paper 131. London: British Museum Press.

Navia, J. 1994. Carbohydrates and dental health. American Journal of Clinical Nutrition 59 (suppl): 719-727.

Nenadić, O. and Greenacre, M. 2007. Correspondence analysis in R, with two- and three-dimensional Graphics: The CA package. Journal of Statistical Software 20: 13. 
Nicholson, P. T. and Shaw, I. 1999. Ancient Egyptian materials and technology. New York: Cambridge University Press.

Nordstrom, H. 1972. A qualitative analysis of the Early and Middle Nubian pottery. In Nordstrom, H. (ed.) Neolithic and A-Group sites, 33-96. Stockholm:

Scandanavian University Books.

O'Connor, D. 1993. Ancient Nubia: Egypt's rival in Africa. Philadelphia: University Museum of Archaeology and Anthropology University of Pennsylvania.

O'Shea, J. 1979. Mortuary variability: An archaeological investigation with case studies from the nineteenth century Central Plains of North America and the Early Bronze Age of southern Hungary. University of Cambridge: Unpublished Ph.D dissertation

O'Shea, J. 1981. Social configuration and the archaeological study of mortuary practices: A case study. In Chapman, R., Kinnes, I. and Randsborg, K. (eds.) The archaeology of death, 39-52. Cambridge: Cambridge University Press.

Onderka, P. 2014. Wad ben Naga. The Sudan Archaeological Research Society colloquium. British Museum

Osman, A. and Edwards, D. (eds.) 2012. The archaeology of a Nubian frontier: Survey on the Third Nile Cataract, Sudan. Bristol: Mauhaus Publishing.

Paris, F. 1995. Essai de classification des monuments funéraires sahariens. Bulletin de la Société Préhistorique Francaise 92: 549-533.

Paris, F. 1997. Burials and the peopling of the Adrar Bous Region. In Barich, B. and Gatto, M. (eds.) Dynamics of populations, movements and responses to climatic change in Africa, 49-61. Rome: Bonsignori.

Parker Pearson, M. 1982. Mortuary practices, society and ideology: An ethnoarchaeological study. In Hodder, I. (ed.) Symbolic and structural archaeology, 99-114. Cambridge: Cambridge University Press.

Parker Pearson, M. 1998. Performance as valuation: Early Bronze Age burial as theatrical complexity. In Bailey, D. (ed.) The archaeology of value: Essays on prestige and the process of valuation, 32-41. Oxford: B.A.R.

Parker Pearson, M. 1999. The archaeology of death and burial. UK: Sutton Publishing. Pauketat, T. 2007. Chiefdoms and other archaeological delusions. Plymouth: Altamira Press.

Paynter, R. 1989. The archaeology of equality and inequality. Annual Review of Anthropology 18: 369-399. 
Peebles, C. and Kus, S. 1977. Some archaeological correlates of ranked societies. American Antiquity 42: 421-428.

Petrie, F. and Quibell, J. 1896. Naqada and Ballas. London: Quaritch.

Philippsen, B. 2013. The freshwater reservoir effect in radiocarbon dating. Heritage Science 1: 1-19.

Phillips, J. 1997. Punt and Aksum: Egypt and the Horn of Africa. Journal of African History 38: 423-457.

Prescott, J. and Hutton, J. 1994. Cosmic ray contributions to dose rates for luminescence and ESR dating: Large depths and long-term time variations. Radiation Measurements 23: 497-500.

Preucel, R. and Hodder, I. (eds.) 1996. Contemporary archaeology in theory: A reader. Oxford: Blackwell Publishers.

Rakita, G., Buikstra, J., Beck, L. and Williams, S. (eds.) 2005. Interacting with the dead: Perspectives on mortuary archaeology for the new millennium. Gainesville: University Press of Florida.

Ray, M. and Dudley Buxton, L. 1914. Some pathological and other conditions observed among the human remains from a prehistoric Ethiopian cemetery in the Southern Sudan, Africa. Proc. XVII Inter. Congr. Med. 23: 231-236.

Reid, A. and Lane, P. 2004. African historical archaeologies. New York: Kluwer Academic/Plenum Publishers.

Reinold, J. 2008. La nécropole néolithique d'el-Kadada au Soudan Central - Volume I Les cimetières A et B (NE-36-O/3-V-2 et NE-36-O/3-V-3) du kôm principal. Paris: Etudes et Recherche sur les Civilisations

Reisner, G. 1923. Excavations at Kerma I. Cambridge: Harvard University Press.

Richard, F. and MacDonald, K. 2015. From invention to ambiguity: The persistence of ethnicity in Africa. In Richard, F. and MacDonald, K. (eds.) Ethnic ambiguity and the African past: Materiality, history and the shaping of cultural identities, 17-

54. Walnut Creek: Left Coast Press, Institute of Archaeology Publications 65.

Richerson, P. and Boyd, R. 2005. Not by genes alone: How culture transformed human evolution. Chicago: University of Chicago Press.

Rilly, C. and Francigny, V. 2010. Excavations at Sedeinga. A new start. Sudan \& Nubia 14: 62-68.

Robb, J. 2007. Burial treatment as transformations of bodily ideology. In Laneri, N. (ed.) Performing burial, 287-298. Chicago: University of Chicago Press. 
Roth, A. 1993. Social Change in the Fourth Dynasty: The spatial organization of pyramids, tombs, and cemeteries. Journal of the American Research Center in Egypt 30: 33-55.

Rouse, I. 1939. Prehistory in Haiti: A study in Method. Yale University Publications in Anthropology 21:

Rouse, I. 1960. The classification of artifacts in archaeology. American Antiquity 25: 313-323.

Sabloff, J. and Smith, R. 1969. The importance of both analytic and taxonomic classification in the Type Variety system. American Antiquity 34: 278-286.

Sadig, A. 2010. The Neolithic of the Middle Nile region: An archaeology of Central Sudan and Nubia. Kampala: Fountain Publishers.

Sadr, K. 1991. The development of nomadism in ancient northeast Africa. Philadelphia: University of Philadelphia Press.

Saenz, C. 1991. Lords of the Waste: Predation, pastoral production, and the process of stratification among the Eastern Twaregs. In Earle, T. (ed.) Chiefdoms: Power, economy, and ideology, 100-118. Cambridge: Cambridge University Press.

Sagar, J. 1922. Notes on the history, religion, and customs of the Nuba. Sudan Notes and Records 5: 137-156.

Salvatori, S. 2008. Social structure of the R12 population: Some hypotheses. In Salvatori, S. and Usai, D. (eds.) A Neolithic cemetery in the Northern Dongola Reach. Excavations at Site R12, 127 - 137. Oxford: BAR.

Salvatori, S. 2012. Disclosing archaeological complexity of the Khartoum Mesolithic: New data at the site and regional Level. African Archaeological Review 29:

Salvatori, S. and Usai, D. 2007. The Sudanese Neolithic revisited. Crippel 26: 323-333.

Salvatori, S. and Usai, D. (eds.) 2008a. A Neolithic cemetery in the Northern Dongola Reach. Excavations at Site R12. Oxford: B.A.R.

Salvatori, S. and Usai, D. 2008b. R12 and the Neolithic of Sudan. New perspectives. In Salvatori, S. and Usai, D. (eds.) A Neolithic cemetery in the Northern Dongola Reach. Excavations at Site R12, 147 - 156. Oxford: B.A.R.

Salvatori, S., Usai, D. and Zerboni, A. 2011. Mesolithic site formation and palaeoenvironment along the White Nile. African Archaeological Review 28: 177 211.

Salzman, P. 1999. Is inequality universal? Current Anthropology 40: 31-61. 
Savage, S. 2001. Some recent trends in the archaeology of predynastic Egypt. Journal of Archaeological Research 9: 101-155.

Savage, S. H. 1997. Descent group competition and economic strategies in predynastic Egypt. Journal of Anthropological Archaeology 16: 226-268.

Saxe, A. 1970. Social dimensions of mortuary practices. University of Michigan, Unpublished Ph.D dissertation

Saxe, A. 1971. Social dimensions of mortuary practices in a Mesolithic population from Wadi Halfa, Sudan. In Brown, J. (ed.) Approaches to the social dimensions of mortuary practices, 39-57. Washington: Memoir 25 of the Society for American Archaeology.

Scott Thompson, M. 2014. Interactions with the incorporeal in the Mississippian and ancestral Puebloan worlds. Arizona State University. Unpublished Ph.D. dissertation.

Service, E. 1958. A profile of primitive culture. New York: Harper.

Service, E. 1962. Primitive social organization: An evolutionary perspective. New York: Random House.

Service, E. 1971. Cultural evolutionism. New York: Rinehart \& Winston.

Service, E. 1975. Origins of the state and civilization. New York: Norton.

Shanks, M. and Tilley, C. Y. 1987. Re-constructing archaeology: theory and practice. New York: Cambridge University Press.

Shaw, I. 2000. The Oxford History of Ancient Egypt. Oxford: Oxford University Press. Shennan, S. 1975. The social organisation at Branč. Antiquity 49: 279-287.

Shennan, S. 1997. Quantifying archaeology. Edinburgh: University of Edinburgh Press (2nd edition).

Shennan, S. 2002. Genes, Memes and Human History. London: Thames \& Hudson.

Shinnie, P. and Anderson, J. 2004. The capital of Kush 2: Meroe excavations, 19731984. Meroitica 20. Wiesbaden: Harrassowitz.

Silverman, H. and Small, D. (eds.) 2002. The space and place of death. Arlington: Archaeological Papers of the American Anthropological Association.

Skalnik, P., Claessen, H. and Oosten, J. 1996. Ideological and symbolic authority: Political culture in Nanun, Northern Ghana. In Ideology and the formation of early states, 84-98. New York: E.J. Brill.

Smith, A. 1992. Origins and spread of pastoralism in Africa. Annual Review of Anthropology 21: 125-141. 
Smith, A. 2000. The Bushmen of southern Africa: A foraging society in transition. Cape Town: David Philip.

Smith, A. 2002. The pastoral landscape in Saharan prehistory. In Lenssen-Erz, T., Tegtmeier, U. and Kröpelin, S. (eds.) Tides of the desert: Contributions to the archaeology and environmental history of Africa in honour of Rudolph Kuper. 14 Africa Praehistorica, Monographs on African Archaeology and Environment, 447-457. Cologne: Heinrich-Barth Institut, University of Cologne.

Smith, M. 1979. A further criticism of the Type-Variety system: The data can't be used. American Antiquity 44: 822-826.

Southall, A. 1988a. On mode of production theory: The foraging mode of production and the kinship mode of production. Dialectical Anthropology 12: 165-192.

Southall, A. 1988b. The Segmentary state in Africa and Asia. Comparative Studies in Society and History: An International Quarterly 30: 52-82.

Southall, A. 1999. The segmentary state and the ritual phase in political economy. In McIntosh, S. K. (ed.) Beyond chiefdoms: Pathways to complexity in Africa, 3138. Cambridge: Cambridge University Press.

Southall, A. and Gutkind, P. 1970. The illusion of tribe. In Peter, C. (ed.) The passing of tribal man in Africa, 28-51. Leiden: Brill.

Spaulding, A. 1953. Statistical techniques for the discovery of artifact types. American Antiquity 18: 305-314.

Spaulding, A. 1954. Reply to Ford. American Antiquity 19: 391-393.

Spaulding, A. 1977. On growth and form in archaeology: Multivariate analysis. Journal of Anthropological Research 33: 1-15.

Spencer, A. J. 1982. Death in Ancient Egypt. London: Penguin Books.

Spencer, C. 1993. Human agency: Biased transmission, and the cultural evolution of chiefly authority. Journal of Anthropological Archaeology 12: 41-74.

Sterner, J. 1995. Life and death in Mandara ceramics. In Baroin, C., Barreteau, D. and von Fraffenreid, C. (eds.) Mort et rites funéraires dans le bassin du Lac Tchad, 63-74. Paris: Orstom.

Stevenson, A. 2009. The predynastic Egyptian cemetery of El-Gerzeh : social identities and mortuary practices. Leuven: Peeters.

Stodder, A. 2005. The bioarchaeology and taphonomy of mortuary ritual on the Sepik Coast, Papua New Guinea. In Rakita, G., Buikstra, J., Beck, L. and Williams, S. (eds.) Interacting with the dead: Perspectives on mortuary archaeology for the 
new millennium, 228-250. Gainesville: University Press of Florida.

Strathern, A. 1981. Death as exchange: Two Melanesian cases. In Humphreys, S. and King, H. (eds.) Mortality and immortality, 205-223. London: Academic Press.

Sullivan, L. and Mainfort, R. (eds.) 2010. Mississipian mortuary practices: Beyond hierarchy and the representationist perspective. Gainesville: University Press of Florida.

Tainter, J. 1978. Mortuary practices and the study of prehistoric social systems. In Schiffer, M. (ed.) Advances in Archaeological Method and Theory, 105-141. New York: Academic Press.

Tarlow, S. 1999. Bereavement and commemoration: An archaeology of mortality Oxford: Blackwell Publishers.

Török, L. 1997. The Kingdom of Kush. Handbook of the Napatan-Meroitic civilization. Leiden: Brill.

Trigger, B. 1970. The Meroitic funerary inscriptions from Armina West. Publications of the Pennsylvannia-Yale Expedition to Egypt. New Haven and Philadelphia: Peabody Museum of Natural History of Yale Univeristy and the University Museum, University of Pennsylvannia.

Trinkaus, K. 1984. Mortuary ritual and mortuary remains. Current Anthropology 25: 674-679.

Turner, B. 1996. The Body and Society: Explorations in Social Theory. London: Sage Publications.

Turner, V. 1969. The ritual process: Structure and anti-structure. New York: Aldine De Gruyter.

Ucko, P. 1969. Ethnography and archaeological interpretation of funerary remains. World Archaeology 1: 262-280.

Usai, D. and Salvatori, S. 2006. Archaeological research south of Omdurman: A preliminary assessment on ceramic and lithic materials from 10-X-6 multistratified mound site along the western bank of the White Nile in Central Sudan. Archéologie du Nil Moyen 10: 203-220.

Usai, D., Salvatori, S., Jakob, T. and David, R. 2014. The Al Khiday cemetery in Central Sudan and its "Classic/Late Meroitic" Period graves. Journal of African Archaeology 12: 183-204.

Vail, J. 1982. Geology of the central Sudan. In Williams, M. and Adamson, D. (eds.) A land between two Niles: Quaternary geology and biology of the Central Sudan, 
51-64. Rotterdam: A.A. Balkema.

Vail, L. 1991. The Creation of Tribalism in Southern Africa. Berkeley: University of California Press.

Valliant, G. 1931. Excavations at Ticoman. American Museum of Natural History, Anthropological Papers 32: 199-439.

Van Beek, W. 2012. The dancing dead: Ritual and religion among the Kapsiki/Higi of North Cameroon and Northeastern Nigeria. Oxford: Oxford University Press.

Van Gennep, A. 1960. The rites of passage. London: Routledge.

Vida, M. 1998. The Italian scene: Approaches to the study of gender. In Whitehouse, R. (ed.) Gender and Italian archaeology: Challenging the stereotypes, 15-22. London: Accordia Research Centre and Institute of Archaeology.

Welsby, D. 1996. The Kingdom of Kush: The Napatan and Meroitic Empires. London: British Museum Press.

Welsby, D. 2001. Life on the desert edge. Seven thousand years of settlement in the northern Dongola Reach. London: Sudanese Archaeology Research Society.

Wendorf, F. and Schild, R. 1998. Nabta Playa and its role in Northeastern African Prehistory. Journal of Anthropological Archaeology 17: 97-123.

Wendorf, F. and Schild, R. 2003. Book review. Droughts, food and culture: Ecological change and food security in Africa's Later Prehistory. African Archaeological Review 20: 121-133.

Wendorf, F., Schild, R. and Associates. 2001. Holocene settlement of the Egyptian Sahara (Volume 1): The archaeology of Nabta Playa. 1: Kluwer Academic/Plenum Publishers.

Wengrow, D. 2006. The archaeology of early Egypt: Social transformations in NorthEast Africa, 10,000 to 2650 BC. Cambridge: Cambridge University Press.

Wengrow, D., Dee, M., Foster, S., Stevenson, A. and Bronk Ramsey, C. 2014. Cultural convergence in the Neolithic of the Nile Valley: A prehistoric perspective on Egypt's place in Africa. Antiquity 88: 95-111.

Wheat, J., Gifford, J. and Wasley, W. 1958. Ceramic variety, type cluster, and ceramic system in southwestern pottery analysis. American Antiquity 24: 34-47.

Whiteman, A. 1971. The geology of the Sudan Republic. Oxford: Clarendon Press.

Whittaker, D. and MacDonald, D. 1989. A colour atlas of forensic dentistry. London: Wolfe Medical Publications Ltd. 
Whittaker, J., Caulkins, D. and Kamp, K. 1998. Evaluating consistency in typology and classification. Journal of Archaeological Method and Theory 5: 129-164.

Wickens, G. 1982. Palaeobotanical speculations and Quaternary environments in the Sudan. In Williams, M. and Adamson, D. (eds.) A land between two Niles: Quaternary geology and biology of the Central Sudan, 23-50. Rotterdam: A.A. Balkema.

Wilkinson, T. 1996. State formation in Egypt: Chronology and society. Oxford: BAR. Williams, B. 1991a. Meroitic remains from Qustul Cemetery Q, Banana Cemetery B, and a Ballana Settlement. Part I. The University of Chicago Oriental Institute Nubian Expedition, Volume 8. Chicago: The Oriental Institute of the University of Chicago.

Williams, B. 1991b. Noubadian X-Group remains from royal complexes in cemeteries $Q$ and 219 and from private cemeteries $Q, R, V, W B, J$, and $M$ at Qustul and Ballana. The University of Chicago Oriental Institute Nubian Expedition, Volume 9. Chicago: The Oriental Institute of the University of Chicago.

Williams, M. 2009. Late Pleistocene and Holocene environments in the Nile Basin. Global and Planetary Change 69: 1-15.

Williams, M. and Adamson, D. 1973. The physiography of the Central Sudan. Geographical Journal 139: 498-508.

Williams, M. and Adamson, D. (eds.) 1982. A land between two Niles: Quaternary geology and biology of the Central Sudan. Rotterdam: A.A. Balkema.

Williams, M., Bari, E., Adamson, D. and Hag Abdulla, H. 1982. Landforms and soils of the Gezira: A Quaternary legacy of the Blue and White Nile rivers. In Williams,

M. and Adamson, D. (eds.) A land between two Niles: Quaternary geology and biology of the Central Sudan, 111-142. Rotterdam: A.A. Balkema.

Williams, M., Williams, F., Duller, G., Munro, R., El Tom, O., Barrows, T., Macklin, M., Woodward, J., Talbot, M., Haberlah, D. and Fluin, J. 2010. Late Quaternary floods and droughts in the Nile Valley, Sudan: New evidence from optically stimulated luminescence and AMS radiocarbon dating. Quaternary Science Reviews 29: 1116-1137.

Wilson, G. 1939. Nyakyusa conventions of burial. Bantu 13: 1-31.

Winchell, F. 2013. The Butana Group ceramics and their place in the Neolithic and Post-Neolithic of Northeast Africa. Oxford: BAR. 
Wobst, M. 1977. Stylstic behavior and information exchange. In Cleland, C. (ed.) For the director: Essays in honor of James B. Griffin, 317-342. Ann Arbor: University of Michigan Press.

Wolf, P. and Nowotnick, P. 2006. Hamadab - A Meroitic urban settlement. Excavations 2001 - 2003. Archéologie du Nil Moyen 10: 257 - 272.

Woolley, C. and MacIver, R. 1910. Karanòg: The Romano-Nubian cemetery. Eckley B. Coxe Junior Expedition to Nubia, Volumes 1-2. Philadelphia: University of Pennslyvannia Museum.

Wotzka, H.-P. (ed.) 2012. Proceedings of the Third International Conference on the archaeology of the Fourth Nile Cataract. University of Cologne, 13-14 July 2006. Köln: Heinrich Barth Institute.

Wright, J. 1967. Type and attribute analysis: Their application to Iroquois culture history. In Tooker, E. (ed.) Iroquois culture, history, and prehistory, 99-100. Proceedings of the 1965 Conference on Iroquois Research. Albany: New York State Museum and Science Service.

Wynne-Jones, S. and Kohring, S. 2007. Socialising complexity. In Kohring, S. and Wynne-Jones, S. (eds.) Socialising complexity, 2-12. Oxford: Oxbow Books.

Yellin, J. 2012. Creating a typology for Meroitic offering tables as a tool for dating/establishing Meroitic chronology. Babson Faculty Research Fund Working Papers Paper 115.

Yoffee, N. 2005. Myths of the archaic state. Evolution of the earliest cities, states, and civilizations. Cambridge: Cambridge University Press.

Yoffee, N. and Sherratt, A. 1993. Archaeological theory: Who sets the agenda. New York: Cambridge University Press.

Zimmerman, D. 1971. Thermoluminescence dating using fine grains from pottery. Archaeometry 13: 29-50.

Zurawski, B. 1987. Test excavations at Jebel Ghaddar. In Grzymski, K. (ed.) Archaeological reconnaissance in Upper Nubia, 40-46. Toronto: Benben Publications. 


\section{Appendix IV: Burials with illustrated pottery sherds ${ }^{2}$}

\section{Burial 334}

Session excavated: 1911-12

Square: K.11, L.12

Stratum: B

Description of grave goods: On chest: unpolished grey ware pottery feeding cup (similar to spouted feeding cups on card for burial 1955 and in Addison's 1949 Plate CXII (5, 7 , 8, 12 and 14)), greenstone celt, pottery sherd. In redim: polished dark grey pottery lipstud, natrolite bead, broken greenstone celt, polished black pottery lipstud.

Image: See card for burial 1955 below

\section{Burial 485}

Session excavated: 1913-14

Square: J.11, K.12

Stratum: B

Description of grave goods: Coarse red ware pottery jar with roughly cut vertical slashes, done before firing but after clay was set; round neck were four applied clay bosses, only three remaining; hole in side, pierced when clay was half dry, probably for insertion of a reed; neck broken off. Sherd from rim of large pot of red-brown ware.

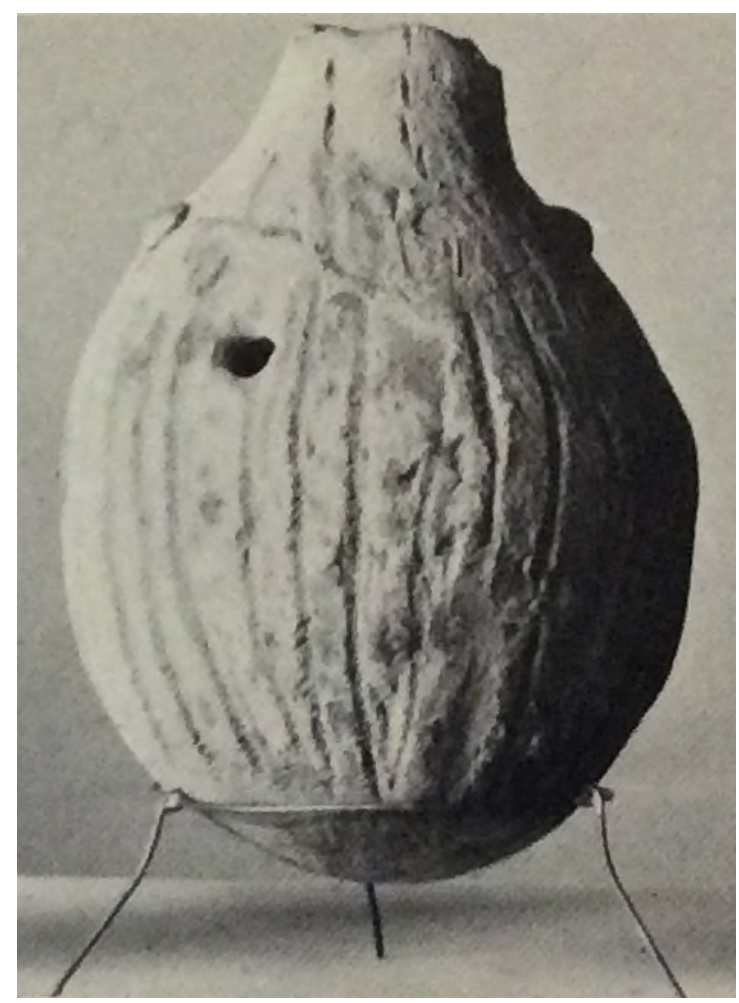

From Addison (1949, Plate CXII 3)

\footnotetext{
${ }^{2}$ Appendices I-III and V are either too large or are spreadsheets containing multiple sheets of data that could not be readily included as printed appendices. Appendix IV contains notes on the 24 burials that have illustrated pottery vessels or sherds. The illustrations are either from the extant grave cards or from Addison's 1949 publication.
} 


\section{Burial 1222b}

Session excavated: 1913-14

Square: O.4, P.5

Stratum: B

Description of grave goods: 3 lipstuds (natrolite, 2 black ware) fallen from jaw. Body partly covered by large sherds from a jar; handmade, coarse, red granite ware pottery with pattern on outside of rim lightly incised before firing; the diameter is 39 x $40 \mathrm{~cm}$ diameter. Large stone pebble to left of legs.

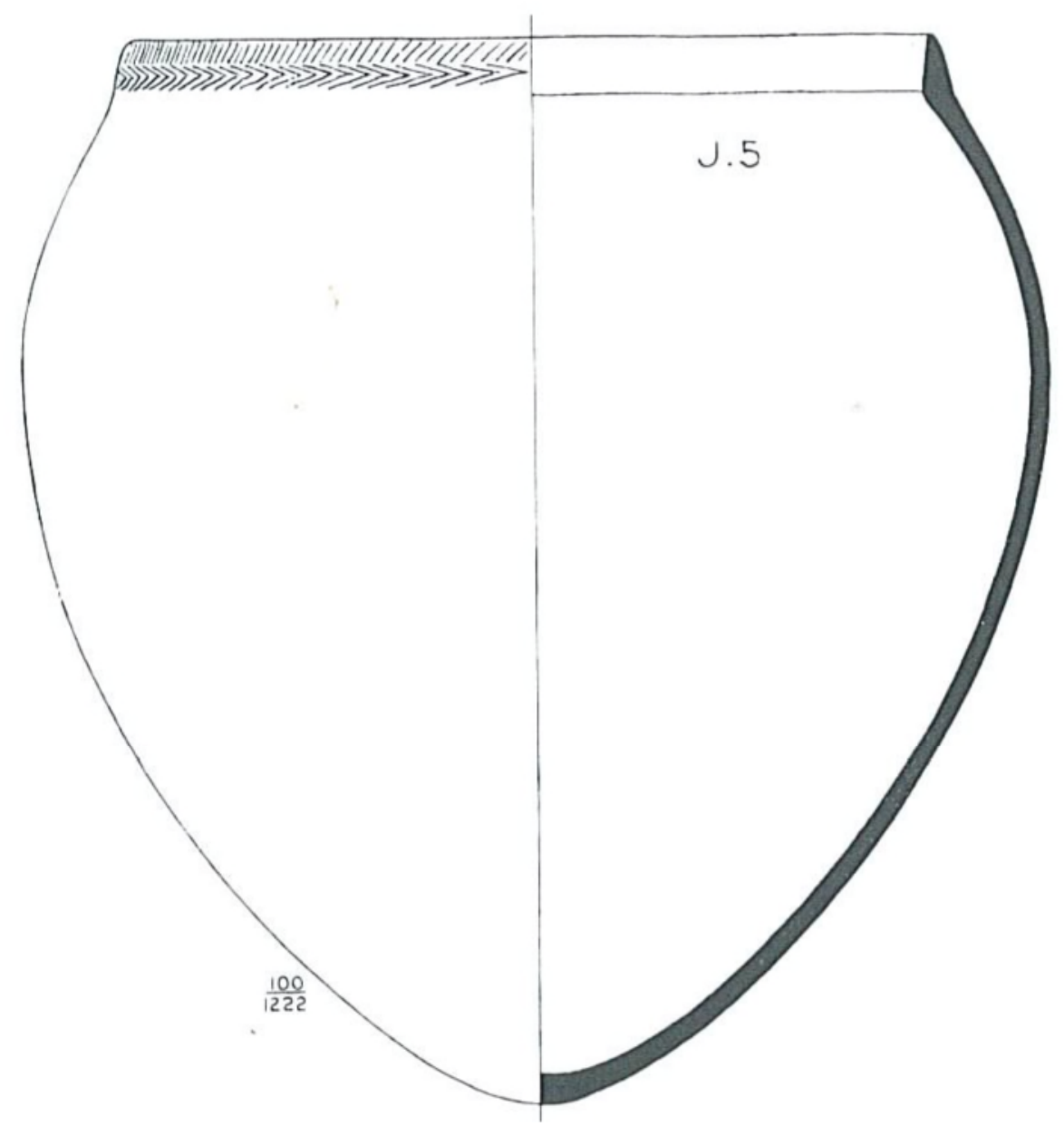

From Addison (1949, Plate XCI ) 


\section{Burial 1225}

Session excavated: $1913-14$

Square: O.4, P.5

Stratum: B

Description of grave goods: 3 lipstuds under head (quartz, natrolite, pottery). 2 large fragments of broken pottery on head; red-ware incised hatching.

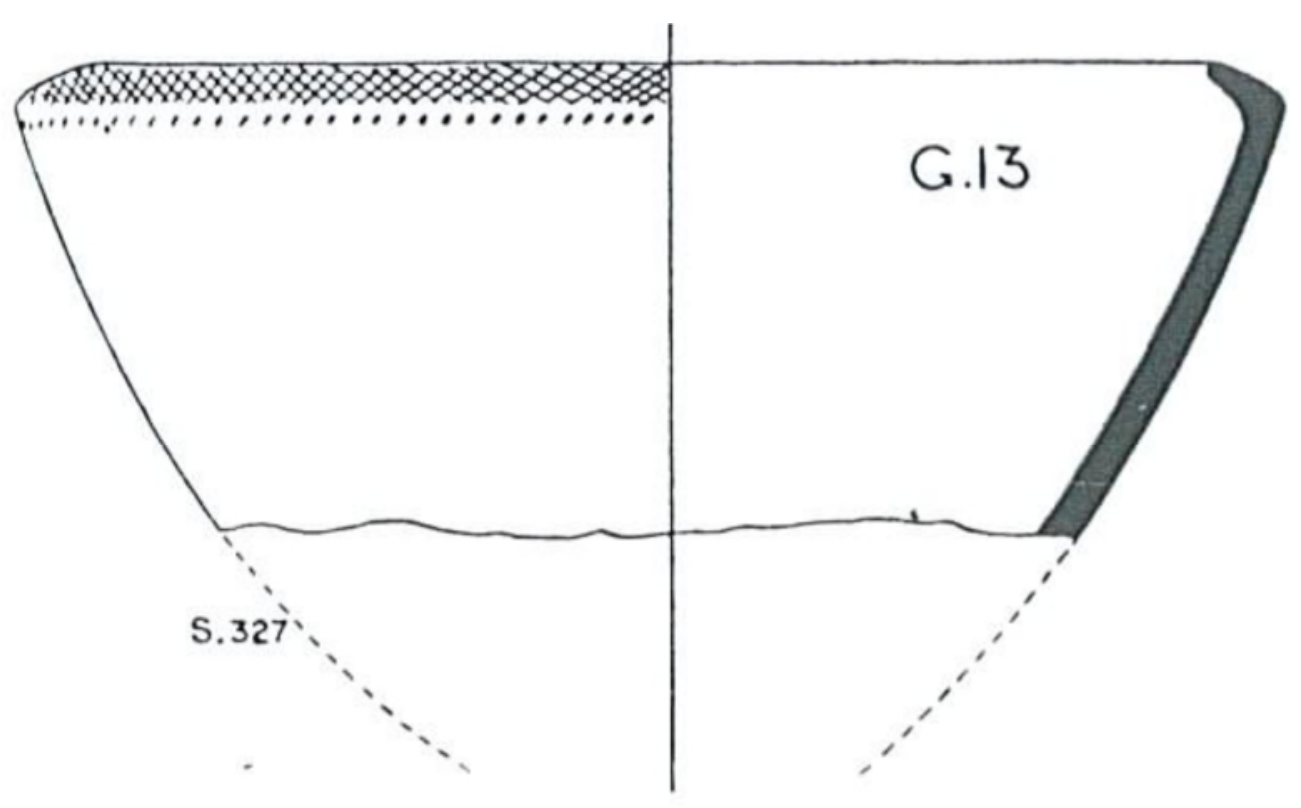

Addison (1949, Plate XC)

From

\section{Burial 1290}

Session excavated: $1913-14$

Square: O.4, P.5

Stratum: C

Description of grave goods: Under left hand was a piece of decorated pottery.

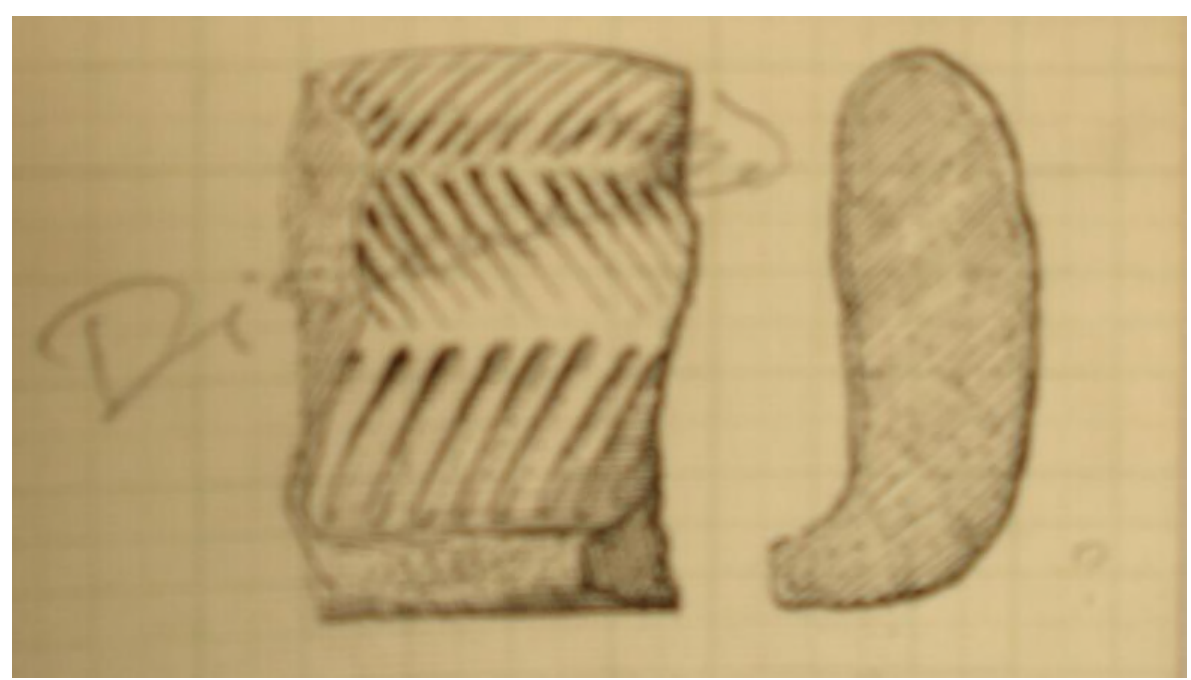

From card 


\section{Burial 1357}

Session excavated: $1913-14$

Square: M.4, N.5

Stratum: C

Description of grave goods: Bowl of polished black granite ware pottery with herringbone pattern lightly incised on rim at knees. Over left hand, a pot cover of grey granite ware pottery made by chipping to shape from the base of a large pot. 2 lipstuds of alabaster and one of black pottery on chest. Pin made from femur of bird by left clavicle.

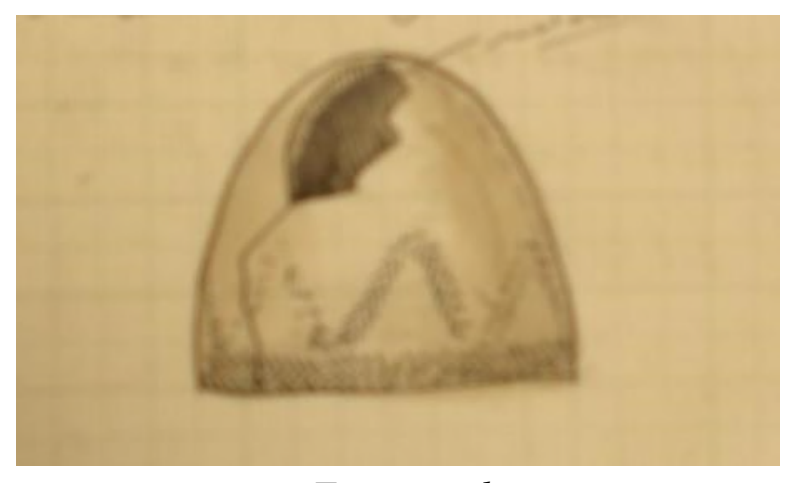

From card

\section{Burial 1625}

Session excavated: 1913-14

Square: J.9, K.10

Stratum: B

Description of grave goods: Fragment of pottery.

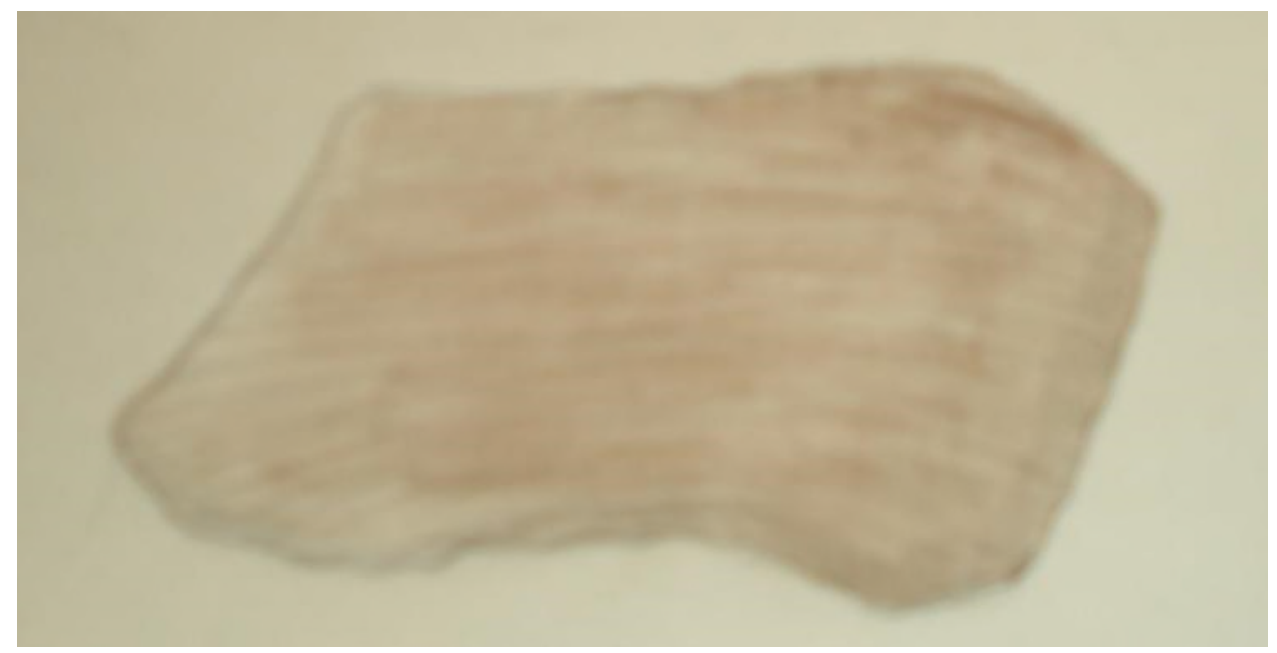

From card 


\section{Burial 1654}

Session excavated: 1913-14

Square: Unknown

Stratum: B

Grave goods description: Pottery feeding cup underneath the head (similar to spouted feeding cups on card for burial 1955 and in Addison's 1949 Plate CXII (5, 7, 8, 12 and 14)).

Image: See the card for burial 1955 below

\section{Burial 1695}

Session excavated: 1913-14

Square: M.3, N.4

Stratum: C

Grave goods description: Upper portion of body covered by pottery sherds (illustrated on the card). Dog's jaw-bone between knees. 8 lipstuds at head (7 pottery, natrolite). Bone pendant at back of head. Sherds from upper part of large jar of red-brown ware, burnished but blackened by firing in some places (see Addison's 1949 Plate XC).

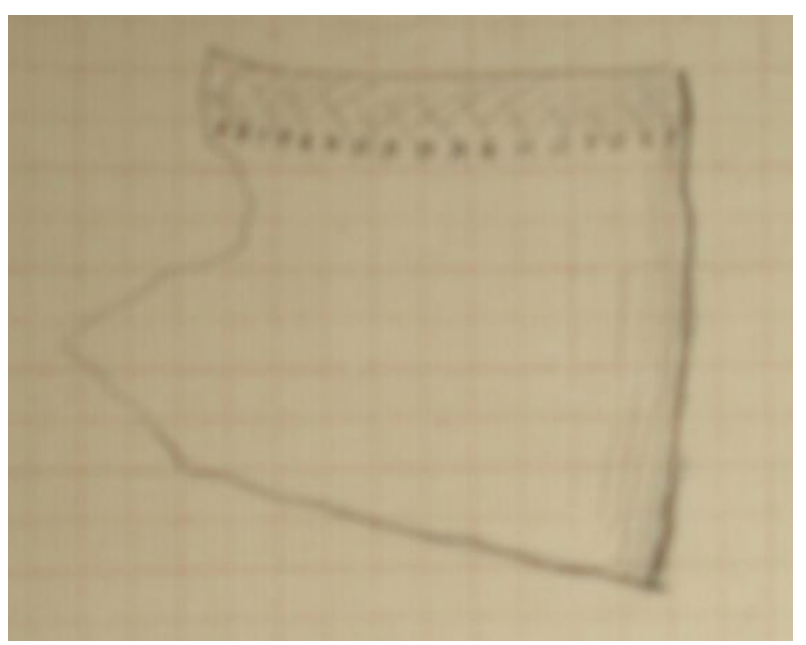

From card 


\section{Burial 1785}

Session excavated: $1913-14$

Square: I.9, J.10

Stratum: B

Grave goods descriptions: Below chin and apparently grasped in right hand, a bowl of granite ware pottery; black inside, polished outside and ornamented with four bands of chevrons impressed with a rocker; four pairs of holes near rim. 2 copper coils by face. Large lump of red ochre inside bowl.

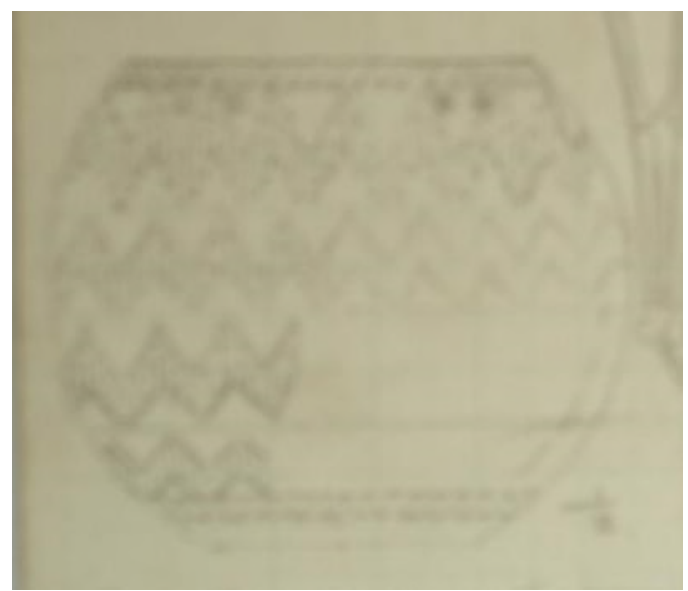

From card

\section{Burial 1955}

Session excavated: 1913-14

Square: I.10, J.11

Stratum: B

Grave goods descriptions: Pottery feeding cup between knees (illustrated on the card. Similar to spouted feeding cups, in Addison's 1949 Plate CXII (5, 7, 8, 12 and 14)). Red pigment between heels and by leg.

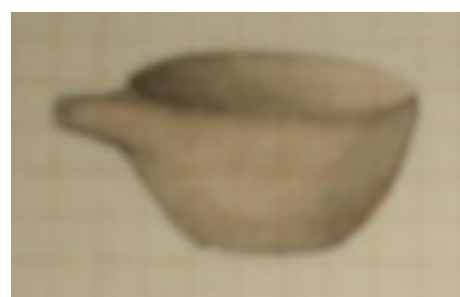

From card 


\section{Burial 1962}

Session excavated: $1913-14$

Square: J.9, K.10

Stratum: B

Grave goods descriptions: Pottery tumbler of black granite ware pottery with incised decoration on the outside in front of face; the inside stained with red ochre; see Addison's 1949 Plate CVIII 16 (and the card). Unpierced Azpatharia rubens shell under head.

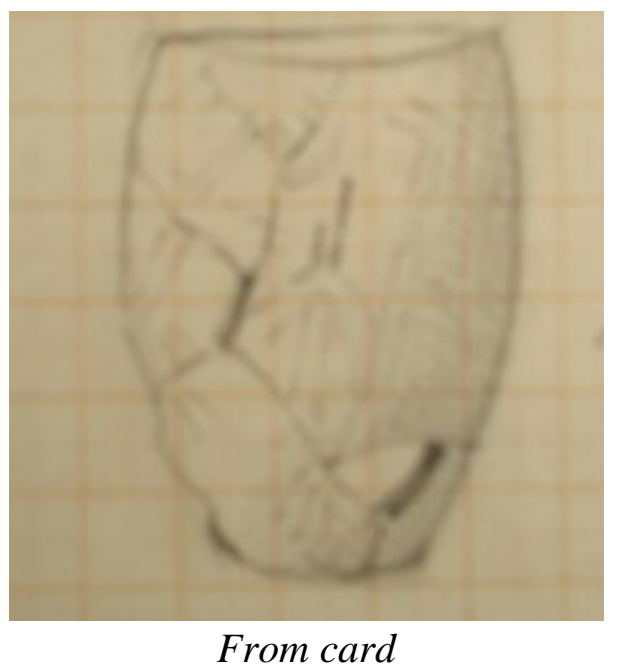

\section{Burial 2000b}

Session excavated: $1913-14$

Square: I.9, J.10

Stratum: C

Grave goods descriptions: Decorated pot in front of face (Addison's 1949 Plate CXI 3 and 4, and illustrated on the card). The pot retains traces of a thin buff slip. On the neck, at equally spaced intervals, are a single tree; a conventionalised human figure; a pair of trees joined; and a pair of human figures joined as if holding hands. Below these, separated from them by a band of dots, is a zone containing 4 somewhat rectangular trees interspersed with a design of dots. The main part of the pot is taken up by two large panels, one on either side, separated by 2 smaller panels. The smaller panels show a design of 2 trees joined and the larger contain a design of opposed chevrons with a filler pattern of tasselled network in the triangular spaces at the meeting of the chevrons. The whole decoration seems to have been impressed by "rockers" of various gauges. The pot was cracked in antiquity and drilled for repair. 


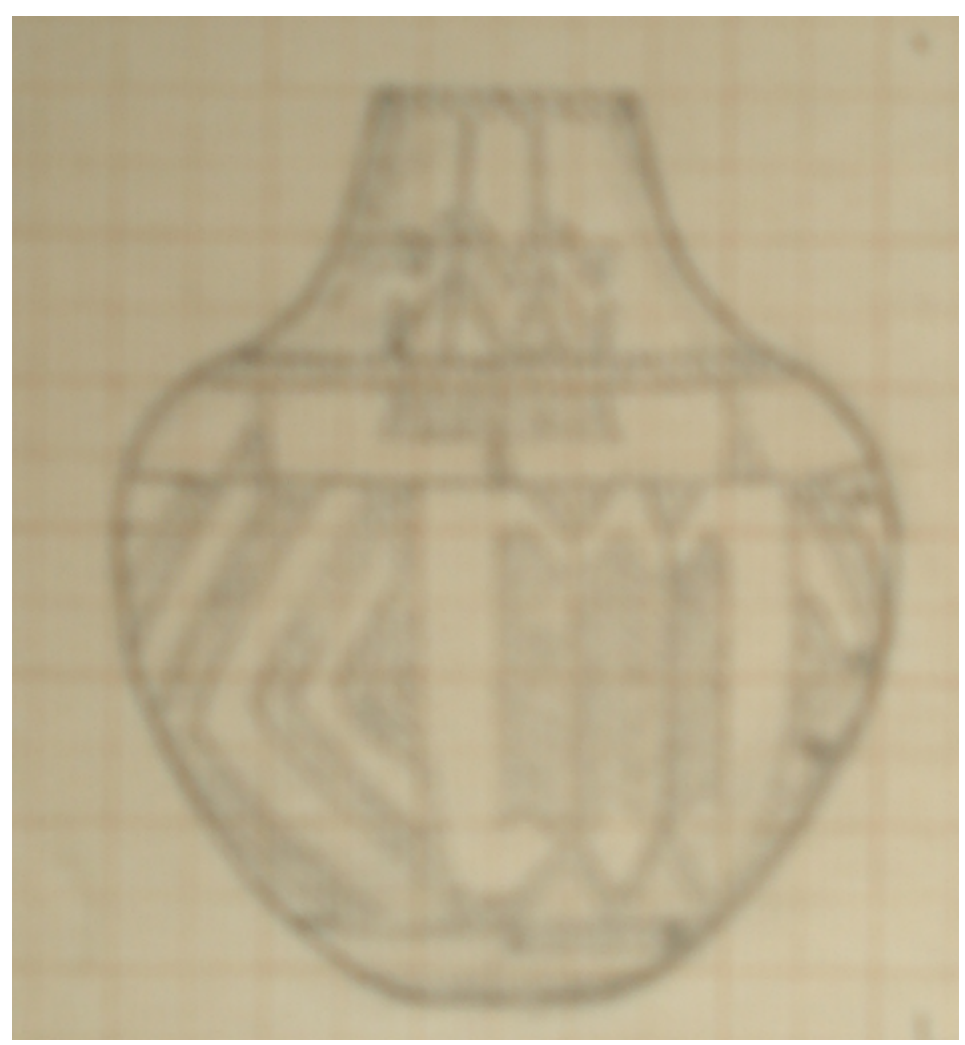

From card

\section{Burial 2088}

Session excavated: $1913-14$

Square: I.9, J.10

Stratum: B

Grave goods descriptions: Over right ear, broken jar of polished brown-red ware pottery with black patches on surface. Rim with incised milling. Two pairs of holes on opposite sides of neck, for suspension. Restored. See Addison's 1949 Plate CXII 4. Also S.3 on Plate XCII (also illustrated on the card).

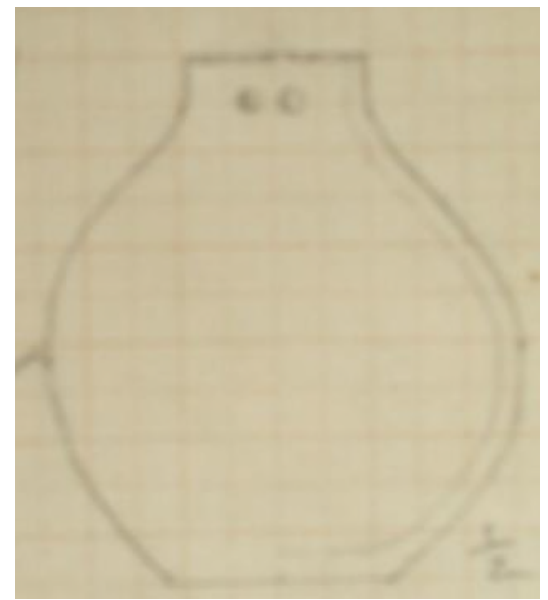

From card 


\section{Burial 2183}

Session excavated: $1913-14$

Square: I.10, J.11

Stratum: B

Grave goods descriptions: Red-ware, pebble-polished tumbler. Black in pieces. Found broken. Incised pattern at rim. See Addison's 1949 Plate CVIII 14 and the card.

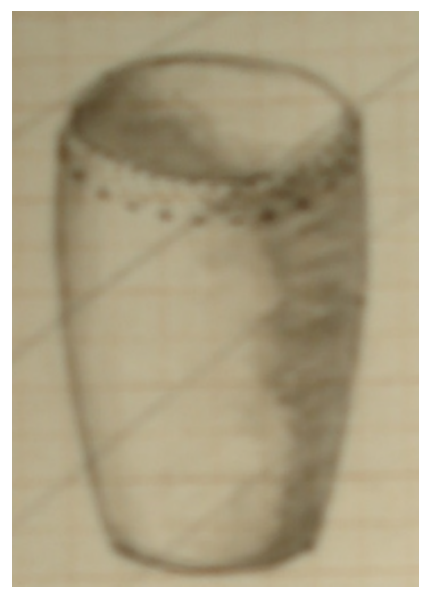

From card

\section{Burial 2193}

Session excavated: 1913-14

Square: I.10, J.11

Stratum: C

Grave goods descriptions: In front of face, large jar of grey-brown granite ware pottery with dark brown polished surface with black patches. Pattern around neck incised before firing. Broken and repaired in antiquity. See Addison's 1949 Plate CXIII 4 and Plate XXXIV, R.2 on Plate XCII, and the card.

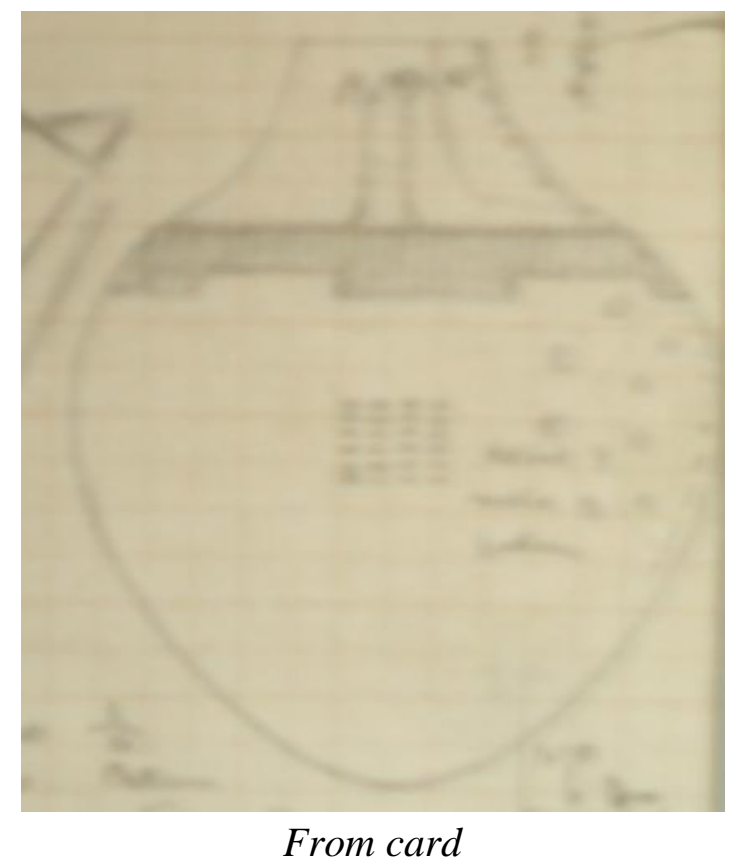




\section{Burial 2221}

Square: I.10, J.11

Stratum: C

Grave goods descriptions: 200-300 faience beads at waist. OES beads also at waist. Large red-ware bowl at feet. Polished brown-ware earstud. Bone clip. Bronze ring.

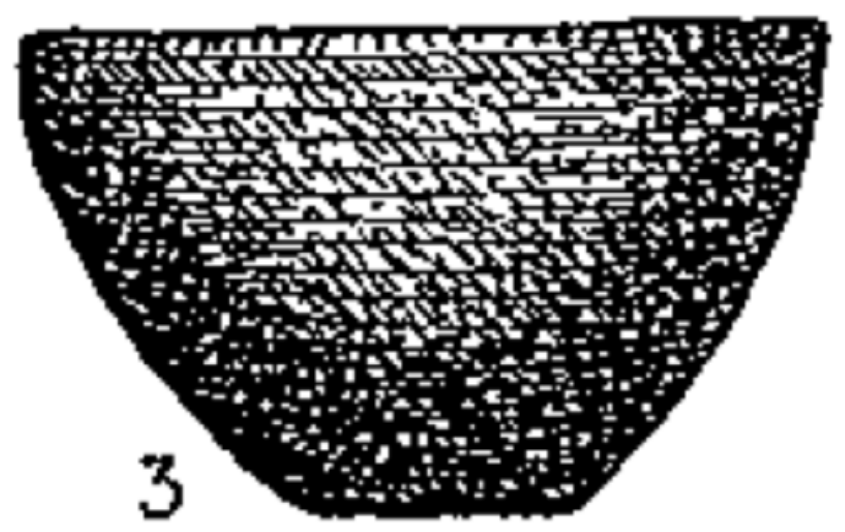

From Addison (1949: 93)

\section{Burial 2247}

Session excavated: 1913-14

Square: M.3, N.4

Stratum: B

Grave goods descriptions: Grey-brown polished pottery lipstud to left of skull. Natrolite lipstud at mouth. Natrolite lipstud, polished black pottery lipstud, position unrecorded. Over head, covering face completely (Addison's 1949 Plate XXIX 3), sherds from a large bowl of hand-made granite brown-ware; burnished; incised pattern on rim (see also Addison's 1949 Plate CX 1 and the card).

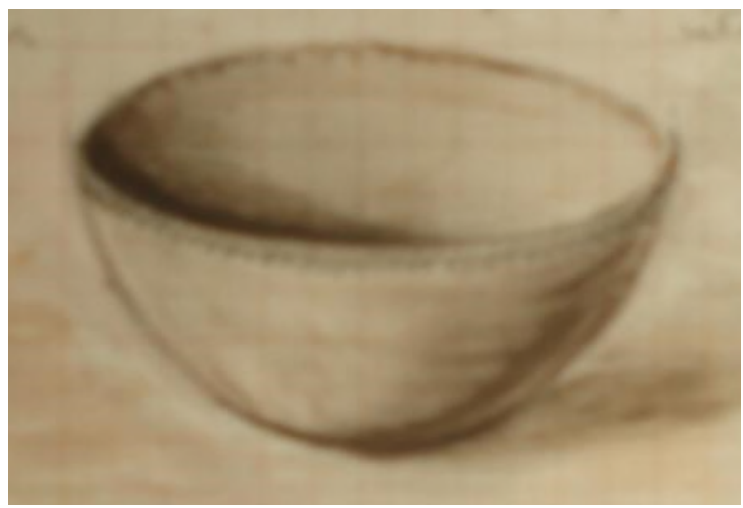

On card 


\section{Burial 2264a}

Session excavated: 1913-14

Square: I.10, J.11

Stratum: D

Grave goods descriptions: Cow's foot in front of knees, another in front of face and a third near left cheekbone. Handmade pot of mottled brown-ware pottery with polished surface and dark-grey to black fracture; rim has a pattern deeply incised before firing; the base is perforated, the hole cut while the clay was wet since the polished brown slip covers its edges (see Plate CXIII 8 and Type T.9 Plate XCIII, and the card). Flask of polished ware pottery varying in surface colour from dark brown to black; the rim is ornamented on top with a chain of impressed ovals; below rim is a deep band of incised dots and slashes applied with a toothed instrument while the clay was wet; the hole in the base was made before firing. Necklace of natrolite beads. Girdle (rahat) at waist of natrolite beads. Sherds of red granite-ware. 23 blue-green faience beads. Fragments of charcoal from floor of grave.

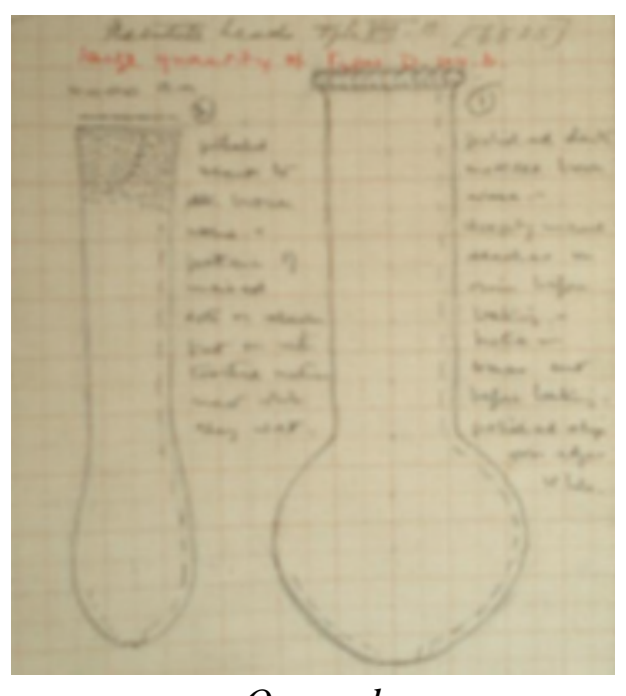

On card 


\section{Burial 2386}

Session excavated: $1913-14$

Square: H.6, I.7

Stratum: B

Grave goods descriptions: Fragment of a jar of plain red granite ware pottery over knees, reconstructed.
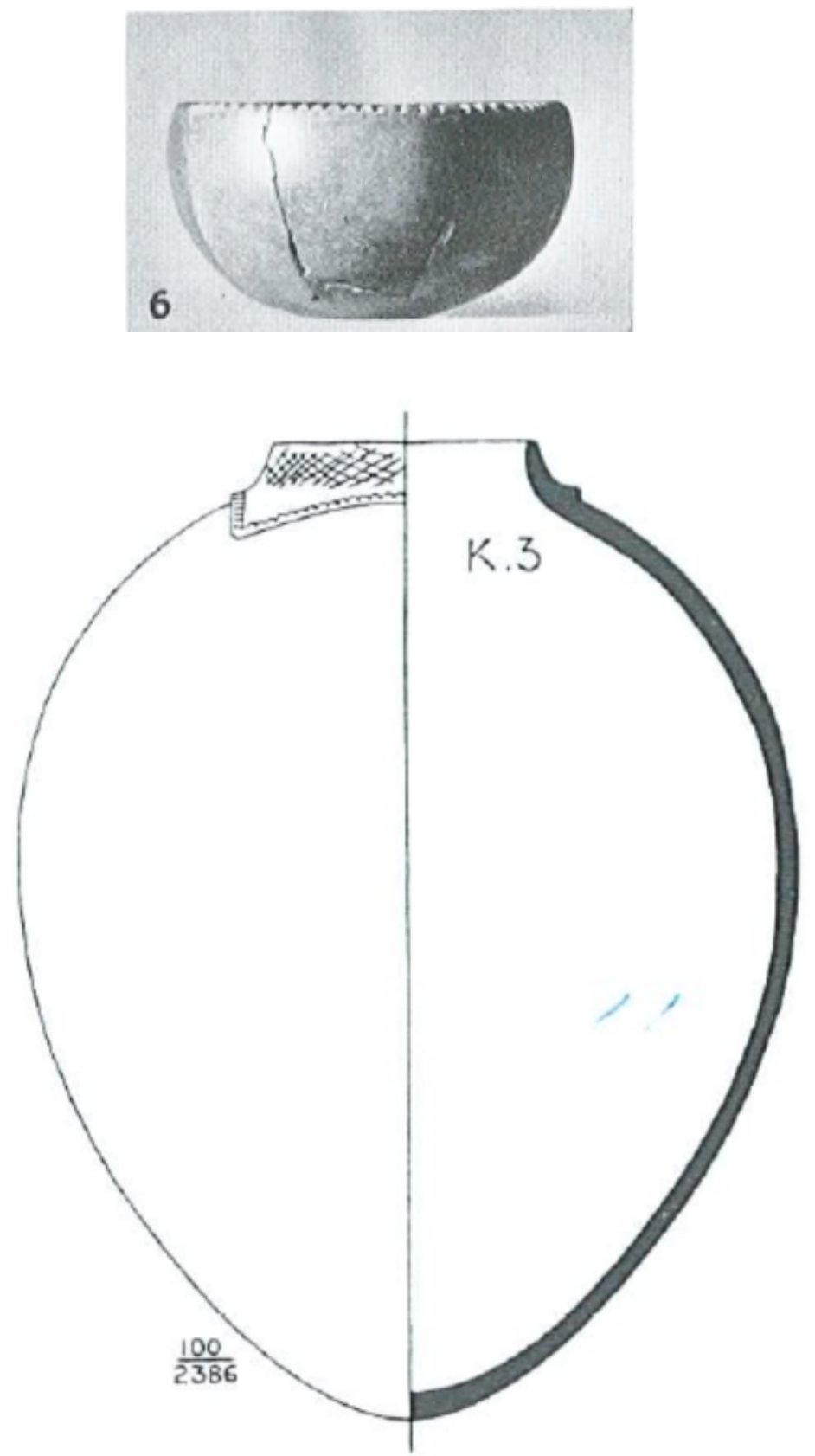

From Addison (1949, Plate CX 6, Plate XCI type K. 3) 


\section{Burial 2424}

Session excavated: 1913-14

Square: I.9, J.10

Stratum: C

Grave goods descriptions: Bowl sherd in front of knees; red-ware pottery with red slip or wash covering outside and extending from 1 to $2 \mathrm{~cm}$ downwards from rim inside. Green-glazed bead. Two natrolite beads.

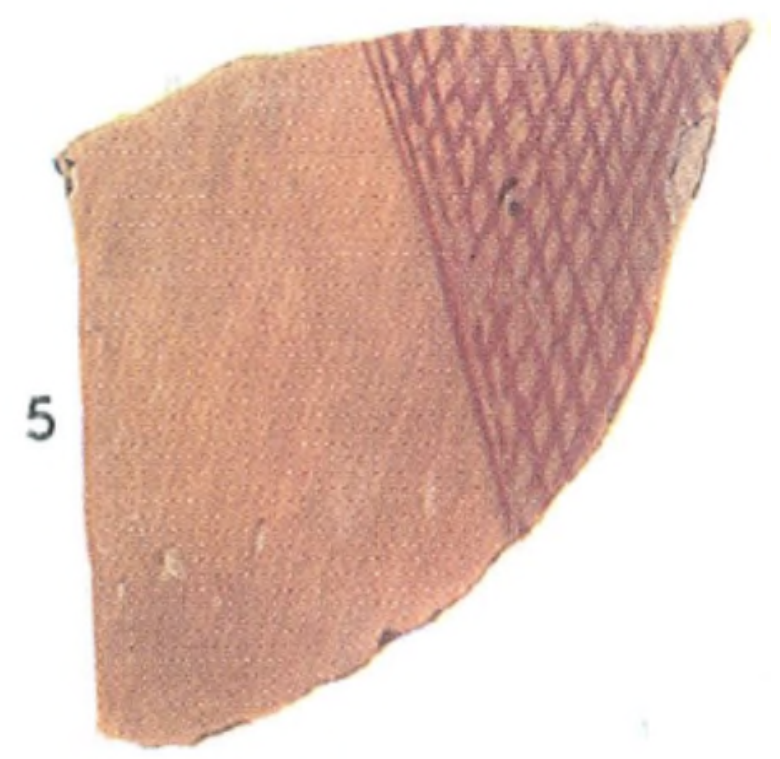

From Addison (1949, Plate CVIII 5)

\section{Burial 2540}

Session excavated: $1913-14$

Square: J.8, K.9

Stratum: B

Grave goods description: Broken, incomplete bowl of polished black-brown incised ware pottery by left femur. The incisions show traces of red ochre filling. Shown restored in Addison's 1949 Plate CIX 6 and on the card.

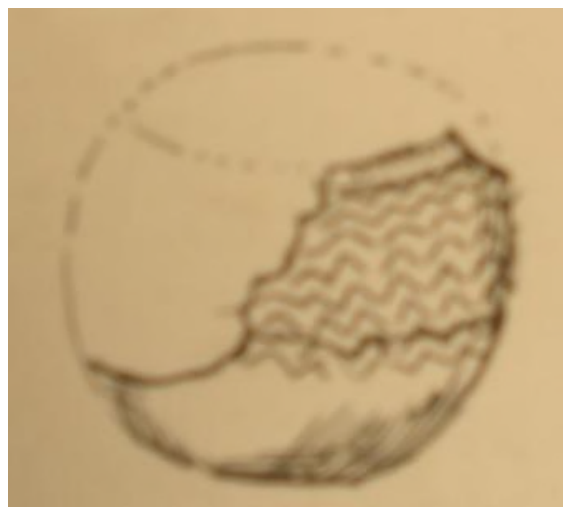

On card 


\section{Burial 2631b}

Session excavated: $1913-14$

Square: N.3, O.4

Stratum: B

Grave goods description: Jar somewhat crudely made of redware; discoloured; found broken but otherwise complete.

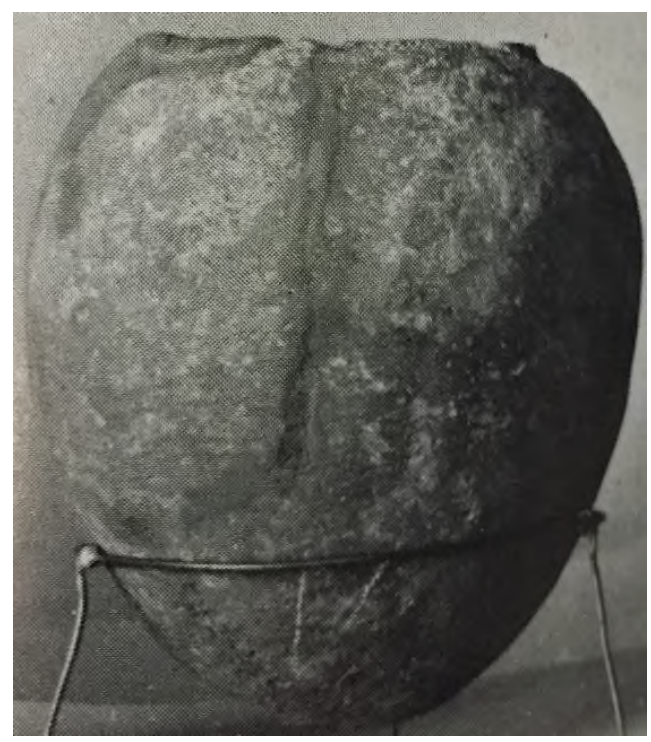

From Addison (1949, Plate CX 7\}

\section{Grave: 2865}

Session excavated: 1913-14

Square: G.7, H.8

Stratum: B

Grave goods description: Fragments of bowl of plain red-ware pottery scattered over body, reconstructed as shown in Addison's 1949 Plate CX 13, also J.4 on Plate XCI.

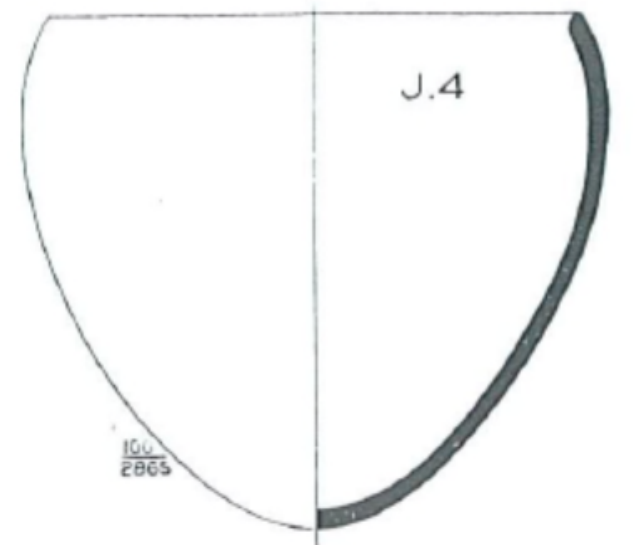

From Addison (1949, Plate XCI, J.4) 